\title{
Farming Systems in the Tropics
}

HANS RUTHENBERG

CLARENDON PRESS - OXFORD

1971 


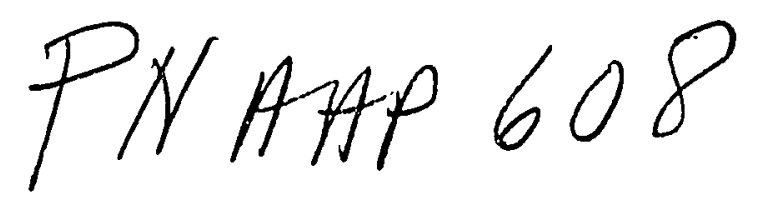

\section{Preface}

THIS book arose from an introductory course of lectures on the characteristics of tropical farming systems for undergraduates at Stuttgart-Hohenheim and Göttingen Universities and for graduates in general agriculture who were preparing for applied work in the tropics. Beyond its use in lesturing, the book is intended to provide the agricultural development worker with a framework into which he can fit the various types of farming that he will encounter, and at the same time to introduce him to the management problems that arise in particular farming systems. The subject is considered in the agro-economic setting. Emphasis is !aid on the interactions between technical and economic aspects of farming. Information about soils, climate, and socioinstitutional factors is deliberately kept short.

Recently, much literature has become available about tropical agriculture, dealing with such crucial topics as soil fertility, irrigation, and practices in plant and animal husbandry. Land-tenure problems, farmers' behaviour, and agricultural-policy measures are increasingly dealt with in a growing number of publications. ! have, therefore, preferred to restrict this book to the farm-management aspects. The primary economir characteristics of the more important tropical farming systems and their broad lines of development are described and analysed. It is hoped that this information, as well as promoting understanding, will be helpful in the planning of meaningtul development policies for agricultural production in tropical countries.

The subject is by no means dealt with exhaustively, and many more farming systems than those depisted deserve consideration. I have tried in the illustrations to cover the major tropical crops, but no emphasis has been laid on a geographical balance. As far as possible, the case studies have been taken from areas that I have visited and where I was in a position to confirm the information cited in the relevant literature. This is the reason why most of the case studies are from Africa and Asia and very few are from Latin America.

In order to describe the economic situation of each type of farming, I have used quantitative information about inputs and outputs, and much of it is expressed in monetary terms. These figures have, of ccurse, to be considered with great caution. They are difficult to compare because of wide differences in price levels and price relationships. Monetary information of this nature is necessary in order to help provide a clear picture of the circumstances of 
farming under different conditions of production. It should not be overlooked, however, that the relevance of the quantitative information depends on the year, on the country, on the farming system, and on the method of estimation.

In the complex task of writing this book $I$ have been greatly assisted by several co-workers. The main debt is, of course, to the numerous smallholders, farmers, and estate managers who so willingly discussed their work and problems. They in fact provided the information tial is presented in this book. Most valuable advice and criticism were given by my friend John D. MacArthur, who read the manuscript a number of times. To him I am indebted for a great number of suggestions and ideas, and for Chapters 2 and 10, which he wrote. Mr. and Mrs. P. C. Brown deserve my thanks for having translated the original German version of the manuscript.

I owe a special word of thanks to the Volkswagen Foundation and the Fritz Thyssen Foundation. The took would not have been possible without the research funds that I received from them. The inclusion of the plates was made possible by a grant from Mr. Heinric'. Herrmann, Stuttgart.

Stuttgart-Hohenheim

HaNS Ruthenderg 


\section{Contents}

LIST OF PLATES

KEY TO TERMS $\quad \mathrm{XV}$

1. INTRODUCTION I

1.1. Definition of the geographical area

1.2. Definition of farming systems 2

1.2.1. Collecting 2

1.2.2. Cultivation 2

1.2.3. Grassland utilization 5

1.2.4. Procedure in this book 5

1.3. Definition of farms 6

2. SOME GENERAL CHARACTERISTICS OF FARMING IN A TROPICAL ENVIRONMENT by J. D. MACARTHUR 8

2.1. The natural environment

2.1.1. Climatic influences 9

2.1.2. Soil conditions 10

2.1.3. Biological environment 11

2.2. Some critical aspects of tropical farming 11

2.2.1. Problems of soil fertility 11

2.2.2. Coping with risk and uncertainty

2.2.3. Low labour productivity 13

2.2.4. The problem of seasonality 14

2.3. The dynamics of tropical farming 15

3. SHIFTING CILTIVATION SYSTEMS 16

3.1. Definition 16

3.2. Types of shirting cultivation and their geographical distribution 16

3.2.1. Vegetation systems 17

3.2.2. Migration systems $\quad 17$

3.2.3. Rolation systems 20

3.2.4. Clearance systems 22

3.2.5. Crepping systems

3.2.6. Tool systems 


\section{CONTENTS}

3.3. General characteristics of shifting systems 24

3.3.1. The spatial organization of cropping 24

3.3.2. Cropping principles 27

3.3.3. Characteristics of the fertilizer economy 31

3.3.4. Characteristics of animal husbandry 36

3.3.5. Characteristics of the labour economy 36

3.4. Three case studies 40

3.4.1. Extensive shifting cultivation with monocropping of the Iban, Sarawak

3.4.2. Shifting cultivation with mixed cropping in Congo-Kinshasa

3.4.3. Shifting cultivation with rotation among the Bemba, Rhodesia

3.5. Weaknesses of the system

3.5.1. Difficulties in the introduction of new methods

3.5.2. The tendency towards 'degraded' shifting systems

3.6. Development paths of shifting systems 48

3.6.1. Improved shifting systems

3.6.2. The change from shifting systems to more intensive types of farming

\section{SEMI-PERMANENT CULTIVATION SYSTEMS}

4.1. Definition

4.2. Types of semi-permanent cultivation and their geographical distribution

4.2.1. Semi-permanent cultivation on the fertile soils of the humid savannas

4.2.2. Semi-permanent cultivation in connection with perennial crops

4.2.3. Semi-permanent cultivation in connection vith irrigation farming

4.2.4. Unregulated ley systems in the drier savannas

4.2.5. Unregulated ley systems in high-altitude areas

4.3. General characteristios of semi-permanent systems 60

4.2.1. Spatial organization of cropping

4.3.2. Cropping principles

4.3.3. Characteristics of the fertilizer economy 65

4.3.4. Characteristics of animal hisbandry 67

4.3.5. Characteristics of the labour economy 69

4.4. Two case studies 73

4.4.1. Semi-permanent farming in the subhumid savanna: rice holdings in the Kilombero Valley, Tanzania

4.4.2. Unregulated ley farming in the drier savanna: cotton-maizemillet holdings in Sukumaland, Tanzania

4.5. Weaknesses of the system

4.5.1. The tendency towards soil mining 77

4.5.2. Degeneration of the livestock economy 77

4.5.3. Bottlenecks in the labour economy 78 


\section{CONTENTS}

4.6. Development paths of semi-permanent systems and unregulated ley systems

4.6.1. Improved systems

4.6.2. Change towards more intensive types of farming

5. SYSTEMS WITH REGULATED LEY FARMING

5.1. Definition

5.2. Types of ley farming and their geographical distribution

5.2.1. Regulated ley systems in traditional smaltholder areas

5.2.2. Regulated ley systems in settlement schemes

5.2.3. Regulated ley systems in large farms

5.3. General characteristics of regulated ley systems 86

5.3.1. Principles of crop and ley management 86

5.3.2. Characteristics of the fertilizer ciconomy

5.3.3. Characteristics of animal husbandry 88

5.3.4. Characteristics of the labour economy 89

5.4. Three case studies

5.4.1. Tobacco farms in Rhodesia 89

5.4.2. Large farms in the Kenya highlands

5.4.3. Smallholdings in the Kenya highlands 94

5.5. Weaknesses of the system 95

5.5.1. The low fertility effect of tropical grass leys 95

5.5.2. Unfavourable capital-output ratio 96

5.5.3. Dependence on improved animal husbandry 96

5.6. Development paths of regulated ley systems 97

5.6.1. Improved ley systems 97

5.6.2. Change from ley systems to other types of farming 97

6. SYSTEMS WITH PERMANENT CULTIVATION ON 99

$\begin{array}{ll}\text { RAIN-FED LAND } & 99 \\ & 99\end{array}$

6.1. Definition
6.2. Types of permanent rain-fed cultivation and their geographical
99 distribution 100

$\begin{array}{ll}\text { 6.2.1. Permanent cultivation in tropical highlands } & 101 \\ \text { 6.2.2. Permanent cultivation in the African savannas } & 101\end{array}$

$\begin{array}{ll}\text { 6.2.2. Permallent cultivation in the African savannas } & 101 \\ 6.23 . \text { Permanent cultivation in monsoon Asia } & 101\end{array}$

6.2.4. Permanent cultivation in the hot, humid tropics 101

6.3. General characteristics of land use with permanent rain-fed cultivation 104

6.3.1. Spatial organization of cropping 104

6.3.2. Cropping principles 105

6.3.3. Characteristics of the fertilizer economy 108

6.3.4. Characteristics of animal husbandry 110

6.3.5. Characteristics of the labour economy 112

6.4. Four case studies

6.4.1. Maize-millet holdings in Kakamega District, Kenya 117

6.4.2. Millet holdings in Ukara, Lake Victoria 118

6.4.3. Groundnut-millet holdings in Senegal 119

6.4.4. Millet-wheat holdings in the Bombay Deccan 
6.5. Weaknesses of the system

6.6. Development paths of permanent cultivation systems 126

$\begin{array}{ll}\text { 6.6.1. Improved permanent cultivation systems } & 126 \\ 6.6 & 126\end{array}$ 6.6.2. Change from permanent rain-fed cultivation to other types of
farming

7. SYSTEMS WITH ARABLE IRRIGATION FARMING

7.1. Definition

7.2. Types of irrigation farming and their geographical distribution

7.2.1. Water supply systems

7.2.2. Cropping systems

7.2.3. Exploitation systems

132

133

138

7.3. General characteristics of irrigation farming

7.3.1. A comparison with rain-fed farming 139

7.3.2. Spatial organization of cropping 139

7.3.3. Cropping principles 142

7.3.4. Characteristics of the fertilizer economy 147

7.3.5. Characteristics of animal husbandry 152

7.3.6. Characteristics of the labour economy 154

7.4.1. Water availability and irrigation farming: five case 160 from India, West Pakistan, and Singapore: five case studies

7.4.2. Wet-rice systems: three case studies from 160 land, and Taiwan

7.4.3. Farming systems in large irrigation schemes

7.5. Weaknesses of the system

7.5.1. Insufficient control of water supplies 181

7.5.2. Wasteful irrigation and husbandry practices 182

7.5.3. Dependence on inadequate institutionactices 183

7.6. Development paths of irrigation farming

7.6.1. Innovations and improved husbandry

7.6.2. Irrigation farming and mechanization 185

$\begin{array}{ll}\text { 7.6.3. Introduction of intensive types of animal husbandry } & 186 \\ & 188\end{array}$

8. SYSTEMS WITH PERENNIAL CROPS 189

8.1. Definition and genesis $\quad 189$

$\begin{array}{ll}\text { 8.1.1. Definition } & 189\end{array}$

$\begin{array}{ll}\text { 8.1.2. Genesis } & 189 \\ & 189\end{array}$ 8.2. Types of farming with perennial crops and their geographical distribu-
tion

8.2.1. Cropping systems 191

8.2.2. Exploitation systems $\quad 192$

3.3. General characteristics of farming systems with perennial crops 193

8.3.1. A comparison with arable farming with perennial crops $\quad 197$

$\begin{array}{lr}\text { 8.3.2. Some farm-management characteristics of perennial crops } & 197 \\ & 201\end{array}$ 
8.4. Estates and smallholdings with perennial field crops 206

8.4.1. Sugar-cane holdings 206

$\begin{array}{ll}\text { 8.4.2. Sisal holdings } & 210\end{array}$

8.4.3. Banana holdings 213

8.5. Estates and smallholdings with shrub crops 218

$\begin{array}{ll}\text { 8.5.1. Coffee holdings } & 218\end{array}$

8.5.2. Tea holdings 228

8.6. Estates and smallholdings with tree crops 232

8.6.1. Cocoa holdings 232

8.6.2. Rubber holdings 234

8.6.3. Oil-palm holdings 240

8.6.4. Coconut-palm holdings 242

8.7. Weaknesses of farming systems with perennial crops 244

8.7.1. Weaknesses of smallholder farming with perennial crops 244

8.7.2. Weaknesses of the estate economy 247

8.8. Development paths of farming systems with perennial crops 248

8.8.1. Increased application of technical innovations 248

8.8.2. From mixed cropping to pure stands and interculture 249

8.8.3. From holdings with one cash crop towards diversified commercial production

8.8.4. Increasing importance of perennial food and fruit crops 251

8.8.5. Integration of estate and smallholder production 251

9. GRAZING SYSTEMS 252

9.1. Definition and geographical distribution of grazing systems 252

9.2. Total nomadism 254

9.2.1. General characteristics of total nomadism 254

9.2.2. A case study: camel nomads in the Sahara 256

9.2.3. Weaknesses of total nomadism 258

9.2.4. Development paths of total nomadism 259

9.3. Semi-nomadism 260

9.3.1. General characteristics of semi-nomadism 260

9.3.2. A case study: semi-nomadism of the Bahima, Uganda 262

9.3.3. Weaknesses of semi-nomadism 264

9.3.4. Development paths of semi-nomadism 267

9.4. Ranching 271

9.4.1. General characteristics of ranching 271

9.4.2. Two case studies 274

9.4.3. Weaknesses of ranching 280

9.4.4. Development paths of ranching 281

10. GENERAL TENDENCIES IN THE DEVELOPMENT OF FARM SYSTEMS by J. D. MACARTHUR 282

BIBLLOORAPHY 287

INDEX 303 


\section{List of Plates}

(Plates appear between Pp 144-145)

1. Fallow vegetation, burnt by shifting cultivators, Cercle d'Allada, Dahomey

2. Mixed cropping of groundnuts, sunflower, and maize in a shifting cultivator's field, Urambo, Tanzania

3. Valley bottoms in the savanna zone of the Ivory Coast being transtormed into fields with irrigated rice

4. Dairy cattle on smallholdings with regulated ley farming in Nyeri District, Kenya.

5. Tobacco is a cash crop well-suited to shifting cultivation in the African savannas. A small entrepreneur at Urambo, Tanzania

6. Valley botioms in the rainforest zone of the Ivory Coast being transformed into fields with irrigated rice

7. Cattle feeding on leaves of Fa:dherbio albida, in Screre country, Senegal

8. Transporting manure from the stable to the field, U'cara Island, Tanzania

9. Applying stable manure and green manure on Ukara Island, Tanzania. The manure is placed at the base of the ridge

10. Smallholder ley farming in Kisii District, Kenya

11. Swiss cows grazing on leys extablished on land traditionally used by shifting cultivators. Bush with tsetse-flies in the background. The picture was taken on a Swiss demonstration farm, close to Cotonou, Dahomey

12. Two-wheel tract $s$, ploughing a rice field in Taiwan

13. Land preparation for rice in Ceylon. The work is being performed by seasonal paid labour

14. Soil preparation for intercropping of sweet potatoes in maturing rice, Taichung District, Taiwan

15. Relay-planting of sugar-cane in growing rice in Taiwan. Note the seed cane in the mud between the rows of rice

16. Rice terraces and rain-fed farming in the Highland of Madagascar

17. Farmer in his rice field, Taichung District, Taiwan

18. Two rice fields close to Madras, India. The field to the rigit shows improved traditional varieties, which tend to lodge. The field to the left shows IR 8, a non-lodging variety which can productively absorb high doses of nitrogen

19. Preparation of a rice field for planting by trampling with buffaloes, in Ceylon. The work is performed after hoe or plough cultivation. In Madagascar the same method is applied and called 'piétinage'

20. View into the banana-coffee-bean plot of a Bahaya holding, Tanzania. The soil is covered with mulcin grass 
21. Multiple cropping system of paddy fields in Taiwan, China

22. A field in the Gezira Scheme, in the Sudan, prepared for planting by the scheme management

23. A tenant in the Managil Extension of the Gezira Scheme, in the Sudan, irrigating his cotton

24. Well-terraced banana-coffee plot on Mt. Kiiimanjaro, Tanzania

25. Coffee plantation, Nyeri District, Kenya

26. Badly eroded tea plantation, Ceylon, medium-altitude level

27. Young tea plantation established with new clones, planted at high density, surrounded by tea which is about 50 years old, Ceylon, high-altitude level

28. Rubber plantation, Ivory Coast

29. Smallholder plot ready for the planting of oil-palms. The woman is planting a cover crop (Centrosema pubescens)

30. Young oil-palm plantation, Ivory Coast

31. Root system of two perennial grasies in c. dry savanna climate, Kongwa, Tanzania

32. Overgrazed ard eroded land in Baringo District, Kenya 


\section{Key to vernacular or local terms}

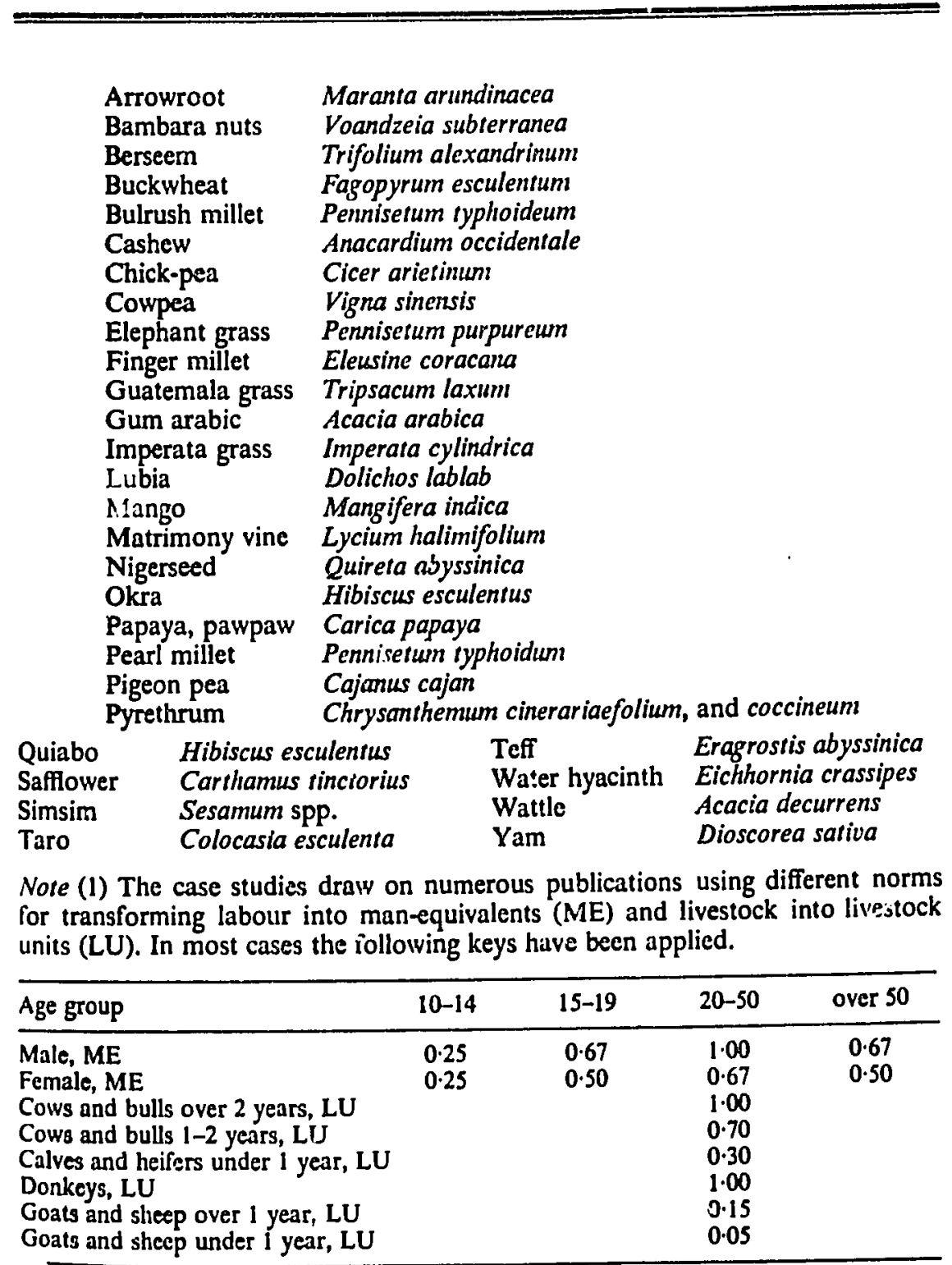

Note (2) In the tables and figures, quotients of standard scientific units have been abbreviated using the index notation: e.g. kilogrammes per hectare becomes $\mathrm{kg}$ $\mathrm{ha}^{-1}$. 


\section{Introduction}

\subsection{Definition of the geographical area}

Geographically, this book deals with tropical farming systems only, although much of the information is valid also for subtropical farming. The tropical regions are generally defined as those lying between $232^{\circ}$ to the north and $23 \frac{1}{2}^{\circ}$ to the south of the equator. This, however, is too rigid a definition for the purpose of dealing with farming systems. I therefore prefer the definition of Waibel (1933), who used the criteria of economic geography, and defined as tropical those regions between the dotted lines in Fig. 1.1.' This definition is generally applied in the following chapters.

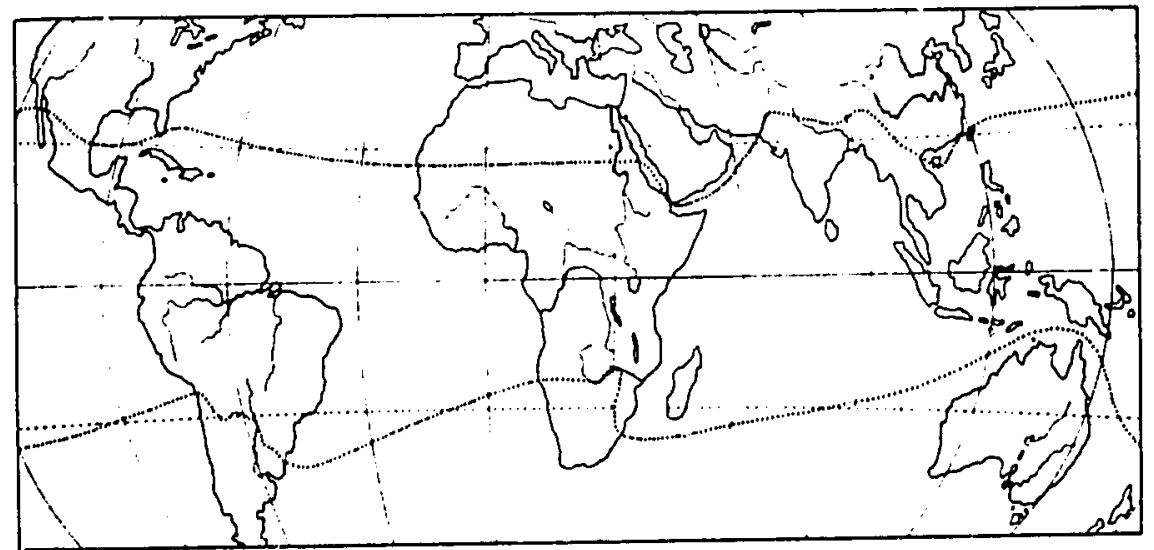

FIG. 1.1. The tropics, defined according to the principles of economic geography (from Manshard 1968, p. 18).

The main ecological regions within the tropics have been classified by Manshard (1968, pp. 36, 64), who distinguishes between (1) the rainforest. which has $0-2 \frac{1}{2}$ arid months, (2) the humid savannas, having $2 \frac{1}{2}-6$ arid months, (3) the dry savannas, with 6-8 arid months, (4) the thorn savannas, which have $8 \frac{1}{2}-10$ arid months, (5) the semi-desert and full desert, where there are more than 10 arid months, and (6) the tropical high-altitude areas.

1 Von Wissman's definition of the tropics, based on climatic criteria, gives almost identical results (see Manshard 1961, p. 13). 


\subsection{Definition of farming systems}

The natural, economic, and socio-institutional conditions of agricultural production vary widely from place to place and over periods of time. In the process of adapting cropping patterns and farming practices to the conditions of each location and the aims of the farmers, more or less distinct types of farm organization have developed. In fact, no farm is organized exactly like any other. For the purpose of agricultural development, however, in order to devise meaningful measures in agricultural policy, it is necessary to classify farms according to their farm-manacement characteristics.

\subsubsection{Collecting}

Collecting is the most direst method of obtaining plant products. It may include either regular or irregular harvesting of uncultivated plants. Hunting and fishing usually go hand in hand with collecting. In prehistoric times, activities of this kind were a major source of food supply. In some regions these activities still provide rather important additions to the subsistence food gained from o:ganized production in arable farming and animal husbandry. Only in a few cases (the wild oil-palms in some parts of West Africa, the gum arabic of the Sudan, the wild honey of Tanzania) is collecting a major cashearning activity.

\subsubsection{Cultivation ${ }^{2}$}

Much more important than collecting are the numerous ty pes of cultivation. The different cultivation systems may be classified according to a number of particular features. The most important classifications that have been adopted by recent authors are as follows:

(a) Classification according to the type of rotation (after Aereboe 1919; Brinkmann 1924; and Woermann 1959). Fallow systim describes a situation where cultivation alternates with an uncultivated long-term fallow, which leads to the regeneration of a wild vegetation of trees, bush, or unused grass. Often, but certainly not in all cases, fallow systems are practised in conjunction with fire-farming, in which the wild vegetation is burned off before planting.

Ley system describes those cases where grass is planted or establishes itself on land that has carried crops for some years. The grass is allowed to remain

\footnotetext{
1 The word cultivation is used in this book in the sense of the preparation and use of land for growing crops. This doss not necessarily imply that the ground around the plants must be loosened.

The word rotation has two meanings according to the time period involved. There is the long-term alternation between various types of land use, such as arable farming, tree farming, grassland use, fallow, etc. In this connection, rotation means the sequence of these basic types of land use on a given field. Within arable farming, there is also the term crop rotation, which means the short-term sequence of different arable crops on one field. In this section, the word is used in the first of these two senses.
} 
for several years and is used for grazing. In the savannas there are extensive areas of wild or unregulated ley farming. In these areas, we find that, after a period of cultivation of several years, the field is covered with grass and shrubs for several more years and serves as rough pasture. Regulated ley farming, with established swaròs during the non-cropping period, is rare in the tropics, although it is found in some highlands (e.g. in Kenya) and in Latin America.

Field systems occur where one arable crop follows another, and where established fields are clearly separated from each other. The grassland associated with field systems is usually treated as permanent grassland, whether it is rough or well cared for, and it is separatcd from the arable land.

Systems with perennial crops, i.e. with crops that cover the land for many years, are in a separate category. Within this category we distinguish between perennial field crops like sugar-cane and sisal, bush crops like tea anć coffee, and tree crops proper like oil-palm and rubber. All kinds of rotation are found. In some cases tree crops are alternated with fallow, in others with arable farming, grazing, or other perennial crops.

(b) Classification according to the intensity of the rotation (after Terra 1958; Nye and Greenland 1961; and Faucher 1949). The fallow and ley systems display considerable variations and degrees of intensity. This is especially true for field-bush rotations and for unregulated ley systems in the African savannas. A relatively simple and appropriate criterion for classification is the relationship between crop cultivation and fallowing within the total length of one cycle of land utilization. Following the suggestion of Joosten (1962), we define the symbol $R$ as the number of years of cultivation multiplied by 100 and divided by the length of the cycle of land utilization. The length of the cycle is the sum of the number of years of arable farming plus the number of fallow years. The characteristic $R$ indicates the proportion of the area under cultivation in relation to the total area available for arable farming. If, for instance, 40 per cent of the available arable land in one holding is cultivated, then $R$ is 40 .

As long as fallow farming has an extensive character, in which many fallow years follow a short period of cultivation, $R$ remains very small. If, for example, eighteen fallow years succeed two years of cultivation, as is frequently the case in the rainforest, $R$ amounts to 10 . This extensive type of fallow farming is generally designated shifting cultivation, because the shifting of fields within a broad area of wild vegetation usually results in the gradual relocation of the farming population. On the other hand, it should not be forgotten that there are a number of regions where stationary populations practise shifting cultivation.

The larger $R$ becomes, the higher is the percentage of the area cultivated annually in relation to the total area available for arable farming, and the more stationary the character of the farming becomes. When cultivation is 
INTRODUCTION

extended so far at the expense of fallowing that the characteristic $R$ reaches or cxceeds the value 30 , then we can hardly speak of a shifting of the fields any more. A level of intensity of land utilization has been achieved that Terra, Nye, and Greenland designate semi-permanent cultivation, and that Faucher designates stationary cultivation with fallowing. A characteristic $R$ value of 50 is obtained, for example, if seven fallow years succeed seven years of cultivation.

When the $R$ value exceeds 70 , and the soil is cultivated nearly every year or even more often, then permanent farming is being practised. Permanent farming, may again be conveniently classified according to the degree of multiplt cropping. An $R$ value of 150 would indicate that 50 per cent of the area is sarrying two crops a year, and a value of 300 would indicate that three crisps a year are teing grown.

(c) Classification according to the water supply. One of the first steps in classifying land utilization is to question whether farming is practised with or without irrigation. In irrigation farming, to ensure that the moisture level of the soil is higher than would occur naturally, a water suppiy is directed into the fields, or the rain-water in the fields is purposefully dammed up. Farming without irrigation is widely referred to as dry farming. In the interest of precise definition, however, it is advisable to speak of dry farming only where in semi-arid climates grain and leguminous crops are alternated with a fallow of one or two years. A distinction between irrigated farming and rainfed farming is therefore preferred.

(d) Classification according to the cropping pattern and animal activities. A most important aspect of the definition of farming systems is usually the classification according to the main crops and the livestock activities of the holdings. Each activity has different requirements as to climate, soils, markets, and inputs. Therefore those farms can be grouped together whose gross returns (sales plus household consumption plus changes in stock) are similarly constituted, to give, for example, coffee-banana holdings or rice-jute noldings.

(e) Classification according to the implements used for cultivation. In addition, holdings are occasionally classified according to the main implements used. In various parts of the world, the land is cultivated by methods that require either no implements, or a few very simple tools. Millet is sown without fire-farming or soil preparation by a few nomads in the Sahara. Shifting cultivators frequently sow in ashes without touching the soil either beforehand or afterwards. Rice growers in Madagascar, Ceylon, and Thailand make use of the treading of animals: a large number of cattle are driven across the moist field to trample down the soil until it becomes a mire ready for planting. In some parts of the world, planting-sticks and digging-sticks have not yet been replaced by hoes, spades, or ploughs. However, with the exception of these pre-technical methods, the mair divisions are (1) hoe 
farming or spade farming; (2) farming with ploughs and animal traction; and (3) farming with ploughs and tractors.

(f) Classification according to the degree of commercialization. There are a number of distinct types according to the percentage of sales in relation to the gross return. Subsistence farms are those where agricultural products are raised with the main purpose of covering only the needs of the household; selling is limited to surpluses of these products. The share of sales in relation to the gross returns is less than 25 per cent. Partly commercialized farms are those where the systematic cultivation of cash crops is practised in addition to production for household needs. However, the percentage of sales still remains below 50 per cent of the gross returns. Semi-commercialized farms are similar, but in addition to production for the household so much cash cropping is carried out that the share of sales amounts to 50-75 per cent of the gross returns. Highly commercialized farms are the remaining type, in which less than 25 per cent of the gross output is consumed by the household.

\subsubsection{Grassland utilization}

The low yields of grassland areas in the arid and semi-arid tropics necessitate either nomadism or semi-nomadism, or the development of ranching systems. It seems advisable, therefore, to classify the different types of livestock farming according to the degree of stationariness of both the animals and those who tend them. According to Dittmar (1954), five main types can be distinguished:

(1) Total nomadism covers systems in which the animal owners do not have a permanent place of residence. They do not practise regular cultivation and their families move with the herds.

(2) Semi-nomadism is a related system where the animal owners have a permanent place of residence near which supplementary cultivation is

- practised. However, for long periods of time they travel with their herds to distant grazing areas.

(3) Transhumance is the situation in which farmers with a permanent place of residence send their lierds, tended by herdsmen, for long periods of time to distant grazing areas.

(4) Partial nomadism is characterized by farmers who live continuously in permanent settlements, and who have herds at their disposal which remain in the vicinity.

(5) Stationary animal husbandry occurs where the animals remain on the holding or in the village throughout the entire year.

\subsubsection{Procedure in this book}

The definition, classifications, and criteria outlined above are ex.lployed in the following chapters. Collecting systems are omitted because of their 
ecoromic insignificance. The book is restricted to cultivation systems and grazing systems, and its main chapiers are organized according to the type end intensity of land use. As major cultivation systems, a distinction is thus made between shifting cultivation systems, semi-permanent cultivation systems, systems with regulated ley farming, systems "'ith permanent cultivation on rain-fed land, systems with arable irrigation farming, and systems with perennial crops. Under the heading of grazing systems, only nomadic grassland use and ranching are considered. The other forms of grassland use are described as part of the relevant cultivation system.

\subsection{Dofinition of farms}

Farming within each system is carried out in holdings, which are more or less distinct managerial units. Following Woermann (1959), holdings are here defined as orjanized, economic units in which plant and animal products are produced for the purposes of gain. The economic aims that underlie such gainfui employment vary from case to case. In larger holdings, market production and profits are the main objectives, whereas for the sinallholderand most of the tropical land is farmed by smallholders-the farm and the household are closely connected. Equally as important as, or even more important than, saleable produce on such a farm is the provision of tood for the household, together with goods for personal consumption like tobacco, or raw materials like wool or materials for building huts. Other important production aims are the safeguarding of the future by arcumulation of capital in the form of animals or plantations, and the increasing of social status by accumulation of wealth or by special technical, social, and economic achievements.

Although agricultural enterprises are usually tied to a clearly defined place, this is not always the case. For example, production by nomads is based on herds that trek from grazing area to grazing area. In shifting cultivation, the fields are shifted over an extensive area. Nomads and shifting cultivators produce for the purposes of gain, but they operate without a stationary habitat.

Holdings are usually, but not always, under the management control of one person. In some cases, there are holdings where a group of people operate on a communal basis without electing or nominating a manager. In smallholder farming in Africa south of the Sahara, it is usual for individual members of a household to cultivate small plots as they think fit and with differing economic aims. In these cases, the holding comprises the various fields belonging to the family as a whole.

Where production for the market has priority, there is usually no difficulty in identifying the holdings and the holding management, but where subsistence farming predominates it is not always easy to recognize and to define 


\section{INTRODUCTION}

ngle holdings, and judgement has to be arbitrary in many ways. Because of re dependence of cropping and use of labour on the requirements of the ousehold, it seems advisable to include in one holding the land and animals hat belong to a household at a given time, or which the members of the lousehold have the right to use. The communal kitchen is usually the defining
haracteristic of the household itself.

Within a farm, the various activities are connected functionally in ways hat can vary from the simple to the very complicated, but in all of them there is a system. Most of the crop and animal activities on a farm are closely related to each other by the common employment of labour, land, and capital. Cultural practices are also closely linked with the various crop and appraisal of all the Chan $_{\mathcal{L}}$ ?s in any one practice usually require a reEach farm is thus a cohesive, since the former balance will have been upset. "Men system in itself.

"Men wish to make their activities "efficient" rather than wasteful' (Herskovits 1964, p. 512). Consequently, "it can be taken as cross-culturally acceptable that, on the whole, the individual tends to maximize his satisfactions in terms of the choices he rnakes. Where the gap between utility and disutility is appreciable and the producer ... is free to make his choice, then, other things being equal, he will make his choice in terms of utility rather than disutility' (Herskovits 1965, p. 18). In describing farming systems and their characteristics, we start therefore with the assumption that they did not come about by chance and that there is always a reason why farming in a specific case is carried out in one way rather than another.

Having thus defined the geographical region with which we are concerned, the farming systems, and the meaning of the word farm or holding, we proceed to a consideration of some of the more important characteristics of farming in the tropical environment and their implications for farm management. 


\title{
2. Some general characteristics of farming in a tropical environment
}

\author{
by J. D. MacArthur
}

FARMS in the tropics, like farms everywhere, are adjusted to the circumstances of the environment in which farmers find themselves. This is particularly true of smallholder agriculture, which predominates in most tropical areas. The levels of production technology and the resources available to smallholders are such that they have only a limited ability to change or adapt their practices to the rigours and pussibilities of each situation. The growing literature on agricultural systems underlines the remarkable ingenuity with which farmers and pastoralists have devised workable systems of production for almost all of the many climatic and social situations that occur within the tropical zone. A full appreciation of the extent and nature of producers' adaptation is best obtained through consideration of the main features both of the natural environment and of some critical aspects of tropical farming. which partly arise from the natural conditions of production.

\subsection{The natural environment}

In this section, attention is drawn to some of the most important features of the natural environment, which can be classified into three main groups covering climatic, soil, and biological conditions. Whilst some valid generalizations can be made about them, it is important to stress at the outset that the tropical areas are characterized by enormous variability, which stems mainly from the different manifestations of climatic effects on the one hand and altitude on the other. Large stretches of uniform ecological conditions, like the North American prairies, or the Black Soil belt of continental U.S.S.R., a.e not found in the tropics. Consequently, generalizations about tropical conditions such as are inade here are inevitably beset with oversimplifications. Interpretation of their importance in particular circumstances requires great care. 


\section{SOME GENERAL CHARACTERISTICS OF FARMING}

\subsubsection{Climatic influences}

Climate is the main distinguishing feature of those areas that are usually considered as falling within the tropical zone, a term which, as Fig. 1.1 shows, generally refers more to places with particular types of climate than to those areas that fall between the two confining lines of latitude. Such areas are normally hot by comparison with other parts of the world. Except where high altitudes modify the effect substantially, coldness is seldom or never a limiting factor of agricultural production. In some parts of the tropics, especially the humid forest zones, and in irrigation areas, crop production is possible at every time of the year. Where the water supply and the quality of the soils are sufficient to make full use of the advantages created by an ample and even supply of solar energy, the production potential of tropical farming is extraordinarily high, as testified by record harvests, which according to Bradfieid (1968) attain the following levels:

(I) Rice in Madras, India: $13400 \mathrm{~kg}$ per hectare in one harvest.

(2) Rice and three sorghum crops per hectare in twelve months in the Philippines: total yield $5000 \mathrm{~kg}$ of rice, $16500 \mathrm{~kg}$ of sorghum.

(3) Sweet potatoes in the Philippines: 30 tons in 90 days.

Most of the tropics, how iver, experience a seasonal pattern of rainfall, with distinct periods of high and low levels of precipitation. This means that soil moisture levels at certain periods are not sufficiently high to sustain plant growth. Moreover, effective rainfall in the tropics is often less than in temperate areas, since evaporation and transpiration losses are much more severe in the heat. Apart from giving rise to a seasonal shortage of soil moisture in some areas, rainfall patterns are also characterized by their great variation between one year and another, and between adjacent places. The degree of this variation can be greatest in those places where mean annual rainfall is lowest. However, in large parts of the tropical world, a considerable degree of uncertainty attaches to the level of rain that will fall in any one season, with both drought and flood as serious possibilities that occur all too frequently. Moreover, when the rains do come, they often occur in a series of very heavy storms, in which a lot of rain falls within a short time. Wherever it occurs, this pattern of precipitation, with its unpredictability and severity, increases the problems and uncertainties of farming.

Another main feature of the tropical climate is the importance of wind. The impact on temperature and rainfall of some of the main rain-bearing winds, especially the monsoons that are associated with the large continental land masses, is well known, as are the more sensational hurricanes and typhoons. However, winds blowing off the hotter land masses-especially the larger deserts-can have dramatic consequences of their own because of their intense drying effect. In many tropical areas the dry season is a time of 


\section{SOME GENERAL CHARACTERISTICS OF FARMING}

fairly high winds, which not only reduce the opportunities for plant growth, but also bring a threat of wind-induced erosion.

A number of other efiects of climate on tropical agriculture can be important. Within the tropical latitudes, there is relatively little variation in day length between one part of the year and another, and on the equator the length of all days of the year is virtually the same. Within the day, the intensity of solar radiation and the air temperature may undergo fairly rapid changes, although both effects are less pronounced in places where and at times when the relative humidity of the atmosphere is high, and when there is a high incidence of cloudiness. This means that, whilst the hours of daylight are limited to something like the length of a typical day in early spring or autumn in temperate latitudes (i.e. 13-15 hours), the heat and intensity of radiation may at times be so great that animals and workers seek the shade, and can pursue productive activities for only a limited period. Altitude reduces the temperature effect, but can intensify the radiation problem beyond comfortable levels.

Climate exerts its influence on farming not only through the control that it imposes on the timing and volume of plant growth, but atso through its effect on livestock production. Excessive heat and humidity can upset animal physiology, causing distress, reducing appetites, and limiting productivity. At the same time, high temperature and/or humidity can make the conservation of harvested produce very difficult, leading to high losses amongst crop reserves kept for use outside the productive season.

\subsubsection{Soil conditions}

Tropical soils vary enormously in type and suitability for farming. Some are derived from materials that are the products of fairly recent geological events, being volcanic or sedimentary in origin, whilst others are derived from very old igneous material. Despite their great variation, however, a few useful generalizations about tropical soils can be inade.

Perhaps their most widespread feature is the extent to which the pattern of precipitation in sudden heavy rainstorms has led to extensive leaching, so that most of the soluble plant nutrients have been carried away. Consequently many soils, particularly in high-rainfall areas, have a low level of natural potential fertility. Also detracting from their fertility status is the low level of organic material that is typical of most of them. Under warm tropical conditions, most organic matter breaks down quickly whenever it is moist, resulting in a rapid but short-term release of nutrients in areas of alternating wet and dry seasons.

Another common characteristic that detracts from their fertility is the poor structure of many tropical soils. Because of this feature, they may not be resilient under intensive cultivation, and this consequently increases the high 
risk of water and wind erosion. Erosion by surface water is a constant danger, especially because of the intensity of tropical storms.

\subsubsection{Biological environmen:}

Partly within the sphere of human control is the hislogical environment: the natural or introduced species of all kinds, which, in tropical conditions, are particularly numerous and varied. In the warmth, many kinds of weeds, fungi, and parasites survive very well wherever moisture levels are high enough, so that domesticated plants and livestock are coristantly subject to competition or parasitic infection and disease. This presents many problems. Not only is cropping beset by the ever present need for clearing and weeding, and the removal of secondary vegetation, but all farm production processes are exposad to high risks from pests and diseases of many kinds. Some of the principle scourges, like the tsetse fly and ticks, are constantly present, as are some of the virus and bacterial agents that cause serious crop and livestock diseases. Others are not a constan' threat, but may build up to plague proportions in a very short time. This is especially true of insect pests, but appiies also to many other species, incliding rodents and even small birds, which can wreak sudden and tremendous havoc amongst growing and harvested crops.

In a pre-technical scciety, the farmers' main palliatives for problems of this kind are adaptation or avoidance. Many of the effects of other biological agents cannot be avoided, but traditional husbandry methods contain many risk-spreading features that are designed particularly to overcome problems of this kind.

\subsection{Some critical aspects of tropical farming}

Farmers who work under the circumstances depicted in the last section are faced with management problems and dilemmas of four main kinds, which derive from certain features of their natural environment and are reflected in the systems of farming that they follow.

\subsubsection{Problems of soil fertility}

First, the numerous problems of maintaining soil fertility in a humid tropical environment have to be considered. The importance of soil fertility and conservation is clearly recognized by most tropical farmers, and practically every system of farming involves measures that are specially adnpted to increase the fertility of land that is being cropped. Essentially, the fertility problem is one of making available in the upper layers of the soil sufficient nutrients (in the right condition of solubility and availability) to allow plants to grow. Under natural conditions, an equilibrium tends to develop in which losses through leaching and surface run-off are made up by the chemical 


\section{SOME GENERAL CHARACTERISTICS OF FARMING}

breakdown of soil minerals and the supply of available nutrients from lower soil layers that deep-rooted plants maintain. In contrast to this natural situation, cropping or other forms of farming are almost always exploitive, in that they involve the removal of nutrient-bearing product materials from the places where they were produced and use of them elsewhere. Often the residues remaining after their use by humans are not returned to the land, but are disposed of so as to be carried away in drainage water. Natural replenishment may in some circumstances keep pace with this loss, whilst farmers may 'concentrate' fertility by gathering crop residues, manure, or natural vegetation in those places where they intend to undertake cropping. However, all of these systems are wasteful in the sense that through the deliberate removal and transplantation of produce, and by the involuntary disturbance of the natural order in ways that can increase the rate of loss, nutrients are removed from the soil and are not replaced. Sooner or later it is inevitable that such a system must lead to either temporary or permanent reductions in soil fertility. Problems of this nature are much more acute in the tropics than elsewhere, because in the warm climate, especially where it is combined with long periods of high humidity, the chemical and biological processes take place very rapidly. The higher the loss of nutrients through leaching, the more easily are the structural properties of the soil destroyed.

Farmers in almost all kinds of situation pay some attention to the problems of soil fertility. Under some conditions, indeed, the problem can become such a major preoccupation that whole farming systems and practices are substantially modified to balance the conflicting and imperative short-term needs of maintaining both production and residual fertility levels. Generally, however, the kinds of measure that can be adopted to protect soil fertility and prevent erosion require a great deal of labour for their construction and development. Obviously, this can impede their progress.

\subsubsection{Coping with risk and uncertainty}

Additional major farm-management problems derive from the high levels of production risk and uncertainty that surround agricultural production in the tropics, especially at low levels of technology. In smallholder farming, the objective of every household, whather commercialized or not, is to produce most of the basic food and other natural-product needs of the family. It is therefore essential that a minimum amount of food of different kinds should be available throughout the year. In mecting this objective, farmers have not only to consider the production risks that may arise from climatic variation and the effects of pests and diseases; they have to allow also for the effect of these same influences on stored produce, where destruction and deterioration can be very rapid.

The particularly dramatic nature of variations of this kind that are associated 
vith tropical production causes farmers to adopt a number of devices to pread their risks and ensure a constant supply of produce, which, because of consumer preference, must be as fresh as possible. Diversification of proluction, so as to grow a range of crops, is a typical risk-spreading devic: ollowed by farmers the world over. The planting of a particular crop att different times over an extended planting period, which will allow some pro. duce to be obtained in either an early or a late season, whichever should occur, and the combination of difierent species in crop mixtures are both practices with an clement of risk-avoidance in their adoption.

From the point of view of farm operation and resource allocation, the need to provide for a minimal production in the very worst possible season can lead to an apparent misallocation of resources, in that the target levels of production for a particular commodity may, in a nornal or good year, be such as to provide a surplus, which will not always find a market. At the same time, some crops may be grown that are not really' the best for a particular production situation. Thus, to overcome the risk problem, farmers may need to employ more resources for subsistence production than would normally be necessary, and they may be obliged to grow for themselves so:ne products for which their land or skills are not well adapted.

\subsubsection{Low labour productivity}

Closely related to the problems just referred to is the low productivity of agricultural labour in the tropics, whether measured in hours per availible worker, or by the physical performance per hour of work, or by the return per hour of work. In the majority of situations, even where land is limited in supply and advanced material inputs like mineral fertilizer and pesticides are not used, the most critical farming input is the labour of the farmer and his family. Most of the work that they have to do is both tedious and strenuous, so not surprisingly farmers show a marked preference for leisure: this his often been demorstrated by the extent to which hired workers are employed to replace them cnce incomes have exceeded very modest levels. Often, how: ever, despite the use of seasonal labour, farmers are severely limited in their scope for increasing output by making higher labour inputs, through the shortness of the growing season during which useful farm work can be done, the low levels of technology at which they typically operate. and the heavy demands in both time and effort that domestic duties make upon certain members of the household.

Where, as very often is the case, labour is the main variable input into farming, its availability can be the limiting factor to production, especially at certain critical times of the year. Consequently farmers seek-and usually quickly take up-new crops, production methods, and product combinations that offer higher returns to labour and are also ecceptably free from risks. It 


\section{SOME GENERAL CHARACTERISTICS OF FARMING}

is, therefore, those processes that offer higher returns on labour that many farmers actively seek, and the development of small-scale production must largcly depend on the discovery and adaptation of practices that will substantially improve returns on work. From the farmer's point of view, labour productivity and work rationalization are considerations of great importance.

\subsubsection{The problem of seasonality}

Farm operation and labour productivity are further hindered by the acute seasonality of many climates, in which wide differences exist between the wet and dry seasons, or seasons with and without irrigation water. Where the water is available in only a few months, all of the crop work needs to be carried out very quickly, beginning often only when the rain softens the soil, and continuing with cultivation, planting, and weeding for as long as crop growth is possible. The urgent need for high labour inputs at this time coincides often with the period when fresh food supplies are most scarce, and low nutritional levels inhibit workers and draught animals from making as great Exertions as they might wish. Certainly this season contrasts strongly with the other months, in which little work to assist crop production can be carried out, and harvesting and maintenance may be the main activities. At such times, a lot of labour cannot find productive work.

Similar problems arise in livestock management. During the rainy season, fodder is abundant and of high quality, and animals can grow, produce milk and other products, recover condition and health, and are capable of sustained work. In the dry weather, the grazing de:eriorates. Animals may lose condition, whilst their productivity declines, often to nil, as lactating animals dry off.

One consequence of the shortness of the cropping season, and the low productivity of manual and animal power at this time, is that the mechanization of cropping can bring high returns, if propeily managed. Usually, where they can be kept, draught animals can bring ar. improvement over manual labour. Draught animals, however, suffer in conditions of high humidity and heat and the accompanying diseases. They also find it much more difficult than tractors to cope with rapidly hardening soils. The greater speed witl which operations can be performed by tractors, and the fact that they can work at times of the year when soil cenditions prevent hand workers or draught animals from carrying out such tasks as cultivation are of crucial importance to the volume of production where the best use must be made of a small amount of rain. It must not be assumed from this that the use of tractors in the tropics is always more practicable than use of the hand hoe or draught animals, but in the context of farm-management characteristics it is important to note that the physical rate of substitution of traction animals by tractors is comparatively high. 


\subsection{The dynamics of tropical tarming}

Despite the difficulties of the natural environment, and the limitations that arise from unfavourable price relations, unstable markets, and the traditional socio-institutional conditions of agricultural production in low-income countries, tropical farming, which is mainly smallholder farming, is a dynamic business, in which small but numerous adjustments are continually being made to the production processes. ${ }^{1}$ Tropical farmers are experienced in adapting their systems and methods of production to different circumstances, albeit slowly and with only a limited success in making major technical discoveries. In the following chapters of this book, seven basically different, main types of farming system are considered, and traditional producers are important in each of them. In every situation, the dominant importance of the three major problems of fertility, uncertainty, and labour productivity is highlighted, together with a consideration of the ways in which technological and institutional changes can be made so as to overcome these basic prcblems. This indicates how production can be transformed from its traditional pattern to a mor: productive and beneficial level. That substantial changes can be brought about through the application of modern technology has been shown countless times. This possibility should not mask the fact that innovation and change, however slow, are normal features of traditional farming. Without a continuous series of small adjustments, these diverse and often well-adapted farming systems could never have been devised. The application of modern technology will generally involve the hastening of processes that were already taking place, permitting increased realization of the astonishingly high levels of production that are possible in tropical areas under optimal conditions.

\footnotetext{
1 The information on economic and socio-institutional conditions of production is deliberately kept short throughout this book (see p. v).
} 


\section{Shifting cultivation systems}

\subsection{Definition}

SHIFTING cultivation is the name we use for agricultural systems that involve an alternation between cropping for a few years on selected and cleared plots and a lengthy period when the soil is rested. Cultivation consequently shifts within an area that is otherwise covered by natural vegetation. The intensity of shifting cultivation varies wideiy. A relatively simple and appropriate criterion of land-use intensity is the relation between the period of cultivation and the period of fallow (see $\$ 1.2 .2$ ).

The shorter the time between the cultivation periods, or the greater the annually cultivated area in relation to the total area, the more stationary does farming become. In the course of this development, short-fallow systems replace long-fallow systems. If the characteristic $R$ is more than 30 , i.e. if 30 per cent of the arable and temporarily used land is cultivated annually, we no longer speak of shifting cultivation but of semi-permanent farming.

\subsection{Types of shifting cultivation and their goographical distribution}

Table 3.1 shows that shifting cultivation is practised principally in rainforest climates and in thinly populated savannas. It is found, however, in all climates and in very varied economic conditions. It was the elementary and pioneering cropping system used by the early agricultural occupants of many forested regions all over the world. Shifting cultivation is today practised by peoples in the interior of New Guinea just coming out of the Stone Age, and also by a large number of partly commercialized farmers in Asia, Africa, and Latin America. There are, however, few pure subsistence holdings, even among the shifting cultivators. In most cases supplementary ca'ih cropping is practised. Shifting cultivation is often a technology of ex/ediency, used because it will work better under a given set of candition's than will any other system available to the practitioner (Spencer 1966, p. 2). In other cases it is a land-use system which may belong to the past but is still carried on because the transition to more productive land-use systems demands more favourable price relations, knowledge, capital, and time.

The forms assumed by shifting cultivation are more varied than in practically any other land-use system. It is therefore useful to consider it in relation 
to several criteria: here a distinction is made between vegetation systems, migration systems, rotation systems, clearance systems, cropping systems, and tool systems.

\subsubsection{Vegetation systems}

We may distinguish on the basis of vegetation between the shifting cultivation of the forest, of the bush savannas, and of the grassland areas. Shifting cultivation in the rainforests is typical of rain-fed farming in humid areas of low population density. Rotations with bush fallowing predominate in the African savannas. Alternation between cultivation and wild grass vegetation is found in some tropical high-altitude areas, in semi-dry climates, and not least where the reduction of the fallow period has led to the growth, while the ground is resting, of largely useless grasses (frequently Imperata species) instead of bush fororest.

Spencer's classification (1966, p. 181) goes even further. He distinguishes between shifting cultivation in (1) virgin forests, (2) mature regenerated forests, frequently called secondary forests, (3) immature regenerated forests, (4) scrub tree growth, and (5) grassland.

\subsubsection{Migration systems}

The continual movement of cropping results, in most systems with shifting cultivation, in a slow migration of the population. The cultivated plots move slowly away from the previous clearing and the vicinity of the hut. At the same time the cost of transporting the harvest increases, especially where root crops are grown. At a certain distance, it becomes advantageous to build a new hut near the field instead of carrying the harvest such a long way.

Shifting of plots is made easier by the very nature of tropical housing; it is often more economic to build a new hut than to repair an old one. The frequency of hut changing varies greatly. In the rainforest, in some cases, a change occurs every two or three years; in the savanna less frequently, sometimes only once every one or two decades.

Allan (1967, p. 4) describes the process in central Africa as follows:

A village or other group within such a concentration will use up the accessible land in its neighbourhood before the area first cultivated has had time to regenerate and a move must then be made to regenerated land ... A series of pictures or aerial photographs made at suitable intervals would show a gradual movement of the larger community across the countryside in a manner suggestive of the
progress of an amoeba on a microscope slide.

By the direction of the migration we can distinguish, according to Spencer (1966, p. 177), between (1) random shifts, (2) linear shifts onto newly cleared adjoining lands, which result in the steady and progressive clearing of mature forests, (3) cyclic shifts within a given area claimed by the group or family, 
TABLE 3.1

The length of the crop and fallow periods under shifting cultivation

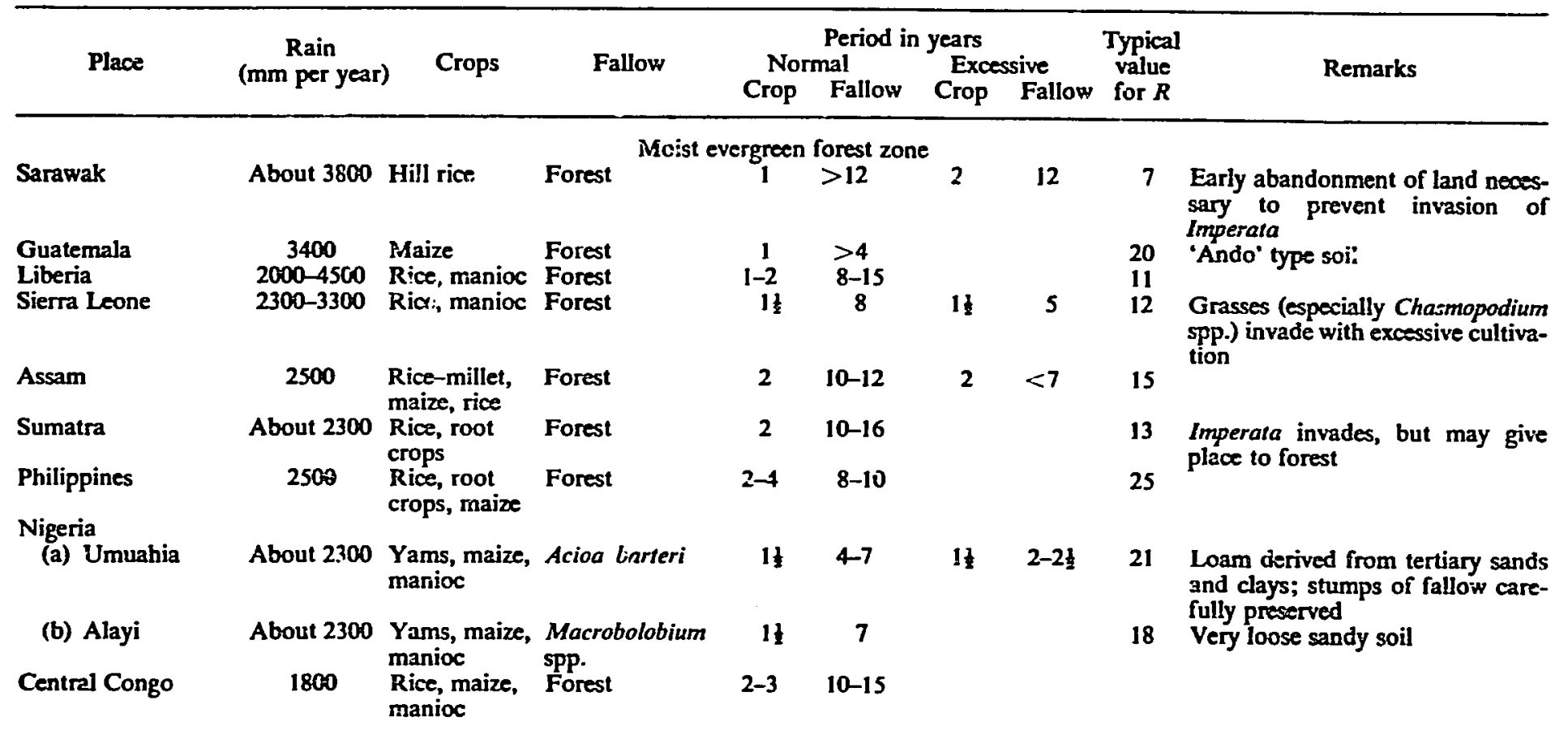


Moist semi-deciduous and dry forest zone

(including humid zone of derived savanna)

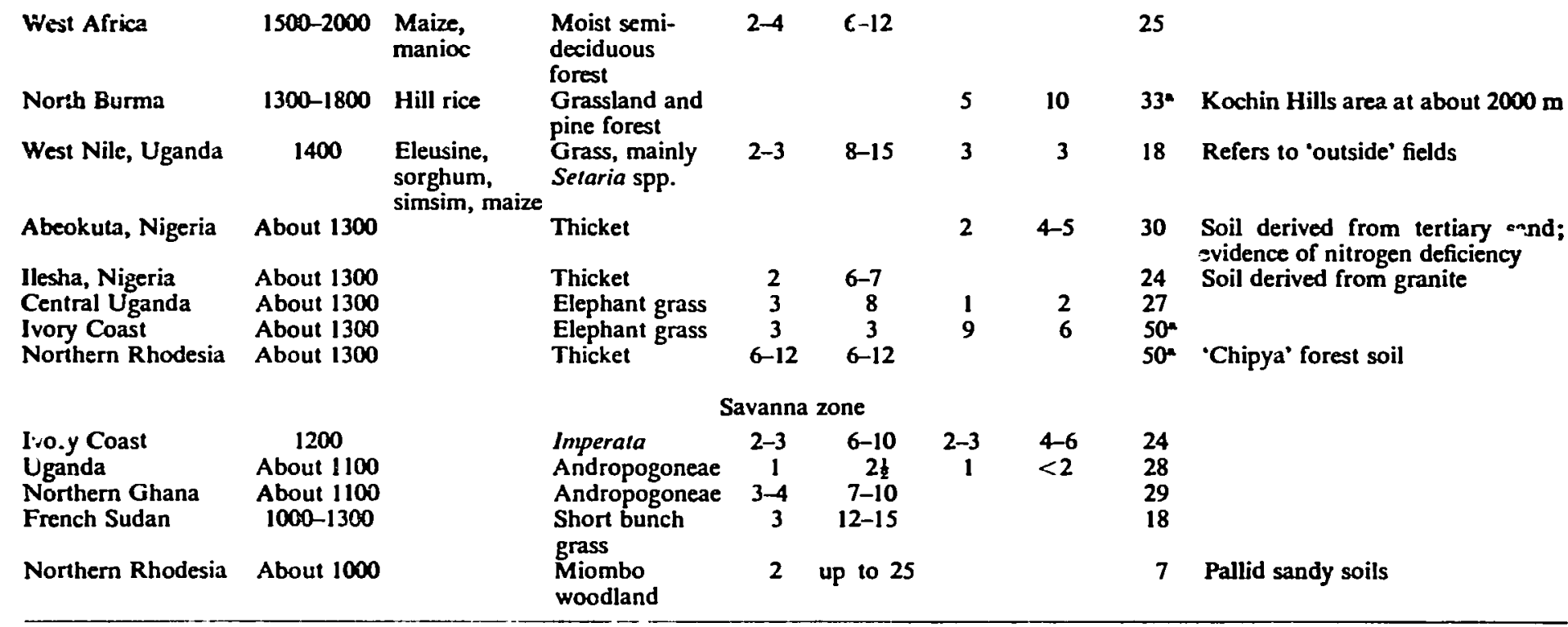

- Semi-permanent cultivation in our terminology.

Source: Nye and Greenland (1961, p. 128). 
and (4) reduced cric shifts, brought about by increasing population densities, which might finally lead to sedentary living.

\subsubsection{Rotation systems}

Shifting farming is practised not only by migrating cultivators but also by sedentary cultivators. In each case, however, cropping and fallowing alternate, and this alternation can have an irregular or regular character. In the case of a regular sequence, a definite number of fallow years follows a definite number of years of cultivation. A further distinguishing characteristic of the rotational pattern is whether land is selected for use in small piots (where, for example, cultivation is restricted to termite mounds, moist valley bottoms, etc.) or whether continuous tracts of land are cultivated.

The rotation systems in rainforest agriculture are mostly simple. Two to four years of cultivation are followed by one to three decades of fallowing. Miracle (1967) calls such patterns 'classical long-fallow systems'. In the savannas of Africa, on the other hand, we often find complicated rotation systems in which short-term fallow periods of 1-2 years, medium-term fallow periods of 3-5 years, and long-term fallow periods of 6 years or more alternate in a single cycle of land use. These combinations of classical, longfallow systems and short-fallow systems aiso predominate in semi-permanent farming. The shcrt-term fallow periods can usually be attributed to unexpected lack of labour during the cultivation period, whereas increasing weed growth and decreasing fertility lead to medium-term and long-term fallow periods (see \$4.3.2).

An example will illustrate this type of situation. In the Kilombero Valley, Tanzania, where shifting cultivation of rice is pursued in an area where elephant grass dominates the natural vegetation (Baum 1968, pp. 32-4), the following rotation systems have evolved according to the settlement density:

\section{Rotation Cycle of 45 Years}

When there is an abundance of land, cultivation takes place within two rotations, one shorter and one longer. As a rule, the shorter rotation runs as follows:

3 years of rice-growing (with one annual harvest)

3 years of grass-fallow.

Several families put their rice plots together into a block, in order to obtain better protection against vermin. They alternate between two blocks, one carrying rice, the other one lying fallow for about 15 years. Thereafter, the families move into a neighbouring area where the 'short rotation' is likewise practised. In a few out of the way parts of the inner valley, families even move into a third area. Then they move back to the first area, which has then lain fallow for $\mathbf{3 0}$ years.

The short rotation of 5 years is thus supplemented by the long rotation over a period of 45 years. This results in a total $R$ value of 17 , i.e. 17 per cent of the cultivated land is used annually [see Fig. 3.1, part I]. The total area composed of the three zones farmed by the families is occupied by these families in accordance with traditional land rights. Immigrants may not settle there without 
permission. As a rule, the household members know their plots in each of the three areas and cultivate them in regular cycles.

\section{II and III. Rosation Cycle of 30 Ycars}

When there is not enough land available for the families to move between three areas, the 'long rotation' is limited to two areas. The families live in each

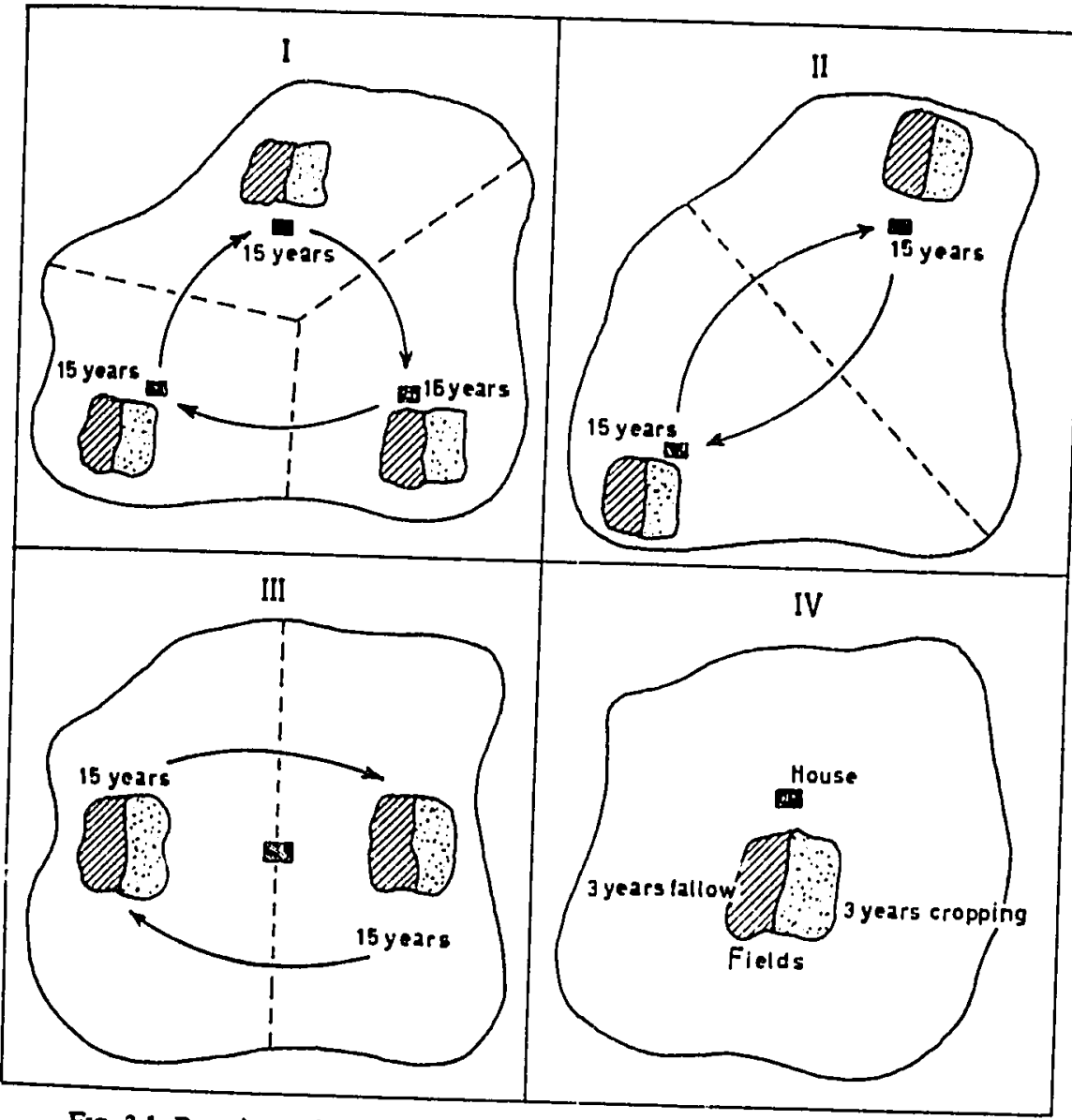

Fra. 3.1. Rotations of shifting cultivators in the Kilombero Valley, Tanzania. I = short rotation: 3 years cropping, 3 years fallow

long rotation: 15 years oicupation, 30 years unoccupied

total duration of rotation c cle: 45 years, frequent changing of huts

II $=$ total duration of rotation: 30 years, semi-stationary housing

III = iotal duration of rotution: 30 years, stationary housing

IV = short rotation only: 3 years cropping, 3 years fallow

one for 15 years and rotate 2-3 years of rice with 2-3 years of fallow. This results in a total $R$ value of 25 , i.e. 25 per cent of the occupied land is cultivated per 3.1, part II]. 
Fig. 3.1, part III represents a modification of this type of shifting cultivation in view of a higher degree of stationariness. The settlers have a permanent dwelling-place, as, for exanple, near the road. The fields, however, are still rotated in 15 year cycles, i.e. the land on one side of the settlement is used for 15 years, alternating 3 years of cultivation and 3 years of fallow. Subsequently the fields on the other side of the settlement are cultivated.

\section{Semi-permanent Farming}

The growing population density is conducive to the "long rotations' being abandoned. Where land becomes increasingly scarce, two to three years of cultivation are followed by the same number of fallow years. The dwelling-place is permanent, either next to the road or in some other favourable location. Fixed and recognized boundaries are established for holdings and fields. Permanent and generally acknowledged rights of use are derived from the traditional land laws. The typical value for this intensity of land use is $R=50$, which results when the years of cultivation are followed by the same number of fallow years.

\subsubsection{Clearance systems}

The type of clearance work and the order it takes vary according to the vegetation that is to be cleared, the distribution of rainfall, the crops grown, the available tools, and the cultural background of the population. Following Miracle (1967, pp. 41-7), we classify the forms clearance takes as follows:

(a) Burn and plant. One of the simplest forms merely involves burning off a thick and dry secondary vegetation. Immediately after burning, maize is planted, and matures before the secondary vegetation has recovered from the burning sufficiently to produce brushwood and leaves. Cook (1921) describes shifting cultivation of this kind in his 'Milpa agriculture' in Central America.

(b) Burn, hoe and cut, plant. The burn, hoe and cut, plant system is reported only in savanna areas, where fire effectively eliminates most of the vegetation. Cutting is limited to the remaining trees and bushes. Except for the reversal of the burning and hoeing operations, this method of agriculture is much like the cut, burn, plant system.

(c) Cut, burn, plant. The cut, burn, plant method of agriculture is the most common one reported. Typically, vegetation is cut--usually towards the end of the dry season-allowed to dry for a while, and then is burnt as the rainy season approaches and the soil must be prepared for planting.

The cut, burn, plant method is divided by Miracle into ten major subdivisions, according to the amount of cutting and burning done and whether further cultivation operatiuns are employed.

(d) Cut, plant, burn. The cut, plant, burn technique is the only system in which the vegetation residue left in the fields is burned after crops are growing, and is reported only in forest areas, or areas near the forest belt which 


\section{SHIFTING CULTIVATION SYSTEMS}

would possibly still be forest except for the activities of man. Usually the crop occupying the field when it is fired is bananas, plantain, or manioc. In such systems, clearing is often done over a relatively long period, and crops are planted as soon as the smaller vegetation has been cut. By the time all trees to be removed have been felled, the planted crops have established themselves, and the field is given a burning, which apparently inflicts little or no damage upon the growing crops.

(e) Cut, bury refuse in mounds, plant. Various sorts of composting operations are reported as an integral part of field preparation in some of the southern African savannas. After vegetation is cut, it is buried in mounds in the field, or perliaps the debris is first burnt and the ashes are buried. In other cases, the debris is buried in inounds and then ignited, possibly because of the beneficial effect of heat on soil fertility (see Nye and Greenland 1961, p. 71).

(f) Cut, add extra wood, burn, plant, hoe. The cut, add extra wood, burn plant, hoe method, generally referred to as chitemene in Zambia, involves cutting bush from a greater area than is to be planted, in order to obtain a hotter fire and a large amount of ash on the land that is to be sown. Among the tribes practising chitemene, the amount of land cleared may be from five to twenty times as much as that cultivated, and the cut debris may be piled in one area forming a large circle or distributed into two or more smaller circles.

(g) Cut, wait one season, plant (forest). Several tribes in the Congo Basin partially cut vegetation, plant bananas, and then wait a season before completing the clearing operations and planting other crops among the established bananas.

(h) Killing trees by ringing, ridging, planting. This series of operations, additional to those mentioned by Miracle, is practised in the dry forests of southern Tanzania. Ringing replaces clearance work. When the trees have lost their leaves the light can reach the ground, and the leaves that have fallen off and vegetation on the ground are dug into the ridges. The trees are never felled; they are left as dead, standing timber.

Shifting systems may also be classified according to how complete the removal of the vegetation has been (Spencer 1966, p. 181). Occasionally the farmers restrict themselves to ringing or creating clearings by felling some trees. If fire does not consume the trunks and the larger branches, these are left lying on the ground, and cultivation is carried on among the debris. In other cases, however, the vegetation is thoroughly burnt off, and in some cases a second fire may be necessary. Differences in clearing technique appear to be fairly well explained by variations in ecological conditions. The simplest and least intensive techniques are found in the humid forest belt. The number of operations and amount of labour required are greater in the savanna areas (Miracle 1967, p. 159). 


\subsubsection{Cropping systems}

Shifting cultivation is almost exclusively carried on as farming with annual and biennial crops. In humid climates we find above all rice economies or root-crop economies where the en!phasis is on manioc, sweet potatoes, yams, and taro. Widespread, and extending into the drier cliniates of the savannas, are maize and millet economies. In between are numerous mixed ecoromies, which are based on root crops as well as grain crops. There is ample evidence to show that shifting cultivators are not static or traditionally fixed in their cropping patterns (Miracle 1967; Baum 1968; Spencer 1966). Most of the crops or varieties grown by African shifting cultivators have been introduced in the last 300 years by traders, settlers, and administrators. According to Spencer (1966, p. 169), a change from vegetative cropping with root crops to grain cropping with rice can be observed in Asia. Where shifting cultivation is practised by sedentary farmers with permanent homesteads, complementary activities are usually to be found: the growing of fruit trees, a permanent garden, plots with irrigated rice, a fish-pond.

\subsubsection{Tool systems}

Shifting cultivation in the rainforest is still occasionally practised without cultivation implements; after burning off, seed is sown in the ashes. The axe and the matchet are the main tools. Where the ground is prepared, as is usually the case, tools for cultivation are required. Following the suggestion of Spencer (1966, p. 131), we can distinguish between digging-stick systems, hoe systems, and plough systems. Digging-stick systems are found in the humid rainforests. Hoe systems predominate in the savannas, particularly where the cultivation period stretches over several years, since in these circumstances soil cultivation and hoeing of weeds are necessary. The plough system can be employed only in shifting cultivation where an unused grass vegetation grows in the fallow periods.

\subsection{General characteristics of shifting systems}

The various shifting systems, from one continent to the next, are characterized by some common organizational features. The relative importance of these features changes according to the local land conditions, but they are recognizable as tendencies in almost all cases. Of special interest in this respect are the spatial organization of cropping, the cropping principles, and the organization of the fertilizer economy, of animal husbandry, and of the labour economy.

\subsubsection{The spatial organization of cropping}

The farmer with a stationary home and land that is permanently cropped tries to create favourable growing conditions for his crops; that is, he tries 
to control nature. Shifting cultivators, on the other hand, are usually highly skilled at adapting their cropping practices to the environment in which they are working. Four aspects of adaptation are important:

(I) The choice of the plot of land to be cultivated. The main determining factors are soil fertility, the effort of clearing the vegetation, the amcunt of weed growth, the danger of vermin, and location in relation to the road and a source of water. On fertile soils, a smaller plot is more able to cover food needs than on poor soils. Fertile soils, however, are by no means preferred in all cases. Expenditure of labour per unit of production is a much more decisive factor. If, with the same effort, three times as much poor land as good land can be cleared and cultivated, even with only half the yield per unit, there is still a net gain (Allan 1967, p. 94).

(2) The choice of crops.

(3) The organization of cropping in mixed cropping, phased planting, and crop rotations.

(4) The arrangement of short-term, middle-ierm, and long-term fallows.

The decisive factor in balancing these requirements is in most cases the very precise knowledge of soils and plants held by the shifting cultivators. Allan $(1967$, p. 5) writes on this subject, about central Africa:

The 'shifting' cultivator has an understanding of his environment suited to his needs. He can rate the fertility of a piece of land and its suitability for one or other of his crops by the vegetation which covers it and by the physical characteristics of the soil; and he can assess the 'staying power' of a soil, the number of seasons for which it can be cropped with satisfactory results, and the number of seasons for which it must be rested before such results can be obtained again. His indicator of initial fertility is the climax vegetation and his index of returning fertility is the succession of vegetational phases that follows cultivation. In many cases hundreds of ise precise and remarkably complete. He has a vocabulary of vegetation associations trees, grasses, and other plants and he identifies particular the basis of 'shifting' cultivation.

Conklin (1957) tells us the same about the rainforest in the Philippines, where the Hanunoo of Mindoro distinguish more than 1600 different plant types, which is a finer classification than that employed by systematic botanists, and includes the astounding number of 430 cultivated species. Conklin's vivid description of what a Hanuno swidden in full swing looks like (pp. 18-19) gives an excellent picture of the degree to which this agriculture apes the generalized diversity of the jungle that it temporarily replaces:

Hanunóo agriculture emphasises the intercropping of many types of domesticated plants. During the late rice-growing seasons, a cross-section view of a new [plot] illustrates the complexity of this type of swidden cropping (which contrasts remarkably with the type of field cropping more familiar to temperate zone farmers). At the sides and agninst the swidden fences there is found an association 
dominated by low-climbing or sprawling legumes (asparagus heans, sieva beans, hyacinth beans, string beans and cowpeas). As one goes out into the center of the swidden. one passes through an association dominated by ripening grain crops, but also including numerous maturing root crops, shrub legumes and tree crops. Poleclimbing yam vines, heart-shaped taro leaves, ground-hugging sweet potato vines, and st::ublike manioc stems are the only visible signs of the large store of starch staples which is building up underground, while the grain crops fruit a metre or so above the swidden floor before giving way to the more widelyspaced and less-rapidly maturing tree crops.

Besides the systematic adaptation to variations of soil within a plot described by Conklin, we find in most shifting systems that cultivation is often different on those plots that are especialiy suited to individual crops. Miracle (1957, p. 13) describes this type of cultivation outside the rotation systems on the main piots:

Cultivated fruits, vegetables, rice, yams, taro, condiments and tobacco are outside the crop sequences and each of these are in a small environment especially favourable to them. Oil-seed, watermelons, tomatoes, mock tomatoes (Solanum spp., grown only for their leaves), roselle, egg plant, red pepper, mangoes, and papayas are grown in the courtyard where they are free from weeds and fertilized by ash and refuse. Bananas are grown on small mounds; and okra, yams, peanuts (as a vegetable), and various vegetables are grown on broken ridges in the court. yard. Rice, bananas, taro, sesame a vegetable), maize and other: are grown on old refuse heaps. Moist, shady spots under the kitchen eaves are used as tobacso nurseries. Ash accumulations found outside the courtyard, especially those resulting from the burning of stumps during the clearing of a field, are used for tobacco and various vegetables. At the base of trees that have been killed, climbing varieties of cowpeas, lima beans, and oil-seed gourds plus bottle gourds and calabashes, are planted. Living trees are used to support yam. Uninhabited termi e mounds are flattened and planted with white sorghum, rice and cowpe as

The attempt to combine cash cropping with a regular supply of foods for household use leads, in most shifting systems, to diversified production units. A shifting holding usually consists of a number of distinct components:

(1) The dwelling-place consists of the huts and the surrounding yard. The materials used in constructing the huts depend on the degree of permanency in housing. If the hut is to be used for less than about six years, then wood and grass are used. If it is to be used for more than six years, then clay is the main building material. Farmers who expect to live permanently in a given place usually endeavour to build stone houses.

(2) Usually a garden plot near the dwellings is cultivated with vegetables, gourds, bananas, etc., as long as the family lives in one place. The longer the family lives in one place, the greater is the number of fruit trees grown near the yard.

(3) The differentiation of production on the outlying fields ensures that each is cultivated with the crop best suited to it, partly by mixed cropping and rotations, and partly by having several plots on different soils. 
(4) In addition to cropping, shifting cultivators gather 'wild' products from the surrounding fallow. These are usually not truly wild plants, but the remains of domestic plants within a 'tumbledown' fallow.

(5) If the farmers live in permanent dwellings, or move only within a limited area, the shifting cultivation is generally supplemented by other major food-producing activities, including planting of tree crops, permanent gardens, permanent irrigation fields, and fish-ponds.

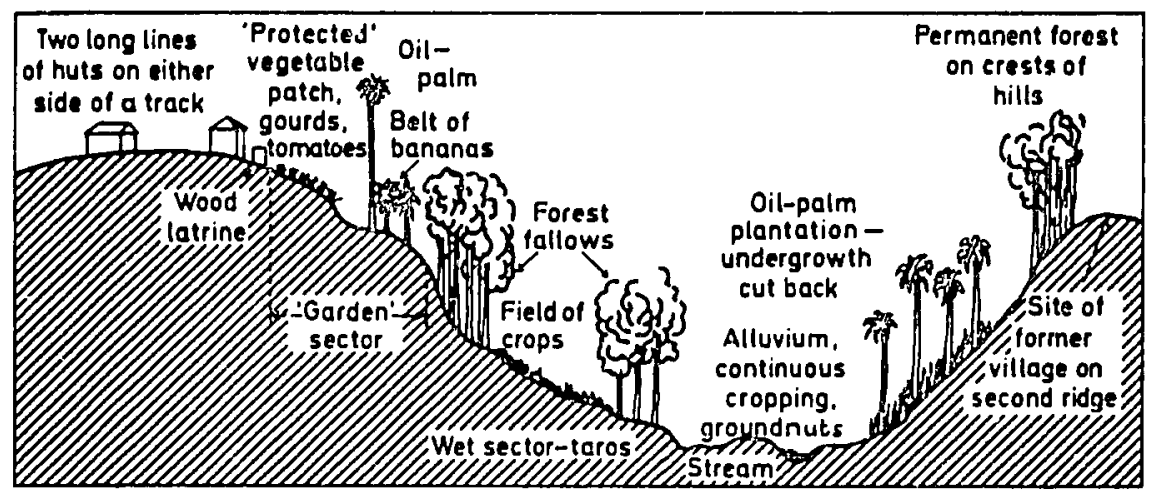

Fig. 3.2. Diagrammatic cross-section of Pene Niolo, Congo-Kinshasa, and its vicinity (1949) (from Dumont 1966, p. 28).

An example of land use in shifting holdings is shown in Fig. 3.2. A crosssection of Pene Niolo, Congo-Kinshasa, and its vicinity shows a typical catena: huts on the ridge, vegetable gardens close to th' "ut, some bananas and oil-palms near to the garden, field crops and forest fallows on the slope, and some continuous cropping on the alluvial soils in the valley bottom. The oil-palms on the opposite slope indicate that cash cropping with permanent crops is practised in addition to the production of field crops mainly for subsistence needs. Cultivators in Pene Niolo have at the same time become sedentary, so that any change of dwelling-place is limited to moving from one ridge to the other.

\subsubsection{Cropping principles}

The adaptability of shifting systems is closely related to three principles of cultivation, which are linked in various ways. These are: mixed cropping, phased planting, and crop rotations, i.e. alternating crop mixtures which are regarded by de Schlippe (1956) as pseudo-rotations. The three principles of cultivation also apply in the semi-permanent or permanent farming of indigenous cultivators, but not in anything like as much variety as is found in shifting systems, which are stimulated by the need to adapi.

(a) Mixed cropping. Mixed cropping, i.e. the simultaneous growth of two 
or more useful plants on the same plot, is an important characteristic of shifting cultivation. ${ }^{1}$ The technique of row cultivation is only rarely applied: the plot is usually uneven, and tree stumps, roots, termite mounds, and low areas with poor drainage would interfere with the rows. A worthwhile labour economy is not achieved, since the farmers in any case rarely work with equipment drawn by animals. Row cultivation, moreover, would not allow the mixture of plants grown on each piece of land to be adapted to the changing soil conditions. In shifting cultivation, therefore, we find predominantly mixed cropping, which is not organized with the help of a formal principle, but is based on the best possible adaptation to the surface condition.

Mixed cropping has a number of advantages:

(1) It reduces susceptibility to disease and pests, and therefore reduces the yield risk.

(2) It allows the adaptation of planting to changing soil conditions. Thus, for example, diferent crops are grown where there is much ash left after fire clearance from those where there is no ash. The plants grown close round a tree stump differ from those where no siumps are left.

(3) It allows cultivation to be adapted to the light and shade requirements of individual crops. Both vertical and horizontal variations of cultivation are facilitated. Thus, for example, medium-height manioc plants grow under bananas, and on the ground pumpkins or beans are found.

(4) In smallholder farming, a varied food supply is usually sought. Over and above this, the household relies on a continuous supply of fresh food, since there are insufficient storage facilities and the storage losses are high. Both aims naturally lead to phased planting and mixed cropping. Table 3.2 shows, with an example of the consumption of a shifting cultivator's family, the variety of products that a tropical smallholding produces, and the frequency of consumption, which should coincide where possible with the harvest, because of the limited storage facilities.

(5) A further advantage of mixed cropping, which it shares with phased planting, is the soil cover provided. Where there is a vertical arrangement, the rain, for example, falls from the bananas onto the manioc and then onto the beans, and only then does it reach the soil. Mixed cropping may

1 Some important definitions:

Mixed cropping: two or more crops grown simultaneously and intermingled; no row cultivation.

Interplanting: long-term annual or biennial crops interplanted with short-term annual crops during the early stages of plant development.

Intercropping: two or more crops grown simultaneously in alternate rows in the same ground.

Interculiure: arable crops grown under perennial crops.

Relay-planting: the maturing annual crop interplanted with seedlings or seeds of the following crop. 
TABLE 3.2

Consumption chart of a shifting cultivator's family in Manhaua, Mozambique

\begin{tabular}{|c|c|c|c|c|c|c|c|c|c|c|c|c|}
\hline & & & & & & & nth & & & & & \\
\hline Product & 1 & 2 & 3 & 4 & 5 & 6 & 7 & 8 & 9 & 10 & 11 & 12 \\
\hline $\begin{array}{l}\text { Crops produced by the family } \\
\text { (1) Staple foods containing starch } \\
\text { Manioc }\end{array}$ & $x$ & $x$ & & & & & & & $x$ & $x$ & $x$ & $x$ \\
\hline Maize in milk-ripeness & & & $x$ & $x$ & & & & & & & & \\
\hline Maize as ripe corn & & & & & $x$ & $x$ & & & & & & \\
\hline Rice & & & & & & $x$ & $x$ & & & & & \\
\hline Sweet potatoes & & & & & & & $x$ & $x$ & $x$ & & & \\
\hline $\begin{array}{l}\text { Sorghum } \\
\text { Sorghum-corn (ecununga) }\end{array}$ & & & & & & & & $x$ & & & & \\
\hline & & & & & & & & $x$ & & & & \\
\hline $\begin{array}{l}\text { Sorghum-cane (maele) } \\
\text { (2) Staple foods containing protein }\end{array}$ & & & & & & & $x$ & $x$ & & & & \\
\hline & & & & & & & & & & & & \\
\hline Beans (jugo) & & & & & & $x$ & & & $\mathbf{x}$ & $x$ & & \\
\hline Beans (manteiga) & & & & & & $\hat{x}$ & & & & & & \\
\hline Green beans (boer boer) & & & & & & & $x$ & $x$ & & & & \\
\hline Green beans (nyemba) & & & $x$ & & & & & & & & & \\
\hline Green beans (jugo) & & & & $x$ & $x$ & & & & & & & \\
\hline Manioc leaves & $x$ & $x$ & $x$ & $x$ & $x$ & $x$ & $x$ & $x$ & $x$ & $x$ & $x$ & $x$ \\
\hline Sweet potato leaves & & & & & & $x$ & $x$ & & & & & \\
\hline Bean leaves of all kinds & & $x$ & $x$ & $x$ & $x$ & $x$ & $x$ & & & & & \\
\hline $\begin{array}{l}\text { (3) Additional foods and spices } \\
\text { Onions }\end{array}$ & & & & & & & & & & & & \\
\hline Tomatoes & & & & & $x$ & $x$ & & & & & $x$ & $x$ \\
\hline Gherkins & & & $x$ & & & & & & & & & \\
\hline Egg-plant (2 kinds) & & & & & & & & & & $x$ & $x$ & $x$ \\
\hline Quiabo (Hibiscus esculentus) & & $x$ & & & & & & & & & & \\
\hline Groundnuts & & & & & $x$ & $x$ & $x$ & $x$ & $x$ & $x$ & & \\
\hline Sugar-cane & & & $x$ & & & & & & & & & \\
\hline Pumpkins & $x$ & $x$ & $x$ & & & & & & & & & \\
\hline $\begin{array}{l}\text { Sorghum-cane (ecununga) } \\
\text { lected food }\end{array}$ & & & & & $x$ & $x$ & & & & & & \\
\hline 4) Staple foods (animal protein) & & & & & & & & & & & & \\
\hline Grasshoppers & $x$ & $x$ & $x$ & & & & & & $x$ & $x$ & & \\
\hline Mice and other rodents & & & & & & $x$ & $x$ & $x$ & & & & \\
\hline Caterpillars & & & & $x$ & $x$ & & & & & & & \\
\hline Larvae of butterflies & & & & & & & & & & & $x$ & $x$ \\
\hline (5) Additional foods & & & & & & & & & & & & \\
\hline Fungi (9 kinds) & $x$ & & $x$ & & & & & & & & & $x$ \\
\hline Wild fruits (7 kinds) & $x$ & & & & & & & & & & $x$ & $x$ \\
\hline Honey & & & & $x$ & $x$ & $x$ & & & & & & \\
\hline
\end{tabular}

Source: Pössinger (1967, p. 199). 
have the same protective effect, therefore, as the original forest or bush vegetation.

By virtue of these advantages, mixed cropping often produces higher yields than monocropping. Webster and Wilson (1967, p. 114), on the basis of extensive field research, write the following:

In the majority of the above experiments more than one acre of crops in pure stand was required to produce the yield of one acre of intercropping. Since the amount of land that can be cultivated by farmers equipped with hand tools is strictly limited, it seems unlikeiy that there would be any general advantage in replacing the traditional practice of mixed cropping by rotations of pure-stand crops, although in certain cases the latter might prove advantageous by reducing the labour of harvesting, or by making it easier to control pests and diseases.

(b) Phased planting. It follows necessarily from inixed cropping that crops cover the soil for varying lengths of time. The systeinatic arrangement of planting dates means that cultivation is phased. The result of this again is a continuous sequence of growth and ho.ivesting. A number of benefits arise from phased planting:

(1) The phasing of labour operations allows the work to be distributed over a longer period.

(2) The combination of periodic planting and weeding may be labour saving.

(3) Planting is not necessarily dependent on renewed soil cultivation.

(4) The risk of failure is distributed. The effects of weather variations are counterbalanced, and pest damage is reduced.

(5) The phasing of harvests ensures a regular supply of food for the household and minimizes the storage losses. Over a period of several months, a single plot may produce a steady stream of harvestable food, for example, maize, beans, peas, and sweet potatoes.

(6) The ground is covered by growing plants for almost the whole year. Consequently, the soil is protected from water and wind erosion.

(c) Rotations. Shifting cultivation with short-ierm cycles is rarely connected with crop rotations. Usually one crop or a given mixture of crops is grown for several years. However, when shifting cultivation is carried on with cultivating periods lasting for several years, or even a decade, crop rotations are evolved-a logical continuation of the tendencies that can already be seen in pliased cropping. De Schlippe (1956, p. 207) calls the change in the composition of mixed cropping pseudo-rotation, but as a rule it is a matter of carefully considered cropping sequences, which can justifiably be considered as actual rotations. Amongst the great number of forms rotations take, several important features can be observed:

(1) In the crop rotations of shifting cultivators, there is rarely a sequence of monocropping. Usually, various mixed crops follow one another, with 
often only a gradual change in the composition of the mixture. Immediately after clearing, crops that require more fertile soils are chiefly planted, like yams in the rainforest, and cotton, maize, groundnuts, and sesame in the savannas. As the cultivation period proceeds, crops that make little demand on soil fertility are preferred. Biennial or semi-perennial crops like manioc or bananas are frequently grown last of all, because these can survive longer than other crops against the competing weed and bush, on account of their height and the shade they create, before gradually disappearing in the tumbledown fallow.

(2) Nearly every plot is different from the point of view of soil type, degree of incline, and distance from the hut, and nearly every field is suited, therefore, to a different crop rotation. The various crop sequences that Richards (1961) found in the fields and gardens and on old hut sites of the Bemba demonstrate this point (Fig. 3.3).

(3) It is rare for one rotation to be applied persistently on a big plot. Division of the plot into several smaller sections is more typical. Each small piece of land then supports a different sequence of crops or mixture of crops. This again is clearly demonstrated in Fig. 3.3.

(4) In shifting systems, it is common for the same mixture of crop types or the same crop to be grown on a suitabie plot for several consecutive years. When the cultivation period increases, growing 'at intervals' sometimes arises, a system typical of the African savannas, when, for instance, two to thres years of grain crops follow two to three years of cotton.

'Much of the most effective human utilization of the natural habitat', writes Geertz (1963, p. 17), 'consists of changing generalized communities into more specialized ones...' This tenciency aiso can be seen in the shifting cultivators' farming principles. As land use becomes increasingly intensified and commercial, organizational principles like monocropping and row cultivation are increasingly preferred to the various types of mixed cropping. Agricultural developments and increasing land shortage gradually lead to more systematic rotations and less varied cropping patterns. Only where there is a high degree of intensity of agriculture, as for example in the irrigation agriculture of Taiwan, do mixed cropping and phased cultivation again become preferable, although under the new conditions of rigid organization that occur when they are combined with row cultivation.

\subsubsection{Characteristics of the fertilizer economy}

(a) The regeneration of soil fertility in long-fallow' sy'stems. The various features of the organization of cropping that are applied by slifting cultivators aim primarily at an optimum use of the existing soil fertility. The basic feature of shifting cultivation is the cost-free, effortless regeneration of soil productivity during the fallow period, especially when the fallow consists of 
forest or bush vegetation. The damper and warmer the climate, and the poorer the soils, the more rapidly the organic substances break down, and the more rapidly the crop yields tend to sink. The first crops are comparatively

Fields
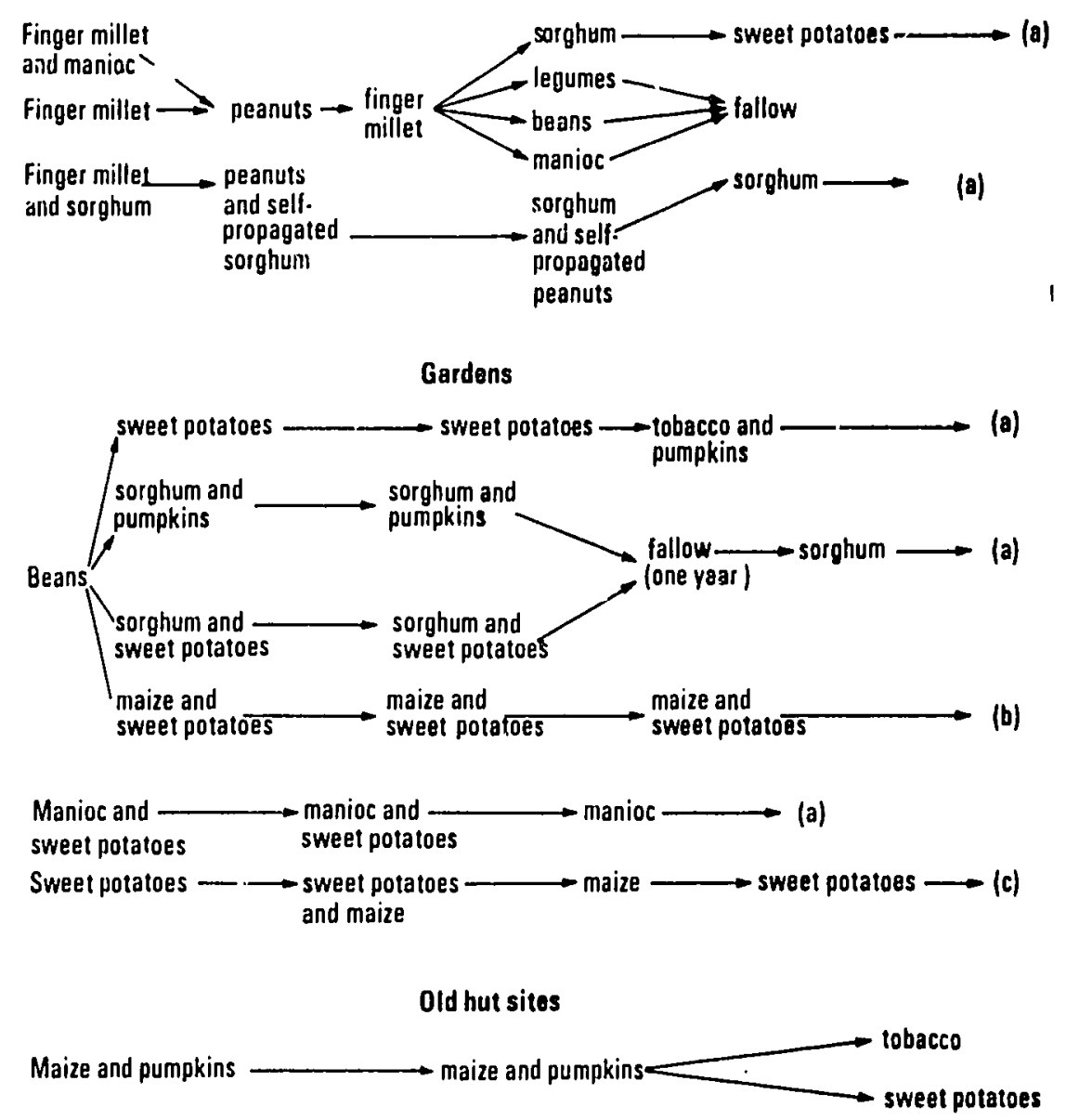

\footnotetext{
(a) No information given on what follows.

(b) Maize and sweet potatoes planted year after year until soil is oxllausted. then sweet potatoes alone as the land crop.

(c) Maıze and pumpkins sown so long as soil is fertile. then toba cco or sweet potatoes.
}

Fig. 3.3. Crop sequences of the Bemba, Rhodesia (Richards 1961; Miracle 1957, p. 110).

ample, but the harvests in the subsequent years become more and more meagre. On unstable soils of the rainforest, for example, the third crop will usually yield only half, or less than that, of the first. A drastic example of 
this is provided by Nye and Greenland (1961) (see Fig. 3.4). If further utilization of the plot no longer promises to be rewarding, the shifting cultivator allows it to lie fallow for a fairly long period, in the course of which the soil fertility regenerates. Shifting cultivation thus aliows soils poor in nutrients regularly to produce relatively high and certain yields in a climate in which arable farming is always a difficult struggle against nature. This is usually achieved without manure, terracing, or any other means of maintaining fertility that involve a high expenditure of labour. If the fallow periods are

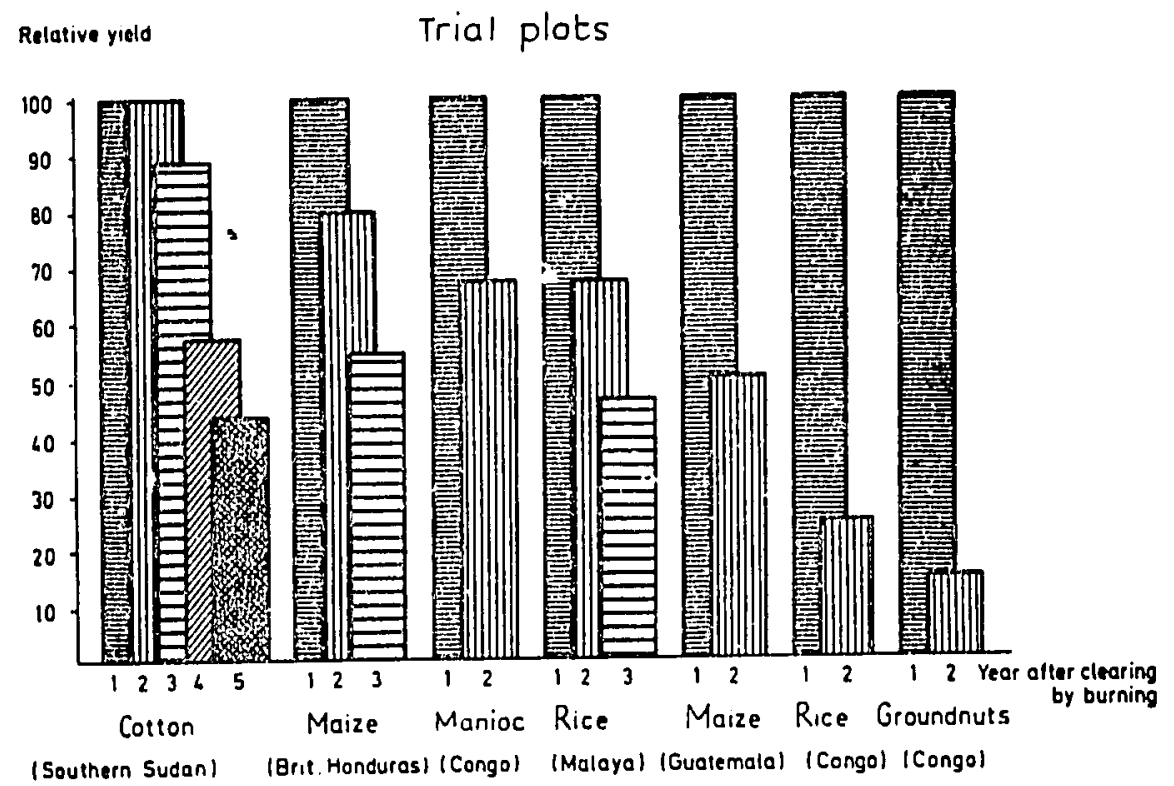

Fig. 3.4. Decline in yields under prolonged cropping without fertilizer in tropical rainfcrest areas (data from Nye and Greenland 1961, pp. 73-4).

long enough, this type of land-use system represents a balanced exploitation of the resources available to farming.

The regeneration of soil fertility in the upper soil layers is largely due to the effects of a forest or tree fallow. The deeper tree and scrub roots ensure that nutrients are brought up from the subsoil. The fallen leaves enrich the surface, and the minerals that the rain-water has leached down are brought up again. Thus Beinaert (1941) established in the rainforest of the Congo (Yangambi) that the supply of organic material in the form of leaves, twigs, etc., amounted to 60 tons per hectare per year. Fallow vegetation covering the soil and the comparatively cool temperatures of the covered soil facilitate the regeneration of all that has been taken out of the soil in the years of cultivation. The forest and bush vegetation during the fallow period also protect the soil from erosion 
by heavy rainfall. In addition, the rapid evaporation from the fallow vegetation lessens, or even stops, the leaching process.

Provided the fallow periods are long enough, a slash and burn system proves to be in no way harmful to the soil. In fact, the yields after a fallow period with secondary forest are in some cases higher than those after the first clearing. The smallness of the plots, the considerable shading of the soil during the cultivation period that arises from mixed cropping and phased planting, the presence of tree stumps in the field, and other factors mean in addition that balanced shifting cultivation involves little risk of erosion damage. Another advantage of field shifting is the fact that losses through plant diseases remain comparatively slight.

(b) Fertilizer application in shifting systems. Since shifting cultivation is associated with a low degree of commercialization, the export of crops over and above the local sale of produce is not a major cause of the loss of nutrients. There is, however, a movement of nutrients from the field to the dwellingpiace, and therefore some change in the location of soil fertility. Secondly, nutrients are lost during the years of cultivation because of washing out and erosion. Particularly important is the loss of the nutrients that are washed away together with the ashes.

The long-term fallow period is the most common method of regenerating the fertility of soil. In addition, however, there are various forms of fertilizing:

(1) Utilization of hut refuse. The first step in the development of a fertilizer economy consists usually of applying household refuse. It is normally put where it can be useful to plant growth. Thus, for example, fertilization of bananas near a hut with household refuse is common among shifting cultivators.

(2) Establishment of gardens on old hut sides. A general practice when the hut has been shifted is to use the old hut site in order to grow crops that demand fertile soil. The movement of the huts means, in fact, that heavily fertilized plots are systematically obtained. This applies particularly where cattle are reared and kept overnight in a kraal near the hut. This practice may be considered as the first step in the development of folding systems (see \$4.3.3).

(3) Green manuring and use of compost. Where ridge or mound cultivation is practised, it is common to clear the vegetation and to allow it to dry before the soil is worked. It is then Jug right into the centre of the ridge or the mound as a green manure. In the Porka system in Ghana, the cleared vegetation is thrown on heaps and later used as compost (Manshard 1968, p. 90).

(4) Working with pit systems. In the pit systems, and the hole system in Tanzania, the fallow vegetation and weeds are collected in pits or in heaps. These are covered with earth, cultivated, and dug over sevtral times. In 
these shifting systems, the cropping period lasts for up to twelve years, and is followed by a long-term fallow period.

(5) Working with heated mounds. With a number of African tribes, the fallow vegetation is covered with earth and then set alight and charred, which results in cultivation taking place on little mounds of carbon. One assumes that the motive behind this practice is the change in yield caused by heating the soil, which may convert nutrients into a more freely available form (Allan 1967, pp. 73-4; Brouwer 1965, p. 17; Miracle 1964, p. 84).

(6) Ashes as fertilizer. Where fire-clearance methods are used, ash in any case serves as fertilizer. In some regions an ash concentration on small plots is achieved with considerable labour cost. In the chitemene system, as practised in some parts of Zambia and southern Tanzania, branches are transported from the forests in the vicinity to the farmland, piled up a metre thick, and burnt to increase the ash fertilizer. According to Allan (1967, p. 86), for the cultivation of one hectare of finger millet tree ash from 2-5 hectares has to be used. Millet is sown in the ash. This method produces comparatively high and certain yields of 15 quintals per hectare on very poor soils. The main disadvantage is the size of the area from which the branches are taken. The forest requires fifteen to twenty years to regenerate. For the annual cultivation of one hectare of finger millet, a nutrient supply of 30-100 hectares of forest is required.

Richards (1961), reporting on the ash system practised by the Bemba, writes:

Cut branches are trimmed enough so that they will lie flat in a pile for burning, and are laid in rows, each man taking care to keep his branches separate $f$ from those of his neighbours. Women later carry the branches to the plot to be cultivated and place them radially, with the smallest diameter to the centre. At the time of Richards's study, branches were cut from an area up to six times as large as that to be planted. Pieces of wood are piled one on the other until the pile is about 65 centimetres high, care being laken to keep the thickness of the pile uniform. The Bemba are said to often single out barren patches of a field as spots where branches were not properly stacked before burning. The last task in piling branches is to - 'tline the edge of the circle with small branches, in order to keep the fire îrom spreading into the bush, and to provide an extra tnickness of ashes at the edge for rrowing gourds. (Taken from Miracle 1964, pp. 13-18.)

Whether, or to what extent, the yields of these systems are to be attributed to the effect of fertilizer or to the yield-promoting effect of heat is an open question:

It may be that this is the mechanism through which the heat of the chitemene burn exercises its main effect, but there is as yet no direct proof. Whatever the explanation, it seems clear that the ash-planting peoples, with no livestock and only the simplest equipment, have devised an effective means of conferring a high if transient fertility on soils of very low intrinsic value. (Allan 1967, p. 74.) 
(7) Application of mineral fertilizer. The use of mineral fertilizer in shifting systems is rare, limited to those with a higher degr(e of cash cropping. Mineral fertilizer has been adopted especially where tobacco and cotton are grown. The majority of shifting systems do not involve the importation of purchased nutrients. They depend on the nutrients present in the soil. This is a precarious basis, and the main reason for the continual movement of shifting cultivators.

\subsubsection{Characteristics of animal husbandry}

The kinds and extent of animal-rearing among shifting cultivators are as varied as the forms of their plant cultivation. In the rainforests, the cultivators have few domestic animals. Mostly there are a few goats, sheep, or chickens. In south-east Asia and West Africa, pig-keeping is often practised. As a supplement we find fishing and collecting caterpillars and other minor sources of animal food. In the humid African savanna, in whick there is often plenty of grass for fodder, the tsetse fly has hitherto prevented cattle-rearing, apart from in limited areas in West Africa and the Congo where tsetseresistant cattle breeds are kept. The situation is different in Latin America, particularly in Brazil, where shifting cultivation and a large herd of cattle are often combined, and the cattle eat the grass on the cleared open spaces. In the drier savannas, animal-rearing among the shifting cultivators is usually on a large scale, and is closely connected with arable cropping. Under these conditions slash and burn agriculture may convert bush-covered land into grazing. The aims and characteristics of cattle-rearing, as they are connected with slash and burn agriculture, are discussed in more detail in Chapters 4 and 9.

\subsubsection{Characteristics of the labour economy}

Shifting cultivation is a system of production, almost without capital, based on labour and the periodic consumption of soil fertility. Practically the whole input consists of manual work. The operations of shifting cultivators can conveniently be classified as follows:

(a) Clearance of wild vegetation. From the standpoint of the labour economy, clearance is the most strenuous activity. Clearing is frequently, but by no means in all cases, carried out within a system of fire-farming. Table 3.3 shows that the input into clearance varies widely (179-1450 hours per hectare) according to the vegetation and the thoroughness of the clearing.

(b) Land preparation and planting. Immediately after burning, planting can often be carried out without cultivating the soil. However, most shifting cultivators do in fact disturb, loosen, and move small amounts of surface soil as part of the operation of planting (Spencer 1966, p. 31). In the savanna, or on grassland, or where cultivation lasts for several years, the soil has to be thoroughly loosened, because it is usually much harder, but on the whole the 
shifting cultivator needs to prepare the soil comparatively little. He replaces, as it were, cultivation with the hoe by clearance work with the axe and matchet. Thorough deep-soil preparation with the hoe is less characteristic of shifting cultivators than of semi-permanent cultivators.

(c) Weeding. The fallow suppresses the growth of weeds, and after fire clearance the soil is often weed free. Many shifting systems manage, therefore, with little weeding. Only as the period of cultivation increases does the effort spent on hoeing and weeding increase. Scaring away birds may, however, demand much time and may compete as an activity for children with going to school.

(d) Harvest, transport of harvest, and processing. Together with clearing, harvesting is the most labour-demanding task. This applies particularly to root economies, in which the transportation of harvested produce-there are usually no roads or carts-and the processing of the crop tend to be time consuming, as for example with manioc.

TABLE 3.3

Labour input into land clearing in shifting systems (man-hours per hectare)

\begin{tabular}{|c|c|c|c|c|c|c|}
\hline & $\begin{array}{l}\text { Virgin } \\
\text { forest } \\
\end{array}$ & $\begin{array}{l}\text { neo } \\
\text { Secondary } \\
\text { forest }\end{array}$ & $\begin{array}{l}\text { Guatemala' } \\
\text { Milpa }\end{array}$ & $\begin{array}{l}\text { Congo }{ }^{c, d} \\
\text { Rainforest }\end{array}$ & $\begin{array}{l}\text { Congod } \\
\text { Savanna }\end{array}$ & $\begin{array}{l}\text { Congo }^{d} \\
\text { Pennisetum } \\
\text { grassland }\end{array}$ \\
\hline $\begin{array}{l}\text { Slashing } \\
\text { and } \\
\text { felling }\end{array}$ & $293-326$ & $147-80$ & 276 & $312-492$ & 222 & 42 \\
\hline $\begin{array}{l}\text { Burning } \\
\text { and } \\
\text { clearing }\end{array}$ & $32-82$ & $32-82$ & 151 & 174-958 & $702-883^{\circ}$ & $780^{\circ}$ \\
\hline Total & $325-408$ & $179-262$ & 427 & $486-1450$ & $924-1105$ & 822 \\
\hline
\end{tabular}

- Clearing for hill rice.

- Clearing for maize.

c Man-days for supervised work, assuming 6 hours per man-day.

- Careful clearing with two burnings.

- Including hoe cultivation: 450 hours per hectare.

Sources: Borneo, Freeman (1955, p. 90); Guatemala, Tax (1963, p. 109); Congo I.N.E.A.C. (1958, p. 17).

In addition, various other activities have to be considered. Tending livestock may be very time consuming where shifting farming is practised by people with a pasturalist background, and where men spend most of their time with their cattle. Getting water often takes much of the wives' time. Visiting local markets is also very time consuming. Work in the fields usually absorbs not more than half the working time. It is important in this connection to realize that the seasonality of labour demand in shifting systems is usually less pronounced than in more intensive arable systems. Clearing, 


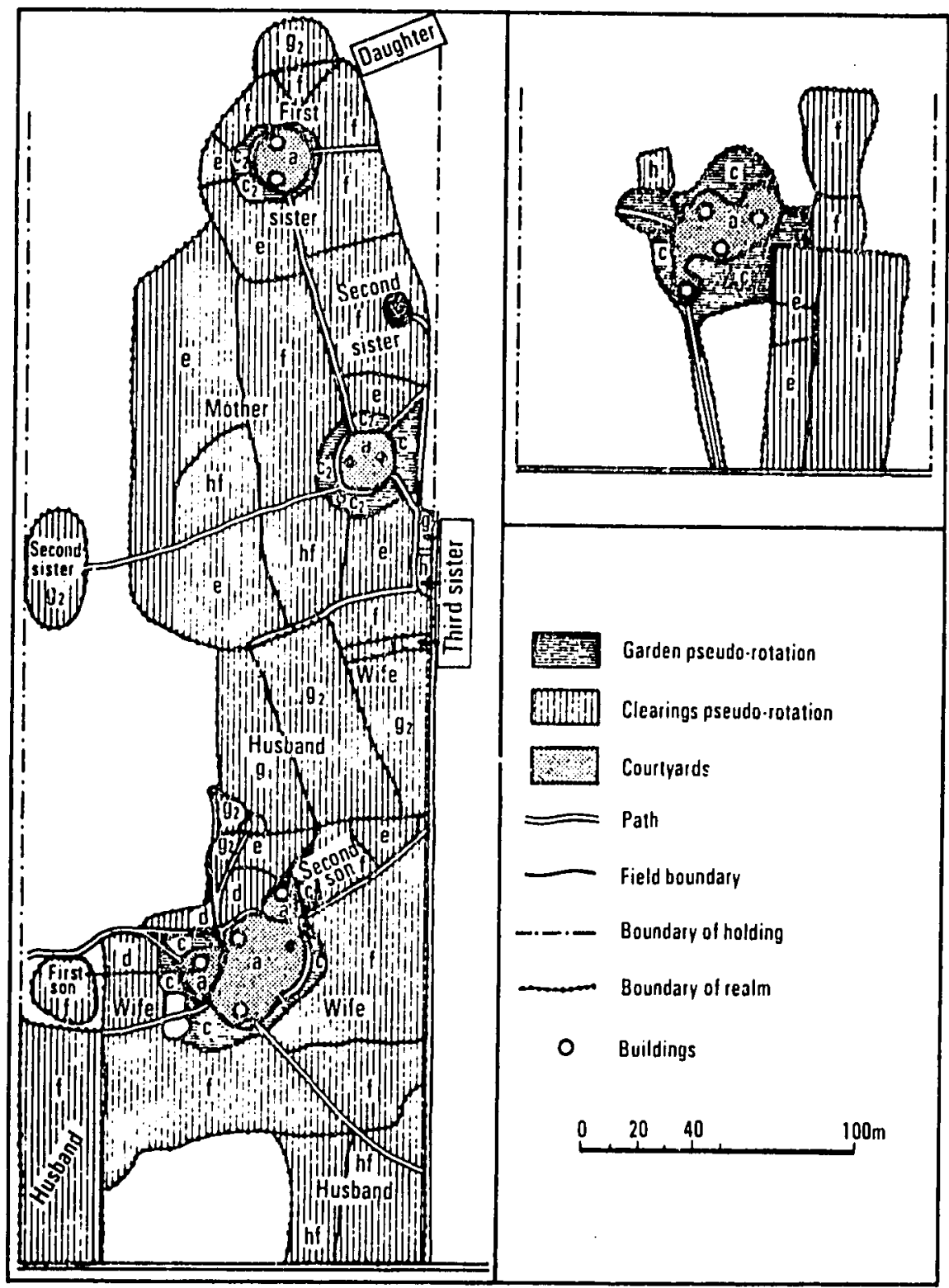

Fio. 3.5. The responsibilities of different members of a household for the individual plots in a Zande holding (from de Schlippe 1956, p. 109).

(a) courtyard; (c) maize-sweet potatoes; (d) maize-oil seed-gourds; (e) groundnutsEleusine; $(\mathrm{f})$ main Eleusine plot; $(\mathrm{g})$ Eleusine-grass; $\left(\mathrm{g}_{1}\right)$ sesame-grass; $\left(\mathrm{g}_{2}\right)$ s same-grass on fire-preserved area; $(h)$ bean patch; (hf) beans-Eleusine or sorghum; (i) cotton field; (j) manioc fallow. 
harvesting, and processing are the major time-consuming activities, and there is more latitude for doing these chores than there is with cultivation or weeding.

In the traditional forms of shifting cultivation, the execution of the labour operations is usually governed by the customs of labour division. A number of main types of labour division can be recognized:

(a) Division of labour with respect to different jobs. A clear division of jobs between men and women is usually found wherever forest and bush vegetation must be cleared. In fire-farming in the forest, clearing is the man's job, while planting, weeding-if done at all-and harvesting are carried out by the women.

(b) Division of labour with respect to plots. Short-term cycles of cropping and fallowing give rise to a fallow vegetation consisting of grass and bush. The input for clearing is comparatively low. Consequently, work is divided between men and women in terms of areas. Both men and women tend to cultivate their own plots. Men do most of the heavy work (clearing) and the women perform the tasks requiring more dexterity (weeding, harvesting). Fig. 3.5 is taken from de Schlippe's book (1956) about the Zande, who live on the borders of the Sudan and the Congo. It provides an example of the distribution of plots to the mernbers of the family.

(c) Division of labour with respect to specific crops. When larger plots are planted with cash crops, then the women are usually responsible for cultivating the food crops, whereas the men farm the plots with cash crops. Housework and collecting firewood are almo.it always women's and children's tasks, while the men are responsible for cutting the wood used for building and for erecting the houses.

TABL $: 3.4$

Labour input in shifting and semi-permanent holdings, Kiberege Strip, Kilombero Valley, Tanzania

\begin{tabular}{|c|c|c|}
\hline & $\begin{array}{l}\text { Shifting cultivation } \\
\text { on the escarpment }\end{array}$ & $\begin{array}{l}\text { Semi-permanent } \\
\text { farming in the } \\
\text { valley }\end{array}$ \\
\hline $\begin{array}{l}\text { Number of holdings } \\
R \text { value } \\
\text { Crop area (ha } \mathrm{ME}^{-1} \text { ) } \\
\text { Rice yield ( } \mathrm{kg} \mathrm{ha}^{-1} \text { ) } \\
\text { Labour input } \mathrm{ha}^{\mathrm{b}} \text { (man-days per ha) } \\
\text { Labour input as \% of the total: }\end{array}$ & $\begin{array}{l}6 \\
15 \\
0.607 \\
1683 \\
272\end{array}$ & $\begin{array}{l}14 \\
55 \\
0.930 \\
1189 \\
247\end{array}$ \\
\hline $\begin{array}{l}\text { Land cultivation } \\
\text { Planting } \\
\text { Weeding } \\
\text { Harvesting }\end{array}$ & $\begin{array}{l}31 \\
19 \\
20 \\
30\end{array}$ & $\begin{array}{l}18 \\
15 \\
31 \\
36\end{array}$ \\
\hline
\end{tabular}

- Data taken from only 4 and 8 holdings respectively.

- The number of huurs worked per day is different for the individual jobs. Thus, clearing takes an average of 6 hours and weeding and harvesting 4 hours.

Source: Baum (1967, p. 37). 
Although the implements of shifting cultivators as a rule are limited to hand-tools unassisted by domestic animals, the productivity of labour is by no means lower than in more intensive forms of traditional land use. Conklin's data from shifting cultivation with rice in the Philippines (1957) indicates that the labour input per quintal of rice compares favourably with the labour cost figures for rice production in irrigated paddies. Information collected by Baum (1968) in the Kilombero Valley indicates that shifting cultivators need 30 per cent less labour per unit of rice than do semi-permanent cultivators (see Table 3.4). There is, however, a change in the timing of labour demand. Shifting cultivators put most of the effort into land clearance and cultivation. while semi-permanent cu!tivators devote most of their time to weeding.

\subsection{Three case studies}

\subsubsection{Extensive shifting cultivation with monocropping of the Iban, Sarawak}

The shifting cultivation of the Iban on the island of Borneo is limited to the cultivation of a single crop: upland rice. Where primary forest has been cleared, rice is grown for two years. Where there is secondary forest, the Iban restrict themselves usually to a single harvest and then the ground is rested for fifteen to twenty-five years. The $R$ value is very low, about 5-6. The Iban combine shifting cultivation with stationary housing in solid "long houses'. When the fields are too distant from the main homestead, smaller groups build huts away from the long house and use the land around them. When the soil fertility has regenerated near the main house, they return. Stationary housing is made possible particularly by the fact that in rice the Iban have a product that is relatively easy to transport.

From the standpoint of household and labour economies, there are disadvantages that arise because the Iban grow only one crop, and have only one harvest a year, but these are partly compensated for by the fact that the families, who live together, help each other out, although they work separately. Over and above this, the growing of the rice crop is phased. The main crop of slow-maturing varieties is supplemented by quick-maturing varieties, so that the household can be supplied soon after the beginning of each new growing season. The rice harvest is thus spread over three months.

According to the material collected by Freeman (1955), shown in Table 3.5, a family of six people grows, on average, 2.2 hectares of rice $(0.37$ hectares per person), and harvested in the unfavourable test year (1959-60) only 16.1 quintals of paddy (7.3 quintals per hectare). The object of production is to supply domestic needs. However, when there are good harvests the surplus is sold. Measured in American dollars the value of the rice yield, and therefore the income from agriculture, amounts to $\$ 80.50$, i.e. $\$ 0.24$ per working day. Families are inclined more and more to supplement their income from arable farming by paid work in the plantations and by planting rubber. 


\subsubsection{Shifting cultivation with mixed cropping in Congo-Kinshasa}

As a rule, shifting systems are not organized as simply as that of the Iban, but are characterized by a variety of crops. A description of a shifting system with diversified cropping in the rainforests of Congo-Kinshasa is given by Tondeur (1956). The head of the family and the tribal chiefs cooperate in selecting the land that is to be cleared, and in allotting the plots to the

TABLE 3.5

Econornic return of rice production by the Iban, Sarawak

\begin{tabular}{|c|c|}
\hline $\begin{array}{l}\text { Persons per household } \\
\text { Rice cultivation (ha) }\end{array}$ & $\begin{array}{l}6 \\
2 \cdot 2\end{array}$ \\
\hline $\begin{array}{l}\text { Yield } \\
\text { Rice (paddy) }\left(\mathrm{q} \mathrm{ha} \mathrm{h}^{-1}\right) \\
\text { Rice (paddy) }\left(\mathrm{q} \mathrm{total} \mathrm{l}^{-1}\right) \\
\text { Gross returns }(\$)^{\mathrm{b}}\end{array}$ & $\begin{array}{c}7.3 \\
16 \cdot 1 \\
80.50\end{array}$ \\
\hline $\begin{array}{l}\text { Land expenditure } \\
\text { Work-daj" }\end{array}$ & 330 \\
\hline $\begin{array}{l}\text { Productivity } \\
\quad \text { Yield per work-day (\$) }\end{array}$ & 0.24 \\
\hline
\end{tabular}

- Less the seed.

- \$5 per quintal of rice (paddy).

Source: Freeman (1955, p. 110).

families. The clearance work consists of (1) chopping down the undergrowth, (2) selective felling of the bigger trees, and (3) burning off. To save labour, since the trunks tend to get thicker at the bottom, the trees are felled about one metre up. Hardwood trees are killed by fire or ringing. Trees with edible fruits, or with leaves that support edible caterpillars, are left untouched. Clearing work is frequently undertaken communally by the men of the village. Burning occurs several weeks after felling, when the timber is dry.

There is no need for the soil to be cultivated immediately after the forest vegetation has been burnt off, since the fire leaves it in a loosened condition. When the rains begin, soiving and planting take place. Rice and millet are sown broadcast, while maize and manioc are planted in holes, which used to be made with a digging-stick, but are usually made nowadays with a hoe. Initially the main crop is rice. When the rice has sprouted, manioc is planted in between. A few weeks later bananas are planted into the mixture of rice and manioc. When the rice has been harvested, manioc becomes the main crop. The stand of manioc and bananas gradually turns into a tumbledown fallow. The land is then allowed to rest for eight to eighteen years. The $R$ value is thus 11-25.

The harvest, transport to the hut, drying of manioc, and transport to the 
market are the principal labour tasks. Although rice has to be plucked ear by ear, manioc and bananas involve an especially high expenditure of labour in transport and preparation. On the other hand, they have advantages from the standpoint of both the labour and household economies. The banana harvest and the supply to the household stretches over a long period of time.

TABLE 3.6

Economic return of shifting cultivation in the Congo-Kinshasa (model calculation per hectare, 1956*)

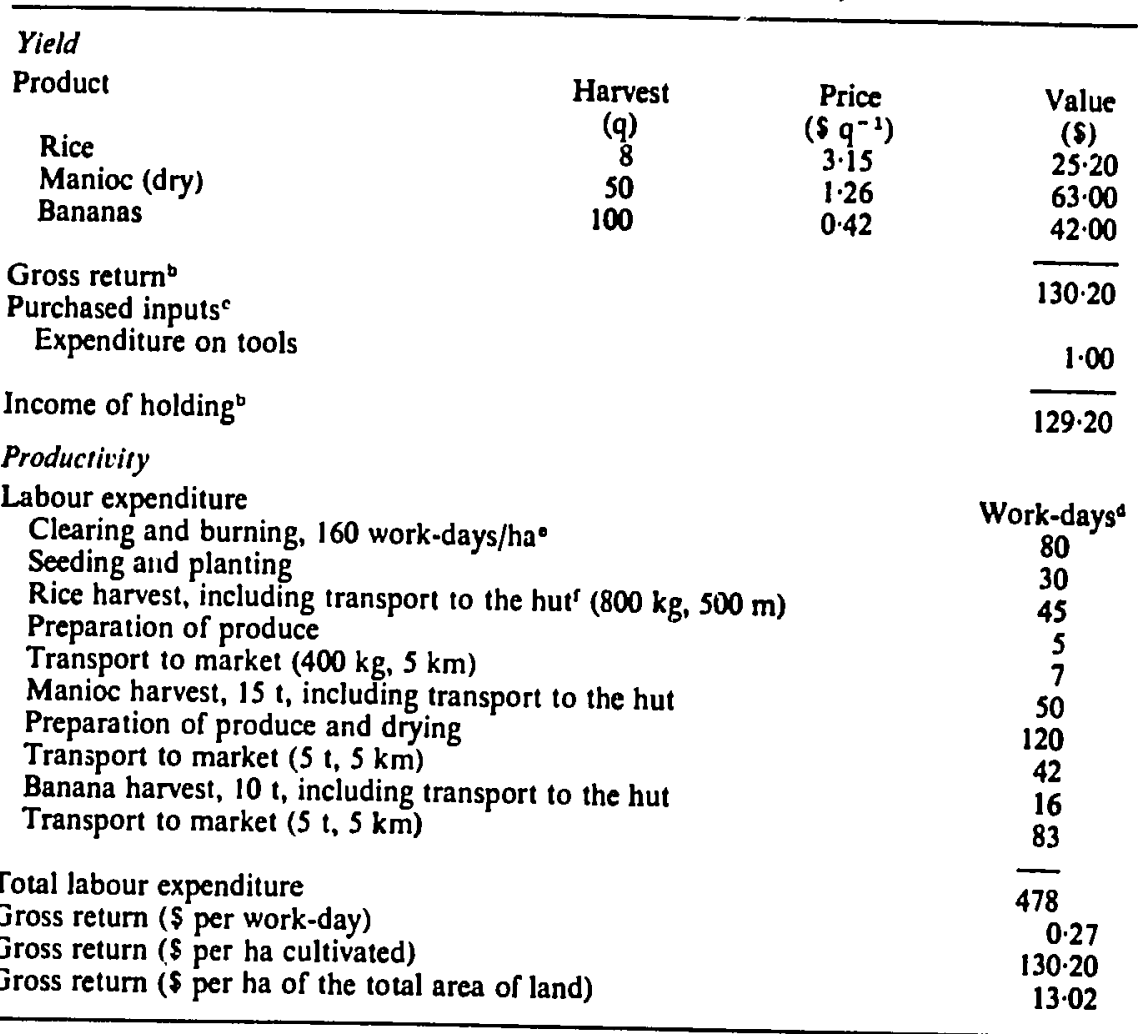

- 2 years of cultivation, 18 fallow years, 0.5 ha annual clearance, 1 ha annual uultivation. Area requirement of the holding: 10 ha.

- Not including the yield from hunting, collecting, and fishing. Domestic consumption: $4 \mathrm{q}$ rice, $50 \mathrm{q}$ bananas is included.

c Not including farm-produced seeds and planting material.

- Tondeur does not supply the number of work-hours per day. Pinxten (1954) estimates in these conditions 4 hours' work a day.

- The labour expenditure of 160 days per ha is very high indeed. Samucl (1950, p. 589) calculated 90 days per ha for similar conditions. The labour expenditure on harvest given by Tondeur corresponds with that of other data.

Iransport for carrying.

Data from: Tondeur (1956, p. 43). 
Manioc can stay in the soil and can be dug out when required or when time is available. Manioc is often grown in excess of need, and what is not used stays in the soil as a safeguard against hunger, being harvested only when another crop unexpectedly fails.

The calculations in Table 3.6 give an idea of the labour input and yield of such a shifting-cultivation holding. Eighteen fallow years follow two years of cropping. Correspondingly the area requirement of a holding amounts to 10 hectares and the annual cultivation to 1 hectare. Tondeur gives the yield of 1 hectare as 8 quintals of rice (paddy), 50 quintals of dried manioc, and 100 quintals of fresh bananas. This prociuction corresponds to a money value of $\$ 130.20$. The input of material resources is small, linited as it is to the expenditure on tools, which accounts for $\$ 1$ annually. Young plants and seeds are taken from the holding. Thus, a holding income of $\$ 129.20$ remains, to be set against 478 work-days expended. 75 per cent of these are devoted to harvest, transport, and processing. ${ }^{1}$ The yield per work-hour amounts to $\$ 0.27$ per work-day with 4-5 work-hours. The yield per hectare, taking into account the total area requirement of the holding, comes to $\$ 13.02$. In addition to this, other produce, often in considerable quantities, is obtained from the garden that is developed near the hut, and from collecting, fishing, and hunting.

\subsubsection{Shifting cultivation with rotation among the Bemba, Rhodesia}

The shifting systems of the dry savannas are different from those of the forest because of the prevalence of long-term cropping periods, which of necessity lead to intensive hoe-cultivation practices. Whereas cultivation in the forest seldom lasts longer than three years, in the savanna it lasts for up to ten years, and sometimes even longer, occasionally interrupted by a oneyear or two-year fallow. Only then is the land rested for one to two decades.

Typical of this type of farming is the Bemba system, which has been described by Richards (1961) (see Fig. 3.3). Some distance from the hut are the cleared fields, or in other words small, irregular plots, the size of which varies from year to year. Immediately after clearing, finger millet is sown, partly as a monocrop, partly interplanted with manioc, and partly mixed with sorghum. The rotation of the individual fields is not as systematic as is usual in permanent farming, but we can well see from Richards's examples that the rotations are different from field to field, and that in each case the crop is grown that is demanded by the household and is relatively well-suited to the holding.

Near the hut is the garden, which is fertilized with ash and refuse, and in which are found plants-legumes, pumpkins, maize, sweet potatoes, and manioc -that require a better soil than those grown in the fields. Just as different crops are grown in different fields, there are also in the garden several sections, each supporting different crops.

2 According to Jurion and Henry $(1967$, p. 320), the time requirements of transport for a family of four planting annually 0.5 heciares of maize, rice, groundnuts, and bananas, amount to 120-40 man-days annually, under the condition of an average distance between hut and plot of 1.5 kilometres, an average load of 35-45 kilograms, and 4-5 journeys per man-day. 
An earlier hut site forms a separate plot, which becomes available when a new hut is built, and it is characterized by a comparatively high fertility. Maize, pumpkins, tobacco, and sweet potatoes are grown here.

\subsection{Weaknesses of the system}

\subsubsection{Difficulties in the introduction of new methods}

The shifting cultivator has been, and still is, a primary agent in the development of mature cultural landscapes out of forested regions. He begins the process of transforming the forested landscape, and he is followed by other settlers who continue the process (Spencer 1966, p. 5).

In temperate and subtropical climates, in the tropical high altitudes, and in the drier savannas of the tropics, the gradual intensification that creates an increase in the value of $R$ has led to a gradual transition from shifting cultivation to semi-permanent cultivation and finally to permanent cultivation. The warmer and damper, in other words the more tropical, the climate, the greater the difficulties that this development encounters. The weakness of tropical shifting cultivation, particularly in the rainforest, lies in the fact that the productivity of labour and soil can hardly be increased within this system. Most shifting systems are not in a position to absorb a growing population, to allow a steady broadening of cash production, or to derive continual and accumulating benefit from yield-increasing and labour-saving technical innovations. The problem obviously does not lie in any antipathy to innovation on the part of the shifting cultivators. Past experience shows that they are willing to include new crops and varieties in their agricultural programmes and do so very quickly.

The Portuguese and Arabs, as well as the colonial governments of the nineteenth and twentieth centuries in Africa, can take the credit for introducing a series of important crops into the indigenous farm economies. The introduction of cash crops like cotton, groundnuts, tobacco, and sesame leads to increased income. Salts from shifting cultivators' holdings are already of considerable importance for the supply of home markets, and in some cases also for export. The yields per hectare can be raised by denser planting, timely weeding, and plant protection. By relieving families of the arduous work required for such tasks as shelling groundnuts, and peeling and drying manioc, local centres for processing free labour for work in the fields. The same applies to the introduction of the bicyclu. which makes the transport of the harvest considerably easier and quicker. But all measures that increase the cropped area or the yield per hectare shorten the fallow period or make the regrowth of a fallow vegetation more difficult; and the fertility of the soil in the tropics is closely related to its content of nutrients and organic matter, and thus to the length of the fallow period and the vigour of the fallow vegetation. 


\section{SHIFTING CULTIVATION SYSTEMS}

In the forest regions and in the tsetse-infested savannas, there is a lack of to provide animal manure. Mineral fertilizer is usually not worth while, because of unfavourable cost-return ratios, which can hard!y be while, busting systems. Shifting cultivation is limited to the hae; $r$,oughs avoided in shifting systems. Shift and tree stumps are cleared, and that would cannot be used unless roos fallow vegetation. In shifting cultivation prevent the growth of the desired the are only foot-paths. The frequent proper tracks are almost unknown; tiere are only foot network of tracks. changes of field would necessitate an exceptionally large network of tracks The absence of tracks, however, prevents tire introduction of carts. The harvest must for the most part be carried or transported by bicycle, and those people who have animal manure have to carry it to the field in baskets.

The shifting of fields leads to the change of hut sites, and much time is lost

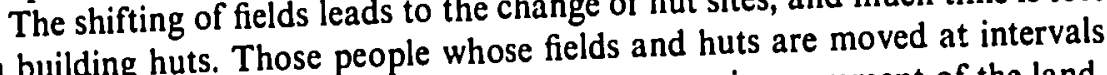
in building huts. Those people work in permanent improvement of the land, have little inclination to invifting cultivation is therefore distinguishable by the and a countryside with shifting cultivation is the permanent improvements, such as irrigation, drainage, and tree plantations. In general, the family units are scattered. The lack of stationary housing and the long distances between fields create difficulties in storing food, collecting surplus produce, and division of labour between farming and non-agricultural pursuits. Shifting cultivation is thus a hindrance to the downs, central political bodies, and advanced development of villages and the farmers societies. The land-use sysctivators are in the habit of regarding the soil as who practise it. Shifting cultivartal that has to be maintained. Where soil a free gift of nature, not as capital that has to be mainded, shifting cultivafertility decreases and land is in the proce land and to look for virgin territory tors are much more inclined to mine the land

\subsubsection{The tendency towards 'degraded' shifting systems}

With increasing population and growing, production for sale, a number of distinct stages of development can be distinguished:

(1) The oldest form is probably the shifting of cultivation and of the farming group in one direction within a primary vegetation.

(2) According to the growing number of other claimants to land, the groups are the total area among themselves, and then each family shifts gin a circle in the area allotted, which is covered by secondary vegetation, circle in the area allocition and moves on after one or seve dwelling $(R=30-50)$ (see Fig. 3.2).

is temporarily practised near the dwalation, instead of circular shifting with (3) With a further increase in poperting, there occurs often the shifting of fields within a fairly limited area, with the tendency to stationary 
housing, where possible along a road. On the permanent site the hut position is sometimes changed.

(4) A continuous increase in population and the development of cash cropping involve an intensification of shifting cultivation by shortening the fallow ( $R$ rises to 30-60). At this stage, the basis of land utilization has changed to such an extent that the system is hist regarded as semipermanent farming. Such systems are considered in the next chapter.

These processes usually lead to a situation of relative overpopulation on land which then loses soil fertility. Without changes in technology and inputs, only a small number of people can be supported compared with other landuse systems.

Naturally the crop yields of shifting systems vary greatly according to climate and soil type. For example, whereas on the typical light soils of the rainforest in the Congo twelve fallow years have to follow three years of cultivation, with the same rainfall on volcanic soils there are only two-year or three-year fallows for the same period of cultivation. In any case, however, the shortening of the fallow or the lengthening of the cultivation period teyond a certain point disturbs the equilibrium of the land-use system. Shifting cultivation, which can bc called 'balanced explo'tation' where the fallow period is sufficiently long, becomes sheer exploitation of the soil fertility. Geertz (1963, p. 26) argues that in the rainforests of south-east Asia, in an ecologically balanced shifting economy, no more than twenty to fifty people can live per square kilometre with guaranteed subsistence.

Figure 3.6 shows these developments in the form of a graph. The yield of the soil drops with the number of cultivation years and recovers in the fallow period. In (a) the fallow period lasts longer than the regeneration of the soil requires. $R$ is low (11). This is shifting cultivation with production reserves. The situation in (b) corresponds to that of shifting cultivation without production reserves $(R=29)$. The fallow period is, however, long enough to restore soil fertility to its original level. (c) shows what happens as the fallow is shortened $(R=46)$. The fallow is no longer sufficient to restore soil productivity and the yields per hectare fall, though since the shortening of the fallow period means that a greater part of the total area is cultivated, the fall in yields per hectare may well be accompanied by a rising total production. However, the result is a continuous degrading process.

The increase in cultivation in \%olves a more thorough clearing, more intense hoeing, and, at the same times, the death of roots and tree stumps. The fallow ground does not produce bush quickly enough, especially on soils with low fertility, after the years of cultivation, so that only arable weeds, grass, bamboo, or wild bananas establish themselves. Bush regeneration is made difficult, and the clearing of bamboo and many types of grass (above all Imperata cylindrica) involves a high labour cost. Where cattle are kept, grazing is an additional impediment to forest or bush regeneration. Spencer 
SHIFTING CULTIVATION SYSTEMS

p. 127) reports that most shifting cultivator groups are conscious of reat of the spread of grassland as shifting systems are intensified. theless, almost everywhere in areas with shifting cultivation, the burning t bush and forest areas takes place in the dry season, partly from habit, to make hunting easier, and partly to get early fresh grass for the
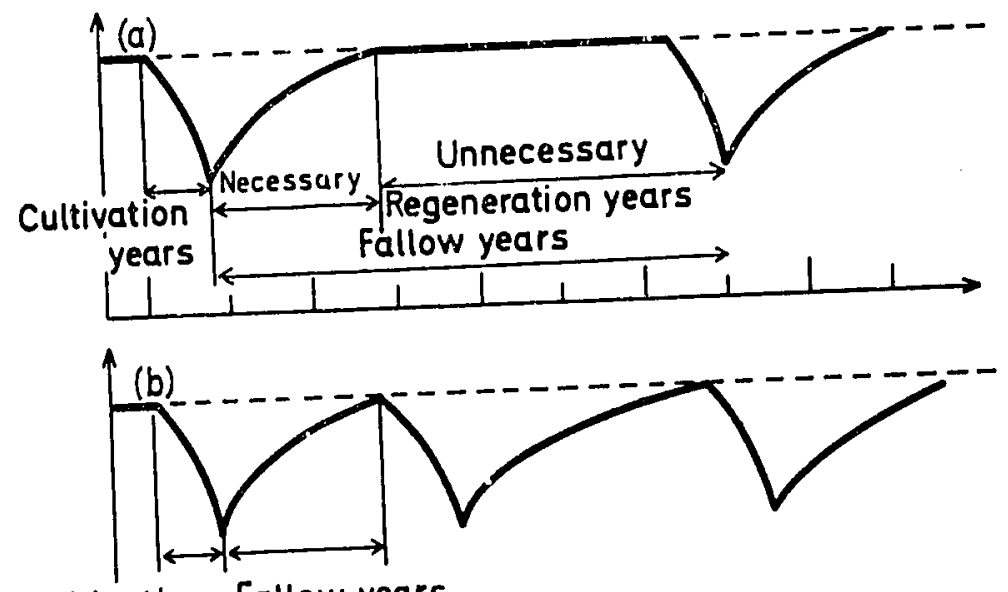

Cultivation Fallow years
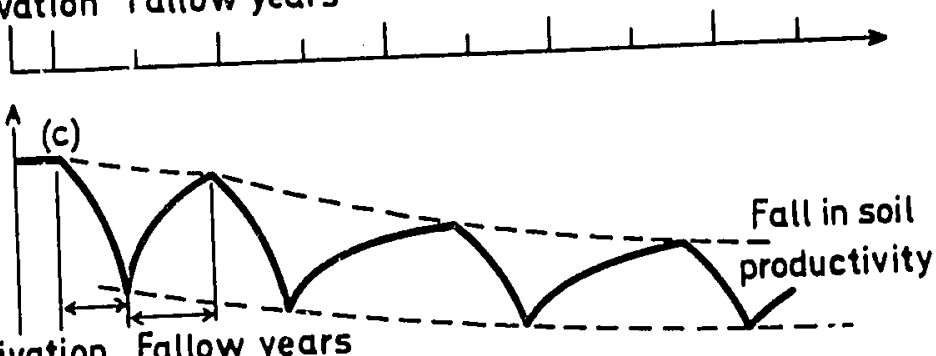

Cultivation Fallow years

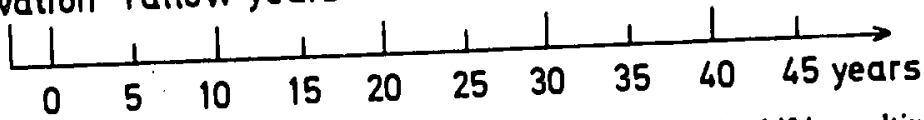

FIO. 3.6. The relation between length of fallow and soil productivity in shifting cultivation (from Guillemin 1956).

cattle before the beginning of the next rainy season. Regular grass fires also help to prevent the growth of forest and bush.

The interaction between grass and fire transforms the countryside of unbalanced shifting systems from a natural forest or bush vegetation into a grass vegetation created by man. In large areas of Africa and Latin America this process is deliberately encouraged because grazing for the cattle is desired. Grasses in the tropics, however, do not have the same ability as bushes or trees to remobilize nutrients and to accumulate organic matter. Trees and shrubs alone have the necessary depth of rooting, the capacity to 
make good use of a large part of the cainfall throughout the whole year, and the ability to retain, in their own structure or in their leaf litter, a substantial portion of the nutrient material available. This involntion, therefore, leads to a countryside which is in grave danger because of loss of fertility and the effects of erosion. ${ }^{1}$

\subsection{Development paths of shifting systems}

Shifting cultivation is obviously not essential in the tropics, but is rather an expression of a certain stage in population density, technology, and price relations. However, in circumstances of relatively mild population pressure, shifting cultivation has been and still is widely suited, ecologically and socioeconomically, to the simple needs of man and the potentialities of the environment. Its replacement by some more satisfactory land-use system is therefore by no means easy in the light of our present knowledge.

The spread of more productive systems of land use is, as a ruie, the result of necessity and incentives. When shifting systems are modified, the incentives come from cash cropping, and the main pressure tends to be the relativ: shortage of land. Increasing cash production, as well as the increasing need for subsistence crops, and both together in interaction with the introduction of technical advances, lead to efforts to regulate and improve shifting systems or to replace them by more efficient patterns of land use.

\subsubsection{Improved shifting systems}

(a) Shifting systems with planted fallow vegetation. Experiments to replace wild vegetation in the form of forest or bush, by planting quick-growing tree or shrub legumes, have as yet not been able to make much headway. De Kroon (1967) reports, however, that planting them in Surinam has proved a technical success. The fallow was shortened by several years. The soil under cover was in excellent condition, easily tilled, and the yield of the succeeding crops higher, but this process has been adopted no more widely in Surinam than in West and East Africa, where similar efforts were made. The main reason is that it is very expensive, i.e. it costs a great deal in terms of labour, in relation to the extra yield, to produce a planted but unused fallow vegetation.

(b) Shifting systems in forestry reserves. The people responsible for forestry in several areas (India, Burma, Indonesia, East Pakistan, East Africa) successfully combine shifting cultivation with planned reforestation. They allow, direct, and control the cultivation of food crops in the forest reserves by a limited number of shifting cultivators. The cultivators are allowed to cut

\footnotetext{
1 Involution is the attainment of higher total income in the area accompanied by a lower income per head, because of population increase. Evolution is the attainment of higher income per head.
} 
down, burn, and farm a certain area of unimproved forest allotted to them, under the condition that the land is vacated after two or three years of cropping and that the forest trees (mahogany, teal., pines, etc.) which are planted in the second year are properly weeded. Then they receive a new plot. This procedure is advantageous to both sides: the farmers have the chance of farming within a restricted area, while there is no danger of forest destruction; the forestry department saves the clearing costs of reforestation, because these are borne by the shifting cultivator. The only, but considerable, disadvantage in this process is that relative!y few shifting cultivators can be absorbed. The felling cycle of the timber is much longer than the usual fallow of fifteen years, reaching eighty years with teak and mahogany and about thirty years with pines. This method is thus well adapted to forest areas with little population pressure, but it is unsuitable for more densely populated areas that are inhabited by shifting cultivators.

(c) Shifting systems in plantations. In Sumatra an ingenious system has been devised which permits the combination of large-scale commercial tobacco production with subsistence production within a shifting system. It is described by Geertz (1963, p. 107) as follows:

$\ldots$ the famous Deli wrapper tobacco is grown only on land which has been lying under forest fallow for at least seven or eight years ... The tobacco planter of East Sumatra is thus a shifting cultivator who raises tobacco only once in a cycle of eight years, and each tobacco plantation therefore requires about eight times as much land as is planted in any one year... When the tobacco companies originally applied to the sultans for agricultural concessions, no attempt was made to sei aside sufficient land for the peasantry, although the contracts stipulated that the companies had to give each peasant family 4 bouw ( 2.9 hectares) of land, so that it could carry on its own traditional form of agriculture. But instead of reducing the size of their concessions by turning over to each family within the concession the stipulated amount of land, the planters preferred to have the use of all the land and to lend the harvested tobacco land to the peasants raising a single rice crop. This meant that the planter had access to all but the actual village land within his concession, while the East Coast peasant no longer had to clear land for his own swidden. Instead, he received from the estate each year in May or June the same amount of land ready for the sowing of upland rice that he would have had to clear had he not lived within a tobacco concession.

Advantageous as this system may be to both sides concerned, it still suffers from the same disadvantage as do most shifting cultivation systems, namely that further intensification is scarcely possible.

(d) The 'couloir' system. A large-scale experiment to regulate and improve shifting systems took place under the Belgian colonial administration in the Congo. In 1960, about two million hectares belonging to 200000 shifting cultivators were cultivated under the couloir system. The system consisted of a sufficiently large and fertile area being selected, declared a paysannat in agreement with the population, and divided into straight strips. The 
individual families each received a strip of forest of 8-12 hectares, of which 1-2 hectares were cleared and cultivated whilst the remainder was fallow. ${ }^{1}$ A rotation of cultivation years and fallow years was established on the plot. The plots cleared by each family were next to each other, so that normally a cleared corridor ran through the forest. As clearance continued, this corridor shifted in one direction and left behind incipient secondary forest (Fig. 3.7).

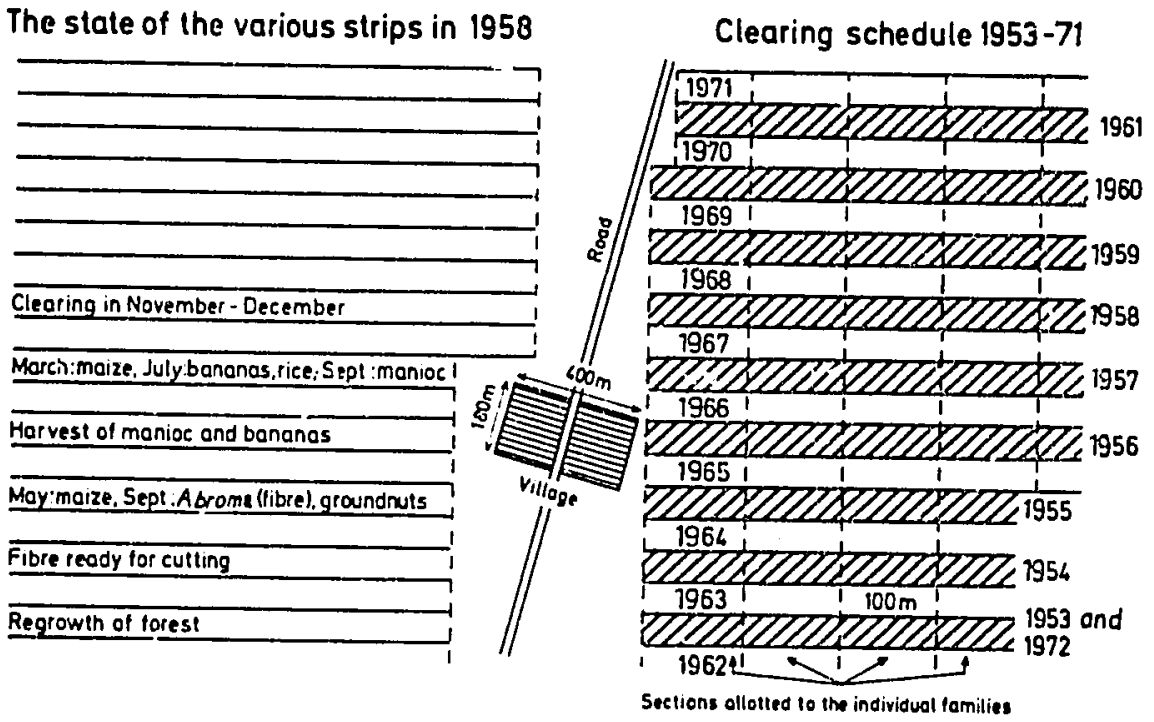

FIG. 3.7. Controlled shifting cultivation in the couloir system (from Dumont 1957, p. 40).

Experience has shown that the best system consists in the opening of east-west strips in the forest, alternating with strips of untouched forest. The strips left unfelled provide shade and seeds inr t!ee regeneration of the felled areas once they have been left to revert to fallow. The optimum width of such a couloir has been established at 100 matres. ${ }^{2}$ Cultivation in the corridor depends on the cultivators' willingness to follow the obligatory rotation, i.e. to grow particular crops according to whether it is the first, second, or third cultivation year. The whole corridor is thus divided up into strips of the same crops.

At Yangambi the rotation was practised that is illustrated in Fig. 3.7. The strip for cropping in a particular year-say 1958-is felled and prepared for cultivation. The following year (1959) the next strip is felled and prepared, and the year after that (1960) the next strip, and so on. When the strip for 1961 has been opened up,

2 An example: 1600 hectares are available for 200 families. The rotation consists of 3 cultivation years and 16 fallow years. The annual clearance amounts therefore to 0.4 hectares, the area of cultivation to 1.2 hectares (Tondeur 1356, p. 77).

${ }^{2}$ For the numerous variations in the organization of the paysannats, sce Pinxten (1954). 


\section{SHIFTING CULTIVATION SYSTEMS}

the one to be exploited next is at the other end of the block, next to the strip that was cleared for 1953. The clearing of alternate strips then proceeds through the b!uck for ten years, each strip being cropped for only one year. When the twentieth year after the start of the work is reached, felling takes place again on the strip first cleared in 1953, where a nineteen-year-old regenerated forest exists. All subsequent strips have also had a nineteen years' fallow before they' are cleared again for cropping.

The regulation of land use by the paysannat system has a number of advantages:

(1) The ratio of cultivated land to fallow land, and thus the preservation of soil fertility, is under control.

(2) The concentrated cultivation of particular crops in one belt, where each family has a section, facilitates the introduction of improvements like rotations, cultivation of cash crops such as cotton, better varieties, row cultivation, planting at optimum times, denser planting, weed control, burning off old cotton stalks, plant protection, etc.

(3) The concentration of cultivation reduces the expenditure of labour on transport. Building tracks becomes an atiractive proposition. Marketing and processing can be organized cooperatively.

Difficulties resulting from varying soil fertility and the varying work capacity of families can be largely overcome in more flexible paysannats. As Fig. 3.8 shows, it is possible under the couloir system to give the participants plots with different soils and of different sizes. Each number designates the plots of one family.

No matter how beneficial some features of the couloir system may have been, it has not survived in the Congo after independence. The shifting cultivator who is used to freedom of movement obviously finds the compulsory rotation of land oppressive. Maintenance of the rotation probably required the administration of the paysannat by an official from an outside institution, with sufficient 'power keys' (like project rules, control of credit and sales) to be able to make the farmers adhere to a system that they would not otherwise have preferred. The planning and supervision of a paysannat thus makes considerable staffing demands.

Undoubtedly the couloir system brings considerable increase in productivity per hectare and per man-unit, but it remains in principle a land-use system that demands a great deal of land, the labour productivity remains at a low level, and it is a system that the participants often feel to be too rigid. In short, it is an attempt at improving and organizing a system which, in the context of agricultural development, will sooner or later disappear anyhow. Newton (1960) reports that at the end of the 1950s the interest in the couloir system in the Congo declined, and that experiments with field-grass systems were increasingly being made. 


\subsubsection{The change from shifting systems to more intensive types of farming}

(a) From shifting to permanent rain-fed farming. The obvious development of shifting systems lies in a progressive shortening of the fallow, which leads finally to permanent agriculture after a period of semi-permanent agriculture
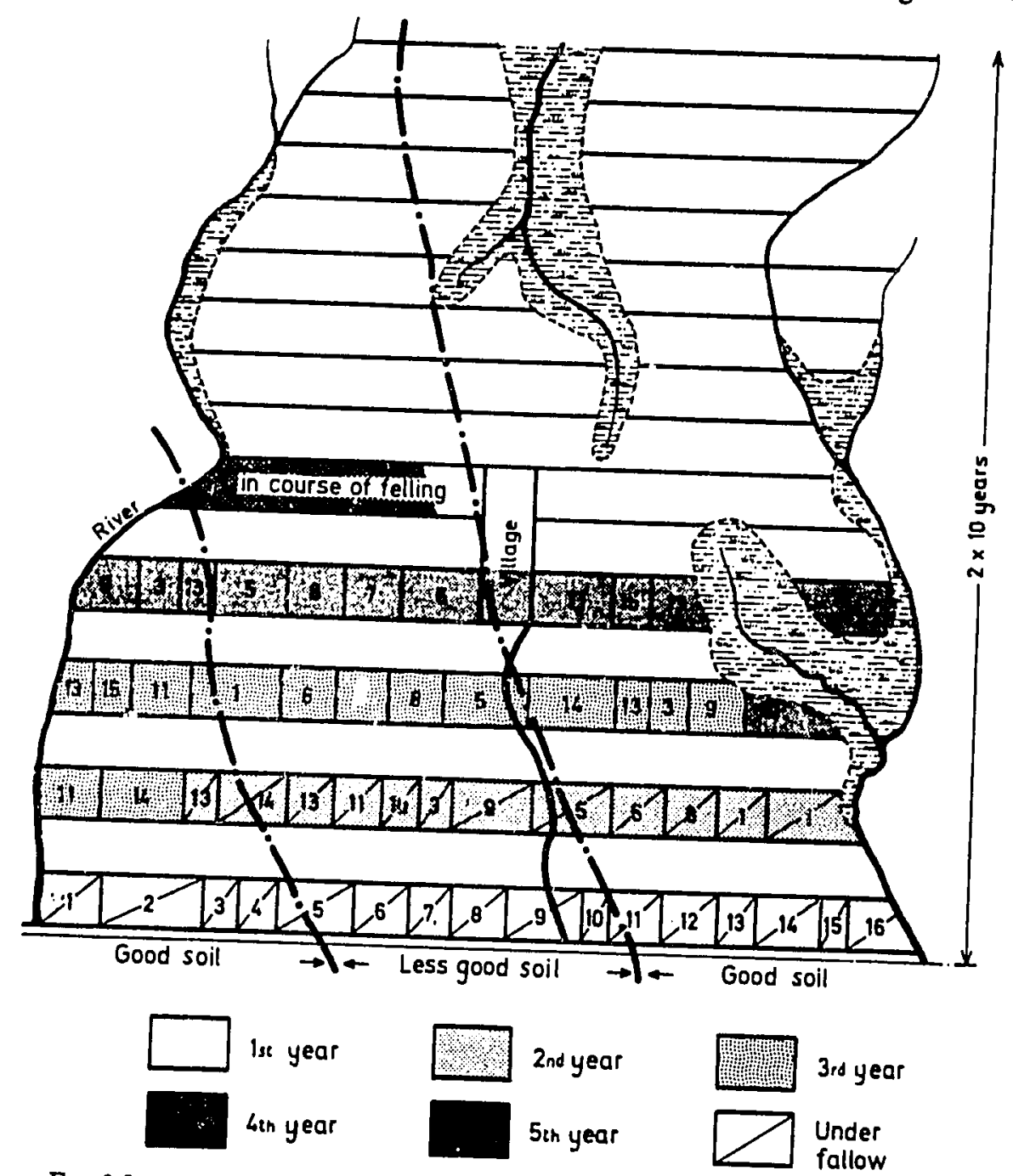

FIG. 3.8. Couloir system with varying size of individual plots (from Brouwer 1965).

or unregulated ley systems. In tropical high-altitude areas, on especially fertile soils and in the dry savannas, the development toward permanent farming has taken place to a considerable degree in a relatively short period. In the rainforest climate, on the other hand, the introduction of systems with 
permanent arable farming proves to be a difficult problem from the standpoint of agronomy and farm economy. The first experiments with this kind of system, which were carried out in Yangambi, were an unequivocal failure. Dumont $(1966$, p. 37) describes them:

On the first experimental plots at Yangambi, the forest was cut down, burnt, and uprooted. The soil was ploughed deep and, as a precaution, sown with Pueraria, Calopogonium, and other leguminous crops which had proved their worth in plantations. Thes z were used as green manure and various grasses (Pennisetum purpureum) were sometimes sown as well. The land was ploughed a second time and then cultivated on a two-year rotation. As the region has rain throughout the year, with only a slight abatement from December to April, it was possible to introduce four breaks into this rotation. A crop of upland rice was followed by two of manioc and one of groundnuts. This was followed by a leguininous cover crop. In this manner it was hoped to begin continuous cultivation on the pattern of temperate agriculture. The ant-hills, which occupied about a third of the area, were not cultivated. The soil was exposed to the harmful effects of chemical photo-oxidation for more than half the time, for thirteen monilis out of twentyfour, to be exact. Deep ploughing, expensive as it was, impaired the soil structure. The absence of a vegetation cover for so much of the period increased the amount of percolotion, and the removal of plant foods irom the topsoil was thus accelerated. The cover crops themselves did not have any apparent effect in improving the soil and their woody stems decomposed too slowly. Bacterial activity was hindered by excessive insolation and was unable to keep up an adequate supply of humus.

The yield of every crop fell rapidly. The ears of rice did not swell. The 150 acres on which the experiment had been conducted had to be abandoned after a few years. Too far from the edge of the forest to be reseeded quickly and with the micro-climate of its soil reduced almost to aridity, the area was still only thinly wooded ten years later. The Belgians frankly recognized their mistakes. Their notions of farming in temperate regions were obviously out of place in the Congo. In 1940 they decided to start again, but this time they took the Bantu system as their only sure starting-point and tried to improve it.

Recent experience shows that permanent cultivation on the light soils that predominate in the humid tropics is possible with heavy applications of mineral fertilizer and the maintenance of sufficient organic matter in the soil. These conditions are scarcely practicable under the input-output conditions of most tropical countries, even where agronomically satisfactory solutions have been worked out. They prove mostly to be too complicated or too unrewarding to be adopted on a large scale by indigenous farmers (see $\S 6.6$ ).

(b) From shifting to regulated ley farming. An alternative possibility of evolution is the replacement of the bush fallow that occupies the land for several years by plants that are themselves usable, regenerate the soil productivity, and allow use of the plough. The obvious way to achieve this is by transition to the ley system. However, arable crops, grasses, and leguminous crops in a rainy climate do not have the capacity of the forest or of tree crops to keep a reasonable balance between leaching and the remobilization of 
nutrients. The experience in Yangambi at the end of the 1950s shows that in a rainy climate ley systems can take the place of forest and bush fallow only with the help of heavy applications of mineral fertilizer. However, the right economic conditions for ley systems demanding much fertilizer are found only rarely (see $\$ 4.6 .2$ ).

(c) From shifting cultivation to perennial crops. The humid tropics are by nature forested, and the natural environment is well suited to perennial crops like bananas and to tree crops, a fact that is widely recognized and used by the shifting cultivators. The slowing down of the shifting cycle leads to stationary housing with more or less permanently cultivated gardens. Permanent banana groves develop, offering soil protection as well as high yields of calories per hectare. Wherever remunerative markets are available, shifting cultivators tend to plant tree crops like rubber, coconuts, and cocoa in their plots, since these are less choked by weeds and demand less of the soil than annual crops. The cultivation years are thus not followed by regeneration of fallow vegetation, but by a stand of tree crops whose effects on the soil resemble those of iorest and bush vegetation. Evolution of this kind has taken place on a large scale. Nowadays in tropical Africa and Asia thousands of hectares that were previously utilized by shifting cultivators support cocoa, oil-palms, and coffee. The evolution from shifting systems to perennial crops is obviously suitable for the natural conditions of the wet tropics in particular: it is also a change that is relatively simple and cheap.

(d) From shifting cultivation to irrigation farming, in particular to paddy rice. The experience of tropical Asia shows that the best system of arable cropping in a warm, damp climate is the concentration of production in the relatively fertile, irrigated valley bottoms, i.e. replacement of shifting cultivation over large areas by irrigation farming, especially with rice, in small, intensively cultivated plots. The transition from the shifting system to the paddy-rice system, or the combination of both methods, can be observed in large areas of the tropics (Madagascar, East Africa, Ceylon, Indonesia). It depends, as a rule, on the initiative of the indigenous population, and obviously represents an evolution that is ideally adapted to the special environmental conditions (see \$6.4.2).

(e) From shifting cultivation to ranching. In some areas in Africa and to a greater degree in Latin America, especially Brazil, shifting cultivation serves as a method of obtaining cleared grazing land. The shifting cultivator obtains the right to clear the land and to cultivate it for several years. Thereafter a new plot is allotted to him. The period of crop farming, however, is not followed by the regeneration of a fallow vegetation of bush, but by the transition into grassland, facilitated by heavy grazing, supplementary bush clearing, and planned burning. Similar methods of using shifting cultivation in order to turn bush into grazing land are widely practised by cattle-owning cultivators in the African savannas. 


\section{Semi-permanent cultivation systems}

\subsection{Definition}

EXPANDING cash production and the growing subsistence needs of an increasing population lead to a gradual extensic.. of arable farming at the expense of the fallow, and short-fallow systems replace long-fallow systems. Cultivateurs avec jachères (Faucher 1949, p. 9) cultivate areas with alternating cropping and bush or grass fallows. Brinkmann $(1924$, p. 959) used the term Umlagewirtschaft to indicate that stationary farms change the cultivated area more often and more regularly than shifting cultivators. In this type of land use the value of $R$ is between 30 and 70. An $R$ value of 50 can be regarded as typical, and arises when, for example three, five, or ten fallow years follow three, five, or ten years of cropping. In such a situation 50 per cent of the arable land is cultivated annually. ${ }^{2}$ The length of fallow is mostly insufficient for fallow vegetation of forest or dense bush to regenerate. Grass or light bush is typical. In areas not infested by the tsetse fly, the fallow vegetation is grazed by cattle, sheep, and goats. The characteristics of these farming systems are distinct from those of shifting cultivation. We classify them as semi-permanent systems. Where the fallow vegetation is systematically grazed we speak of unregulated ley systems.

Table 4.1 illustrates this development amongst the Bailundu of Angola. Within a few decades, the reduction of fallows has increased the $R$ value from 17 in the traditional system to 31 in hoe systems and 54 in plough systems.

Semi-permanent farming is usually characterized by clcarly defined holdings with largely permanent field divisions. Quasi-stationary housing predominates, since the changing of hut sites is a matter of moving short distances only. Families generally have de facto or registered ownership of the land, in contrast with most shifting systems, in which the holding boundaries are not usually clearly defined, housing is more or less of a migratory nature, and land rights are even less precisely defined.

\footnotetext{
1 A further criterion is that several fallow years succeed several cultivation years. In semidry climates of the subtropics the continuous rotation grain-fallow is widespread. From the point of vi $k^{\prime}$ of farm management, these dry-farming systems are fundamentally different from semi-permanent farming.
} 
Most semi-permanent farmers practise hoe cultivation in the form of a soil-conserving and yield-maintaining, but labour-demanding, ridge or mound culture. They usually cultivate a larger area than shifting cultivators in the same environment, with a fairly large cash-crop area, which may take half of the total land cropped. In Africa in particular, the economic importance of semi-permanent farming is far greater than that of shifting systems. Most of the population and areas that would normally be associated with shifting cultivation are in fact part of semi-permanent cultivation systems.

TABLE 4.1

Development of the land-use system of the Bailundu, Angola

\begin{tabular}{ccc}
$\begin{array}{c}\text { Traditional farming } \\
\text { system, which has } \\
\text { almost disappeared } \\
R=17\end{array}$ & $\begin{array}{c}\text { Hoe systems } \\
\text { predominant } \\
\text { at present } \\
R=29\end{array}$ & $\begin{array}{c}\text { Plough systems, } \\
\text { which are } \\
\text { expanding } \\
R=54\end{array}$ \\
\hline $\begin{array}{l}6 \text { years arable farming } \\
5 \text { years pasture }\end{array}$ & $\begin{array}{l}\text { 6 years arable farming } \\
5 \text { years pasture } \\
15 \text { years bush fallow }\end{array}$ & $\begin{array}{l}\text { 6 years arable farming } \\
5 \text { years pasture }\end{array}$ \\
\hline
\end{tabular}

Source: Tössinger (1967, p. 114).

These systems are chiefly to be found where the soils and climate allow a relatively short crop-fallow cycle, i.e. a high $R$ value, withcut rapidly decreasing yields.

In general terms, a reduction of the fallow period causes a reduction of the yields per hectare, unless there is fertilizer application or manuring, which is normally not the case in these systems. The warmer and the rainier the climate, and the poorer the soils, the more necessary is the long-tern forest or bush fallow, and the less likelihood there is of semi-permanent farming being successfully developed. It is therefore not a typical system in the humid forest zone. The main regions where it is found ale the dry and humid savanna climates and at high altitudes, where there is less leaching and the soils tend to be richer. Under these conditions, extension of cropping at the expense of the fallow may lead to a rising overall production from the total area available, in spite of decreasing yields per hectare cropped. The lower yield per hectare cultivated is usually more than balanced by cropping a larger area. Semi-permanent cultivation is found also on high-fertility soils, especially on alluvial and colluvial soils in river valleys, and at the more fertile bases of slopes, i.e. where the motive for fallowing is less the regeneration of soil fertility than the suppression of weed growth. 


\section{TABLE 4.2}

Intensity of fallow systems and farming patterns in the Kilombero Valley, Tanzania

\begin{tabular}{|c|c|c|c|c|}
\hline System of land use & $\begin{array}{c}\text { Extensive shifting } \\
\text { cultivation }\end{array}$ & $\begin{array}{l}\text { Intensive shifting } \\
\text { cultivation }\end{array}$ & Semi-permanent farming & Permanent farming \\
\hline $\begin{array}{l}R \text { value } \\
\text { Permanency of the } \\
\text { dwelling-place }\end{array}$ & $\begin{array}{l}15 \\
\text { Frequent shifting of } \\
\text { dwelling-place and garden }\end{array}$ & $\begin{array}{l}\quad 30 \\
\text { lnfrequent shifting of } \\
\text { dwelling-place and garden; } \\
\text { sometimes stationary } \\
\text { housing }\end{array}$ & $\begin{array}{l}50 \\
\text { Stationary housing and } \\
\text { garden }\end{array}$ & $\begin{array}{l}\text { Stationary housing and } \\
\text { garden }\end{array}$ \\
\hline $\begin{array}{l}\text { Housing material } \\
\text { Main input }\end{array}$ & $\begin{array}{l}\text { Tree poles } \\
\text { High input for clearing; } \\
\text { low input for weeding }\end{array}$ & $\begin{array}{l}\text { Tree poles and clay } \\
\text { High input for clearing; } \\
\text { low inpu: for weeding }\end{array}$ & \multirow{2}{*}{\multicolumn{2}{|c|}{$\begin{array}{l}\text { Clay/tin roof Stone/tin roof } \\
\text { High input for weeding; low input for clearing; increasing } \\
\text { application of agricultural innovations; increasing invest- } \\
\text { ments } \\
\text { lntroduction of insecticides; introduction of mineral ferti- } \\
\text { lizer; increasing planting of perennial crops }\end{array}$}} \\
\hline $\begin{array}{l}\text { Typical agricultural } \\
\text { innovations }\end{array}$ & $\begin{array}{l}\text { New annual crops and new } \\
\text { crop varieties }\end{array}$ & $\begin{array}{l}\text { New annual crops and } \\
\text { varieties; some new } \\
\text { permanent crops }\end{array}$ & & \\
\hline
\end{tabular}

Source: Baum (1968, p. 36). 


\subsection{Types of semi-permanent cultivation and their geographical distribution}

Semi-permanent cultivation has thus developed in different soil and climatic conditions from shifting cultivation. Looking at the various types from the farm-management angle, we classify them in five main groups.

\subsubsection{Semi-permanemt cultivation on the fertile soils of the humid savannas}

Where alluvial or volcanic soils of high fertility are found in tropical regions with heavy rainfall, the cultivator's problem is less one of conserving soil fertility than of controlling weed growth. Consequently, fallow years may be replaced by more labour input, and cultivators cilange from : 'iffing to semi-permanent cultivation wherever cash cropping or concentration of population demands a more intensive use of land. Table 4.2 shows a course of development that is typical of the fertile areas of the humid savannas in Africa, the particular example being the fertile plain covered with elephant grass in the Kilombero Valley in Tanzania.

Soil fertility permitting, people prefer to enjoy the advantages afforded by the accessibility of markets, water, and neighbours. The easily recognizable tendency to move into areas already somewhat densely populated is an indication that these last advantages are considered more important than the higher labour input per unit of yield required in semi-permanent systems as compared with shifting systems.

Baum (1968, p. 35) writes:

The intensification of rotation cycles and the tendency towards stationary living bring about changes in farming pattern. Stationary dwellings are accompanied by permanent gardens where more and more beans, maize, sweet potatoes, manioc and fruit trees are planted. Whocver has the means builds himself a solid house with a tin roof. Where semi-permanent or even permanent farming is being practised, technical innovations are spreading. New crops are planted. Interesi in selling the produce grows in direct correlation to the degree of permanency in farming. Here and there, tractor ploughs are used, and cotton is treated with insecticides.

\subsubsection{Semi-permanent cultivation in connection with perennial crops}

Semi-permanent cultivation also establishes itself where the planting of tree crops gives risc to stationary living and farming. An intensified rotation of cropping and fallow necessarily follows where more and more land is planted with trees for market production, and less and less land remains available for subsistence crops. Thus the planting of trees often cause: the change from shifting systems to semi-permanent and permanent systems. In these types of farming, tropical root crops usually constitute a high proportion of the total cultivation. Little livestock is kept, since in Africa this form of cultivation is mainly found in regions infested by the tsetse fly. Examples 


\section{SEMI-PERMANENT CULTIVATION SYSTEMS}

of semi-permanent land use of this kind can be seen particularly in the forest areas of West Africa. They are discussed in Chapter 8.

4.2.3. Semi-permanent cultivation in connection with irrigation forming

Similar conditions occur in permanent irrigation farming, especially in Similar conditions occur in permanent irrigation farming,
wet-rice systems. Paddy-rice cultivation requires permanent homes and creates a relative shortage of rain-fed land paddy-rice cultivation in irrigated Where shifting cultivators change to paddy-rice cultivation in irte lonstems in valley bottoms, short-fallow systems usually replace long-allow systems in the surrounding hill country. Especially clear exaniples of developments of this kind can be seen in Madagascar and Indonesia 'see Chapter 7).

4.2.4. Unregulated ley systems in the drier savannas

intery savannas. As cultivation spreads at the expense of fallows, forest or bush vegetation gives 年 the tsetse fly dotted with patches of bush. In Af be ke and the grass fallows and harvest to be displaced, so that cattle can be kept, and the residues can be used as fodder. The concentration of cattle dung in the kraals folding system. Fallow systems of this nature may be considered as a stage in the transition to ley farming proper and are therefore called unregulated ley farming.

The economic importance of this kind of land-use system is considerable, especially in Africa. The cotton holdings of the savannas in western and eastern Africa, and the groundnut-millet holdings in western Africa, may be classified wholly or partly as a form of unregulated ley farming.

4.2.5. Unregulated ley systems in high-altitude areas

Greatly reduced dependence on fallow is the outstanding feature of the systems in temperate, high-altitude areas of Africa, Asia, and

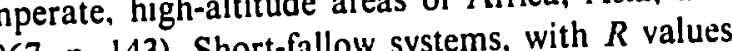
Latin America (Miracle 1967, p. 143). Short-fallow systems, are consequently that are much higher than in long-fallow shifing systems, are consequently widespread in tropical high altitudes. The fallow vegetation consists as a rule of grass which is used for grazing; in other words we find wild wespread in ley systems, as in the drier savannas. This kind of farming is widespread in for example, the highlands of Burundi, Tanzania, Kenya, and Ethiopia Comparatively large areas of unregulated ley systems exist in the mountainous

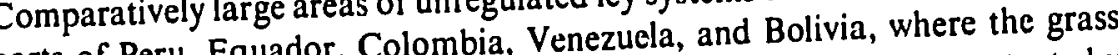
parts of Peru, Equador, Colombia, Venezucher, by fallow is grazed by sheep, llamas, and alpacas, and, to a . Some unregulated cattle (Dion 1950; Fals-Borda farming is still to be found in mountainous areas of northern India 
(Himachal Pradesh). In these areas, double cropping with rice and wheat is carried out for some years, and followed by several years of grazing.

In most cases we still do not find the permanent field divisions that characterize regular ley systems. Instead, suitable parts of the grazing area are cropped for a few years and then left to go back to grass.

\subsection{General characteristics of semi-permanent systems}

Semi-permanent systems are of particular importance in Africa south of the Sahara. The description of general characteristics, therefore, refers principally to African conditions, especially those prevailing in the African savannas.

\subsubsection{Spatial organization of cropping}

Semi-permanent systems, like the shifting systems from which they have usually developed, are characterized less by attempts at controlling nature than by complex and skilful adaptation to the natural conditions of production. A typical feature is the juxtaposition of plots used for different crops, especially where the soils change over a short distance.

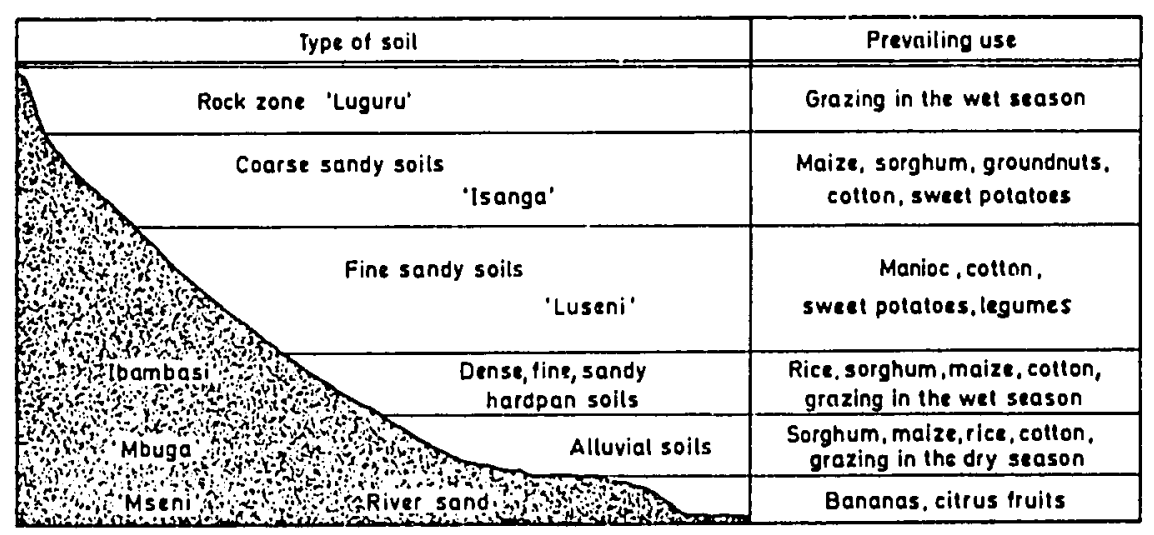

Fig. 4.1. The catena and the principal uses of the different types of soil in Sukumaland, Tanzania (from Rotenhan 1968, p. 58).

Figure 4.1 shows the catena of various soils in Sukumaland, Tanzania. The most suitable crops are grown on each type of soil. A Sukuma holding consists, where possible, of a strip of land running through all the soil levels. At the top of the slope are the fields with maize and sorghum, followed by plots chiefly planted with cotton and manioc. The hardpan soils serve principally for grazing. :inally, in the valley bottom, we find plots with rice and sweet potatoes.

Figure 4.2 illustrates, with an example from Senegal, the horizontal differentiation that has developed in western and eastern Africa with the introduction of cash crops into arable farming (Pelissier 1966; Dumont 1966, p. 66; Froelich, Alexandre, 
and Cornevin 1963). The intensity of croppirg decreases in concentric circles from the domestic gardens in the vicinity of the huts to the often widely scattered peripheral fields.

Holdings of this type usually include a great number of various subsistence and cash activities carried out on different plots within the holding area, so

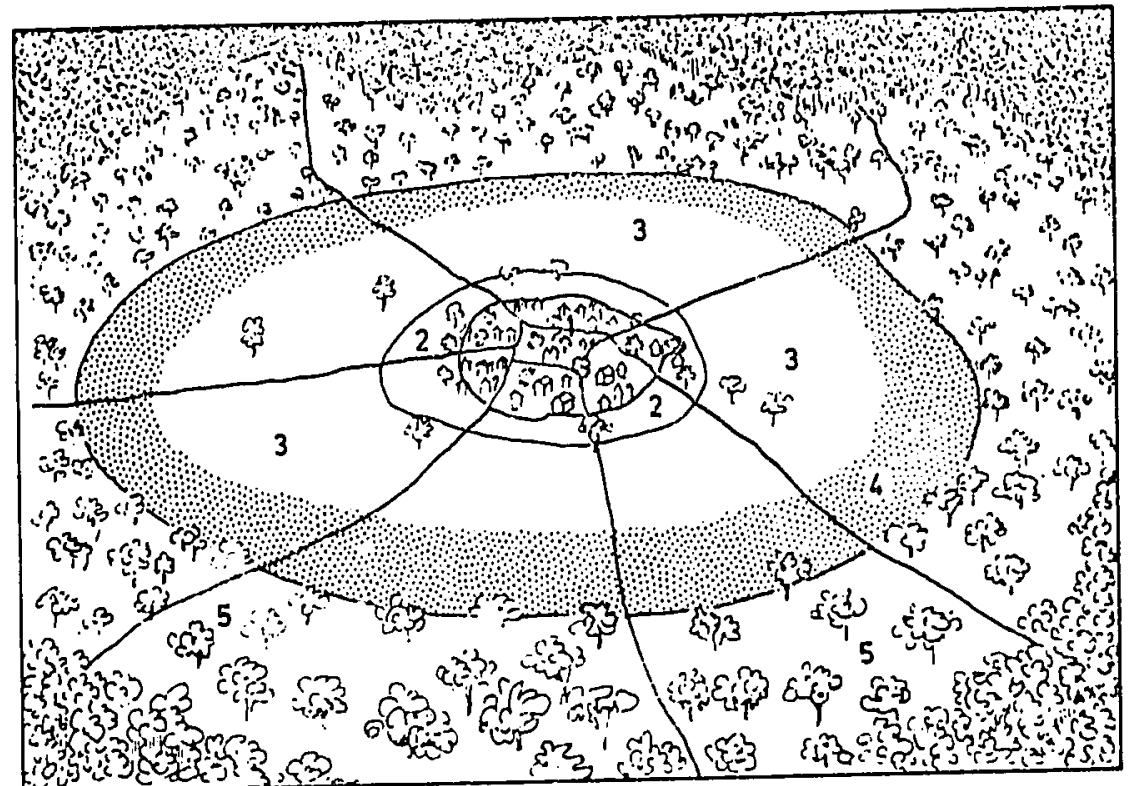

FIG. 4.2. Spatial organization of land use in N'Gayene, Senegal (from Pelissier 1966, p. 474). (1) Houses and gardens; (2) permanent cultivation; (3) semi-permansnt cultivation;

(()) intensive shifting cultivation; (5) bush and extensive shifting cultivation.

much so that semi-permanent farming may be considered as one of the most diversified farming systems in the tropics. The main features of these holdings are as follows:

(1) Permanent gardens with fruit trees and perennial crops like bananas and papayas are found in the immediate vicinity of the hut, which is either no longer shifted or is moved only a short distance at long intervals.

(2) Near the huts or villages, what is called the dung-land is mostly cultivated. It is used for crops that require more fertile soils, and should guarantee a good yield. The intensity of land use frequently corresponds to garden culture.

(3) Adjoining this we find semi-permanently used fields in concentric circles of varying size. These fields are often used for growirig the staple food and cash crops. The fallow is mostly used as pasture.

(4) The intensity of the crop cycle decreases proportionately to the distance 
from the farmstead. Between the cropping years the ground is left fallow for long periods; in other words, shifting cultivation is practised.

(5) In some areas the holdings include plots in valley bottoms, which are used for cropping sweet potatoes, taro, or sugar-cane. On the valley bottoms rice cultivation is also widely practised. It should be noted in addition that on moist plots millet or maize is cropped in the dry season, thus providing the household with an off-season supply of fresh food.

(6) Trees are often found scattered over the area: fruit trees (e.g. mangoes in eastern Africa), fodder trees (e.g. Faidherbia albida in Senegal), or sisal hedges.

(7) Where cattle are kept, a calf enclosure is occasionally found near the hut or inside the kraal.

(8) The fallow and communal pasture are grazed by cattle, sheep, and goats.

(9) Livestock-rearing in a stationary homestead is supplemented here and there by a certain amount of nomadic herding: some of the herds belonging to the cultivators graze on remote grazing areas watched over by herdsmen.

By no means all holdings that are classified as belonging to semi-permanent systems incorporate all the activities cited above. In most cases, however, there is a catena in land use, or a spatial differentiation within the holding; and there is a combination of intensive agriculture and shifting cultivation, providing as it does for adjustment to differing soil conditions and labour requirements in holdings of partly commercialized farmers with stationary housing.

\subsubsection{Cropping principles}

The main source of semi-permanent cultivators' sustenance is arable farming, with animals playing a supplementary role only. In the savannas, crop yields vary considerably from year to year, more so than those obtained by shifting cultivators in the humid forest zones. Consequently, semipermanent cultivators try atove all to secure a reliable supply of food. Another aim is to obtain tasty food: millets and maize are usually preferred to manioc or sweet potatoes. In addition, there is as a rule a dominating cash crop like cotton, groundnuts, or tobacco in each farming system. These are the usual objectives on which the organization of cropping is based, and they require some basically different cropping principles from those that are typical of shifting cultivation.

(a) Pure stands and mixed cropping. Mixed cropping usually still predominates in semi-permanent systems. The cultivation of cash crops, however, has led to a considerable number of pure stands. Cotton, groundnuts, rice, and tobacco are usually cultivated only in pure stands.

(b) Phased planting. A widely practised principle is phased planting of 
each crop, even though losses due to late planting are considerable. The point is illustrated by the practice followed in Sukumaland, Tanzania (see Fig. 4.3). The cultivators point to the unreliability of the rain, particularly in the drier regions. To allow for this uncertainty, they distribute the planting of their clops over a long period, preferring to spread the risk instead of aiming at maximum yields. They also prefer to spread the demand for labour over several months by phased planting. Houschold requirements offer an additional explanation, planting being so timed that the farmers can get food from the garden or field for continuous periods of several months. Thus the planting of subsistence crops in particular, such as beans, sweet potatoes, groundnuts, and maize, is spread over several months.

(c) Crop rotation. As short-faliow systems replace long-fallow systems, we can see the pseudo-rotation (de Schlippe 1956) being increasingly displaced by proper crop rotations. When compared with the crop mixtures and pseudo-rotations of shifting cultivators, the rotations show several distinct tendencies:

(1) Whereas the rotations of shifting cultivators tend to include a wide range of different crops, as cuitivation becomes more permanent cropping is restricted to fewer crops on each type of soil.

(2) There is a tendency to use different rotations for the particular soils of different plots.

(3) Fixed and regular sequences of crops like rotations of the kind found in permanent cropping have by no means yet evolved, but crops demanding fertile soil are increasingly being planted at the beginning of the period of cultivation, and crops demanding less fertility are planted at the end.

(d) Fallow systems. The organization of fallowing in semi-permanent cultivation is as a rule especially varied. According to Rotenhan (1968, p. 64), the variety of forms that it takes can be classified in the following way:

(1) There is a half-year's fallow if the land is not used during a six-month period between the harvest and the following planting. In most wet-dry climates, the six-month fallow is the rule on all arable land.

(2) There is a proper fallow, if no crops at all are grown on the land during the whole year. The ground is left to be covered naturally by grass or bush. Subject to the influence of climate and soil in most African savanna areas, a short-grass steppe develops. With increasing length of the fallow, this short-grasis steppe changes into bush vegetation.

A distinction can be made between different forms of proper fallow:

(1) Permanent fallow exists on those arable plots that are not likely to be used for cultivation in the foreseeable tuture. They usually serve as grazing areas. 

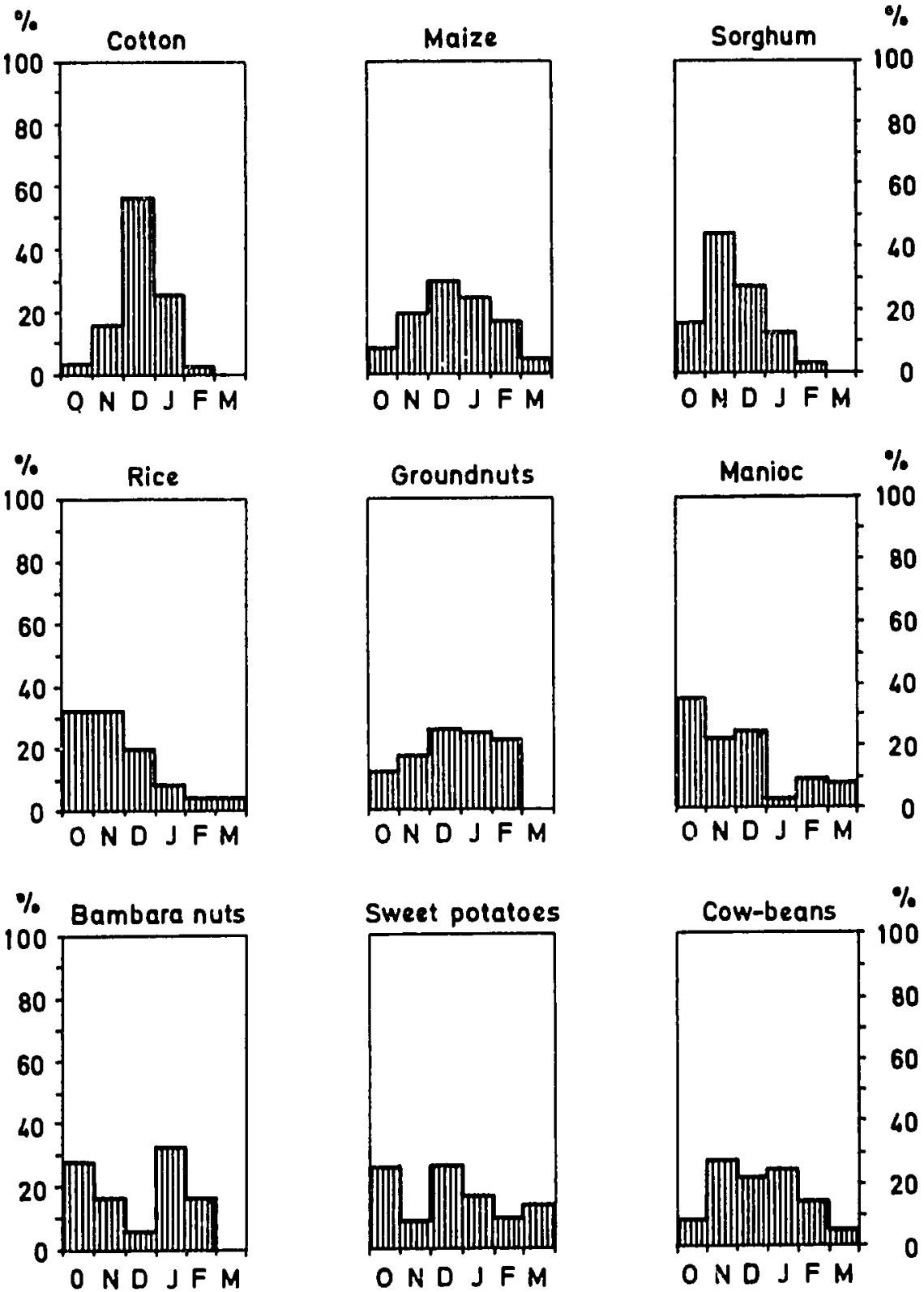

Fig. 4.3. Phased planting in Sukumaland, Tanzania. Seve,itty-five holdings in three locations were studied, each with several hundred plots, and with only minor differences at the beginning of the rainy season. The percentage of the total area used for each crop sown in different months is shown. (From Rotenhan 1968, $\mathrm{F} .62$.) 
(2) If the yields from a plot that has long been cultivated have fallen so much that further cultivation appears uneconomical, then it is given a long-rest fallow of five to twenty years. Frequently several fields at once cease to be cropped, so that we can speak of fallow blocks as opposed to cultivated blocks.

(3) There is a medium-term fallow if a plot of arable land within a cultivated area is left uncultivated for two to five years. The aim of this form of fallow is to combine the regeneration of the soil fertility with the elimination of weeds. Medium-term fallows are particularly widespread.

(4) The short-term fallow of one to two years has generally not the aim of restoring soil fertility, but is caused rather by other circumstances, such as the illness of a farmer or unfavourable weather, which may make the planting of the field difficult.

The high degree of diversification of semi-permanent cropping can be regarded partly as the inheritance from shifting cultivation as practised earlier, and partly as adaptation to a more intensive stage of land use.

\subsubsection{Characteristics of the fertilizer economy}

The higher intensity of land use necessitates more highly evolved manuring techniques, although it must be recognized that in most semi-permanent systems, as in shifting systems, the fertilizer economy is still undeveloped. The cuntinuity of cropping depends on either:

(1) high soil fertility, which is not visibly impaired by frequent cropping, in which case fallow periods are not interpolated so much to regenerate fertility as to eradicate weed growth; or

(2) the ability of the soil to regenerate during the fallow period, which consists principally of grass; or

(3) stabilization of yields at a low level.

In high-altitude tropical areas with a temperate climate, and in the drier savannas, grass fallows are usually able to regenerate soil fertility. In these conditions and on very fertile soils, semi-permanent cultivation can be regarded as a balanced land-use system. This does not, however, apply to the large areas of semi-permanent cultivation in the humid savannas, where the soils are of only moderate fertility. In these conditions, repeated cropping with short, unfertilized grass fallows brings about a long-term deterioration of the land. Repeated cultivation favours erosion, in particular gully-erosion and sheet-erosion. Furthermore, grasses with shallow roots are less effective than trees or bush in reducing the leaching action of rainfall. Thus Portères (1956), for example, has demonstrated that in some areas of Senegal the soil eventually loses its structure: clay components are washed out, the soil 
recomes increasingly pervious, the proportion of sand in the topsoil increases, and the ability to retain water is reduced.

In so far as cultivators have recognized the problem of soil mining and practise manuring, a number of fertility-restoring methods can be identified: (a) Shifting of the hut and kraal. It is in any case traditional for the home and farmstead to be shifted at fairly long intervals.

The huts become dilapidated after some years, the site foul and eroded, the kitchen gardens reach the point of exhaustion, and it is better to move to a new site than to attempt to rehabilitate the old dwellings. These rebuilding moves are generally short, scmetimes a mile or more but often no more than a few hundred yards ... (Allan 1967, p. 7.)

The wish to obtain an especially fertile plot that can scrve as a permanent garden for some time also motivates the shifting of the holding and the kraal.

(b) Systematic folding. In sume cases we also find a systematic folding economy (Froelich et al. 1963, p. 71; Dumont 1966, p. 65; Pelissier 1966). Where semi-permanent cultivation is combined with livestock-rearing, the cultivators can use the manure from the kraals. Transporting the manure to the fields, however, and digging it into the soil present considerable problems where there are no tracks, carts, or draught animals. The cultivators therefore prefer to move the kraal and, in the case of the Wasukuma (sce \$4.4.2), for example, they do so irregularly, thereby obtaining a series of manured plots. In some areas of Senegal, and on the west coast of Madagascar and Ethiopia, the kraals are moved regularly, so that fairly large plots are systematically manured. In these cases, it is the area around the farmstead which is treated in this way, with the consequence that it can be cropped more or less permanently (see \$4.3.1).

(c) Green manuring. A widespread practice in hoe cultivation, especially in ridge cultivation, is for the fallow and weed vegetation to be dug systematically into the soil. Sometimes the gathering of green manure from further afield is organized as well. Pössinger (1968, p. 117) reports, for example, that farmers in Luanda, Angola, artificially increase the size of termite mounds, which are preferred for cropping. The cultivators pile up maize straw, manioc stalks, and other plant waste in a circle around the mound, and the termites break down this plant material on the spot.

(d) Mineral fertilizers. Where cotton, groundnuts, tobacco, and other annuals are grown as cash crops, more and more cultivators apply mineral fertilizers. Mineral fertilizer-when it is economically worth while-can be introduced comparatively easily in semi-permanent farming, because it can be applied efficiently on small plots without requiring tracks, carts, or much labour. At the same time, it can be stored without appreciable detcrioration, is easy to apply, and produces an increased crop after a relatively short period. For these reasons, it is usually easier to introduce the application of 
mineral fertilizers in semi-permanent farming than to introduce manuring with available cattle dung.

Even though the various stages of incipient fertilization may be worthy of note, it must nevertheless be remembered that they are mostly inadequate. Semi-permanent land-use systems often represent nothing more than degraded forms of previously balanced systems of shifting cultivation.

\section{4. .4. Characteristics of animal husbandry}

Whereas shifting cultivation is largely practised with little or no livestock, in semi-permanent systems we often find large stocks of cattle. In extended areas of the African savannas, it is the interaction of arable cropping and cattle-keeping that keeps the tsetse fly at bay. Slash and burr agriculture thins out the forest or bush vegetation and destroys the breeding grounds of the tsetse fly; intensive grazing prevents bush regeneration and therefore prevents the insect from re-cstablishing itself. Arable cropping and animal husbandry in unregulated ley systems are consequently closely dependent cn each other.

The aims of stock-keeping are varied:

(1) Cattle are kept to cover the risk of harvest failure or sickness. When land is not privately owned, cattle are kept as a means of support in old age.

(2) In close relation to this there are social functions. Cattle act as brideprice, while a large herd is a status symbol.

(3) Farmers want a supply of meat and milk for the household; sale of this produce is not very important.

(4) A factor of increasing importance is the provision of the traction power for ox-plough cultivation.

(5) Only in a few cases do semi-permanent cultivators consider the contribution of manure as an essential purpose of stock-keeping, although it might be of considerable relevance to their farming.

Harvest residues, fallow grazing, and natural grazing provide the fodder. Communal use of grazing land is customary: everybody has the right to allow any number of animals to graze on the fallows, pastures, and stubbles. Fodder cropping is practically non-existent. Occasionally, balanced feeding is achieved by seasonally moving the livestock to grazing areas some distance away, which have not been used earlier in the season.

The composition of the livestock herds depends above all on the availability of fodder. Where there is good grassland with sufficient watering places, the number of cattle per family is high, and a high proportion of the stock consists of male animals. With increasing shortage of grazing and higher cattle densitios, primarily female stock is kept, the male calves being 
slaughtered soon after birth. Where fodder is not sufficient to keep large herds in one place, the lending out of cattle is common.

TABLE 4.3

Management indicators of cattle husbandry in Sukumuland, Tanzania

\begin{tabular}{lcccc}
\hline & $\begin{array}{c}\text { Shinyanga } \\
\text { Semi-permanent } \\
\text { cultivation }\end{array}$ & $\begin{array}{c}\text { Kwimba } \\
\text { Permanent } \\
\text { cultivation }\end{array}$ & Total survey \\
\hline $\begin{array}{l}\text { Number of cattle surveyed } \\
\text { Average age of cattle }\end{array}$ & 472 & 296 & 49 & 817 \\
$\begin{array}{c}\text { over 1 year } \\
\text { Average age of female } \\
\text { animals }\end{array}$ & 7.6 & 9.1 & 5.9 & 7.5 \\
$\begin{array}{l}\text { Average age for bearing } \\
\text { first calves (months) }\end{array}$ & 3.2 & 10.9 & 10.3 & 10.0 \\
$\begin{array}{l}\text { Calving interval (months) } \\
\text { Calves per 100 female } \\
\text { animals }\end{array}$ & 16 & 37 & 54 & 39 \\
\hline
\end{tabular}

- Animals with more than two calves.

- Live births.

Sources: Rotenhan 1966, pp. 56-7.

Table 4.3 illustrates the cattle economy in a typical dry savanna in three regions of Sukumaland, Tanzania, namely Shinyanga, where the $R$ value is 39, with a relatively large amount of grazing land; Kwimba, which has an $R$ value of about 33, with less grazing; and Ukerewe, where the $R$ value is about 75, with permanent cultivation.

One hundred cows between three and six years old can be expected to produce on average thirty-six calves, and both male and female calves are raised, although only 60 per cent reach their second year. A fully grown new generation of twenty-two animals is therefore produced by one hundred cows. They bear their first calves at thirty-nine months, and the intercalving period is eighteen months. Excluding the milk consumed by the calf, there is a yield of about 600 ki'ograms in a lactation period of 246 days. The number of animals consumed, including calves, constitutes 10 per cent of the total stock annually. There is no selling on a large scale. Of all the animals consumed, 75 per cent are those that dic or have to be slaughtered, and only 25 per cent are slaughtered specifically for consumption. Efforts to control losses caused by disease by means of dipping, de-stocking campaigns, and projects to introduce organized use of grassland have not so far been successful. Table 4.3 shows clearly that performance is generally low and decreases with increasing shorlage of fallows, e. with higher $R$ values.

An important sociological feature is the fact that the ownership of livestock is much more concentrated than the cropping of land. In Sukumaland, for example, 25 per cent of the families crop 55 per cent of the cultivation area, but 25 per cent own 80 per cent of the animals (see Fig. 4.4). 


\section{SEMI-PERMANENT CULTIVATION SYSTEMS}

3.5. Characteristics of the lahour economy

Important differences between shifting and semi-permanent systemis may so be found in the labour economy. The increasing degree of permanency land use, and the increasing amount of cash cropping, induces rather riking changes:

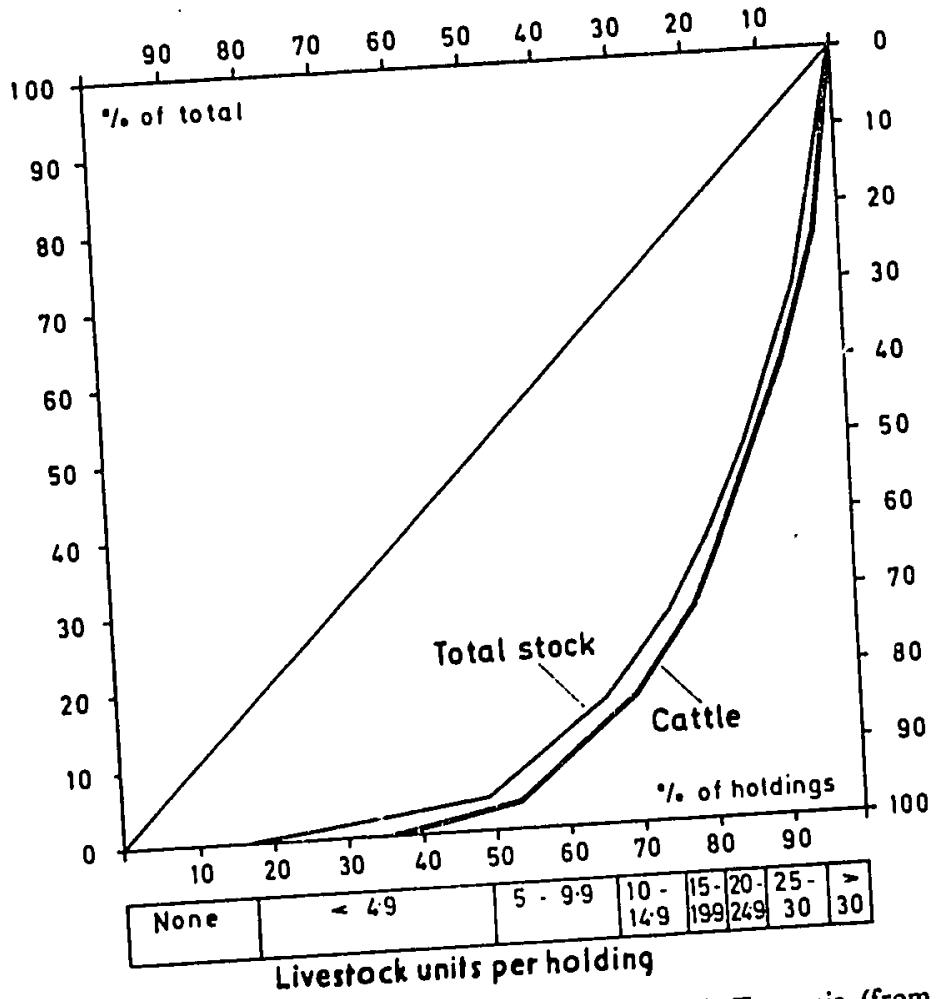

Fic. 4.4. Distribution of livestock property in Sukumaland, Tanzania (from Rotenhan
$1966, \mathrm{p} .57$ ).

(a) Technical. There is a change in work pattern. Tree felling and clearing are the main jobs of fire-farming shifting cultivators; the more tedious tasks of cultivating with the hoe and of weeding are the particularly demanding activities of the semi-perried out with ploughs and weeders. where these processes cannot yet be care that people work for more (b) Economic. It is almost alwami-permanent cultivation is more often hours each day, firstly because seer unit of output than shifting cultivation, than not more time demanding pering requires additional working time. and secondly because cash creppearch, semi-permanent cultivators in SukuAccording to Rotennan's research, semi-permanent during the growing season,
maland work for an average of $6 t$ hours a day during 
which lasts for about eight months (1966, p. 70). Haswell (1963) gives a similar figure of 6.4 hours daily for groundnut holdings in Gambia.

(c) Sociological. We find a change from the rather rigid traditional division of labour between the sexes, which is still typical of many shifting systems, towards a more flexible use of the available labour force. The demands of cash cropping seem to be the driving force belind this. An important feature is the increasing involvement of men in field work such as weeding and harvesting. This in turn indicates a new tendency in farm management. Traditionally, several persons in the household cultivate the food they need for themselves and their dependants on a plot that might be considered a sub-farm within the family holding. With increasing permanency and commercialization, land and labour use within a holding seem to become more centrally organized.

Typical of semi-permanent land use in the African savannas is the cultivation with hand-tools of comparatively large areas of 2-8 hectares per family. The labour input per hectare is rather high. A lot of hard work has to be done in the growing seasen. Table 4.4 gives an idea of the size and composition of the labour input in several savanna crops. On the light soils of Senegal, where a deep cultivation of the soil before cropping is usually not practised, the input in land preparation and planting is comparatively low. The labour input is much higher in the classical hoe-farming arcas of Sukumaland, where careful ridge cultivation is practised. Almost 400 hours per hectare are required for land preparation under these circunistances. The cultivated area varies accordingly. 6-8 hectares of crops is the average figure per household in Senegal, while 3 hectares is the norm in Sukumaland.

A significant change in the work situation is brought about by the introduction of the ox plough, which is technically possible wherever areas with a fallow vegetation of gras; have been de-stumped. First and foremost, it eases the burden of work sy relieving the hard toil of land cultivation. At the same time, fields of mostly regular rectangular shape are formed, the size of fields increases, and the cropped area is expanded at the expense of the fallow (see Table 4.5). Where the ox plough is not combined with the oxdrawn weeder and row cultivation, as, for example, in cotton cropping in Sukumaland, the labour economy in cultivation may easily be cancelled out by the greater work required for weeding. For the full success of aninal traction, to obtain the greatest possible reduction in the work-load, the oxdrawn weeder and cart, as well as the plough, are necessary. The great reduction of labour input in groundnut cultivation in Senegal stems from this combination (see Table 4.4).

A further feature of this land-use system is the seasonal nature of labour demand. In shifting systems, the task of clearing does not have the same rigid timetable as has cultivation for the semi-permanent cultivator. He must wait 
TABLE 4.4

Labour input in typical savanna crops

\begin{tabular}{|c|c|c|c|c|c|c|c|}
\hline $\begin{array}{l}\text { Crop } \\
\text { Location } \\
\text { Country } \\
\text { Year }\end{array}$ & \multicolumn{5}{|c|}{ Labow } & \multicolumn{2}{|c|}{ Ox-plough cultivation } \\
\hline $\begin{array}{l}\text { Land preparation and } \\
\text { planting (hours ha } \mathrm{h}^{-1} \text { ) } \\
\text { Weeding (hours ha } \\
\text { We }\end{array}$ & $\begin{array}{l}169 \\
376\end{array}$ & $\begin{array}{r}88 \\
180\end{array}$ & $\begin{array}{l}152 \\
252\end{array}$ & $\begin{array}{l}390 \\
250\end{array}$ & $\begin{array}{l}370 \\
430\end{array}$ & $\begin{array}{l}136 \\
110\end{array}$ & $\begin{array}{l}120 \\
700\end{array}$ \\
\hline $\begin{array}{l}\text { Harvesting and } \\
\text { preparation for sale } \\
\text { (hours ha }\end{array}$ & $\begin{array}{l}210 \\
755\end{array}$ & $\begin{array}{l}208 \\
476\end{array}$ & $\begin{array}{r}64 \\
468\end{array}$ & $\begin{array}{l}300 \\
940\end{array}$ & $\begin{array}{r}690 \\
1490\end{array}$ & $\begin{array}{l}210 \\
456\end{array}$ & $\begin{array}{r}700 \\
1520\end{array}$ \\
\hline
\end{tabular}

Total (hours ha-1) $755 \quad 476$

Sources: - Bureau pour le développement de la production agricole (1965, p. 27). 214, 238).

- Bureau pour le développement de la production
c Rotenhan (1968, table 6, p. 75).

- Rotenhan (1968, développement de la production agricole $(1965$, p. 35$)$. 
Table 4.5

Characteristics of thoe and plough regions in Sukumaland, Tanzania

\begin{tabular}{lcc}
\hline & $\begin{array}{c}\text { Hoc region } \\
\text { Ukerewe, Kwimba }\end{array}$ & $\begin{array}{c}\text { Plough region } \\
\text { Shinyanga }\end{array}$ \\
\hline Basic method & Ridge cultivation & Flat cultivation \\
Shapu of fields & Irregular & Regular \\
Average size of fields (ha) & 0.5 & 0.9 \\
Cultivated area per farm (ha) & 2.4 & 3.3 \\
Area cultivated per worker (ha) & 0.7 & 1.3 \\
\hline
\end{tabular}

Source: Rotenhan (1968, p. 56).

until the beginning of the rainy season to cultivate, whereas the shifting cultivator can carry out clearance work in the dry season. Over and above this, there are sometimes certain jobs that are fixed to a timetable and require a heavy labour input in weeding and often in harvesting. Such is the case, for example, with groundnuts. As Fig. 4.5 shows, both in Sukumaland and
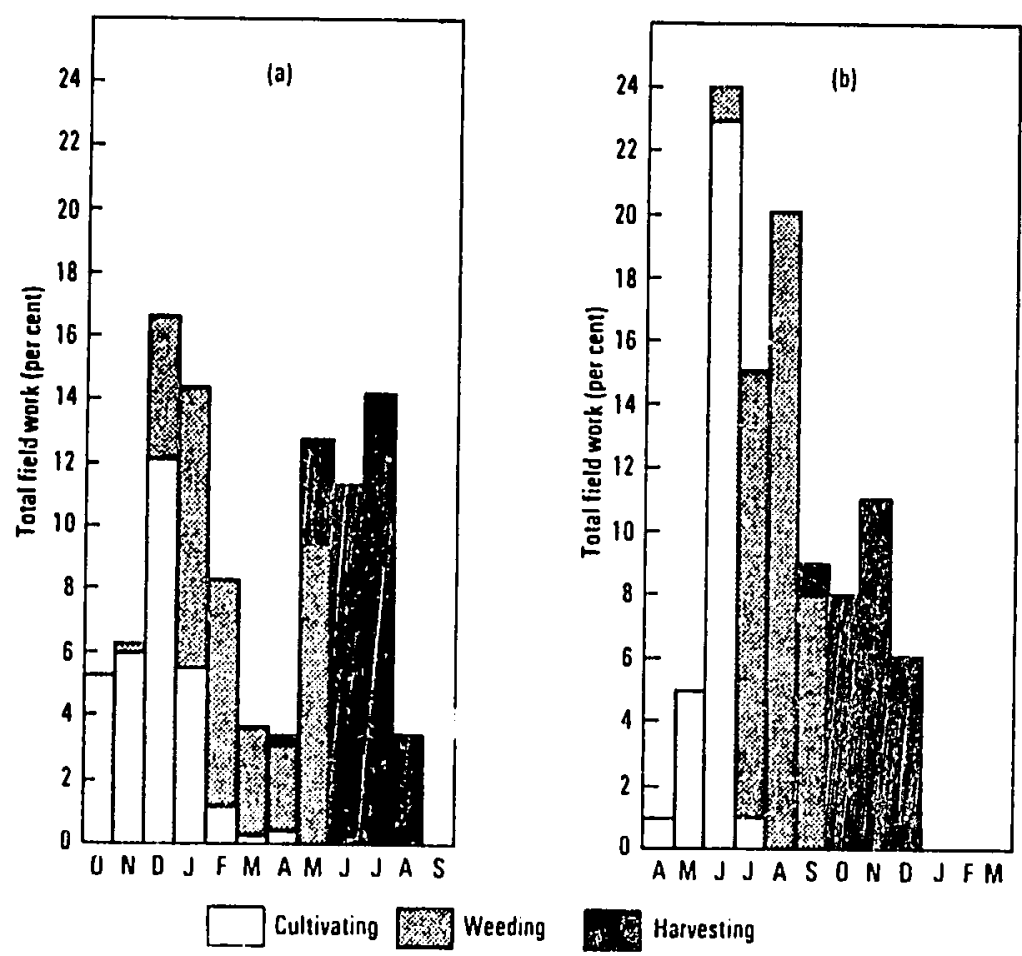

Fig. 4.5. Seasonal distribution of field work in semi-permanent farming systems of Tanzania and Senegal (from Lacombe-Orlhac 1967, annex 1; Rotenhan 1968, p. 63). (a) Cottonmillet holdings in Sukumaland, Tanzania. (b) Groundnut-millet holdings in Senegal. 
Senegal 90 per cent of the field work is concentrated into six months, and 50-60 per cent in only three of those months. Since ticld work, apart from herding of cattle, is almost the total work of the holding, considerable underemployment occurs during the remaining months. In this connection, we must bear in mind that the number of work-hours per day does not give a satisfactory idea of the different labour demands. In seasons of peak demand un labour, performance per hour is considerably higher.

Finally, it should be pointed out that the labour economy of partly commercialized, semi-permanent systems is usually far removed from the uniformity of traditional subsistence farming. Differences in the man to land ratio, differences in the choice of crops and the adoption of innovations, different access to development services, and different opportunities for cash cropping-these factors all combine to bring about a wide variation in the size of enterprises and in the smallholders' performance within a given location. In most semi-permanent systems, only a few hectares are cultivated and a few animals kept, i.e. the size of agricultural enterprise is rather small. Tliss, however, does not mean that the average area cultivated by each family or each worker is about the same. Within each type of farming, even wher land is still ample, we find striking differences as to the area cultivated per family and per member of the available labour force. The equality that characterizes traditional shifting systems, in which each family cultivates only what is required to cover subsistence needs and everyone uses the same practices, no longer exists. Within semi-permanent cultivation systems, we find larger and smaller units, richer and poorer families. The differentiation in cropping is the more noticeable the greater the extent of land shortage and the higher the degree of commercialization.

Even more pronounced are the variations in performance. On average the hours of field work per available man-equivalent are low. There are, however, wide fluctuations in the input of work per hectare and returns per hour of work within the range of production possibilities offered by a semi-permanent system. Farm-managerial ability, pai ticularly in cash cropping, is one of the major factors differentiating progressive producers from others. The explanation is an obvious one: semi-permanent cultivators differ widely, much more than shifting cultivators, as to their physical effort, their drive, and their knowledge.

\subsection{Two case studies}

4.4.1. Semi-permanent farming in the subhumid savanna: rice holdings in the Kilombero Valley, Tanzania

The Kilombero Valley in Tanzania is warm and humid, receiving 12002000 millimetres of rain annually. Most of the valley is flooded every year. The vegetation on the heavy, black-cotton soil ('mbuga') of the plain consists 
TABLE 4.6

Farm-management data of semi-permanent holdings

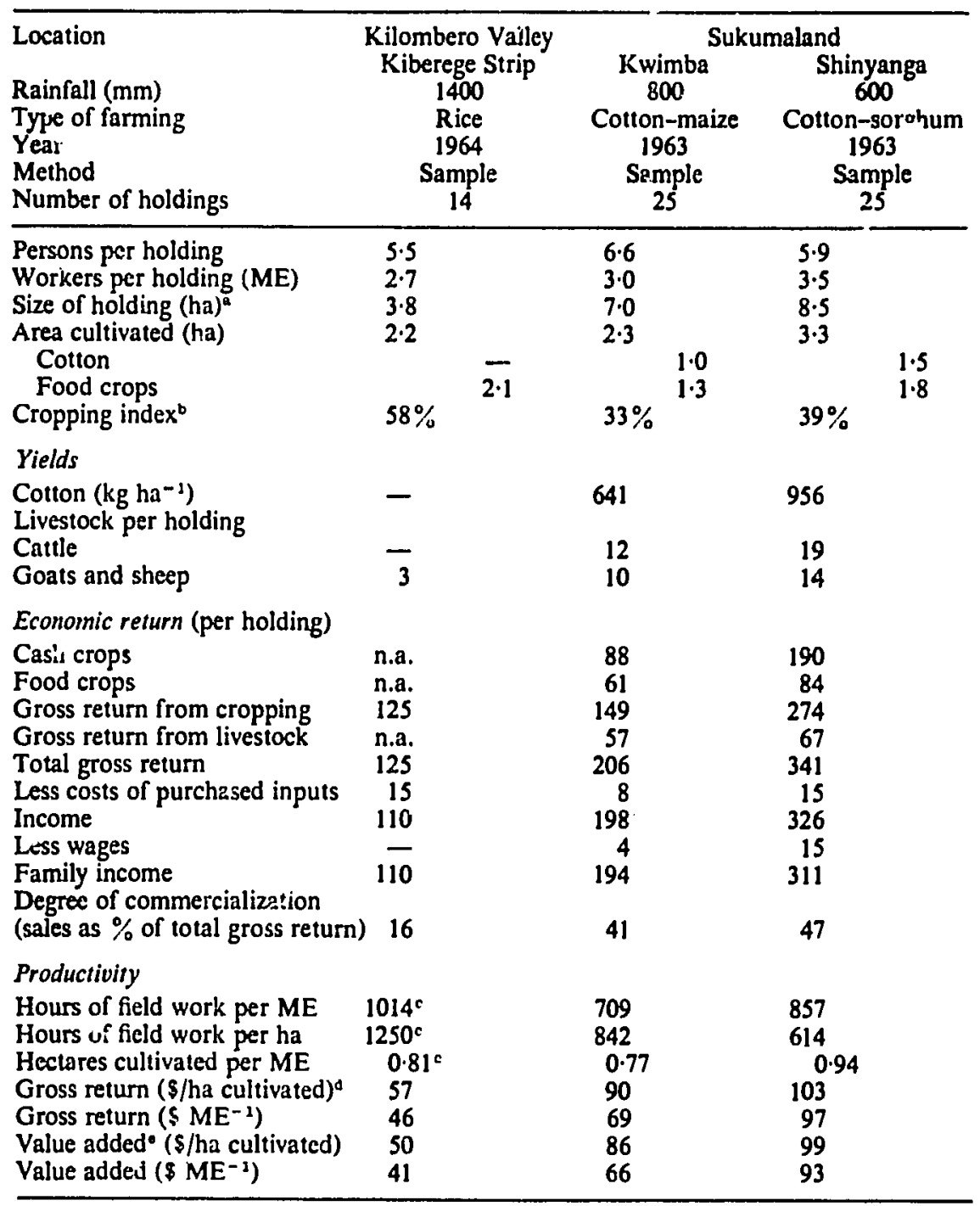

- Areas over which the farmer has a right of usage.

- Percentage of occupied and arable iand that is cropped.

c Four holdings only.

- The comparability is limited because of livestock returns which are not derived from cultivated area.

- Value added $=$ income in smallholdings (gross return minus purchased inputs) $=$ net return + wages, salaries, taxes, etc., on large farms.

Sources: Baum (1968, p. 40); Rotenhan (1968, p. 55). 
mainly of elephant grass. Most of the valley is empty or thinly populated. The population is concentrated in the Kiberege Strip, lying on the western side of the valley, which throughout the year has access to a road, and therefore to a market. Higher population density along the road has given rise to the transition from shifting to semi-permanent cultivation. The concentration of population has brought about a relative shortage of land. The right of use is strictly observed even for fallow land.

In a pilot study of fourteen holdings, the total average arable area amounted to 3.8 hectares, of which 2.2 hectares ( 57 per cent) were cropped eacl year. Land is brought into cultivation in the sequence grass clearance-burning-'.lceing-broadcast sowing of rice. Two or three years of rice, followed by the same period of fallow, is the normal rotation. The encroachment of grass into the field is the main reason for fallowing. Rice cultivation, with yields of about 10 quintals per hectare, is supplemenied by' manioc or wet-season maize, beans, and sweet potatoes. Housing has become stationary. Bananas and papayas are grown near the hut, and the older the settlement the higher and larger are the mango and coconut groves nearby. Livestor.k is restricted to a few goats, sheep, and chickens, and the presence of the tsetse fly has hitherto prevented cattle-keeping from being introduced. Table 4.6 shows the econornic returns from this type of farming. The gross return from cropping amounts to \$125, with a labour input of 2750 hours of field work per annum, resulting in a gross return per work-hour of about $\$ 0.05$. Only a small part, 16 per cent of the gross return, is sold. These are therefore typically subsistence holdings.

\subsubsection{Unregulated ley farming in the drier satanna: cotton-maize-mille: holdings in Sukumaland, Tanzania}

An example of arable farming in the drier savanna is the Wasukuma's land use in the cultivation steppe to the south of Lake Victoria which has a rainfall of 600-800 millimetres during the six-month rainy season. A typical Sukuma farm is a strip of land stretching from the top of a hill to the bottom of a valley, which includes different types of soil carrying different crops (see Figs. 4.1 and 4.6).

Cropping per holding amounts to $2 \cdot 3$ hectares annually and takes up about half the land available for cultivation. 1-1.5 hectares are cropped with cotton. 1.5-2 hectares carry maize, sorghus:, legumes, and manioc for personal consumption. Rice and sweet potatoes are cropped on separate plots in the valley bottoms. The different ways in which the land is used are the result less of rotating various crops than of successively cropping the plant or plant mixture that thrives best on the particular soils until the yields decline. The last crops to be grown are manioc and millets, and then the land goes back to grass and the plot becomes grazing fallow for a number of years. Normally six to eight years of fallow succeed six to eight years of cropping.

The holdings are defined by clear boundaries, which are frequently sisal hedges, whose leaves are processed in the off-season. In some parts of Sukumaland, clearly recognizable field boundaries have already been developed, in addition to the fixed holding boundaries. The soil is still cultivated for the most part with the hoe. Cotton and crops for home consumption are planted in ridges 1.3-1.5 metres apart. 
In the north-eastern and southern border areas, ox ploughs are increasingly used. In some areas, tractor ploughing has been introduced.

A holding normally has 7-8 livestock units in the form of 11 Zebu cattle, 4 sheep, 4 goats, and a number of chickens. Thanks to a variety of soil types, the Wasukuma have a natural system of fodder supply. In the dry season, from the end of June to the beginning of Ontober, the vide valley bottoms ('mbuga'), where a lct of fodder grows, lose their swampy character and can be grazed. In the rainy season the fallow land is grazed. Households that possess a larger number of livestuck arritr.pe

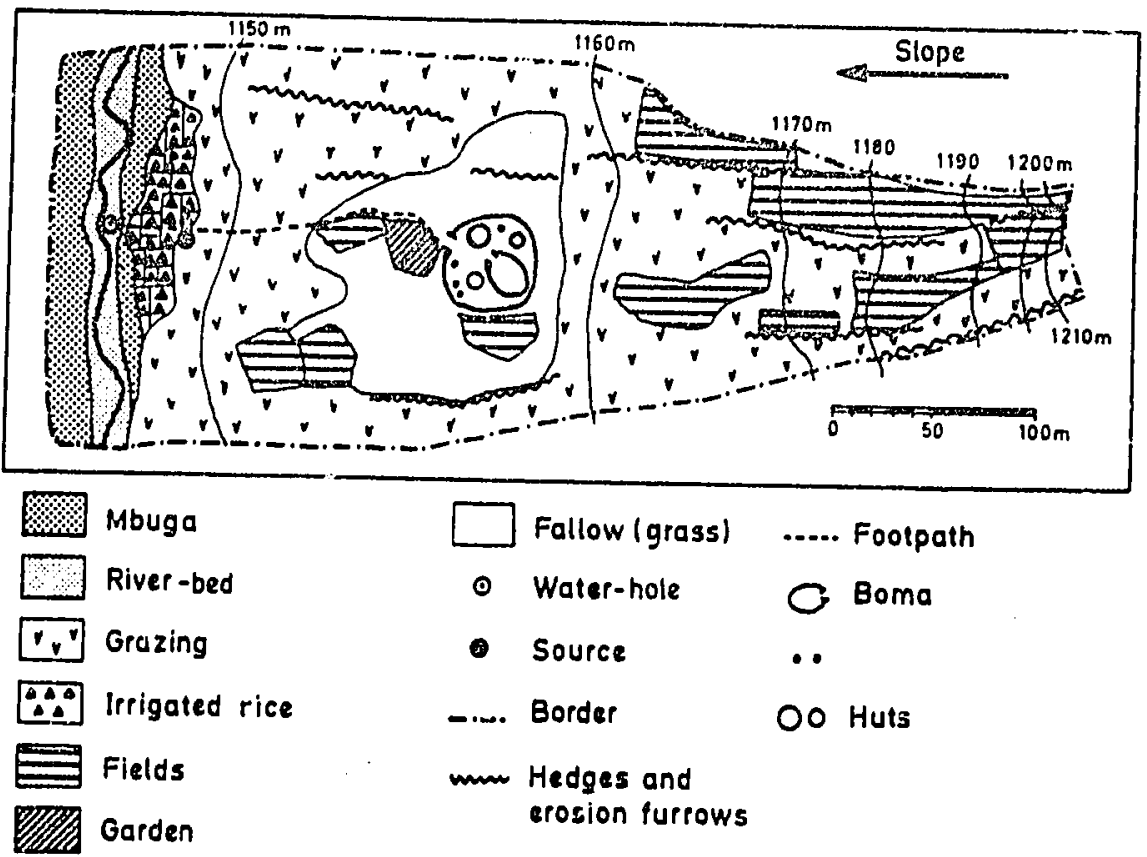

Ftc. 1.6. Land use in a Sukuma holding, Tanzania (from Ludwig 1967, p. 104).

for $\mathrm{sc}$ ne of the animals to be grazed in remoter steppe areas. However, arable farming and animal husbandry are not integrated. The livestock is fed on pastures, fallow, and harvest residues. Cattle dung from the kraals is not utilized unless the kraal is sinfted and a garden is laid out on the old site. Mineral fertilizer is being applied increasingly to cotton.

Rotenhan (1968; see Table 4.6) estimates the average gross return of a holding to be $\$ 206-341$. Ti.e costs for purchased inputs and wages are small; the 'amily income comes to only slightly less than the gross value of production. There is an income of $\$ 66-93$ for $709-857$ hours of field labour per worker, i.e. $\$ 0.09-0.10$ per
huur of work.

\subsection{Weaknesses of the system}

Semi-permanent cultivation in partly commercialized holdings is distinguished from shifting systems both by more intensive land use and by the 
SEMI-PERMANENT CULTIVATION SYSTEMS

tt that technical innovations can be more easily applied. People live in tionary housing with permanent gardens. New varieties and production :thods can make headway, especially where a major cash crop is grown, ie cotton or groundnuts. Cultivation with ploughs is possible where the llow vegetation consists of grass. At the same time, the first steps are being ken in investing labour in plantations of perennial crops, permanent roads, nd other long-term capital works.

\subsection{The tendency towards soil mining}

Desrite these derolopment advantages, a number of basic drawbacks hould be noted. The main problems are those of maintaining soil fertility. Manuring with animal dung and fodder cropping are exceptional, and the effectiveness of mineral fertilizers is usually marginal because of unfavourable price relations and short-comings in husbandry, particularly in weeding. Other things being equal, the yiclds per hectare are often less than in shifting systems. At the same time, in many areas, especially where the plough has replaced the hoe, erosion damage is on the increase. Normally semi-permanent cultivation does not constitute a stable system of land use, since it generally amounts to either rapid or gradual forms of soil mining, especially in the drier savannas.

\subsubsection{Degeneration of the livestock economy}

Another conspicuous aspect of semi-permanent systems is the degeneration of the livestock economy once grazing becomes scarce. Static animalhusbandry practices within a changing farming system almost inevitably lead to problems. As long as there is sufficient grazing land available, the herds per family are of a good size and the cattle are well fed. An increase in the area needed for arable farming necessitates a reduction of the grazing area. Simultaneously, the proceeds from crop farming are partly being invested in cattle, in order to gain security and status. The results are an increase in the cattle population and a reduction in the grazing area, causing complementary danage. The condition of the cattle deteriorates and erosion increases. On over-grazed land, a high proportion of the rain runs off as flash floods. Over-grazing encourages the thickening of bush, particularly those species on which livestock do not browse. Thus in the long run over-grazing reduces the carrying capacity of the grazing area, reduces the length and the effectiveness of the fallow period, and increases the amount of clearance work.

The practice of unorganized communal grazing is at the root of the problem. Usually everybody has the right to graze all his cattle on the available grazing, including the fallows. No improvement of the grazing economy is of value, however, unless the stock numbers are limited to the car ying capacity 
of the grazing land, and unless the movement of stock within any given area is controlled by a rotational grazing system.

\subsubsection{Bottlenecks in the labour economy'}

In most semi-pcrmanent farming systems only about one-third to twothirds of the available labour capacity is absorbed in field work. Nevertheless, cultivators almost cverywhere, regardless of the degree of underemployment, unanimously feel that labour shortage is the most important factor limiting output. When asked about this, they almost invariably argue that they would like to produce more and earn more, but they are not in a position either to cultivate larger areas, or to change to labour-demanding crops, or to cultivate, plant, weed, and harvest in time. or to increase the labour input per hectare of a given crop, because there is not enough free family labour available during the relevant weeks, and there are not enough funds to pay hired labour. Much, if not most, of the cultivated land is neitier planted nor weeded according to a timetable that would maximize yields.

The fact that important labour shortages within family holdings and a high degree of underemployment go hand in hand may be traced back to a number of major factors:

(1) It is well known that labour peaks in agriculture, particularly with arable crops, occur seasonally. The Wasukuma, for instance, have a great deal of work to do between December and April. In the second half of the summer there is no field work at all.

(2) Agricultural work is not the only work that has to be performed in smallholdings. In fourteen cotton-maize holdings in Machakos District, Kenya, Heyer (1965) established that on average throughout the year the relation of work-hours on the land to household work is 1 to 1.7 , i.e. general household work is much more time consuming than field work.

(3) The labour capacity of the various persons in the household is not utilized equally, because of traditional concepts of the way in which work is divided between men and women. It may be, for instance, that the women cannot weed in time because the work connected with the household demands too much attention. On the other hand, the men who are unemployed at this time do not consider that tending the food crops should be part of their work.

(4) Another important factor is the low efficiency per hour of work. This is caused for one thing by unsuitable hand implements. In Sukumaland, for instance, the weeds are hoed with the sarne hoe that is used for ridging. The usual hoe is well adapted to the latter activity, but not at all to the former. In addition, smallholders are accustomed to making a concentrated, sustained effort only in connection with a few procedures, such as felling, clearing, and hoe cultivation. The other jobs have traditionally been done in a leisurely manner. 
SEMI-PERMANENT CULTIVATION SYSTEMS

Finally, the extent of underemployment is calculated according to ns of working hours per year and per man-equivalent. The smalllers who refer to difficulties in the labour economy are naturally not liliar with such norms. Many of them do not accomplish more work :ause they regard a five-hour day, even at planting time, as a complete lization $C^{-}$heir working capacity.

lany of the problems of the labour economy in semi-permanent land use e because these systems are a transitional phase between shifting and manent land use. The advances in the labour economy that are characterc of permanent arable farming-row riultivation, ploughing, mechanical eding, proper farm layout, and so on-have not yet been introduced on large scale. Usually the transition to cash cropping, with its consequent bour demands, takes place within a fairly short period, before the farmers re accustomed to longer hours of work per day. On the other hand, the ropping areas are relatively large, and the labour requirement is seasonal. Jonsequently, there is a lively interest among semi-permanent cultivators in labour-saving innovations, even more than in yield-increasing innovations. Farmers in Sukumaland do not generally change from hoe work to ox ploughing to gain higher returns, but to replace hard work with the hoe by easier work with the plough. Particularly striking is the general interest in tractors. Wherever finance is available, and the return per hectare high enough to justify tractor ploughing, smallholders endeavour to buy tractors or to hire tractor services.

\subsection{Development paths of semi-permanent systems and unregulated ley systems}

Production increase in semi-permanent land-use systems normally results from extending the crop area by clearing the land in neighbouring extension areas and from reducing the fallow area. It is most obvious that measures must be introduced that will lead to higher returns per hectare if involution is not to replace evolution. Classification of the possibilities for higher returns per hectare entails differentiation between innovations that give rise to improved semi-permanent systems, and new combinations that eventually create other, more productive systems.

\subsubsection{Improved systems}

In considering field cultivation, we inust emphasize the supreme importance of better husbandry. Established routines of work, which might have been the best in shifting systems, are still practised in semi-permanent systems, although the actual farming is more intensive. Consequently, there is much 
scope for better husbandry. The main shorl-comings in husbandry that could be at least partially remedied are usually the following:

(1) Bottlenecks in the labour economy often result in late planting.

(2) Most farmers tend to use plant spacing that is greater than is advisable. They aim at robust individual plants and overlook the advantages of an optimum plant density.

(3) No other factor is as much to blame for poor yields as late weeding. This can be only partly explained by labour problems. Probably farmers would harvest more if they planted smaller plots and devoted more care

to weeding. vation of better-yielding types of cotton and groundnuts brought noticeable successes in a number of cases.

(5) The lack of field roads and carts makes the application of kraal manure difficult. This makes the introduction of mineral fertilizers all the more relevant in some locations.

(6) Few other measures promise such great increases in returns in relation to the additional costs as the supplementation of the plough by an oxdrawn weeder, in conjunction with the introduction of row cultivation.

(7) The quality of ploughing with oxen is very poor even where ploughs are used. Proper ploughing would not only raise yields, but would also significantly reduce the weeding task.

(8) Where it is felt to be worth-while to keep tractors, very real improvements are possible, especially timely cultivation, the better ploughing-in of weeds, deeper ploughing, and more effective use of mineral fertilizers.

(9) In areas infested by the tsetse fly, the introduction of N'dama breeds, which are resistant to trypanosomes should be considered, in order to reap the benefits that cattle may bring.

Semi-permanent land-use systems as a whole represent a promising step towards introducing technical innovations into farming witi. fallows, and therefore towards agricultural development. The scope for application of innovations is incomparably greater than in shifting systems.

\subsubsection{Change towards more intensive types of farming}

In most semi-permanent land-use systems, grass or bush vegetation grows in the fallow period and is then grazed. It is therefore natural to seek the solution to the problem caused by soil mining in semi-permanent farming through the change-over from unregulated to regulated ley systems. This involves replacement of the several years of fallow, with their natural rege eration of grass and bush, by deliberate cultivation of a plant or plant mixture which is more productive than the fallow vegetation, regenerates suil fertility, and allows plough cultivation. However, the econcmics of ley farming in the 
tropics are not yet proved, and short-term leys in the drier areas are very unlikely to maintain fertility without liberal additions of fertilizers or manure (see §5.6).

The expense of such a fundamental change in the farming system should also be borne in mind. Ley systems call for considerable investment in clearing, livestock, fences, implements, carts, tracks, and buildings. The cost of draught oxen and their necessary accessories alone amounts to two or three times as much as the gross annual earnings from these holdings. Another pre-condition for regulated ley farming is land consolidation. Holdings have to be in one block, with fields large enough for plough cultivation.

The fact that a 'technological jump' must be made presents further obstacles. In the holdings in Sukumaland mentioned above 2 . whole series of innovations have to be adopted in combination if success is to follow, and the same applies to most semi-permanent systems. It is simply not enough to encourage the use of ox-carts to take animal manure from the kraals to the fields, since the tracks also have to exist. But since there are none, unpaid communal work is necessary to build them.

Farmers can scarcely be expected to establish leys and buy seeds and mineral fertilizer for them without obtaining a direct economic return. Keeping dairy animals again necessitates the harvest, transport, and storage of fodder, correct feeding, and, above all, keeping the animals healthy. The problems that are raised can in general be solved technically, but the economics are usually marginal. The producer's prices are mostly tno low to be a sufficient incentive to change. The technological jump can, moreover, scarcely be accomplished by an individual without the consent or the active support of the group, and this further complicates the issue. Profitatle dairy farming involves keeping breeds with a high milk yield, maintaining their health, and making available suitable male animals or semen. The effectiveness of the necessary y:: arinary care on a single farm is doubtful unless neighbouring animals are also treated. Fodder cropping clashes with traditional rights, because the fallow pasturage has been available for everybody's animals for generations. Thus, for anyoine wanting to crop fodder plants on the fallow it is necessary for the others to agree to renounce their grazing rights. It is generally the case that recommendations for a transfer to regulated ley systems with dairying, fodder cropping, dung and mineral manuring, etc., can be expected to siceed only where there has been a land shortage for a number of decades. Where there is no such pressure, there is little desire to change, especially as, tven with the continuing loss of soil fertility, farmers can still gain a comparatively high income.

Another way of introducing stable systems of rain-fed farming is through settlements under close supervision. Farmers taking part in a settlement plan have to obey the project leader in matters concerning rotations, fertilizing, 
animal-keeping, fodder, veterinary supervision, and so on. The lack of knowledge and finance that prevent the individual from making the leap into proper ley farming are counteracted in the settlement by the rules of the supervisor and the credit afforded by the supporters of the settlement. In Africa, south of the Sahara, there are numerous examples of this kind of approach to the modernization of agriculture, but they usually reveal an unsatisfactory ratio between input and yield. Most settlements need continual financial support, or they are abandoned after a few years. The reasons are usually quite straightforward: on the one hand, the cost of personnel for supervision is high; on the other hand, the land that is mostly used is capable of producing only moderate yields. Close supervision, which can be rewarding in irrigation agriculture and with certain perennial crops, is normally not worth while with ley systems, unless cash crops with a high return per unit of area, like tobacco, can be cultivated. Given this situation, for the time being probably nothing can be done but to accept forms of semi-permanent cultivation that are detrimental to soil preservation. The long-term hope is that increasing . sumercialization will demonstrate more and more clearly the inadequacy of the system and create enough incentive for the farmers to remedy the situation. It is very possible that the judgment of Rounce (1949) applies generally to semi-permanent cultivation. He 'vrote about Sukumaland: 'A situation of overpopulated villages and impoverished soils must be passed before better husbandry can spread' (quoted from Rotenhan 1966, p. 52). 


\section{Systı}

\subsection{Definition}

WE speak of a regulated ley system where several years of arable cropping are followed by several years of ley. In British romenclature, only those fields that are deliberately planted to grass, clover, or lucerne are normally considered as ley. This, however, is too narrow a definition for the tropics. The German nomenclature, where the word 'ley' is used wherever several years of arable cropping are followed by several years of grass and clover utilized for livestock production, is preferable. A distinction is then made between unregulated and regulated ley systems. Unregulated ley systems in the tropics are characterized by a natural fallow vegetation of various grass species, a certain amount of bush growth on the pasture, communal grazing, and a lack of pasture management, all of which make such systems often more akin to short-term fallow systems than to regulated liy systems. Individual grazing, fencing, pasture management, and rotational use of the grassland are the usual characteristics of regulated ley systems. The seeding or planting of grass leys, the production of hay or silage, and the application of mineral fertilizer are indicators of intensive types. Ley systems show a more or less regular alternation between arable farming and leys. The sum of the arable years and the ley years tells us the rotation cycle. The leys may be used either for grazing or as meadows producing roughage for stabled cattle. In $:$ ! nost all tropical ley systems both regulated and unregulated grazing are practised. It should be noted, however, that the border line between unregulated and regulated systems is often difficult to draw.

\subsection{Types of ley farming and their geographical distribution}

Regulated ley systems, which are widespread in the subtropics of the northern and southern hemisphere. are rare in the tropics. Those that do occur are more or less restricted to areas that show one or more special features, namely:

(1) Those where vigorous growth of palatible grasses is possible. 
(2) Those where the dependence on the long-fallow system is not pronounced, i.e. where relatively few years of grass are suficient to restore soil fertility.

(3) Those where land becomes so scarce that intensification is required beyond permanent grazing or unregulated ley farming, yet is not so scarce that permanent cropping is necessary.

(4) Those where the health risks of intensive animal-keeping are comparatively low.

(5) Those where price relations favour intensive forms of meat and milk production.

(6) Those where sufficient draught animals or tractors are available to plough the leys.

(7) Those where farmers have sufficient knowledge and capital to organise a proper fodder economy over the year.

These conditions are often to be found in high-altitude large-farm areas. In addition, some types of regulated ley farming have developed in the drier savannas, but ley systems in the humid tropics are still in the experimental stage.

The organization of ley systems is closely related to farm size. We can therefore classify the main forms into three principal groups.

\subsubsection{Regulated ley systems in traditional smallholder areas}

There are but few cases where the evolution of indigenous farming leads to regulated ley systems. A noteworthy exception is the land system of the Serere in Senegal, where cropping and grazing are systematically alternated. Even more important is the ley system in the highlands of Ethiopia, where the vigorous growth of palatable grasses, the use of the horse-drawn or oxdrawn plough, and permanent rights of land-ownership seem to have been the decisive factors that induced the change from unregulated to regulated ley farming. A unique feature of the Ethiopian lcy system is the cultivation of a Festuceae called teff (Eragrostis abyssinica). Teff is a grain crop which supplies a highly appreciated food. Agronomically, however, it is much more a ley grass than a grain crop, combining as it does the soil-restoring and fodder-producing properties of a ley grass with food production. ${ }^{2}$

In other African areas, ley farming has been introduced through the development efforts of various agricultural extension departments. Cases in point are the economically important ley systems in the Kano Plains, Nigeria, in medium-altitude areas of Uganda (Teso system), and in high-altitude areas of Kenya.

1 The following rotation cycle, with six arable and six ley years, which is practised in the area around $P$ because of the prisesince of teff in the rotation: teff-maize-nigerseed (Quireta abyssinica)teff-maize-nigertized-six years of unimproved leys. 
The intensification and modernization of the arable activities in these landuse systems is, however, not usually accompanied by improved animal husbandry. Unimproved local breeds are kept. Fodder production on the leys is rather low and unevenly distributed over the year. The return of meat and milk per hectare and per inadequately fed head of livestock is low as well. Noteworthy exceptions are some traditional smallholder areas in Kenya with intensive dairy production based on grade cattle (see MacArthur 1964).

\subsubsection{Regulated ley systems in settlement schemes}

The African savannas are literally dotted with settlement schemes, most of which aim at the introduction of regulated ley systems and modern animal husbandry. The organization of production within settlements is usually considered as an instrument for introducing the complete set of innovations that is required for the jump into a new and demanding technology. In the Kenya highlands, settlement of ex-European farms and estates led to the establishment of numerous smallholdings with ley farming and intensive milk production as major planning objectives, which achieved a certain degree of success. However, few of the numerous smaller settlement schemes, which are to be found in medium-altitude and low-altitude areas of East and West Africa, and which were planned to incorporate mixed farming with leys, have proved to be successful in either a technical or an economic sense. They may be considered worthwhile pilot schemes, but cannot yet be regarded as economically viable and established farming systems.

\subsubsection{Regulated ley systems in large farms}

Most established ley systems are found on large, mechanized farms, primarily because the use of the tractor is possible only with a complete clearance of bush and stumps, i.e. it requires a fallow vegetation of grass. Furthermore, the profitability of the leys depends on modern forms of animal husbandry, which are much more easily introduced in large than in small farms.

The following examples of large-farm ley systems are among the most important:

(1) The tobacco farms in the drier African savanna of Zambia and Rhodesia are largely based on leys. The prime objective of the ley is not to produce fodder but to free the soil from nematodes.

(2) In the Kenya highlands, wheat, pyrethrum, sheep, and beef and dairy cattle are the main branches of activity in large modern ley farms (MacArthur and England 1963). Less evolved ley systems are to be found in the highlands of Angola and Mozambique (Pössinger 1967).

(3) Numerous varied types of regulated ley farm are to be found in South and Central America, mainly in the humid savannas. Sugar-cane growers in Cuba put leys between two sequences of sugar-cane for rotational reasons and in order to ease peaks in labour demand. Coffee growers in southern 
Brazil cultivate some of their crop lands within ley systems, because dairying has become a paying proposition. In addition, there are a great number of ley systems at various altitudes in the Andes.

(4) Irrigated land in sparsely populated areas is occasionally farmed along the lines of a ley system. A case in point is the combination of two to three years of rice followed by five to ten years of irrigated pasture in New South Wales, Australia.

\subsection{General characteristics of regulated ley systems}

\subsubsection{Principles of crop and ley management}

Cropping becomes clearer and more uniform as farming is carried on within clearly demarcated fields. The various distinct patterns in the spatial organization of cropping that we find in shifting and semi-permanent systems are rarely found in proper ley systems. Fields are more uniformly cultivated, and planted predominantly in pure stands. Pseudc-rotations, with overlapping larvests and planting dates, are replaced by clear-cut crop rotations. Nutrient concentration around the homestead is uncommon because of the available transport facilities (carts, tractors, field roads) on the one hand, and because of the preference for night grazing on the other.

The relevant farm-management features are rather different from those of unregulated ley systems. In the analysis of regulated ley systems, the following aspects are of most importance:

(a) The ratio of arable years to ley years or of ley area to crop area is an indicator of the intensity of land use. In general, the number of grass years is relatively high and the ley system cxtensive where:

(1) soils are heavy and wet, as they frequently are in some high-altitude areas;

(2) crop yields are uncertain, as in the drier savannas;

(3) the land has steep slopes;

(4) labour is expensive; and

(5) price conditions are more favourable to stock-keeping than to arable farming.

(b) The cycle of arable and grass years. Long-term cycles between cropping and grass years are indicative of extensively organized ley systems. Shortterm cycles uccur principally where the holding has a relatively large amount of permanent grazing and where, therefore, the livestock economy is not absolutely dependent on the fodder contribution from the leys. On the other hand, long-term cycles are preferred:

(1) on heavy soils;

(2) where traction power for ploughing the ley is scarce; and

(3) where establishing leys is expensive. 


\section{SYSTEMS WITH REGULATEIS LEY FARMING}

The number of ley years depends, moreover, on the choice of the grasses and legumes grown.

(c) The intensity of cropping. In temperate climates the management of leys and stock exercises a great influence on the pattern of arable farming within the holding. In most tropical ley systems these interactions are less pronounced. The main emphasis is usually on cash crops during the arable years. In addition, some arable fodder is grown to bridge the dry season. Otherwise, cropping and the use of the leys are two distinct activities.

(d) The intensity of ley management. This varies widely. As far as ley establishment is concerned, the following systems are distinguishable:

(1) Often a sign of extensive ley farming is a natural grass regeneration. This, however, may not be true where grass growth is prolific. In the highlands of Kenya and Ethiopia, naturally regenerated grass is found even in comparatively intensively farmed holdings. Smallholders rely almost entirely on natural grass regeneration.

(2) Ley establishment by the sowing of grass seed is in general restricted to large holdings.

(3) A number of especially productive grasses, e.g. $Y$ ikuyu grass and elephant grass, are always established by the planting of vegetation material, not seeds. Planting is also the usual practice where (for example in the highlands of Kenya) the change is made in smallholdings from naturally to artificially established swards. In any case, planting depends on the availability of ample labour.

(4) Ley systems achieve the highest productivity where it is possible to sow clover-grass mixtures.

Leys can be distinguished on the basis of management according to:

(1) whether the leys are fenced;

(2) whether rotational grazing is practised; and

(3) the intensity of labour input in grassland nıanagement.

The usual way in which leys are used is for grazing. In some cases grass is also cut to make hay or silage. In the tropical highlands, however, haymaking suffers because of the heavy dew, or because it coincides with the rainy season. Thus, it is usually more advantageous to meet the fodder requirement with roughage and silage.

\subsubsection{Characteristics of the fertilizer economy}

The continuity of cropping in ley systems is usually built on the soilconserving and fertility-regenerating capacity of grass leys. Regulated systems fulfil these functions better than unregulated systems for a number of reasons:

(1) The fencing of leys and the systematic rotation of cropping and grass reduce the tanger of over-grazing and the resulting erosion damage. 
(2) The systematic establishment, management, and use of the leys bring about a better snil coverage and allow the development of a dense root system.

(3) Regulated ley systems are occasionally combined with folding systems, in which there is more manure because of the more intensive stocking.

(4) Where ley farming is practised with clover-grass mixtures, as for instance in the highlands of Kenya, not only is there a significant increase in the quantity and quality of fodder, but an increase in nitrogen fixation is also brought about.

It should be stressed, however, that the soil-preserving characteristics of leys as grown in temperate climates or at high altitudes cannot be simply sepeated in medium-altitude and low-altitude tropics. Webster and Wilson (1967, p. 318) write in this connection:

The grass ley probably has a modest, direct, beneficial effect on the nutrient and physical status of the surface soil, and, compared with continuous cultivation, a rotation including a grass break is likely to be advantageous in reducing erosion and decreasing the incidence of weeds, pests and diseases in the arable crops. However, unfertilized grass leys are no more effective in maintaining fertility than are fallows of natural regeneration.

A large number of well-tried clover-grass mixtures have recently been developed for the subtropics and some tropicai high-altitude areas. In Australia and Kenya thry are already being extensively used. However, there are to date no correspondingly suitable legumes for incorporation in leys in low-altitude or medium-altitude tropical areas.

Mineral fertilizing is becoming increasingly important in commercialized ley holdings with extensive cash cropping. However, in these holdings mineral fertilizer is used specifically for the cash crops. Only in exceptional cases so far has mineral fertilizer been used on grass leys.

\subsubsection{Characteristics of animal husbandry}

The obstacles preventing rationalization of the animal economy that are found in unregulated ley systems with communal grazing exist in regulated ley systems only where communal grazing is not replaced by definite grazing rights on each holding. In so far as this has occurred, there is a tendency for more intensive forms of animal husbandry to be employed, whereby the production of beef and heifers tends to be of primary importance on large holdings, and milk production on small holdings.

Regulated ley systems frequently show advanced husbandry practices. On settlement schemes and large farms, we usually find improved or grade cattle and planned breeding programmes. Whereas semi-permanent cultivators keep their animıals overnight in a kraal with fencing, in regulated ley systems night grazing is possible, and the need to walk long distances from 


\section{SYSTEMS WITH REGULATED LEY FARMING}

the kraal to the grazing areas and water is thus obviated. Furthermore, fencing makes it possible to graze calves, heifers, and cows separately. Another characteristic of regulated ley systems is the more intensive fodder economy: rotational grazing and arable fodder production are standard procedures. However, the use of concentrates, which is important in tropical systems with permanent arable farming, plays a lesser role in ley systems.

The tropical highlands with sufficient rainfall afford especially favourable conditions for low-cost animal production in regulated ley systems. It is much easier and cheaper to keep grade animals healthy in the cool mountain areas than in hotter climates. When the rainfall is evenly distributed, the cattle may graze almost all the year. Arable fodder rnight provide some additional roughage in a dry spell. A good example of low-cost animal production in the large-farm economy of some parts of the Kenya Highlands.

\subsubsection{Characteristics of the labour economy}

Whereas unregulated ley systems are mainly hoe economies, in regulated systems we find plough cultivation, largely because of the traction power required to plough the leys. Where the holdings are too small to keep draught animals or tractors, ploughing is usually undertaken by a contractor, as for example is widely practised in Kenya.

Ley systems as a whole may require a low labour input per unit of output in relation to other farming systems. The weeds that grow on arable land are suppressed during the grass years. In fact, the labour input in weeding is very often less than in systens with permanent farming. Whereas the clearance work in unregulated systems has still to be done largely with the hoe, in regulated systems the sward is broken with the plough. In most areas the use of tractors in ley systems becomes a financially viable proposition. A further important point is that work in animal husbandry involves the relatively regular employment of labour.

\subsection{Three case studies}

\subsubsection{Tobacco farms in Rhodesia}

The tobacco holdings of the Sand Veld in Rhodesia show the evolution of shifting cultivation to regulated ley farming within a few decades. They normally cover a total area of approximately 1000 hectares, of which onehalf to two-thirds is regarded as suitable for arable farming, but only a part of this is suitable for tobacco.

In the case of the holding depicted in Table 5.1, the tobacco area amounts to 35 the rest of the holding hectares, with 22 hestares of maize and 5 hect in these holdings. Virginia tobacco is is grazed by a herd of cattle, as is common in these holdings. Vir labour input and is technically
the mainstay of the farm economy: it requires a high labol 
difficult to produce, but it yields harvest of 1000 kilograms, worth $\$ 1000$, of dried tobacco per hectare. In the sample case, tobacco constitutes practically the only cash product. Maize, beans, and cattle are used mainly for payments in kind to farm workers.

\section{TABLE 5.1}

Farm-management data from a tobacco holding in Rhodesia

\begin{tabular}{|c|c|c|}
\hline \multirow{2}{*}{$\begin{array}{l}\text { Rainfall (mm) } \\
\text { Type of farming } \\
\text { Year } \\
\text { Method } \\
\text { Workers (ME) } \\
\text { Size of holding (ha) } \\
\text { Potential arable land (ha) } \\
\text { Area cultivated (ha) } \\
\text { Tobacco (ha) } \\
\text { Food crops (ha) } \\
\text { Livestock per holding (LU) }\end{array}$} & \multicolumn{2}{|c|}{$\begin{array}{c}900 \\
\text { Tobacco-holding } \\
\text { 1962-3 } \\
\text { Model }\end{array}$} \\
\hline & $\begin{array}{l}482.6 \\
850 \\
600 \\
62 \\
90\end{array}$ & $\begin{array}{l}35 \\
27\end{array}$ \\
\hline $\begin{array}{l}\text { Yields } \\
\text { Tobacco }\left(\mathrm{kg} \mathrm{ha}^{-1}\right) \\
\text { Tobacco }\left(\$ \mathrm{ha}^{-1}\right) \\
\text { Maize }\left(\mathrm{kg} \mathrm{ha} \mathrm{h}^{-1}\right)\end{array}$ & $\begin{array}{l}1000 \\
1000 \\
1200\end{array}$ & \\
\hline $\begin{array}{l}\text { Economic return ( } \$ \text { per holding) } \\
\text { Gross return } \\
\text { Tobacco } \\
\text { Cost of material inputs } \\
\text { Machinery } \\
\text { Pesticides, fertilizers, etc. } \\
\text { Income } \\
\text { Less wages } \\
\text { Profit }\end{array}$ & $\begin{array}{r}38000^{\circ} \\
19950 \\
18050 \\
8550 \\
9500\end{array}$ & $\begin{array}{l}92 \% \\
36 \% \\
19 \%\end{array}$ \\
\hline $\begin{array}{l}\text { Productivity } \\
\text { Gross return (\$/ha potential arable land) } \\
\text { Gross return ( } \$ / \text { ha cultivated land) } \\
\left.\text { Gross return ( } \$ \mathrm{ME}^{-1}\right) \\
\text { Value added ( } \$ / \text { ha potential arable land) } \\
\text { Value added ( } \$ / \text { ha cultivated land) } \\
\left.\text { Value added ( } \$ \mathrm{ME}^{-1}\right)\end{array}$ & $\begin{array}{r}63 \\
61,3 \\
792 \\
30 \\
291 \\
376\end{array}$ & \\
\hline
\end{tabular}

- Key: man $19-60$ years $=1.00 \mathrm{ME}$

$\operatorname{man} 15-19$ years $=0.67 \mathrm{ME}$

wonlan $19-60$ years $=0.67 \mathrm{ME}$

woman $15-19$ years $=0.50 \mathrm{ME}$

child $10-15$ years $=0.25 \mathrm{ME}$

- One-third of the ME are women and children.

c Livestock produce, maize, and beans are mainly used for payments in kind.

Sources: Haviland (1952); Rhodesia Ministry of Agriculture (1963, p. 12).

The chief problem in the farm economy of these holdings is that of achieving high yields of good-quality tobacco per hectare. For this, not only must 
SYSTEMS WITH REGULATED LEY FARMING

cropping be carried out in a technically correct way, but fertile soils must be prepared-fertility meaning in this case less the presence of nutrients than the absence of nematodes. Tobacco cropping shifted originaily within a holding covered by 'Miombo' forest. Suitable plots were selected, cleared, used for a number of years, and then abandoned to secondary vegetation. Elimination of nematodes necessitates either ten years of bush fallow, or three to four years of ley with grasses that are inimical to nematodes. In production conditions like these, semi-permanent land use serves as a stage in the developrnent of fully integrated ley systems. In large holdings that operate tractors, forest clearing includes removal of tree stumps. Tobacco cropping leaves the soil ready for ploughing and further use. The cultivation of maize presents a problem, however, because maize produces low harvests on tobacco soils, and it is also a host plant for nematodes. Tobacce and maize, therefore, must be grown separatel; on compatible soils within the holding. Green-manure crops between the years of tobacco prove to be too costly and entail a high amount of cultivation. Planted grass is therefore an attractive and practical crop for alternation with tobacco. The followirig rotations have been developed in consequence:

(1) tobacco-tobacco-leys ( $3-5$ years); and

(2) tobacco-maize-tobacco-leys (3-5 year s).

In some holdings, the leys consist of grasses that are not eaten by cattle, and the only reason for growing them is to eliminate nematodes. But in other cases the pastures are used as cattle grazing. In these cases the productive ley replaces a system of deliberately planted fallow vegetation. The combination of tobacco cropping and cattle-k ping is characierized by a number of advantages:

(A) The holding in any case consists partly of large areas of non-arable land, which can be used only for grazing.

(2) Cattle husbandry produces comparatively steady returns, whereas the yields from tobacco cropping fluctuate widely.

(3) The production of beef and its use as payment in kind reduce the wage cost of tobacco growing.

(4) The labour force, which is used onij' seasonally for tobacco, can be used in the out-of-season period for work connected with the livestock activities.

In large holdings, it is relatively easy to carry out the change-over from shifting cultivation with tobacco to semi-permanent farming with systematically established fallow vegetation, and finally to a ley system. Large-scale tobacco growers can usually command the necessary capital or credit, and the knowledge, both of which present major problems for smallholders. 


\subsubsection{Large farms in the Kenya highlands}

The Kenya highlands are among the few tropical regions where the transition from unregulated to regulated ley systems is being accomplished with relative ease. The climate is naturally suitable for the growth of grasses and for keeping grade cattle. The production potential was first developed on large farms, but impruved practices are now spreading into the smallholder areas. Table 5.2 contains the data for large and small farms that are typical of the area.

TABle 5.2

Farm-managemem data from large and small ley farms in the Keny'a highlands

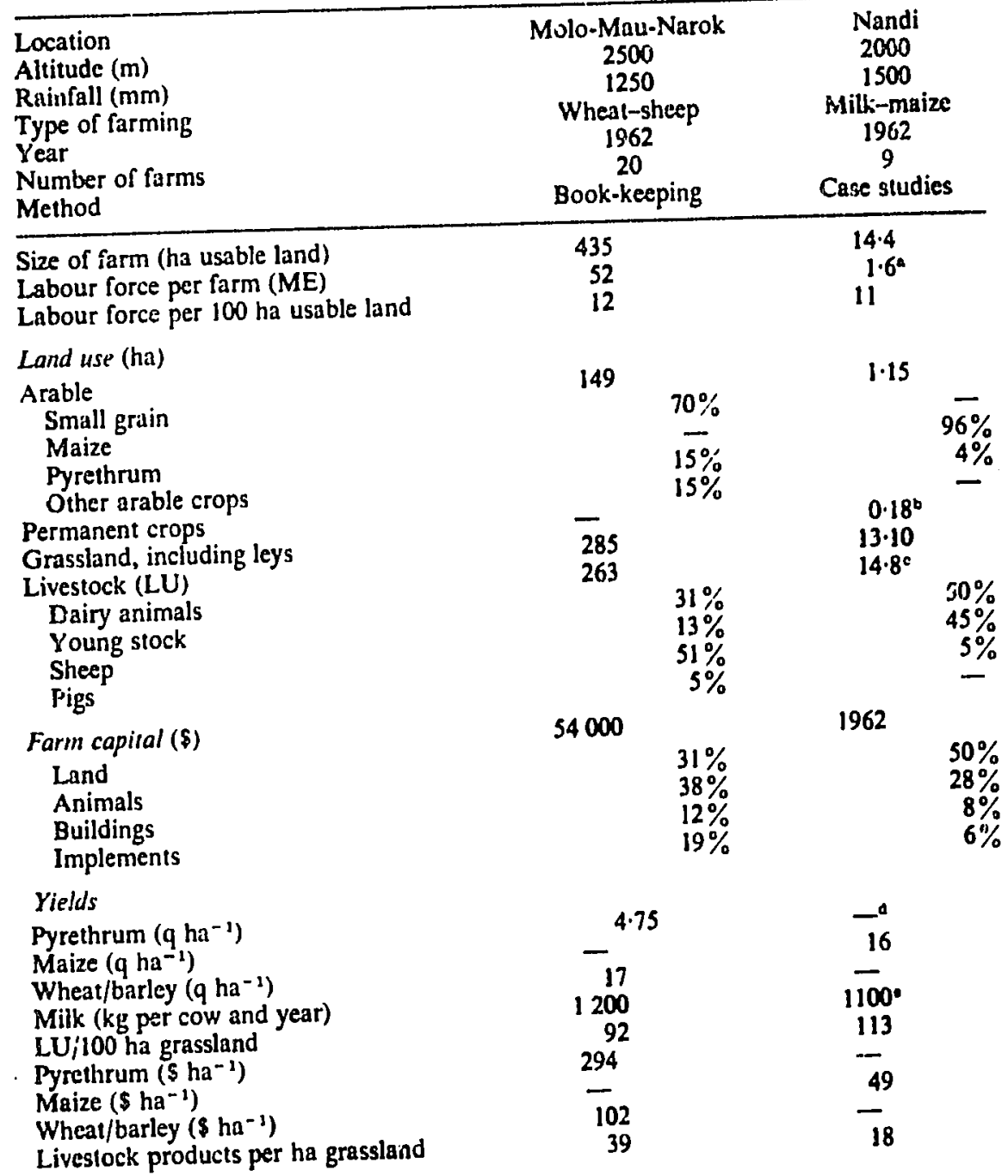


SYSTEMS WITH REGULATED LEY FARMING

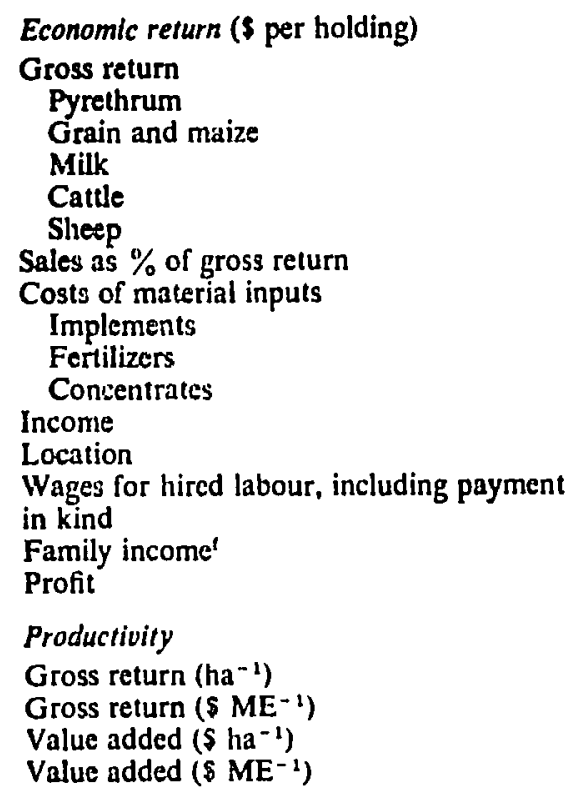

Productivity

Gross return (ha- $\left.{ }^{-1}\right)$

Gross return ( $\$ \mathrm{ME}^{-1}$ )

Value added ( $\left.\$ \mathrm{ha}^{-1}\right)$

Value added (\$ $\mathrm{ME}^{-1}$ )

29838<smiles>C1C[14CH2][Te]C1</smiles>

$\begin{array}{lr}5417 & 51 \\ 8237 & 176\end{array}$

355

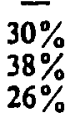

62

128

n.a.

$2 \%$

$22 \%$

Nandi

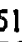

176

Most farmers work elsewhere some of the time, and get an income from a source outside the farm-for the most part they have key positions in local government, local cooperatives, etc. Seasonal labourers are cmployed in addition to the above-mentioned permanent labour force.

- Young plantations of tea and coffee.

- Of these, 5.8 LU are grade cattle (Gucrnsey, Ayrshire, Sahiwal), the remainder being improved native Zebu cattle.

- Young plantations.

- Refers only to grade milk corvs.

Only from farming.

Dasa from: MacArthur and England (1963); MacArthur, 1962-63.

On the large farms depicted in Table 5.2, a third of the land is used for pyrethrum, ${ }^{2}$ wheat, and barley. Pyrethrum, with gross yields of more than $\$ 250$ per hectare on the one hand, and requiring a high manual labour input on the other, is the most intensive crop. In terms of area, wheat and barley are the most important, with yields of 15-20 quintals per hectare and a gross income of \$100-150. Grain cropping is fully mechanized.

Four to six years of cultivation with wheat, pyrethrum, fodder oats, barley, etc., are followed sometimes by waturally established leys, but normally by planted or sown leys. There are five to ten years of ley before the land is ploughed again and used for arable cropping. The grass is mainly used ior woolled sheep and dairy cattle.

We can see from Table 5.2 that the number of livestock units per 100 hectares of grassland is lower in the large farms. They nevertheless attain a much higher output per hectare of grassland, because of improved husbandry techniques and more cconomic management.

${ }^{1}$ A daisy-like fiower whose blossom is harvested and dried. Pyrethrin, an insecticide, is extracted from the dried flowers. 


\subsubsection{Smallholdings in the Kenl'a highlands}

The returns from the holdings in Nandi District apply to a region where a traditionally pastoralist tribe has been settled since the turn of the century. In the 1950s, tile Nandi divided up the land, which had hitherto been communally owned and mainly used for grazing, into individual holdings. Since then, clearly demarcated and fenced holdings of 10-20 hectares have existed. Cattle-keeping and maize cropping form the basis of their economy. The cattle are still predominantly the indigenous Zebus. A great number of lowquality cattle are kept, which is typical of unimproved cattle husbandry in Africa. The cattle density, at 113 head per 100 hectares, is far above the optimum capacity of unfertilized and untended pastures.

The Nandi prefer maize cropping to wheat cropping. Tile maize is largely used for home consumption. The yield is more certain than that of wheat, which may be attacked by rust. Maize can be cropped without costly machjnery, and theft can be controlled-which is not always easy in large holdings. Maize cropping rotates in the grassland. It is ploughed with oxen, and cultivated, weeded, and harvested with hand-tools. In recent years, tractor ploughing has gained ground rapidly. Owing to the combined effect of the cool climate and the short days that are typical of areas on the equator, the maize grows slowly and is harvested as much as eight to ten months after planting. The yields, at 6-16 quintals per hectare, are very low. The land is used for only three maize crops, after which the plot is abandoned to natural grass. Cultivation follow's again after an interval of fifteen to twenty years. Occasionally, when the kraal is shifted, maize is planted on manured land.

An increasing number of Nandi farmers are becoming commercially active. More and more hybrid maize is being planted. Some farmers plant tea and sell the leaves to neighbouring tea factories. Attempts to improve animal husbandry are especially widespread and important. Guernsey, Jersey, and Ayrshire cows are bought to produce milk, which is sold through cooperative dairies. Weekly dipping of all cattle as protection against the tick that carries east coast fever is a usual practice throughout the area. The cows no longer spend the night in the kraal but on the pastures, where they are able to graze continuously, especially in the cooler morning and evening hours. Cows producing a high yield of milk are given concentrates. Artificial insemination has been introduced. The improvement of the fodder economy goes hand in hand with improvement of animal husbandry. Use of fencing and rotational use of the grazing areas are already practised by some farmers. Here and there, natural grass growth is already being replaced by the sowing of Rhodes grass or the planting of Kikuyu grass. In some cases, elephant grass is planted. Already a few farmers produce maize silage as a fodder reserve for the three-month dry season. 
SYSTEMS WITH REGULATED LEY FARMING

\subsection{Weaknesses of the system}

We can see from the examples in Kenya that the tropical highlands, where soil and climate allow good fodder grasses to grow the whole year round, and where there is organized marketing. provide favourable conditions for ley farming supporting intensive beef or dairy production. As soon as we leave the tropical altitudes and enter a warmer climate, however, ley systems meet with an increasing number of cbstacles:

(1) The fodder value of tropical grasses is usually low.

(2) The obstacles to the keeping of grade cattle multiply. Problems arise both in keeping the animals healthy and in feeding them. The alternation of wet and dry seasons means that a lot of attention must be paid to fodder production and conservation lor the dry period.

(3) Comparatively high yields of maize, manioc, sorghum, and other crops may be set against the increasing difficulties of ley cultivation and cattle husbandry. In other words, arable farning has a high relative advantage compared with ley farming.

The warmer the climate becomes, the greater is the teclunological jump required by a regulated ley system. In the highlands of $\mathrm{Kenya}$, at an altitude of 2000 metres, and with a rainfall of more than 1000 millimetres, we find many examples of a gradual change, even among the smallholders. But as the altitude decreases, or as the rainfall becomes less and is linited to the rainy seasons, we find scarcely any ley systems. A number of reasons account for this situation.

\subsubsection{The low fertility effect of tropical grass ley's}

Tropical cultivated pastures are generally of grass alone, and frequently of only one species of grass. Their efiect on the yield of arable crops is by no means unequivocally batter than that of natural regeneration. With regard to their value to the farm economy as a whole, Webster and Wilson (1967, p. 318) have concluded:

Hence it is unlikely to be worthwhile expending labour and money on planting grass unless an appreciably better return can be obtained from animal production on the ley thari from natural regeneration. Furthermore, although increased crop yields are normaliy obtained from a grass ley, these increases do not usually compensate for the loss of cropping during the ley period, so that the maintenance of fertility is, in part, achieved at the expense of a reduction in the total amount of crop products removed from the land. Clearly, alternate husbandry will only be satisfactory if crop yields during the arable break and animal production from the ley can be raised to levels that together more than compensate for the loss of cropping during the grass break. It seems unlikely that this can be achieved without a use of fertilizers which most tropical farmers cannot at present afford, or without a much greater ability in husbandry than the majority at present possess. 


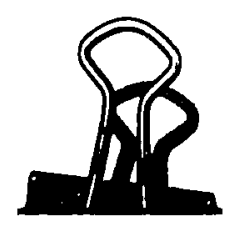

It might be expected that the inclusion of legumes in tropical leys would improve the fertility-restoring properties of the leys. This, however, is a particularly difficult problem. With certain local exceptions, no satisfactory legumes have been found for inclusion in tropical leys. There is also insufficient information yet on the extent to which nitrogen is fixed by pasture legumes in the tropics (Webster and Wilson 1967, pp. 298, 311).

\subsubsection{Unfavourable capital-output ratio}

Regulated ley systems, in contrast with unregulated ley systems, require the following investments:

(1) complete land clearance, i.e. the removal of trees, bush, and roots;

(2) fencing; and

(3) sufficient traction power-tractors or oxen-and the necessary implements for mechanical cultivation, because regulated ley farming and plough cultivation are highly complernentary to each other.

In addition, it is frequently necessary to invest in a number of improvements, including:

(4) seeding or planting of leys:

(5) purchase of improved cattle;

(6) cattle pens, dips, ctc.;

(7) water supplies;

(8) carts for the transport of manure;

(9) roads;

(10) drainage and the levelling of termite hills;

(11) tsetse control; and

(12) land consolidation and the demarcation of fields.

Some of these improvements can be carried out by the available labour force in the slack months, but as a rule they involve considerable financial outlays: ploughing the leys requires a good deal of traction power, and to use this traction power economically in a holding requires a holding size that is rarely found in smallholder agriculture in the tropics. Aikali (1967) quotes, for example, for northern Jigeria minimum sizes of 8-16 hectares for ley farms with ox-plough cultivation. In this context, Webster and Wilson (1967, p. 297) write, 'Land tenure systems under which the land is communally owned, or held by individuals on short-term, insecure leases, may make farmers uninterested in establishing leys. Fragmentation of holdings, resulting in small, scattered and unmanageable plots of land, has a like effect.'

\subsubsection{Dependence on improved animal husbandry}

The return from animal husbandry determines to a large extent the economic practicability of grass leys. Consequently, regulated ley systems remain 
more or less uneconomic wherever animal husbandry is organized on traditional lines, because under these conditions the farmer does not receive a sufficient return to justify any appreciable expenditure on the establishment and improvement of leys. The introduction of improved animal husbandry, however, depends not only on better feeding and better care of the animals, but above all on the provision of better communications, abatioirs, organized markets, and prices conducive to the production of quality meat, milk, or other livestock products.

\subsection{Dovelopment paths of rogulated lay systems}

\subsubsection{Improved ley systems}

Where the transition to regulated ley systems has been accomplished, there is, as a rule, much scope for increased production, provided that price relations are favourable. The first steps that are taken are usually the following:

(a) Imtensification of arable cropping is often of primary importance. The use of new crop varieties, of mineral fertilizer and herbicides, the investment in traction power and implements, and in particular the introduction of better husbandry continually offer scope for greater production.

(b) Intensified use of grassland, requiring more time and substantial investments, usually follows after a considerable time lag. Seeding or planting of the leys, intensive rotations of the grazing, and the application of mineral fertilizer are important indicators of the improved use of the leys. The most important step in ley improvement is the inclusion of legumes wherever feasible.

(c) Improvements in animal husbandry are usually of key importance; including disease control, artificial insemination, adequate feeding all the year round, reduction of the calving interval, proper calf-rearing, and so on.

(d) Interactions between arable cropping and animal production. Night bedding in cattle pens will result in the production of more manure, the application of which may well increase arable yields significantly. Another inportant aspect is the substitution of tractors for draught animals. The replacement of oxen by a tractor usually offers more scope for meat and milk production.

\subsubsection{Change from ley systems to other types of farming}

A ley system must show itself to be better than tumbledown grassland or other fallow systems in (1) having a better fertility-restoring capacity, (2) supporting more livestock preduction, and (3) allowing a more efficient use of the farm labour; and the combined effect of these advantages must be higher by quite a substantial margin than the costs of establishing a full leyfarming system. In many parts of the tropics these essential advantages cannot yet be obtained. 


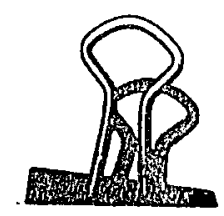

The fact that regulated ley systems have spread and been able to hold their own in the tropics orly in exceptional cases indicates that the expansion path of tropical rain-fed farming usually leads directly from shifting or semipermanent systems to permanent farming. Only occasionally are ley systems being intensified. A more noticeable tendency is for the area of unregulated leys in each holding to be progressively reduced, until finally permanent farming is practised. Usually, it is economically more profitable in smallholdings to expand the cropping of high-yielding cash crops, and if necessary to practice arable fodder cropping, than to intensify the ley system. Alkali (1967), for example, with reference to northern Nigeria, describes the policy of agricultural advisers as follows: 'The system of aiternate husbandry was scrapped mainly because the current design of ox-drawn implements was incapable of ploughing up leys, and also there was no proof that a system of leys was better than permanent pasture or permanent arable cropping.'

The tendency for farmers to prefier permanent cropping systems to ley systems stems not least from basic technical advances. New varieties of maize, wheat, sorghum, cotton, groundnuts, etc. have made arable farming more profitable. With the increased availability and use of mineral fertilizers, the farmers are less dependent than before on the fertility-restoring properties of leys. Thanks to herbicides and mechanical weeders, they no longer need leys to save labour in weed control. The tendency to expand arable farming at the expense of the leys will probably be reversed only when the rotation value and the fodder value of the leys are raised decisively by inclusion of legumes, and when at the same time the price conditions begin to favour 


\section{Systems with permanent cultivation on rain-fed land}

\subsection{Definition}

A continual expansion of arable farming at the expense of the fallow or ley transforms semi-permanent and ley systems into systen.3 with permanent cultivation. This class includes those farming systems in which fallows or leys are only rarely, and for a short term, interpolated between the cultivation of arable crops, with the result that the $R$ value exceeds 70 . In contrast with fallow or ley systens, farming systems of this kind are normally characterized by (1) a permanent division within the holding between arable land and grassland, which is seldom or never cultivated; (2) clearly demarcated fields; and (3) a predominance of annual and biannual crops.

Often, permanently cultivated rain-fid plots are a supplementary activity in holdings that are predominantly devoted to irrigation farming or tree crops. In particular, the growing of wet rice in valley bottoms is often combined with the cultivation of permanently cropped rain-fed plots on the slopes. The same applies where the planting of fruit trees has led to stationary housing and where the shortage of land in the vicinity of the tree-crop areas has led to permanent cropping. The following accounts are restricted, however, to those farming systems in which permanent rain-fed cropping is the main activity.

\subsection{Types of permanent rain-fed cultivation and their geographical distribution}

The evolution from shifting or semi-permanent systems towards permanent arable cropping on rain-fed land characterizes the development of agriculture in densely populated regions with temperate climates. In the tropics, permanent cultivation is still fairly limited in its occurrence. Where increasing population density and cash cropping necessitate the intensification of land use, other possibilities are as a rule preferred:

(1) Irrigation farming is spreading; in particular, irrigated rice proves to be a simple and highly productive permanent use of land in tropical climates. With the problem of conservation of soil fertility in rain-fed 
farming, and as the pressure of population increases, there is an obvious tendency to concentrate production on what is topographically the lowest land, because that is where the most fertile soils occur, and often irrigation is possible in these valley bottoms.

(2) The planting of perennial crops, in particular of tree crops, is increasing. By this means, arable farming, which is 'alien' to nature in the tropics, is replaced by crops whose effect on the soil is similar to that of forest or bush vegetation.

Systems with permanent rain-fed arable farming are thus no more typical of tropical land use than are regulated ley systems. They are found where the following conditions apply:

(1) The population density is very high and irrigation farming is either not possible or has not yet been adopted. There are numerous areas where a Malthusian process of impoverishment has compelled intensification.

(2) The soils allow permanent rain-fed cropping without a drastic decline in yields. Cases of this kind are usually found where the climate has an extended dry period, during which leaching is not taking place.

(3) An intensive fertilizer economy is practised.

Most traditional types of permanent rain-fed farming in the tropics are relatively poor forms of agriculture. The main forms are outlined below.

\subsubsection{Permanent cultivation in tropical highlands}

The evolution path of arable land use in densely populated tropical highlands is similar to that of moderate climates: shifting cultivation $\rightarrow$ unregulated ley systems $\rightarrow$ permanent arable cropping. The decline in soil fertility that accompanies more intensive land use witiout fertilization is less pronounced than in a hot and humid climate. Yields usually stabilize at a level sufficiently high to make permanent cultivation advantageous, even without heavy inputs of fertilizer. The main problem encountered in permanent cropping in high altitudes is not so much the constant reduction of soil fertility as the loss of soil through erosion.

Permanent rain-fed cultivation with maize and beans is widely practised in the Mexican highlands and in several smallholder areas of the Andes. Potatoes, vegetables, and millets are the main crops of permanent cultivators in the Nilgiris Mountains of southern India. In parts of Ethiopia, ley systems have been replaced by permanent cropping with wheat, teff, millet, and numerous other crops. Maize, beans, manioc, and millets are the predominant crops grown by permanent cultivators in the highland areas of East Africa. 


\subsubsection{Permanent cultivation in the African savannas}

Table 6.1 provides information about areas in Africa where permanent cropping is traditional and where improved techniques are applied. Systems of great economic importance are located in the East African highlands. Only a few cases are found in high-rainfall, low-altitude areas. The savannas, however, oiving to higher population densities and increasing cash cropping, are already dotted with small but expanding systems with permanent cultivation.

Where the process of ensuring the food supply for a slowly expanding population has led to the gradual spread of permanent cropping, as for example in Ukara, Lake Victoria (see \$6.4.2), often sophisticated methods of manuring have spread. The traditional methods of maintaining fertility, however, require a high labour input. The holdings are small and their yield in relation to the labour input is low. By contrast, in those areas where permanent cropping has developed through increased cash cropping by a local peasantry, as for example in the groundnut areas of Senegal and northern Nigeria, the situation is quite different. Incomes are higher, but soils are mined with little regard for future returns. "lechnical and biological innovations that can give stability to permanent cropping on soils of moderate fertility have been introduced only in exceptional cases. The more rapidly the commercialization of production has been achieved, the less farmers usually worry ahout conserving the soil. This applies at least until the possibilities of finding new land for cropping are exhausted.

\subsubsection{Permasient cultivation in monsoon Asia}

Permanent rain-fed farming prevails over large parts of India. The predominance of this relatively poor form of agriculture reflects the handicap from which much Indian clevelopment suffers. The farming is usually mixed, often in combination with irrigated plots. Fodder production, manuring, terracing, and other soil-preserving measures are applied, but they are normally irsufficient to maintain soil fertility at its original level. Consequently, yields persist at a low level. Ceertz (1963, p. 29), taking as an example rain-fed farming in Java, describes this process as follows:

On virgin soils a rapid decline in yield usually takes place, in the absence of fertilization, within the first two or three years, but after ten or twenty years the yield tends to remain stable more or less indefintely. This has been borne out by experiments in various parts of tropical Asia... On infertile soils and with inadequate fertilization the yield stabilizes at a very low level, as is the case now in Ceylon and most of South Asia, but it stabilizes. Why this should be so is not yet entirely understood.

\subsubsection{Permanent cultivation in the hot, humid tropics}

The permanent cultivation of rain-fed land in a hot, humid climate presents some of the most troublesome problems of tropical agriculture. The 
TABle 6.1

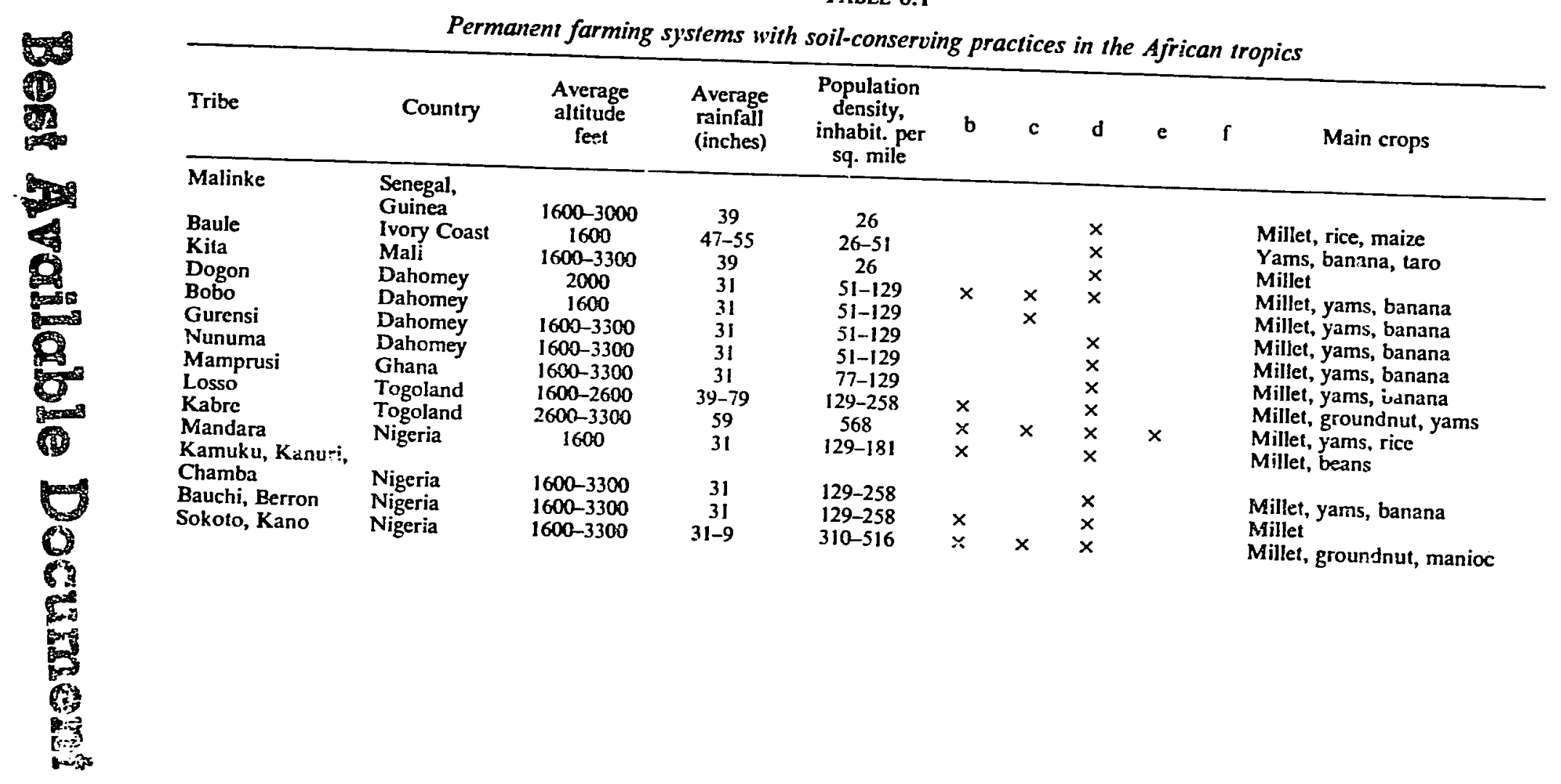


Batta, Mundang,

Mandji, Bamum,

Dama, Musgu

Bana, Adamawa

Kuru, Bari

Cameroons
Cameroons

2600-5000

$5000-6600$

$1600-3300$

Sudan

5000

$31-5$

-9
-59
-55

129-258

258-387

$x$

$x$

$\times$
$\times$$\quad$ Millet, yams, banana

Millet, beans,

Millet

$\begin{array}{ll}\text { Konso } & \text { Ethiopia } \\ \text { Tigre } & \text { Ethiopia }\end{array}$

$5000-6600$

$24-39$

490
$258-387$

$\begin{array}{ll}x \\ x & x\end{array}$

Kipsigi, Kikuyu,

Nandi, Suk, Keyu Kenya

Rundi Burundi

Ruanda

$5000-5600$

$55-71$

129-387

$5600-6600 \quad 39-55 \quad 258-387$

$5000-6600 \quad 39-55 \quad 387-516$

Kiga Uganda

$5000-6600$

$31-59$

$387-516$
$129-258$

Katengo, Makonde Tanzania

$3300-5000$

$39-47$

$7 \mathrm{~T}-258$

$\begin{array}{lll}x & x & x \\ x & x & x\end{array}$

Millet, coston, maize

Millet

Sandawe, lraque,

Mbugu, Shambala,

39-55 51-258

$\begin{array}{ll}x & x \\ x & x\end{array}$

$\begin{array}{ll}x & x \\ x & x\end{array}$

$x \quad x$

$x$

Maize, manioc

Maize, banana, sweet potatoes

Banana, millet, sweet potatoes

Maize, banana, beans

Maize, millet, manioc

Maize, millet

$2600-5000 \quad 31-47 \quad 25-258 \quad \times$

Millet, maize, beans

Pare, Meru, Teita Tanzania

$5000-5500 \quad 59-79$

129-258

$\times x$

Millet, maize, beans

Millet, manioc, rice

- Terracing. c Irrigation farming.

63

542

' Leading crops and important mixed crops. 


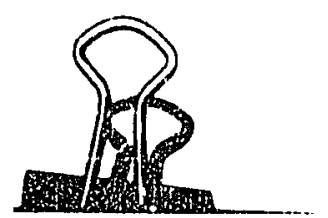

traditional solution is gardening. ${ }^{1}$ especially w'ilere the population density is very high, where labour is cheap, and where profitable markets are at hand. Permanent gardens can already be found in shifting systems where the hut change is infrequent. In permanent farming, they develop into an important branch of the holding, and one which can become dominant where there is a town in the vicinity or where there is a marked shortage of land. Thus, in densely populated Java, one-fifth of the land used for agriculture is reported as being plots that are more like gardens than fields.

Examples of rain-fed permanent cropping based on vegetables, and which preserve the soil, and are economically successful, can be found in Chinese agriculture, for example in Taiwan. Here the permanence of cropping is based on an intensive fertilizing with orgaric and mineral fertilizers, supplemented by measures for erosion control, and careful cuitivation. In other densely populated areas, for example in Java and in the West Indies, root-crop systems (manioc, sweei potatoes) have principally developed, and are associated with various tree crops.

There are as yet few examples of economically promising systems of lowintensity permanent rain-fed farming in the humid tropics. Research stations provide us with an increasing number of rotations that would maintain soil fertility, but these rotations usually depend on traction power and mineral fertilizer. They include several green-manure or fodder crops, which have a low economic return. Rain-fed cultivation in the humid tropics frequently lacks a lucrative cash crop. In short, there may be technically feasible solutions to the problems of permanent cultivation, but their economic returns are as yet still marginal.

\subsection{General characteristics or land use with permanent rain-fed cultivation}

Even though the forms of permanent rain-fed cropping in the tropics may be varied, a number of characteristics are typical of the system.

\subsubsection{Spatial organization of cropping}

A basic difference between permanent cultivation systems and fallow or ley systems is the fact that the cultivator in a permanent system can no longer select a plot that is suited to the particular crop; instead, he must decide which crop will grow best on the given plot. We commonly find permanent

\footnotetext{
${ }^{1}$ Garden cropping is distinguished from arable cropping by the following features, which are usually, but by no means in all cases, found simultancously: (1) cropping those plants for personal consumption that cannot be collested nor supplied by arable farming. (2) smail plots, (3) proximity to the house, (4) fencing, (5) mixed or dense planting of a great number of annual, semi-permanent, and perennial crops, (6) a high intensity of land use, (7) land cultivation several times a year, (8) permanence of cultivation, and (9) cultivation with hand implements.
}

\section{Bes Avorlloble Document}


land-use systems with distinct spatial differentiations of cropping, and with rotations including a great number of crops. There are three basic types of spatial organization:

(a) Organization of cropping according to different soils within a catena. Where the types of soils vary within a catena, the differentiation of cropping mainly arises from the planting of each type of soil with the most suitable crop or mixture of crops. A case in point is land use in a valley on Ukara, lake Victoria (Fig. 6.1). Rice, sweet potatoes, vegetables, and sorghum predominate in the valley bottoms, manioc (cassa\%a) and Leguminosac are the 'pediment crops' and the slopes of the 'Inselberg' serve as grazing.

(b) Organization of cropping in concentric belts. The tendency to cropping in concentric belts is caused by stationary housing. The older the farmyard and the greater the difficulties of transporting manure, the more markedly does cropping change as the distance from the farmstead increases. In the farmstead or village we almost always find fruit trees, papayas, bananas, etc. Usually there is an adjoining belt of heavily fertilized garden. As the distance increases, the fertilizer input declines and the more frequent are the fallows.

(c) Organization of cropping according to the micro-climate. The differences in the micro-climate (the amount of rain, sunlight, land gradiert, and danger of wind damage or flooding) help to diversify cropping. In the valley bottoms and flooded plains we frequently find some rice, occasionally surrounded by embankments, indicating the tendency to supplement permanent rain-fed farming by prinitive types of irrigation (see §7.1).

Such first steps towards a differentiation of cropping within the holding may be found in shifting systems (see \$3.3.1) and are common in semipermanent systems (see; $\$ 4.3 .1$ ). In permanent systems, however, they are considerably more pronounced because of the stationary nature of the housing.

\subsubsection{Cropping principles}

A further feature of permanent cultivation systems is the variety of forms of mixed cropping, of relay-planting, and of rotations that occur.

(a) Mixed cropping and relay-planting. Provided land is scarce and labour ample, mixed cropping is as common in permanent systems as in shifting and semi-permanent systems (see $§ 3.3 .2$ (a)). Relay-planting is the usual practice in intensively cropped areas with extended rainy seasons, or where several rainy seasons overlap (see $\$ 2.3 .2(b)$ ).

This is exemplified in Kerya by the Kikuyu practice of cropping maize, beans, sweet potatoes, and pigeon peas. When the rainy season begins, at the end of March or the beginning of April, the women plant the inaize and peas broadcast on the plot, which has been prepared with the hoe by the men. When the seed has germinated, the women go over the field again and plant two different sorts of bean, an early-maturing and a late-maturing variety, among the growing maize and 

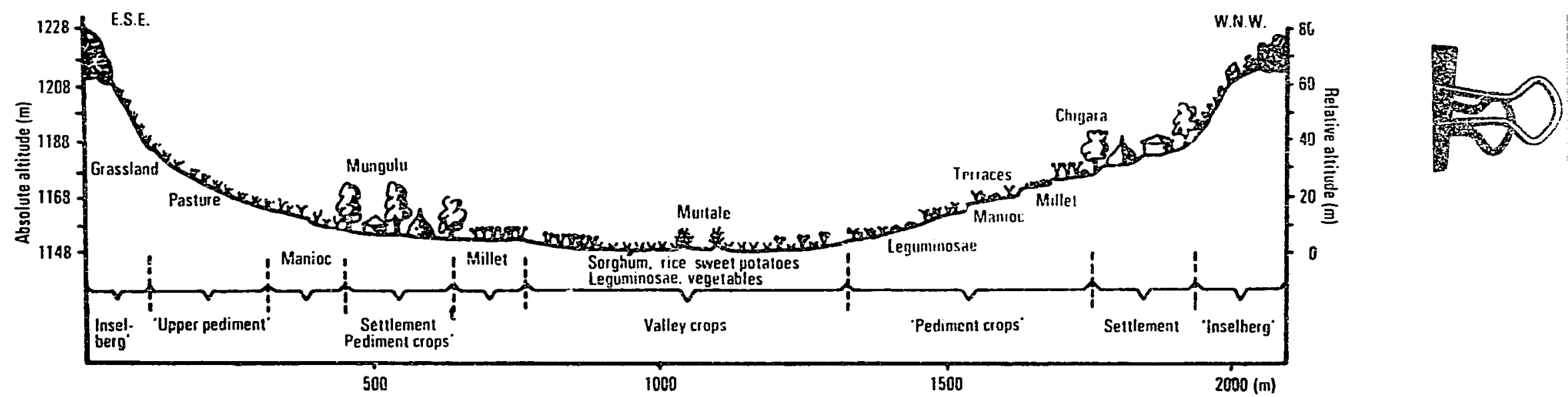

Frg. 6.1. Profile of a valley on Ukara Isiand, Lake Victoria, showing land use within a catena (from Ludwig 1967, p. 100). 
pigeon peas. When the bean seed has sprouted, a third planting takes place. The field, which has produced a great deal of weed in the meantime, is weeded. At the same time, sweet-potato seedlings are planted in the growing stands of maize, peas, and beans. The early-maturing beans produce the first yield from the middle of June. Maize and late-maturing beans are harvested from the middle of August. Sweet potatoes and pigeon peas are harvested from the plot as required from September onwards.

In regions with several overlapping rainy seasons, relay-planting can become continuous cropping, i.e. when one crop is hervested the plot is already being used by the next interplanied crop.

(b) Crop rotations. Whereas it is often difincult in semi-permanent systems to recognize a systematic sequence of crops (it is for this reason that de Schlippe (1956) speaks of 'pseudo-rotations'), in permanent cultivation systems there are generally quite definite rotations. The rolation patierns of tropical permanent farming systems are of confusing variecy. The great number of forms they take may be classified according to the following criteria:

(1) In regions with distinct and short rainy seasons, one crop a year is sown usually, occasionally supplemented by a catch crop. In the intervening dry period, the plot lies fallow. These are, therefore, systems with seasonal cropping. In contrast, continuous cropping (where planting takes place before or immediately after the harvest) in rain-fed farming can be practised cnly where the rainfall is fairly high and evenly distributed. The fertilizer and labour requirements per hectare of continuous cropping are naturally considerabiy higher than for seasonal cropping.

(2) A distinction must be made between annual, biennial, triennial, and other rotations of different lengths. Annual rotations with two or more crops a year may be found in regions with extended rainy seasons or continuous cultivation. Biennial rotations in these rainfall areas often comprise three crops, one of which, for example sugar-cane or manioc, occupies the plot for a particularly long time. In general, rotations in areas with seasonal cropping occupy more years than in areas with continuous cultivation.

(3) The length of the vegetation cycle of the crops cultivated is an important structural element of rotations. Arable farming in the tropics is in this respect much more varied than in temperate climates. The rotation may be composed of annual short-term crops (e.g. beans, cabbages, or sweet potatoes), aniual long-term crops (e.g. cotton or maize), and biennial crops (e.g. manioc, sugar-cane). The cropping index (see Table 6.3 on p. 120) (the cropped area as a percentage of the arable land) is consequently of only limited application as a measure of intensity in permanent farming systems. The input in the case of a biennial arable crop that occupies the 


\section{SYSTEMS WiTH PERMANENT CULTIVATION}

plot for sixteen months is sonetimes higher than that of several annual short-term crops, which can be cultivated in the same time.

(4) Apart from this, the farm-economic aspects of crop rotations depend on whether soil-preserving or soil-exhausting crops are cultivated. In general, fodder crops, especially legumes, are considered to have a beneficial effect on the subsequent crops, while crops like maize or cotton are considered to put a strain on soil fertility

(5) The rotations, and the crop elements of the rotation, may be arranged according to crop yields and input requirenient. When millet is displaced by maize in a rotation, or maize by a root crop like manioc, production measured in kilocalories per hectare increases considerably, but at the same time labour and fertilizer requirements usually increase also.

\subsubsection{Characteristics of the fertilizer economy'}

The methods of fertilizing in tropical permanent rain-fed farming are as varied as the rotations. In most cases, the fertilization is insufficient, and we find soil mining, and stagnation at a low yield per year. Generally speaking, however, permanent cultivators on rain-fed land practise some methods of fertilization, and the more so where the original fertility was low and the longer ago the change sccurred from fallow systems to permanent cropping. The principal fertilizing methods of semi-permanent cultivation or of unregulated ley systems are scarcely practicable in these cases, since permanent cropping requires stationary housing. The moving of the hut sites, and the consequent creation of fertile gardens, can take place only within a restricted area, and is hardly equivalent to the 'human folding' which is so coumon among semi-permanent cultivators. The cattle numbers are usually insufficient for folding systems, unless extensive grazing areas are available. Also, permanent cropping has to forgo the erosion protection that ley systems provide in the years between cultivation. Permanent cultivators who do practise fertilization and erosion control sepend on other methods, with a higher labour input.

Various traditional methods of erosion control have been employed, from ridge and mound cultivation to terracing and the use of baskets to carry back the soil that has been washed away. In particular, stone terraces in traditional, rain-fed farming systems are an indication of a long-term, acute land shortage, which has helped to make erosion control part of the cultural heritage of the local people. Although these practices are traditionally known, they are rarely employed in farming systems where cash cropping has been introduced and where land shortage is a recent phenomenon. In many of these situations, particularly in the drier savannas, gullies increase rapidly in number and size, soil conservation usually being neglected as cash cropping and incomes per head intrease, mainly because of the unfavourable short-term input-output relationship of the labour invested. The 
way out of this urdesirable situation probatly does not lie in a return to traditional agricultura! methods, but in additional cash cropping, which, by changing the economic settivis, can ma're sjil conservation economically worth while. The tractor-drawn plough beconzes very important in this connection, becuuse it enables the farmer to carry out soil-conservation measures like contour ploughing, mechanized ridging, atid rivehanized terracing, which cannot be done with an ox ple $\lrcorner g l$.

of special interest is the devel-pment of the fertilizer economy in permanent rain-fed farming. The primary task is the replacoment of nutrients and organic matter. From the standpoint of the evolusion of farming systems, a number of stages ma; be distinguished:

(1) Manuring begins as a rule with the collection and transport of household refuse.

(2) Next comes the application of animal manure, which is sometimes increased by stabling and the provision of bedding.

(3) Cultivation of green-manure crops is an incication of a more advanced fertilizer economy.

(4) Processing of household refuse, harvest residues, and farmstead earth in compost is characteristic of a higher levil of intensity.

(5) The use of night soil is traditional with Chinese cultivators. It is rare in Africa and only practised by sone tribes with a long-term land shortage (in Ethiopia (Nowak 1954) and Mali (Duniont 1966, p. 50),

Increase in the intensity of cropring entails the inpert of nutrients and organic matter. Traditionally, this couti toke one of the following forms:

(1) Areas outside the holding are grared, and nimat manure collects in the farmyard, mainly at night. In this way nutrients are concentrated on the permanently cropped land. This is a priitejite that is practised generally. (2) Nutrients are imported in fuel. The seircin for fuel has siripped extensive bush or forest land near densely ponuiater areas (needles, leaves, twigs). The ashes serve as fertilizer, either cirectly or as a component of compost.

(3) An indication of a special lack of nutrients is the collection of leaves and branches as green manure, which is applicd directly to the land (see $\S 6.4 .2)$.

(4) In traditional Chinese agriculture, oil-cake, fish, and other organic materials were bought as manures.

A general feature of traditional forms of intensive fettilization is the high labour input; this is the case both in preparation of composi and in collection of aninal manure, and lies especially in the difficulties of transport that are part and parcel of most forms of organic manuring. Whereas in shifting and semi-permanent systems the fertilizer is produced where it is used, i.e. it 
scarcely needs to be transported, the permanent cultivator with stationary housing must transport the material. Consequently, we find the tendency to concentrate the fertilizer on the gardens near the farmyard, particularly where the lack of transport is acute and there are no carts, draught animals, or field tracks. Bottlenecks in transport are the reason why old Chinese towns are often surrounded by a belt of black soils, which are enriched with nutrients and humus. Elsewhere, the saying that 'those fields are most fertile which can hear the cock crowing' reflects the same situation.

A further feature of the fertilizer economy in densely populated arcas is the burning of straw and cow manure. Since thcre is no fallow vegetation to provide fuel, as is the case in shifting and semi-permanent systems, straw and cow manure are frequently the only available and economic types of tradjtional fuel.

Technical progress has scarcely altered the produclion conditions in any branch of agriculture so much as in the fertilizer economy of holdings with permanent cropping:

(1) Mineral fertilizer is of primary importance; compared with organic fertilizers it proves to be labour saving because of its high nutrient concentration and the relative ease with which it can be transported.

(2) New crops and cultivation methods for green-menure crops are available. The use of tractors can provide more scope for increased green manuring, since the work is carried out more quickly.

(3) Where intensive livestock-keeping is practised, the fertilizer cycle is extended by the import of nutrients as purchased concentrates.

(4) Progress in transport vehicles like ox-carts, tractors with trailers, or lorries and the devclopment towards a comprehensive road network facilitate the transport of manure, night soil, etc.

Thus we may say that agricultural innovations have drastically changed the fertility probiem in permanent rain-fed farming in the tropics. Technical solutions are available. Unfortunately, however, the price relations are often too unfavourable to make intensive fertilizing economic at the present stage.

\subsubsection{Characseristics of animal husbandry}

Traditional famming on permanently cropped, rain-fed land in the tropics is usually combined with small herds per family, but high cattle densities per 100 hectares. The role of livestock in these conditions differs from that of stock in semi-permanent cultivation or ley farming. The aim is not only to produce milk and meat, but increasingly to provide traction power and manure. The hoarding of the cattle is not important, because the available grazing is limited, and also because permanent cropping is usually coupled with private land rights, and the acquisition of land is an alternative way of gaining status and security. 
The fodder basis primarily determines which forms of animal husbandry predominate in permanent cropping systems, zad to what extent they are carried on. In this connection ve can distinguish two principal forms.

(a) Animal husbandry in systems with exlensive grazing areas. Where extensive areas are still available, cattle husbandry is mostly organized on lines similar to those in semi-permanent systems. The animals are communally grazed and in the charge of herdsmen by day, and they return to the farm at night. Emphasis is put on coivs, female calves, and heifers. The husbandry practices are more or less the same as those of semi-permanent cultivators, but there are fundamental differences in the fodder economy, which is based increasingly on the productivity of arable farming, e.g. on the seasonal distribution of grazing between the arable land and the more distant grazing areas.

A typical example of animal husbandry in an African farming system which passed recently from semi-permanent to permanent farming is supplied by Guillard (1965) in his monograph about the village of Golonpoui in northern Cameroon (see Fig. 6.2). At the beginning of the rainy period in June or July, the animals graze on the arable land that is not yet cultivated or is lying fallow. As cropping progresses, the animals are concentrated on the fallows of the semi-permanently used land, which are 2-3 kilometres from the village. In October, millet straw from the permanent gardens provides additional fodder. At the beginning of the dry season, the animals are driven to bush grazing further afield. This is interrupted in January and February, when harvest residues are eaten. The animals spend the rest of the dry season, from February to May, in the more distant grazing areas. In addition, the leaves and fruits of odd acacias (Faldheriba albida) scattered in the arable land are used.

(b) Animal husbandry in sysiens without extensive grazing areas. As arable cultivation spreads at the expense of the grazing area, there is a tendency for farmers to reduce the number of animals kept, or to hire out the cattle to nomads who are hardly ever near the village. Roadside grazing, seasonal fallows, and harvest residues constitute the remaining fodder basis. The lower limit to the number of caitle kept is determined by the number of traction animals required. Hoe cultivators may come to have no cattle at all. With the reduction of the grazing areas, the rearing of goats, pigs, and fowls increases in relative importance. In requiring less grazing land and providing smaller units for sale or consumption, this kind of stock is better suited to the economic condition of smallholdings.

The reduction in the inportance of livestock that occurs as land becomes increasingly scarce can be halted only by the introduction of fodder crops, which are practically unknown in fallow systems. The need for traction animals is usually the first cause for a step in this direction, since the feeding of traction animals can scarcely be avoided. Where subsections of the holding can be irrigated, they are in many cases used chiefly to supply the traction animals with fodder. Beyond this, traditional farming systems on permanently 
cropped rain-fed land are rarely in a position to support a substantial volume of fodder production. In most cases, the livestock economy, although important in numbers, stagnates at a low level of productivity (see also $\$ 6.6 .1$ ).
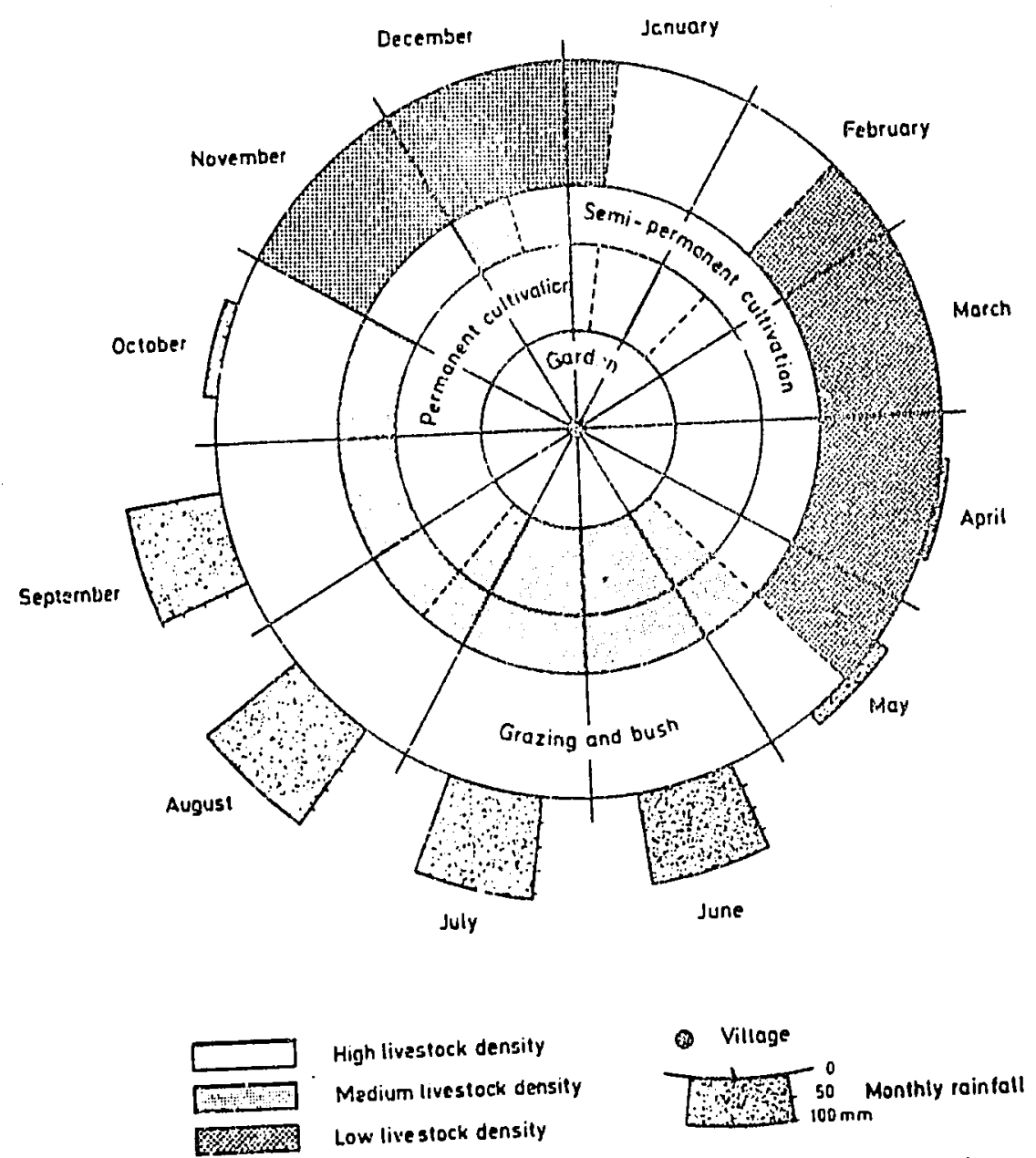

of cattle on the village land during the different scasons in Golonpoui, Fia. 6.2. Distribution of cattle on the village (from Guillard 1965, p. 305).

\subsubsection{Characteristics of the labour economy}

African permanent cultivators still rely mostly on hoe cultivation, although forest and bush fallows, which are the compelling technical reasons for hoe farming, no longer exist. Hoe cultivation usually remains because farm size in relation to family size is so small that there is no room for livestock. This is true for densely populated highlands like the Kisii and Kikuyu Districts 
in Kenya. In Asia and Latin America, however, we find a different and varied tool system, which involves plough cultivation, carts, and animal traction. The plough makes it possible to cultivate larger areas and to improve the timing of cultivation. On the other hand, disadvantages are (1) the fodder requirement of the draught animals, (2) the poorer quality of animal ploughing compared with hoe cultivation, and (3) the increased danger of erosion. Communal work, which we often find in shifting systems and still sometimes

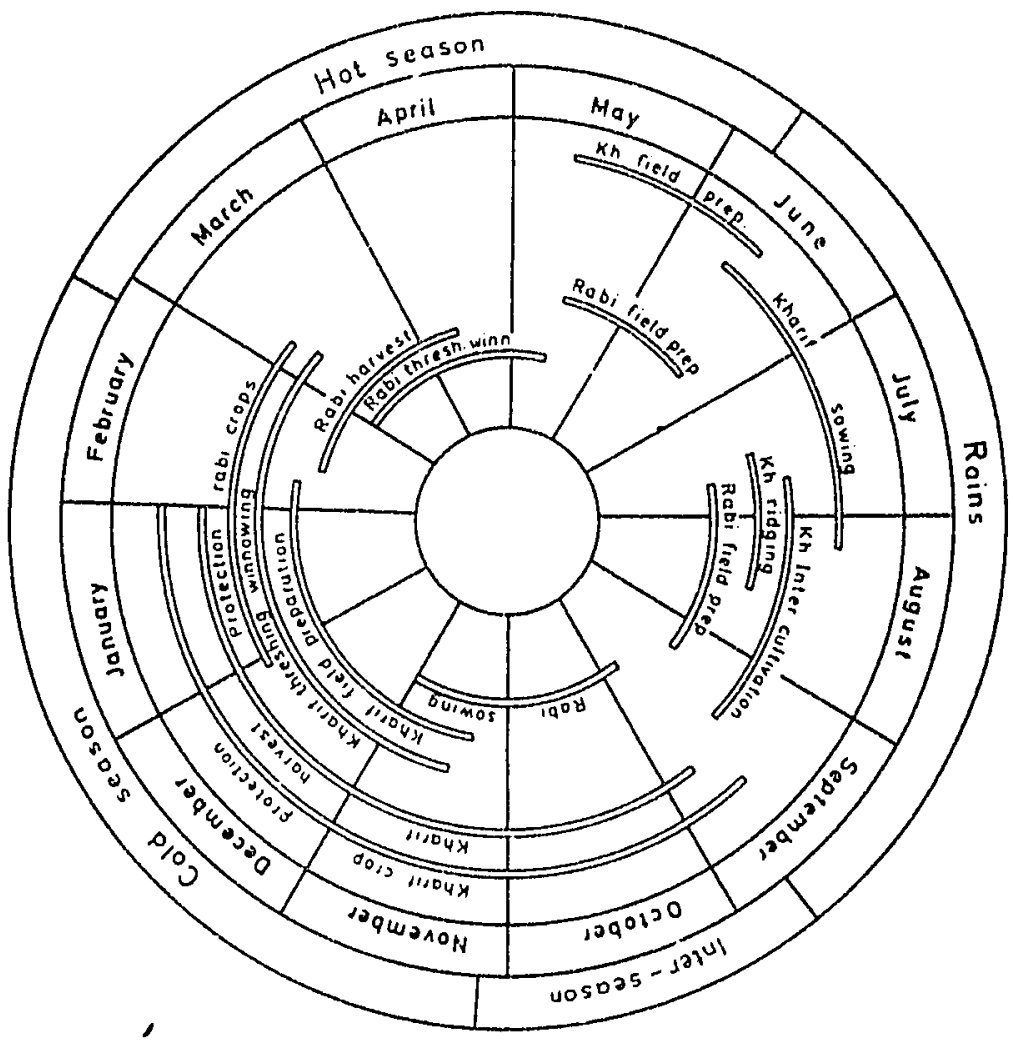

Fı. 6.3. Annual agricultural labour cycle in a system of permanent rain-fed farming in the West Nimar District, central India (from Leshnik 1966, p. 61).

in semi-permanent systems, scarcely plays any part at all, and this is a further feature of permanent cultivation systems. Similarly, the tendency disappears for the land belonging to a household to be divided up into smaller units cultivated by members of the family for themselves. In plough culture, we usually see centrally organized holdings, where the farmer directs the family labour and employs hired labour if need be.

(a) Seasonality of labour demand. With the transition to permanent cultivation, the seasonal concentration of labour tends to become even more acute 
than in fallow systems. The work is concentrated in the rainy season, not least because draught animals and hoe cultivators are unable to cultivate the soil in the dry season. A fairly regular use of the labour force is found only in a few favourable regions where double cropping can be practised.

The situation in the West Nimar district in India illustrates this (see Fig. 6.3). Cotton, wheat, and sorghum are the chief crops, and wheat is usually grown in winter (rabi season) on a plot which is then left fallow. The main summer crops (kharif season) are sorghum and cotton. The distribution of cropping over two seasons brings about a relatively balanced use of labour. The time when there is little labour demand is limited to February-May.

In most cases with permanent rain-fed cropping, however, we find only one pronounced rainy season, with little scope for multiple cropping. Consequently, labour demand is decidedly seasonal. High population densities and a high degree of underemployment on the one hand, and insufficient labour at the beginning of the rainy season on the other are probably not as marked in any other land-use system as in permanent rain-fed cropping.

Figure 6.4 illustrates the situation in an intensive arable farming area in northern Cameroon. The total available time is recorded under several headings. The distribution of field work is highly seasonal for both the man and his wife. Most of the time between the high labour demands for field work is filled with various kinds of work around the hut. Sickness takes only a small percentage of the total time. It should not be overlooked, however, that on two occasions both were sick together, and once this took place during a time of high labour demand (October 1957). It may appear from Fig. 6.4 that field and homestead work logether lead to the full employment of man and wife. It is, however, difficult to present working time in terms of days. The length of the working day differs (work here was measured in half-daily units), and the intensity of work is much higher during peaks of labour demand than in slack seasons.

It is not only the workers who are underemployed. Where plough cultivation exists, the traction animals too are only seasonally employed. Yet the seasonal nature of work requires a large number of driur,ht animals, since every cultivator wants to plough his land at the right time and sets value on having his own animals. Lack of draught nower is one :inportant reason for late and inefficient cultivation of fields. $\dot{C}_{0}$;erently, a considerable part of the arable land is used to provide draught animals with fodder, while they work at full capacity for short periods only. This is particularly true in India.

(b) Low producrivity of labour. Table 6.2 provides some information about typical labour input in permanently cropped areas. This is, as a rule, lower than in fallow systems because of the reduced input in land preparation. Particularly where plough cultivation is practised, labour requirements per hectare are significantly lower. The available information is insufficient to relate labour input to yields and to derive general conclusions about variation of labour productivity in terms of grain-equivalents per hour of work with increasing permanency of cropping. However, several case studies indicate 
that, with increasing permanency of cropping, output per man-hour and per man-equivalent available is likely to decrease (Boserup 1965; Rotenhan 1966; Ludwig 1967). It is for this reason that the husbandry patterns of
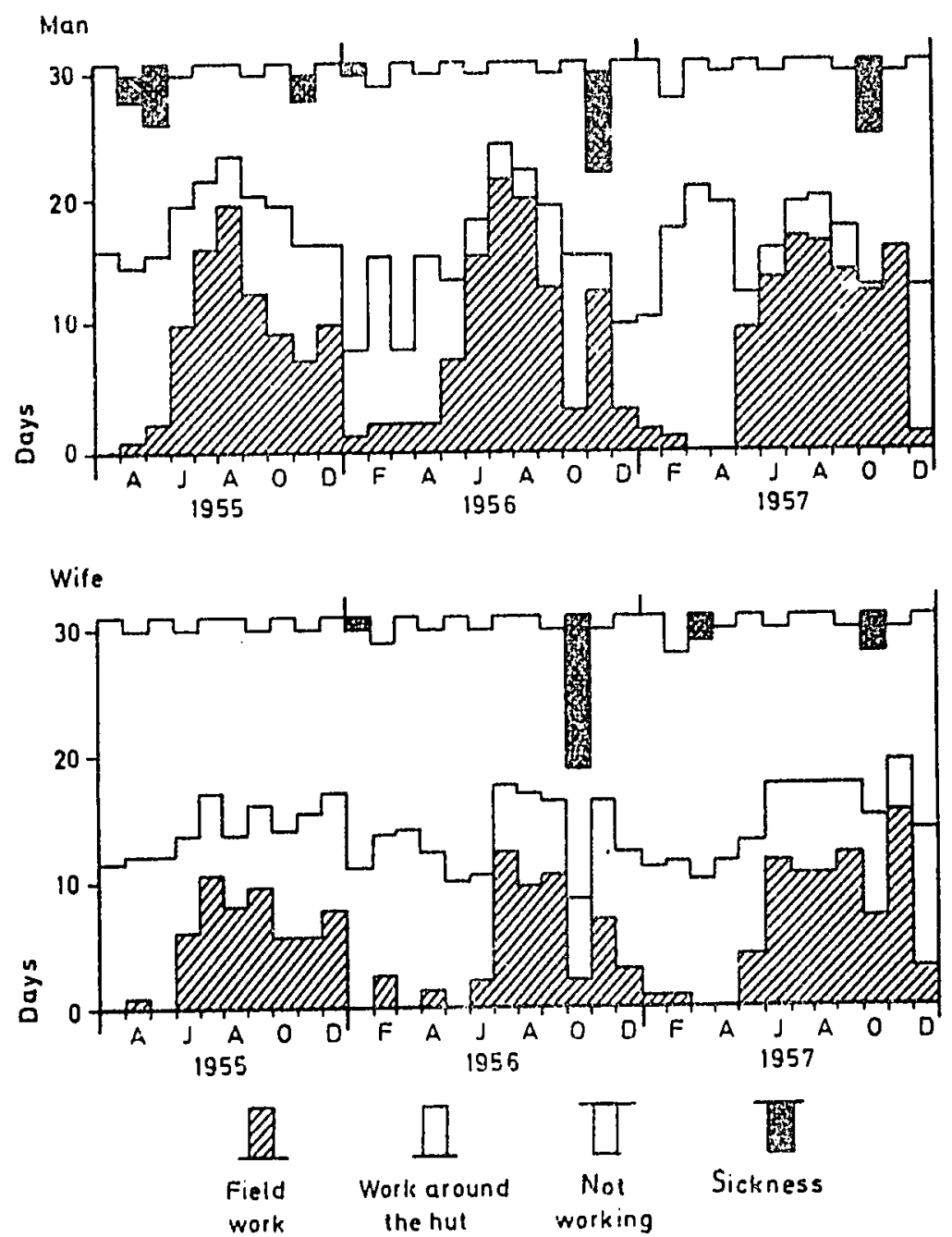

FIG. 6.4. Seasonal distribution of work of a hoe-cultivation holding with permanent rainfed farming at Golonpoui, northern Cameroon (from Guillard 1965, p. 343).

permanent cultivation in Africa are described by Gourou (1966) as 'siege methods', by which he implies that they cane into existence because the tribes were surrounded by hostile neighbours, which prevented the extension of farming in fallow systems into expansion areas. The African peasants-the Wakara (see $\$ 6.4 .2$ ) being a case in point-are apparently quite aware of the 
TABLE 6.2

Labour input in holdings with permanent cropping (man-hours per hectare) derived from farm-management surveys

\begin{tabular}{|c|c|c|c|c|c|c|}
\hline $\begin{array}{l}\text { Crop } \\
\text { Location } \\
\text { Year }\end{array}$ & Millet & aizetwion? & India (Bombay) & $\begin{array}{l}\text { ghum } \\
\text { Cameroon (Golonpoui) }\end{array}$ & $\begin{array}{l}\text { Sweet potatoes } \\
\text { Taiwan }\end{array}$ & $\begin{array}{c}\text { Manice } \\
\text { Madagascar (Tananarive) }\end{array}$ \\
\hline Cultivation inethod & Hoe & Plough & Plough & Hoe & Plough & Hoe/spade \\
\hline $\begin{array}{l}\text { Land preparation } \\
\text { and tillage } \\
\text { Sowing/planting } \\
\text { Weoding } \\
\text { Harvesting } \\
\text { Total } \\
\end{array}$ & $\begin{array}{r}38^{\circ} \\
256 \\
62 \\
356 \\
\end{array}$ & $\begin{array}{r}66 \\
8 \\
86 \\
64 \\
224\end{array}$ & $\begin{array}{r}32 \\
16 \\
32 \\
56 \\
136 \\
\end{array}$ & $\begin{array}{r}136 \\
120 \\
216 \\
80 \\
552 \\
\end{array}$ & $\begin{array}{c}13^{b} \\
242 \\
216 \\
333 \\
804\end{array}$ & $\begin{array}{r}152 \\
70 \\
76 \\
148 \\
446\end{array}$ \\
\hline $\begin{array}{l}\text { Without threshi } \\
\text { - Summer crop w } \\
\text { Sandy soils; no }\end{array}$ & $\begin{array}{l}\text { repa } \\
\text { addit } \\
\text { tion }\end{array}$ & $\begin{array}{l}r \text { sa } \\
\text { tiva } \\
\text { win }\end{array}$ & & & & \\
\hline $\begin{array}{r}\text { Sources: Millet, } \mathrm{Bl} \\
\text { Guillard } \\
\text { Agricultu }\end{array}$ & out & mo & ivel $\mathrm{B}$ & $\begin{array}{l}96, \text {, p. 236); so } \\
\text { roduction agric } \\
\text { développemen }\end{array}$ & $\begin{array}{l}\text { Boserup (19 } \\
\text { 18); sweet f } \\
\text { on agricole }\end{array}$ & $\begin{array}{l}\text { 0); sorghum (Car } \\
\text { s, Taiwan Depar } \\
\text { p. 228) }\end{array}$ \\
\hline
\end{tabular}


Ict that under their system of permanent cultivation they produce yields nat are higher per hectare than those obtained in more extensive systems, ut are lower per man-hour. Wherever conditions permit them to leave their :rowded home area, because new land is opened up for settlement, they mmediately turn to fallow systems.

\subsection{Four case studies}

The following examples give an idea of the various forms taken by permanent rain-fed cropping. The first example from Kenya shows permanent cropping on fertile soils. The remarkable efforts by hoe cultivators in Ukara are an indication of how African farmers in a siege situation have developed the same methods of soil conservation as have Chinese farmers, but are nevertheless only delaying and not stopping the decline in soil fertility. Land use in Senegal is a typical case of soil mining, except in the mixedfarming system of the Serere. The farming system in the Bombay Deccan shows the final stage in the Malthusian process: stagnation on a very low level of yield and productivity.

\subsubsection{Maize-millet holdings in Kakamega District, Kenya}

The Kakamega District of Kenya is very densely populated: there are 500-600 people supported by agriculture per square kilometre. The stage has been reached where the customary fallow period of several years has been almost totally displaced. The basis of permanent rain-fed farming, in sume cases with two crops annually, is a deep fertile soil and a good rainfall pattern.

One family normally owns 1-3 hectares. For generations; maize, sorghum, fingel: millet, and beans have been the main crops. Both hoe cultivation and ox ploughing are practised. A rotation typical in the 1950s runs as follows:

(1) Spring (long rainy season) Maize mixed with beans Autumn (short rainy season) Partiy maize, partly beans, grown separately

(2) Spring Autumn

Maize mixed with beans

(3) Spring

Fallow used as pasture

Autumn

(4) Spring Sorghum

Sorgnum (self-sown)

futumn

Finger millet

Fallow used as pasture

In recent years maize, especially the new hybrid varieties, has come to occupy a more important position in the rotation.

A fallow period of several years is retained only in the border areas of the densely populated region, or in the few holdings with larger areas of land. Behind the huts are banana groves, consisting of eariy-maturing and late-maturing varieties for both cooking and eating. The women tend a kitchen garden. In the spring, peas and beans are planted among the bananas, while in the autumn, a plot is sown with yegetables. Two or three Zebus cattle and a few sheep and heris are kept. The fodder 
basis consists of grass in the spacious homestead, roadside grazing, harvest residues, fallow, and communal pasture.

The farmers of the Kakamega District have been cultivating for some decades without fallow or fertilizer. Until a few years ago, the available dung was used for fuel, together with straw and weeds, and the concentration of nutrients in the kraals was at best utilized for a banana grove. The iniensive campaign on the part of the Agricultural Advisory Service has in the meantime caused a number of farners to collect and use animal manure. Where maize-recently also hybrid maize--is grown as a cash crop, mineral fertilizer has been adopted.

\subsubsection{Millet holdings in Ukara, Lake Victoria}

The Wakara, who live tightly packed (500 persons per square kilometie) on a little island in Lake Victoria, 1000 metres above sea level, similarly practise permanent rain-fed farming. The soils are derived from weathered granite, with little natural fertility. The need to guarantee the food for a dense population on these soils has caused the Wakara to develop and apply the highly refined practices of a soil-conserving agriculture, although no influence from immigrant people is recognizable.

The average Wakara family has only I hectare of arable land at its disposal, and this is cultivated by hoe. The land is cultivated chiefly according to a three-year rotation:

(1) Summer season Bulrush millet, with manure and inierpianted legumes for

Winter season green manure (Crotalaria striata)

Growth of the green manure

Bulrush millet, with green manure dug in; groundnuts

Winter season

(3) Summer season

Winter season planted among the ripening millet

Growth of groundnuts

Bulrush millet, with manure

Sorghum or manioc (in the case of manioc, a fourth year of manioc follows)

In addition, small patches of irrigated rice are cultivated in the valley bottoms, and hill land in the interior of the island is grazed.

The crucial problem in the $:$ Vakara holdings is that of acquiring manure, which can be done only by the production of fodder. The two or three cattle and the one or two goats and sheep that are kept on the average holding are fed with harvest residues, leaves of growing sweet potatoes and manioc, weeds collected while hoeing, fodder grasses planted and watered on the island shores, and ratoon rice, which grows on rice plots at the beginnings of the dry season. There are also some grazing areas. Sometimes the animals are tethered, in order to economize on the available grazing. The animals occupy one half of their hut and stand in deep litter. Bedding consists of the remains from harvesting and fodder, leaves and branclies of trees and bushes, old roofing grass, and any other suitable material that becomes available. The household ash is applied to the nursery beds for rice. As well as using green manure, the Wakara use jeaf manure; leaves from trees that are not suitable as fodder are carried to the field and dug into the soil. 
Even though the agriculture of the Wakara may be remarkable, it is rgely a relic of a poorer past. Their careful cultivation is not motivated o much by the desire to increase their income as to guarantee the livelihood f a growing number of people. The Wakara obviously work harder than the reighbouring tribes, but they are nevertheless poorer. When they migrate o the mainland, they change to the semi-permanent agriculture of the Wasukuma, which, considering the labour input, provides a disproportionately better income. The Wakara's land use is an isolated example. The population in the surrounding areas regard staying on the island, where people are obliged to work from morning till evening merely to cover their needs, as stupid, and the methods that they are obliged to use to manure their land as dirty.

The Wakara's example shows that, in traditional conditions on moderately fertile tropical soils, there must be a special emergency situation before smallholders will adopt the labour-demanding techniques that are essential features of permanent rain-fed farming with soil conservation.

\subsubsection{Groundnut-millet holdings in Senegal}

Where the problem of ensuring the subsistence-food supply of a slowly expanding population has entailed a gradual extension of permanent rain-fed farming, as for example in Ukara, or on a large scale in China, more or les's intensive methods of traditional fertilizing have spread, and this guarantees permanent cropping. These methods do require, however, a high labour input, and the yield is low in relation to the amount of work done. Where permanent rain-fed farming has developed on the basis of an increase in market production by the local people, the situation is usually quite different. The more rapidly production is commercialized, the less do the farmers worry usually about conserving the soil.

An example of this occurs in the groundnut-millet holdings of Senegal (see Table 6.3). The commercialization of the area began about 1850, and it has accelerated in the last forty years. Rotations with the two crops groundnuts and millet predominate. Where there is still enough land available, three to five years of cropping are followed by a fallow of the sane duration. in many regions, however. cropping is practised for seven to twelve years, and only then is a fallow period of three to four years introduced, and in most cases there is no fallow period at all.

Increasing numbers of farmers are thus changing from semi-permanent to permanent land use, in which fallows are either short or absent. Groundnuts and millets are mostly grown on the flat, without previous cultivation with either hoe or plough. The traditional method of superficial hand clearing before planting is by far the least costly. Groundnuts are increasingly planted with a seeder, giving row cultivation. The use of improved varieties and the application of mineral fertilizer to groundnuts as well as to millets have become standard practices. The quality of the first two weedings conditions the yield, especially when fertilizer has been applied. Horse-drawn or ox-drawn weeders are widely used. 
TABLE 6.3

Farm-management data from maize-millet holdings, Kakamega District, Kenya; millet holdings on Ukara lsland, Lake Victoria; and groundnutmillet holdings in Senegal

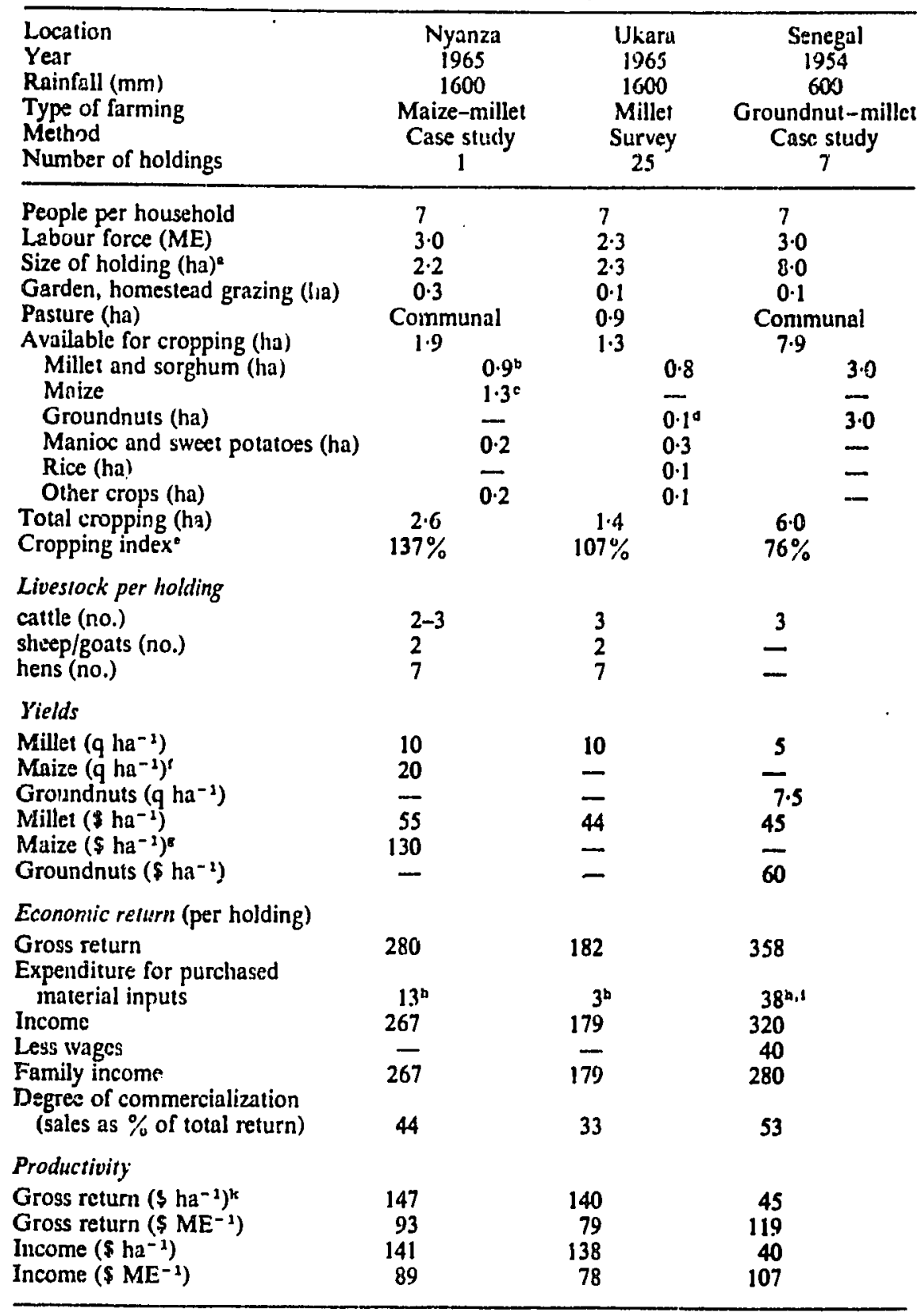




\section{ON RAIN-FED LAND}

Because of the relatively large area of land per worker, and because the groundnuts are grown as a major cash crop, farmers in Senegal attain a comparatively but it is acquired at the expense of continual impoverishment of the soils. Areas whose fertility has been exhausted by some decades of cultivation are abandoned, and new ones are cleared. Large areas where formerly widespread cropping was practised yield scarcely anything today. The farmers, who strive to earn as much cash as possible from groundnuts, are obviously not conof soil fertility. Referring to this point, the report of the research station at Bambcy stated that 'further farming within the traditional land-use systern must lead to the ruin of Senegal' (Tourte 1954).

The land-use system of the Serere in Senegal is an exception to the general practice. This tribe practises a biannual rotation of millet and groundnuts with almost no tallow, but this appears to have no harmful effect on the soil. The explanation lies in the integration of cropping and animal husbandry. The land of the Serere. which receives not more than 600 millimetres of rain annually, supports 60-70 head of cattle per 100 hectares of total area, half of which is cropped and the other half more or less permanently grazed. The arable land is fertilized by systematic folding. The bare land is also protected between harvest time and the next sowing by a leguminous tree (Faidherbia albida), which comes into leaf during the dry season, thus providing valuable fodder when grazing is scarce. It loses its leaves in the rainy season, and does not therefore interfere with farming operations. The ccuntryside, dotted with smaller and larger Faidherbia albida, resembles a widely spaced orchard (Dumont 1966, p. 121). Permanent cropping is thus associated with permanent grazing and a permanent fodder supply from trees in the dry season.

\subsubsection{Millet-wheat holdings in the Bombay' Deccan}

Whereas, on the one hand, the Wakara try, through various fertilizing methods, to maintain soil fertility in permanent farming, and on the other

- In Nyanza and Senegal without pasture: in Ukara including individually owned pastures.
0.2 hectares are planted in the autumn.

c Of which 1.0 hectare maize-bean mixture is planted in spring, and 0.3 hectares pure

stand of maize in autumn.

- Bambara groundnuts.

- Cropping index: area cropped as a percentage of the area available for cropping.

t Plus a bean yield of 3 quintals per hectare.

r Maize and beans together.

n Unconfirmed estimate.

1 Principally purchase of groundnut seeds.

1 Most families in Nyanza get an income from work outside the holding.

Senegal only a small number of households have

$*$ In relation to the area available for cropping.
Dafa from: Nyanza, personal surveys (1965); Ukara, Ludwig (1967, p. 206); Senegal.

Tolirte (1954). 
hand we can observe in Senegal an obvious decline in suil fertility, in large areas of India the yields in the course of several centuries of permanent cropping have stabilized at a very low level, especially where thare is no irrigation and the soils are naturally poor. This is illustrated by the millet-wheat holdings of the Bombay Deccan, which is known as a famine area.

A typical holding of the area comprises 6-7 hectares of arable land. 10 per cent of the land can be irrigated from time to time with the nelp of wells or tanks. In summer (kharif season). millet and sorghum are grow, $n$, and in winter (rabi) wheat. Supplementing this, we find small irrigated plots of sugar-cance and vegetables. The cropping area amounts in all to 107 per cent of the arable land (see Table 6.4). Cultivation is carried out with a woodien plough with an iron spike. Seed-harrows and hand drill machines are found here and there.

Low yields per hectare lead to the low gross return per farm of only $\$ 113$, or $\$ 17$ per hectare, at price levels of 1957 . There remains a family income of only $\$ 82$, or $\$ 30$ per available worker, which is far less than in the African systems illustrated in Table 6.3. Only about half of the labour capacity available is employed in work on the holding. The main object of production is to ensure food for the family and draught animals.

Admittedly, the millet-wheat holdings reveal some featurcs that indicate an advanced level of agricultural technique. Animal manure and compost are taken by ox-cart to the fields. Grass and bedding are collected from waste land and become part of the animal nanure, so that nutrients from land outside the holding are imported onto the arable land, particularly the irrigated plots. Grazing is supplemented by arable fodder, and some hay is produced. But all this is not enough: the soils are poor and the rainfall uncertain: the yields of 2-4 quintals per hectare of millet and 3-4 quintals por hectare of whest are lower than the yields usually found in shifting cultivation.

The holdings are burdened by having to keep work animals. Draught oxen consume about one-third of the gross production, and they are only used to half their capacity. It is, however, essential to keep work aninals to guarantee a livelihood, beciuse largc areas inust be cultivated and this can be done only with the plough. The need to keep draught animals increases the need to keep cows, the main point of which is not so much to supply milk and manure-meat is in any case not eaten-but to produce bull calves. Slaughter of cattle, even of old and useless animals, is barred in the area both by traditional value systems and by legal prohibition. ${ }^{1}$ The holding suffers, therefore, not only from the immediate burden of draught animals, but also from the burden of keeping several cows whose principal function is to continue the supply of draught animals, without being used as draught animals themselves.

\subsection{Weaknesses of the system}

The scope for increasing production within traditional agricultural methods diminishes as land reserves are exhausted and yields per hectare stagnate at a low level. Permanent farming carried out on impoverished soils may well te

\footnotetext{
${ }^{2}$ Section 4 , Article 48 of the Indian Constitution asserts that the states should take steps for preserving and improving the breeds, and prohibiting the slaughter of cows, calves and other milk and draught cattle'.
} 


\section{3}

TABLE 6.4

Farm-management data of a millet-wheat holdisg in the Bombay Deccan,

\begin{tabular}{|c|c|}
\hline $\begin{array}{l}\text { Rainfall (mm) } \\
\text { Year } \\
\text { Number of holdings } \\
\text { Method }\end{array}$ & $\begin{array}{c}700 \\
1957 \\
99 \\
\text { Sample survey }\end{array}$ \\
\hline $\begin{array}{l}\text { Persons per houschold } \\
\text { Labour forct (ME) }\end{array}$ & $\begin{array}{l}7 \\
2 \cdot 8\end{array}$ \\
\hline $\begin{array}{l}\text { Size of holding } \\
\text { Arable land area (ha) }\end{array}$ & 6.63 \\
\hline $\begin{array}{l}\text { Summer croppiry (ha) } \\
\text { Millet } \\
\text { Sorghum } \\
\text { Chick-peas } \\
\text { Groundnuts } \\
\text { Other grain/legutrats } \\
\text { Other crops }\end{array}$ & $\begin{array}{l}2.63 \\
0.93 \\
0.35 \\
0.28 \text { (with some irrigation) } \\
0.99 \\
0.35\end{array}$ \\
\hline $\begin{array}{l}\text { Winter cropping (ha) } \\
\text { Wheat/safflower }\end{array}$ & 1.35 \\
\hline $\begin{array}{l}\text { Both seasons (ha) } \\
\text { Sugar-cane } \\
\text { Vegetables } \\
\text { Toial } \\
\text { Cropping index }\end{array}$ & $\begin{array}{l}0.07 \text { (irrigaied) } \\
0.14 \text { (irrigated) } \\
7.09 \\
107 \%\end{array}$ \\
\hline $\begin{array}{l}\text { Cropping index } \\
\text { Livestock per holding }\end{array}$ & $107 \%$ \\
\hline $\begin{array}{l}\text { Draught animals (no.) } \\
\text { Milk cows (no.) } \\
\text { Goats/shecp (no.) }\end{array}$ & $\begin{array}{l}3 \\
2-3 \\
1-2\end{array}$ \\
\hline $\begin{array}{l}\text { Farm capital (\$ per holding) } \\
\text { Land } \\
\text { Implements } \\
\text { Livestock } \\
\text { Farm tuildings }\end{array}$ & $\begin{array}{r}74 \% \\
4 \% \\
17 \% \\
4 \%\end{array}$ \\
\hline
\end{tabular}

Yields

Wheat $(\mathrm{q} \mathrm{ha}-1)$

Millet $\left(q \mathrm{ha}^{-1}\right) \quad 2.6$

Chick-peas $\left(q^{h} a^{-1}\right)$

Milk (kg per cow and year) 110

Wheat ( $\left.\$ \mathrm{ha}^{-1}\right)$

Millet (\$ ha-1) 17

Chick-peas $\left(\$ \mathrm{ha}^{-1}\right) \quad 15$

Economic refurn (\$ per holding) 113

Gross return 113

$\begin{array}{ll}\text { Expenditure for purchased material inputs } & 18 \\ \text { Tax, etc. } & 13\end{array}$

Family income

82

Productivity

Gross return $\left(\$ \mathrm{ha}^{-1}\right)$

Gross return (\$ $\left.\mathrm{ME}^{-1}\right)$

$\begin{array}{ll}\text { Value added }\left(\$ \mathrm{ha}^{-1}\right) & 12 \\ \text { Valuc added }\left(\$ \mathrm{MF}^{-1}\right) & 30\end{array}$

$\begin{array}{ll}\text { Valuc added ( } \$ \mathrm{MF}^{-1} \text { ) } & 30 \\ \text { Employment of avaulable labour capacity } & 49 \%\end{array}$

A! price levels of 1957. The all-India index number of wholesale prices of agricultural commodities stood at 109 in January 1957, and at 211 in January 1967 (base: 1952-3 = 100). Indian agriculture in brief. p. 154. 9ih edn, Delhi (1968).

Data from: Driver and Deasi (19.57). 
considered as a final stage in the land development that begins with shifting cultivation, leads to semi-permanent farming yielding somewhat higher incomes per hour of work, and ends with a low-level equilibrium in permanent rain-fed farming.

The growing population's increasing subsistence demands and the extension of cash cropping, in order to cover increasing cash demands, are the driving forces behind changes in farming systems. Three overlapping phases may be distinguished in respect of these processes:

(1) The first step consists usually of extending a given farming system by establishing new smallholdings in expansion areas, wherever they are
available.

(2) When therc are no more expansion areas available, or when the distance between the expansion areas and the original settlement area becomes too large, intra-farm land reclamation acquires importance, and cultivation is extended at the expense of the fallow. The transition from shifting cultivation to semi-permanent and permanent farming occurs slowly but surely. (3) Cropping patterns change at the same time. As land use becomes more permanent, the relative suitability of some crops diminishes, while that of others increases. Thus a change in the type of crop ensues. The cultivation of such crops as manioc and sweet potatces gains ground, since they yield high and certain calorie returns per hectare and per hour of work, and therefore release land and labour for the cultivation of cash crops. Millets and maize diminish in relative importance. ${ }^{1}$

As long as these three possibilities still exist we can count on rates of production growth that are at least as high as those of population growth. However, as soon as production reserves of this type are exhausted, there is a distinct danger that, to follow the nomenclature of Geertz (1963), agricultural evolution will turn into involution. Increasing subsistence demand leads to the reduction of the cash-crop area, and low-yielding though high-quality foodstuffs, such as millet and maize, are replaced by high-yielding but lowquality food crops, like manioc and sweet potatees. The greater the population density and the smaller the farms, the higher is the percentage of crops like manioc and sweet potatoes and the lower the percentage of maize in the subsistence food. The final stage of this type of involution consists of very small holdings, without room for cash cropping, which grow root crops

${ }^{2}$ Yields in traditional farming are frequently about 6 quintals per hectare for millet 12 quintals per hectare for maize, 80 quintals per hectare for sweet potatoes, and 100 quintals per hectare for manicc. These amouni, in kilocalories per hectare, to 2060 (millet), period of millet, inaize, and sweet potatoes 33800 (manioc). If we estimate the growing months, the monthly retums in kotatoes to be 4 months and that of manioc to be 18 1070 , with sweet potatoes 1930 and with per hectare are with millet 515, with maize long period, 1880 . 
almost exclusively. The families living by this type of farming are particularly poorly nourished, diseases are more widespread than elsewhere, and the extent of underernployment is particularly great.

The system of land use in Ukara in Lake Victoria is a remarkable attempt to overcome this process of pauperization. But even when all imaginable measures open to pre-machine men are applied to retain the fertility of the soil, as they actually are on Ukara, it is apparently not possible to avoid decreasing returns per hour of work when land use is intensified on tropical soils within the traditional state of agriculture. The average returns per hour of work are particularly low on Ukara (sce Table 6.3).

A similar involution can be observed in the animal economy. In unregulated ley systems with sufficient grazing, the herds per family are large and the animals well fed. A spatial increase in arable farming reduces the grazing area until almost all of the land is annually cropped. The production of fodder crops is neither customary nor competitive. This usually gives rise to a situation with high numbers of poorly fed cattle. In some cases, cattle are replaced by goats and sheep. Only in exceptional cases is the cattle eronomy integrated into some type of mixed farming. The cattle numbers per family decrease, therefore, with increasing permanency of cultivation, although livestock densities per 100 hectares may be high. The final phase of this involution is reached when the livestock economy is reduced to small herds of animals per family-mainly goats-which live on crop residues and on areas unfit for cultivation.

Neither of the methods to increase output that are practised so skilfully by smallholders-extending the cropping area and changing the cropping pattern-is sufficient to sccure a rising income for a growing population. There is a great danger of stagnation at a somewhat higher level of income, or of a decline in incomes, once these possibilities are exhausted.

Increasing land shortage reduces not only the marginal returns of labour but often also those of land. The smaller the holding, the lower are, as a rule, the average gross return and the marginal gross return per hectare, simply because the smaller the holiting the smalier is the scope for cash production with crops yielding high returns per hectare.

A situation like this is revealed, 0 axnmple, in three neighbouring districts in Sukumaland. In the thinly populated Shinyanga area the fumily income rises rapidly and constantly as the labour citpacity increases. In the more densely populated Kwimba area labour productivity is alriady considerably lower. Finally, on the island of Ukerewe, Lake Victoria, where permanent cropping is practised, there is scarcely any connection between farnily incone and the family's labour capacity (see Fig. 6.5).

Because of the priority attached to subsistence-food production, the smallholdings with permanent rain-fed farming are caught in a situation that might well be called a 'low-level equilibrium trap'. The only way out, except 
by migration, is to attain high returns per hectare and per animal by intro. ducing yield-increasing innovations.
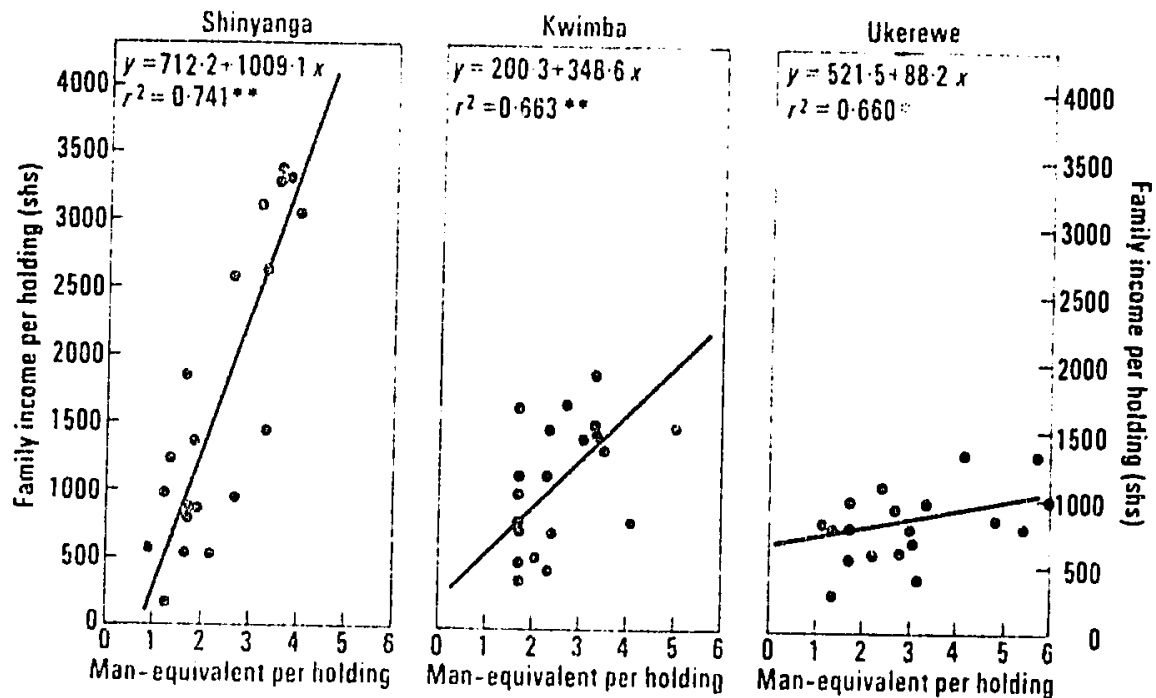

FIG. 6.5. The relation between land availability and labour productivity in three areas of Sukumaland. Tanzania (from Rotenhan 1968. p. 78). Twelve families out of the total of seventy-five studied have been omitted hecause they receive non-agricultura! incomes.

\subsection{Covelopment parihs of permanent cultivation systams}

\subsubsection{Improved permanent cultivation systems}

(a) Technical immovations. The possibilities for intensification and improvement of permanent arable farmin $\tilde{E}$ on rain-fed land have been drastically changed by technical progress. Intensive cropping with decreasing soil fertility and low yields per hectare used to be the final stage, a blind alley in the development of tropical farming systems for those who had not enough land for fallowing and not enough water for irrigation. Now, we have an almost unlimited number of useful innovations, which are of limited applicability in shifting and semi-permanent systems, but which, from a teclinical standpoint, are fully applicable in permanent farming. These inciude:

(1) new crops, new or improved varieties, and improved animals;

(2) new types of material inputs, such as mineral fertilizer, pesticides, equipment, and tractors; and

(3) new and improved husbandry practices, which have become worth while because of new activities, better varieties, and new types of input.

The work of many research stations indicates that permanent arable cropping with high yields can be practised in a tropical climate, with the 
liberal use of organic and mineral fertilizer, terracing, and soil-conserving rotations. The interaction between better varieties of new crops, mineral fertilizer, irmproved husbandry, and the use of tractors is of especial importance for permanent cultivation systems. The proper timing of operations, which in rain.fed farning tends to be a major determinarit of yields per hectare, can be achieved much better with tractors than with hoe or oxplough cultivation. On the other hand, we must not overlook the fact that the realization of ith that is technically and economically possible in permanent rain-fed farming requires significant institutional changes: appropriate types of land rights, land consolidation, efficient services, and a wide range of oth ' $r$ associated structural elements, without. which full development catnnot be achieved.

It is important to realize that new farming inputs have to be purchased. The way out of the low-level production trap of traditional permanent cropping is dependent on cash prodıction and on markets. Prices must be sufficiently attractive to induce changes in input fatterns. These preliminary requirenents do not yet exist in most ci.ses, so that most permanent rain-fed farming stili takes place at a low level of productivity.

(b) Introduction of new rotations. Even more demanding than the introduction of new cash crops and new inputs is the introduction of mixed farming, which might be considered the nost important step in putting pormanent cropping systems on a sound, self-sustaining basis. Two main starting points may be distinguished: the combination of foclder production on the arable land with intensive types of animal husbandry, and the inclusion of greenmanure crops in the rotation.

The first way is the more intensive one, especially with dairying. Conspicuous increases in output may be expected, becalise of the inclusion of leguminous fodder crops in the rotation, liberal application of manure, the application of fertilizer, better soil cultivation, and other soil-improving and conserving practices. ${ }^{1}$ On the other hand, the high input of labour and crpital connected with intensive animal production must not be forgotten. In permanent farming, stabling with no grazing (cut and carry systems) is often preferred to keeping the cattle on pastures. Consequently, to the high investment required for dairy stock, which is also incurred in regulated ley systenws, must be added the cost of stables, the provision of water, spreading manure, and transport for fodder and nunure. Mixed farming on a low level of intensity,

\footnotetext{
1 Acrording to Guinard (1957), in the West African savannas 10 tons of animal manure per hecate is required annually for permanent cropping of millet or sorghum. It has been suggesied that, in East Alrica, diressing of the order of $2 \frac{1}{2}$ tons of ? rmyard inanure per hectare par year, or 7.5 cons every three years, or 15 tons every five years. is probably necesary to maintain yields in the absence of mineral fertilizers (Webster and Wilson 1967, p. 18 (8). Very soall quantitics of manure, anounting to $2 \mathrm{t}$ tons per hectare per year, were

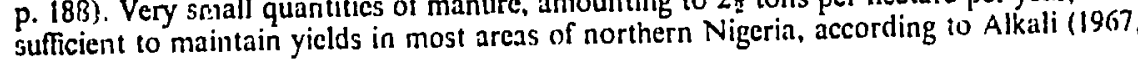
p. 8).
} 
with a poor fertilizing system and traditional patterns of animal husbandry, is widely practised in India and yields low returns. But intensive mixed cropping, including heavy manuring and high-technology animal husbandry. is so far seldom found in the tropics because it requires so much in capital, knowledge, and markets. ${ }^{1}$

Intensive green manuring is technically easier, substantially cheaper, and probably conserves the soil equally well. ${ }^{2}$ The capital costs of livestock and the costs of transporting fodder and manure are not incurred: the greenmanure crop is plougher ine the soil where it grows. The main problems of a mixed-farming system based on green manure are:

(1) Insufficient land supply-farmers cannot forgo the income derived from cropping the land that is expected to carry the green-manure crop.

(2) The cost of mineral fertilizer for the green-manure crop.

(3) The amount of traction power required to plough in the green manure -animal or hoe cultivation is often inadequate and tractors are essential.

(4) The retention of nitrogen as the green-manure crop rots, because it is often diffcult to plough in the green-manure crop in time, especially in the drier savannas.

(5) The difficulty of arranging for green-manure crops to cover the soil in the dry season and protect it from the sun. Thus, ploughing in is best done at the end of the dry season. However, a good seedbed, resulting from the careful ploughing in of the green manure, camnot be created very easily at this time of the year.

Intensive green manuring is tied to effective traction power and to favourable price conditions, but not to the same extent as is intersive animal husbandry. The developments so far in Africa, particularly in Wesi Africa, indicate that permanent cropping systems with green mantiring are more economical, and therefore are more likely in spread rapidly, than systems with intensive animal husbandry. In the in:ermediate forest zone of Ivory Coast, for instance, where there are two rainy seasons, rain-fed rice and cotton are grown in one year for two to three years, followed by two to three years of a green-manure crop (Stylosanthes).

(c) Introduction of intensive permanent pastures. Where permanent cultivators in the tropics have permanent pastures, these pastures are, except in

${ }^{2}$ A special form of mixed farming is the combination of mixed rain-fed cropping with fodder cropping from bushes and trees. In West Africa, we already find an instance of this which is economically important: the seeding of Faidherbia albida (see \$6.4.3), which, with row planting at the edges of fields, can be used in combination with plough culture. The disadvantages of this kind of combination are (1) the slow growth of the Faidherbia albida, (2) the difficulties of seeding (the seeds do not germinate until they have passed through the stomachs of the cattle), and (3) the thorns on the branches, which are tolerated by only the undemanding Zebu cattle.

2 In the savannas of West Africa, 30 tons of green manure are said to have the same fertilizing effect as 10 tons of animal manure (Guinard 1967). 
some highlands, almost always on land that is unfit for cultivation and provides only poor grazing. It is conceivable, on the basis of more recent technical progress, that future arable systems in the tropics will have intensively used, permanent pastures on potentially arable land. In the humid tropics the growth of herbage is rapid, and heavy yields of green inaterisl may be obtained from sown or planted stands with a heavy application of mineral fertilizer. Onc hectare of properly managed grass in humid tropical areas is capable of supplying enough green fodder for four, or even six, cows (Whyte 1967, p. 126).

The difficulties of using tropical grasses are summed up by Whyte (1967, p. 56) as follows:

However, quality is usisally below that of good herbage fro'n the temperate zone, particularly in respect of dry matter. As one of the direct effects of a tropical climate is to depress the appetite, a low dry matter content further reduces the ability of the animal to obtain enough dry matter for maintenance and production. The dry matter intake of dairy cattie in Trinidad during the wet season is significantly less than that of the same animals during the dry season.

The problem is further complicated, because the crude fibre content of humid tropical herbage apprears to be consistently higher than that of temperate herbage at the same siage of growth, an additional disadvantage to animals that are finding difficulty in eating sufficient bulk of watery forage.

He continues (p. 81):

There are only very limited areas in the humid tropics where the rainfall is so uniformly distributed throughout the year that supplementation of available grazing resources is unnecessary when farms are stocked to full capacity. There is also a fairly long period in eacil year when the growth of pastures and fodder crops is greater than the refutirements of the farm animals. Unfortunately, even when the best haryesting practices are adopted, the tropical grasses that are best suited to hot humid enviromments are relatively coarse and of only limited nutritive value. Even when nutrient losses in conservation aie reduced to a minimum, the final product will be inferior in quality to conserved fodders in the temperate zonc. The fundamental problem with which agronomists in the humid tropics have to contend is the fact that the surplus herbage which may be harvested for conservation usually grows at a time when weather conditions are quite unfavourable for the maling of good hay and/or silage.

In many respects the first steps have been taken to overcome these problems. New fodder plants, which are locally unknown, are being made available. Silage made from grass or fodder crops grown on the arable land can help to provide fodder in the dry season.

As improved permanent pastures are created, it is debatable whether grazing systems should be preferred to zero-grazing. Whyte (1967, p. 69) writes:

The argunients genarally produced relate to the extra costs and labour involved in cutting the feed and cariying it to the animals, and to the fact that this system breaks the fertility cycle--the movement of plant nutrients from the soil to the 
plant, to the grazing animal and back to the soil in the form of dung and urine.

The grazing of highly bred, highly productive dairy cows in the tropics or in the hot summers of the subtropics raises a number of problems relating to heat load. Under tropical conditions with a long growing season, extended, if necessary, by seasonal irrigution with clean water, cowshed wash or sewage, very high yields of palatable tropical grass may be obtained. Two factors then arise:

(a) There is on average temperate pastures a loss of 40 per cent of the herbage, due to trampling and urinc poisoning; on tall, 'igh-yielding tropical pastures this percentage may even be higher, when grazed, and the loss of precious feed represented by that percentage may be too great to contenplate; and

(b) There must be a threshold value for yield, above which too much of the herbage is rendered unpalataile through the dropping of very large amounts of dung and urine by grazing animals.

Thus, the higher the yield from a tropical grass crop, the less can one justify grazing it. Some specialists say that when labour is still available and cheap, it is prefcrable to adopt the cut-and-carry system or zero-grazing and obtain 100 per cert of the yield, provided arrangements are made for full return of animal fertility back from the cowsheds to the land. It would be argued that the 40 per cent loss due to grazing and trampling is worth more than the costs inyolved in the cul-and-carry system. Others would say that the nore expensive the labour, the more economic will the cut-and-carry systen be compared with grazing, as it can be highly mechanized, can assure the effective utilization of all the fodder produced on intensively cultivated land, and will make it possible to obtain a higher return per labour hour than in any other system.

Where intensive dairy production is found in the tropics, for example in the West Indies and in various Latin American countries, grazing systems on permanent pastures are usually preferred. In smallholdings with tree crops (see $§ 8.4-8.6$ ), and in irrigation farming (see $\$ 7.4$ ), cut and carry systems are, however, establishing themselves.

\subsubsection{Change from permanent rain-fed cultivation to other types of farming}

(a) From rain-fed cultivation to irrigation farming. Generally speaking, we find among permanent cultivators in the tropics the tendency-wherever there is the opportunity-to develop irrigation at the expense of rain-fed farming, especially where holdings are small. Even small irrigated plots can be important in reducing the risk of harvest failure, in using labour and traction power regularly and to their full capacity, and in producing a regular supply of fodder.

Over the centuries, in south-east Asia particularly, the change from shifting and semi-permanent systems to wet-rice systems has taken place (Pelzer 1957, p. 75). Wet-rice developments begin, as a rule, by using valley bottoms, and as the land becomes more scarce terracing is developed on the slopes. In Madagascar this process is in full swing, and in East Africa it is in the initial stages. Relatively large areas could be made suitable for wet rice in Africa and Latin America. 
Whereas we may expect an accelerated change from shifting, semipermanent, and permanent rain-fed farming to irrigation farming, and particularly to vet rice in Africa and Latin America, it seems doubtful whether this tendency will continue in the densely populated regions of south-east Asia. The conversion of marginal hill land to irrigated terraces requires a high input of capital and manual labot'r. The rice terraces on the slope are mostly narrow, and it is difficult to mechanize the labour operations. With the new means of increasing the yield on the existing rice land, by using new varieties, mineral fcrtilizer, pesticides, ecc., it is in general more profirable to use the existing areas more intensively than to create new rice terraces. Technical progress has, moreover, considerably improved the production of rain-fed farming, so that the transition to wet rice no longer represents the only way of increasing the productivity of land and laboui. Under the conditions of traditional agriculture, however, it was nore or less the only way.

(b) From rain-fed cultication to perchniai crops. The change-over to perennial crops, particularly bananas, for food and to various tree crops for cash, is another obvious tendency as population density rises and commercialization increases. Bananas produce aimost :s many kilocalories per hectare as tropical root crops, with less labour per unit of starch. Banana groves offer an almost complete cover cor the soil and improve its fertility. They are clearly an attractive alternative to permanerat arable cropping wherever soil and climate are suitable.

Over and above this, there are many indications that tiee or bush crops are gaining in inportance as development takes place. On the slopes of suitable areas small plantations are frequently spreading at the cost of permanent arable farning. Examples are the coffee and the tea plantations of the Kikuyu in Kenya, and the tea and fruit plantations of the smallholders in Taiwan. It can usually be observed that the displacement of permanent arable farming by tree or bush crops depends on the cash-cropping opportunities, i.e. on the availability of attractive markets. 


\section{Systems with arable irrigation farming}

\subsection{Dofinition}

IN tropical arable farming, irrigation systems are of particular importance. The emphasis on irrigation is especially pronounced where the cliniate is warm, the population density high, and the land intensively farmed. 'Irrigation' describes those practices that are adopted to supply water to an area where crops are grown, so as to reduce the length and the frequency of the periods in which a lack of soil moisture is the limiting factor to plant growth. This is done in two main ways. Water that has fallen as rain on another piece of land may be collected and led onto the area that is to be irrigated. This procedure is usually called artificial irrigation. Alternatively, water falling on a given area may be impounded and held there, in order to reduce run-off.

In irrigation farming we therefore include a number of primitive forms of water delivery and water impounding, which do not necessarily ensure a regular and reliable water supply to the plants. In widespread areas of the tropics, rice is first irrigated in the sense of being wet-ficld rice. The felds are ploughed and planted in the rainiest season of the year and have earth walls round them, within which the rain-water falling on the field itself or coming from neighbouring areas is impounded. Later, at some point bofore the maturity of the plants or the ripering of the grain, many of these fields dry out, owing to the cessation of the rains and the absence of water supplies. This canrot accurately be called irrigation rice, but neither is it properly termed dry-land rice. Certainly, in terms of agronomy and farm management, the features of this transitional form correspond rather to those of irrigation farming than to those of rain-fed farming. We thus include wet rice, and corresponding primitive methods in other crops, among the forms taken by irrigation farming.

\subsection{Types of irrigation farming and their goographical distribution}

The guiding principle of rain-fed farming is the adaptation of cropping to the conditions of soil and climate. Irrigation systems, on the other hand, because they involve increasing control of water and reliability of water 
SYSTEMS WITH ARABLE IRRIGATION FARMING

supplies, are characterized by a 'control of nature'. Both water supply and soil conditions become increasingly subject to human control. Therefore, we classify the forms that irrigation farming takes according to the water supply system, the cropping system, and the exploitation system.

\subsubsection{Water supply systems}

Table 7.1 gives a synopsis of the various possible methods of water supply, water distribution, and water application. Water for irrigation can be obtained from uatural flows by diversion, damming, or pumping. The various

\section{TABLE 7.1}

Irrigation methods

(1) Methods of obtaining water

(a) Diversion of water from natural flows (river, stream or spring)

(b) Damming:

(i) Retention of tidal water

(ii) Impounding of rain-water in paddy fields

(iii) Retention of the water of seasonal streams in tanks and small dams

(iv) Retention of river water in large dans

(v) Exploitation of natural stores of water, lakes, exc.

(c) Pumping:

(i) Manpower-pumping by foot, using a lever arm, etc.

(ii) Wind and water power-wind pumps, water wheels, etc.

(iii) Animal power-winches, inclined plane, etc.

(iv) Motor pumps

(2) Methods of water distribution
(a) Ditches (lined and unlined)
(b) Flumes
(c) Pipelines

(3) Mathods of water application
(a) Flooding (controlled and uncontrolled)
(b) Basin irrigation
(c) Furrow irrigation
(d) Sprinkler irrigation
(e) Inderground infiltration

ways of damming water are particularly prolific. They range from relatively simple methods like retention of tidal water (rice irrigation on the coast of Java, date irrigation in Schatt al Arab, Iraq), growing of swamp rice in aaturally flooded areas of river valleys, and impounding of rainfall in paddy 

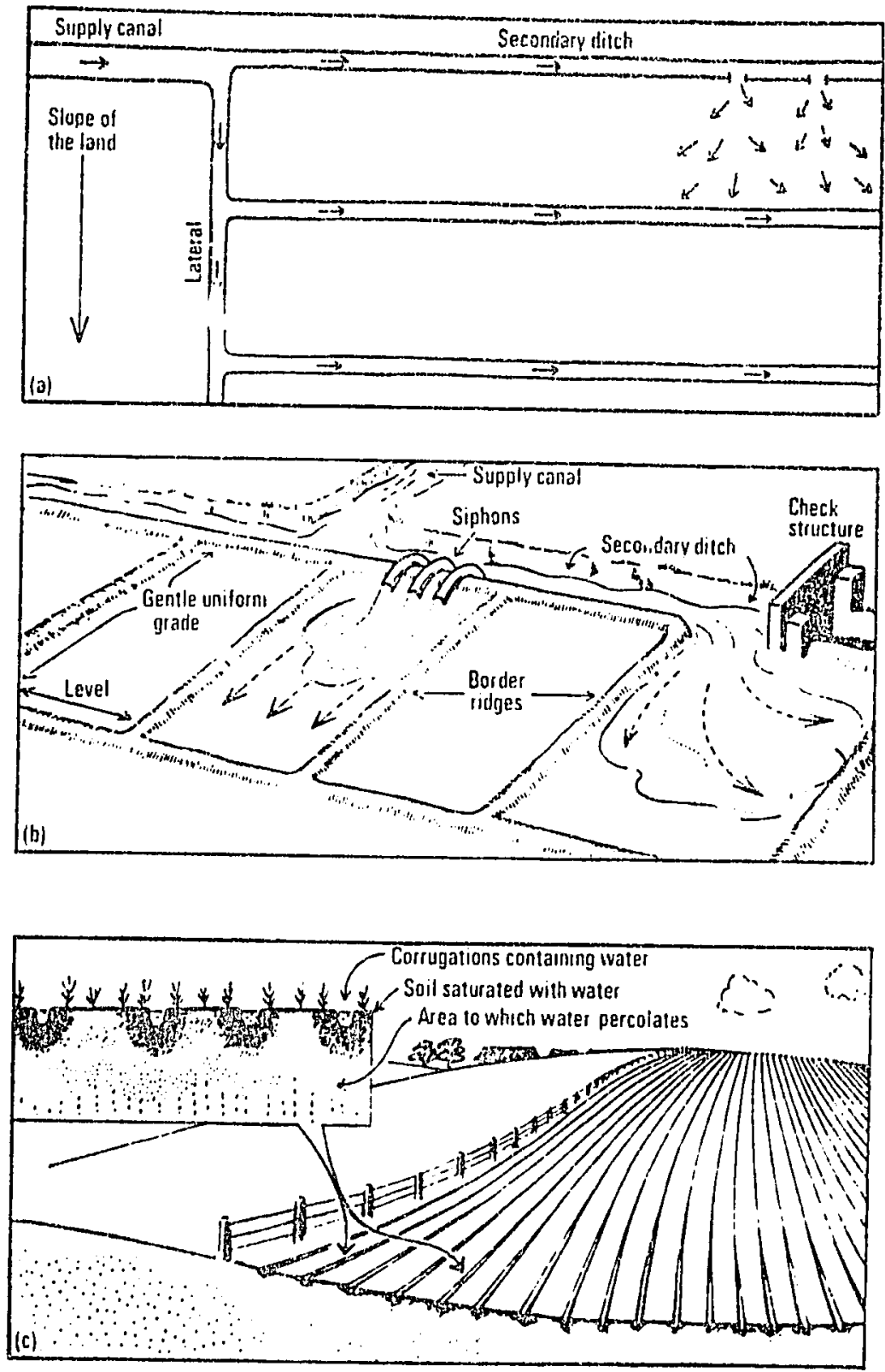

FIG. 7.1. Types of surface irrigation. (a) Flood irrigation; (b) basin irrigation; (c) furrow irrigation (from Cantor 1967, p. 31 ). 
SYSTEMS WITH ARABLE IRRIGATION FARMING 135 fields, to more sophisticated and artificial methods, especially the damming of water courses, which can involve capital works of enormous size and cost. ${ }^{1}$

Water is conveyed either on the surface in canals ne ditches, above ground through flumes, or underground in pipelines. The inain methods of applying water in the fields are by flooding, basin, furrow, and sprinkler irrigation (see Fig. 7.1). Flooding is the practice of letting water onto a larger plot, the water being distributed either into basins or by furrows. Basin irrigation is the practice mostly applied in intensively cropped smallholdings: wet rice is almost always basin irrigated. Here water stands in the basin during all or part of the vegetation cycle. Water distribution with the help of small basins is also usual for irrigated vegetable production. Furrow irrigation is usually associated witl the use of a tractor and comparatively large, well-levellct fields, as, for instance, fields for cotton-growing in Gezira, Sucian. There are, however, numerous intermediate forms between basin and furrow irrigation. Large-scale irrigation schemes, with sizeable dans and extensive caral systems, are found principally in the subtropics. In the tropics, irrigation is mainly basin irrigation. Supply of witer by traditional pump methods that employ people or animals is common, particularly in India, bux in recent times the motor pump has spread rapidly in the tropics. Sprinkler irrigation in the tropics is still in its initial stages and mostly applied to perennia! crops like sugar-cane or coffec.

Cropping patterns and the farm-management problems of an irrigated holding are decisively influenced by the degree of water availability and water reliability.

(a) Water availability and land use. Water uvailability on the holding can be considered from a number of different points of view:

(1) The availability of water in relation to area. Holdings on which it is possible for all the land to be irrigated aie found principally in the flood plains of large rivers (China) or near canals (Punjab).

Where irrigation is supplied by small streams or springs, usually only a part of the holding area cat be irrigated. In these cases the holding contains two distinct types of farming: irrigated production and supplementary rairn-fed cropping.

(2) The availability of water in relation to time. Holdings whose land is irrigated the whole year round, thanks to water supplies that flow all the year, are in the especially privileged position of being able to crop intensively and contiluously. This is true, for example, of oasis agriculture, and

2 Particularly ingenious methods for obtaining water are used ir. highly populated but ry areas. An example is the method of water procurement in the Yemen. Rainfall on rocky surfaces is conveyed into adjoining earth-bound fieids. In sonie arens-for instance

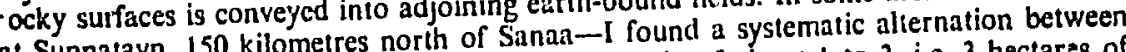
at a rocky surfaces in a ratio of about 1 to 3 , i.e. 3 hectares of fields and completely eroded ronvey about 50 per cent of the 300 millinetres of rainfall they rocks with a high run-off convely ar 


\section{SYSTEMS WITH ARABLE IRRIGATION FARMING}

of rice-growing in Taiwan, Java, southern India, etc., where there are two or more harvests annually.

Water discharges from rivers generally have peak periods, and irrigation farming has to be adapted to the avaiiability of water during the year. In holdings whose water supply is sufficient for irrigation in only one g:owing season, the question arises as to whether rain-fed farming is possible for the rest of the year. In the semi-dry or dry zones, the irrigation area lies fallow in the dry season, or serves as pasture. In south-east Asia, the production of monsoon rice in paddics is typically confined to the wet season. Where the rainfall is high enough, however-for example in Ceylon and the highlands of Madagascar-irrigation farming and rain-fed farming alternate on the same land: in the summer it supports wet rice; in the drier, winter season non-irrigated grain or legumes. The availability of irrigation water in the dry season is of particular value in areas with pronounced and heavy rainy seasons, because during the rains crop development is often stunted owing to waterlogging, cloudiness, and plant disease. Crop yields are usually much higher during the dry season.

(3) The availability of water in relation to quantity. Over and above this, we distinguish between: (i) crops that rely fully on irrigation, and could not be grown at all if additional water were not available; (ii) the supplementary irrigation of crops that could also be grown without additional water, but yield higher returns on irrigation; and (iii) semi-irrigated fields, which receive surplus water from fully irrigated fields whenever there is surplus water available.

In the first two cases a further distinction may be made according to whether irrigation holdings have plenty of water; or water is scarce in relation to plant needs, or must be bought at high prices.

Where there is no lack of water-as for example in the Burmese rice holdings-the objectives of farm management lie less in maximizing the value of output per cubic metre of water than in naximizing the value of output per hectare or per worker. In other cases-for example in the cotton holdings of Gezira, in the Sudan-a high productivity per hectare is of less importance than a high productivity per unit of water.

Limited availability of water leads necessarily to systems of water distribution, which then influence land use. In most irrigated areas, a common water supply is shared by a number of users. Division of the water in such cases may be based upon established priorities for use, or the users may share equally in the available supply, with division based upon the area irrigated by each farmer. The total flow is sometimes divided among the users so that, according to this entitlement, each obtains his share as a continuous flow throughout the season. A more common practice, however, is to rotate the use of the full stream among users. The length of time during which each 
user is entitled to make use of the water is usually based upon the area irrigated by him, and is limited so that all users will have an opportunity to share in the use of the water at reasonable intervals. Another method of distributing irrigation water, which is used on the more highly developed irrigation projects, is delivery of water to the users upon request. This requires the maintenance of a flow of water in the entire canal system througliout the irrigation season.

The cost of the wattr, which is met from water charges, taxes on irrigable land, or betterment levies, is also an important factor in determining the irrigation method used. Where water costs are high, water-saving irrigation methods will be applied. and crops will be grown that yield comparatively high returns per unit of water (Boucher 1967, p. 3).

(b) Water reliability and land use. It is the ultimate objective of irrigation works to put the isrigator in such a position that he has water under his centrol at all times. This ideal arrangement is, however, not usually attained. Most irrigators in the tropics, work under the threat of flood or drought. The reliability of water supplies is a decisive factor in the organizntion of irrigation systems, which can be classified according to this.

(1) The water supply is particularly unreliable where it depends on seasonal flooding. Thus, for example, in river-flooded areas on the west coast of Madagascar, in the Niger Delta, in Mali, on the flood plains of the Amazon Basin, or in the Rufiji Delta. Tanzania, rice is planted on land where water is sure to collect during the flood season. The flood water is normally sufficient to produre a reasonable rice crop.

(2) In swamp-rice systems use is made of naturally dammed water. For example, in Ceylon and West and East Africa, damp, swampy hollows are planted with rice in the rairy' season.

(3) Water supplies fluctua a videly where natural rainfall is impounded in paddies. The farmer has, as 1 rule, no influence on the water supply for his rice, but he tries to adapt the run-off from the basin to the requirements of the rice crop.

(4) Water supplies obtained by diverting the natural flow of streams, or by storing water in tanks and small dams, will normally fluctuate in quantity during the irrigation season, and will vary from year to year. The same often applies in the case of wells, which may become dry after years with poor rainfall. Consequently, some of the irrigators will have to reckon with reduced water supplies in some years.

(5) The most productive forms of irrigation farming are associated with a controlled and reliable water delivery. This is usually the case where the water is obtained from a large surface reservoir or by pumping from an underground reservoir (Boucher 1967, p. 2). 
With a decrease in the control and reliability of the water supply, production risks increase, and these become greater as the intensity of farming increases. Irrigation systems with uncontrolled and unreliable water supplies are therefore in general more extensively managed and offer reduced scope for introducing agricultural innovations. As the water supply becomes less reliable, crops like sorghum, with a lower productivity but a low susceptibility to partial drought, are given priority over other, better but inore vulnerable crop types.

(c) Water quality and land use. Another important factor influencing lend use is the quality of water, in particular its content of salt, which may determine irrigation methods and cropping patterns as well as investments in drainage. Where the salt content of the water is high, we find a preference for salt-tolerant crops like date-palms, coiton, rice, barley, lucerne, and cabbage. As far as possible, farmers will try to irrigate in those seasons when the salt content of the water is relatively low, and they will prefer irrigation methods like sprinkler irrigation, which reduce the irnport of water and thus of salt. Under extensive farming conditions, fallowing, shifting of the crop area, and rotational irrigation are used to prevent the loss of land due to excessive salt accumulation in the soil.

\subsubsection{Cropping systems}

The close relationship between water supply, availability and reliability on the one side and socio-economic conditions on the other has caused various cropping systems to develop. The principal difference is between wetw rice systems and other arable irrigation systems.

In wet-rice systems, the land is flooded and the crop is grown in wet soils from the t:me of transplanting or seeding until harvest approaches. The mcthods used are not common to other crops, because the physical, chemical, and biological conditions in flooded rice fields differ substantially both from those met in rain-fed farming and from those that occur in other types of irrization systems (see \$7.4.2). Wet-rice systems have for centuries been the most important form of land use in south-east Asia, in terms of both area and the economy. In Africa and Latin America, wet-rice cultivation is spriading quickly.

Other major tropical irrigation crops are cotton, sugar-cane, groundnuts, wheat, and vegetables. Large arcas of irrigated cotton are grown in India and the Sudan. In India, we find also important farming systems with sugar-cane and wheat as the dominant irrigation crops. Numerous minor irrigation systems, frequently based on various arable crops and on vegetable production, are found in practically all parts of the tropics.

\subsubsection{Exploitation systems}

While we can say that shifting and semi-permanent systems are the province of smallholders, that regulated ley systems tend to be best suited to 
SYSTEMIS WITH ARABLE IRRIGATION FARMINO

units that are sufficiently large for arimal or tractor ploughing, and that tropical permanent rain-fed farming is again the province of smallholdars, we cannot genaralize about fans size in tropical irrigation farming. T"raditionally, irrigation furming and ligh population densities are two charrcker. istics of the sane seting. Sut while high population densities tend tc favour small farm sizes, thers is the tendency to manage all the area irrigated from one source as a single, large unit, and the more expensive the irrigation system was to develop. the more pronounced is this trend.

Where smallholders ate independent in their water supply, either because they have springs and wells of their owis, or because impounded rain-water is sufficient for wet-rice production, they are equally inciependent in organizing their land use. In minor irrigation schemes of up to about 300 hectares, numerous smallholders usually operate either as teriants, getting their water from the landlord, or as owner.fatmers, sharing the water according to traditional, purchased, or cooperatively agreed entitlements. Under such conditions, land use depends alinost entirely on water rights, in other words on the timing and quantity of water distribution. Water use in medium-sized (300-5000 hectares) and large (more than 5000 hretares) irrigation schemes is usually organized by some kind of scheme management or irrigation adininistration, and sometines the scherne management is in a position to enforce definite patterns of land use.

\subsection{General characteristics of irrigation farming}

\subsubsection{A comparison with rain-fed farming}

Irrigation farming has distinct advantages compared with rain-fed farming. Because of irrigation, the natural, ample, and regular supply of solar energy that is characteristic of the tropics is allied firstly with the ample and regular supply of water created by investments, and secondly with the nutrients brought by the water. ${ }^{2}$ Moreover, irrigation, particularly in the form of impounding, avoids the stress to plant growth that is connected with very high temperatures on the soil surface. At the same time, the conditions for agricultural production are improved, particularly when the water supply is ample, regular, and reliable.

(I) Irrigation farming compared with rain-fed faiming under similar conditions produces higher gross yields per hectare. The basic possibilities (the realization depends naturally on the local conditions) are that:

(i) higher yields per heciare of a particular crop inay be achieved:

(ii) several harvests a year may be produced;

'Mainiy by silting. In some sases, ground water shows a ligh content of nitrate. At the Jumeisha form near Hodeida. North Yemen, the amount of nitrogett brought into the soil by irrigation from weils was found to be more than 100 tilograminis per hectare. 
(iii) crops may be grown that produce comparatively high yields per hectare, some of which may demand a water supply all the year round; (iv) it becomes morc profitable to use additional labour and other inputs; and

(v) continuous rice cultivation becomes possible, thereby extending the area of this relatively high-yielding crop.

(2) Irrigation farming allows permanent land use, provided that salt damage can be avoided. In the case of rice cropping, it means that permanent agriculture can be carried on fo: centurics with high yields per unit area and withoust impairing soil fertility. The control of water reduces erosion.

(3) Yield fluctuations from year to year ars reduced. With reliable water supplies, production is almost independent of the weather. Annual fluctuations of yield are less than those in rain-fed farming.

(4) Irrigation farming leads to relatively more continuous production. The chance of a regular household supply of food and cash income improves. The same applies also both to the provision of cattle with fodder and to the employment of the labour force, draught animals, implements, and buildings.

(5) Arable irrigation farming is relatively adaptable with regard to both type and intensity of production. Holdings with perennial crops are obliged to adhere to one type of production for a long time. In holdings with rainfed farming, the rainfall determines the range of possible crops, and the less it rains the narrower is this range. In irrigation farming, such limiting factors are much less compelling. By eliminating the problem of urrought, irrigation makes it possible to diversify production.

(6) Irrigation farming allows the productive employment of a relatively large number of workers per hectare. It therefore enables a relatively high income to be earned without the use of expensive equipment, or it reduces the cost of such equipment when measured against the return. In hoe systems, one family can scarcely cultivate more than 2-3 hectares, which in rain-fed farming permits only a minimal standard of living to be obtained, but in irrigation farming the same area will allow a high standard of living. The increase in production on a small, irrigated plot means that the part of the proceeds spent on traction power is relatively small.

(7) Irrigation development gives value to reighbouring land that could not otherwise be utilized, or would be under-utilized. Irrigation may pirmit speculative use of rain-fed land that would not otherwise be used. Rain-fed farming on soils with marginal rainfall, or stock-keeping on dry pastures, is in many cases only possible because irrigation production guarantees some yield reliability. 
SYSTEMS WITH ARABLE IRRIGATION FARMING 141
arguments may be summarized by saying that, in comparison with These arguments may be summanized by saying that, in contuges of manurain-fed farming, irrigatiot left so much to chance; there is a more continuous facturing. Matters are not lefs better contĩol of the production factors; and production process; there is a better control

However, against the mariy advantages of irrigation farming must be set definite costs and requirements:

(1) It necessitates a high level of investment in water supply, delivery, and distribution works, and in land preparation. In the case of large schemes, development costs of $\$ 500-2000$ per hectars (or aunual costs of \$0.003-0.02 per cubic metre of water) are typical. High levels of investment entail a heavy burder. of fixed costs, so that water has to be bought for a high price. It is still often more profitable to practise rain-fed farming and ascept its disadvantages than to invest in irrigation. Often, in arid areas, water is considered to be a unique resource, and therefore engineering or agronomic feasibility are considered sufficient conditions to justify investment. This may lead to a misallocation of resources (Carruthers 1968, p. 6). (2) in addition to the high level of the initial investment, irrigation farming in its common form demands a continuous high level of lahour or machine input to supply the water (drawing, purnping, maintenance of the sjstem), and to prepare and maintain the fields and water-distribution or drainage channels.

(3) Irrigation farming, as a rule, requires the cooperation of several farmers, or their willingness to accept instructions from a private or public water lord. Moreover, an irrigation holding requires communal work to maintain and improve the water-delivery system. In the larger irrigation systems, a disciplined schedule and scale of water distribution among the beneficiaries is one of the most important pre-conditions for economic success (Wittfogel 1931).

(4) Irrigation farming may offer great production possibilities, but a good deal of knowledge is necessary if they are to be fully exploited, for production is technically complicated. One problem of particular gravity is the spread among the irrigation farmers of diseases like malaria and bilharzia. which are encouraged by the water, so that medical costs have to be considered in addition to the costs of irrigation development.

It must also be borne in mind that production techniques and land tenure are interrelated. W'nereas in shifting and semi-permanent systems communal land ownership with established rights of usage prevails, we generally find in permanent farming individual land ownership with owner-farmers or tenants. In irrigation farming, landlord-tenant relationships, provided that they have not yet been abolished by land reforms, are even more typical than in rain-fed farming. The prevalence of landlord-tenant relationships is perhaps due to 
the fact that, for water distribution to several irrigators, institutional arrangements on a larger scale are needed.

\subsubsection{Spatial organization of cropping}

Having outlined some of the generally important farm-management characteristics of irrigation farming, we can now consider the more specific organizational features. Again, we find that the various plots of a holding are, as a rule, not uniformly cropped, but that definite spatial cropping patterns prevail. There is, however, a basic difference in this respect between rain-fed and irrigation farming. In rain-fed farming, the spatial organization of production is based primarily on the varying intensity of manure application, in other words on the distance from the farmstead and the consequent transport problems. In irrigation farming, it is based primarily on the availability of water. Three different forms may be noted in this respect, based on whether only a section of the farm area is irrigable land; or all of the land is irrigable, but water supplies are insufficient to provide all of it with the optimum amount of water; or water reliability varies from plor to plot.

(a) Spatial organization of partly irrigable holdings. Where only a part of the holding area can be irrigated, land use is diversified, more often than not in the form of a catena. The cultivator usually concentrates his work on the lowest topographical level, which is gererally more fertile and easier to irrigate. The seasonally or continuously irrigated fields which are the centre of the holding, and which are usually close to the water supply-a spring, river, or canal-may be supplemented in different ways:

(1) There may be gardens close to the farmstead. The combination of irrigated rice fields and comparatively large gardens, containing various vegetables, tiee crops, and ponds, is the basic pattern of rice holdings in large areas of south-east Asia.

(2) Permanent or semi-permanent arable culti,ation may be practised on rain-fed land. This is the basic pattern of most of the holdings with minor irrigation. Irrigation farming close to a spring or small river in the valley bottoms, with rain-fed farming on the surrounding slopes, is typical of many Indian farms and of rice holdings in south-east Asia, Madagascar, and other places.

(3) Perennial crops may be grown on rain-fed land. Commonly, we find only small plots for crops for home use, but scmetimes there are substantial plantations of cash crops like rubber and coconut-palms.

These activities are found in different combinations and proportions, and provide a variety of farming systems, differing widely in complexity and intensity. Two examples are given in Figs. 7.2 and 7.3.

The situation depicted in Fig. 7.2 is typical of most holdings with wet-rice production in Africa south of the Sahara. The rice paddies are situated close to the 
SYTEMS WITH ARABLE IRRIGATION FARMING 143

iver, and the neiphbouring slopes are used for rain-fed farming. One of the major advantages of the combination of wet rice with upland farming is the better distribution of labeur requirements.

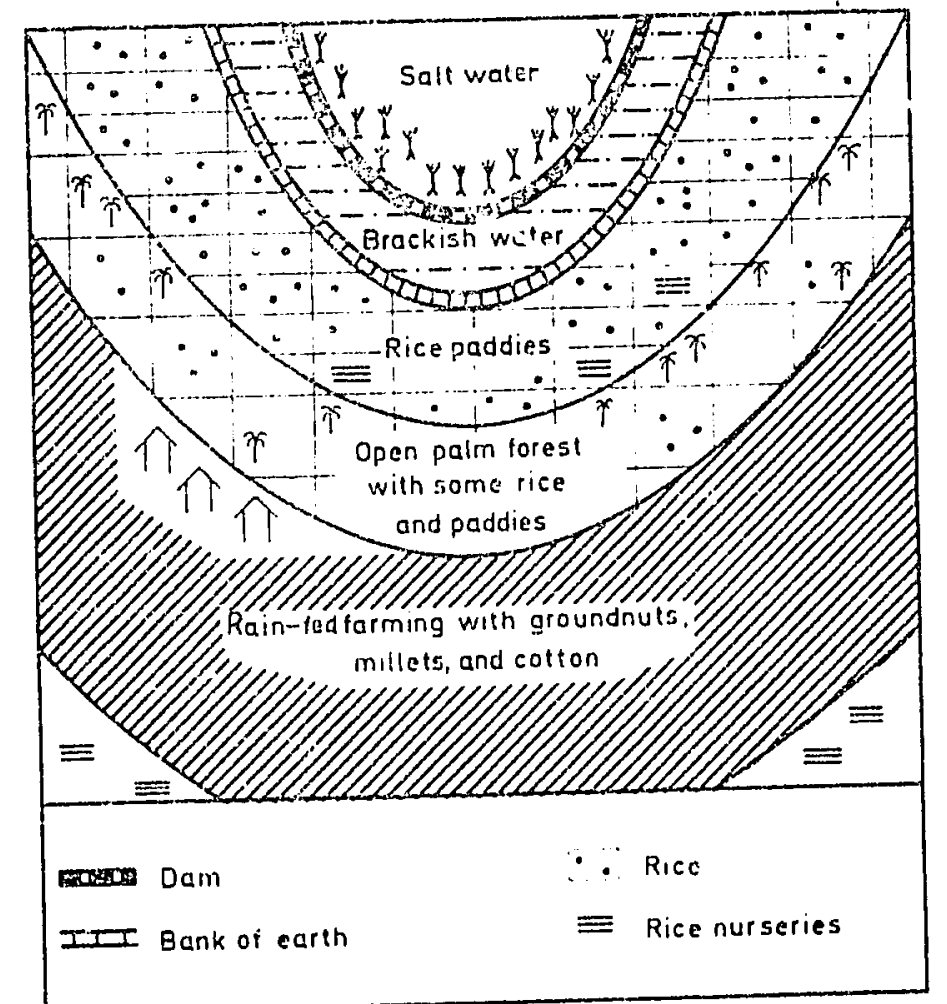

Fig. 7.2. Cropping pattern in the region of the Lower Gambia River (from Mohr 1968, p. 67).

The spatial diversification of cropping is even more developed in south-east Asia, as shown in Fig. 7.3, which is taken from Singapore.

(1) The valley bottoms are used for rice fields.

(2) In addition, on the low land there are ponds, which produce fish and pig feed (green fodder).

(3) In the imnediate vicinity of the ponds are the pigsties, the waste food from which is put into the ponds to feed the fish.

which is put into the ponds tols plots with water-demanding varieties like

(4) Then come the main vegetable plo irrigation is taken from the ponds.

cabbage, lettucc, etc. The water for itrigation is taken frombers, which require little 5egetable varieties like beans, tomato

water, are grown on the higher land. (6) After this come non-irrigated plots with root crops like manioc

potatoes, which are somet stres are principally grown, but there is also some tobacco.

(8) Finally, the high plateau is utilized for tree crops like rubber and coconuts. 


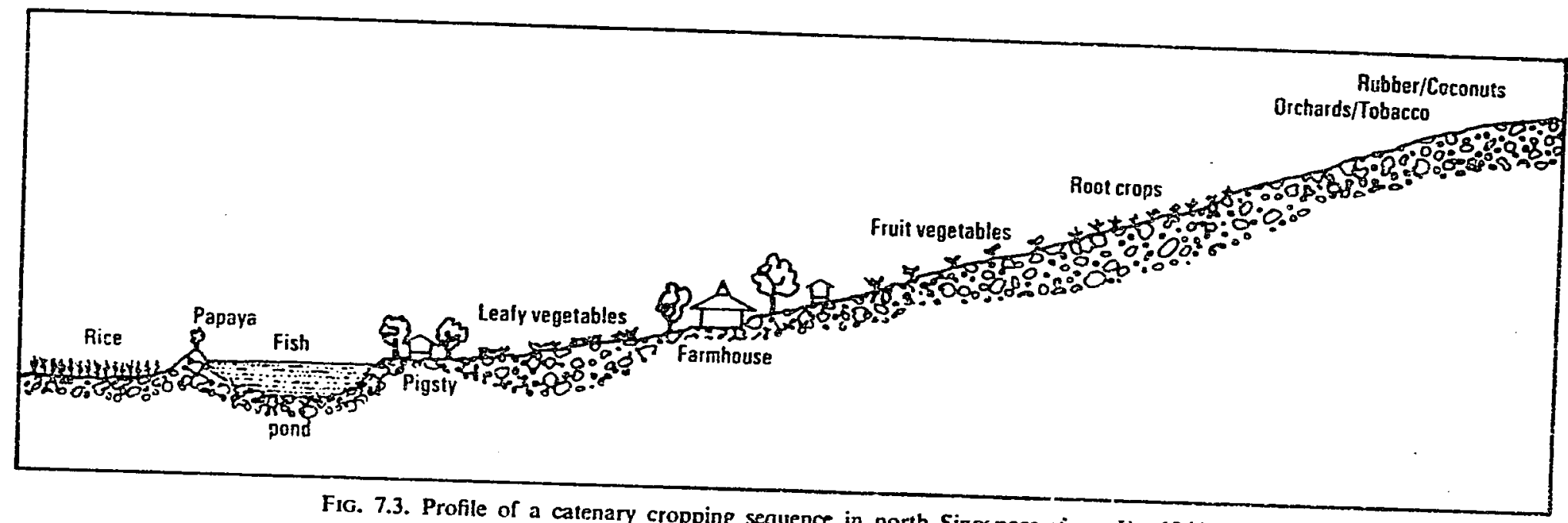

FIG. 7.3. Profile of a catenary cropping sequence in north Singapore (irom !jo 1964, Fig. 1). 


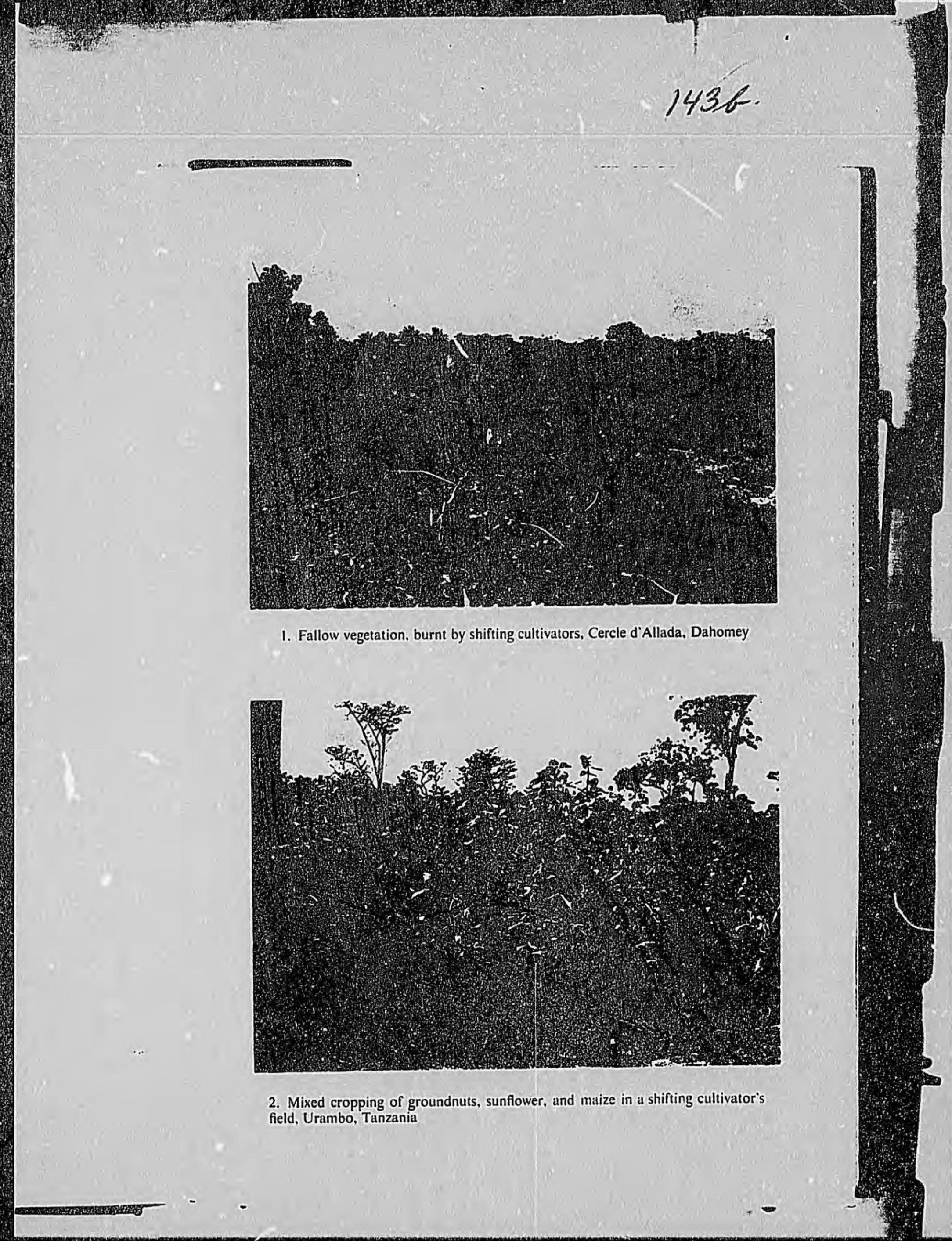




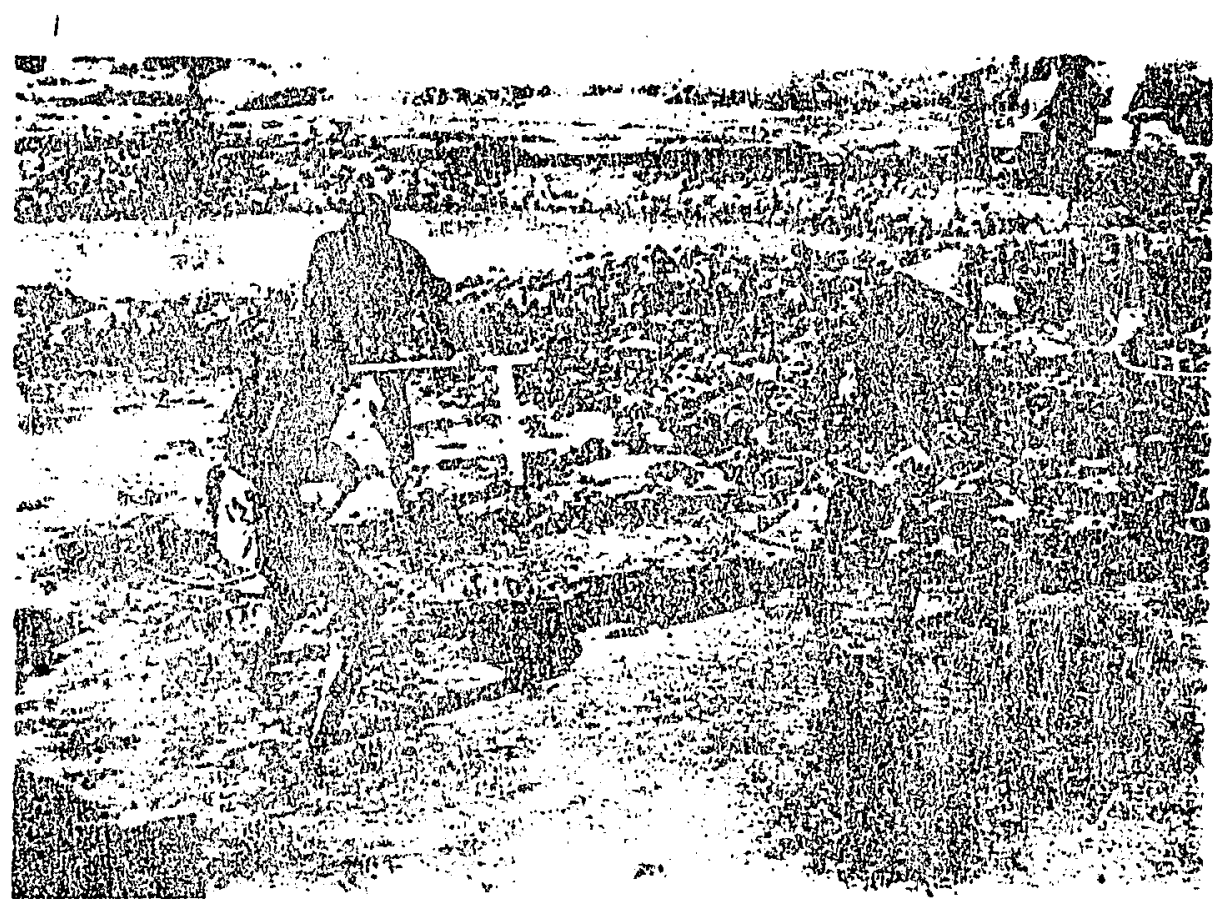

3. Valley bottoms in the savanna zone of the Ivory Coast being transformed into fields with irrigated rice

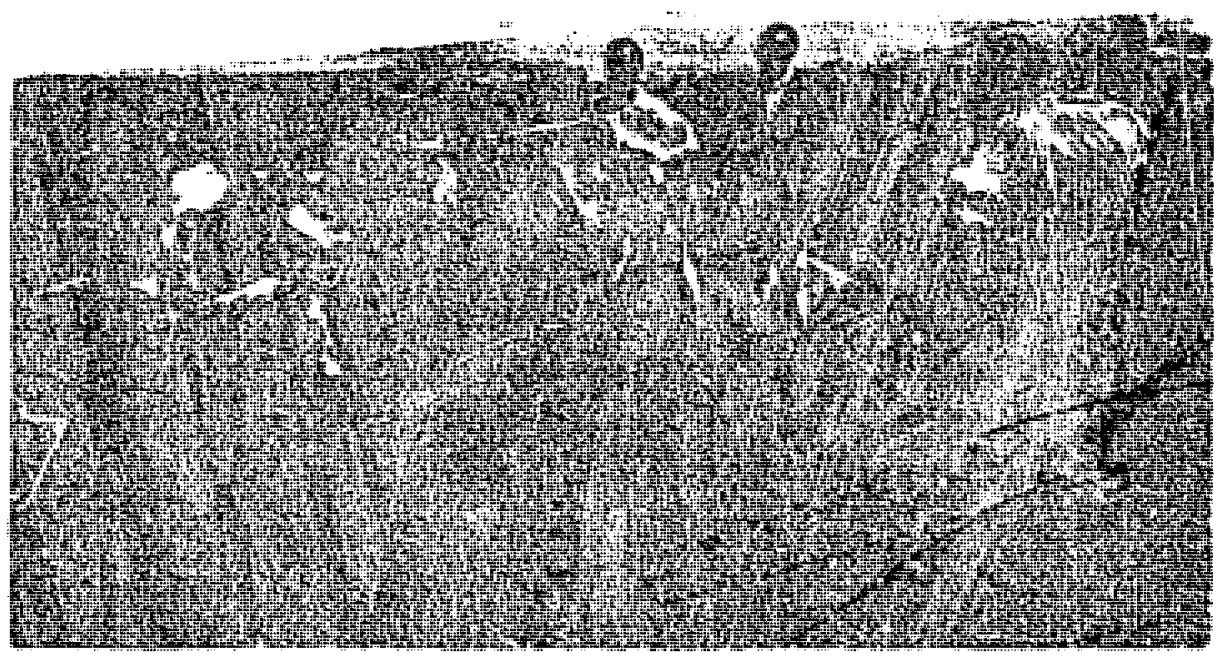

4. Dairy cattle on smallholdings with regulated ley farming in Nyeri D:strict, Kenya 


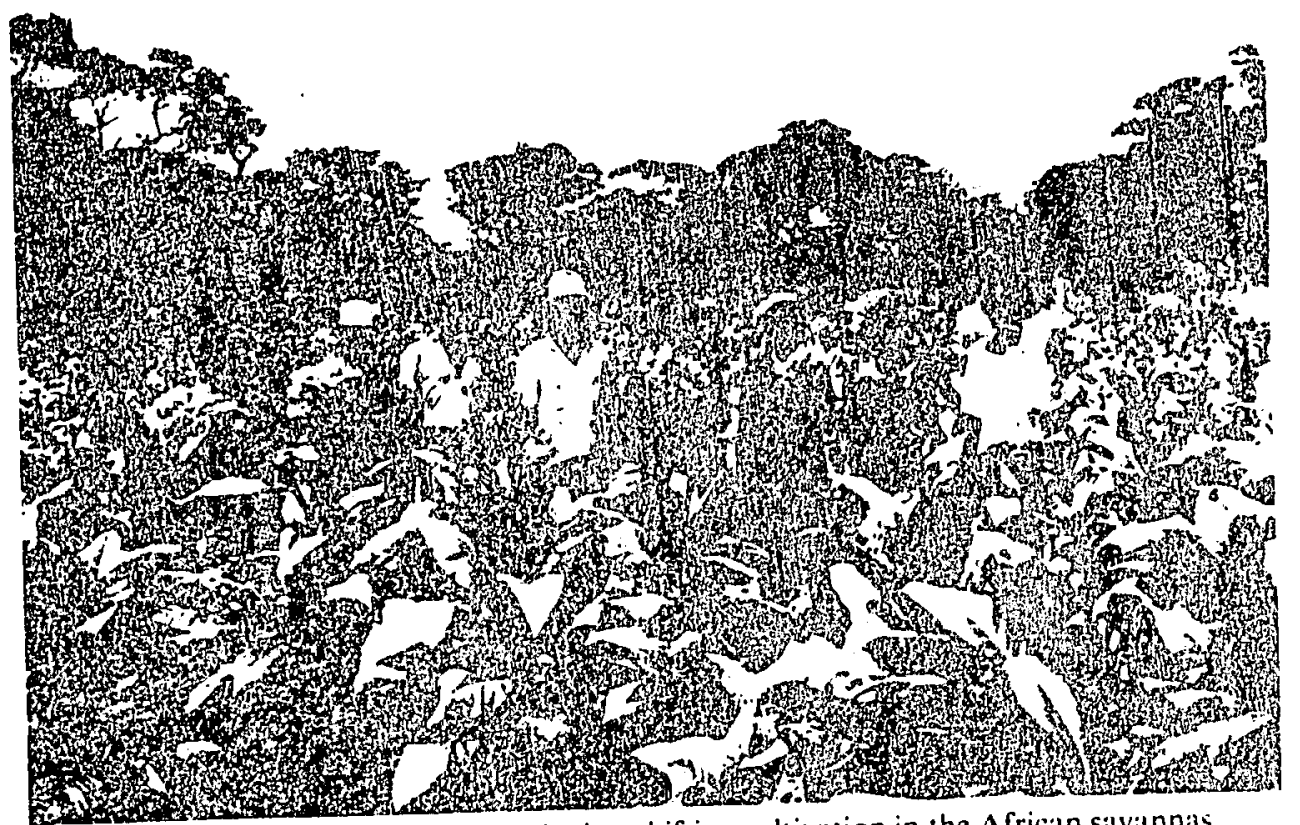

5. Tobacco is a cash crop well-suited to shifting cultivation in the African savannas. A small entrepreneur at Urambo. Tanzania

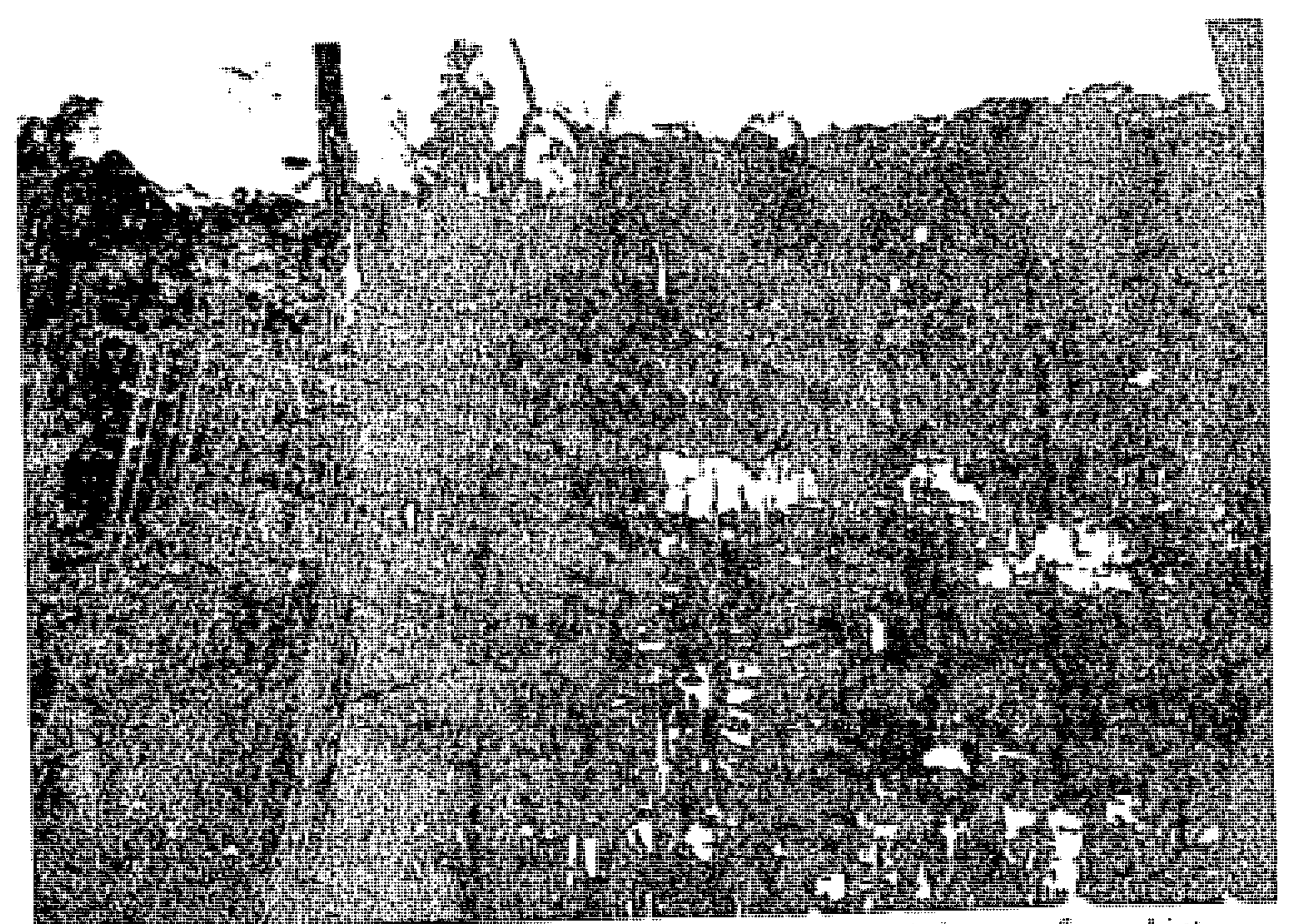

6. Valley bottoms in the rainforest zone of the lvory Coast being tratisfortied into lields with irrigilted rice 


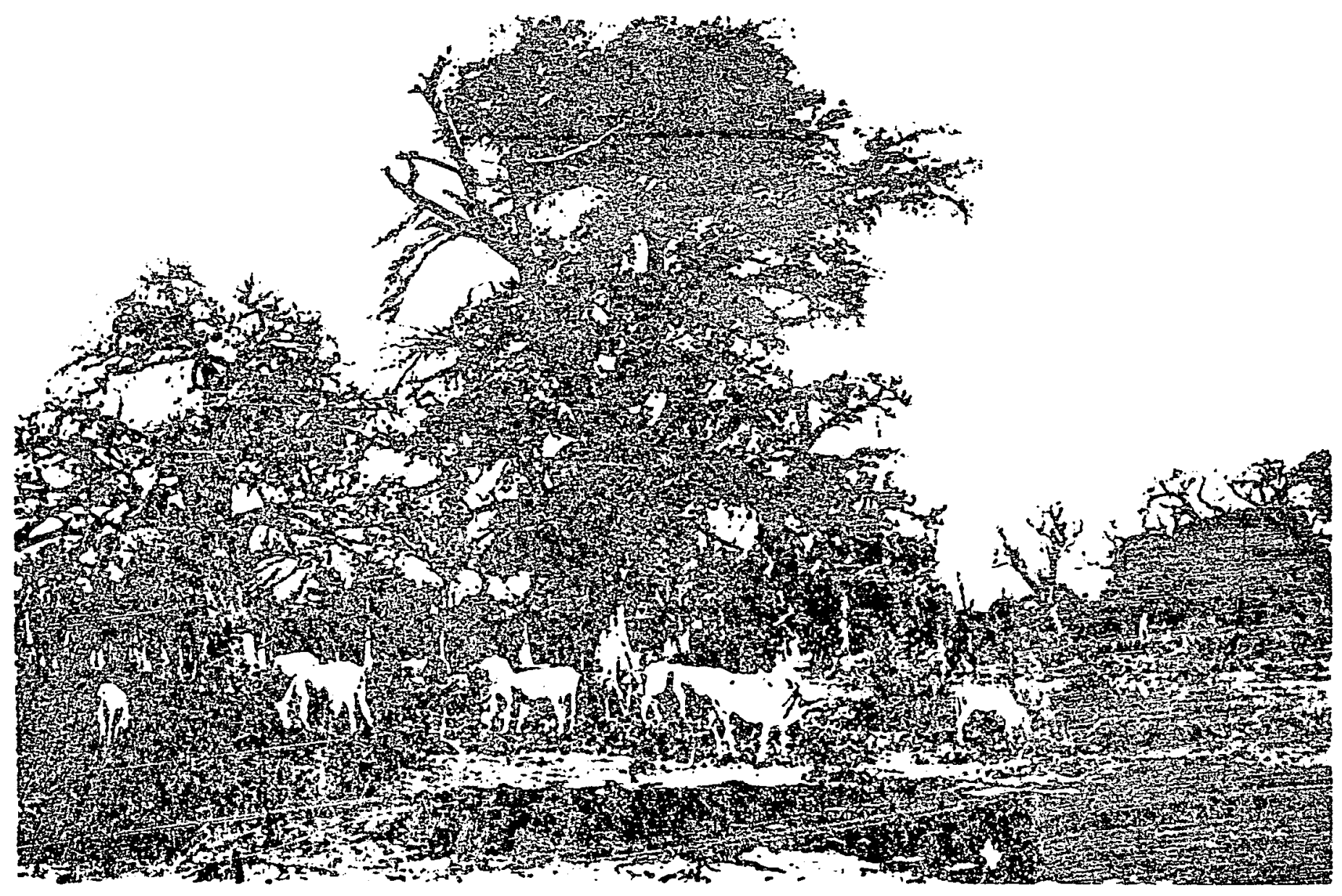

7. Cattle feon leaves of eding Faitherhia culbida, in Serere country. Senegal 
8. Transporting manure iroun the stable to the field. Ukaris Island. Tanzania
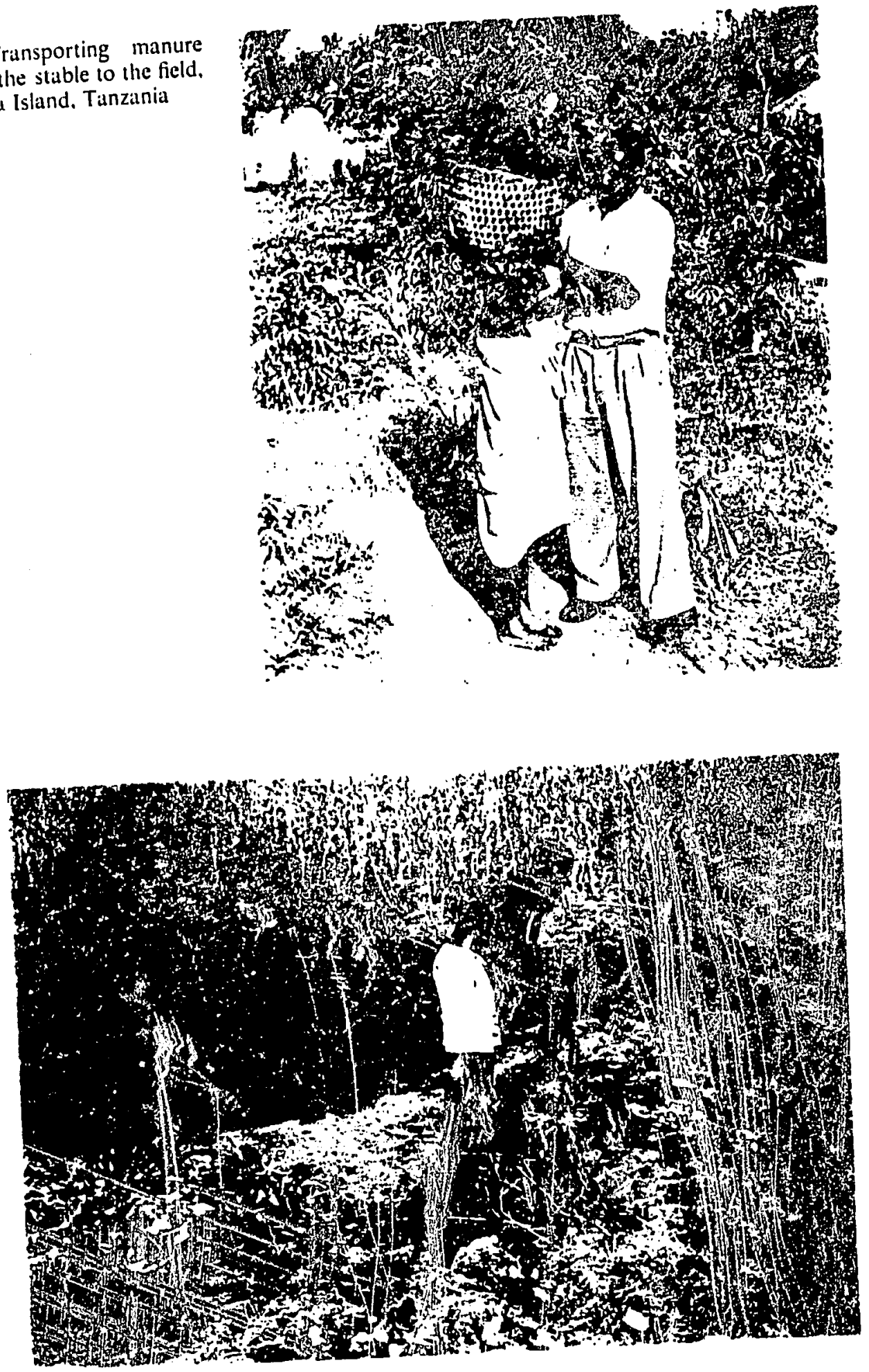

and green manure on Lkara listand. Tanzania. The 9. Applying stable manure and green man 


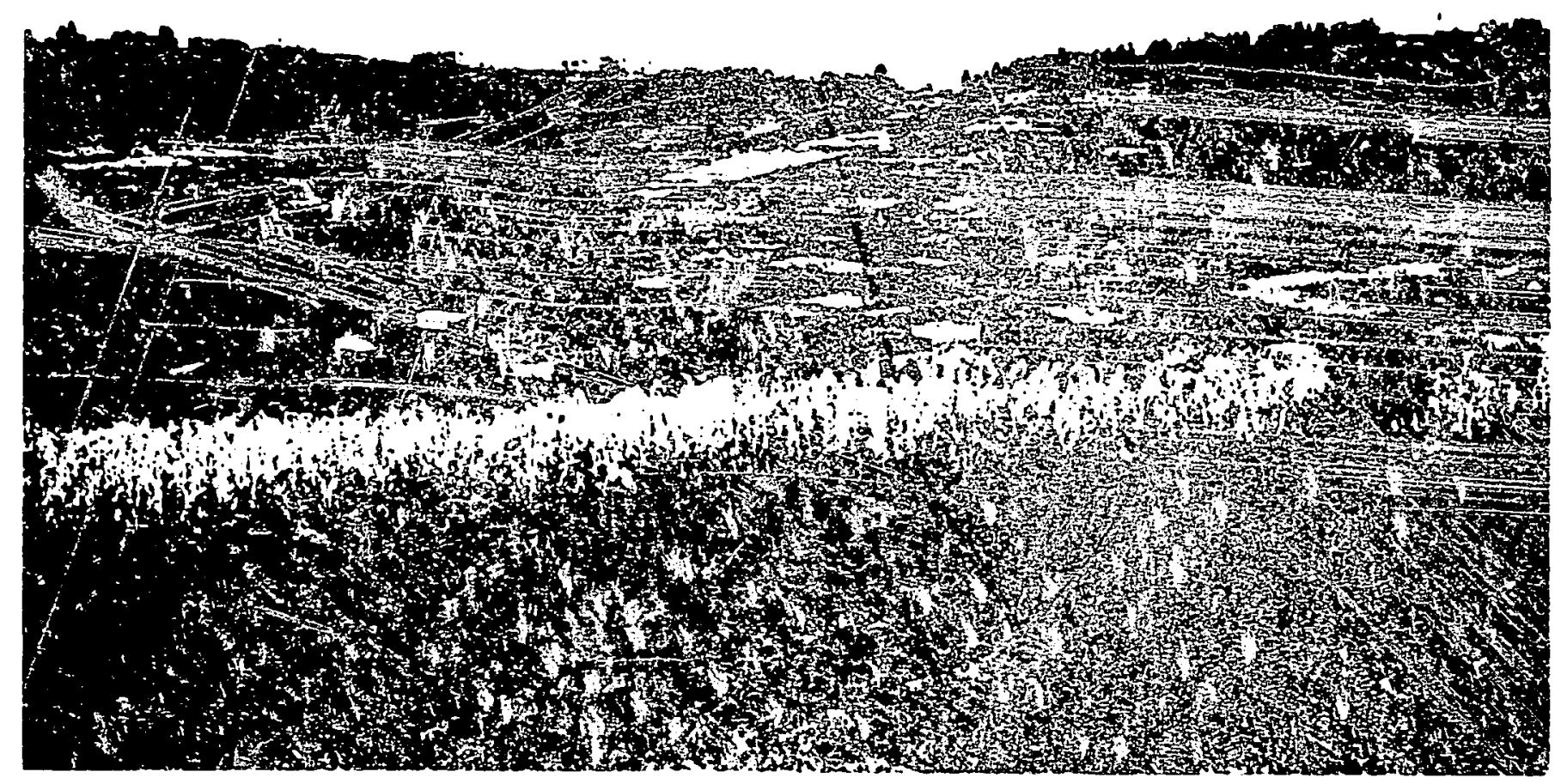

10. Smallholder ley farming in Kisii District. Kenya 


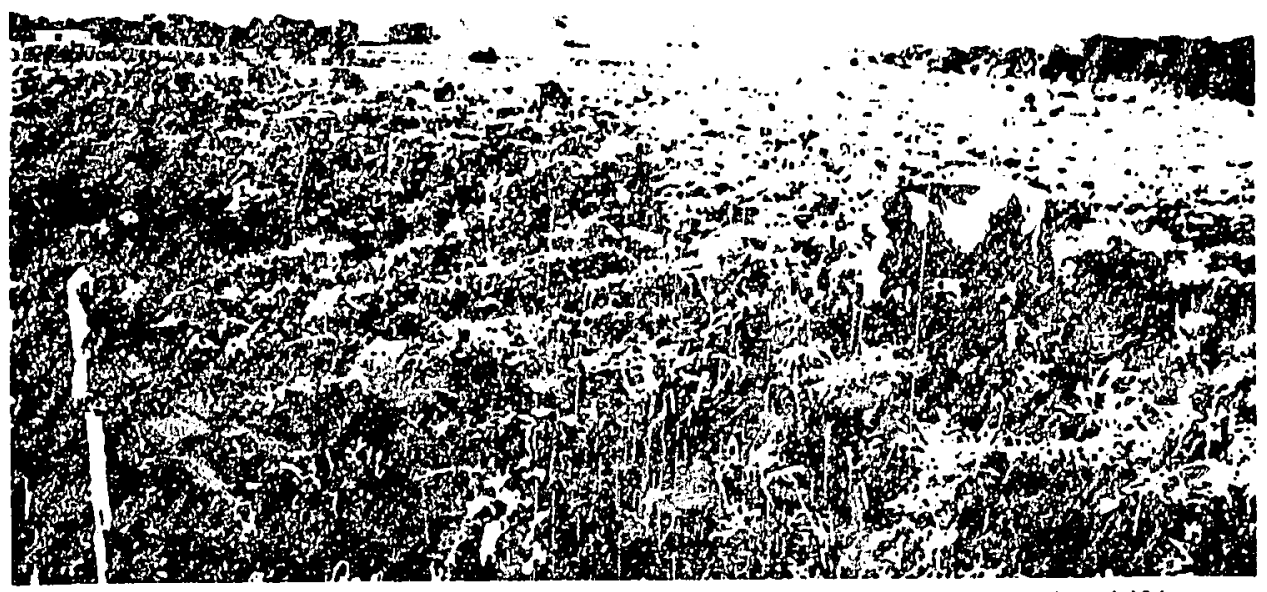

11. Swiss cows grazing on leys established on land traditionally used by shifting cultivators. Bush with tsetse-flies in the background. The picture was taken on a Siviss demonstration farm, close to Cotonou. Dahomey

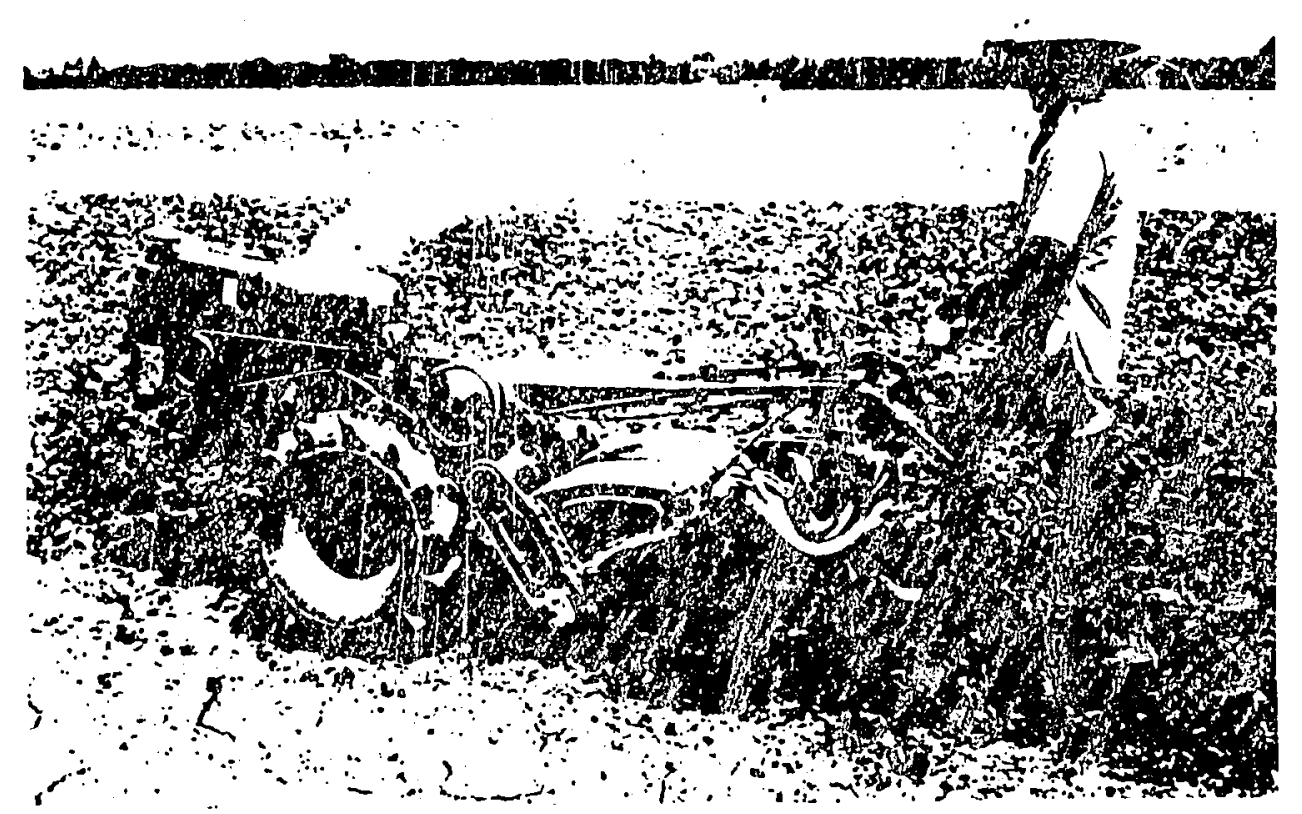

12. Two-wheel tractor, ploughing a rice field in Taiwan 


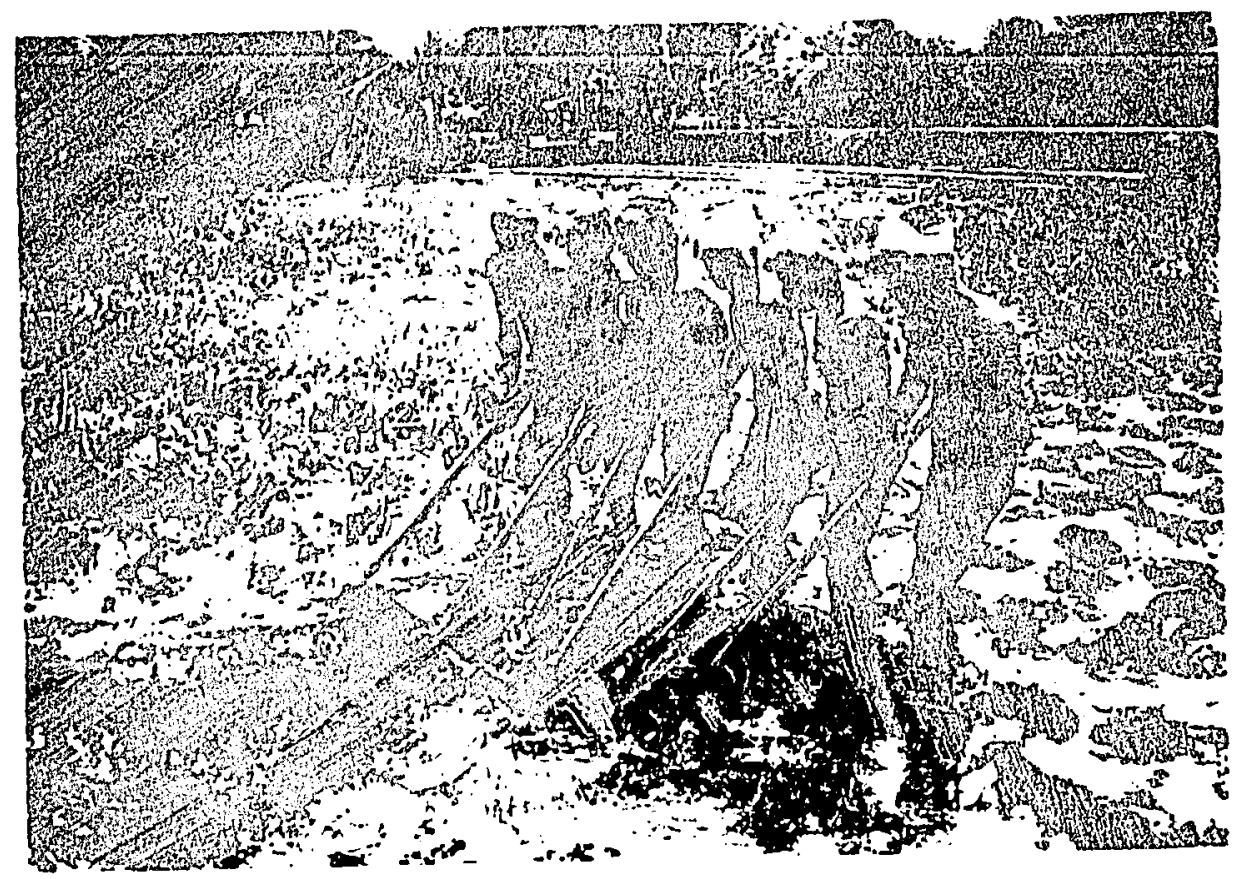

13. Land preparation for rice in Ceylon. The work is being performed by seasonal paid labour

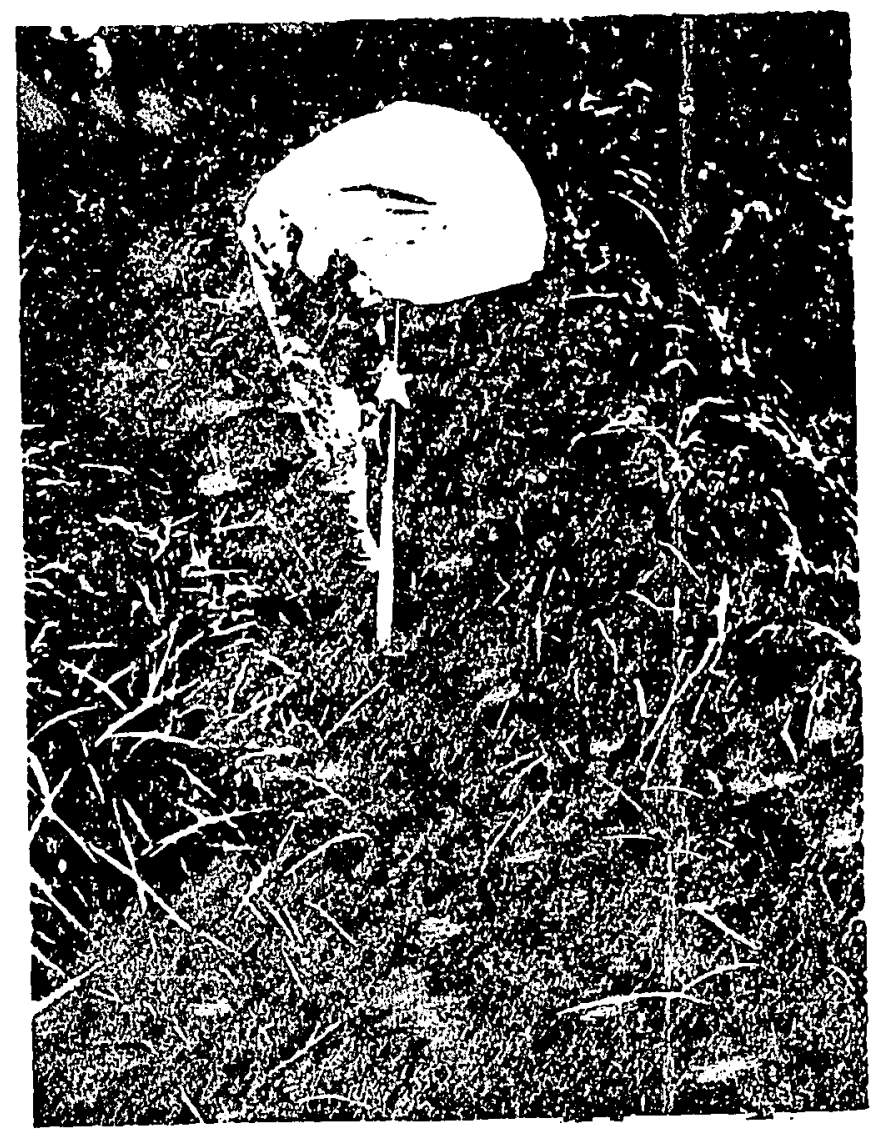

14. Soil preparation for intercropping of sweet potatoes in maturing rice. Taichung District, Tuiwan 


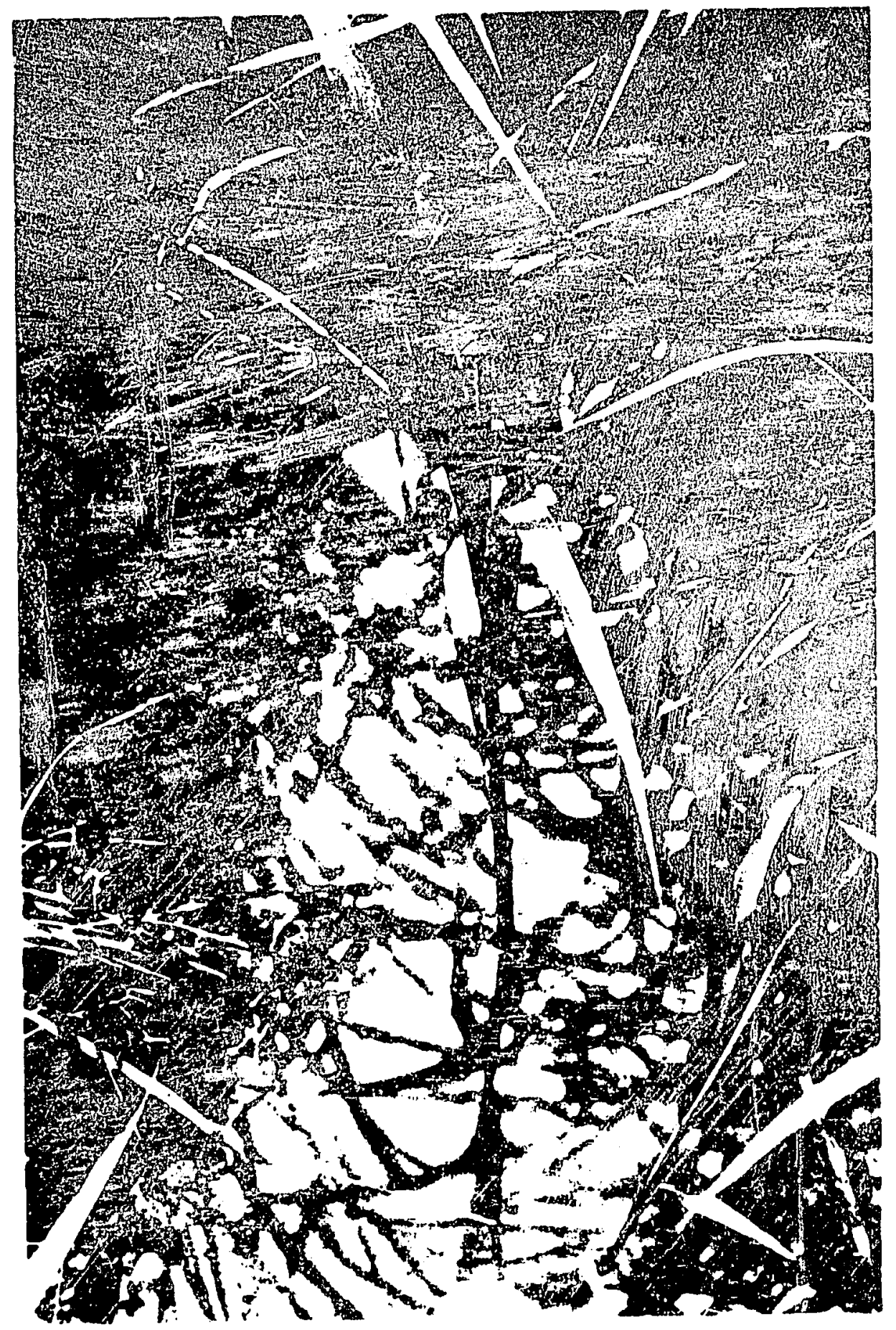

15 Relay-planting of sugar-cane in growing rice in Taiwan. Note the seed care in the mud between the rows of rice 


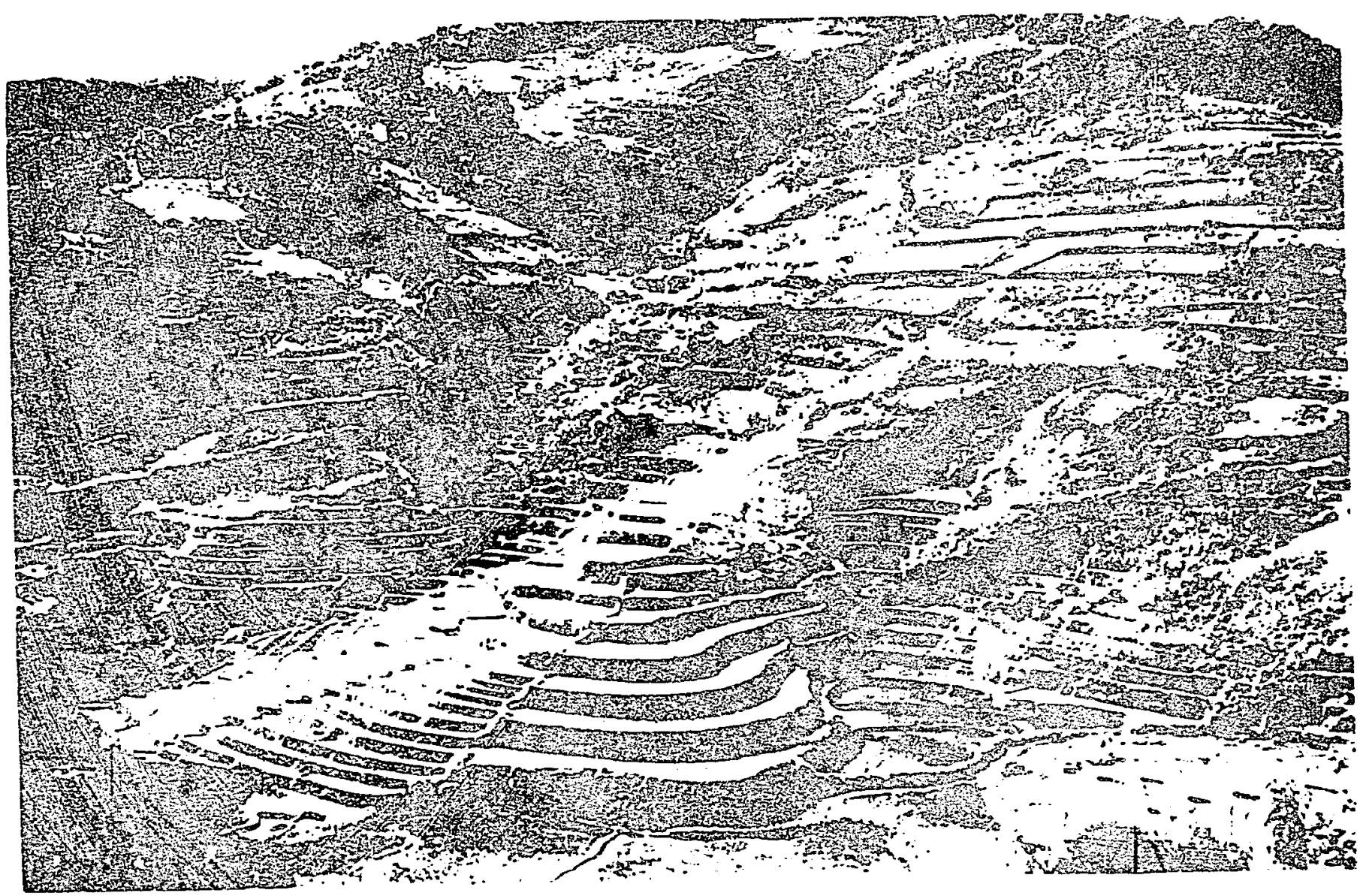

16. Rice terraces and rain-fed farming in the Highland of Madlagaisear 


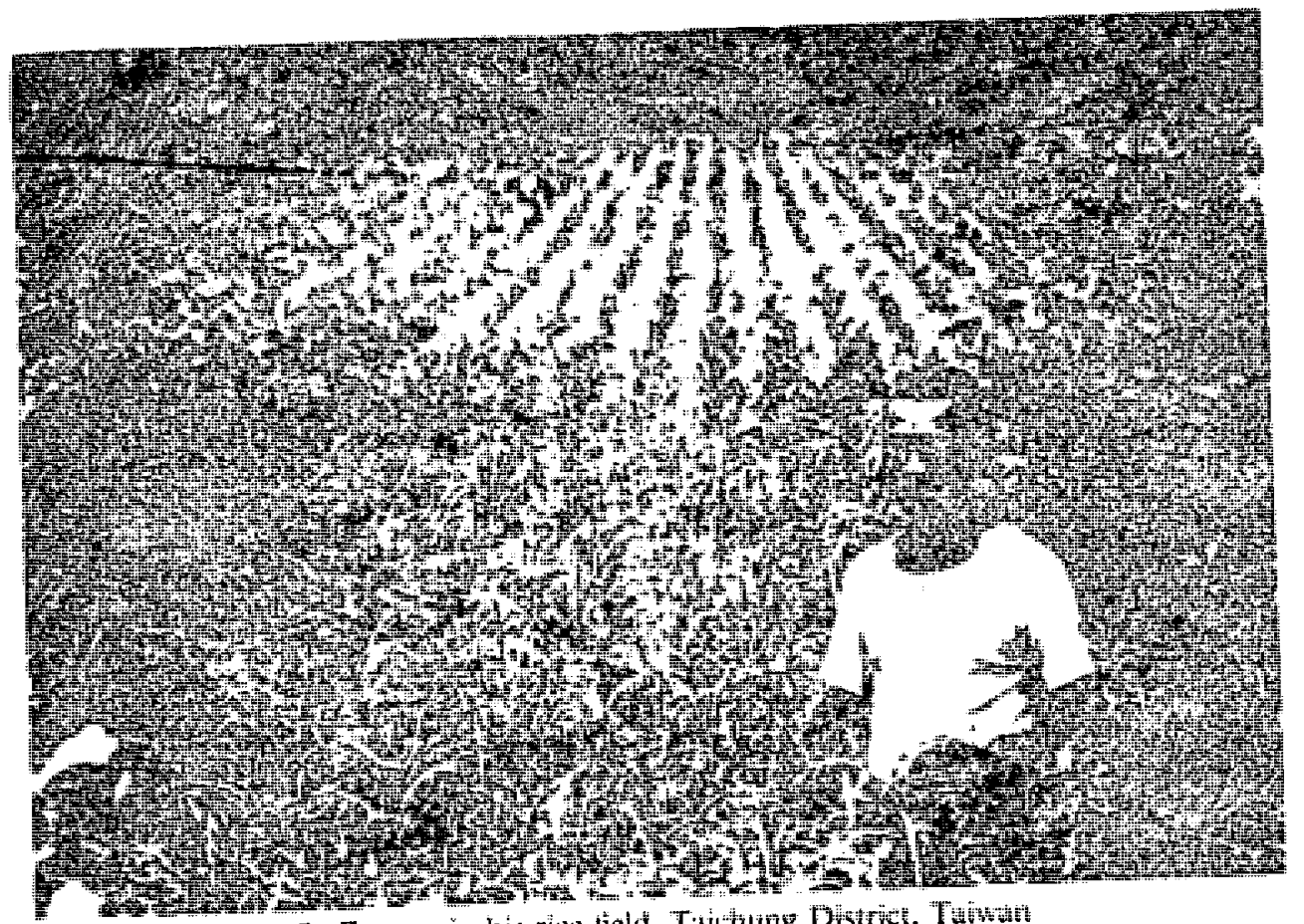

17. Farmer in his rice held. Tathiting Dostries, Tumath

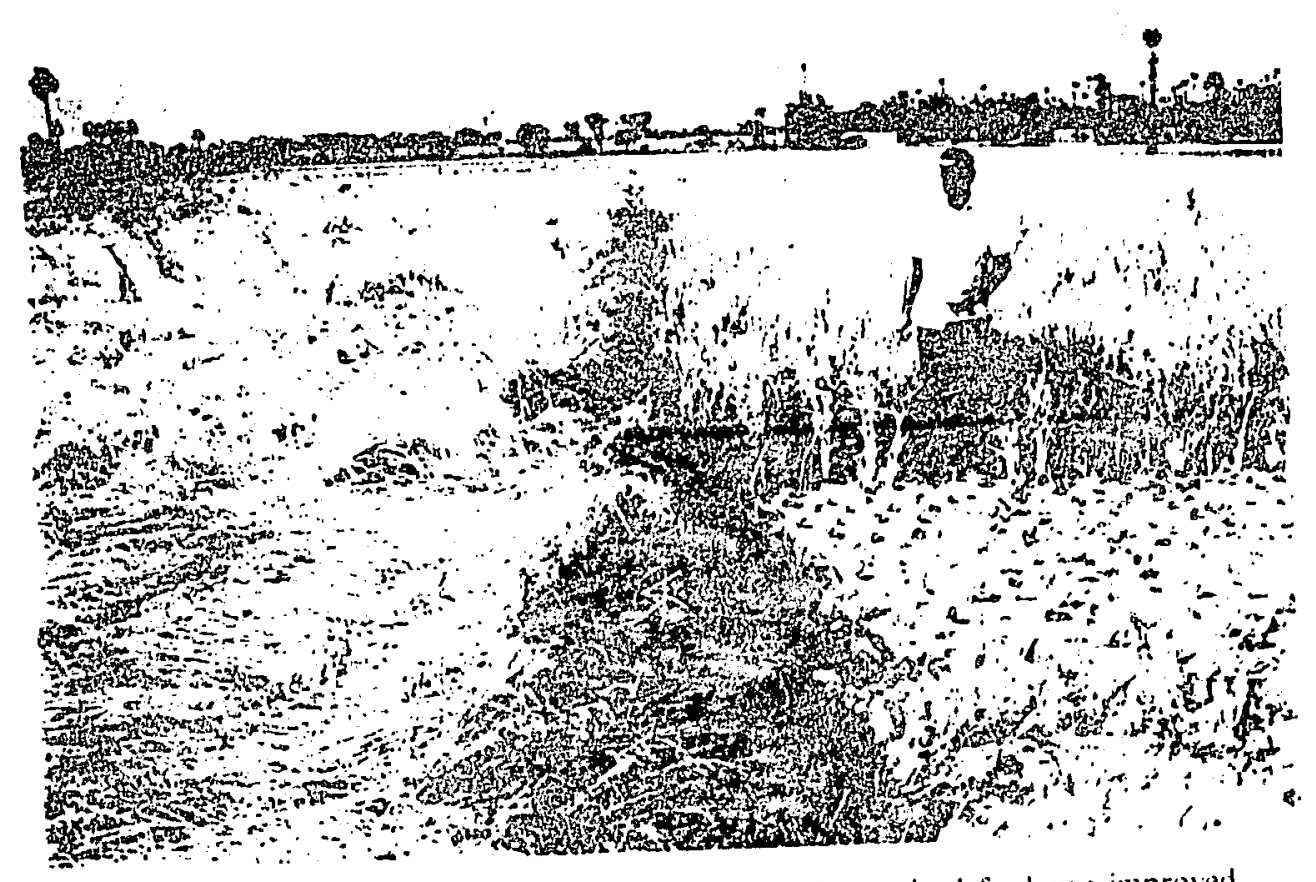

Tho rice tields close to Madras, India. The field to the left shows improved 18. Two rice helds close to Madd to lodge. The tield to the right shows IR s. a nonlodging variety which can productively absorb high doses of nitrogen (sec Fig. 7.10) 


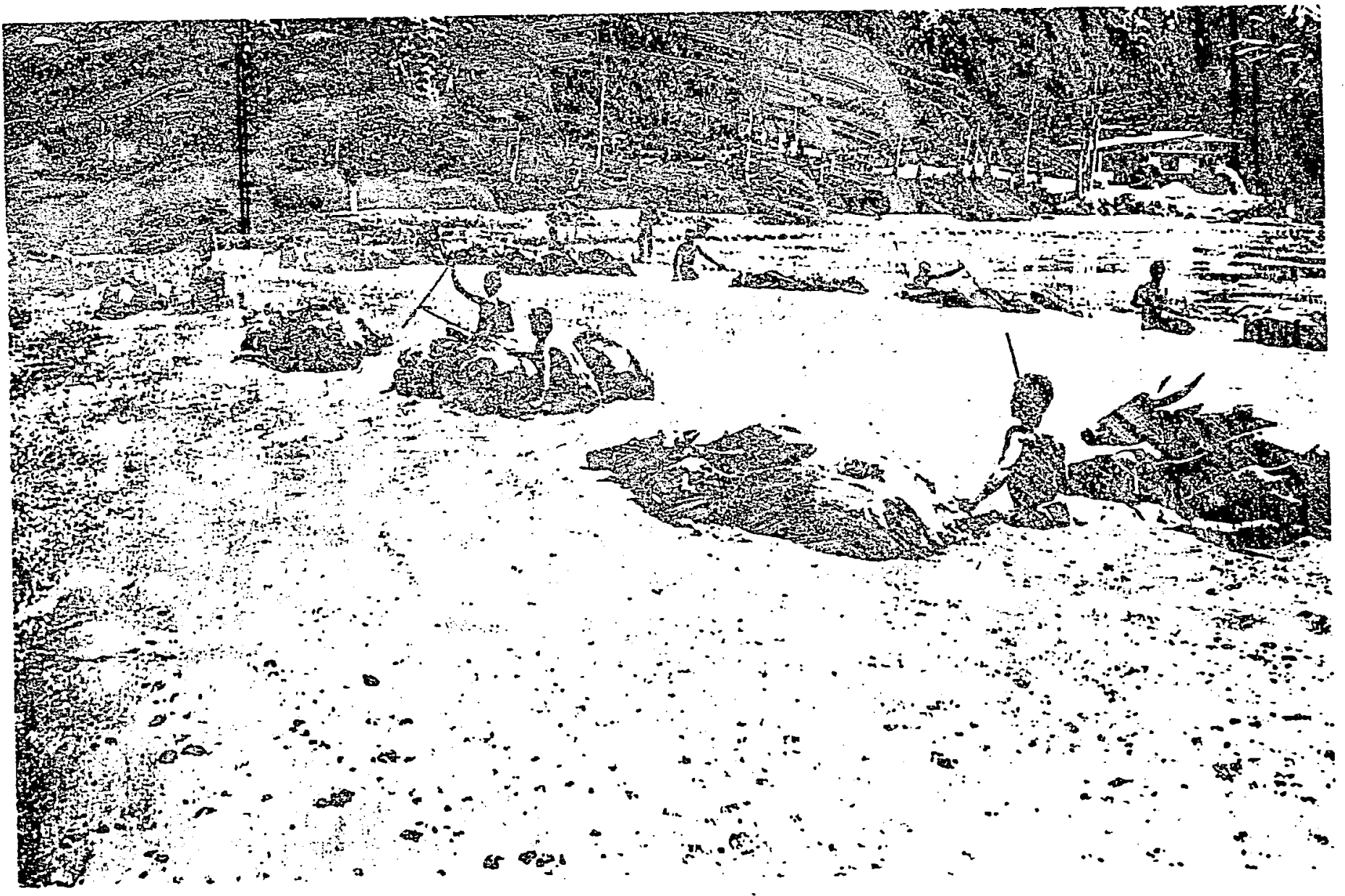

19. Preparation of a rice field for planting by trampling with iuffaloes, in Ceylon. The work is performed after hoe or plough cultivation. In Madagascar the same method is applied and called "piétinage" 


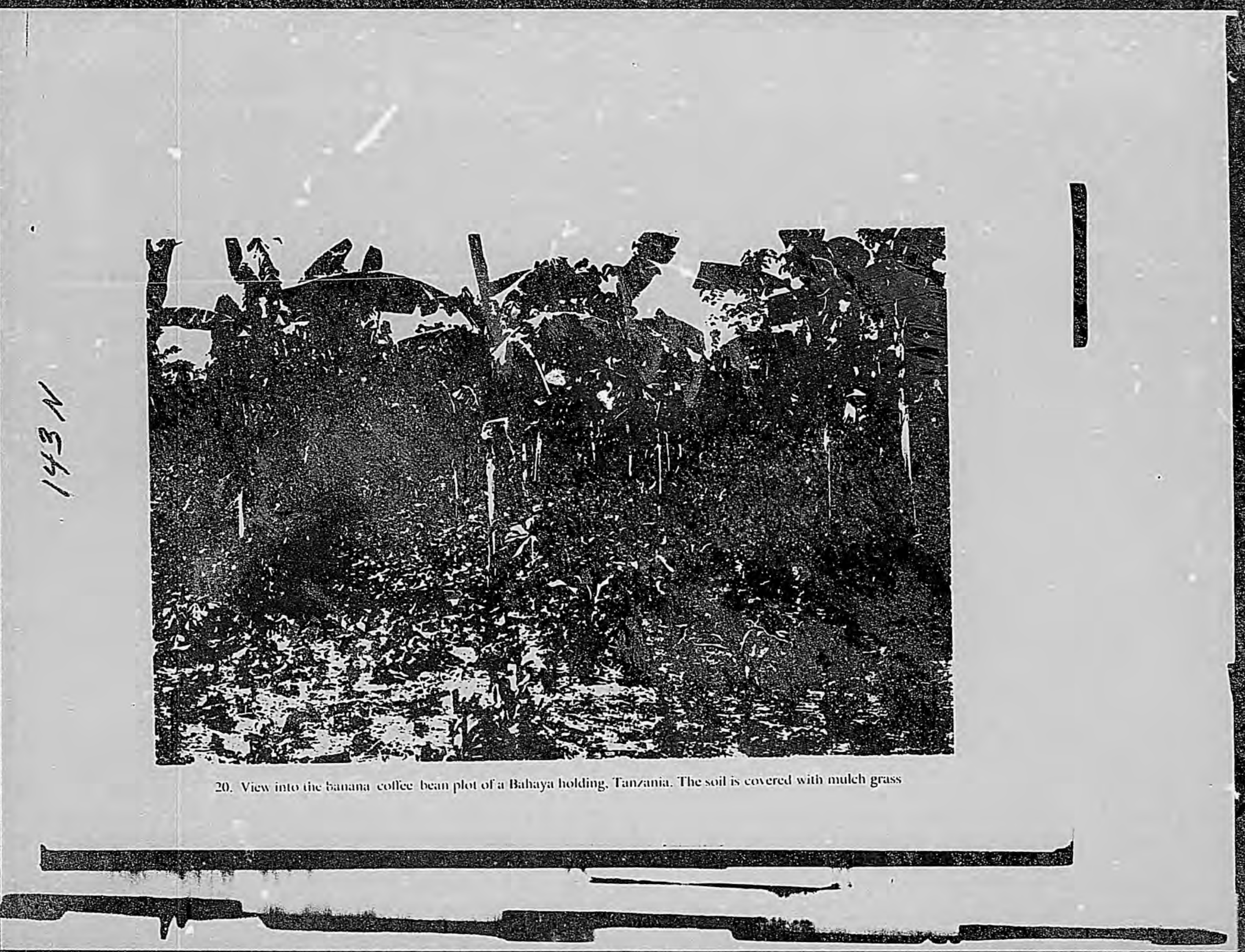




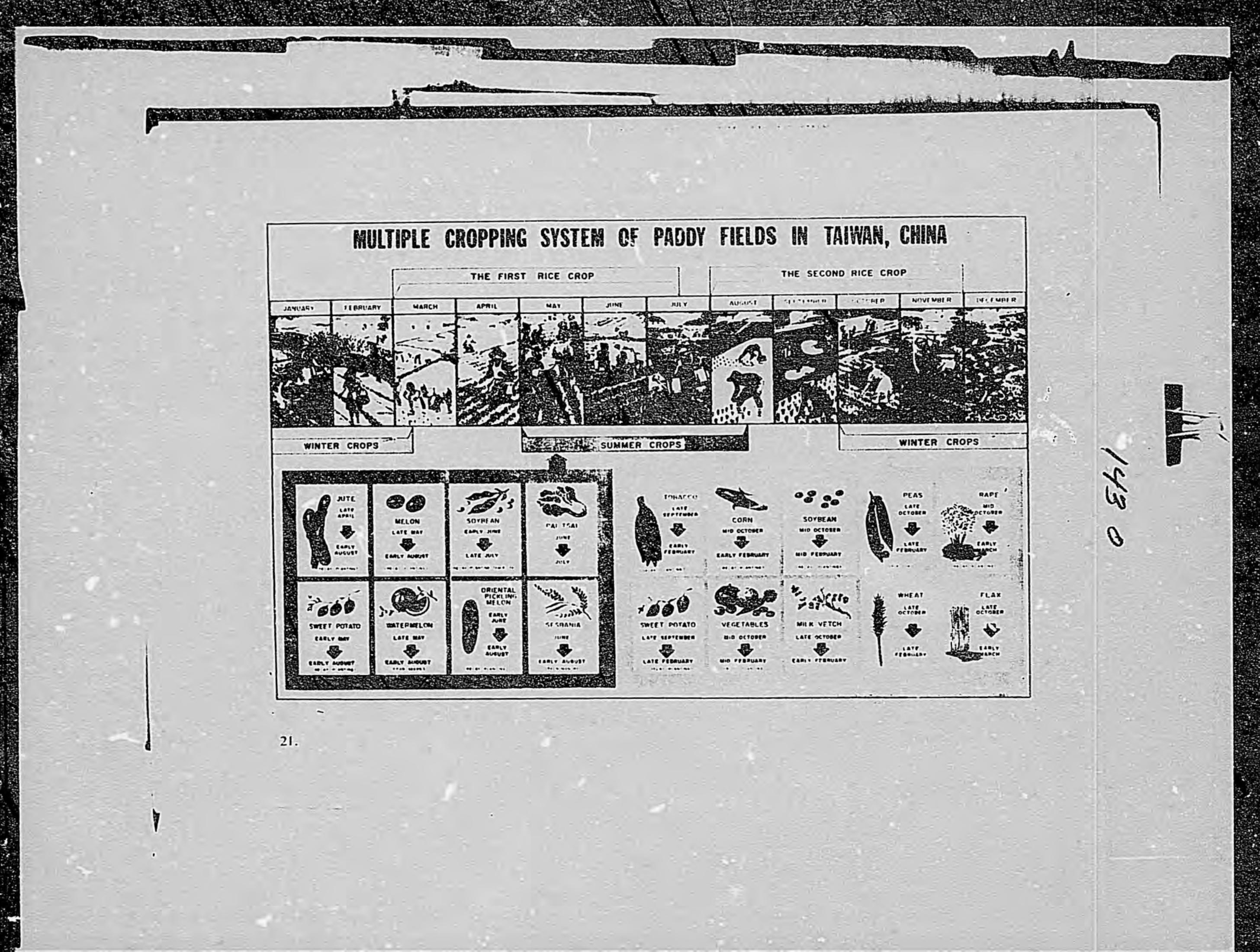




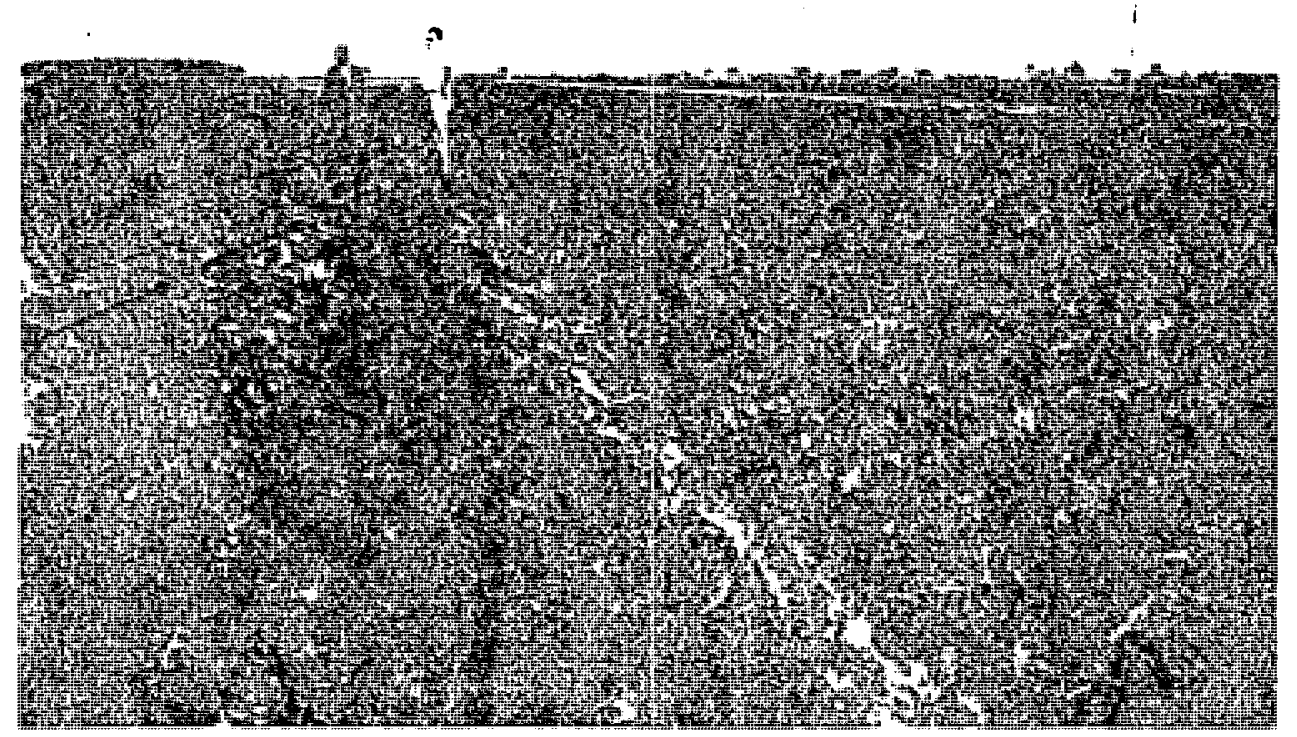

22. A tield in the Gezira Sc'ame. in the Sudan. prepared for planting by the scheme management

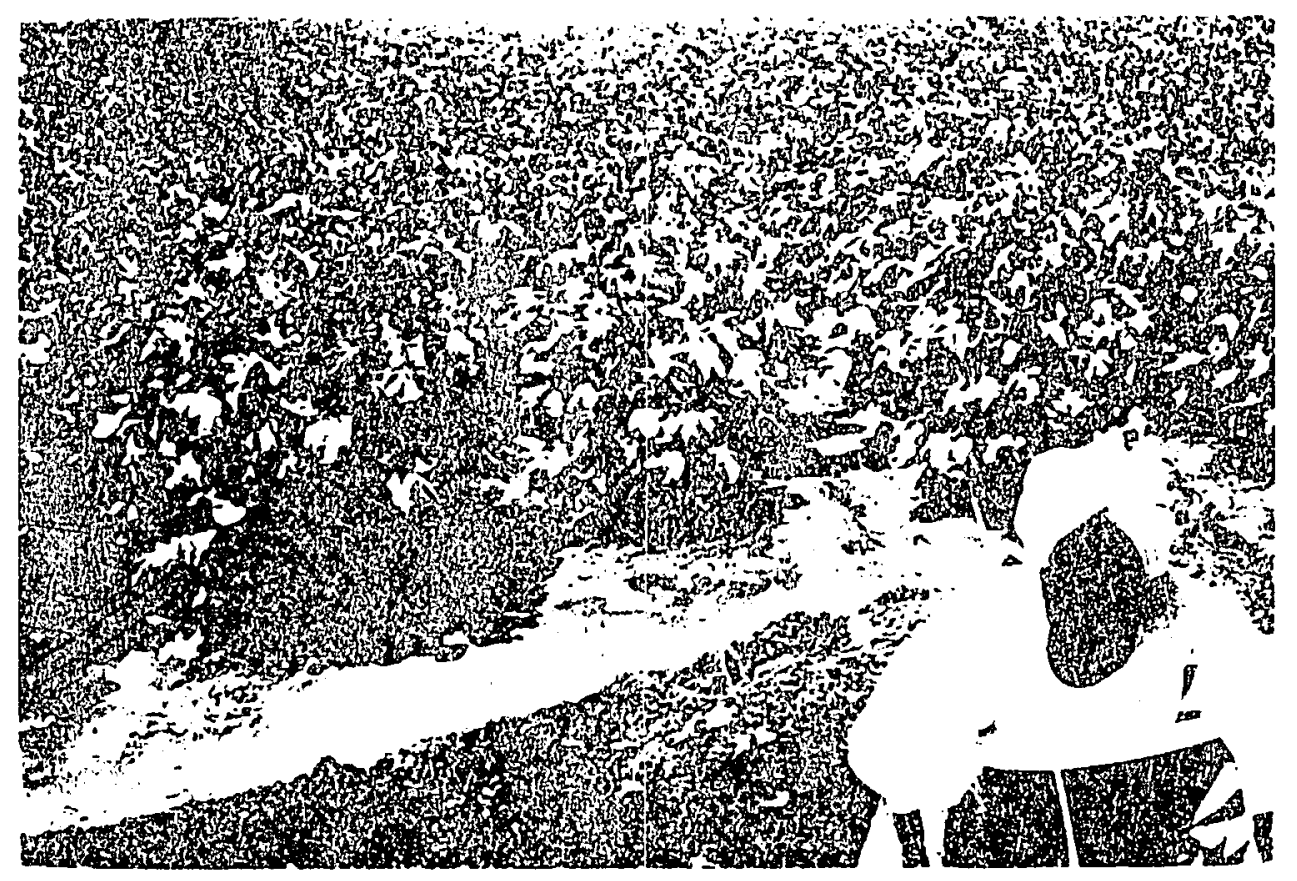

23. A tenant in the Managil Extension of the Ciezira Scheme, in the Sudan. irrigating his collon 


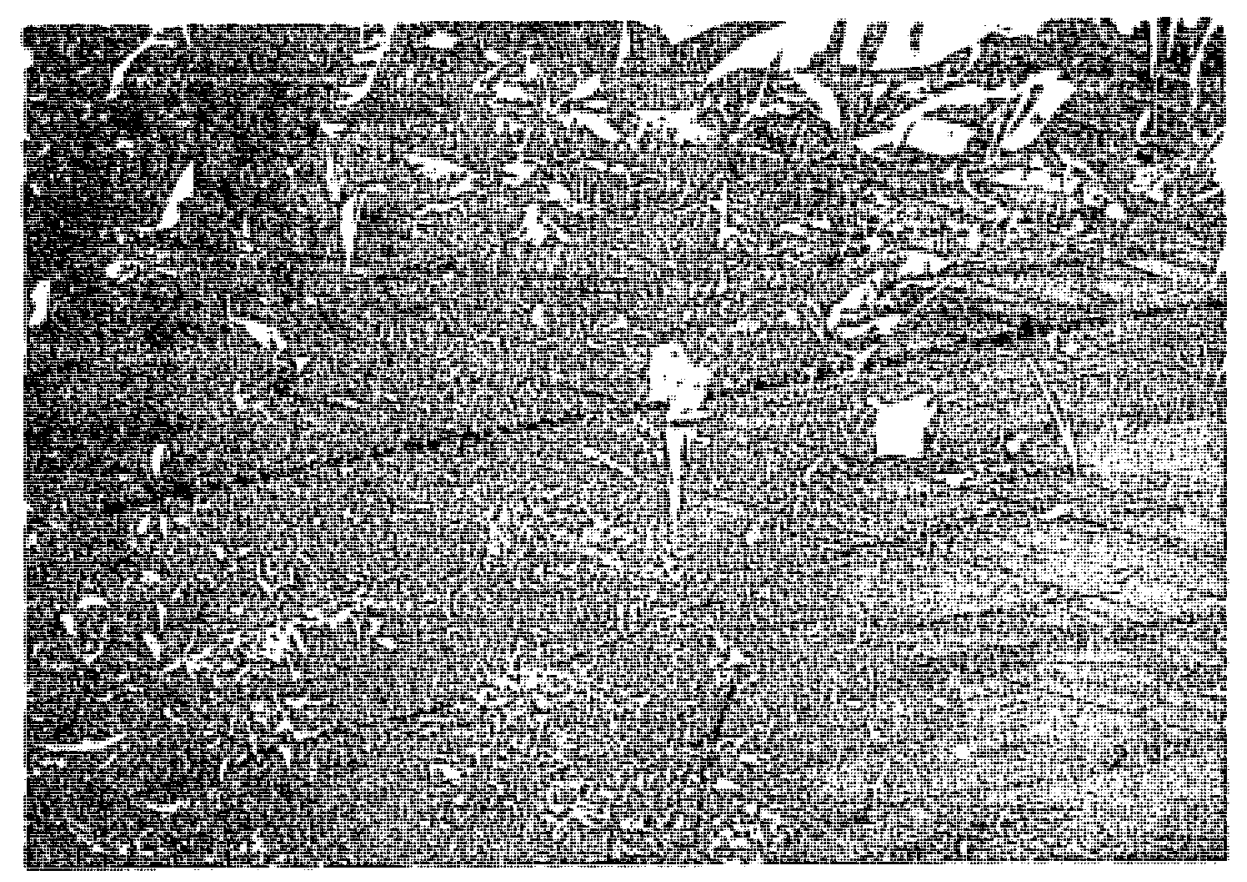

24. Il ell-terraced banana cofice plot on MI. Kilimanjaro. Tamzania

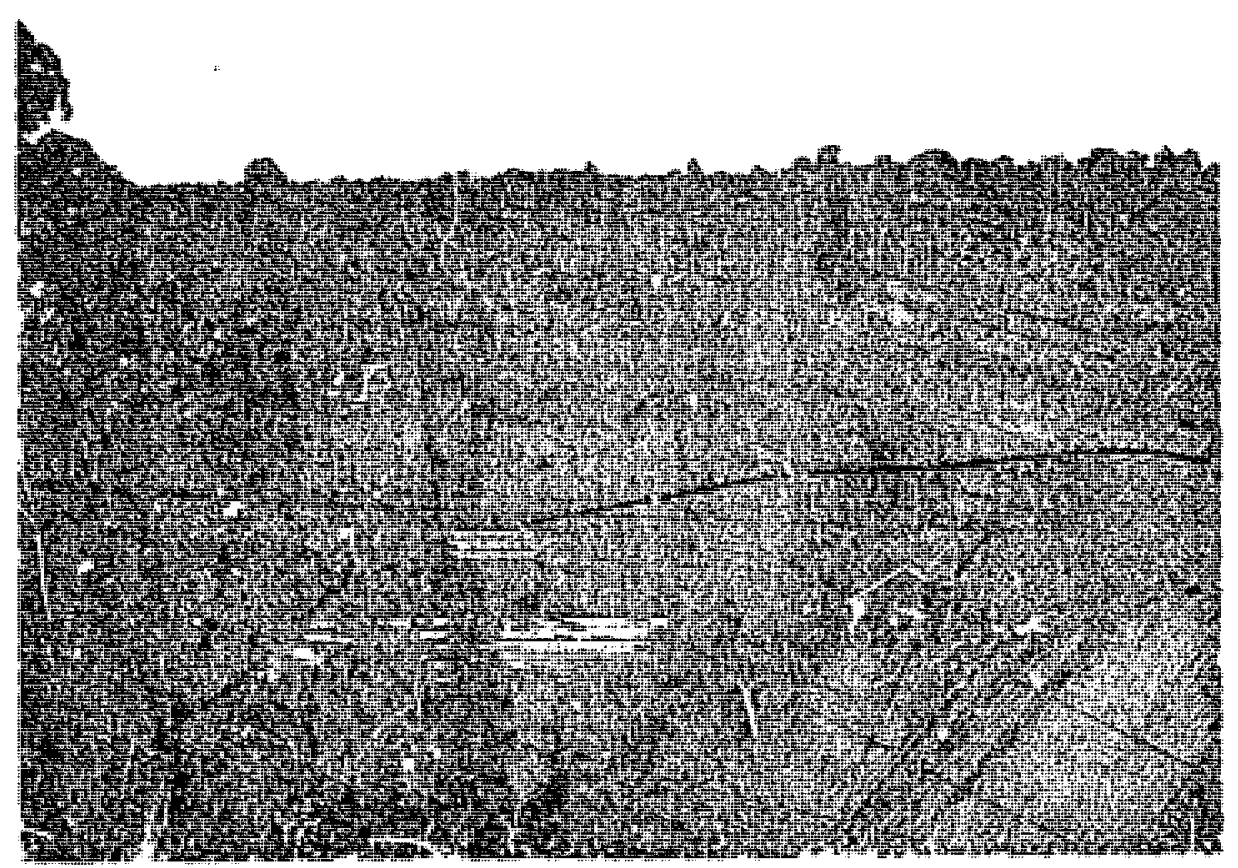

25. Colfee plantattion. Nyeri District. Kenyai 


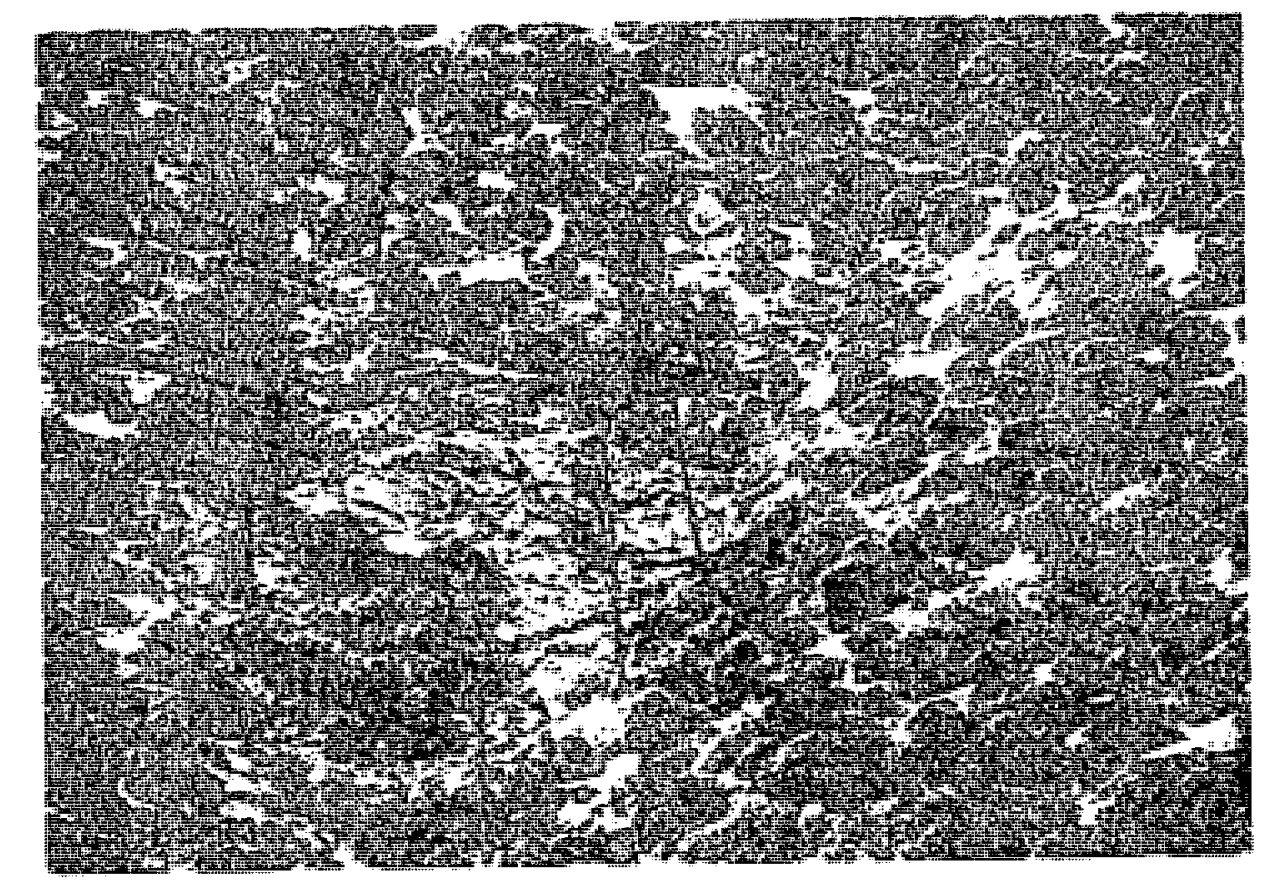

26. Bidly eroded tea plantation. Cevlon. medium-altitude level

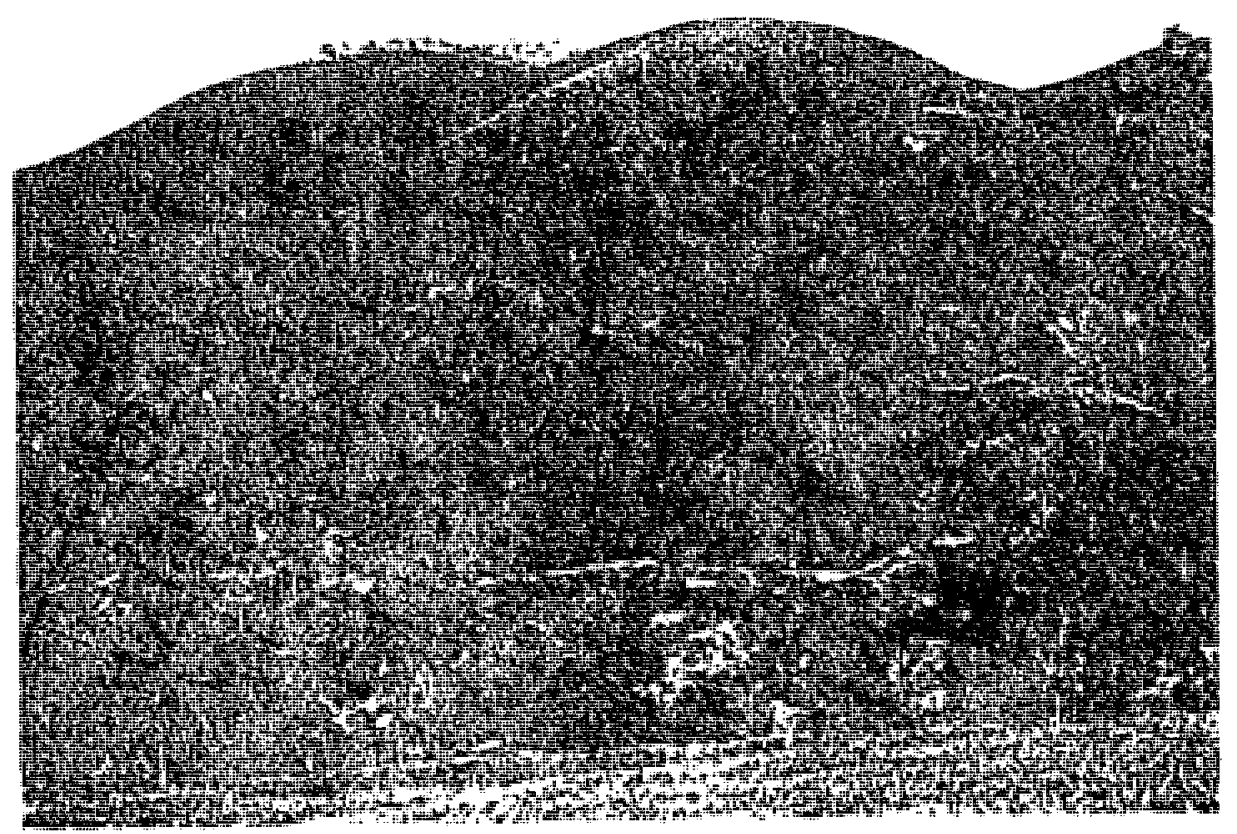

27. Young lea platrtation established with new clones. planted at high density. surrounded by tea which is about 50 years old. Ceylon. high-iltitude level 


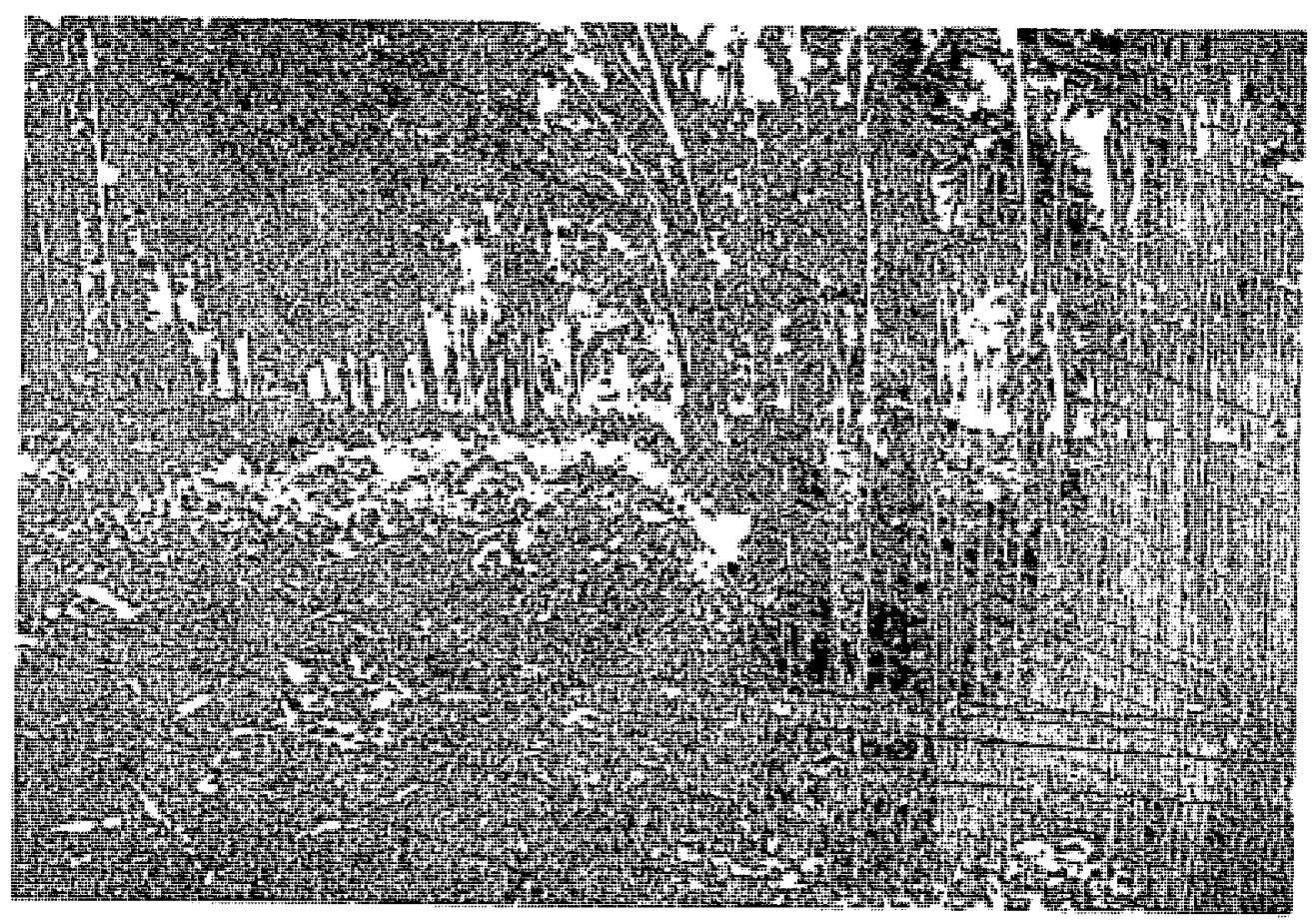

28. Rubber plantation, Wory Coust

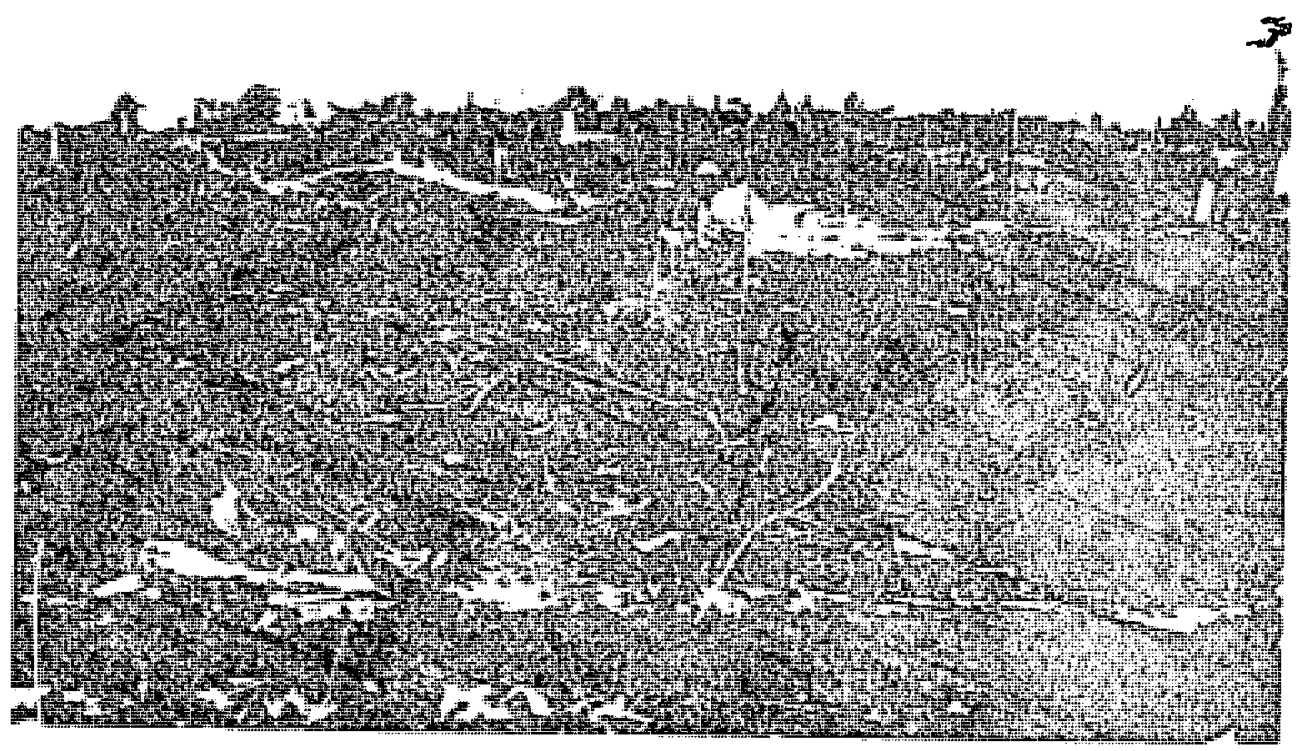

29. Smallholder plot ready for the planting of oil-palms. The womin is planting a coner crop I cimmosuma jubcoscrons) 


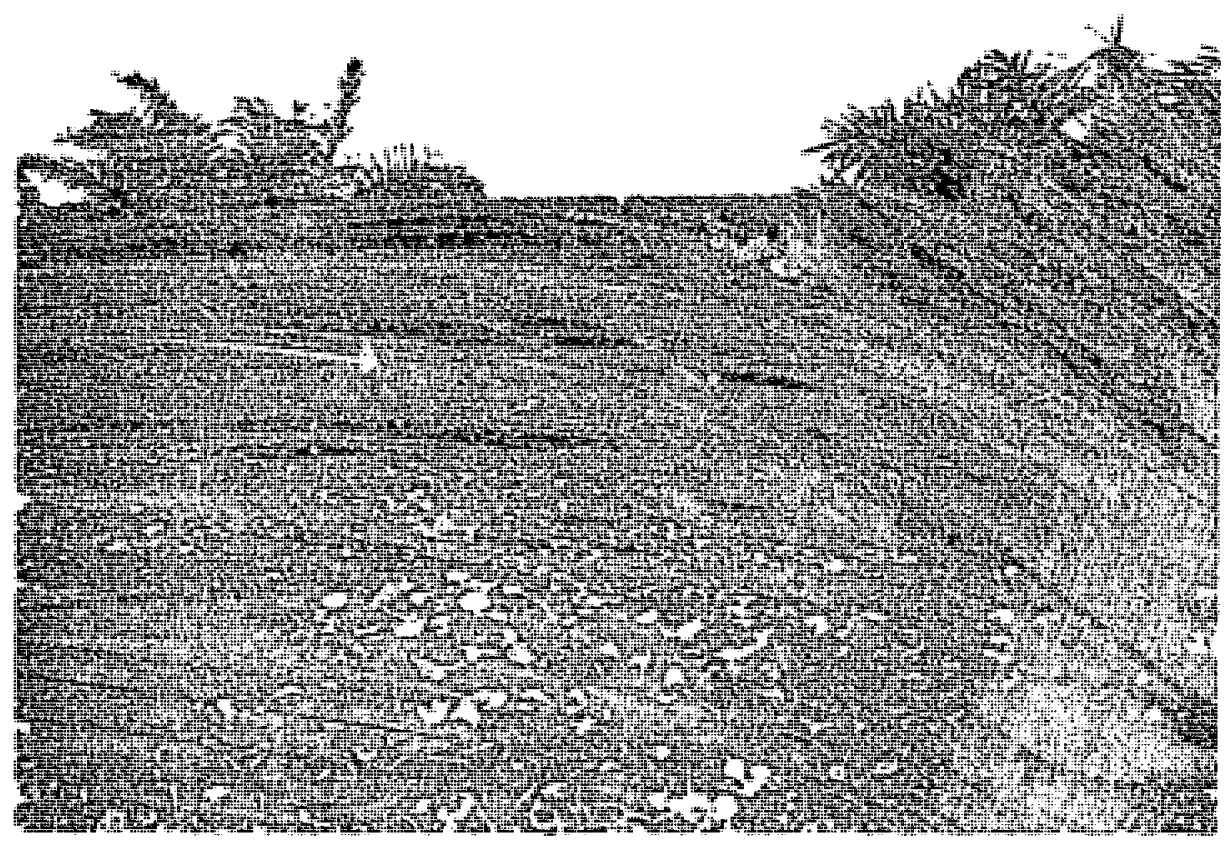

30. Young oil-palin plantation. Fory Coast

31. Root system of two perennial grasses in a dry Savanna climate. Kongwai. Tanzania

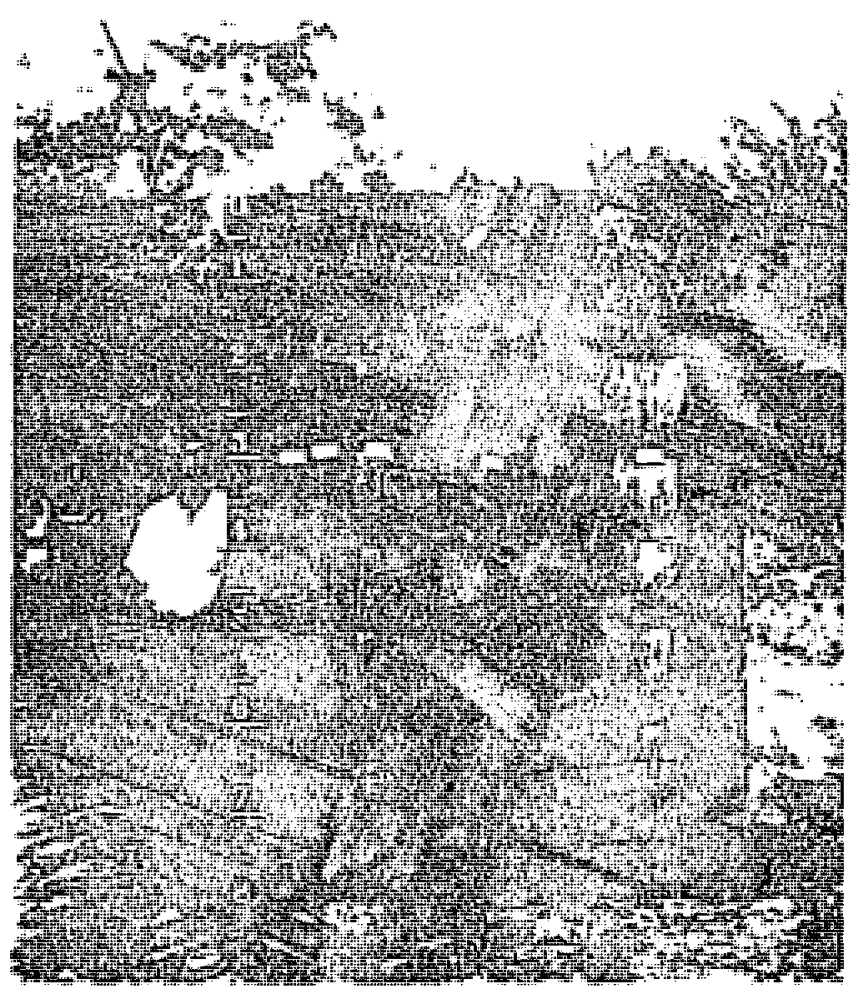




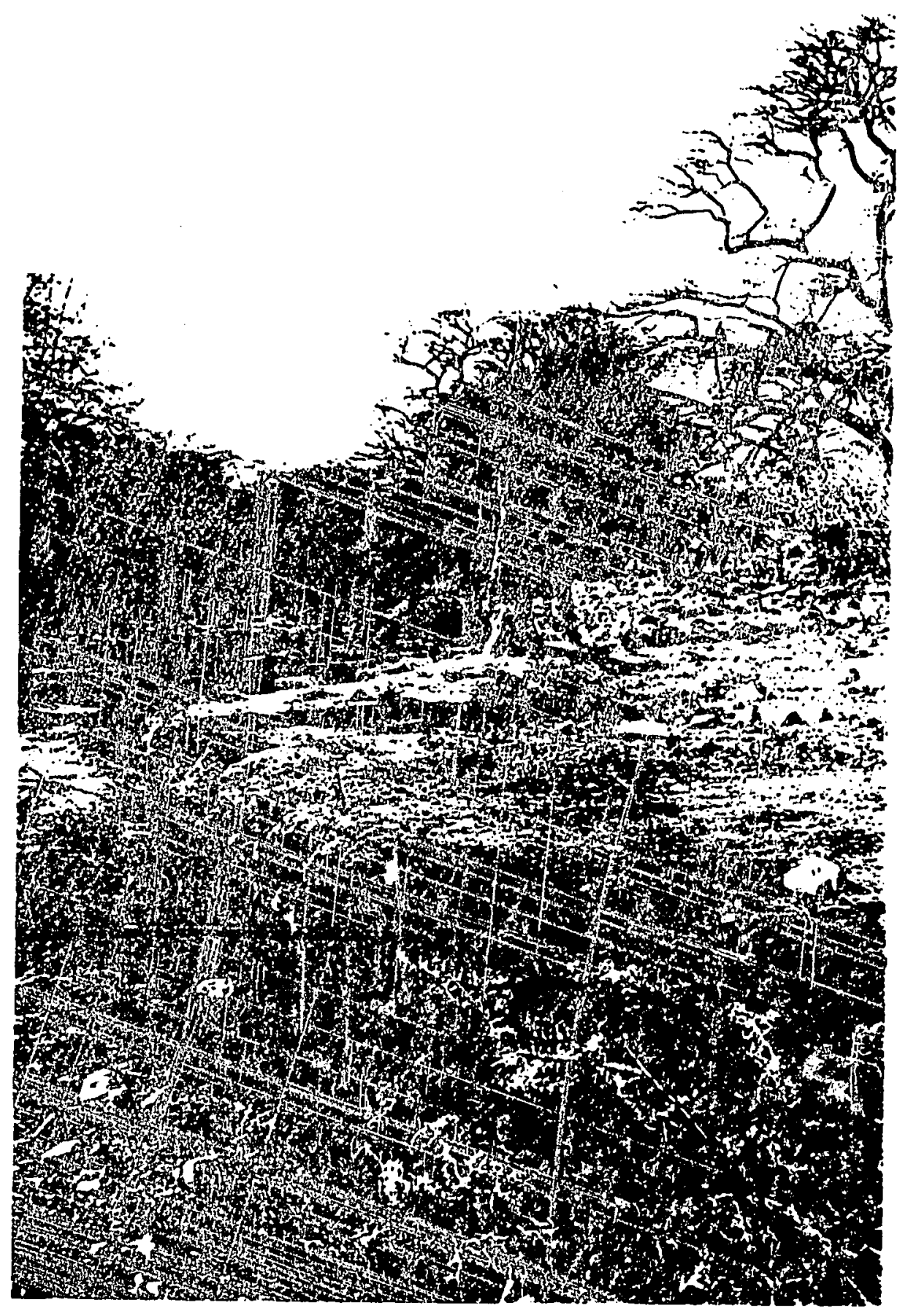

32. Overgrazed and eroded land in Baringo District, Kenya 
SYSTEMS WITH ARABLE IRRIGATION FARMING

The various activities are not organized independently of each other; in particular, arable cropping on irrigated and on rain-fed land is closely related. Where the irrigated plot is small, and contributes only 10-30 per cent of the ho iding return, it is used essentially as a supplement to rain-fed farming, rincipally producing fodder in the dry season, and regularly supplying the household and neighbouring markets with perishable food like vegetables. Where staple food crops are grown. the primary intention is to guarantee the household's food supply. Since in most cases the irrigated land is cropped with particular intensity, any organic fertilizer from the holding is applied to the irrigated land. Where there is a relatively large irrigated area, rain-fed farming becomes a supplement to irrigation farming. The marginal return of additional labour on the irrigated land is usually higher than on the rain-fed land, with the result that the holding has on the one hand carefully and intensively cropped irrigated fields, and on the other hand extensively used rain-ied areas supplying seasonal grazing, fuel, litter, or undemanding food crops like manioc.

(b) Spatial organization of totally irrigable holdings with limited water supplies (rotational irrigation). Where the total holding area is irrigable, but supply is insufficient to provide the optimum amount of water for a given crop, it is advisable only in exceptional cases to distribute the available water uniformly. Instead, systems with rotational irrigation are usually practised, i.e. the water delivery to the field follows a definite pattern from season to season or from year to year. We find primitive forms of rotational irrigation in the oasis agriculture of the Sahara. Nicolaisen (1963, p. 203) reports oasis farming where the irrigated plot is cropped with grain twice a year for six or seven years. after which it is left fallow and a different plot is irrigated and cultivated. In this shifting system of irrigation, the problems of soil fertility and of salting are solved without effort, because of the fallow period.

In intensive agriculture, systems with rotational irrigation are incomparably more complicated, but also more productive. They are especially highly developed in Taiwan.

In the example shown in Fig. 7.4 only a third of the area can be cropped with wet rice in summer. The other two-thirds supports sugar-cane and various short-term arable crops, which can grow pioperly with the natural rainfall. For the third supporting sugar-cane, which is not irrigated in summer, the little watter available for irrigation in winter and spring is enough for initial growth, and as autumn approaches and the crop begins to ripen water is no longer necessary. Since the rice on the first third also needs no more water, sugar-cuane can then be planted on the last third and irrigated until Miay of the secund year. The crop rotation for each of the three plots is arranged in such a sequence that the full rotation on the holding"s three plots is: sugar-cane (first year until January of the second year)-green manure (February to Mity of the second year)-irrigated rice (July to Octuber of the second year)-iweet potatoes (November of the second year to April of the third year)non-irriguted rice, soya beans, or groundnuts (May to September or October of the third year). 


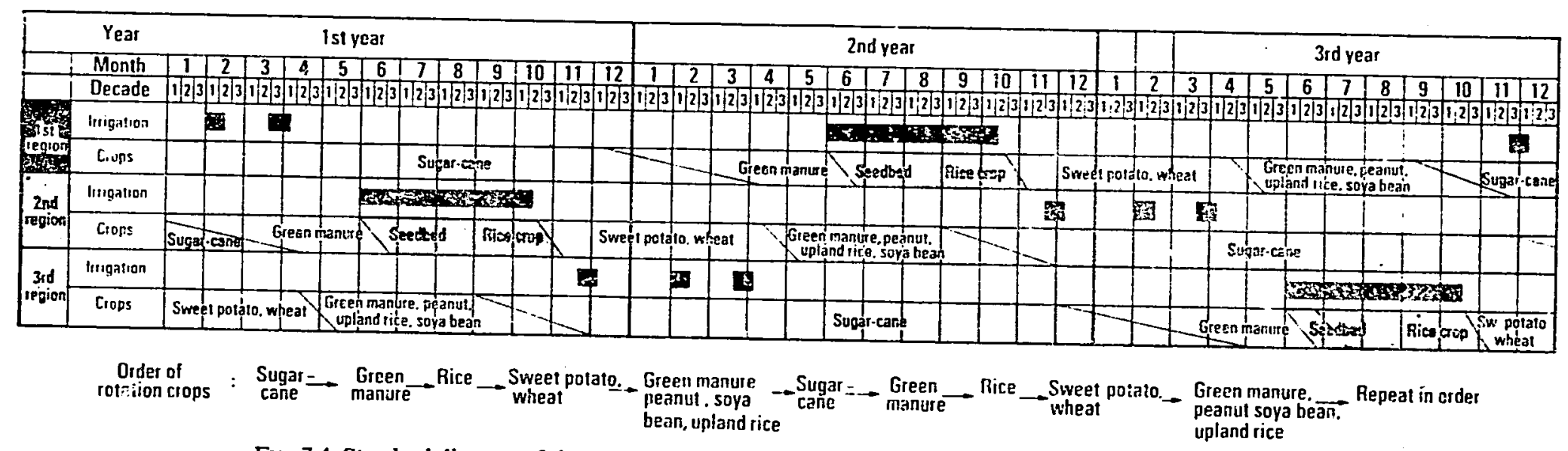

FiG. 7.4. Standard diagram of three-year rotation irrigation (from the Chia-Nan Irrigation Assnciation, Taiwan). 
We can see from the examplc in Taiwan that the spatial emphasis in systems with rotational irrigation changes from year to year. The type and intensity of land use is, however, the same on all plots included in rotational irrigation.

(c) Spatial organization of holdings with uncontrolled water supplies. Other types of spatial pattern in irrigation farming may be found on holdings with uncertain water supplies and where the degree of uncertainty is different on different plots. Here again, the cultivators tend to adapt themselves to the conditions of the various fields by the selection of crops, varieties, and planting dates that fit the expectations of water supply.

An example of this is the wet-rice cropping in the vicinity of Tananarive, Madagascar. The plots in the valley bottoms, which have a relatively ample and sure supply of water for a long period, are planted first with slow-maturing varieties in AprilMay, and these produce relatively high yields. The terraces on the slopes are planted with the standard varieties from October to December. Plots on the upper slopes, where the yield is particularly uncertain, are planted up to March, according to the volume of rainfall, and resulting water availability.

Similarly, the Pakistani rice-jute farmer plants different varieties of rice on fields at various levels according to the danger of flooding and the ability of the variety to withstand it (see $\$ 7.4 .2(\mathrm{~b})$ ).

\subsubsection{Cropping principles}

In irrigation farming distinct cropping principles are applied, in addition to definite spatial patterns of organization. Diversification in this respect is the more common where the water supply is ample and constant, the climate is warm, and the population density and local purchasing power are high. This does not mean that irrigation farming and diversified farning necessarily go together. Irrigated monocropping with sugar-cane, cotton, and in particular with rice, is very important in some areas. There is, however, a tendency in irrigation holdings to increase yields per hectare-and in some cases also per man-hour-by following such practices as ratooning, rotations. relayplanting, interplanting, and intercropping.

(a) Ratooning. In rain-fed farming, ratooning, in which two or more consecutive c:ops are taken from a single planting, is a practice generally applied to sugar-cane and sometimes to sorghum, although it is of scarcely any significance as far as other crops are concerned. In irrigation farming, the possibilitics for ratooning increase. Ratoon rice is found in low-intensity rice production, where it serves mostly as dry-season grazing and only in exceptional cases is the grain harvested. Highly intensive forms of ratooning have been developed in th: Philippines and Taiwan. The sequence: rice (110 days)-surghum (85 days)-sorghum, first ratoon (80 days)-sorghum, second ratoon ( 80 days) is mentioned by Bradfield (1968) as a production possibility of tropical irrigallion larming within one year. 


\section{SYSTEMS WITH ARABLE IRRIGATION FARMING}

(b) Crop rotations. The crop rotations in irrigation farming may be classified according to (I) whether seasonal or continuous cropping is practised, (2) whether the rotation is based on one, two, or more crops a year, (3) whether short-term, long-term, annual, or biannual crops are grown, (4) which crops there are, and (5) what input demands the crops make (see $§ 6.3 .2$ (b)).

Among the many factors determining the crop rotation, the availability and reliability of water supplies play a decisive role in irrigation farming. In addition, interactions between rainfall and irrigation have to be considered. Multiple cropping is much easier to organize in areas with only one rainy season and irrigation during the rest of the y'ear than in areas with two rainy seasons, where planting and harvesting have to be adapted to the rainfall. Consequently, the most intensive and diversified types of irrigation farming are found in areas with a single rainy season, as is the case in Taiwan. We can see from the rotations practised in Taiwan that are illustrated in Table 7.2 how the crop rotation, depending on the availability of water, varies under otherwise similar production conditions.

TABLE 7.2

Crop rotations on irrigated land in Taiwan

Fields irrigated for the whole year

1. Rice (February/March-July), rice (July/August-November), fallow (NovemberFebruary)

2. Rice (February-June), rice (July-November), green manure (November-January)

3. Rice (March-July), rice (August-November), wheat (December-February)

4. Rice (February-July), rice (July-November), vegetables (October-January)

5. Rice (February-June), vegetubles (June-July), rice (July-November), sweet potatoes (November-February)

6. Rice (February-June), rice (July-October), tobacco (October-February)

Fields irrigable for, ilf a year

7. Rice (March/Ap il-July), sweet potatoes (August/September-January/February)

8. Rice (July-Nove mber), vegetables (October-March), green manure (March-June)

9. Rice (July-November), sweet potatoes (October-May), green manure (May-July)

10. Rice (May-September), sweet potatoes (September-A pril), vegetables (May-Decem. ber), soya beans (December-May)

11. Rice (March-July), vegetables (July-March)

Fields with rotational irrigation

12. Rice (June-October), sweet potatoes (November-March/May), non-irrigated rice (May/June-Septentber/October), sugar-cane (October-January of the 3rd year), green manure (February-May)

13. Rice (July-November), sugar-cane (October-January of the 2nd year), sweet potatoes (January-June), groundnuts (July-December), groundnuts (January-June)

14. Rice (July-November), sweet potatoes (November-May), groundnuts (July-October), vegetables (October-May), groundnuts (July-October), sweet potatoes (NovemberMay)

Source: Chen (1963, p. 239). 
SYSTEMS WITH ARABLE IRRIGATION FARMING 149

(1) The most frequent crop rotation on permanently irrigable land consists of two crops of rice and one non-irrigated winter crop. which is most irequently sweet potatoes, maize. or wheat. On poorly drained plots, the usual rotation is rice-rice-faliow or rice-rice-green manure. As the size of holding decreases, vegetable cropping becomes more important.

(2) On plots with summer irrigation only, and prior to the summer rice, we find as a rule vegetables or swr: potatoes, and the final crop is usually a green-manure plant.

(3) In areas with rotational irrigation, the limited availability of water necessitates alternating combinations of the principal crops rice and sugarcane. so that rotations of two to three years with five or six crops are combined with the usual one-year rotations with two to five crops which predominate where the plots are permanently irrigated (see $\$ 7.3 .2(\mathrm{~b})$ ).

Plate 21 gives an example of the extraordinarily high levels of land-use intensity that are possible in tropical irrigation farming. The rotation practised in Taichung District, Taiwan, includes four or tive crops in one year. not all of which are short-term crops. Cropping within one year on a single piece of land is as follows.

In February the rice nurseries are laid out. In March the rice is planted, and it is harvested in June. Summer rice is not planted until August. In the interim the socalled summer crops can be grown. such as jute. melons, soya beans, sweet potatoes. and various green-manure plants and vegetiables. Some of these crops can be planted as early as May in the growing rice stand (relay-planting). Between the second rice harvest and the planting of the spring rice. in the four months of the cool season when growth is slow, the so-called winter crops are cultivated, including tobacco. maize, soya beans, peas, seed rape, sweet potatoes, wheat, hax. various greenmanure plants, and vegetables. Some of these crops can similarly be planted in the growing summer-rice stand, and sometimes by adopting this method the use of the field can be concentrated so that two winter crops are possible.

Generally, in production conditions like these, there is a strong tendency to grow those crops that produce as high a yield as possible per month of tield use. The $t$ me for which various crops occupy the field can be shortened considerably by raising the plants in nurseries. Indeed, cultivators try to leave the plants for as long as possible in the nurseries, and crops that lend themselves to this method are preferred. Moreover. it is necessary to prepare the field immediately after the harvest for the plants: a plot which in the morning is yellow with ripening rice should be green in the evening with newly planted rice.

(c) Relar-planting. Multiple-cropping systems, as depicted in Plate 21, depend to a high degree on relay-planting techniques-the rotation crop is planted in the ripening stand of the previous crop. In the case of rice, relayplanting takes place up to seven weeks before the harvest and, so that the relay crop can get enough light, the panicles of the ripening rice athove the 


\section{SYSTEMS WITH ARABLE IRRIGATION FARMING}

row of plants are pulled apart. With some crops, relay-planting is combined with the practice of raising the plants in nurseries.

An example of this is jute-growing in Taichung District, Taiwan. The growing period of jute from sowing to harvesting is 120 days in the summer, but oetween the spring and summer rice the plot is available for onlysery, and they are then solved by keeping the jute plants for 40 days in the. The pure stand of jute is thus planted in the rice field 40 days before the rice hartest. The pure and the planting of restricted to the 40 days between the harvesting a minimum as ine jute is planted in summer rice. Disturbance to the rice is holes filled with compost. The losses in yiedd 20 per cent, but these losses are more rice. amount to 5-10 per cent, and of jute jute.
than outweighed by the additional yield of jut

The extent of relay-planting depends on the available labour force and on the soils. On soils that tend to be heavy, the land must be prepared after the harvest and before it is used again. In other cases, crops for relay-planting need to be planted in dry land. and drainage facilities may not be sufficient. It must also be borne in inind that the additional water requirements can be net only where the rainfall or the irrigation capacity is adequate. Relayplanting in rice holdings is practised particularly in early summer, but relayplanting in the growing summer rice suffers from the disadvantage that the Indica varieties, which are planted in summer, tend to bend over. Thus, not only have the ripening rice panicles to be separated. but also the rice has to be tied up.

(d) Interplanting. Another form of cropping possibility consists of planting one short-term crop at about the same time as a crop res. ring more than a vear to ripen, for example sugar-cane or manioc. The mixture of crops does not last until the main crop ripens. as in the case of rice, but only while the longer-growing plant is still young. Sugar-cane. which is planted in the autumn, develops slowly in the somewhat cooler winter months. The space between the rows of cane can therefore be used for short-term crops, like sweet potatoes, groundnuts. flax. or vegetables, without making any appreciable difference to the growth of the sugar-cane. When there is a sufficient supply of water, the combination of relay-planting and interplanting has proved its worth. The sugar-cane is interplanted in the ripening rice in the autumn (muddy-in method). After the rice harvest, an intermediate crop is planted in the ro... of sugar-cane. Experience has shown that planting should take place in every second row only, so that it is possible to weed and manure each crop individually.

Figure 7.5 gives an exumple of combined relay-planting and interplanting. The sugar-cane is planted in Sepiember in the ripening rice, so that it can benefit from the relatively warm days. After the rice harvest, every second
growing cane is planted with sweel potatoes. flax, or vegetables. 
(1) Crop rotation of the rice and the winter and summer cash crops

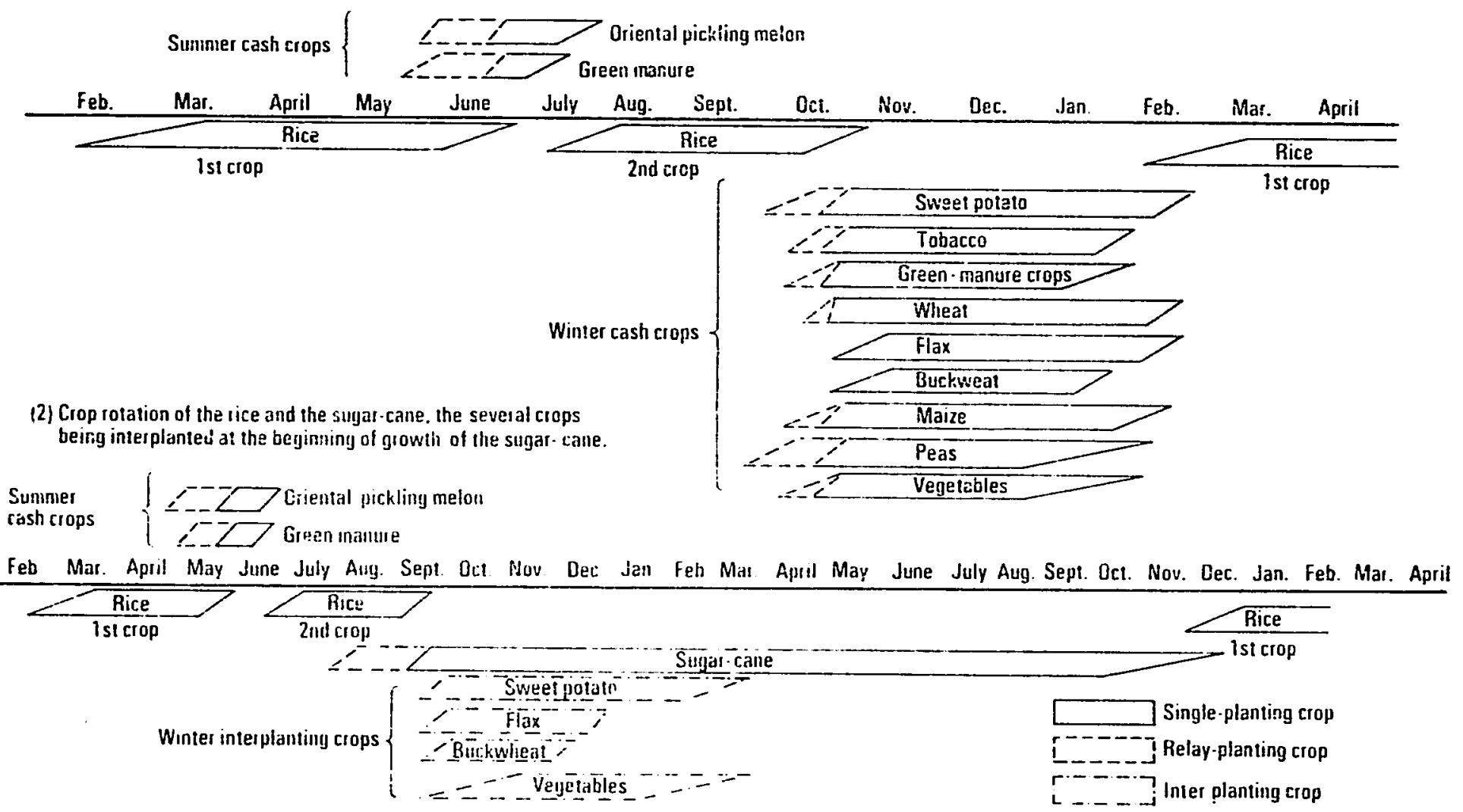

Fici. 7.5. Rotations with relay-planting and interciopping in Taiwan (from lso 1964). 


\section{SYSTEMS WITH ARABLE IRRIGATION FARMING}

(e) Intercropping. Relay-planting and interplanting lead necessarily to intercropping. i.c. different crops are planted in alternate rows, but with the advantage that the mixed crop grows during those stages of the vegetation cycle when the crops impair each other's growth relatively little. It should be remembered that intercropping also occurs in irrigation farming where two or more plants with approximately the same growing per st are planted on approximately the same date. These are preferably crops that are compatible. ${ }^{2}$ An example is the intercropping of sweet potatoes with seed rape, in which the seed rape is planted about a week after the sweet potatoes and harvested a week before them. A general feature of intercropping in intensive irrigation holdings is the practice of row cultivation, which allows each crop to be given its own specific fertilizer and weeding.

\subsubsection{Characieristics of the fertilizer econom!}

The discussion of the various cropping principles indicates the high degree of intensity that irrigation farming can attain. It is obvious that, in order to exploit the prodw-tion potential of irrigation farming, high yiclds, multiple cropping. and leac..ing have to be accompanied by a highly intensive fertilizer economy, and by efforts to prevent salting.

Most of the irrigated land in the tropics. particularly most of the wet-rice areas, is still cultivated year after year without much manuring. Rice-growing over long periods without fertilizer application does not appear to lower soil fertility. for the following reasons:

(1) In several latge river basins, soil fertility is maintained by the annual deposition of silt.

(2) In addition to silt. nutrients are brought in solution with the water. The paddies with wet rice are often on difierent levels and are slightly inclined, so that the water runs from the high forest land to the sea, draining slowly from one rice field to the next. and thus conveying nutrients from the higher levels to the lower plots.

(3) In the rice terraces, the usual poor quality of tropical soils is improved because of the fixation of nitrogen by the blue-green algae which proliferate in the warm water, the slower rate of decomposition of organic matter, and the greater availability of many of the nutrient elements while the soil is waterlogged (Webster and Wilson 1967, p. 209).

(4) Angladette (1966, p. 171) remarks on the observation that soils improve their quality for wet-rice production with time, because of the

1 A particularly interesting case of intercropping in irrigation farıning is reported from South Arcol District, Madras State. India. Cotton. finger millet, and groundnuts are pianted in December-January at about the same time. Millet is harvested at the end of March. Groundnut harvest takes place at the end of May. Thereafter the cotton receives an additional manuring and irrigation. The cotton, which was previously stunted, now grows vigorously, and is harvested in August. 
impounding of water and its influence on chemical processes in the soil. This process takes fifty to one hundred years.

Intensive irrigation farming, however, requires manuring and fertilizing as well as the beneficial influences connected with water application and water impounding. Traditional types of intensive inanuring have developed in those areas where water supplies are sufficient and reliable and where population densities are high. Nowhere else in the world has the fertilizer economy of traditional farming systems reached such a level of intensity in the effort to reduce the loss in nutrients as in Chinese irrige.icn farming. The father of organic chemistry, von Liebig, in comparing nineteenth-century German agriculture with contemporary Chinese farming (1878, p. 453), viewed the former as the procedure of a child compared to that of a mature and experienced man'. Weoster and Wilson (1967. pp. 210-11) summarize the intensive manuriig practices used in south-east Asian irrigation farming as follows:

All animal manure, household and crop wastes, and plant ashes derived from fitel, are carefully collected and applied to ti:e land. usually in the form of composts. Night soil is widely used, commonly teing stored in earthenware receptacles, diluted with water and thriftily applied to individual plants at appropriate intervals. ${ }^{1}$ Mud, rich in organic mattor. is periodically dug out from canals, reservoirs and fish ponds and spread on the land, or used in composts. Green manures may be included in the rotation, sometimes for direct ploughing-in but more often for composting. Hillsides bearing trees and shrubs are regularly cut over to provide material for trampling into the mud of the rice rields, or for the preparation of composts. Great use is made of composts, care being taken to see that they are well rotted, with much of their organic matter broken down, so that they rapidly releas: nutrients to a growing crop. It should be mentioned, however, that although the fertility of the densely populated alluvial plains of China has been naintaincd at a relatively high level by deposits of silt from irrigation of floodwater, by application of night soil. and, to a lesser extent, by green matnuring with vegetation imported from hilly land. this has been done partly at the expense of other land. Much hilly land in China has been depleted of fertility. and the general level of fertility of lands other than the alluvial plains is only moderate.

It is intcresting to observe that the concentric rings of land with decreasing fertility at increasing distance from the farmstead that are frequent in rain-fed systems are ratrely found in irrigation systems. With the exception of the gardens near the farmyard. which receive more fertilizing. manures and composts are usually distributed more or less equally over the irrigated land.

\footnotetext{
${ }^{1}$ Night soil is a traditional fertilizer of high productivity. It is, however, a carrier ol various intestinal diseases. Buck $(1930$, p. 265) writes this about traditional China: 'Fron an economic standpoint it would probably be cheaper to throw away night soil than to incur the losses concurrent with ill-health which result from its use." The transition to mineral fertilizer results in reduced losses thrumgh disease and reduced costs of health care.
} 


\section{SYSTEMS WITH ARABLE IRRIGATION FARMING}

\subsubsection{Characteristics of animal husbandry}

The intensitication of irrigation farming is closely tied to an intensive fertilizer economy. Cattle activities, however, are not in gencral intensively organized. In the irrigated farming systems of the subtropics, stock-keeping is of growing significance. In Israel. Japan, and Maghreb th ;roduction of milk and meat is increasingly based on irrigated fodder cro ring. However, conditions in the tropics for the moment are different. Arable cropping receives priority. as it always has. although it is usually supplemented by various livestock activities.

In a few cases, irrigation farmers practise a division of labour with seminomadic herdsmen. The fallows of Gezira, in the Sudan, for instance. are grazed in the dry season by migrating herds of cattle, sheep, and goats. As a rule, however. we find stationary animal-keeping with low livestock numbers per holding but rather high livestock densities, rising to 2 livestock units per hectare in intensive irrigation areas of India and China (Buck 19\%, p. 255). The main objective in keeping cattle and buffaloes is the provision of traction power for ploughing and pumping. The provision of manur is a secondary function. and the production of meat and milk is usually of less importance. The need of the irrigation farmer's family for protein is not usually met from cattle and buffalo products. but by small animals, sheep, goats, pigs, poultry. and fish. Pigs are of particular importance in south-east Asia, being fed partly on crop res duts and parly on heusehold waste. Ducks are typical of the Chinese type of holding. and chickens are found almost everywhere in the tropics. Part of the animal excreta may be used to fertilize fish-ponds, and mud from the pond may be applied to the gardens.

Attention should also be drawn to forms of combined irrigation fa-ming and fish production. Fish are found almost everywhere in the water distribution system. In many places, the fish-pond by the house is a typical feature of irrigated holdings. Hickling (1961) notes the integration of various forms of fish production into crop rotations:

(1) In Travancore, southern India, after the rice harvest the plot is filled with brackish water, and in this way prawns are brought into the field. When the tide recedes. the water passes through nets. and the prawns are collected. The yield amounts to 700-1600 kilograns of prawns per hectare in the dry season (p. 263).

(2) In Java, Madagascar, and other places, fish are scinletimes found in the growing rice. For this to be possible there must be a sufficient and continuous depth of water. Fish are brought to the plot in the irrigation water, or they can be put in 5 days after planting. Hickling (1961, p. 265) quotes a yield of 28-50 kilograms of fish per hectare in 100 days.

(3) In some cases, land is used alternately for rice cropping and as a fishpond. The water is let in after the rice harvest. The yield of fish that swim 
SYSTEMS WITH ARABLE IRRIGATION FARMING

in with the water amounts to about 3 kilograms per hectare in five to six months. By introducing tilapia, up to 300 kilograms per hectare can be produced in 3 months.

(4) In some plantations in Guyana, the sugar-cane land is covered with brackish water for nine months before the next planting, and the plot can be used for fish (tilapia).

\subsubsection{Characteristics of the labour economy}

As we might expect, the labour input of irrigated holdings shows great variation, depending on the system of ivater distribution, the intensity of land use, and the degree of mechanization. Where labour is particularly plentiful, hoe and spads systems occur, relying entiraly on manual labour. Ir. most irrigation systems, farmers employ animal power for ploughing, transport, and pumping. The use of the tractor is rapidly spreading, for irrigation farming can support higher monetary inputs in cultivation than can rain-fed farming. Despite the varied forms of organization, however, some features and tendencies are found that distinguish the labour economy of irrigation farms from that of rain-fed farming.

(a) High labour input. Irrigation farming in the tropics almost always involves a high :nput per hectare of manual labour. This is because of the extra operations in irrigation, such as maintenance of channels, control of water distribution, and land preparation. The manual labour injest is particularly high where water has to be pumped by hand or with the aid of animals. In the example of rice production in Madras (Table 7.3), these tasks amounted to 48 per cent of the total. According to Buck (1930, p. 306), farmers in Hopeh Province, China, in 1923 spent on irrigation 58 per cent of the total labour input in wheat and 27 per cent of the total labour input in vegetables. In regions that depend mainly on inundation. the labour demand for irrigation is comparatively low. However, the provision of controlled water supplies and of careful water delivery is usually connected with a high labour input.

Of even greater importance is the labour input resulting from the choice of intensive crops, and the greater amount of labour involved in cultivation. weeding, and harvesting. The methods of producing and applying manure, compost, green manure. etc., require a great deal of labour. especially where multiple cropping, relay-planting, and intercropping play a major part. This kind of production method is not only expensive in terms of field labour; a considerable input is also needed to maintain the irrigation system and nursery beds. Thus the basic difference from rain-fed farming is not simply that more work is involved in cultivating each hectare, but also that irrigation often facilitates a higher frequency in cropping.

Table 7.3 indicates the level of labour input for one crop of wet rice. With the exception of the example in the Uniled States, it fluctuates between 456 man-hours per hectare on Madagasear and 1663 man-hours per hectare in Japan. and thus is 
TABLE 7.3

Labour input in wet-rice production in various coumtrics (man-hours per hectare for one crop)

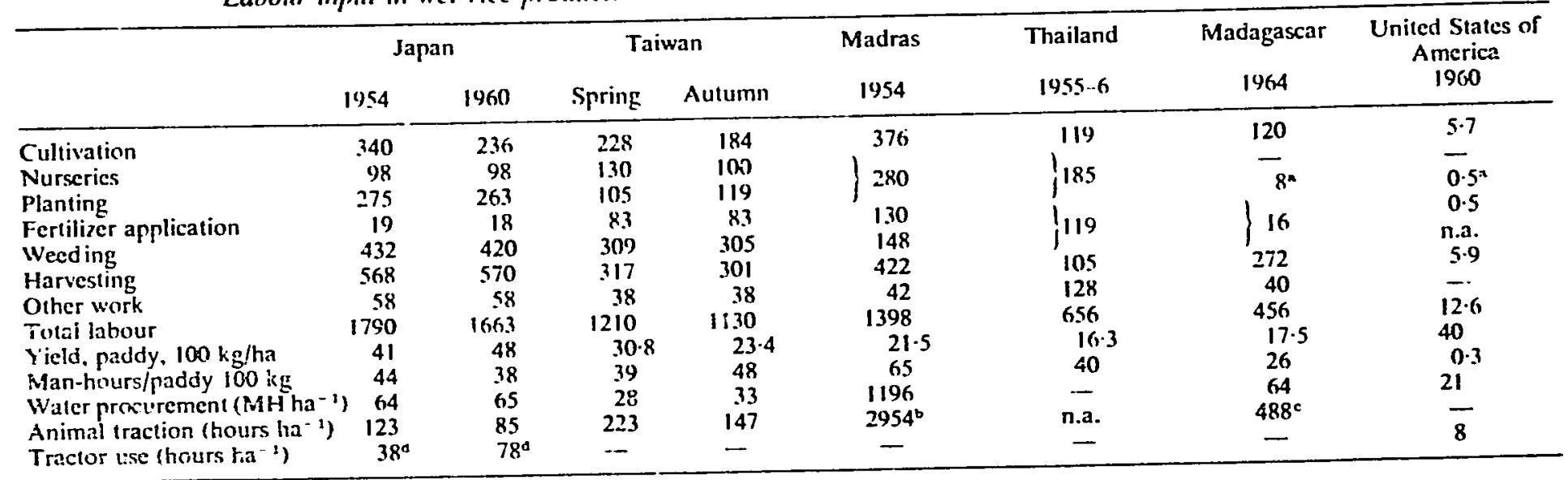

Tractor lise (hours fa- ${ }^{-1}$ )

- Sowing.

- Including animal hours for water procurement.

- Cullivation by pieringe.

- Cultivation by piétina

Two-wheel tractors.

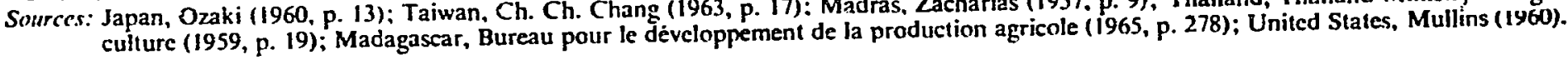




\section{SYSTEMS WITH ARABLE IRRIGATION FARMING}

much higher than the labour requirement in rain-fed cropping. Within irrigation farming, the labour input tends to rise with increasing availability and reliability of water. As multiple cropping increases, there is a disproportionate rise in labour input, and for example in intensive wet-rice systems on Taiwan it reaches $4000-$ 5000 man-hours per hectare. We find the highest recorded labour input-1000015000 man-hours per hectare-in irrigated vegetable holdings of the Chinese type (see $\$ 7.4 .1(\mathrm{c})$ ).

(b) High marginal returns on labour. The production functions of labour in irrigation systems are, as a rule, different from those in rain-fed farming. The marginal returns on labour in rain-fed farming are usually lower and decrease more rapidly with greater employment of labour than in irrigation farming. For a wide range of labour inputs, marginal returns in irrigation farming decrease slowly or remain almost constant.

This is shown in Fig. 7.6. In the irrigation areas of Uttar Pradesh in India, the marginal returns on labour are much higher (and remain high for considerable labour inputs) than in rain-fed farming in Andrha Pradesh, which shows marginal returns on labour close to zero. The production functions of wet-rice growing in the Philippines show the marginal returns on labour in artificially irrigated holdings with a reliable supply of water in comparison with the marginal return in those holdings that rely on the impounding of rainfall. The functions clearly show that much more labour can be absorbed productively with the help of reliable artificial irrigation.

More often than not, the improvement of water supplies and of farming techniques on irrigated land shows higher marginal returns on labour than the constructior of new, but less adequately managed irrigation facilities and irrigation plots. As to rice, Geertz (1963, p. 35) writes: 'The capacity of most terraces to respond to loving care is amazing.'

(c) Less pronounced peaks in labour demand. Farming systems with seasonal irrigation suffer, like rain-fed farming, from seasonal underemploynent of the available capacities of labour and traction power. In large irrigation schemes with one major cash crop, the peak in labour demand and the resulting problems of the employment of seasonal labour (the provision of credit for their payment, the necessity of using expensive machinery, and so on) may be even more pronounced than in more diversified rain-licd systems. In wet-rice systems with but one crop a year, the underemployment of the labour force and the great number of draught animals is proverbial. The animals work several hours a day for about 40-70 days. During the rest of the time they graze on embankments, waste land, and other such places, but are not required for work.

This is demonstrated in Fig. 7.7. Ri:e holdings in the central plain of Thailand with but one crop al year show a highly peaked denland in labour for planting and harvesting. Diversified cropping with rice and various other irrigation crops in the northern zone of Thailand shows a better distribution of work, but we still find a pronounced peak in labour demand between November and March. Multiple cropping in the middle rice region of Taiwan is connected with an almost even 


\section{SYSTEMS WITH ARABLE IRRIGATION FARMING}

employment of the family labour. The peaks in labour demand are met by seasonal labour.

Seasonal underemployment in irrigation farming may, however, be reduced or even abolished by an improvement in the water supplies, and wherever continuous cropping is practised employment is found throughout the year. Relay-planting helps to reduce labour peaks at harvest time and when the
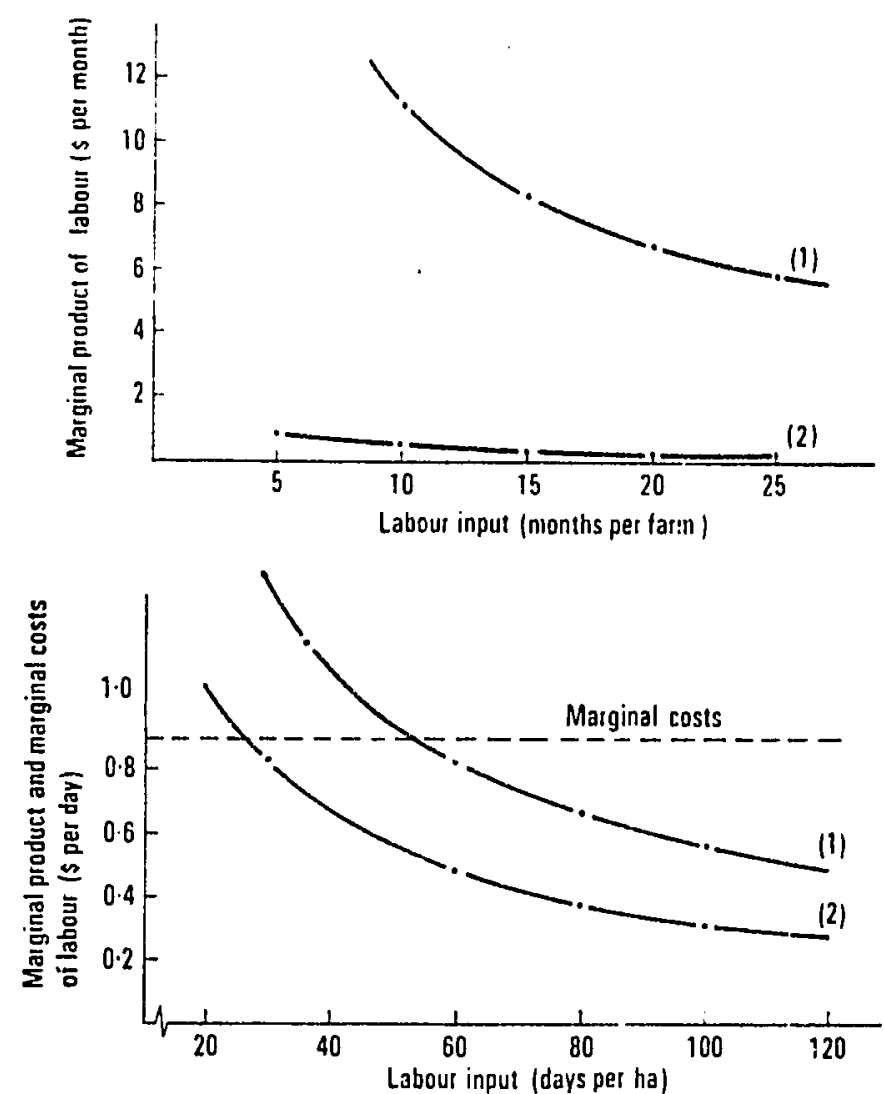

FIG. 7.6. Marginal returns on labour in irrigated and rain-fed farms. (a) (1) Marginal returns per labour month in irrigation areas in West Uttar Pradesh 1955-6. 6.5 farms; average farm size 4.7 ha; average labour input 9.3 months. (2) Marginal relurns jur !abour month in unirrigated farming. Andrha Pradesh 1953-4. 72 farms: average fam, sis 3.7 ha: average labour input 19.6 months. (b) (1) Marginal returns per man-day in 1 ifificially irrigated wet-rice farming in the Philippines 1964-5. 24 farms: average farn size 4 ha; average labour input 75 man-days. (2) Marginal returns per man-day in wet-rice farming with impounded rainfall in the Philippines 1964-5. 12 farms; average farm size 4 ha; average labour input 64 man-days. The coefficients for labour in the production functions are significant. It should not be overlooked, however, that estimates of the marginal return of labour are not free from serious shert-comings (specification bias, multicollinearity, etc.) The functions in the figure are expected to show general tendencies only. From Agrawal and Foreman (1959), cited by Heady and Dillon (1961. p. 621): Barker and Soothipan (1968). 
next planting takes place. Commercial stock-keeping can be another way of creating regular employment for the available labour. It is noticeable, moreover, that irrigated and rain-fed farming combine very well in this respect. The labour requirements of both kinds of holding frequently do not coincide, and the cultivation of rain-fed land, especially in holdings with seasonal irrigation, can help to regulate the use of labour.

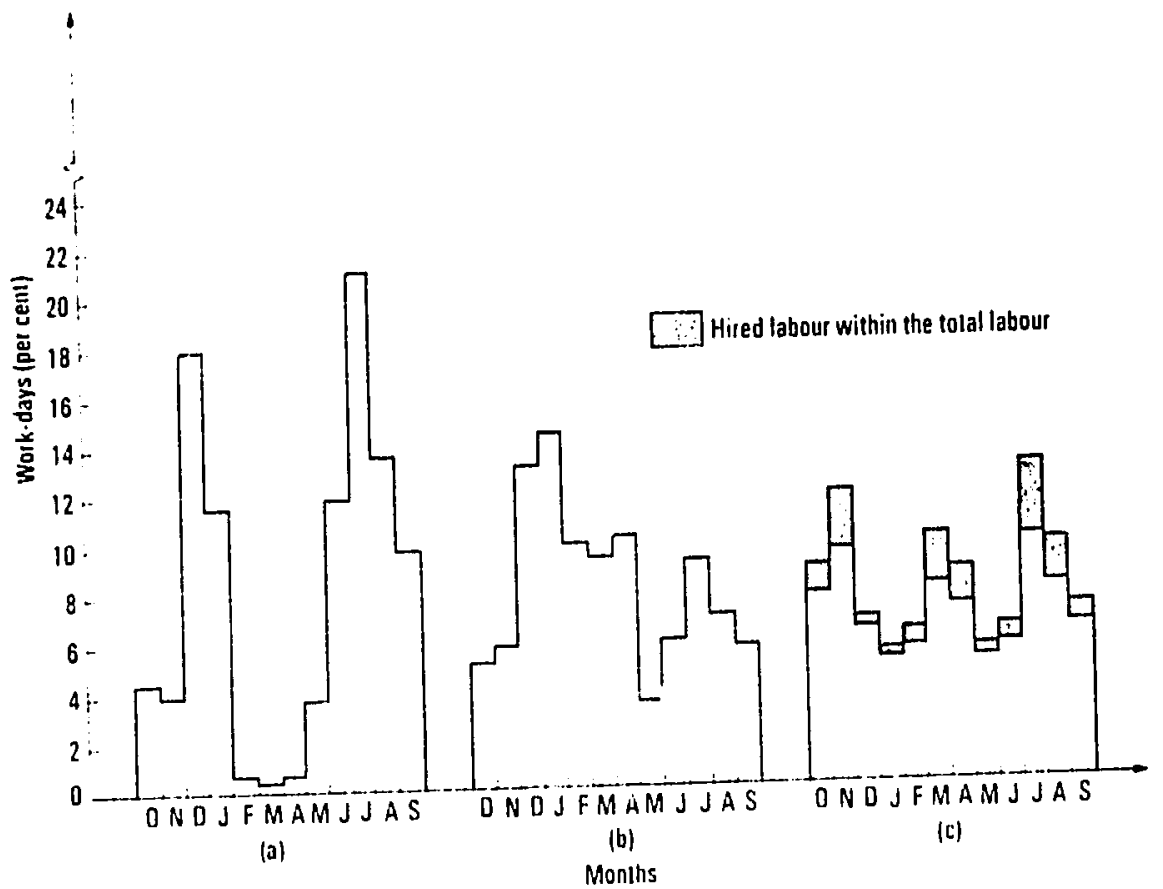

Fig. 7.7. Monthly distribution of work-days on rice holdings in Thailand and on Taiwan. (a) Tha: - nd central plain; monocropping with rice. Total labour input: 1332 work-days at 6 hours per day on 4.7 ha. (b) Thailand northern zone: divarsified cropping with rice and other arable crops. Total labour input: n.a. (c) Taiwan middle rice region; multiple with two rice crops and other arable crops. Total labour input: 501 work-days (a) 0.96 ha. From Kusthungkham and Ong (1964, p. 69); Taiwan agriculture (1966. pp. 174-7): Thailand Ministry of Agriculture (1959. tables 35,39 ).

(d) Better plaming of the labour economy. Another advantage of irrigation farming is bitior labour planning. The labour operations in rain-fed farming depend on rainfall, which fluctuates in quantity and in timing. The irrigator, however, usually knows when he will acquire water. In systems with controlled irrigation. irrigation dates and water quantities can be adjusted to the labour economy of the holding and vice versi. This is especially apparent in intensive wet-rice systems. Neither drought nor rainfall essentially affects the production process, so that planting and weed control can be undertaken 
TABLE 7.4

Farm-management data of irrigation farms with tarious aiable crops in India and Pakistan ${ }^{\mathrm{a}}$

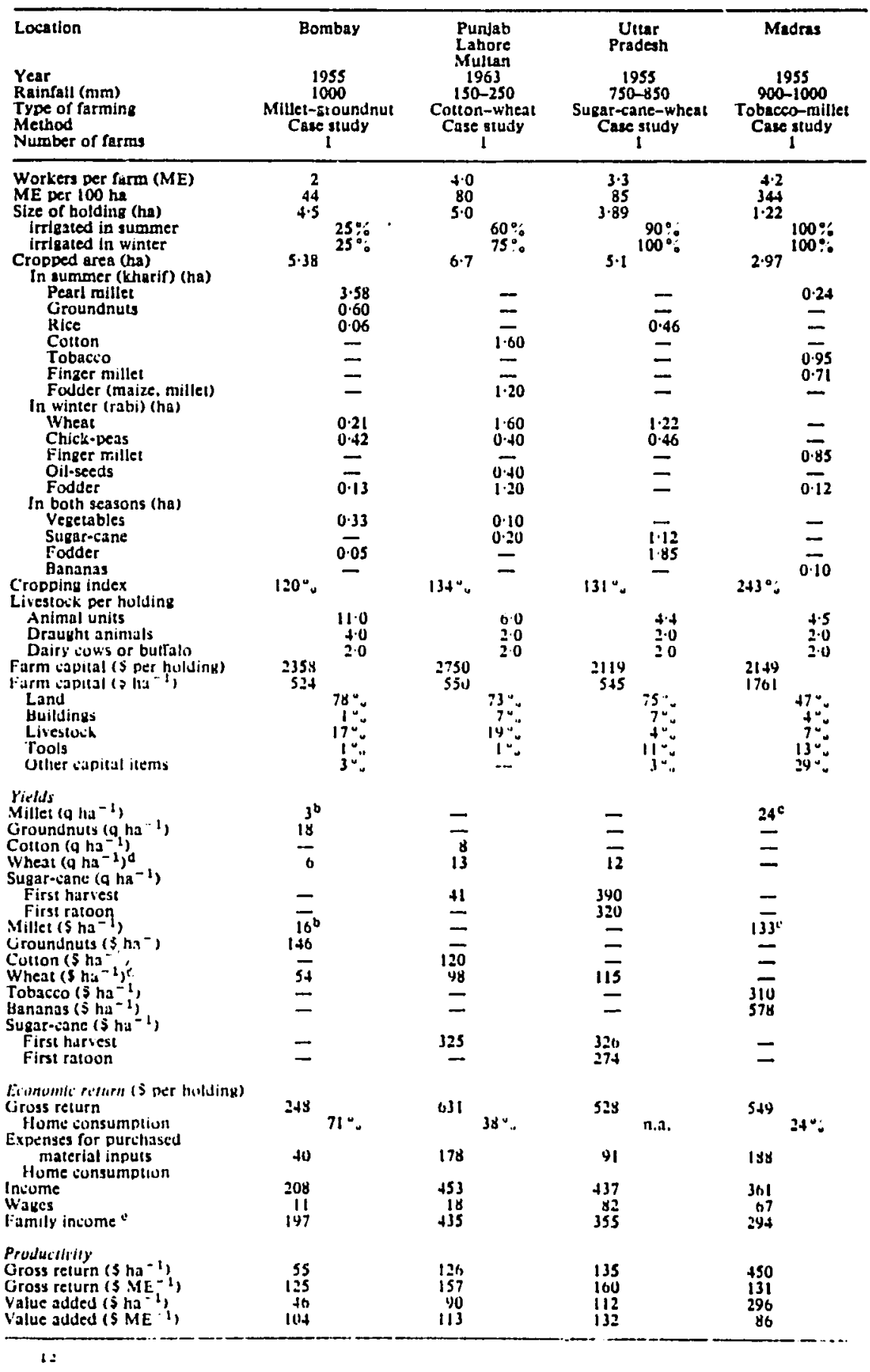




\section{SYSTEMS WITH ARABLE IRRIGATION FARMING}

Rain-fed farming and grazing contribute to irrigation farming in that they supply fodder for cattle and goats, while any stable manure is applied to the irrigated field. Thus stock-keeping helps to accumulate nutrients on the irrigated area. The four work aninals are used for drawing water, and their labour is esscatial for the higher yields per unit arca of the irrigated field. Milk cows, on the other hand, are kept mainly because their bull calves are used as the next generation of draught animals, and thus cattle-keeping as a whole serves primarily' to supply animal power. At the same time, the irrigated area also assists animal-keeping, in that in the dry season an even supply of fodder is guaranteed by planting small plots of fodder sorghum and lucerne.

Only a quarter of the gross yield is sold. and the primary aim of production is to cover subsistence requirements. The family income amounts to $\$ 197$, which corresponds approximately to the income of an Indian farm labourer in 1955. Irrigation in this case affords little more than a bare existence. even when measured against the generally poor conditions in Indian agriculture.

(b) A wheat-cotton holding in the Punjab. The wheat-cotton holding in the Pakistani Punjab demonstrates that. by sowing twice a year, an increase in both the frequency and the extent of cropping is obtained. The water is not sufficient, however, for cultivation of the total area twice a year. In summer, 40 per cent lies fallow and in winter 25 per cent. althougl the total area of land, from the point of view of channel creation and levelling, is irrigable. In these conditions, there is no emphasis on one particular plot, as there is in the millet-groundnut holding mentioned above. Rotational farning, including half-ycarly fallows, is applied on all the land. The farmer concentrates not so much on crops that produce a high return as on crops that can make the best use of the water, which has to be paid for.

Cotton, sorghum, and fodder maize (kharif crops) are cropped in summer. Winter cropping (rabi crops) takes the form mainly of wheat, oil-seed, and chickpeas. Growing berseen (clover), and in January-February fodder maize, guarantees fodder rich in protein during the winter montlis. Double rotations are usual: wheat in winter is followed by cotton or, if a half-year fallow period is introduced, by maize cr rape.

Cattle are kept for two main purposes, namely work and milk production. Almost 7 hectares have to be cropped annually. and to prepare the wheat seedbed with the desi-plough requires 5-10 days labour. Two draught oxen are kept in consequence. Milk is produced by buffalo cows. The stable manure is applied to the cotton, whereas wheat is usually manured with mineral fertilizer. On account of the size of the irrigated area under double cropping and the comparatively high yields per hectare, the gross yields, income, and labour productivity are much higher than in the Bombay example.

Since 1963, when the data were collected. new wheat varieties have been introduced, which, supported by some additional fertilizer, yield 20-30 quintals per hectare, even under average farming conditions. Higher yields of wheat, together with an increase in the area of wheat at the expense of other rabi crops, led to it remarkable improvement of the farm-economic situation compared with 1963.

(c) A sugar-cane-whlceat holding in Utlar Pradesh. In the sugar-cane-wheat holding in Uttar Pradesh, the ample and regular availability of water allows sugarcane, an intensive cash crop, to be cultivated. Household food requirements are met by wheat and rice.

Holdings of this type already have considerable latitude in forming crop rotations. Two-year and three-year crop rotations are practised, encompassing three four, or five crops. The following are examples: 
Two-year rotations: sugar-cane-cotton-arable fodder; sugar-cane-arable fodder-chick-peas

Three-year rotations: maize-wheat/chick-peas-cotton-arable fodder-sugar-cane;

sugar-cane-ratoon-pearl millet-fallow.

In our example, almost a third of the arable land is planted to sugar-cane, which is intensively fertilized with up to 20-30 tons of stable manure per hectare.

Extensive cropping of fodder legumes, particularly berseem, helps to guarantee the yield of sugar-cane, directly through the effect of the rotation and indirectly through animal feed and the resulting stable manure. The wages for seasonal labour constitute a large part of the expenditure. In 1955 from the holding a family income of $\$ 355$ remained. Since 1955 new varieties and mineral fertilizer have been introduced, supported by rising prices in the sixties.

(d) A tobacco-millet holding in Madras State. In the tobacco-millet holding in Madras, 4.2 man-equivalents are employed on 1.22 hectares of arable land. The possibility of intensitication that irrigation offers is being exploited to a high degree. The annual cropped area covers almost 3 hectares. which is 243 per cent of the land available. The land supports two or three crops annually, and they are erops that demand a high level of labour and fertilization. The stress is on the cash crop, tobacio. Houschold food requirements are met by the cropping of finger millet, which produces remarkiably high yields per hectare. Smaller plots are used for arable fodder and baminas. The holding keeps two draught animals and two dairy animals, which grate on communal palsures. The number of cows kept is based only partly on economic considerations, because cow-keeping in this area is still partiy a question of religious tradition.

High cropping intensity involves a high degree of fertilization. and in holdings of his nature, 6 cons of siable mianure per animal unit can be relied on, that is 22 tons per hectare annually with +.5 head of caltle and $1 \cdot 22$ hectares. In acidition, the larmers make compost and buy animal manure, oil-calke. bone-meal, and mineral fertilizer. Another dominating item of expenditure is the keeping of two draught oxen on 1.22 hectares. The estimated costs of keeping draught animals are higher than the e.penditure on manual labour, meitsured in terms of local wage levels. but the farmer cannot manage without draugint animals. since practically 3 hectares have to be cultivated and provided with witer.

On this holding, the high income from cropping each area of land wo or three times ä year largely compensates for the scarcity of land. The fact that full advantage is being taken of the possibilities for intensification through irrigation means that the farmer succeeds in making up for the disadvantage of having a small area of land.

(e) A Chinese type of cegelu ite hohling in Singapore. There is hardly a more intensive farmer or gardener in the world than the Chinese vegetable producer, who has adapted the subtropical Chinese system of market gardening to the humid tropics of south-cast Asia. Table 7.5 shows the farm-management data of a holding of 1.21 hectares in Singapore, run by three brothers. The vegetable gardens occupy the fiat land of the holding, covering not more than 0.6 hectares. The garden land is divided into 127 beds. Dispersed among the beds are five man-made ponds. These not only provide water for the vegetables, but also function as sites for growing water hyacinth, an important source of pig fodder. In addition, they are stocked with tish. The ground between the gardens and the hill slope is occupied by dwellings and farm buildings. The hillside of the holding is left unutilized, except for some fruit trees.

The bulk of the vegetables produced are of the quick-growing, leafy type, mainly 
TABLE 7.5

Farm-management data of a Chinese type of vegetable holding in Singapore

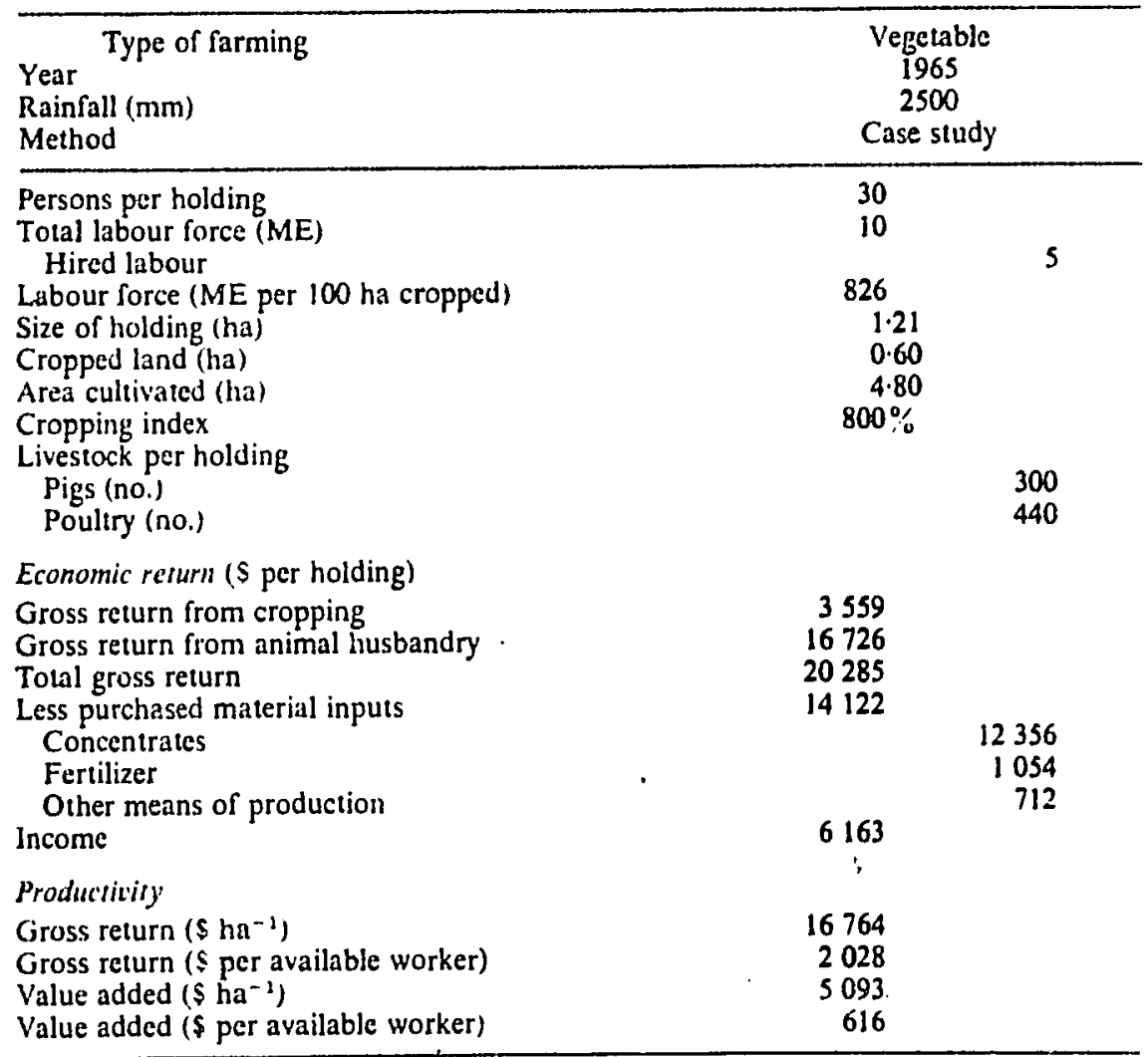

Source: Compiled from Ng Kay Fong, Tan Chee Lian, and R. Wikkramatileke (1966). This publication does not contain a farm-management balance sheet. The figures in this table in some instances had to be derived from various data, and they give only a rough idea of the economic state of the holding.

Brassicaceae. Most of them are grown in stages-first in the nursery beds, and iater in the main production beds. The vegetables usually occupy the production beds for 4-6 weeks. In the afternoon or the morning following the harvest, the beds are planted again. The fallow beds amount normally to not more than $5-10$ per cent of the total. The average number of crops per year and per bed hovers around eight. Fig. 7.8, taken from farms in Hong Kong, shows the sequence of cropping that is typical for this type of farming. The rainfall, amounting to 2500 millimetres annually, is too irregular and inadequate to rely on. The watering of the vegetables is roughly equivalent to an additional rainfall of 1400 millimetres per year.

The land provides hardly more than the physical medium for plant roots. The gardens are fertilized with both farm-produced and purchased fertilizers, including diluted pig manure, chicken droppings, mud from the ponds, compost, prawn dust (a product of the shrimp industry), and mineral fertilizer. Night soil is traditionally used in the farming system, but is no longer allowed for vegetable production. 
SYSTEMS WITH ARABLE IRRIGATION FARMING

The rearing of pigs and poultry, livestock activities which lend themselves to a high turnover, is an important part of the farming system. The pigs are fed on concentrates and on a mash prepared from vegetable waste. Apart from supplying much of the income, livestock also provides an important source of manure. Most of the nutrients are nct imported as purchased fertilizers, but as feeding stuff.

Intensive techniques thus enable the Chinese market gardener to cultivate vegetables successfully in an environr. 2 nt where natural soil fertility is low, rainfall irregular, natural soil aeration often inadequate, solar radiation often too intense, and harmful organisms numerous.

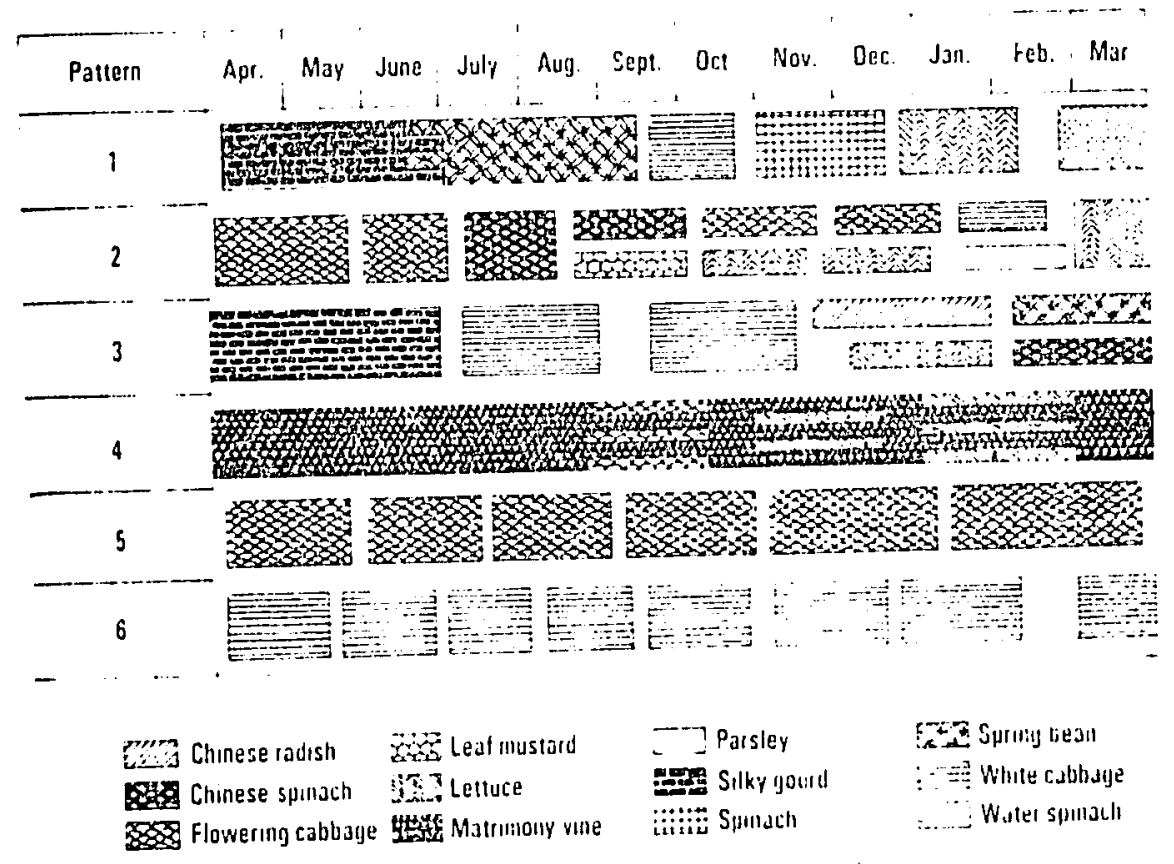

FIG. 7.8. Multiple-cropping system on some Hong Kong farms (irum W'ong 1968).

(f) Conclusions. The examples from India and Pakistan show the influence that differing levels of water availability have on the organization of holdings. In the millet-groundnut holding. the cperative factor from the management point of view is the interrelation between irrigated and non-irrigated fields. In the second example it is the expansion of cash production through double cropping. and in the third it is the growing of a highly priced cash crop. which takes a lot of water and fertilizer. The fourth example illustrates the production possibilities of small plots when a tropical climate, water. good soil, and plentiful fertilizing are combined. Finally, in the Sifth example, the Chinese type of vegetable holding, ample rainfall, an unlimited supply of irrigation water, tropical hea!. close markets. and cultivation in the hands of particularly careful farmers all coincide. At the same time. the decisive 
principle of intensive, tropical, irrigation farming becomes apparent: the concentration of production in a small area, which is worked with a high intensity.

7.4.2. Wet-rice sy'stems: three case studies from East Pakistan, Thailand, and Taiwan

(a) Characteristics of wet-rice cultivation. In climates with heavy rainfall, rice is one of the usual crops in rain-fed farming. particularly aniong shifting cultivators. Much more important than this upland or dry rice is wet rice, or rice cropped on plots that are covered with water permanently, or at least for a lengthy period, during growth. The main types of wet-rice cultivation are as follows:

(1) Real deep-water rice is grown, for example in Bengal, where seeding or planting takes place before the rainy season, and the growth of the rice keeps pace with the rising water. Along some coasts of south-east Asia there are harvests of floating rice, which is sown from a boat and develops rhizomes 6-7 metres long.

(2) In rain-fed farming, rice is normally sown broadcast. This practice is still sometimes retained in irrigation farming, for example in Ceylon and some parts of India, when water is impuunded in the paddy fields after the sowing. This is a procedure that we term the traditional sowing method.

(3) In south-east Asia, rice is traditionally started in a nursery ben, and 6-8 weeks after sowing it is transplanted into the puddled mud of the field. The production is carried out without many purchased inputs. This method is called the traditional south-cast Asin method, but it is common also in Madagascar and is spreading in Africa.

(4) The modernized transplanting method, which is largely influenced by the Japanese method of rice cultivation, is common in Taiwan, and is being introduced into African and other south-east Asian countries, and this is the most intensive method. It differs from the traditional method in its high input of purchased materials and in the special care taken with the nurseries and with cultivation in general.

(5) Whereas the methods named above are based on the use of much manual and some animal labcur, the American method of sowing is characterized by a low manual labour input, extensive use of machinery, and high labour productivity. The soil is prepared with a tractor, and the rice is sown with drills or from aeruplanes and reaped with combini harvesters. Northern Australia and Surinam are tropical arcas where this type of cultivation is practised. Weed killers, which reduce the need for nursery techniques, are beginning to make modern sowing techniques attractive in some low-income countries also.

No other agricultural product in the tropics and subtropics has anything like the same economic importance as wet rice. It constitutes the basis of the 
economy in most Asian countries, and it is expanding in $\Lambda$ frica. The expansion of wet-rice cultivation in the tropics and subtropics is based principally on the following facts:

(1) It permits constant land use, even for centuries, without decline in yields.

(2) It produces high:, certain yields per hectare and consequently allows the concentration of population.

(3) It enjoys a relatively favoured position within traditional agriculture: man!lfactured inputs like mineral fertilizer, herbicides, and implements make wet-rice cropping more productive, but even the rational use of the traditional production factors of soil, work, and water can produce a relatively high yield.

The really important phenomenon is the permanence of rice cropping. Increased population densities in traditional rain-fed systems result sooner or later in a deterioration of the habitat. In a wet-rice region the hatitat remains undamaged. Some areas of Java. for example, support 2000 persons per square kilometre, without any significant decline in rice production per hectare (Geertz 1963, p. 33). Many of the famous terraced slopes in the Philippines have been planted to rice annually for more than 2000 years. Wet rice fosters, therefore, cconomic stability, a dense population, and an advanced civilization. It forms the technical basis for the formation of permanent Kulturlandschaften ${ }^{1}$ in the vet valley bottoms, which contrast noticeably with the shifting cultivation of the adjoining forest landscapes. Experience in tropical Asia shows that these two types of land use represent the two forms of arable farming that are most suited to the productior conditions of a warm. damp climate. On the one hand there is irrigated rice culture. with high population densities, permanent housing. high labour inputs, and high yields per hectare, conquering the difficulties nature presents by conscious manipulation of the countryside. On the other hand there is shifting cultivation, with low population densities, semi-nomadic populations, low labour input. a low yield per hectare of the total area. and adaptation to nature.

In order to practice balanced cultivation where there is a shortage of land it is often essential to make the transition from the most extensive system of land use to one of the most intensive systems. and, in addition, to cuncentrate production in the valleys and plains. The advantage of this transition is not really that there is a higher average return on the labour input. The point is rather that, whereas intensified shifting cultivation is accompanied by rapidly sinking marginal returns from extra labour input, intensified irrigated rice. at least up to a high level of yield, seems to have almost constant marginal returns from extra labour. Low average but comparatively high marginal

\footnotetext{
1 Landscapes ctrongly infuenced by human ellorts to make then useful for man.
} 


\section{SYSTEMS WITH ARABLE IRRIGATION FARMING}

returns characterize the farm-management situation in rice holdings, wherever

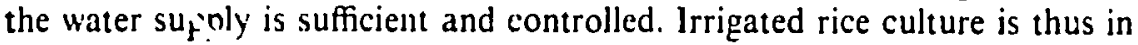
a position to aissorb productively much more labour. At the same time it permits food prociaction to be concentrated in narrowly circumscribed areas, and, with comparatively short transport routes and the concentration of population, the formation of towns can occur. In this way, irrigated rice has laid the foundation for Asian culture.

Rice can be adapted to suit most types of agronomic conditions. It thrives in the mountains and at sea level. in the tropics and in the warmer regions of the temperate zones, on good and on poor soils (with differences in yield of course). in the desert and where there is a heavy rainfall, provided that heat and water are available to a sufficient degree. Irrigated rice is not as strongly affected by wate iogging. floods, and salty soils as other crops. By the cropping of rice, areas that would otherwise be waste land can be opened up for agricul: ural production. In fact, as long as there is a suitable supply of water, some rice can be produced on soils that are too infertile to produce any other graill crop (Jordan 1967, p. 3). Rice grows well on its own-and monocropping is therefore possible - but it can also be included in crop rotations without any difficulty. The various labour operations, like preparation of the soil. planting. and weeding. are largely independent of the weather, provided there is enough water. There are nany varieties, with different growing times (100-200 days), differing demands on soil and climatc. differing abilities to benefit from fertilizer, alid a lange of other characteristics.

In handling and transporting, rice shares the advantage of all cereals over the root crops, while in storage it suffers smaller losses than practicaliy any other tropical food crop. Raw paddy is resistant to insect attack in storage. and parboiled milled rice is similarly resistant. Another advantage of rice as a food is its ease of preparation, and its low requirement of fuel in comparison with bread. Rice also has a high nutritive value, and its protein is of an exceptionally high quality and digestibiity for a vegetable protein, while it is also exceedingly palatable (Jordan 1967, p. 5).

Furthermore. wet-rice production can be fitted into most social and economic structures. Rice cropping is practised in large and small holdings. in countries with high and low wage levels, almost without implements or with a very high investment in machinery. In short, irrigated rice growing is more adapiable than practically any other type of agricultural production. Rice is also an ideal crop for a rapidly developing country, as the technique for its cultivation can be made to keep in line with the development of the country as a whole, and its extent is unlikely to be restricted due to rising economic levels, as may happen with other crops (Jordan 1967. pp. 4-5). It is this adaptability, not only to agronomic conditions but also to social and economic conditions, that makes wet rice so extremely attractive as a crop. 
SYSTEMS WITH ARABLE IRRIGATION FARMING

The basic features in the organization of various types of rice holding can be demonstrated with a few examples taken from rice-jute holdings with an unregulated water supply in Bengal, monocrop rice holdings in Thailand, and a holding with multiple cropping in Taiwan. Table 7.6 contains farmmanagement data of rice holdings in Japan and the United States, so that comparisons may be drawn.

(b) Rire-jute holdings in East and West Bengal. In the Ganges Delta in East Fakistan, 1500-1700 millimetres of rain fall in summer on relatively fertile soils. Ai the beginning of the rainy season the water accumulates in the fields, supplemented by flood water from the rivers. At the end of the rainy season the land is covered with water up to one metre in depth. Thus nature supplies water free, and with it silt and nutrients are introduced. But nature does not supply the water regularly and in optimum amounts: sometimes there is too much water and sometimes too little. Consequently production conditions have been developed that in many respects combine the features of irrigation farming and rain-fed farming, and can therefore be regarded as an intermediate stage between these two forms of land use.

Rice and jute are the main srops. The typical East Bengal holding that is illustrated in Table 7.6 comprises 2.3 hectares of arable land, divided into 22 plots to minimize risk. In the rainy period, the whole plot is cultivated. 1.5 hectares are used for various forms of rice cropping, and 0.3 hectares for jute. Directly after the rainy season, a part of the arable land is cropped with ligumes, wheat, and oil-seed. Total cropping amounts to 3.0 hectares, or 150 per cent of the available area. A rice-jute holding normally includes four head of caltle, of which two are draught oxen. The fodder basis sonsists of rice stralv. fallow grazing, and roadside grazing. There are scarcely any pastures. Stable manure is used as fuel, and if any is left over it is applied to the jute.

In the case of the rice farmers of Bengal-and similar ubservations can be made elsewhere in wet-rice farming-various measures are taken in order to idipt production to an unreliable water supply:

(1) The farm land consists preferably not of one block but of numerous pluts on different soil types and at different altitudes. Some of them are expected to yield reliable returns. In the case study, the alverage farm has 22 plots.

(2) Various varieties are grown. In the area oi the case study there are 25 different rice varieties. The higher the risk of drought on a given plot the greater the preference for quickly maturing varieties (aus). The higher the risk of flooding, the greater the preference for varieties with long stalks $(a m a n)$. There are also distinct varieties for each season.

(3) The hightr the risk, the greater the preference for seeding rice instead of transplanting. Most of the rice in the area of the case study is seeded.

(4) Husbandry practices in nursery establishments are tuned to the reliability of water supplies, i.e. they are the more intensive the higher the 
Table 7.6

Farm-management data of rice farms in East Bcugal (Pakistan). Hest Bengal (India). Thailand, Taiuan, Japan,

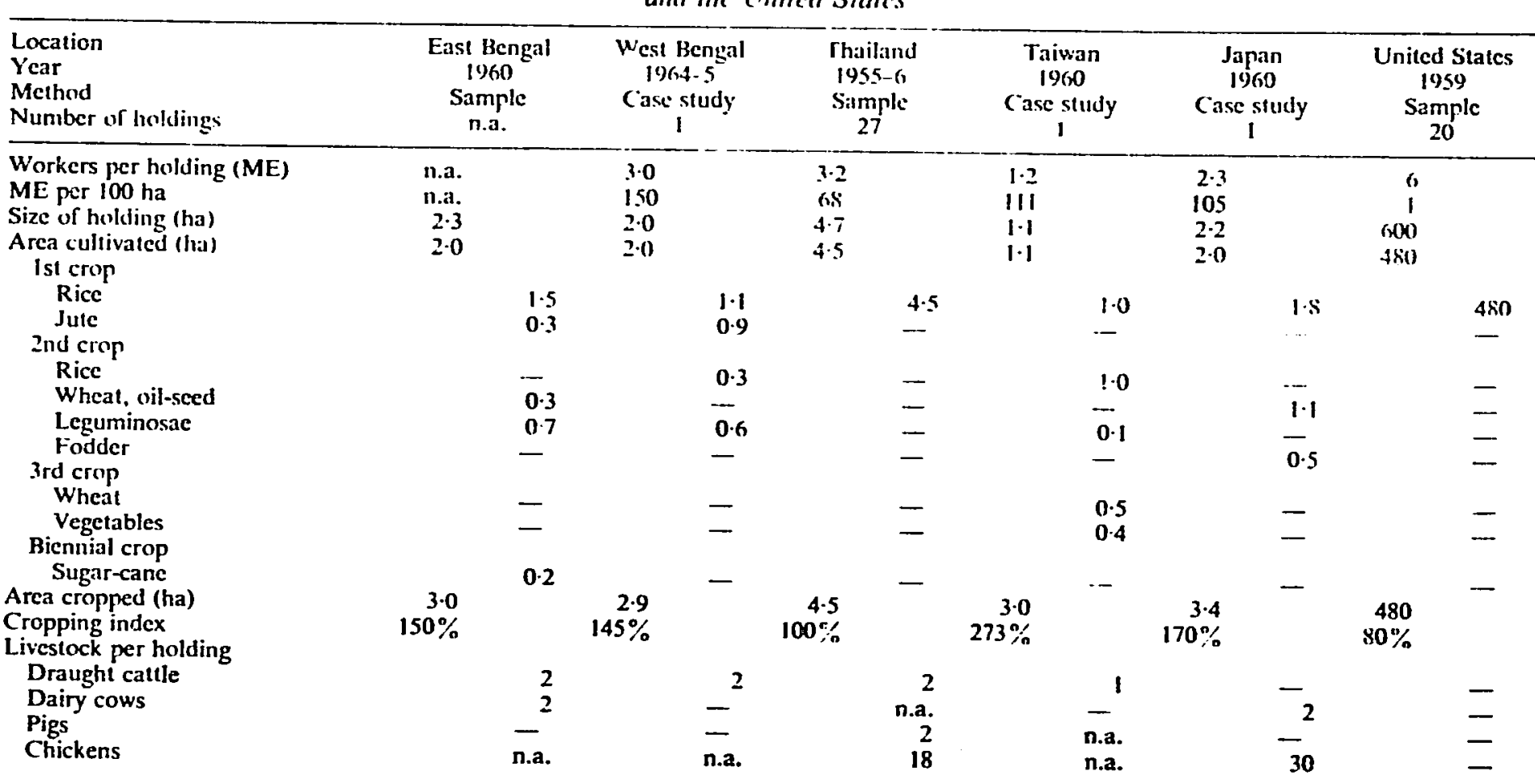




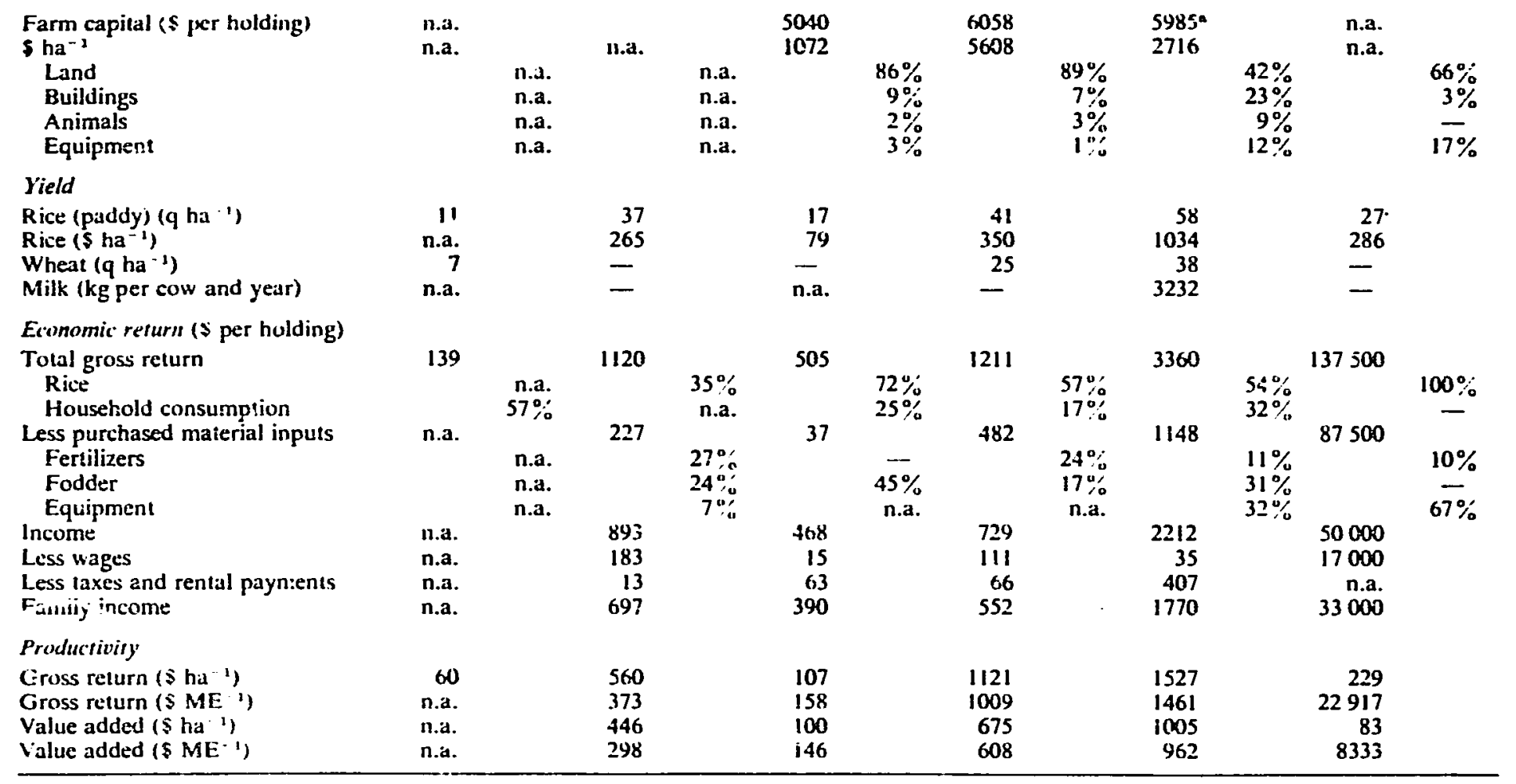

"Tax value, below market value.
Sources: Kung (1962); West Bengal Government (1968, p. 93); Ozbilen (1962-3); Thailand Ministry of Agriculture (1959); Japan Ministry of
Agriculture (1960); Andreae (1964).
East Bengal
1960
Yest Bengal
$1964-5$
Thass-6
Taiwan
1960
Japan
1960
1959 


\section{SYSTEMS WITH ARABLE IRRIGATION FARMING}

chances are that sulficient water will be available when seedlings of an optimum size are available for transplanting.

(5) Transplanting occurs only after heavy rainfall indicates that the monsoon has definitely started. This may mean a loss of time and yield in average years, but risks to production are lower.

(6) Mineral fertilizer is often not applied at the times that would be optimum with reliable water supplies. Many farmers wait until rainfall has been ample enougl to indicate that sufficient water will be available. (This can be observed particularly in areals with unreliable monsoons. as for instance in Madras Stitte.)

(7) Rice farmers with unreliable witer supplies tend to supplement food production by growing crops that yield less per hectare but sinow a high yield reliability. such as various: millets.

(8) Rice serves principally to supply food, whereas jute is the principal commercial crop. It is sensitive to waterlogging in its early stages, and it competes with rice less for the fower ficlds than for the higher ones, where water builds up only when the rainy season is well under way. Jute requires more manual labour (approximately 150 work-days of 8 hours per hectare) than sown rice (approximately 75 work-days of 8 hours per hectare). Harvesting is particularly laborious. for in the months of peak rainfall the jutc. which is standing in deep water, is cut. tied up in bundles. and left to ret.

The rice-jute holdings of East Bengal have considerable production potential. owing to the fertility of the soil and the ample water supply. but development of this potential meets with a number of obstacles:

(1) The irregularity of the water supply is of overwhelming importance. and damage due to flooding as well as drought is frequent. Bengal has a long history of famine. The amount of water required to guarantee yields in irrigation farming is often not available.

(2) As well as the uncertain availability of water, there is the high cost of draught power. According to Ozbilen's investigation (1962-3), there are 133 draught oxen per 100 hectares of arable land, and they burden the holdings disproportionately. because of the fodder that has to be purchased or the amount of fallow grazing required. In other words, provision of feed for the cattle and the expunsion of double cropping compete for land. On the other hand. this type of land-use system must have effective traction power, because it is important to make full use of the best planting
dates as determined by the rainfall.

(3) The second annual planting is difficult, because the water supply is limited to a few months and in the dry season there is no irrigating at all. The sccond crops must manage with the moisture remaining in the soil after the first harvest. These carch crops are predominantly legumes, which 
have a short vegetative period and low yields After a short monsoon there is scarcely any point in a second crop; it is only a practicable proposition in years with a long monsoon and on soils that are able to retain moisture.

The jute-rice holding in West Bengal, which contıasts with that in East Bengal (see Table 7.6), produces under almost identical conditions of soil and climate. It has, however, the advantige of a regular supply of water and is less exposed to looding. The markets of Calcutta are close by and prices are relatively high. Land use is therefore much more intensive; in particular, yields ite higher, thanks to the combined effects of new rice varieties, mineral fertulizer, and controlled irrigation.

(c) Rice holdings in Thailand. In the fertile, comparatively thinly populated rice-growing areas of Burma and Thailand, rice is planted in smiall fields, the paddies, which are seldom larger than 0.5 hectares, and are irrigated by water drawn from the river during the rainy season. They belong to relatively larger export-orientated looklings than in Pakistan. The conditions we find in Nakom-Phatom Province int Thailand illustrate this type of farmirg.

Whereas in the densely populated regions of India or Java rarely more than 2 hectares per holding are used for rice, wo tind here 4.5 licetares of rice. This area supports rice once a vear, year after year, and has done so for centuries. After the rice harvest, the soil quickly dries out, hardens, and lies fallow until the next planting, during which time it serves as grazing. This kind of holding has. apart from the rice fields, a fair-sized garden, work cattle. and some poultry. The fact that a couple of pigs are kept indicates the similarity to the Chinese type of rice holding. where pig-keeping is custonary.

Since harvesting takes place only once a yeur. slow-mlaturing varieties. which produce a comparatively high yield. are preteried. The method of cultivation shows the basic features of the traditional southern Asian rice culcure, namely:

(1) The raising of seedlings in nursery beds.

(2) Levelling and preparation of the walter-overed soil with draught animals, plough, and harrow ( $8-12$ ploughings with iron-shod ploughs. usually not deeper than $3-4$ inches).

(3) Transplanting about two months after germination.

(4) A reasonably well-regulated water supply (in some holdings in the region of this example, water is already conveyed by pumps).

(5) Harvesting of the ears with a knife or sickle. the straw being left for the most part on the fields.

(6) Transportation of the harvest to the farm on dry land by carrying, by sledge. or by bicycle.

(7) Threshing by hand or by the trampling of animals.

(8) Drying of the rice in the sun. 
As the water supply is regulated effectively, the planting method is preferred to the sowing method. and there are indeed obvious advantages: g: owing the seedlings in murserics saves seed, water, and time. since only relatively small areas (a tenth of the cropping area) need to be irrigated in the first two months of growth. The farmers have these two months to prepare the soil and suppress the weeds in the paddies. Moreoter. transplanting produces yields higher than those of sown rice. While the certainty of the yield is also greater. and the crop ripens more el enly. Mudern. intensisc ricegrowing methods are. however. not yet applied. Neither organic nor inorganic fertilizer is common: people rely on the nutrients brough by the water. They de not plant in rows. neither is it customary to combat wecd growth systematically: Between plaming and harvesting. the labour input is limited to the control of the water supply and the scaring of birds from the ripening field. The yields. at about 1.7 lom of paddy per hectare. ate scarcely half of what is normally obtained in Tiliwan.

The main economic feillure of the lype of rice production is that. despie low rice prices, a comparatively high family income is atlained. Rice holdings of this kind are found in countrics that are dependent on the export of rice. and whose farmer consequently receive a low price as producers. In Thailand, this is only 0.05 per States $\$ 0.10$. The holding input is in conseguene per kilogram and in the United holdings in the example input is in consequence limied to land and labour. In the is allotted to equipment hut 86 per ate 7.6. only 3 per cent of the holding capital per holding are kept to 36 . per efent is allotted to the soil. The purchased inputs fodder, mainly for the $: 36$. and of this sum practically half is used for purchasing low prices and the small expendimals. Because of the soil fertility. and despite the is achieved. A large proportion of the production means. at gross return of $\$ 505$ keted. The family proportion of the output, approximately 75 per cent. is marpayment of rent are taken amounts to $\$ 390$, when non-agricultural earnings and income is comparativel high. particularly when wolding area is rented land). This is relatively low on account of the low price of rice.

The economic problem in this type of holding is caused by the fact that the labour and soil potential are insufficiently exploited. The family has at its disposal 3.19 man-equivalents and. with 250 work-days a year. a total of 800 work-days. The holding. however, uses only 362 work-days annually. Planting and harvesting constitute the work peaks, and in the intervening time the farmers have litle to do. In addition to the need for improvement in the method of rice cropping. therefore. there is also the question of full employment of the arailable labour and land by double cropping. Because the soil hardens so quickly, the chances of sowing a second time after the rice harvest are slighi. One solution. already' adopted in some cases. lies in additional irrigation with the help of pumps during the dry season.

(d) A rice farm with multiple cropping in Taichung District. Tainan. The relatively small rice holdings of Taiwan are on an island with a long-term 
SYSTEMS WITH ARABLE IRRIGATION FARMING 175 land shortage. skilled and efficient labourers and farmers, easy access to new technologies, and rising purchasing power. In addition the arion systems Taichung District, ferther control. Consequently, methods of rice production have ombine high productivity per hectare with high productivity per man-hour.

The highly intensive rice-growing method in Taivan, which benefited from Japanese experience, has traditionally been distinguished by:

(1) intensive organic fertilizing (night soil, animal manure, fish, oil-cake. green manure, ash, etc.);

(2) two rice harvests a year where the water supply is sufficient:

and in more recent times by:

(3) varieties that are suited to heavy applications of fertilizer:

(4) a high level of mineral fertilizing in the nursery, at transplanting, and during growth:

(5) treatment of the seed with fungicides:

(6) the employment of pesticides and herbicides:

(7) early transplanting three weeks after sowing;

(8) particular care in nursery techniques and in preparing the field:

(9) planting of rows from north to south to take full advantage of the sunshine:

(10) optimum distances between rows and between plants:

(11) the use of improved implements:

(12) several hoeing and ridging operations (four times in forty days):

(13) the alternation between drainage of water and a high dose of water during the growth period: and

(14) the threshing of the harvest by means of small, stationary threshing machines.

Intensive rice production of this type is practised in the holding depicted in Table 7.6. The total farm area of 1.08 hectares is about average for the island. Multiple cropping reaches the index figure of 273 , which is 1 \%pical for the Taichung District. Spring rice summer rice, and a winter crop (wheat. cabbage, sweet potatoes. seed rape) are usually grown on each plot (see Plate 7.5). The total area cropped thus amounts to 3.00 hectares. In addition, we tind poultry and livestock activities, which contribute about a quarter of the total gross returns. One butialo is kept for cultivation work. Mineral fertilizer and concentrates are the important purchised inputs. $320 \mathrm{~kg} \mathrm{~N}, 200 \mathrm{~kg} \mathrm{P} \mathrm{O}_{5}$, and $200 \mathrm{~kg} \mathrm{~K} . \mathrm{O}$ are applied per hectare and per year.

Multiple cropping, high yields per hectare of each crop, and a high level of liveproduction are the key factors behind the high return per hectare and per holding, and this in spite of the low prices for the products, which are much less than inapan. The gross return amounts to $\$ 1211$. of which 17 per cent is consumed in the hasas. there remains a family income of $\$ 552$. 
For comparison, Table 7.6 includes farm-management data for Japanese and American rice farms. Japanese rice farms differ increasingly from Taiwanese farms because of the introduction of tractor ploughing (single-axle tractors), mechanized harvesting, increased fodder growing, and dairy production. Where dairy animals are kept, the fertilizer economy acquires a different character. The supply of nutrients through mineral fertilizer is replaced more and more by fodder concentrates, whose nutrients reach the soil as stable manure. The return per hectare and per man-equivalent in the Japanese case study is even higher than in Taiwan. This, however, is mainly owing to the higher prices to the producer. The American rice holdings show that michanized rice production combines very high labour productivity with a medium level of returns per hectare.

\subsubsection{Farming systems in large irrigation schemes}

(a) Characteristic's of production under close supervision. Recently, smallholder settlements have been increasingly established in areas that are being opened up for arable farming in large-scale irrigation projects. It is a characteristic of large-scale irrigation developments that there is a great measure of physical interdependence between different users of the water, and, therefore, to achieve maximum benefit, the resources must be planned and operated as part of an integrated system (Carruthers 1968, p. 7). In several countries, large-scale enterprises have been created by the government and are operated by government-backed agencies. The farm-management position of smallholders in these irrigation schemes is different from their position in holdings that obtain water from minor irrigation works. The minor schemes have been set up in the course of time not so much by the use of capital as by work on the part of the local population. For this reason, they rarsly entail high fixed costs. Large irrigation schemes, on the other hand, necessarily involve high fixed costs, and this means high productivity and high water charges. The farmers, who are not as a rule highly experienced in modern irrigation farming, are not in a position to realize the production potential within a reasonably short period after the water has been made available. The answer to the problem is production under close supervision, that is, the obligatory application of modern techniques by all water users. The state, which has the right to distribute land to settlers and to grant water rights, has a "power key' by which it can introduce better techniques. This is selective pressure in the sense that it is used only on those smallholders who are interested in becoming irrigation settlers. They must agree to abide by a series of principles that guarantee technically and economically efficient production. At the same time, participants may retain ownership of the means of production that they possessed previously, or which have come into their possession, with the proviso that they may not dispose of this property just as they please. 
SYSTEMS WITH ARABLE IRRIGATION FARMING

They are dependent in this respect on the rules laid down by the scheme management.

In large irrigation schemes the management functions are usually not in the hands of one man, but partly in the hands of the scheme agency and partly in those of the cultivators.

(1) The project manager runs the framework of the scheme. He sees that production is carried on in an organized fashion; he arranges the acquisi:ion of water, he organizes tractor ploughing, the supply of purchased inputs. and the marketing. His function is that of a strict but benevolent and technically progressive landlord. Cooperative management is hardly feasible in irrigation schemes. The task of distributing water and supervising production is too delicate to be left to a group of people who are the representatives of the irrigators. The successful running of large irrigation schemes obviously requires a high degree of centralized authority (see Wittfogel 1931).

(2) The smallholders do the work delegated to their plot. Within the rules, which are laid down by the project agency and can be organized and enforced on a broad or narrow basis according to the knowledge and the drive of the irrigators, the smallholders operate at their own discretion. Their position is often closer to that of sharecroppers than of independent firmers. Frequently they are tenants.

(3) The irrigators can. if necessary, join lorces and cooperate in certain undertakings. as for example raising credit or selling theil produce. The activities of the cooperative are again supervized by the project manage-

The details supplied by Giglioli (1965, p. 202) give us an iden of the returns of production under close supervision in one of the most successful irrigation schemes in Africa, the iMwen-Tebere irrigation scheme in Kenya. He writes:

Tenants are allocated four one-acre plots as a rice holding. Only one trop of transplanted rice is grown per year... No rotation is practised... The rules are very comprehensive ... and ... particularly detailed on matters relating to cropping practices. water control, absentee ownership, and disposal of the crop. Manligement has rhree disciplinary tools to deal with recalcitrants. These are, in order of increasing severity: written warnings, prosecution and termination of licence. Selection (of tenants) has been limited to the disinherited, and the Clan Committee have a very human tendency to unload onto the Settement the less desirable members of their community... (Nevertheless) in the three years that the Irrigation Rules have been in force only 19 tenants have had their licences terminated (Mwea section only). The basic organizational unit ... is a block of 2400 acres of irrigated rice. supporting 600 families ... The Assistant Agricultural Officer is in charge of all activities on the b!nck... The day to day supervision . . . is in the hands of the Field Assistants. Each man is responsible for 150 tenants... All water control is in the hands of the Settlement staff. A tenant is not allowed to interfere in any way with the water regime in this field ... the Head Water Guard and his Guards are responsible for execution ... The 


\section{SYSTEMS WITH ARABLE IRRIGATION FARMING}

last link in the chain between the Manager and the tenants is constituted by the Head Cultivator ... a tenant selected for his farming and leadership qualities ... The introduction of mechanical cultivation has made possible a degree of planning and discipline and extension unthought of in the past. The orderly progression of cultural operations made possible by mechanization of puddling has produced an atmosphere in which strict discipline can be enforced without opposition... It is now possible to meet every group of tenants ... hefore the beginning of each stage of the cultivation and to indoctrinate them on the measures. Repetitive indoctriıation made possible by mechanization is showing its effectiveness by both the increase in yield and the even distribution of the increase over all the tenants on the Settlement.

Irrigation farming under close supervision combines a number of advantages that characterize small-scale and large-scale farming. The stimulus for efficient production, which is generated by the direct relationship between the individual's efforts and the returns of the land, is maintained. Every irrigator receives an income according to the yield of his land; since the quality and amount of land and other inputs provided for each settler are the same, the yield is mainly a direct reflection of the amount and skill of the labour input. Large-scale operations, such as ploughing or spraying with pesticides, can be organized by the management on a large-field basis. The plots of the irrigators can be arranged in such a way that large machinery can be used efficiently. Innovations like new varieties or crops can easily be introduced by the scheme management.

(b) A case study: the Gezira scheme, in the Sudan. The biggest example of large-scale irrigation farming under close supervision is the Gezira scheme in the Sudan. In the project area, which including extensions comprises 756000 hectares and 73000 tenants, the land was leased or bought from its owners, reorganized, and detaloped for cropping with cotton, sorghum, and various fodder legumes. The division of operations between the government, the scheme management and the tenants is well defined.

The government has four main responsibilities:

(1) It buys or leases the land from its owners and pays small rents.

(2) It builds and maintains dams and the primary and secondary distribution and drainage channels.

(3) It finances the acquisition of water and land development.

(4) Finally, it establishes the scheme management as an autonomous body -the Gezira Board.

The scheme management is responsible for the following functions:

(I) It distributes the land among the leaseholders and enters into lease contracts with them. In the original Gezira area, the smallest irrigation unit is a rectangle of 1420 metres by 292 metres. Each of these blocks is divided up into nine plots, each of $4 \cdot 22$ hectares. Each leaseholder receives one plot of land in four blocks, giving 16.8 hectares altogether. Further 


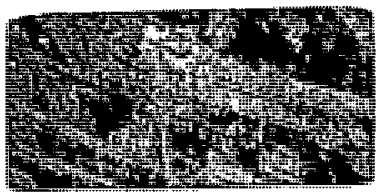

SYSTEMS WITH ARABLE IRRIGATION FARMING 179

subdivisions and amalgamations are permissible. The holdings in the Managil extension are laid out on a smaller scale $(6.3$ hectares), because the original holding size was too great for the tenants' labour force to manage.

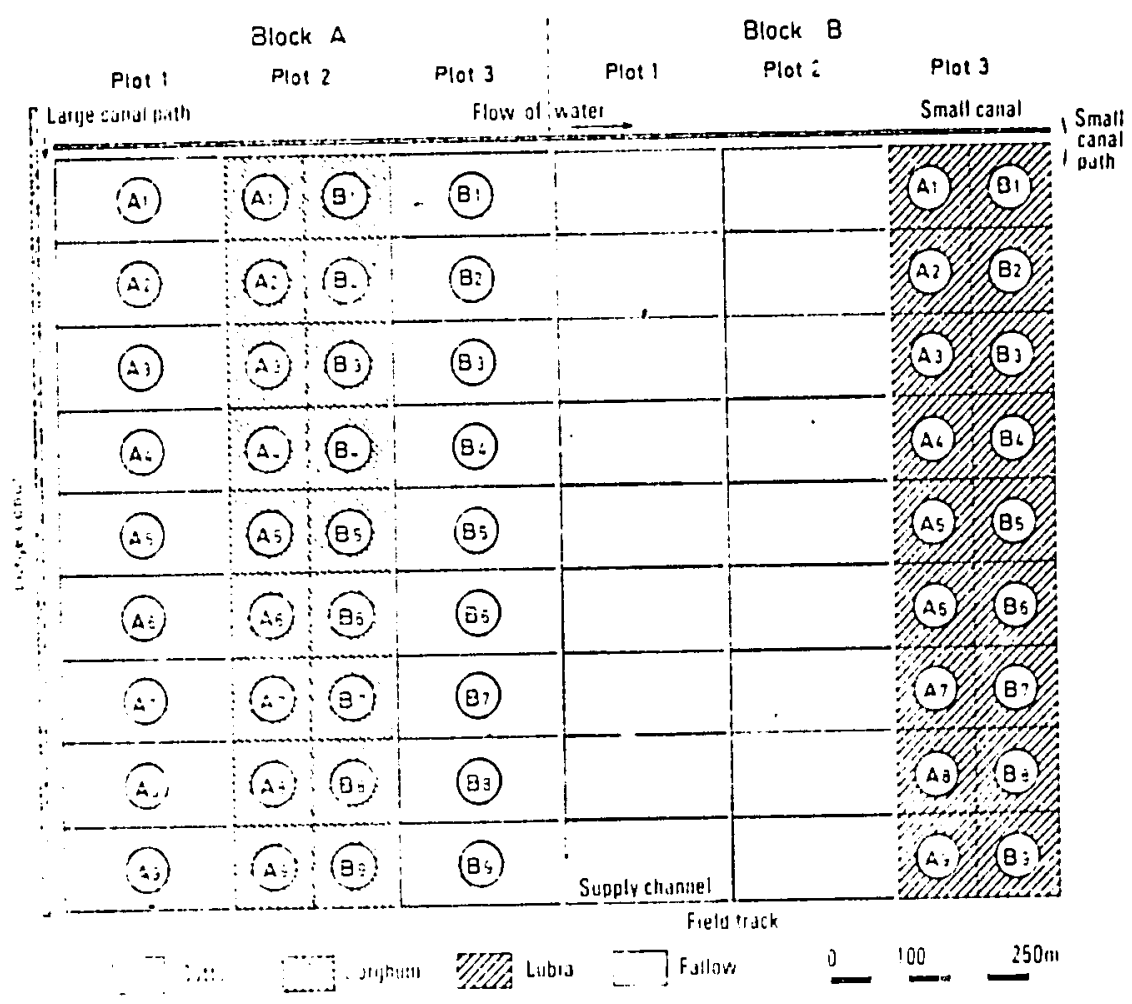

FIG. 7.9. Organization ol water delivery. land use, and field layout in the Mandgil extension of the Geririt scheme, Sudan, Two blocks, each with nine holdings are shown (three plots of $2 \cdot 1$ ha per holdingl. Al and $B 1$ are the cultivators of the lirst strip. calch larming $2 \cdot 1$ ha cotton. 1 1)5 hat wirght'in. and 1.05 ha lubia. From Wörz (1966, p. 33).

(2) Land use is not open to the settler but prescribed by management. The usual crop rotation. embracing eight years, is as follows: cotton-fallowfallow-cotton-fallow-sorghum-lubia( Dolichos lablat)-fallow. In the Managil extension. a six-field crop rotation was introduced: cottonfallow-cotton-lubia-sorghum-fallow. Fig. 7.9 shows the plot division in this rotation and illustrates the connection of smallholder farming with large-field mantagement. Each field is 2.1 hectares in size and forms. with seven others. a unit of 16.8 hectares (see Table 7.7). Each tenant uses his plots in obligatory rotation. Thus, for example, tenant Al uses a cotton field of 2.1 hectures. half a sorghum field, and half a lubia field. In the 
180 SYSTEMS WITH ARABLE IRRIGATION FARMING

following year his cropping is adjusted according to the rotation, but only within the strip that he has been allotted together with the tenant Bl.

(3) It organizes the water supply, maintains the canal systems, and levels the land. The date when the waier is supplied and the amount are determined by the Board. Furrow irrigation is supplied twelve to fifteen times

TABLE 7.7

Farm-management data of a tenant holding in the Gezira, the Sudan (1949)

Source: Versluys (1053-4).

in the growth period of cotton, i.e. 1200 millimetres, which is supplemented by 200-400 millimetres of rain in a year.

(4) The annual preparation of the soil with tractors is also carried out by the scheme management and presents the tenants with land ready to be mechanization.

(5) Seed, mineral fertilizer, and other material inputs are supplied.

(6) Pest control is centrally undertaken by the management. 
(7) It also ensures that operations delegated to the tenants are carried out according to plan.

(8) The transport, preparation, and sale of cotion is centrally organized.

(9) The scheme management organizes the distribution of small amounis of credit for the payment of seasonal labour for cotton picking.

(10) It is responsible for the collection, ginning, sorting, storing, and sale of cotton.

(11) It also finances research.

(12) It supports the social institutions in the project area.

The tenants are assigned special tasks:

(1) They are resporsible for all manual work-seeding, weeding, harvesting, uprooting old cotton stalks, ditch clearance, etc. The work must be carried out at specific times. Each block is under the supervision of a block inspector, who checks the timing of operations in cotton growing, but the tenants are left to do the work themselves, or to employ seasonal workers. (2) The cotton has to be surrendered by them to the scheme management.

(3) Tenants can keep their cattle in the project area. The fallow is used as communal grazing. Cropping of fodder legumes bridges the fodder shortage in the dry season.

(4) Farmein are members of a tenants' organization, which represents the interests of the tenants at the scheme management level.

The harvested crops of sorghum, other crop products, and animal products belong to the tenant in their entirety (sce Table 7.7). The dues of the project management are deducted from $c_{2}$ ton receipts. First of all, those cost items are deducted that have to be carried by the project and the cultivator jointly. These include: mincra! fertilizer, seed, pest control, tractor ploughing for uprooting cotton stalls (which are burned after the harvest), the wages of field guards, the sosts of iransport, processing, and marketing of the cotton, and applied research. The amount remaining after these deductions is distributed as follows: tenants 48 per cent, government of the Sudan 36 per cent, ${ }^{1}$ Gezira Board 10 pei cent, reserve fund of the tenants, social fund, and local communities sech 2 per cent. The payments are apportioned to the individual tenants, and thus each tenant receives an income that amounts to 48 per cent of the value of $h_{i}$ cotton, in addition to the return from his other activities.

\subsection{Weaknesses of the system}

Agricultural innovations during the last decade have increased so rapidly that the gap between actual and optimum output is usually high, and particularly so in irrigation farming. The main weaknesses of irrigation systems

1 The government's share decliricd from 40 per cent in 1965 and the smallholders' share increased from 4.4 per cent in 196.5 and 42 per cent in 1960 . 


\section{SYSTEMS WITH ARABLE IRRIGATION FARMING}

are not inherent in the system âs such, as is the case in shifting systems and generally to a lesser extent in rain-fed farming. The major weaknesses lie rather in the inadequacy of water control, husbandry practices, and irrigation institutions.

\subsubsection{Insufficient control of water supplies}

The most important bottlenecks in irrigation farming are usually the insufficiency and unreliability of vater supplies in the season when water is needed, and waterlogging at other times. This is particularly trus for terraces with wet rics, for minor irrigations with various arable crops, and for the large river plains, where drainage is often a great problem. lrrigation water should be under the centrol of the irrigator at all times, and this is usually not the case. Most of the wet rice in Asia and Africa is grown during the rainy season without a reliable source of watcr. Wert-rice production relying mainly on impounded rainfall rarely exceeds 3.5 tons per hectare, while twice the yield can be expected with controlled irrigation, even without improved practices. The major reasons why wet-rice producers harvest low average yields are primarily outside the control of the individual farmer. The modifications in the environment necessary to achieve effective water controlirrigation and drainage, during both the wet and the dry seasons-will have to come primarily from investment in water-distribution structures. Public investment and communal work are required to narrow the gap between typical and potential yields in wet-rice production (see Ruttan 1966, pp. 32-3).

The failure to develop an effective water storage, transportation, and drainage system in large parts of the tropics is partly die to the physical geograplyy of the areas concerned. Japan and Taiwan, for instance, are characterized by short river valleys anu narrow coastal plains, which lend themselves to locally organized, small-scale, labour-intensive irrigation, and drainage works. Most other rice-growing countries in south-cast Asia and Africa are characterized by broad river valleys and plains. Under these conditions, the physical geography dictates the organization of large systems of water distribution on a national basis. The construction of such systems requires high levels of capital investment. Accomplishment of this scale of investment is held up by the generally low profitability of large-scale irrigation schemes, which is to be attributed mainly to low product prices, and difficult organization and administration.

The rational use of water in minor irrigations, which in terms of area and production potential are even more important than large schemes, suffers for various reasons, the most conspicuous being the following: inappropriate water and land rights, administr ative inadequacies, difficultics in organization of underemployed rural labour witlsout payment in communal work, difficulties in organization of efficient cooperatives for water use, lack of small 
SYSTEMS WITH ARABLE IRRIGATION FARMING

amounts of credit, and lack of incentives for farmers who are prepared to undertake development.

\subsubsection{Wasteful irrigation and husbandry practices}

Wasteful irrigation practices, which prevail in most of the minor irrigation areas, are another drawback of irrigation farming. Much water is lost in field canals because of seepage. Attempts to irrigate iand with an uneven surface generally rcsult in low efficiency of water use and low crop yields. Sufincient drainage is a prerequisite for high yields and the prevention of loss of land due to salting. Misuse of irrigation water, in particular to in soil salinity, water, call cause soll erosion in terms of output per cubic metre of water and and can thus lower efficiency in the sharing of per unit of investment in is bastout water meters, as is customary in minor water on a rotational basis witheut waters, often leads to the uneconomic use irrigations that supply several ir to their full share at each turn, irrespective of water. The users will tend to take their full share at of the water needs of their crops.

Wasteful irrigation practices encouries, mineral fertilizers, and pesticides have tional farming, although new varieties, minesibilities. The numerous problems created a new situation winnovations are dealt with elsewhere. ${ }^{2}$ In this connection, it is necessary to point out that irrigation farming, because of its production potential, depends more on the willingness of farmers to change and on knowledge, skill, ana drive than do other land-use systems. Multiple cropping makes special demands. Preparation of the land, planting, and harvesting can be accomplished several times within a year only if the cultivators are prepared to work hard and to discipline themselves to observe the necessary schedule of work.

\subsubsection{Dependence on inadequate institutional arrangements}

Short-comings due to uncontrolled irrigation and inadequate husbandry practices are, however, only partly a matter of lack of knowledge, skill, and drive. In irrigation systems, closing of the gap between actual and optimum farming depends more than in any other land-use system on institutional arrangements that promote production. This is particularly true of land and water rights.

Irrigation is a practice that relatively few farmers are able to organize on their own. Water storage, supply, and drainage are complex processes that can be carried out only through joint action that will affect a large number of individual farmers. Consequently, the way in which these tinings are organized

\footnotetext{
1 Ruthenberg (1964, 1966, 1967).
} 


\section{SYSTEMS WITH ARABLE IRRIGATION FARMING}

can be a crucial factor in the progress of irrigation farming. Often the functions of land ownership anci water supply on the one hand, and their use in farming on the other, are divided between different people: the private or public landlord and the smallholder. A practice detrimental to irrigation farming in such a situation is sharecropping, wlich reduces the incentives for intensification. On the other hand, a high fixed monetary charge per unit of land, in the form of either a land or a water charge, although highly effecive in introducing intensive farming, is politically difficult to implement. In some regions, where the normal rainfall is adequate, the farmers tend to regard irrigation only as an insurance against years with insufficient rainfall, because water is free of charge or there is no fixed water charge sufficiently high to induce more intensive farming.

A number of projects that have been operating for years-the Gezira scheme in the Sudan is the nost famous example-show that irrigation farming under close supervision allows modern farming techniques to be used by unskilled smaltholders where required. Production under close supervision, however, is not a generally applicable princip?e. The approach shows several weaknesses, the most important of which seem to be the following:

(1) High costs of supervision and mechanization have to be borne either by the tenants or the government. Projects must be large enough io work economically. Since the scherne managements only rarely have any competition to contend with, there is the danger that top-heavy, authoritarian, and arbitrary bureaucracies might develop.

(2) The layout has to be simple and uniform. Concentration on one or two major cash crops is advisable. The patterns of land use are necessarily rigid. Smallholder farming under close supervjsion is not characterized by variety in cropping like other types of irrigated smallholder farming, though this variety helps to increase yields and reduce risk.

(3) The tenants are inclined to emplny labourers and to become miniature landlords. The more compulsive and complete the supervision is, the smaller the scope for individual initiative and the less willing farmers are to invest in their holdings.

(4) Production under close supervision is usually unpopular, and the success of production depends, therefore, upon political backing. The participants very rapidly feel themselves to be capable of running the production properly without supervision, an opinion that is not as a rule confirmed in actual practice.

Minor irrigation areas are too snall to be organized along the lines of production under close supervision. The traditional landlord, who had the authority to distribute or sell water economically, has largely been abolished by land reforms, but most of them were neither benevolent nor technically progressive. Cooperatives may fill the gap, but experience shows that it is 
very difficult indeed to organize irrigation properly without the backing of some outside authority, and this suns contrary to the principle of cooperative action.

\subsection{Devolopment paths of irrigation farming}

Further development of holdings with arable irrigation farming will lead to fundamentally difierent land-use systems only in exceptional cases. The change to irrigated tree crops or to irrigated pasture are two relevant possibilities. The return to extensive grazing is another possibility where land is lost die to salting. As a rule, the real issue for farm managernent is how to increase production within the framework of arable irrigation farming. The following basic possibilities present themselves:

(1) Increase of the irrigated area, by increase of water supplies; or obtaining of a more efficient use of the available water.

(2) Increase in the land productivity, by getting higher yislds per crop cultivated; change to higher yielding crops; and increase in multiple cropping to get higher output per month and per hectare.

Irrigation farming in Japan and Taiwan is particularly advanced in its use of these possibilities. Although the ecology of much of the tropics and the price relationships that usually prevail rule out a direct transfer of the production techniques of these two countries, some of the principles successfully applied in economically advanced countries of high population density may be taken as indicators to the development path of other irrigation systems in the tropics.

\subsubsection{Innovations and improved husbandry}

There is much scope for economizing on water use in irrigation farming. Carruthers $(1969$, p. 34) summarizes the relevant approaches in the following way:

(1) Adaptation of cropping pattern to the availability and the reliability of water supplies.

(2) Allowing crops to draw upon stored soil moisture.

(3) Allowing crops to suffer water stress for some time, if this can contribute to increasing overall production with the given resources of water, labour, and capital.

(4) Fulfilment of leaching requirements at times of the year when there is no peak demand for water.

These are economic rather than technical criteria for determining water application. Furthermore, there is a good chance that imporiant watersaving innovations might be developed in the near future. A case in point is the replacement of the continuous flooding of rice by intermittent irrigation. 


\section{SYSTEMS WITH ARABLE IRRIGATION FARMING}

Even more important in the short run are innovations in plant development. A two-fold or three-fold increase in yields per hectare and per crop under field conditions can be realized in extended areas, thanks to the interaction between improved irrigation, improved varieties, increased application of mineral fertilizer, the use of pesticides in combination with proper nursery techniques, planting, and weeding. Particularly far-reaching is the impact on rice production. In fully irrigated areas with traditional farming it was common for average yields to hover around 2-3 tons per hectare in the wet season and 2.5-3.5 tons in the dry season, with some particularly careful farmers reaching yields of about $4-5$ tons. The new rice varieties seem to have a yield potential under field conditions of $\epsilon$ tons in the wet season and 8 tons in the dry season (Ruttan 1966, p. 32).

The general principle is illustrated ty Fig. 7.10, which shows the interaction between the application of nitrogen and lise of rice varieties of the short, erect type. These varieties show several advantages compared with improved indigenous tall varieties:

(1) They have superior yield-increasing characteristics like a high number of effective tillers per crown, a large number of grains per panicle, heavy grains giving a high 1000-grain weight, and a large number of fertile grains per panicle.

(2) They are early maturing, thus making it possible to expand multiple cropping.

(3) They are not sensitive to the length of the day, i.e. they can be grown in any season.

These advantages are clearly more important than the disadvantages, which are higher susceptibility to various plant diseases, less straw, and slightly different cooking qualities.

Innovations in irrigation and plant development thus offer much scope for economies of scale by increasing the output on a given area.

\subsubsection{Irrigation farming and mechanization}

Most tropical irrigation farıning relies mainly on hand labour and animal power. Mechanization has been introduced to a significant degree oniy in large schemes with controlled production. There is, however, some evidence from the subtropics that irrigation farming, mechanization, and employment are largely complementary to each other. Furrow irrigation and the use of machinery combine well, because levelling of the land fo: the furrows usually leads to even fields of sufficient si<e for tractor ploughing and ridging. A principal disadvantage of basin irigation is that the small dams which keep the water in numerous small basins interfere with the movement of animaldrawn or tractcr-drawn equipment. In Japan, however, established and 
SYSTEMS WITH ARABLE IRRIGATION FARMING 187 economically promising prototypes for mechanization of small farms with basin irrigation have been developed. In rain-fed farming, farm machinery often replaces farm labour. In irrigation this is frequently not the case,

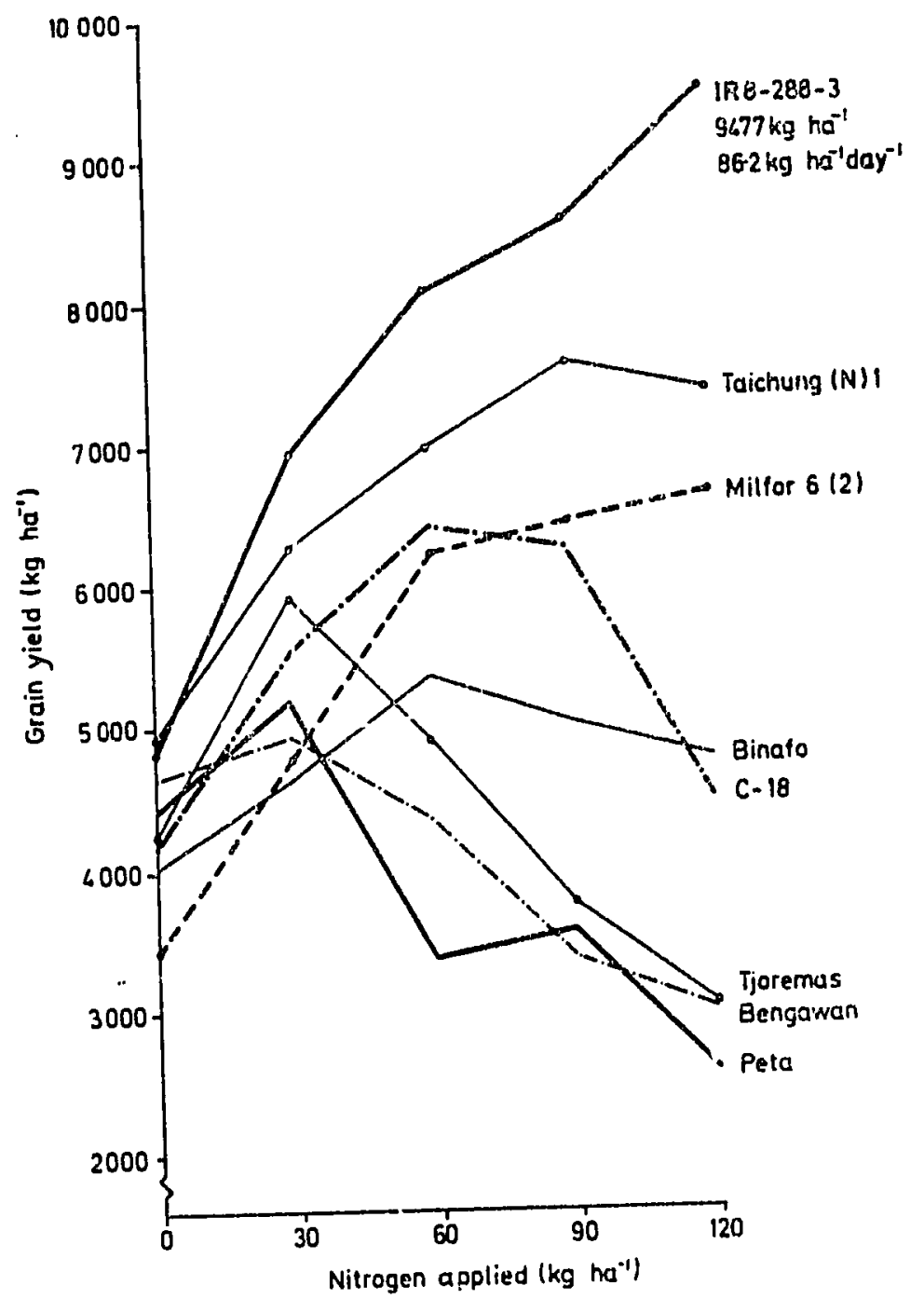

Fio. 7.10. Responses of difierent varieties of rice to nitrogen fertilization (from Bradfield 1968).

because tractor ploughing eases the peaks in demand for traction power, and this may make increased multiple cropping possible. The tractor may also be used for pumping, and thus may increase the irrigated area and the reliability of water supplies. 


\section{SYSTEMS WITH ARABLE IRRIGATION FARMING}

The scope for multiplc cropping in systems with adequatc irrigation depends largely on operations being carried out rapidly at the right time. The bottlenecks often arise in periods of only a few days, when there is insufticient labour available to carry out tasks whose timing is particularly critical. Intensive irrigation farming, even in smallholdings with arnple labour, can therefore be stimulated by improved implements, in particular single-axle tractors. Where the ratio between input and return justifies the use of tractors, they are introdued into irrigation systems relatively quickly, and bring about particularly conspicuous production increases.

\subsubsection{Introduction of intensive types of animal husbandry}

As the tractor replaces the draught animal, the tendency in irrigation holdings is increasingly to introduce intensive types of animal husbandry, dairying in particular. In any case, harvest residues and grass growth on the edges of tracks and canals usually provide fooder that cannot be used in any other way. There are the additional possibilities of multiple cropping with fodder crops, and the introduction of fodder plants into the rotation. With various grasses like elephant grass, Setaria splendida, and Guatemala grass, yields of 50-100 tons fresh weight per hectare and per year can be attained with irrigation. It will perhaps be easier to cover the rapidly growing need for animal protein in iropical countries by intensification of animal activities in irrigation farming (fish, poultry. pigs, and milk) rather than by improved grazing in hill country or dry areas (ranching). The production of milk and beef on intensively irrigated grassland, with lygh returns per hectare, might perhaps be a morc economic and realistic approach to the development of a tropical cattle industry than any preoccupation with large grazing areas of low productivity. 


\section{Systems with perennial crops}

\subsection{Definiviton and genesis}

\subsubsection{Definition}

A FORH of land use in the humid savannas and the rainforest areas, and as typical as shifting cultivation and irrigation farming, is the cultivation of perennial crops, primarily tree and shrub crops with growth cycles of several decades. Crops like sugar-cane, pineapple, and sisal, which eccupy the land for several years but not for as long as shrubs or tiees, are akin to arable crops from a farm-management point of view, and are best regarded as perennial field crops. Bananas are also included in this category, although the farmmanagement characteristics of bananas are distinctive.

Palms, trees, bushes, bananas, and various perennial field crops are grown in gardens and fields under alınost all tropical farming systems. This chapter, however, is concerned with those farming systems in which perenrial crops are the main activity, in terms of their contribution to the gross return. Perennial crops are growa in estates and smallholdings. The terms 'estate' and 'plantation' usually designate large units. To avoid confusion, any land that is planted with perennial crops will be called a plantation and the corresponding holding an estate, provided it is large in area and operated by a large number of paid workers.

\subsubsection{Genesis}

Plantations of peranizial crops, in particular of tree and shrub crops, may come into existence in various ways. Large estates prefer to clear and plant, and where land is ample estates tend to shift their plantations either within the estate's boundary or by acquiring virgin land, i.e. to clear new land and to abandon run-down sites. Until recently, shifting of this kind was practised with cofiee in southern Biazil, and it is at present spreading into Paraguay. Intra-farm shifting was customary for Central American banana estates and East African sisal estates that had suficient land in reserve. But as land besomes scarce, plantations tend to become stationary within the estate boundary.

The genesis of snallholder plantations does not usually follow the sequence clear and plant. Two main types of development in smaliholder plantations are distinguishable. The development sequence: 
(1) exploitation of fruit trees or palms that grow naturally in forests or exploitation of infillings (irregularly planted seedlings) in the forest;

(2) exploitation of systematically established plantations under the cover of some remaining forest trees; and

(3) exploitation of systematically established plantations with no forest trees left;

is characteristic of the way coffee cropping has developed in Ethiopia, West Africa, and Madagascar, and oil-palms and cacao in many areas of West Africa have evolved in a similar manner. Plantations are developed directly from forest vegetation mainly where there are extensive forest areas. However, more frequently the evolution of smallholder plantations has followed a different sequence, srenming from shifting and semi-permanent arable farming. It usually includes four phases:

(1) The planting of perennial crops around the house slows down the rotation cycle of shifting cultivators.

(2) The area devoted to perennial crops is extended. Cleared plots with arable crops are interplanted with perennial plants.

(3) In time, the perennial crops predominate in the mixed-cropping system, and young stands of tiee crops are usually interplanted with arable crops.

(4) As the perennial crop creates more and more shade, intercropping becomes less important.

When this occurs, the cycle arable cultivation-fallow is replaced by the sequence arable cropping-perennial crops, and at the same time shifting systems become stationary. Perennial-crop cultivation does not, however, always lead to stationary farming. The abandonment of old plantations and the establishment of new ones, i.c. the slow shifting of tree-crop production, can also be found. The slow movement of cocoa holdings in forest areas of Ghana is a case in point. Generally, however, the introduction into smallholdings of commercial production with perennial crops is associated with stationary farming. Groeneveld (1968, p. 222) and Meillassoux (1964) illustrate how cultivation of shrub or tree crops is integrated into an arable system.

Figure 8.1 shows the establishment of smallholder coconut-palm plantations. Manioc, maize, peas, or beans, and also coconut-palm seedlings are planted or sown on one plot simultaneously. The annial crops, maize, beans, and peas are harvested after three to five months. Their harvest also provides the final weeding for the manioc. The manioc harvest commences 13-15 months after planting and continues on the same plot up to the twenty-fourth month. The planting of manioc, peas, and beans is repeated on two to three consecutive occasions. Meanwhile, the young coconut-palms are growing. By weeding the arable crops and thereby preventing the bush from regenerating, the farmer also protects the palms. After four to six years, arable cultivation comes to an end. The plot is left to the coconut-palms, which at this time yield their first nuts. A fallow ensues after three to four manioc cycles and 
can extend over several decades. In the meantime (eight to ten years after the first planting), the coconut-palms have grown so large that the regererating bush can no longer endanger their development. The establishment of smallholder coconut plantations is thus a by-product of arable subsistence farming. The stands of coconut-palms are set up without expenditure for clearance and care, since the planting proceeds almost without cost and efiort as a consequence of the manioc cultivation. On the other hand, palm development is slower, owing to interculture. It should be noted, however, that the area of coconut-palms is dependelt upon the extent of

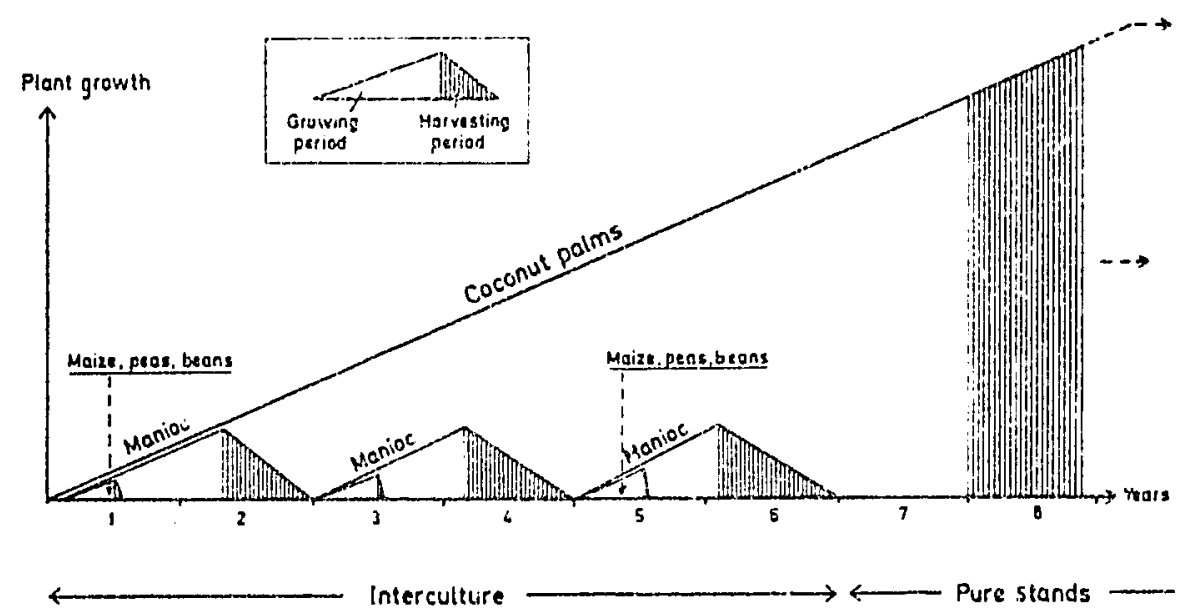

FIG. 8.1. Interculture of coconut-palms and various arable crops, Tanga, Tnnzania (from Groeneveld 1968, p. 223).

manioc cultivation, since young palms are planted only where manioc is cultivated on freshly clcared bushland with soils suitable for coconut-palms. Planting of additional coconut-palms would give rise to high expenditure for clearing and tending the palms solely for their own sake.

Figure 8.2 provides an example of this type of cropping from the Ivory Coast. Whereas in the manioc-coconut system the permanent crop is planted right at the beginning of the cropping cycle, the smallholders of the Ivory Coast plant their coffee later. After clearing the land, yams and manioc are grown, interplanted with short-term crops like groundnuts and beans. About a year after clearance, coffee is interplanted, and occupies the plot for fifteen to thirty years, together with spontaneous bush.

\subsection{Types of iarming with perennial crops and thoir geographical distribution}

The various ways in which plantations are established give rise to different types of farming with perennial crops, which can be conveniently classified according to their cropping and exploitation systenis. 


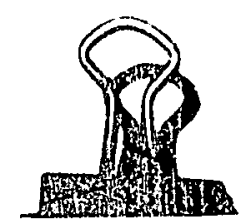

\subsubsection{Cropping systems}

On the $b$ ssis of the length of the vegetation cycle and the amount of cultivation involved, the following cropping systems can be distinguished:

(a) Perennial field crops. Here, we include sugar-cane, pineapple, sisal. bananas, and other similar types, which do not have the characteristics of shrubs or trees. With the notable exception of bananas, they mostly require a considerable degree of cultivation, and can thus be considered from the farm-management angle as something between arable farming and tree crops.

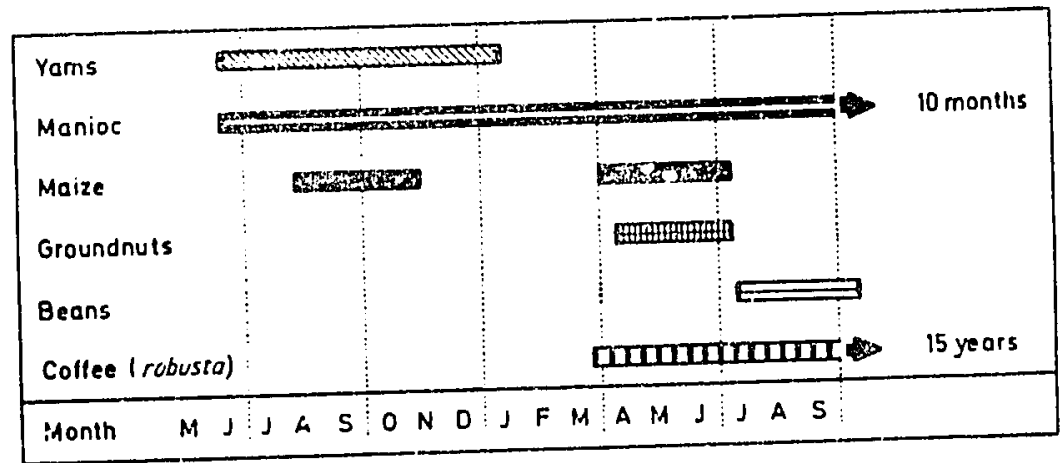

Fio. 8.2. Interplanting of coffee into arable piots of shifting cultivators with stationary housing, Ivory Coast (from Mcillassoux 1964).

Where these crops are grown for export, cultivation and the transportation of the harvested produce are often largely mechanized. Crops of this kind are therefore grown principally on large estates. The regions where they can be grown are determined not so much by climate and soil conditions as by the availability of markets, transport, labour, ard technical knowledge.

(b) Shrub crops. Coffee ant tea are typical shrub crops. The vegetation cycle lasts longer than that of tin perp-uslal field crops mentioned above. Shrub crops usualiy differ from tree crops in the high input of manual labour required for weeding and pruning. They usually yield an end product that requires early processing and can thus be transported subsequently at relatively low costs. Tea-cropping and coffee-cropping areas are therefore determined principaliy by soil and climatic conditions.

(c) Tree crops. Finally, tree crops like cocoa, rubber, coconul-palms, and oil-palms constitute another group. The difference between them and other perennial crops is their particularly long vegetation cycles, and the lower labour input required for their maintenance and weeding. Work in a tree planiation is usually less strenuous than with shrub crops, and takes place largely in the shade. 


\subsubsection{Exploitation systems}

Whereas arable farming in the tropics has been from time immemorial a domain of the smallholder, until the twentieth century cultivation of perennial crups for cash was carried out mainly in large estat:s. However, this distinct:on no longer applies. Platutations vary in size from very large estates of over several thousand hectares down to only a few shrubs and trees. Almost all types of perennial crop are grown in large estates as well as in smailholdings, although some are better suited to large-scale production than others, and are mainly to be found in estates. The distinction between cropping systems is, therefore, in many respects a distinction between large-scale and smallscale production.

(a) Estates. Although virtually all perennial crops are grown by smallholders, whose production tends to increase steadily, there is still important large-scale production, of which the following are the most important examples:

(1) sugar-cane estates in almost all tropical regions;

(2) banana estates in Latin America and West Africa;

(3) sisal estates in East Africa, Indonesia, and Madagascar;

(4) tea estates in India. Ceylon. and East Africa;

(5) rubber estates in Liberia, Malaysia, Ceylon, and Indonesia;

(6) oil-palm estates in West Africa, Malaysia, and Indonesia;

(7) coffee estates in El Salvador, Brazil, Kenya, Angola, etc.;

(8) coconut estates in Malaysia, Ceylon, Indonesia, India, and the Philippines.

In estate production, a distinction can be made between individual planters and firms, the former operating usually fairly small estates. In the normal way, the owner of the small planiation is also the estate manager, and he owns only one estate. This form of undertaking in the tropics is typified on the one hand by the shortage of working capital, exposure to risks, and often obsolete technology, and on the other by adaptability and low overheacls. Firms, howiver, usually each own several estates. The tendency to cultivate very large areas spring from the necessity to use industrial processing and transport to their utmost capacity, in order to recoup the high costs of overheads through ecorionies of scalc. The motive underlyirng this kind of large-scale preduction is frequcritly to obtain a regular supply of goods of constant quality, whether for delivery to a factory (tea and sisal), or for delivery to an established market (export bananas). Almost always, production of this kind is associated with well-developed, reliable marketing outlets. The producing firms often regard their farming activities as a necessary evil, undertaken only because other farmers are not in a position to provide the raw materials in the desired way. On estates, emphasis is often laid more on 


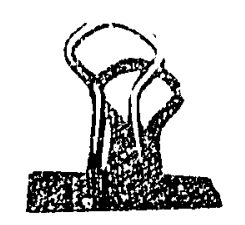

194

SYSTEMS WITH PERENNIAL CROPS

industrial processing and the organizition of transport than on producing the raw material.

Large-scale cultivation of perennial crops is found usually in the form of pure stands, and there is an obvious trend towards monoculture. This is for a number of reasons:

(1) The producer is interested only in obtaining large quantities of a single raw macerial.

(2) Where monoculture is carried out, unskilled laoour can be more easily supervised and brought to a relatively high degrce of productivity.

(3) A relatively large part of the cost consists of paying the wages that managers can command, and diversified production is not worth while in many cases because additional skilled personnel would he required.

(4) The production conditions favour monoculture. With a number of perennial crops, labour is required so regularly that it is not necessary to diversify production in order to find productive employment all the year round for the labour ferce. Monoculture does not inevitably lead to soil erosion. Indeed, with several perennial crops monoculture can even be termed soil-conserving compared with arable farming.

(5) Whereas smallholders usually have to operaie where they are settled, and adapt to the natural habitat, and are thus cornpelled to diversify production, the firm can select the most favourable economic and natural location, which is chiefly on land suitable for monoculture.

In addition to estates with monoculture of perennial crops, Jiversified large-scale estates occlir that are engaged in other activities to supplement the main crop. The following forms can be distinguished:

(1) The predorninnnt tree crop may be supplemented by one or several other perennial crops, which can be integrated either by mixed croppingfor instance bananas under coconut-palms-or by part of the land carrying another perennial crop.

(2) The perennial crop may oe supplemented by arable farming. Managers of estates choose only rarely to grow arable crops between the rows of tree or shrub crops. Instead, they prefer to use separate plots, as for example in the coffce holdings in Brazil, which grow maize, rice, cotton, groundnuts, and onions (see \$8.5.1. (a)).

(3) Perennial crops may be supplemented by stock-keeping, particularly cattle, for example, dairying in the cofice estates of Brazil, beef production in some sisal estates of East Africa, and dairying among the coconut-palms in Ceylon and East Africa.

The motives behind diversification in estates are different in kind from those in smallholdings. Subsistence needs do not play a great part, since in 
general the workers are allocated some land to cover their food requirements. Hardly any draught animais are kept, which means that there is no need to crop fodder. Similariy, the idea behind diversification is rarely to employ the available labour force more regulariy and to its eapacity, since many of the cstates have seasonal latour at their disposal in the surrounding countryside. Reduction of risk by a more varied production is of more importance, but there are two factors that are usually vital to diversification: the need to make better use of soils with different fertility, and the wish to exploit favourable marketing prospects. These two motives are inanifested particularly ciearly where there is a shortage of land, and where urban markets have been developed with a demand for a diversified supply of farm producc.

(b) Smallholelings. A large and growing proportion of perennial crop cultivation is in the hands of smallholders. Of particular importance for the worid's economy are the semi-commercialized holdings, for example:

(!) the cocoa holdings in Ghana, Nigeria, and Trinidad;

(2) the rubber holdings in Malaysia, Nigeria, and Ceylon;

(3) the coffee holdings in Colombia, the Ivory Coast, Kenya, and Madagascar;

(4) the oil-palm holdings in West Africa;

(5) the coconuı-palm holdings in the Philippines, Ceyion, Venezuela, and Sarnoa;

(6) cashew nolcings in India, Tanzania, and Mrzambique;

(7) vanilla holdings in Mariagascar;

(8) sisal holdings in north-east Brazil; and

(9) banana holdings in Central America, South America, and Asia.

The primary cash crop is usually supplemented by yams, manioc, rice, maize, beans, etc., for household use. A sirikingly large pioportion of the cash production is in the hands of a numerically sniall but economically important group of smallholders, who employ seasonal labour, and who might be termed small entrepreneurs.

The development of these hcldings from pure subsistence arming brings about a situation where the household's food requirements compete with the desire to earn money with cash crops. The competition for land takes two main forms:

(1) In some cases, perennial crops are grown on separate plots as supplementary activities. The husbandry techniques are usually similar to tiose on large estates, and operations are often carried out by seasonal, paid labour. However, as cash cropping increases, there is less land available for meeting food requirements. At the same, time, arable farming is undergoing a change, which as a rule is a process of degradation, because the 
fallow is shortened and fertility declines. Farmers are obliged to abandon millet and maize, for example, and to transfer more and more to manioc. Manioc is eaten with less relish, but it does supply a larger number of calories per hectare and per hour of work. Not infrequently the stage is reacheci where 'dualistic' peasant holdings evolve, i.e. within a small-scale holding the interrelation between the two branches of production is as weak as that between the large estate and the traditional subsistence holdings in a clualistic society. Arable farming is carried on by the family in the traditional way, although with reduced fallows and declining yields. The plantations of the same holding are regarded as a special undertaking, and new husbandry and economic standards apply (Blanckenburg 1964). (2) In other cases, cash crops and subsistence crops are grown in mixed stands. The degree of competition is reflected by the composition of the mixed stand. Thus, when coffee and plantains are grown in mised stands, the proportion of the subsistence crop (plantains) tends to be greater the more people per hectare there are to be fed, and vice versa. Compared with the dualistic smallholdings, mixed cropping has the advantage that the progressive degradation of the arable branch is avoided. On the other hand, mixed cropping proves to be an obstacle to such technical advances as use of mineral fertilizer and plant protection.

Besides the semi-commercialized holdings that have developed from subsistence farming, smallholdings are found that have corne into being in consequence of large-scale undertakings or in relation to non-farm work. This applies primarily to the great number of part-time farmers who frequently cultivate perennial crops. People work for a few years in towns, large-scale holdings, and mines as seasonal workers, or on a regular wageearning basis. Their own holding provides a base and a measure of support, and a home in old age, because, through the investment of savings in shrub or tree crops, the holding can offer a relatively high degree of security.

Moreover, smallholder plantation farming has sometimes been evolved on land where it is no longer profitable to operate on a large scale. The smallholdings command the labour of their families, for whom there is usually no alternative but to work their own land. It pays them to buy land from zundown estates and to establish small plantations. In some areas, like southern Brazil, this proceciure has led to the spread of smallholder coffee farming on land that has been purchased from run-down coffee estates, in which the new producers take advantage of the marketing channels created by largescale production. Their organization of land use is very sinilar to that in estates.

Finaliy, a trend of increasing importance is the establishment of plantations by middle-class entrepreneurs who aim at a reliable return on capital and a secure farm as a base for their old age. 


\subsection{General characteristics of farming systems with parennial crops}

Although perennial crops are a heterogeneous group, grown under various circumstances by various types of farmer, some common characteristics exist, which are mainly reievant to shrub and tres crops and which to a lesser degree apply also to several perennial field crops (see Table 8.1). As a

TABLE 8.1

Some features of the principa! Perennial crops

\begin{tabular}{|c|c|c|c|c|c|}
\hline Crop & $\begin{array}{l}\text { Years to } \\
\text { first crop }\end{array}$ & $\begin{array}{l}\text { Years to } \\
\text { matirity }\end{array}$ & $\begin{array}{l}\text { Years of } \\
\text { production }\end{array}$ & $\begin{array}{l}\text { Harvested } \\
\text { portion }\end{array}$ & $\begin{array}{l}\text { Urgency for } \\
\text { processing }\end{array}$ \\
\hline $\begin{array}{l}\text { Perennial field crops } \\
\text { Sugar-cane } \\
\text { Bananas (export) } \\
\text { Pineapples } \\
\text { Sisal }\end{array}$ & $\begin{array}{c}1-1 \cdot 5 \\
1-2 \\
1 \cdot 5 \\
3\end{array}$ & $\begin{array}{c}1-1 \cdot 5 \\
3 \\
2 \\
5\end{array}$ & $\begin{array}{l}4-6 \\
5-50 \\
3-5 \\
8\end{array}$ & $\begin{array}{l}\text { Stem } \\
\text { Fruit } \\
\text { Fruit } \\
\text { Leaf }\end{array}$ & $\begin{array}{l}\text { High } \\
\text { High } \\
\text { Fair } \\
\text { Fair }\end{array}$ \\
\hline $\begin{array}{l}\text { Shrub crops } \\
\text { Coffee } \\
\text { Tea }\end{array}$ & $\begin{array}{l}3 \\
3\end{array}$ & $\begin{array}{r}5-6 \\
6\end{array}$ & $\begin{array}{r}12-50 \\
50\end{array}$ & $\begin{array}{l}\text { Fruit } \\
\text { Leaf }\end{array}$ & $\begin{array}{l}\text { High } \\
\text { High }\end{array}$ \\
\hline $\begin{array}{l}\text { Tree crops } \\
\text { Cijlpalm } \\
\text { Rubber } \\
\text { Cocoa } \\
\text { Coconuts } \\
\text { Cloves }\end{array}$ & $\begin{array}{l}3-4 \\
4-7 \\
8-11 \\
4-6 \\
8-9\end{array}$ & $\begin{array}{r}7-9 \\
3-1 ! \\
15-20 \\
8-15 \\
20\end{array}$ & $\begin{array}{c}35 \\
35 \\
80-100 \\
60 \\
100\end{array}$ & $\begin{array}{l}\text { Fruit } \\
\text { Sap } \\
\text { Seed } \\
\text { Fruit } \\
\text { Flower buds }\end{array}$ & $\begin{array}{l}\text { High } \\
\text { Fair } \\
\text { Low } \\
\text { Low } \\
\text { Fair }\end{array}$ \\
\hline
\end{tabular}

Source: MacArthur (1969).

first step, the farm-management characteristics of perennial cropping can be compared with those of arable farming, and then some general principles, applied by farmers to fit perennial crops into their farming systems, can be outlined. The various aspects of the maintenance of soil fertility, of animal lusbandry, and of the labour economy are discussed within the case studies.

\subsubsection{A comparison with arable farming}

Cultivation of perennial crops involves a number of rarm-management characteristics that in many ways can be regarded as advantages compared with those of arable farming:

(1) Perennial crops give rise to stationary living and to investment in permanent improvernents like houses, tracks, irrigation systems, etc. Where perennial crops are grown, the individual ownership of land tends to become established.

(2) Most perennial crops are characterized by a comparatively high productivity per hectare. This encourages the use of fertilizer and thus the conservation of soil fertility. On account of their high productivity per 


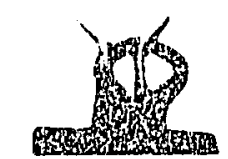

hectare, some yerennial crops actually economize on land use. Thus in Bukoba, Tanzania, $0 \cdot 3$ heciares of bananas mixed with beans are sufficient to cover the basic food requirements of one family, whereas in arable farming the annual cultivation of about 1.2 hectares is necessary to meet the same need.

Most perennial crops produce by-products that are valuable to the household, can be fed to livestock, or can be sold in local markets: fuel for the kitchen. timber for construction purposes, branches for covering roofs, tops and by-products for fodder, etc.

(3) There is a good chance of conserving fertility when perennial crops are grown. The frequency and intensity of cultivation is disproportionately less than in arable farming. Perennial crops shade the soil and permit or require a permanent cover of grass or leguninous vegetation. Some tree and shrub crops influence the soil in the same way as the forest, and moreover permanent planting encourages the cosstruction of ierraces, the control of water courses, and other permanent land irnprovements. No matter how great the destruction of fertility is in cultivation of some perennial crops, like coffee in southern Brazil or tea in Ceylon, the fact remains that the damage is usually less than in arable farming under similar conditions.

(4) Various perennial crops allow the farm-management advantages of monoculture without a reduction in soil fertility. Properly husbanded, pure stands of rubber, oil-palms, or tea may well be considered as soil-conserving types of land use.

(5) For some perennial crops, land can be used that is either out of the questions for arable farming, or would be usable only if high costs could be borne. Examples are steep slopes (bananas, tea, rubber); rccky terrain (tea, rubber); land with unreliable rainfall (sisal); and land where there is a high salt conteni in the water (date-palms).

(6) Important perennial crops like coffee, tea, cocoa, and sisal require a great deal of manual labour, but repay it with a relatively high income. They are therefore suited to the production conditions of developing countries, which are characterized by the availability of plenty of cheap labour.

(7) The labour required for many perennial crops can be spread fairly evenly over the year. This facilitates the expansion of monoculture. Moreover, most operations required by perennial crops tend to be disproportionately easier and more agreeable than in arable farming, particularly hoe farming.

(8) The fluctuations in the yield of crops like sisal, rubber, and coconutpalms are small-at least smaller than in arable farming under similar conditions. Thus, the sisal hedges in north-east Brazil and in the smallholdings on Lake Victoria are cut chiefly when arable crops suffer harvest 
failure; in other words they can counterbalance such risks. Similarly, fodder bushes and trees are a source of fodder when required. The greater certainty of yields from perennial crops is important in small-scale tropical holdings, chiefiy because the yields from arable rain-fed farming are often unreliable.

(9) The products are chiefly goods that can be transported and stored, and have a high value per unit of weight, or they acquire these qualities through industrial processing. Perennial export crops make it possible to develop areas for commercial production where only subsistence farming could otharwise be practised.

(10) Perennial crops mresent considerable scope fo: intensification according to variety, raising and planting method, density, fertilization, pruning, harvest, and processing. With some crops, irrigation is sensible and increases the yieldi appreciably. With perennial crops the economic scope for increased production is greatly enhanced by various technical innovations. (11) In the case of most perennial crops, cultivation can begin with only a few plants. The enterprising individual can progress without having to overcome any particular teclnological threshold, nor is he dependent on the cooperation of neighbours to the same extent as in irrigation farning, for instance.

(12) Wealth in the form of plantations, and therefore security in old age, can be accumulared by planting shrubs and trees. This is particula:ly important where there is no private ownership of arable land, and where investment in caltle as security is not possible.

(13) Perennial crops give rise io social differentiation-perhaps more than ariy other cash crop. A family's inconie is based on the number of trees and shruhs it has and their yield. This forms an outlet for the common human desire to excel, and at the same time provides an acditional incentive towards economic activity.

On the credit side we find that perennial crups have many agro-economic advantages, which naturally do not obtain in every case, but which charactcrize the group as a whole. But on the debit side there are certain important farm-management requirements that have to be met:

(1) Creation of plantations usually requires a high initial investment per hectare. Yields do not reach their capacity until some years after planting (see Table 8.2). To cultivate perennial crops it is necessary to finance the establishment of the plantation; maintain plants during the years when there are no yields; and bear the burden of accruing interest or-which is more important in smallholdings-forgo for some years the return in food or cash that the plot would have yielded under arable farming.

On the other hand, a plantation is a form of investment, which a family 


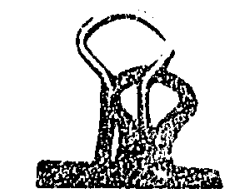

can build up by supplementing small amounts of cash with much unpaid family labour.

(2) For many of these crops, it is very important that processing should take place within a relatively short period after harvesting. In the absence of early treatment, which is designed to effect some change in the composition of the produce, chemical or biological deterioration would set in and

TABLE: 8.2

The economics of plantation development in the West African forest zone (per hectare, fields only, without nurseries and overheads)

\begin{tabular}{|c|c|c|c|c|c|c|c|c|c|c|}
\hline Age o & $0^{\mathrm{a}}$ & $1^{b}$ & 2 & 3 & 4 & 5 & 6 & 7 & 8 & 9 \\
\hline \multicolumn{11}{|c|}{ Oil-palm (Jiory Coast, 1968) } \\
\hline $\begin{array}{l}\text { Labour (hours) } \\
\text { Wages (\$) } \\
\text { Material inputs (\$) } \\
\text { Total input (\$) } \\
\text { Yield }\end{array}$ & $\begin{array}{l}816 \\
106 \\
354^{\circ} \\
460\end{array}$ & $\begin{array}{r}328 \\
42 \\
30 \\
72\end{array}$ & $\begin{array}{l}126 \\
18 \\
-18\end{array}$ & $\begin{array}{r}280 \\
36 \\
12 \\
48\end{array}$ & $\begin{array}{r}272 \\
35 \\
12 \\
47\end{array}$ & $\begin{array}{r}352 \\
45 \\
12 \\
57\end{array}$ & $\begin{array}{r}432 \\
55 \\
12 \\
67\end{array}$ & $\begin{array}{r}432 \\
55 \\
12 \\
67\end{array}$ & $\begin{array}{r}432 \\
55 \\
12 \\
67\end{array}$ & $\begin{array}{r}432 \\
55 \\
12 \\
67\end{array}$ \\
\hline (tons bunch-weip & $\frac{-}{-460}$ & $\overline{-}$ & $\overline{-18}$ & $\frac{-}{-43}$ & $\begin{array}{r}1 \\
16 \\
-31\end{array}$ & $\begin{array}{r}7.0 \\
112 \\
+55\end{array}$ & $\begin{array}{r}9.0 \\
144 \\
+77\end{array}$ & $\begin{array}{r}12 \cdot 5 \\
200 \\
+133\end{array}$ & $\begin{array}{r}15.0 \\
240 \\
+173\end{array}$ & $\begin{array}{r}16.0 \\
256 \\
+189\end{array}$ \\
\hline \multicolumn{11}{|c|}{ Cocoa (Nigeria, 1961) } \\
\hline $\begin{array}{l}\text { Labour (hours) } \\
\text { Wages (\$) } \\
\text { Material inputs (\$) } \\
\text { Total input (\$) } \\
\text { Yicld (kg) } \\
\text { Gross return (\$) } \\
\text { Net return (\$) }\end{array}$ & $\begin{array}{r}1604 \\
161 \\
97 \\
158 \\
- \\
-158\end{array}$ & $\begin{array}{r}520 \\
54 \\
42 \\
96 \\
- \\
-96\end{array}$ & $\begin{array}{r}520 \\
54 \\
60 \\
114 \\
- \\
-114\end{array}$ & $\begin{array}{r}408 \\
54 \\
57 \\
111 \\
- \\
-111\end{array}$ & $\begin{array}{r}497 \\
41 \\
58 \\
99 \\
130 \\
45 \\
-54\end{array}$ & $\begin{array}{r}432 \\
50 \\
88 \\
138 \\
250 \\
87 \\
-51\end{array}$ & $\begin{array}{r}480 \\
43 \\
88 \\
131 \\
380 \\
133 \\
+2\end{array}$ & $\begin{array}{r}552 \\
48 \\
98 \\
146 \\
500 \\
175 \\
+29\end{array}$ & $\begin{array}{r}552 \\
55 \\
98 \\
153 \\
880 \\
304 \\
+151 \\
\end{array}$ & $\begin{array}{r}553 \\
55 \\
98 \\
153 \\
1160 \\
385 \\
+232\end{array}$ \\
\hline \multicolumn{11}{|c|}{ Rubber (Nigeria, 196!) } \\
\hline $\begin{array}{l}\text { Labour (hours) } \\
\text { Wages ( }(\xi) \\
\text { Material inputs } \\
\text { Total input }(\$) \\
\text { Yield (kg)' } \\
\text { Gross return }(\$)^{\prime}\end{array}$ & $\begin{array}{r}1178 \\
185 \\
171 \\
286 \\
- \\
-286 \\
\end{array}$ & $\begin{array}{r}513 \\
51 \\
52 \\
103 \\
- \\
-103\end{array}$ & $\begin{array}{r}449 \\
45 \\
21 \\
66 \\
- \\
-66 \\
\end{array}$ & $\begin{array}{r}368 \\
37 \\
31 \\
68 \\
- \\
-68 \\
\end{array}$ & $\begin{array}{r}328 \\
33 \\
70 \\
103 \\
- \\
-103 \\
\end{array}$ & $\begin{array}{r}1200 \\
33 \\
17 \\
50 \\
- \\
-50 \\
\end{array}$ & $\begin{array}{r}1200 \\
120 \\
57 \\
177 \\
400 \\
132 \\
-45 \\
\end{array}$ & $\begin{array}{r}1200 \\
120 \\
17 \\
137 \\
650 \\
215 \\
+78 \\
\end{array}$ & $\begin{array}{r}1250 \\
120 \\
57 \\
177 \\
900 \\
297 \\
+120 \\
\end{array}$ & $\begin{array}{r}1200 \\
120 \\
37 \\
157 \\
1100 \\
339 \\
+182 \\
\end{array}$ \\
\hline \multirow{2}{*}{\multicolumn{11}{|c|}{$\begin{array}{l}\text { Year of clearing. } \\
\text { - Year of planting. } \\
\text { The labour input is low because of mechanical clcaring. From year } 6 \text { onwards, one-third } \\
\text { of labour is required for plantation upkeep and two-thirds for harvesting. } \\
\text { Costs of mechanical clearing mainly. } \\
\text { Price of } \$ 16 \text { per ton of bunches, delivered to the factory. } \\
\text { Mainly plant material, fertilizer, and pesticides. } \\
\text { About five-sixths of the labour from year } 5 \text { onwards is tapping. } \\
\text { From the } 6 \text { th year onvards fertilizer is applied every second year. } \\
\text { Yields according to Ccylon Rubber Research Institute. }\end{array}$}} \\
\hline & & & & & & & & & & \\
\hline
\end{tabular}


either reduce the quantity of valuable constituents extractable from the harvested material-oil-palm and sugar-cane especially-or else spoil the quality of the final product, as with bananas, coffee, and tea (see Table 8.1). (3) Where perennial crops are the raw material for a local industry, in addition to the initial costs of the plantations it is necessary to invest in a local processing plant; to invest in transport for bringing the product to the factory; and to arrange delivery very carefully, so that the processing plant can work to capacity.

(4) Consequentiy, holdings with prsennial cxport crops, like irrigation holdings, operate with high fixed costs, out, unlike arable irrigation holdings, they are committed to one type of production for a long time.

(5) Plantation husbandry demands different kinds of work and skills from those of arable farming. Cultivation is of less importance, and with several crops not even necessary. Weeding is labour demanding only in the early phases of plantation developmeni. Instead, much work is required for raising plants in nurseries, planting, pruning in the case of shrubs, spraying. mulching, harvesting, and so on. The labour input is particularly high when crops are being established and with mature crops. The intervening period usually requires little attention. In comparisons of arable production with shrub-crop and tree-crop production, it is also important to realize that the influence of husbandry measures may extend over years and decades. Poor plant development. unskilled pruning, and delay in pest control may damage the crops for years to come, while in arable rropping, last year's failure may be avoided next year (MacArthur 1969).

(6) Another disadvantage of perennial crops is that the work is difficult to mechanize. Where cultivation, weed control, and transport in bulk strain the labour economy, as in sugar-cane and sisal estates, mechanization is more likely to follow. With tree and shrub crops, where the main emphasis is on tending of the crops and harvesting, operations cannot ie mechanized at all, or only with rather poor rates of substitution.

In assessing the various advantages and requirements of perennial crops, it is clear that, provided market outlets are available, they are relatively well suited to tropical agriculture, and several of the shrub and tree crops are particularly suited to srnallholder production.

\subsubsection{Some farm-management characteristics of peremial crops}

(a) The spatial and vertical organization of cropping. Large estates are usually uniformly organized, but in smallholdings, planting patterns near the house or village are mostly different from those some distance away, so that more or less pronounced spatial patterns are found in the arrangement of the varicus perennial crops. In this respect they are not basically different from arable crops, where spatial arrangements of cropping in smaltholder farming are coinmon. 


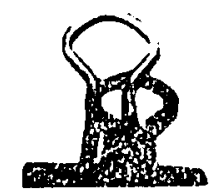

A specific feature of shrub and tree crops is their vertical arrangement, since plants differ in height and in light requirements. In estates we occusionally find a 'two-storey physiognomy', i.e. two perennial crops-for instance rubber and cocoa-are interplanted. In smaillholdings $y / e$ find multi-storey physiognomies, including not only perennial crops but also various annual
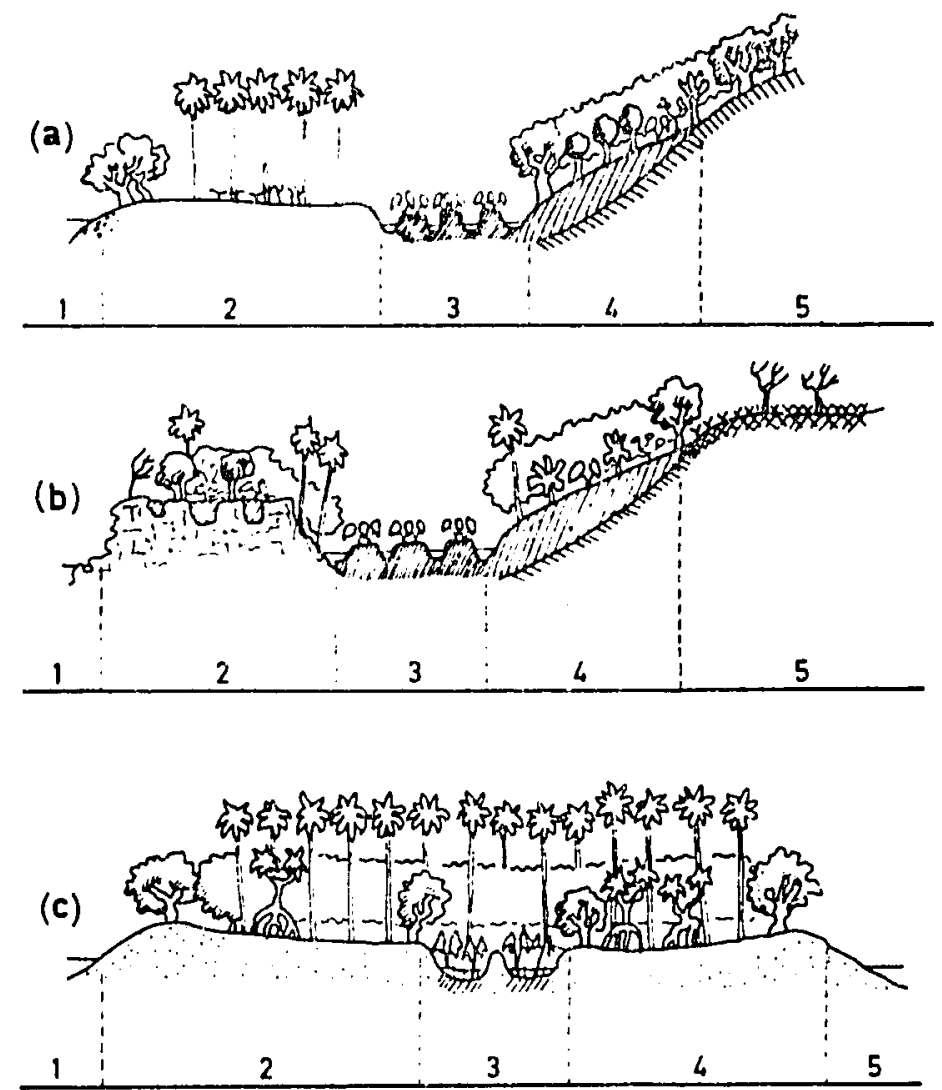

Fio. 8.3. Various types of land use on Polynesian islands. (a) High island, Rarotonga: (1) ocean; (2) coral calcimorphic soils, growing cosonuts, sweet potatoes, tomatoes; (3) hydromorphic soils, taro gardens; (4) colluvium clay loam, citrus fruits and gardens; (5) lateritic soils, scrub and secondary forest. (b) High island, Atiu: (1) ocean; (2) uplifted coral plateau with clay loam in pockets, : few gardens and coconuts; (3) hyoromorphic soils, taro gardens; (4) colluvium clay loam, gardens; (5) lateritic soils, ferns and Casuarina. (c) Atoll, Tarawa: (1) occan; (2) coral calcimorphic soils, coconut and Pandanus; (3) Cyrtosperma pits; (4) coral calcimorphic soils, coconuts, and Pandlanus; (5) lagoon. From Barrau (1961, p. 26).

crops. A typical case in point is the land use on some Polynesian islands, as depicted by Barrau (1961). In Fig. 8.3 (a), (b), and (c) show distinct spatial arrangements in land use combined with several two-storey and three-storey physiognomies. 
(b) Monoculture, inserculture, and combination with grazing. The spatial and vertical organization of cropping leads naturally to various crop combinations within a holding and within a field. Large estates usually prefer to cultivate pure siands, in order to make optimum use of the husbandry techniques specificaliy required by one plant. Where production is concerned with only one crop, pure stands result in monoculture, of which two types have to be distinguished. From the standpoint of farm management, we have monocuiture where only one crop is growy in the holding. This is usually the case in oil-palm or banama estates. From the standpoint of agronomy, we have inonoculture where one field is planted with the same crop for each succeeding vegetation cycle, which is usually the cas: with sugar-cane or sisal. Both types of monoculture are identical in some but certainly not in all cases.

While estates tend to prefer pure stands and monoculture, smallholdings usually prefer intercropping, because it helps them to obtain higher shortterm returns, higher returns per hectare (lower returns per unit of labour being accepted), and the benefits of a more diversificd production.

However, some types of intercropping are also frevalent in estates. The following types of intercropping with perennial cropls are important:

(1) Perennial crops and coyer crops. In large estates, the planting of legulminous creepers (e.g. Centrosema pubescens, Pueraria javanica) as cover crops is a usual practice in protecting the soi! in the early stages of plant development (oil-palm, cacao, rubber) or to help in weed control (sisal!.

(2) Tree crops and shade plants. Some tree crops need sliade in their early stages. The shade plants frequently produce a yield of their own, for instance bananas shading coftes.

(3) Perennial crops of various sizes. A widespread practice, in estates as well as in smallholdings, is the combination of yarious perennial crops of differing heights (sce $\$ 8.4 .3$ (b)). This multi-storty physiognomy is closer to the natural climax vegetation than are pure stands. In some cases, interculture of this kind is limited to the carly stages of plantation development. (4) Perennial crups and annual cropping. In large estates, perennial and annual crops are not usually combined, whereas in smallholdings their combination predominares. With some crops, like rubber, oil-palms, and coffec, interculture is limited to the early stages of plant development, and arable crops are grown only until the main crop branches out and forms too dense a shade for annual crops. With other crops, like cocor:ut-palms, arable farming continues to be practised under mature stands.

(5) Peremnial crops and grazing. In addition we find various combinations of perennial crops with grazing. In some cases (sisal, oil-palms), grazing is limited to the early stages of plant development, when ainple grass grows between the rows. In other cases (as frequently with cocunut-palms) cattle may graze under mature stands. 
The importance of interculture varies with the type of crop, the farm size, and price relations. Interculture is generally of inportance in smallholdings where the farmer, by practising arable farming in the early stages of shrubcrop or tree-crop development, may significantly reciuce the costs of plantation establishment. This may be more important economisally than the reduction in future returns which is likely to result from poorer development of the dominant crop.

(c) Vegetation und production cycles. Another variable peculiar to perennial crops is the length of the production cycle and the distribution of input requirements and returns over several years. MacArthur (1969) summarizes this as follows:

During the early stages there is a slow but accelerating build-up towards maturity, when maximum yiclds are obtainable. A high level of production is thereafter obtained for several years, but ... age ... begins to affect the levels of produstion, and yields fall off. With tree crops a fairly distinct type of production pattern can be discerned, but with crops whose natural form is that of a bush or shrub, preductivity can be renewed through pruning back alnost all of the growth above the ground and permitting new main stems to grow up from the capitated main stem.

This gerueralized scheme is subject to many exceptions. Sisal follows a peculiar pattern wherein leaves grow and can be harvested for a given period until the plant puts up a stem with a flowering head, after which no new leaves are produced and the plant dies. Pineapple and sugar-cane grow in a series of 'ratoons' or successive waves of new shoots which grow up from the root stock, and the yield level falls steadily after the first harvest.

...this ... usually implies that there is a period during the early strges of growth (which can last for several years) when annual costs will excred the value of harvested prodice, but eventually a stage will be reached when new costs anch year will be less than the product value. This phase may' persist for a vary long time, but there will come a stage ... when production will fall to such a low level that its value is insufficient to cover annual production costs. At this stage, the crop's useful life will be over. W'ith sisal, there is a firm limit fixed by the botanicai behaviour of the plant, whilst with other crops like pineapples ... and sugar-cane the point of unprofitable diminishing output is encountered after only a few years. Theoretically', it may be possible for naturally or artificially self-regenerating crops like banana, coffee and teat to remain in profitable production almost indefinitely, but most plants of these species, if they do not ... fall victim to a disease ... are eventually superceded by new varieties of the crop whose yields exceed those of established plants by so mucn that they merit uprooting and replacement, despite the interruption in producticn that this means.

Consequently, in the case of shrub and tree crops we distinguish between the following stages in plantation development:

(1) The period between clearing and planting and the beginning of the crop's useful life (in the calculations in Table 8.2 for cocoa, rubber and oil-palms, this period is four years). 
(2) The time between pianting and the year after which the annual costs are covered by the annual yield (in the examples five to six years).

(3) The period between planting and the year after which the capacity yield is produced (in the examples eight years).

(4) The period of capacity production, which begins when the first full yield is produced. In the following years, a regular yield, sometimes rising or falling slightly, is produced. This period comes to an end wheil the yield tends to decline more rapidly.

(5) The length of land occupation. A.ccording to the level of running costs, the availability of land for planting, the cost of replanting, and the returns of new plantations in relation to old ones, it is sometimes advisable to continue using the land beyond the period of full production, i.e. in spite of rather low yields. The period of land use thus extends from the first to the 'ast harvest.

(6) The growth cycle, i.e. the time between creation of the plantation and clearance of it or letting it run wild.

Plantation farmers may influence the economic length of the production cycle of their various perennial crops. Extension of the time in nurseries, special husbandry techniques, proper weeding, and manuring may reduce the initial period before a crop is obtained, while interculture may delay development. Pruning and harvesting techniques may hasten or delay returns. Husbandry practices in general influence the economic life of perennial crops. With sugar-cane the grower has to decide the number of ratoons. With shrub and tree crops in general the grower has to choose between production cycles of various lengths, and has to decide when to cease cropping and to plant afiesh. Shori production cycles are frequently, but not always, an indication of intensive farming.

(a) Rotations. When a stand of perennial crops is created, the way in which the plot is used is fixed for a long time. An annual change in the use of the plot, such as we find in arable farming with crop rotations, is only pnssible to the extent that interculture can be practised. In perennial cropping longterm rotations do occur, and the following are the basic types:

(1) Perennial crops may be followed by a lengthy forest or bush fallow. Thus old cacao plantations in West Africa revert to bush vegetation, whicn is then cleared after one or two decades. The rotation runs: fallow-rain-fed farming-cacao-fallow or rubber (Blanckenburg 1964, p. 38). Planned reforestation after coffee cultivation is practised occasicnally in Latin America (Sick 1969, p. 164).

(2) Perennial crops may be fullowed by grassland. Thus in southern Brazil old coffee plantations are chopped down and the ground becomes covered with grass and serves as rough pasture. In tropical high-rainfall areas, an 
even more negative sequence can be observed: exhausted coffee plots gradually turn into fields of useless Imperata grass.

(3) Perennial crops may be followed by arable farming. The Kavirondo of Nyanza, Kenya, for example, cut down their banana groves after about ten years and sow the plots with miller (Wagner 1956, p. 29).

(4) One perennial crop may be followed by another. The change may occur by uprooting and replanting. On some banana plantations in Central America, for instance, cacao or oil-palms are planted after bananas. It may also occur by under-planting the outgoing crop by a new one. Thus, in some estates in Ceylon, old rubber is underplanted with cacao. The rubber slowly gives $\%$ is a pure stand of cocoa. With declining cocoa yielo's the area is cleared and planted with rubber again.

(5) A perennial crop, or a mixture of perennial crops, may be renewed by continuous planting. as in the coffee plantations of El Salvador, or the coconut plantations in Ceylon.

The sequence is determined partly by the characteristics of the particular crop and partly by the availability of land and price relations. Where there is plenty of land, one of several growth cycles of perennial crops are followed by many years of forest or bush fallow. As land becomes more scarce, there is a tendency to replace the fallow by use of the land for pasture or arable crops, or perennial crops may follow each other. Where it is technically pnssible, contintious replanting (infilling) is a sign that land is particularly scarce.

\subsection{Estates and smallholdings with perennial field cropgs}

The basic farm-management characteristics of perennial-crop production are best depicted by reference tc existing types of farming in both the estate and the smallholder types of economy.

\subsubsection{Sugar-cane holdings}

Commercial sugar-cane production is carried out in three distinct exploitation systems (see Table 8.3). Firstly we have large-scale units conbining cane production and a factory for processing. Secondly we find plantations of large and medıun size producing mainly or exclusively cane for sale to factories. Thirdly we have smallholder production, where cane is produced in addition to subsistence food. Large estates are often surrounded hy a belt of smallscale producers, who sell cane to the factory and provide extra labour for cane-cutting.

(a) Sugar-cane estates in Mauritius. The examples from Mauritius in Table 8.4 illustrate the farm-management characterisiics of sugar-cane production. Of the 91000 hectares of land used for agriculture on this island, 
84000 carry sugar-cane, and 23 estates equipped with factories occupy onehalf of this area. The other half is cultivated by cane-selling farmers. The major part belongs to a few large estutes aret the rest is divided up into 24000

\section{Table 8.3}

Yield, growing season, and land orgunization in major cane-producing countries

\begin{tabular}{|c|c|c|c|}
\hline Countsy & $\begin{array}{c}\text { Average } \\
\text { cane yield } \\
\text { (t ha:-1) } \\
1955 / 0- \\
1959 / 60\end{array}$ & $\begin{array}{l}\text { Estimated } \\
\text { average } \\
\text { growing } \\
\text { season } \\
\text { (months) }\end{array}$ & Land organization \\
\hline $\begin{array}{l}\text { Hawaii } \\
\text { Peru }\end{array}$ & 207 & 23 & Predominantly in estates; irrigation \\
\hline $\begin{array}{l}\text { Peru } \\
\text { United Arab Republic }\end{array}$ & $\begin{array}{l}165 \\
103\end{array}$ & $\begin{array}{l}17 \\
20\end{array}$ & Mostly in large estates; irrigation \\
\hline British Guiana & 97 & 13 & Large estates; some cooperatives \\
\hline Florida (United States) & 88 & 14 & Very large estates; irrigation \\
\hline Barbados & 84 & 13 & $\begin{array}{l}80 \text { per cent mill-owned estates; } 20 \text { per } \\
\text { cent peasant farms }\end{array}$ \\
\hline Taiwan & 79 & 18 & $\begin{array}{l}\text { One-third mill-owned cstates; balance } \\
\text { is peasant production }\end{array}$ \\
\hline Indonesia & 78 & 18 & $\begin{array}{l}75 \text { per cent large estates; } 25 \text { per cent } \\
\text { peasant production }\end{array}$ \\
\hline South Africa & 77 & 18 & $\begin{array}{l}25 \text { per cent factory citates; } 75 \text { per cent } \\
\text { small and medium-sized farms }\end{array}$ \\
\hline Trinidad & 72 & 13 & 50 per cent estate production \\
\hline Australia & 67 & 13 & $\begin{array}{l}\text { Mostly medium-sized independt. } \\
\text { farms }\end{array}$ \\
\hline Puerto Rico & 64 & 14 & Mostly peasant production \\
\hline Mauritius & 62 & 13 & 50 per cent mill estates \\
\hline Jamaica & 58 & 13 & $5 j$ per cent mill estates \\
\hline Fiji & 58 & 14 & $\begin{array}{l}\text { Mcitly small farms; cooperative har- } \\
\text { yesting }\end{array}$ \\
\hline Mexico & s? & 13 & $\begin{array}{l}\text { Small growers organized into large } \\
\text { cooperaives }\end{array}$ \\
\hline Reunion & 56 & 14 & 46 per cent large estates \\
\hline Louisiana (United States) & 52 & 10 & Medium-sized holdings \\
\hline Cuba & 42 & 13 & $\begin{array}{l}\text { As of } 1961,35 \text { per cent couperatives } \\
\text { and } 65 \text { per cent state and individual } \\
\text { farms }\end{array}$ \\
\hline Brazil & 42 & 13 & $\begin{array}{l}\text { No more than } 50 \text { per cent mill-estate } \\
\text { cane (by law) }\end{array}$ \\
\hline $\begin{array}{l}\text { Argentina } \\
\text { India }\end{array}$ & $\begin{array}{l}35 \\
34\end{array}$ & $\begin{array}{l}10 \\
13\end{array}$ & $\begin{array}{l}\text { One-third estatc-grown cane } \\
\text { Mostly smallholdings; larger-scale irri- } \\
\text { gated farms in the south }\end{array}$ \\
\hline
\end{tabular}

Source: Frank (1967, p. 83).

smallholdings each with an average area of about one hectare. Each estate crops an average of 1800 hectares of sugar-cane, and of this, 200 hectares are newly planted and 1600 hectares are yielding cane. A number of basic farmmanagement features of sugar-cane estates can be observed: 


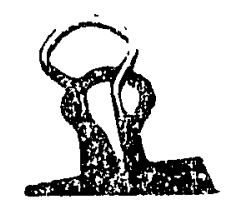

(1) A high degree of intensity. Sugar-cane estates constitute an intensive form of tropical land use. In the example of Mauritius, the gross return amounts to $\$ 500$ per hectare, which is several times the return from annual

TABLE 8.4

Farm-management data of sugar-cane, banana, and sisal estates

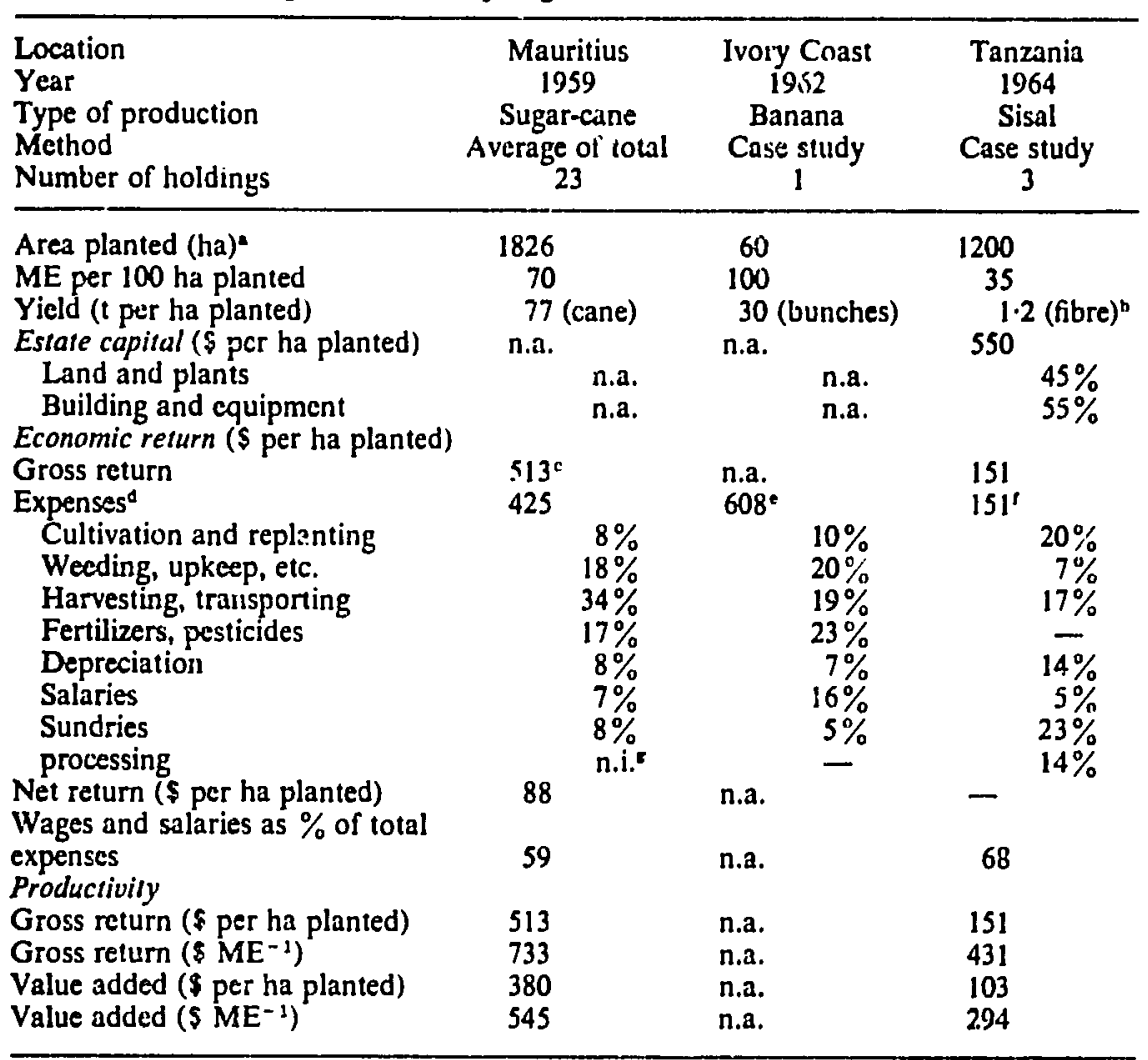

- Plantation crop only.

- Yield of sisal in cutting age.

c Investment in 1964, without factory.

- Not including interest payments.

- Including processing and transport to harbour.

- Including factory processing.

n.i. = not included.

Sources: Mauritius, Commission of Enquiry (1962); Ivory Coast, Champion (1963, p. 206); Tanzania, Pössinger (1967, pp. 16-22).

arable crops under these conditions, and this in spite of the fact that in Mauritius a relatively extensive form of cane cropping is carried on, with five to nine ratoons. 
(2) The preservation of soil fertility. Sugar-cane is mostly grown in monoculture, and for more than a century on some plantations. Cane production involves the removal of large amounts of plant nutrients from the field. It may nevertheless be assumed that cane growing aids soil fertility, for the following reasons:

(i) Dense vegetation covers the soil for most of the year.

(ii) Large quantities of organic matter are conveyed to the soil in the form of trash, and by an extended root system, supplemented by plentiful fertilizer (formerly manure preduced by the many oxen required for transport, but nowadays minera! fertilizers).

Burning, however, represents a possible danger to soil fertility. It has been introduced into high-wage economies as harvesting has been mechanized.

(3) High labour input. Labour costs are the greatest expense on sugar-cane estates. In the examples from Mauritius, 59 per cent of the total costs in 1959 consisted of wages and salaries; 70 man-equivalents per 100 hectares were employed. In contrast with most other perennial crops, operations with sugar-cane, including harvesting, can be fully mechanized, and they actually are in high-wage economies like Hawaii, Queensland, and South Africa. However, the estates in Mauritius in 1959 still relied on seasonal labour to cope with the peak in iabour demand during cane-cuting.

(4) High capital input. The economy of sugar-cane estates is highly sensitive, to transport costs, because cane is heavy, bulky, and perishable. Large sums niust be invested in field tracks, roads, tractors, lorries, cranes, etc.

(5) The development path. Sugar-cane cropping has shown itself able to benefit from yield-increasing innovations to which sugar-beet is far less responsive: improved varieties, improved disease control, sprinkler irrigation, increased application of mineral fertilizer, improved cultivation practices, etc. The subtropical cane growers are mostly ahead of the tropical producers in applying these techniques. Thus, if the trend continues, the yields per hectare are likely to carry on rising, and proven mechanical methods to be adopted where the wage level makes it necessary. Sugar-cane cropping tends towards monoculture, although yields from rotations are usually higher. The practice of incorporating a few years of field grass between the cane-cropping cycles, which was common when the estates depended on large numbers of oxen and therefore on a fodder and manuring system, has become rare now that tractors and mineral fertiiizers have been introduced. Where the cropping cycles are interrupted by arable crops, we find either green-manure crops on large estates or intensive crops in smallholdings, like tobacco in Pucrto Rico and rice in Taiwan.

The trend towards monoculture is closely linked to the development of large: processing plants and tine transport problems that they entail. Thus. 


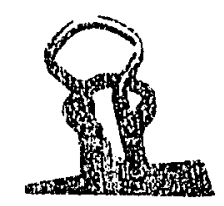

210

SYSTEMS WITH PERENNIAL CROPS

in Mauritius for exarnple, the sugar factories in 1832 had an average processing capacity of 200 tons, in 1903 of 3000 tons, and in 1961 of 24000 tons. As the capacity of factories has been increased, and when the plots are near the factory and transport is easy, other crops are even less able to compete with sugar-cane.

(b) Sugar-cane smallholdings. Sugar-cane is definitely a crop that is most suitable for estates, because it is bulky and perishabie, and costs limit the distance over which it can be carried. The modern factory should therefore stand in the centre of a relatively compact cane area, where cane is grown in monoculture. Monoculture, however, rarely fits into the working pattern of smallholdings. Canc cutting cieates peaks in labour demand that can hardly be tackled by the labour capacity of a smallholding. The organization of cooperative cutting is usially a very difficult and intricate undertaking. Also, cane production must be accompanied by thorough cultivation, which is best carried out with heavy tractors, and cane is very susceptible to poor husbajdry and numerous diseases. It is therefore more important than with other crops that technical advances should be available to the estate manager. Moreover, the smallholder cannot establish a sugar piantation as cheaply as he can a tree or shrub plantation. The superiority of large-scale producers of caute was so great in, for example, former Dutch Java that the smallholders recognized the advantage of leasing land to estates.

Smallholder production of cane has proved to be competitive only:

(1) in satellite holdings near an estate-often on adjoining marginal land, as for example in Mauritius, where this type of holding produces cane and is also a source of seasonal labour;

(2) in an area with a good transport systen, where the smallholders are settled as tenants and are subject to closely supervised contract farming, including supervised cooperative harvesting, as in the Fiji Islands in the South Pacific; or

(3) in places where the smallholders have technical training and farm very intensively, as in Taiwan.

Thus if estate production is not feasible or desired, sugar-cane can be grown in medium-sized holöings (cultivated by tractor) more economically than in smaliholdings. Such medium-sized holdings are typical of production in, for instance, Queensland, Australia.

\subsubsection{Sisal holdings}

Sisal, like sugar-cane, is a typical estate crop, and for similar reasons. Most sisal estates are part of larger firms operating several undertakings. Small holder sisal, except in the north-east of Brazil, is economically hardly
significant. 
(a) Sisul estates in Tanzaria. The growth cycle of the sisal plant and the processing capacity of the factory determine the organization of a sisal estate. A decorticator has a given annual capacity to process leaf into fibre (1500-2400 tons). The object of planting is to guarantee regular delivery of the right amounts of leaf during the year, and for year after year.

The growth cycle of sisal, in a well-organized holding, lasts nine years. The plantation must therefore have nine fields, in which to have sisal at all stages of growth, to guarantee regular delivery (see Table 8.5). Under favourable conditions of production, one hectare produces 12 tons of fibre in nine

TABLE 8.5

Model of a balanced rotational sisal-planting programine

\begin{tabular}{|c|c|c|c|c|}
\hline $\begin{array}{c}\text { Area required } \\
\text { (ha) }\end{array}$ & $\begin{array}{c}\text { Age of sisal } \\
\text { (years) }\end{array}$ & $\begin{array}{l}\text { Assumed yield } \\
\text { of fibre } \\
\left(\mathrm{c} h a^{-1}\right)\end{array}$ & $\begin{array}{l}\text { Total tonnage } \\
\text { of leaves per } \\
\text { year }\end{array}$ & $\begin{array}{l}\text { Total tonnage } \\
\text { of fibre per } \\
\text { year }\end{array}$ \\
\hline 125 & 1 & - & - & - \\
\hline 125 & 2 & - & - & - \\
\hline 125 & 3 & 0.8 & 4500 & 100 \\
\hline 125 & 4 & $1 \cdot 5$ & 6750 & 188 \\
\hline 125 & 5 & 2.0 & 7000 & 250 \\
\hline 125 & 6 & $3 \cdot 0$ & 8500 & 375 \\
\hline 125 & 7 & 2.7 & 7000 & 337 \\
\hline 125 & 8 & $2 \cdot 0$ & 6250 & 250 \\
\hline 125 & 9 & - & - & - \\
\hline \multirow{4}{*}{\multicolumn{2}{|c|}{$\begin{array}{l}\text { Total } 1125 \\
\text { Area of sisal (ha) } \\
\text { Area fallow for replanting (ha) } \\
\text { Area for nurseries, roads, etc. (ha) }\end{array}$}} & $12 \cdot 0$ & 40000 & 1500 \\
\hline & & & 1000 & \\
\hline & & & 125 & \\
\hline & & & 75 & \\
\hline \multicolumn{2}{|c|}{ rotal area of plantation (ha) } & & 1200 & \\
\hline
\end{tabular}

The calculation of the holding programme is based on a yield of $12 \mathrm{tha}^{-1}$ of fibre produced over 6 years. The calculation refers to an unusually well-managed holding.

Source: Lock (1962, p. 317).

years, and, with this level of yield in the example, nine fields of 125 hectares each are necessary if a decorticator with the capacity of 1500 tons is to work to full capacity, i.e. the area of sisal must be 1125 hectares. There are also seedbeds, etc. Thus an efficienily organized sisal holding must crop 1200 hectares, and where yields per hectare are lower the necessary size of field and plantati $\quad$ is correspondingly higher. Most sisal estates have fallow land in reserve as well as cropped areas. The following feat:ıres are typical of sisal estates

(1) There is a high initial investment in the factory, the water supply to the factory, plantations, equipment, and buildings. According to the data of Guillebaud (1958) and Pössinger (1967) for the years 1958 and 1964, an investment of $\$ 550$ was required to produce a ton of fibre per year. 
(2) The transport costs are ingh, 40000 tons of leaf have to be taken every year to the decorticator, which means a journey of 160000 ton kilometres at an average of 4 kilometres from field to factory. Consequently fields have to be concentrated round the factory and transport routes.

(3) Declining soil fertility is a major problem in this type of ferming. Yields tend to fall seriousty after several rotations of sisal, and, because of the price of sisal fibre, it would not at the moment pay to apply mineral fertilizer. However, recently developed hybrid sisal could transform this situation by changing sisal from an extensive to an inteusive crop, producing two to three times the customary yields.

(4) A main technical problem is the achievernent of a high yield of fibre per ton of leaf. According to the quility of the leaf, but mainly according to how the decorticator is adjusted, the return varies between 3 per cent and 5 per cent of leaf-weight. Estate managers usually pay inost attention to the processing of the leaf, and regard planting as a secondary activity. (5) The main labour tasks on a sisal estate-replanting, weed control, and harvesting-can be spread evenly over the year. According to Lock, in 1959 a 1500-ton estate needed 1200 workers, or 100 workers per 100 hectares in an estate with high efficiency per hectare. Sisal cropping is more amenable to mechanization than most other perennial crops (for controlling weeds, loading leaf, etc.), and in 1965 in Tanzania 35 man-equivalents per 100 hectares of sisal were used, compared with 70-100 man-equivalents ten years previously. Nevertheless the main operation, cutting of the leaf, must still be done by hand.

(6) Harvest fluctuations from year to year are relatively small. However, price fluctuations do affect this export crop, perhaps even more than almost any other. Falling prices in recent years, due to the competition from artificial fibre, may force sisal producers with high costs-largely those with yields less than one ton per hectare-to change to other activities. They may turn to cattle and a variety of crops such as cotton and maize, sunflower and rain-fed rice, or abandon farming altogether and leave the land lying idle.

(b) Sisal smollholdings. Sisal production in smallholdings is found on an importarit scale ouly in the north-east of Brazil, where sisal is intercropped with maize. Because the yields of maize are uncertain, sisal serves primarily to counterbalance the risk of a poor harvest. The sisal is processed with small, mobile decortication machines (raspadors), which produce unbrushed fibre. The further processing is done in brusling and baling factories. The produce is of poor quality, however, and the labour input is high. This applies even more to smallholder sisal in East Africa, where hedge sisal is processed by hand into unbrushed fibre. With falling world market prices, production is no longer competitive and has ceased almost altogether. Efforts to introduce 
sisal as a settlement crop have been made in Kenya and Tanzania, but without a reasonable chance of success (Pössinger 1967).

The reasons for the poor performance of smallholder sisal are even more obvious than with sugar-cane. Sisal production without a processing factory yields low-quality produce at very high labour inputs. Smallholder sisal in combination with factory processing is extremely difficult to organize because of:

(1) the rotation cycle in cropping (see Table 8.5 )-a smallholder would need ten separate fields;

(2) the need for heavy equiprnent in establishing the plantation;

(3) the peak in labour demand for cutting, because sufficient leaf for truck transport has to be cut in a given day; and

(4) the bulky nature of the harvested produce, which is perishable and has to be delivered in definite quantities at definite times.

\subsubsection{Banana holdings}

Bananas are not only one of the most important food crops in the tropics, but also an outstanding export crop. They combine many of the advantages of annual arable crops and perennial crops:

(1) The gross return per hectare, measured in calories or money, is usually high. The input for clearing the land is low, establishment of the plantation is relatively simple, and the first yield is produced twelve months after planting. The banana does require a high degree of humidity, but apart from this it is adaptable, and will even grow on soils of poor fertility and in cooler mountain locations.

(2) The adaptability of the banana stems from the great number of varieties, which not only are suitable for differint purposes (for cooking, beer; and use as a fresh fruit), but also have varying location requirements, and grow to different heights (the tall-stemmed banana and the dwarf banana). Bananas also yield valuable by-products. In southern India, for instance, green leaves are sold to urban households, where they serve as plates. Elsewhere, dry banana leaves serve as roofing material.

(3) By providing plenty of shade, trash, and permanent cover on slopes, the banana helps to maintain soil fertility and reduces erosion. It makes the application of large amounts of fertilizer worth while and responds well to fertilization with mulch, manures, and mineral fertilizers. Bananas may occupy a plot permanently.

(4) The yield of bananas is produced relatively regularly, and where they are for local consumption there is a supply of food all the year round. In the special case of the Ensete banana, Ethiopia (Ensete ed:la Horan), the starch is stored in the stem, and, as with manioc, there are starch reserves available in the living plant. 
(5) The labour requirement is high, varying from 0.5-3.0 man-equivalents per hectare $(0.3-1.0$ man-equivalents in plantations), but there are no pronounced labour peaks, and the ratio between labour input and the return of calories is usually better than with most annual food crops.

(6) Finally, the banana is compatible with other crops, facilisating both mixed cropping and its incorporation in a rotation.

On the other hand, there is the danger of damage by the wind, and the high cost of controlling banana diseases. The Panama disease is reported to have increased production costs in several parts of Latin America to the point when export production is no longer competitive. The fact that the fruit is perishable is another drawback, and processing and conserving are scarcely worth-while.

Whereas sugar-canc plantations tend towards monoculture, banana cropping usually leads to diversified farming. In large plantations it is usual to plant tree crops like oil-palms, rubber, or cocoa immediately after a few years of bananas. Smallholders usually combine banana production for sale and subsistence with other activities, either in separate blocks or as mixed cropping. It is notewnrthy that there seem to be rather pronounced complementary effects between banaria production in smallholdings and animal husbandry. Cattle and pigs feed on banana leaves, stalks, and fruits, and their manure is of high value in increasing banana production.

(a) Banara estates in Central America. Until recently, bananas for export were grown mainly on large estates, because it is necessary to deliver large quantities of a perishable commodity of uniform quality at the right time. These conditions can be fulfilled more easily in large-scale than in smallholder producion. The management characteristics of a large banana estate in Honduras are described by May and Plaza (1958).

A typical banana p'-ntation in Central America belonging to the United Fruit Company comprises a banana-growing area of 8000 hectares, together with extensive land reserves and waste land. Only the best soils are planted with bananas, and the workers are allowed to use the remainder as they wish, or it is left as waste land. The holding as a whole is split up into twenty-two or twenty-three sections, each of 350 hectares. The terrain is divided up like a chess-board and drained if necessary. The cleared vegetation is not burned. Bananas are planted in rows on the cleared land. Usually there are two pipe systems (which are permanent), one for sprinkler irrigation, the other for spraying pesticides. The aim is $750-800$ fruit-bcaring stems per hectare, with a yield per hactare of 27 tons sient-weight ${ }^{1}$ or 23 tons fruit-weight. The United Fruit Company works on an average loss of 25 per cent of the harvest. Harvesting talies place at all times of the year, and the bunches of bananas are carried from the tree to padded carts or pack donkeys, after which they are taken to collecting points where there is a rail connection. The buncher are sorted, washed, dried, packed, and hung in special trucks to be iransported. The permanent workers in one section witl 350 hectares of bananas number 150. Harvesting all the year

1 Weight of banana bunches including the fruit stem. 


\section{SYSTEMS WITH PEREINIAL, CROPS}

round permits a high degrze of specialization, so that about eighty men are occupied with harvesting all the time, forty with plant protection, five with watering, sixteen with loading, and five with supervision.

In recent years, large-scale units have been replaced by mainly nediumsized estates with 10-100 hectares of bananes. In Latin Annerica and West Africa, the people who produce and box all the barmes are iscreasingly sinall eutrepreueurs, the company acting chielly as maketing agent, and providing loans and technical assistance. Toble 8.6 (p. 208) presents the farm-management data of one such holding in Ivory Coast. The high financial outlay on ferilizers and disease control is particularly noteworthy.

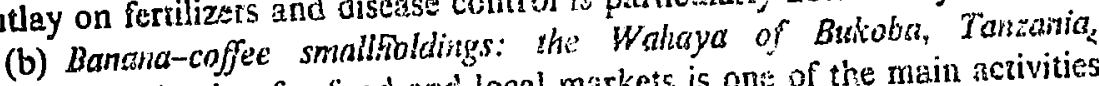
Banana production for food and local markets is ont of the main acivities of tropical srallholders, wherever raintall and temperature are sufficient for banana growing. A case in point is the banana-coliee culture of the Wahaya, which is particularly interesting because of the inteligent adaptation of banana production to the difficuit natural conditions of the location.

The Bukoba Districh receives ample and well-disteibuted rainfall averaging 2000 millimetres annually. "The soils, however, are badly ieached and very poor. The average holding comprises 1.4 hectans, of which 0.80 hectares are homestads carrying mainly cooking bananas, which are usually used as subsistence food, but which are is so sold to markets as Sar away as Dar-es-Salaam. Bananas, which yield more than half of the gross rciurn, are interplanted with Coffect robusta cofiet, maize, and beans. In addition to the homestead, the holding includes 0.6 hectares of open, infertile grassiand.

Fig. 8.4 shows the layout $f$ a Bahaya holding. The so-called homestead (1), a banana plot with coffee and several other crops in mixed stands, is sitnated around the hut. At the edge of the lomestead there is usually a garden growing predominantly root crops (2). At some distance from the homestead lies the grassland (3) belonging to the farm. Here small plots are cultivated on a short-term basis. The grassland serves as pasture and supplies mulch to the homestead. In addition to the grassland that belongs to the farm, everyone càn make use of communal grassland. Within the homestead both a spatial and a vertical order in plant growth is recognizable (see Fig. 8.4 (b) and (c)):

(1) Directly around the hut and the cattle kraal, the holding focal point where the soil has received the most manurc, a dense growth of bananas can be found. The greater the distance away from the hut, the less manure is applied. The bananas become thinner. More and more cofiee tre:s. maize plants, and beans grow between the bananas until the belt of bananas around the centre of the holding gives way to a belt of banana-coffee cultivation. Gradually the mixed stand of banana-coffee-beans is succeeded by one consisting of banana-maize-beans or cofiee-beans. In some cases, the belt of mixed stands is supplemented by a plot with pure stands of new 
(a)

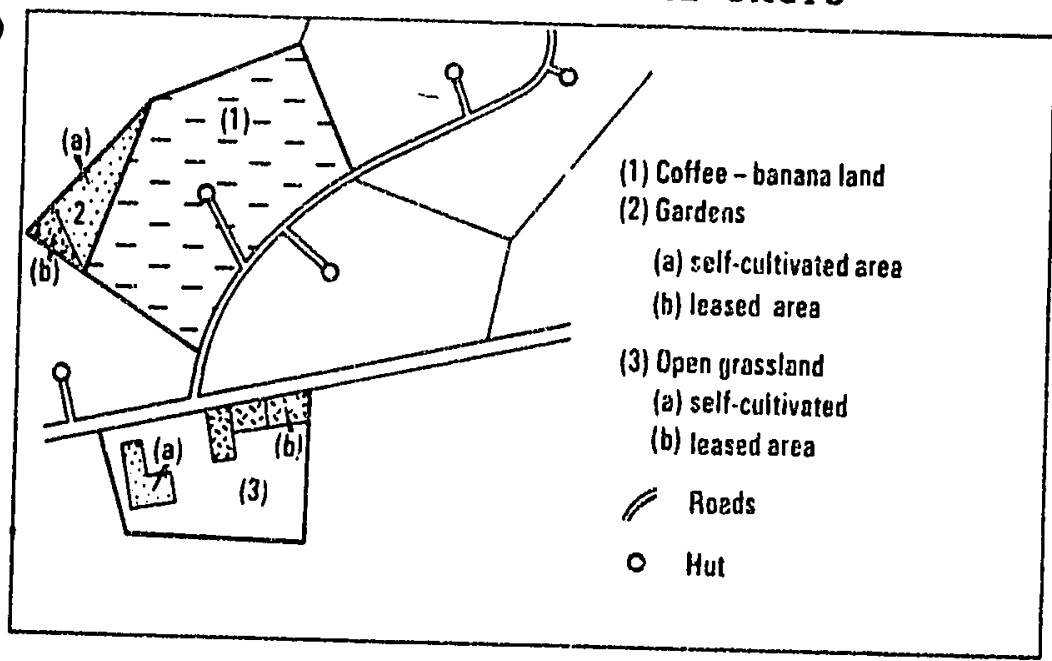

(b)

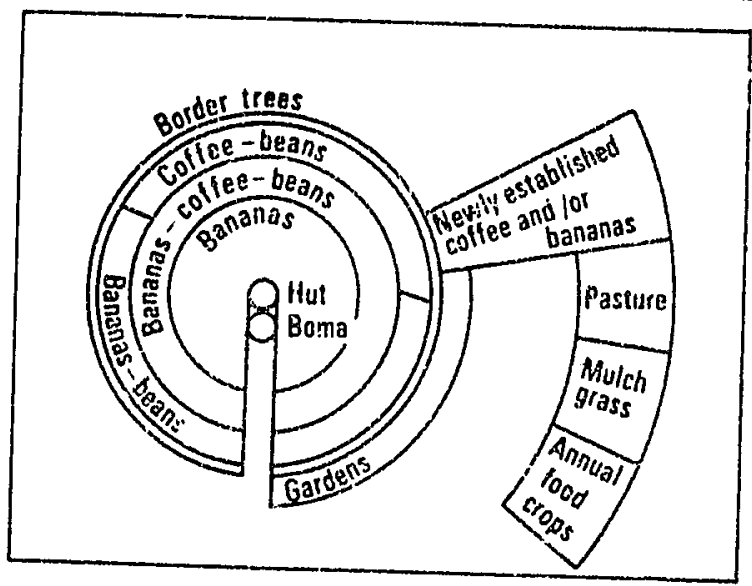

(c)

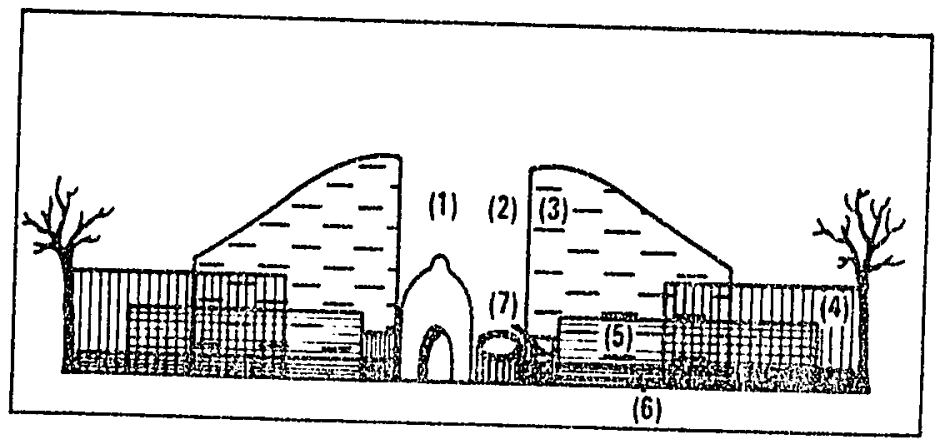
(1) Hut
(3) Banana
(2) Boina
(4) Coffee
(5) Maize
(6) Beans
(7) Vegetables

Fig. 8.4. Land use in a Bahaya holding, Bukoba, Tanzania: (a) layout; (b) horizontal order; (c) vertical order. From Friedrich (1968, p. 175). 
coffee. Land use is thus organized in coricentric circles around the central hut, the bands ranging in width from a tew feet to several dozen yards.

(2) Besides the spatial order of plant growth, there is a vertical one. On the heavily fertilized soil close to the house, the bananas reach unusual heights, casting dark shadows upon the ground, where only some arrowroots grow. Bananas close to the centre of the farm frequently grow twice as high as those growing on the less fertile edges of the holding. With the distance from the hut increasing and the supply of manure and mulch material growing less, and at the sane time the heights and shading of the bananas decressing, more coffee trees can be found growing between the bananas. If the density of the banana-coffee vegetation permits it, the ground is covered with beans, so that, in accordance with their need for light, three crops are growing one above the other: beans, coffee, and bananas. Arrowroot, yams, tobacco, maize, and vegetables are aiso grown where possible, in such a way that on difierent plots different crops are grown, which are compatible with regard to their light requirements. At the same time, the ground is given complete protection by a thick layer of mulch.

Naturally, the various belts around the hut are not kept strictly separate; instead, we find a gradual transition in the combination of plants, which may vary from one location to another, from one farm to another, and even on any one farm, according to the nature of the soil and the site of the slopes. The determining factors in the cultivation of the homestead are the fertility of the soil, domestic needs, the land available, and-occasionally-the influence of extension officers. The way mixed cropping is apportioned depends primarily upon domestic requirements. In cases of large families with small plots of land, bananas are given priority, and there is fittle room left for coffee. In contrast with this, there is proportionately much coffee where a family has at its disposal a relatively large homestead.

Bananas at Bukoba are a permanent crop. Sorne of the homesteads have carried bananas for more than sixty years, and this permanency of farming is based on intensive manuring. The export of nutrients is limited to some dried coffee. Instead, there is a substantial import of nutrients by the gathering of fuel, the purchase of food, the use of ample mulch collected from the open grassland, and the fact that the cattle are kept in stables and their manure systematically applied. The build-up in soil fertility is the more marked the older the homestead. The man farming an old plot, which in the course of time hr 3 received much refuse and mulch, can rely on his bananas having a denser growth and a richer yield than a man cultivating a new plot.

One-third of the farmers own cattle, usually 3-4 head. The cattle graze on the open grassland and produce mainly manure for the banana land. The production of rnilk and meat is very low. Friedrich (1968, p. 159) gives the following information: calving interval 25.5 months, weaning loss 30 per cent, daily milk production 


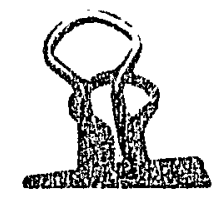

during the six-month lactation period about 1.5 kilograms, and 20 per cent of the cows are probably sterile. The average milk production per $c r w$ and per year, over and above calf-rearing, is thus estimated at 50 kilograms. The most important product of the cattle eccnomy is obviously manure (see Fig. 8.5). On farms where

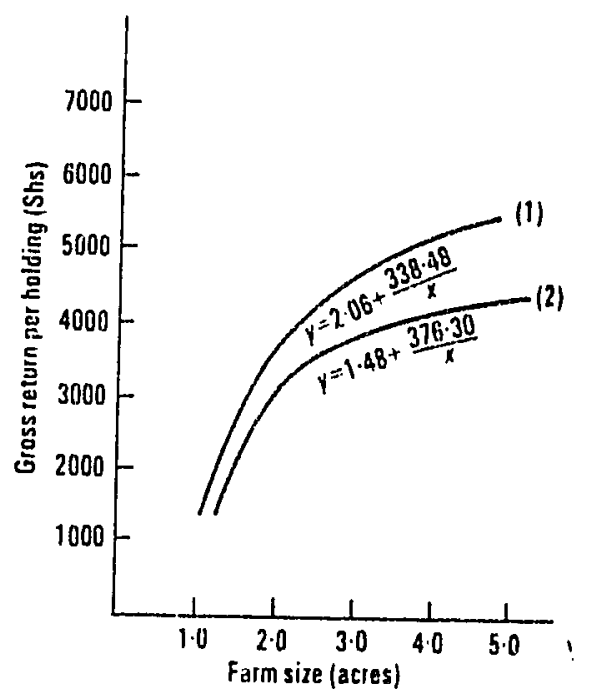

FIG. 8.5. The relation between farm size and gross return in Bahaya holdings with and without cattle. (1) Farms with cattle: $R^{2}=0.98, n=16$. (2) Farms without cattle: $R^{2}=$ $0.51, n=13$. From Friedrich $(1068$, p. 204).

cattle are kept, the gross return per hectare of banana-coffee land is on average \$200 above that of farms without cattle. If we assume-certainly not entirely correctly--that the additiondl al srage gross return on farms with livestock is wholly due to the manure, we arrive at an annual manure value per livestock unit of $\$ 78$ (130 shillings). This figure may explain the Wahaya's interest in obtaining cattle, and thus manurs.

Table 8.6 shows the economic return of Bahaya farming, which is higher than in most other jarming systems of Tanzania. The more successful farmers are quite obviously those who produce more per heclare. 58 per cent of their labour capacity is employed, as compared with the average of 37 per cent.

\subsection{Estates and smallholdinge with shrub crops}

Coffee and tea are the main representatives of a distinct group of crops that botanically are tree crops but because of their farm-management characteristics are termed shrub crops. The main difference in cultural practice between these and tree crops is the high input for weeding and pruning. Both aspects are tied to the shrub-like appearance of the plants. 


\subsubsection{Coffee holdings}

The production of arabica coffee in most countries was usually started on estates and then spread to smallholdings. A numbar of the frirm-mamagement features of cofies promoted this patiern of development:

(1) Coffee growing is adaptable to wide differenses in farming intensity and to various forms of mixed cropping and intercropping.

TABLE 8.6

Farm-managemenu data of banana-coffee holdings in Bukoba, Tanzania, 1964-5

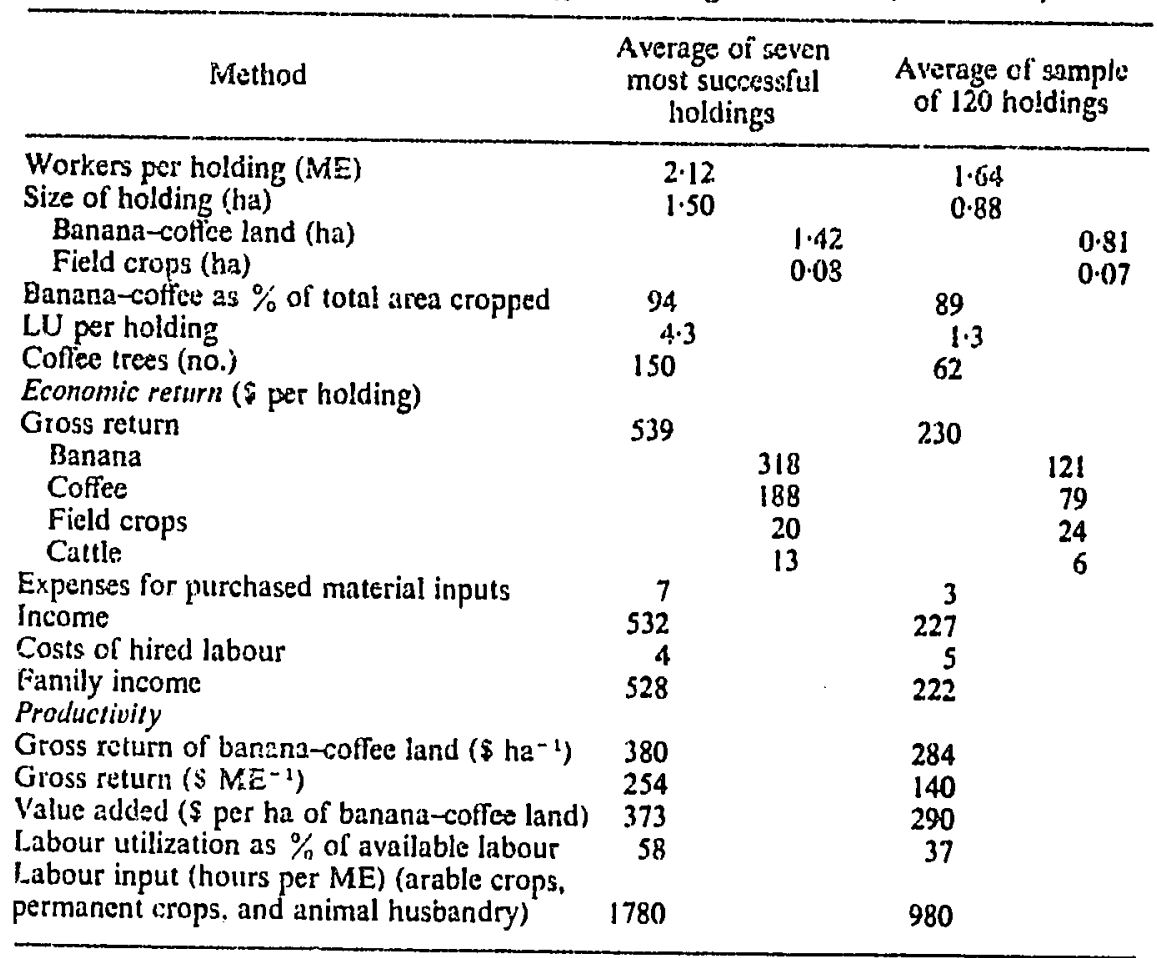

Source: Friedrich (1968, p. 206).

(2) Coffee production at low levels of yield is not very susceptible to plant disease.

(3) By far the most important input in coffee production is manual labour.

(4) The produce may be dr' ed on the farmi or processed in small pulperies. Transport of cherries to large pulperies is a problem, but by no means comparable with that of transporting sisal leaf or sugar-cane.

(5) The introduction of coffee into subsistence holdings does not usually lead to pronounced peaks in labour demand. 
Because coffee cropping suits small-scale farming, expansion in various parts of the world since the 1930s took place primarily in smallholdings, as in southern Brazil and East Africa. On the other hand, estate production has recently gained in competitiveness, owing chiefly to the more rapid application of technical advances like improved varieties, mineral fertilizing, plant protection, pruning techniques and processing.

(a) Coffee estates in southern Brazil and Kenya. The cofiee estates in southern Brazil are mosily a few hundred hectares in area and are run on a wage or contract basis. Holdings normally have at their disposal:

(1) a large coffee plantation, which occupies $15-3 n$ per cent of the overall area;

(2) a large pasture consisting of $40-60$ per cent of the holding, supporting about 50 head of livestock per 100 hectares of grassland;

(3) arable land for the workers as payment in kind; and

(4) odd pieces of forest or waste land.

In some cases we find arable land cropped with maize, non-irrigated rice, legumes, cotton, etc., a special crop like sugar-cane or onions, or a marketorientated dairy herd.

The different branches of the holding are cultivated extensively. The coffee stands are mainly very old and yield low returns. Fertilization with animal manure and mineral fertilizers is limited to progressive holdings. When the one harvest takes place, ripe, unripe, and overripe cherries are all picked together and prepared 'dry'. A commodity of moderate quality is produced on a large scale, the co.?ee yield per hectare being on average only 4 quintals, although in the examples in Table 8.7 it reaches $7-12$ quintals. The efficiency of the grassland is that of rough grazing rather than pasture, and the milk yields per cow exceed 1500 kilograms in only a few cases.

The holdings in Table 8.7 illustrate the ways in which this holding system is developing. In the case of the holding with 668 hectares, the purchasing power of neighbouring cowns has caused dairying to be expanded, so that only one-half of the holding return is derived from colfee. In the holding with 454 hectares, the growing urban dentand has led to a special crop, in this case onions. In other holdings, like the one with 716 hectares, coffee cropping has been modernized, a step reflected in younger stands and higher efficiency per unit area. The introduction of mineral fertilizing in conjunction with sprays has given coffee the power to compete again with other forms of land use.

Coffee estates in other parts of Latin America and in Africa are usually less diversified than those in southern Brazil, where urban purchasing power is comparatively high. In Kenya for instance, most coifee estates are specialized undertakings. In the case study depicted in Table 8.10 (p. 229), half of the farm area is pianted with coffee, the rest being waste land, or producing mulch material. 
TABLE 8.7

Farm-management data of diversified coffec estates in Sao PL:IJ, Brazil, 1958

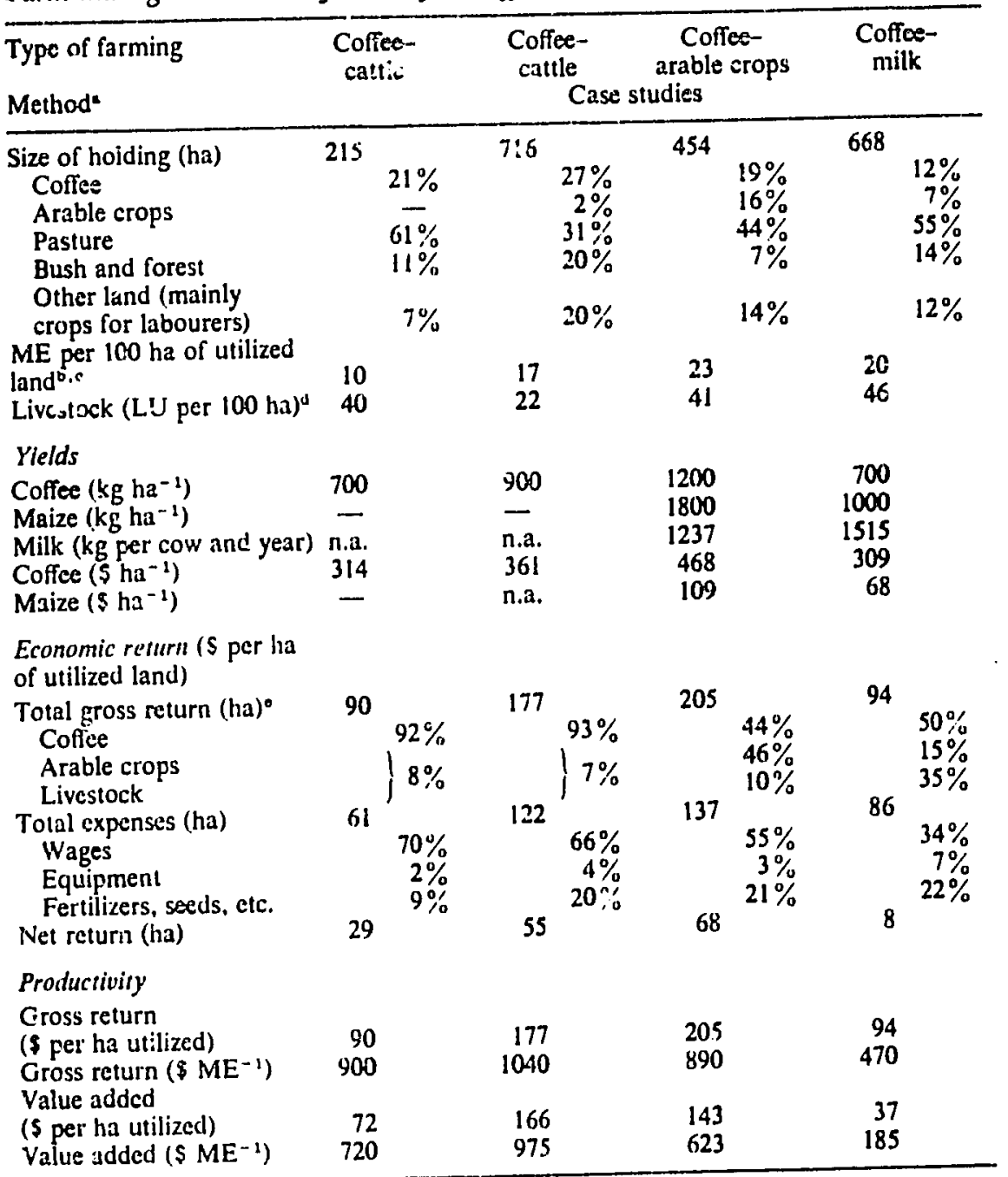

a Case studies nos. SF-40, LF-150, MF-2, MF-1.

- The labour force is related io land utilized, i.c. coffec land + arable land + pasture, not including bush or land for labourers.

- Not including production on labourers' fields, food to the farmer's household, or renting value of the farmhouse.

Source: Fond and Agriculture Organization (1960, part 1). 
Considering the farm-economic data of the coffee estates in southern Brazil and Kenya (see Table 8.7 and 8.10 ), we may summarize their farm. management characteristics as follows:

(1) A high degree of intensiry per hectare planted with coffee, with gross returns far above most arable crops under similar circumstances, and usually also above most tree crops thai suit the location. The duration of the cycle is an indication of the degree of intensity. With extensive cultivation, the coffee stands are replaced after twenty-five to thirty-five years; :vith intensive cultivation they are replaced after twelve to eighteen years. (2) Soil fertility is not as easily maintained in estates with monoculture as in smallholdings with a banana-coffee mixture. Intensively mulched and manured coffee plantations in Guatemala are reported to produce coffee for one hundied years without reduction in soil fertility. Extensive coffee production, however, frequently results in soil mining.

(3) Manual labour and salaries are important input items, requiring about half of the total costs. The level of coffee output per hectare is closely related to the level of labour input, since the extra work that is involved in applying intensive husbandry techniques (see $\$ 8.5 .1$ (c)) may result in substantial increases in quantity and quality.

(4) The capital input, except in trees, roads, and pulperies, is low compared with most othur estate crops.

(5) Estate production with a ligh level of yicld is exposed to considerable production risks: frost is a particular hazard in southern Brazil; coffee berry disease has brought great losses to the planters of Kenya.

(b) Coffee smallholdings in Tanzania and southern Brazil. Both robusta and arabica coffee are extensively grown in smallholdings, whel a coffee production is combined with various other activities. Three distinct types may be distinguished:

(1) Coffee may be grown under a cover of natural foresi, and rarely mixed with food crops. This is true for most of the robusta production in West Afric 2 and the arabica production of Ethiopia.

(2) Coffee may be grown in a mixture with bananas and various other food crops. This is true of some rob!ssta coffee and of much of the arabica coffee in Latin American and East African smallholdings. Mixed stands are frequently the outcome of introducing coffee into fallow systems.

(3) Coffee may be grown in purc stands, except for some interculture in the early stages of plantation development. This is true of smallholder coffee in southern Brazil and Kenya.

The following is an outline of the farm-management characteristics of holdings growing coffee in mixed and pure stands: 
(1) Coffee-banana holdings on Mount Kilimanjaro, Tanzania. In the course of five decades an important and particularly interesting farming system has developed in the coffee-banana belt on the fertile, well-watered slopes of Mount Kilimanjaro (see Table 8.8). These are small farms of

TABLE 8.8

Farm-management dista of coffee smallholdings in Tanzania and Brazil

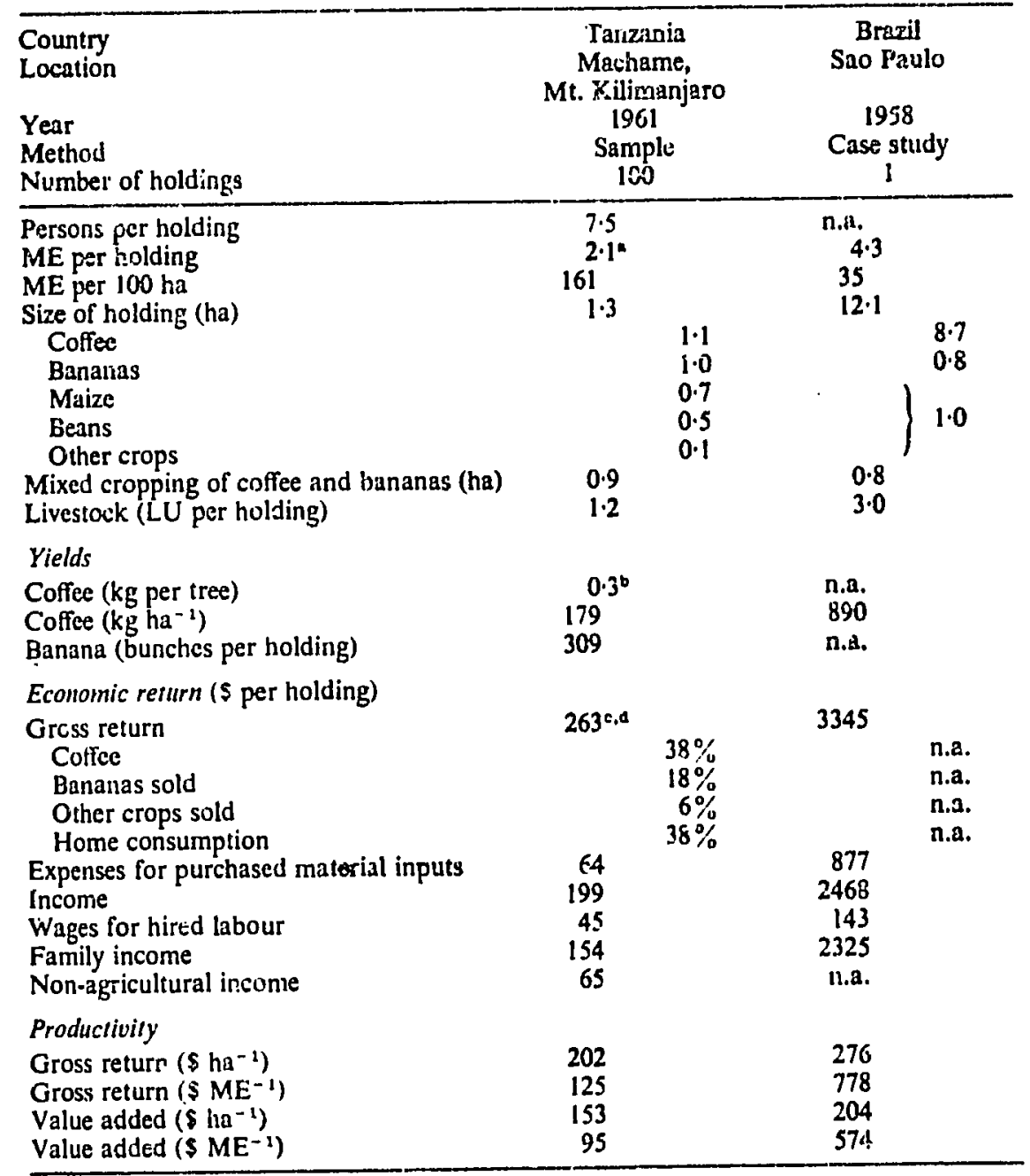

- Including family members receiving other income and 0.5 man-equivalents of non-family labour.

- Average of 1960 and 1961.

- The sample year 1961 was exceptionally poor.

- Without renting value of farmiouse.

Sources: Tanzania, Beck (1964): Brazil, Food and Agriculture Organization (1960). 
about 1.0 hectare, on whicl coffee and bananas are grown in mixed stands. In addition, a few miles lower down the mountain farmers cultivate a plot of maize. Most or the farms keep some cattle and goats, which are stabled throughout the year. The animals are fed with the leaves and stems of bananas. Grass and hay is brought from the lower sieppe, the women carrying bundles of it on their heads for miles. The goats feed on the leaves of hediges surrounding each holding. The main purpose of this system of animal husbandry is to obtain manure.

The various farm activities are integrated to a remai able extent. Bananas supply food, the raw marerial for the brewing of beti, snme cash, foddcr for cattle, and mulching material. The manure for both coifee and bananas cones from the cattle, which also supply animal proteins.

Planting is arranged according to the light requiremenis of each crop. Light permitting, beans are grown nearest the ground, and above them the coffee trees, which in turn grow in the shade of bananas. The sinaller the farm the greater the preference given to bananas, because under present methods of cultivation they yield in terms of money the highest gross return per hectare.

jeck's (196.3) study of 1961 , a particularly poor year, shows that on averase, a 1-2-hectare holding of this type yielded a gross return of $\$ 263$. The r.tain outlay was the wage bill for outside labour. One-thire of the families derived an income from outside the farms, usually by working on nearby estates. The average family incorne in 1961 was quoted at $\$ 219$. According to another more widespread but less systematic enquiry in 1959, the returns from coffee and bananas were considerably higher, even on smaller farms.

Worthy of note are the beginnings of commercial milk production. The income from coffee has resulted in a greater demand for milk. Some farmers are buying Jersey cows from the estates in order to sell milk to their neighbours. The annual milk yield per grade cow was about 2000 iitres in 1961 . Some farmers buy additional bran and pyrethrum cake; they also grow grass for focider, either in terraces between the coffee or in separate plots. If the cows are prol erly looked after-so some of the better farmers sayfodder grass shows greater moneiary returns per hectare than eitner coffee or bananas. Hence grass becomes another cash crop. The farmers are encouraged to grow their own grass because the purchase of hay from the steppe carries the danger of introducing ticlis and thus east coast fever and other diseases. Disease-prone grade cattle are kept healthy by stablefeeding with home-grown fodder all the year round.

The fact that this Wachagga farming is commercialized to such an extent has also led to changes in the attitude to land ienure. Land has become the private property of individual farmers. It is openly bought or sold, and can be used as security against government loans.

(2) Coffee sitios in southern Brazil. Where coffee is grown in pure stands, 
most smallholdings are highly commercisiized, and the same husbandry techniques as in estates are applied with varying degrees of care. Economically important examples of this art ine coffice holdings in southern Brazil, which account for the major part of local production.

Table 8.8 contains the data of a holding typical of this kind, whose efficiency is above average. The area cropped with coffee is 3.7 hectares, most of which carries pure stands. Young coffee plantations are also used for growing maize, rice, and beans. 3 hectares of pasture support 5 cattle. Arable farming and cattle-keeping serve only to cover household food requirements. The holding is operated by family labour. At harvest time, which is a relatively short period in this area (unlike other coffee-growing areas of the world), a number of sedsonal workers are employed.

The result of using a relatively small labour force is an extengive form of coffee growing. Four plants are put into one hole. The branches arte not pruned, so that work is linited to control of weeds and harvesing. The tree is stripped when most of the cherries are ripe, and they are then placed in drying sheds. In this way coffee is produced at half the price of coffee in the holdings on Kilimanjaro. The cropping area and size of the harvest is disproportionately larger.

The good results from the holding shown in Table 8.8 derive from the use of a relatively young plantation that is heavily fertilized. This is not usually the case in Brazilian sitios, the jields averaging orily 4 quintals of cofiee per hectare. However, there are signs of improvement, such as the intensification of dairying, which produces animal manure, or, as in our example, the development of smallholdings with heavily fertilized pure stands of coffee.

(c) Husbandry techniques of coffee production in various countries. The comparison of husbandry techniques in various coffee-growing areas provides an idea of the socio-economic adaptability of coffee pioduction. This can be illustrated further by a comparison of labour input, zusts, and returns of production of arabica coffee in three Latin American countries and in Keliya.

(1) Traditional coffee cropping in Sao Paulo. The aim in coffee cropping in Brazil is to produce large quantities of moderate quality, using a large area of land and as few workers as possible. The traditional method of farming is relatively extensive. Coffee is sown in the field and not planted. 800 seed holes per hectare are the norm, and as the plants grow they are thinned out, leaving two to six plants in each hole. The struggle for light causes the individual branches to bend outwards, and fruit-bearing branches to be formed without any pruning. Hoeing the weeds is the only major operation. Coffee occupies the plot for a relatively long time, normally four years, before the first yield is produced. The plot is used 
over a long period: two-thirds of the trees in holdings in Sac Paulo are more than twelve years old and half are more than twenty-five years, whereas the meximum yield is reached in the seventh to ninth year. People prefer, however, to have large areas carrying old stands with a low yield to save the cost of frequent replanting. The cherries are not harvested selectively, but when most of them are ripe. All the cherries growing on

\section{TABLE 8.9}

Labour input per hectare of established coffee in several countries (hours per hectare)

\begin{tabular}{|c|c|c|c|c|}
\hline $\begin{array}{l}\text { Country } \\
\text { Exploitation system }\end{array}$ & $\begin{array}{c}\text { Brazil } \\
\text { Estates }\end{array}$ & $\begin{array}{c}\text { Columbia } \\
\text { Smallholdings }\end{array}$ & $\begin{array}{c}\text { El Salvador } \\
\text { Estates }\end{array}$ & $\begin{array}{l}\text { Kenya } \\
\text { Estaies }\end{array}$ \\
\hline $\begin{array}{l}\text { Weeding and decouching } \\
\text { Pruning } \\
\text { Care of shade irees } \\
\text { Infillings } \\
\text { Mulching, iertilizer } \\
\text { application, and erosion } \\
\text { control } \\
\text { Plant protection } \\
\text { Harvesting } \\
\text { Sundries }\end{array}$ & $\begin{array}{r}209 \\
15 \\
- \\
6\end{array}$ & $\begin{array}{r}254 \\
63 \\
29 \\
24\end{array}$ & $\begin{array}{r}219 \\
227 \\
151 \\
86\end{array}$ & $\begin{array}{r}259 \\
120 \\
912 \\
48\end{array}$ \\
\hline $\begin{array}{l}\text { Total labour (hours per ha) } \\
\text { Wage costs }\left(\$ \mathrm{ha}^{-1}\right)^{\mathrm{b} . \mathrm{c}} \\
\text { Yield, green coffee }\left(\mathrm{kg} \mathrm{ha}^{-1}\right) \\
\text { Price }\left(\$ \mathrm{t}^{-1}\right) \\
\text { Gross margin }\left(\mathrm{ha}^{-1}\right) \\
\text { Wage costs as \% of gross } \\
\text { margin } \\
\text { Gross margin ( } \$ \text { per hour } \\
\text { of work) }\end{array}$ & $\begin{array}{r}576 \\
92 \\
446 \\
450 \\
201 \\
\\
45 \\
0.35\end{array}$ & $\begin{array}{r}799 \\
104 \\
523 \\
704 \\
368 \\
\\
28\end{array}$ & $\begin{array}{r}1566 \\
157 \\
660 \\
955 \\
630\end{array}$ & $\begin{array}{r}2615 \\
158 \\
840 \\
875 \\
735 \\
22\end{array}$ \\
\hline
\end{tabular}

- Direct costs for upkeep and harvesting only, without general charges, overheads, or processing.

- Total labour input valued at local wages: Brazil $\$ 0.16$ per hour; Columbia $\$ 0.13$ per hour; El Salvador $\$ 0.10$ per hour; Kenya $\$ 0.06$ per hour.

- Rate of exchange: Brazil, $100 \mathrm{cr}=$ U.S. $\$ 1.32$; El Salvador, source in U.S. \$; Kenya, 1 shilling $=$ U.S. $\$ 0 \cdot 12$; Columbia, 1 pesos $=$ U.S. $\$ 0.234$.

Sources: Food and Agriculture Organization (1958, pp. 24, 28, 43, 45, 49, 50, 79, 105, 117 , 138); (1960, part 1, pp. 20, 48, part 2, pp. 48, 55, 61); Kenya Coffee Growers Association (1968).

the tree are shaken or stripped off, and oried in the air on drying floors or in drying sheds. Air-drying is preferred to the pulping and fermentation method, because the latter requires selective harvesting. This in turn requires a high labour input at harvest time, and in Sao Paulo harvesting takes place in a few concentrated months, a situation that distirguishes it from coffee-growing regions near the equator. 


\section{SYSTEMS WITH PERENNIAL CROPS}

The Brazilian method demands an average input of only 576 manequivalent hours per hectare. There are no appreciable costs of fertilizing and planting materiai. On the other hand, the yields are low, the quality is r.verage, and the gross monetary return per hectare is small. The cost of labour amounts to 31 per cent of the gross return, so that per manequivalent-hour there is a gross return of $\$ 0.35$ (see Table 8.9).

The husbandry techniques described above are on the way out. Production is increasingly coming from new plantations, with plants raised in nursery beds and planted in fertilized holes-four plants to each holealong contour lines. Mineral fertilizer and mulch aie applied. The $\pi$ is, however, little pruning, little selective harvesting, and the produce is stil! sun-dried (Nixdorf 1968).

(2) Coffee growing in Columbia. In Columbia, coffee is produced mainly in peasant holdings, which normally comprise 10 hectares of usable land with 3 hectares devoted to coffee. They are in mountain locations, where the population density is relatively high and land is correspondingly scarce. Coffee cropping is, therefore, more intensive than in Brazil. Instead of seeding the coffee, the farmers plant seedlings, but only some of the plants are raised in nursery beds. Adventitious suckers are still commonly used for replanting (this is the most extensive form of planting possible). The plant density of about 2000 trees per hectare is very high. The growing stands are shaded by bananas, which also produce a yield, but where there are older stands they are sometimes shaded by trees that compete less with the coffee for light and nutrients than do bananas. There is not a great deal of pruning. Fertilizing is rare and the orly cultivation is weeding and annual topping to keep the trees down to a manageable size.

Harvesting takes place throughout the year, and it is selective according to ripeness. The cherries are pulped before undergoing fermentation, which demands more labour and investment than the air-drying methods. The holdings are equipped with the necessary hand-tools and facilities. The labour input in the Columbian method, an average of 799 hours per hectare, is far above that of Brazil, but this higher input is counterbalanced by a somewhat higher yield of considerably better qua!.ty. The labour costs constitute 24 per cent of the gross return, and a gross return per manequivalent-hour of 50.57 remains.

(3) Coffee cropping in El Salvador. Coffee cropping in El Salvador has attained a particularly high degree of intensity. Plants are raised with great care and a high labour input, first in a seedbed and then in a nursery bed. Only selected young plants are used, and they are planted out when they are one or two years old, which is comparatively late. The point of this is to reduce as much as possible the period when no yield is produced, and this is also how total clearance and replanting can be avoided. The seedlings replace trees that have already been chopped down, or they are planted 
near trees with a poor crop, which are chopped down as soon as the new plants begin to bear fruit. In this way, stands are being permanently rejuvenated. Except in particularly high locations, the coffee grows under shade trees, like mangoes or avocados, which themselves often produce an economic return. The young plants are put in holes fertilized with organic or mineral fertilizer. The coffee tress are also ireated with compost and mineral fertilizer during their fruitless early years. They are frequently and carefully pruned, erosion is controlied by terracing, harvesting is selective, and the wet fermentation method is used. The labour input of 1566 hours per hectare is three times as high as in Brazil, but compared with the data from Brazil it is compensated less by higher yields than by better prices. The wage bill accounts for 24 per cent of the gross return, so that the gross return per man-equivalent-hour is $\$ 0^{\circ} 40$.

(4) Coffee-growing techniques in Kenya. Coffee growing in Kenya is even more labour demanding than in El Salvador, although the production techniques are similar. The labour spent on weeding and decouching is particularly high. The pruning requires twice the number of work-hours as in El Salvador. The same is true of selective harvesting. The data thus indicate that the labour efficiency per man-hour is much lower in Kenya than in El Salvador. The higher input in man-hours is offset by Jower wages. To+al wage costs in Kenya and El Salvador are almost at the same level. The same appiies to prices. The gross margin per hectare, hotvever, is higher, while the gross margin per hour of work. is much lower.

The data in Table 8.9, comparing labour input and yields from coffee plantations with different growing methods, must be treated with caution. They are average values from surveys of the Food and Agriculture Organization dating back to the late fifties. There are great variations of performance within each area. Moreover, the rates of exchange have introduced their own distortions. The value of the comparison does not lie, therefore, in any of the details, but rather in the demonstration of the gieat numbers of possible methods and in the fact that there are definite reasons for the cropping methods that have been chosen.

\subsubsection{Tea holdings}

Growing of tea in suitable areas depends on the processing capacities of tea factories. In Ceylon and Assam, there are still many small factories in operation with a processing capacity of less than 110000 kilagrams of made tea a year. The tea area required by a factury of this kind is 50-100 hactares according to the level of yield. The size of these holdings is typical for the indigenous owner-planter. The tea estates belonging to firms have larger processing capacitics and larger plantations. In the highlands of Kenya the smallest size, according to McWilliam (1959), is a processing capacity of 
25000 kilograms of tea and 200 hectares. The optimum estate size is twice this. Besides the estates, we alsc find occasional tea-growing holdings whose harvest is sold to a neighbouring factory. In Kenya, Ceylon, and Java, these are run chiefly by small-scale producers. In Japan and Taiwan, the smallho!ders process their own tea by traditional hand methods.

(a) Tea estates in Ceylon. Table 8.10 shows data of input and yield on a tea. estate in Ceylon, where most of the tea is more than 50 years old. $\Lambda$

TABLE 8.10

Furm-management data of a coffee estate in Kenya and a tea estate in Ceylon

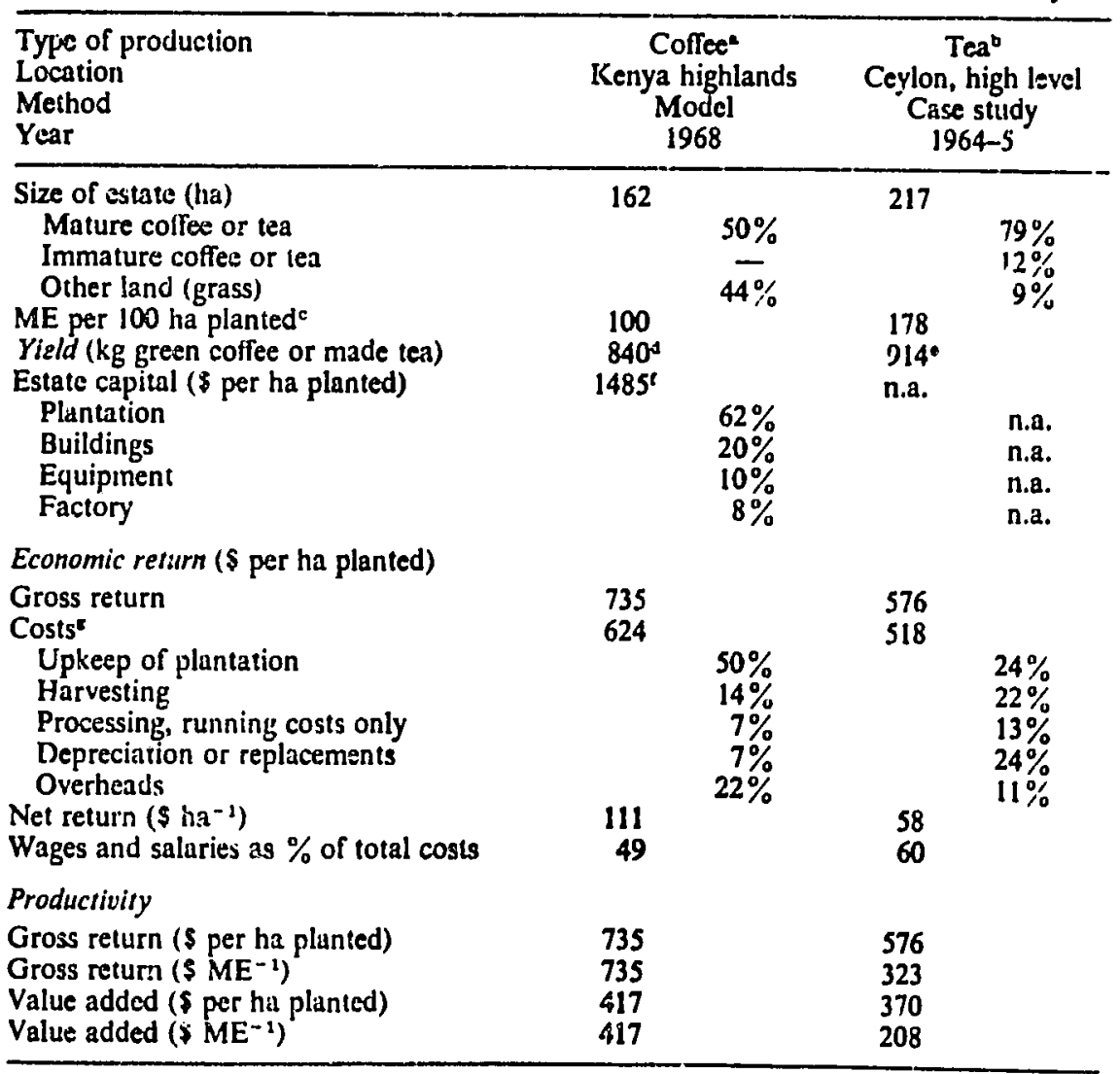

- Based on estate records.

- Accounts of a well-run estate.

- Including factory labour and seasoual labour.

a Average of all estates: $700 \mathrm{~kg}$.

- Estate average: $600 \mathrm{~kg}$.

Planning figures for a newly established estate.

- Net of interests.

Sources: Coffec, Kenya Coffec Growers Association (1968); ten, estate accounts, personal enquiries. 
special advantage from the angle of farm management is the regularity of the labour operations. In Assam and East Africa, 80-90 per cant of the harvest of leaf occurs in 5-6 months, whereas in Ceylon it occurs in 7-8 months. Ten estates are generally characterized by the following farmmanagement features:

(1) Tea is an intensive form of tropical land use. In the exanple ir Table 8.10 , the yield is 914 kilograms of made tea per hectare, i.e. $\$ 576$ per hectare. Improved planting and plucking techniques, in conjunction with mineral fertilizing, have made a vital contribution to the increase of average yields in northeeast India from 625 to 1075 kilograms in the last forty years. Fields with new clones, in a good tca climate, planted at high densities, and with high applications of mineral fertilizer (320 kilograns nitrogen per hectare), yield in Ceylon $3000-4000$ kilograms of made tea per hectare. In addition they are earlier yielding than traditional tea.

(2) A tea plantation is permanent and the yield is reliable. A plantation produces regularly will on!y minor fluctuations from year to year. It is common to find tea plantations being used continuously for fifty years, and in Japan plantations are still cultivated that are over 150 years old. Replanting becomes necessary when there are too many missing bushes, or when the productivity of the established bushes is low in comparison with that of improved clones.

Conservation of soil fertility on tea estates is a problem similar to that of coffee cropping, in that it depends largely on hustandry techniques. Modern plantations with lintle space between the plants, growing along the contours, showing a dense table of tea leaves, and with heavy fertilizing may well be regarded as a soil-preserving type of land use.

(3) The main costs are thuse of labour. Practically 80 per cent of the costs of establishing a plantation without a factory and 60 per cent of the costs of a mature plantation are wages and salaries. In Ceylon. we find a Jabour input of 5690 work-hours per hectare (see Table 8.11), 44 per cent of which is spent on harvesting the leaf ( 4000 shoots have to be picked for one kilogram of made teat). 19 per cent is spent on hoeing weeds and 8 per cent on work in the factory. The labour demand hovers around 2 man-equivalents per hecture of tea, and almost half is female labour employed in plucking. Tea plantutions are very sensitive to wage levels, and success depends on the availability of plenty of cheap labour, since operations cannot be easily mecnanized, mainly because of the inability of the plucking machines to discriminate between tea leaves for quality, and to avoid damaging the tea bushes. In addition, it is difficult to mechanize tea planting on sloping land. In Ceylon, for instance, the employment ratio for iabour--approximately $2 \cdot 2$ man-equivalents per hectare of tea-has changed little over the last forty years (Lim 1965, p. 18). Plucking shears, 
with which a yield per day of 10-15 kilograms of green leaf can be increased to 100-150 kilograms, are used in Russia, Japan, and Taiwan, but only occasionally in Assam or Ceylon. They do reduce the quality of the leaf, however. Another feature of tea production is the rigid timing of operations, because the leaf has to be plucked at regular intervals and processed a few hours later. Thus, tea plantaticns can be disrupted much more easily by strikes than can sisal or rubber plantations.

TABLE 8.11

Composition of labour use on five cstablished tea estates in Ceylon

\begin{tabular}{ll}
\hline Total labour hours per ha & 5690 \\
Plucking tea leaf & $44 \%$ \\
Weeding & $19 \%$ \\
Manuring & $4 \%$ \\
Dusting and spraying & $4 \%$ \\
Bush sanitation & $3 \%$ \\
Green manure & $3 \%$ \\
Pruning & $2 \%$ \\
Maintenance of roads & $6 \%$ \\
Factory labour & $8 \%$ \\
Services & $7 \%$ \\
\hline
\end{tabular}

Source: Wright (1953, p. 59).

(4) High initial investments are necessary. The replacentent of a plantation of one hectare in Ceylon costs from \$1000-1500. In Kenya, McWilliam (1959) quotes from $\$ 2000-4000$ per hectare for a new plantation and $\$ 87500$ for a tea factory serving 200 hectares. Thus a 200 -hectare plantation costs at least $\$ 500000$, and, since there inust be this high initial investment, there is a burden of high fixed costs.

(b) Smallholder tea. Tea is a typical estate crop for various reasons: firstly because the green leaf riust be properly plucked and processed within a few hours, and this is very difficult to organize with numerous smallholdings. and secondly because of the importance of refined techniques in plant raising. plant establishment, fertilizing, plucking, and in particular pruning, all of which have to be applied for optimum yields. Smallholder tea in Ceylon yields significantly less than estate tea. Nevertheless, smallholder tea has been introduced on a large scale in Kenya, and is also being introduced in various other countries. The key to the striking initial success in Kenya is the very thorough organization, the supervision of planting, husbandry, plucking (bud and two leaves only), and delivery of green leaf. Tea is grown in smallholdings that include numerous other activities like maize, potaioes, coffee, and milk production with grade cattle. There is, however, almost no interplanting, pure stands being cultivated according to closely prescribed rules adapted from the estate economy. 
Smallholder tea in Taiwan is quite differint, because the production aim is a tea of low quality but high return per hectare (up to 4000 kilograms of dry tea). Harvesting with shears takes place four tirnes a year. Mineral fertilizers are intercropped together with mainly pig manure, and large areas of tea in Taiwan are intercropped with sweet potatoes and groundnuts.

\subsection{Estatos and smallholdings with troo crops}

Crops like cocoa, rubber, oil-paims, and coconuts are tree crops proper. They differ from the shrub crops dealt with above in that they need more years to reach the bearing age, their vegetation cycles are longer, and they present a less intensive form of land use. High costs for establishing plantations and for harvesting and low costs for plantation maintenance are the most obvious characteristics of this group.

\subsubsection{Cucoa holdings}

Cocoa is a typical smallholder crop, mainly because cocoa can easily be established in combination with arable farming. It fits into various forms of low, and processing can be done, husbandry demands are comparatively Estate production is, however, practised inple equipment on the holding, for instanze, and is usually ained at quality refined processing techniques. in the tropics is usually tied to the estate system of tree-crop development backward population. This is true for cocostem, particularly in areas with a p. 235 shows the farm-inanagement data Production Guinea. Table 8.13 on on tea estates. Plantation maintenance, Production is far less intensive than main cost items. A special feature of the hrvest, and amortization are the Australian personnel are employed, is a high sal: on in New Guinea, where

(b) Cocoa smallholdings of the Yorubal salary for the manager. estate production is smallholder production, which More important than Africa. In the tribal area of the Yoruba, in the last fedominates in West 150000 largely commercialized small-scale producers decades, more than themselves.

In these holdings we can distinguish clearly between cocoa cropping and subsistence farming. A typical cocoa holding consists of $1.0-1.5$ hectares of cocoa and land belonging to the holding usually crops (see Table 8.12 ). The fallow and waste the arable land. Stock consists of a few goats, to twice or four times the area of land-use system has evolved from shifting, sheep, and chickens. The Yoruba's 
permanent and partly semi-permanent. ${ }^{1}$ After clearance, yams, maize, and manioc are cropped for two to three years. During arable cropping, cocon is sometimes sown and sometimes planted among the subsistence crops. Manioc, bananas, and papaya create shade at the beginning, and a plantation of cocoa develops, mixed with cola tiees and oil-palms. Land planted in this way cannot be used for arable cropping for a long time. The yields of cocoa that this method produces are very

TABLE 8.12

Farm-management data of Nigeria cocoa holdings

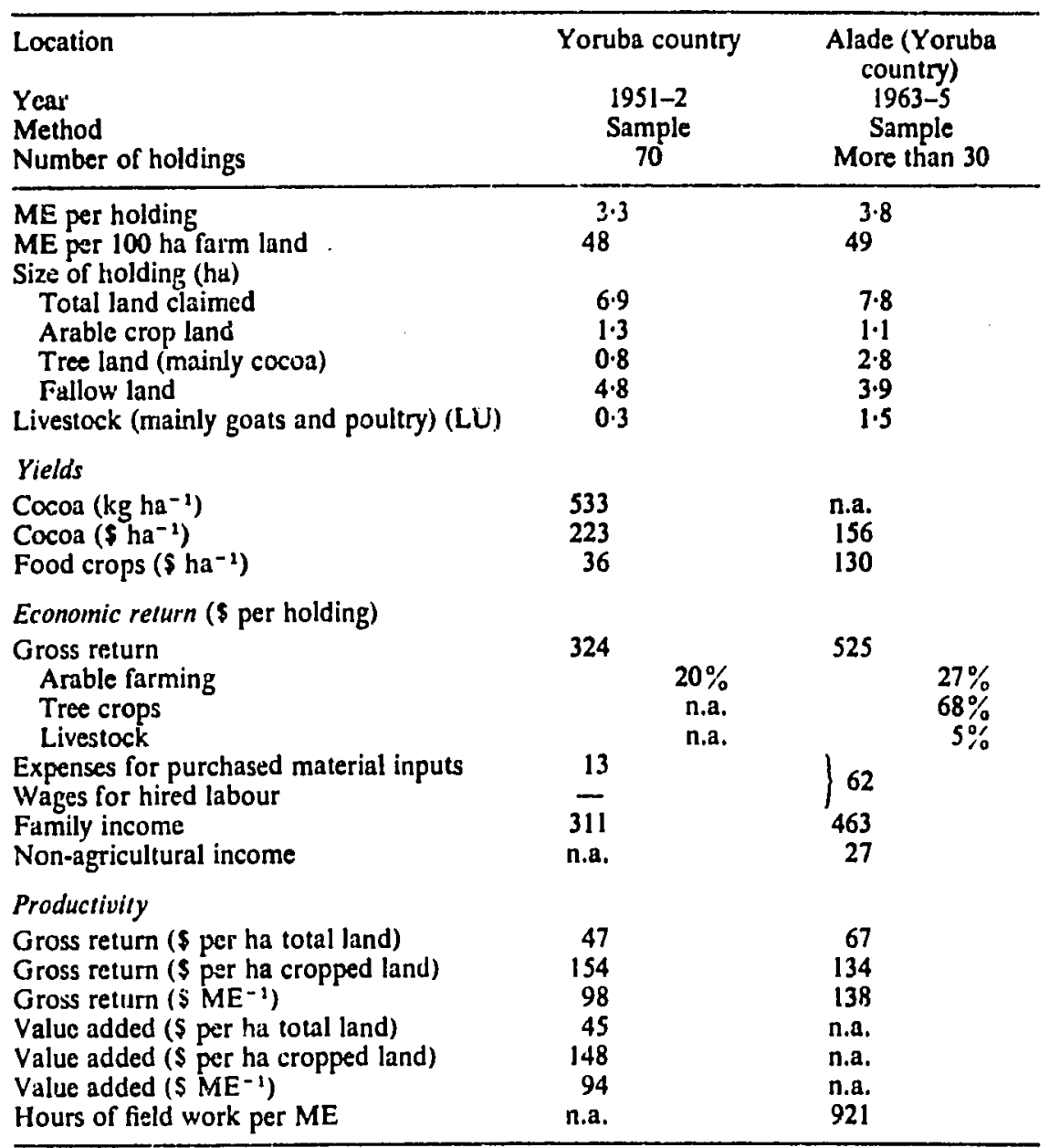

Suurces: Galetti, Baldwin, and Dina (1956); Upton (1967).

${ }^{1}$ In Ghana, the place where the nost cocoa is produced by smallholders, the conditions were originally different. The rapid expansion of cropping is due to the activity of small entrepreneurs settling in the area, who move on and buy new land as soon as cropping is no longer profitable. 
low at 533 kilograms per hectare (the average yield in Ghana is also low, with about 300 kilograms per hectare), since a reasonable yield expectation in modem cocoa plantations is 2000 kilograms per hectare. On the other hand, the costs of establishing the plantation and cultivating it are also low.

The arable brancl of the holding continues alongside the tree crops with practically no modification. The same plot carries a variety of crops arranged more or less in a vertical order. The ground layer consists of creeping crops such as groundnuts, pumpkins, gourds and calabashes, melons, and creeping beans; the lower erect layer comprises manioc, maize, peppers, and erect beans; and the upper climbing layer is made up of yams and climbing beans.

The extension of cocoa growing naturally leads to a reduction in fallowing. The ratio of fallow years to cultivation years decreases from $3: 1$ in less densely populated areas, to $1: 1$ in the middle of the cocoa region. At the same time, subsistence farming undergoes a change. Manioc is given priority, because it makes relatively low demands on soil fertility and produces more calories per hectare and per work-hour.

Galetti, Baldwin, and Lyinar (1956) calculated that in 1951-2 the gross return of a holding like this in the region of Ibadan was \$323. Upton's more recent estimate $(1963-5)$ amuunts to $\$ 525$, of which a good half is derived from cocoa (Upton 1967). Material inputs are low, and capital, apart from plants, consists only of a few hand implenents and a rack for diying the cocoa beans. The problem is how to meet the labour demands that the arable branch of the holding presents. Cropping more than one hectare with subsistence crops usually fully occupies the labour force of a family of hoe farmers. The Yoruba farmers employ, therefore, a good deal of seasonal labour.

\subsubsection{Rubber holdings}

Rubber is grown extensively by both large and small producers, although the objectives and the techniques of production differ. Production in estates is geared to the principle of maximizing financial returns, while smallholder rubber is part of an integrated farming system, with rubber serving as a supplementary source of income.

(a) Rubber estates in Malaysia. Rubber estates are mainly situated in Malaysia, Sumatra, and Ceylon. Table 8.13 provides some information about the economics of estate production. The main farm-management characteristics are as follows:

(1) Rubber production, although yielding much more than rain-fed arable farming under similar circumstances, is less intensive than, for instance, tea or coffee production. The established estate depicted in Table 8.13 yields 900 kilograms per hectare, valued at $\$ 212$. With traditional varieties it is about seven years from planting to tapping, which is a significantly longer unproductive period than with the permanent crops dealt wi:h so far. (2) Soil fertility is well preserved in rubber plantations, which have the appearance of a forest in temperate climates. 
(3) Manual labour is the main item of cost. Salaries and wages amount to 76 per cent of the total costs (see Table 8.14). 3.3 hectares per man are reported in our case study. whereas 1.5 hec*ares per man is the national average for estates in Ceylon, and the ratio has remained almost unchanged

TABI.E 2.13

Farm-rianagement data of cocua, rubber, oil-palm and coconut-palm estales

\begin{tabular}{|c|c|c|c|c|}
\hline $\begin{array}{l}\text { Type of production } \\
\text { Location } \\
\text { Year } \\
\text { Method }\end{array}$ & $\begin{array}{c}\text { Cocoa } \\
\text { New Guinea } \\
\text { 1958 } \\
\text { Model }^{a}\end{array}$ & $\begin{array}{l}\text { Rubber } \\
\text { Malaya } \\
1961 \\
\text { Case studies }\end{array}$ & $\begin{array}{c}\text { Oil-palm } \\
\text { Cameroon } \\
1968 \\
\text { Moriel }^{\text {Con }}\end{array}$ & $\begin{array}{c}\text { Coconut } \\
\text { Ceylon } \\
1969 \\
\text { Case atudies }\end{array}$ \\
\hline $\begin{array}{l}\text { Area plauted (l:a)c } \\
\text { ME pel } 10 \mathrm{~h} \mathrm{~h}^{\mathrm{a}} \\
\text { Yicld }\left(\mathrm{kg} \mathrm{haa^{-1 }}\right)\end{array}$ & $\begin{array}{c}400 \\
90 \\
750 \\
\text { (dry beans) }\end{array}$ & $\begin{array}{c}40 u \\
30 \\
900 \\
\text { (C. } y \text { rabber) }\end{array}$ & $\begin{array}{l}4400 \\
25 \\
2500 \text { (oil) } \\
600 \text { (kernels) }\end{array}$ & $\begin{array}{l}2.00 \\
30 \\
1260 \text { (copra) } \\
7300 \text { (nuts) }\end{array}$ \\
\hline $\begin{array}{l}\text { Estate capital, } \\
\text { (\$ per hi plantest) } \\
\text { Plantations, rovds, ctc. } \\
\text { Buildings, equipment, } \\
\text { factory }\end{array}$ & $\begin{array}{r}1000^{\circ} \\
69 \% \\
31 \%\end{array}$ & $\begin{array}{r}1000 \% \\
71 \% \\
29 \%\end{array}$ & $1580^{\prime}$ & n.a. \\
\hline $\begin{array}{l}\text { Economic roturn } \\
\text { (S per ha planted) }\end{array}$ & & & & \\
\hline $\begin{array}{l}\text { Gross return } \\
\text { Costs' }\end{array}$ & $\begin{array}{l}268 \\
175\end{array}$ & $\begin{array}{l}212 \\
167\end{array}$ & $\begin{array}{l}467 \\
346\end{array}$ & $\begin{array}{l}165 \\
118\end{array}$ \\
\hline $\begin{array}{l}\text { Upkeep of plantation } \\
\text { Harvesting, transport' } \\
\text { Processingk } \\
\text { Equipmert! } \\
\text { Depreciation } \\
\text { Overhcals, inc!uding }\end{array}$ & $\begin{array}{l}20 \% \\
29 \% \\
13 \% \\
20 \%\end{array}$ & $\begin{array}{r}8 \% \\
26 \% \\
8 \% \\
17 \% \\
29 \%\end{array}$ & $\begin{array}{l}11 \% \\
11 \% \\
5 \% \\
8 \% \\
39 \%\end{array}$ & $\begin{array}{c}41 \% \\
14 \% \\
-\overline{1} \% \\
19 \%\end{array}$ \\
\hline $\begin{array}{l}\text { managcment } \\
\text { Net return }\left(5 \mathrm{ha}^{-1}\right)\end{array}$ & $93 \quad 18 \%$ & $45 \quad 12 \%$ & 121 & $47 \quad 13 \%$ \\
\hline \multicolumn{5}{|l|}{ Productivity } \\
\hline $\begin{array}{l}\text { Gross return (s ha- }{ }^{-1} \text { ) } \\
\text { Gross return (s } \mathrm{ME}^{-1} \text { ) }\end{array}$ & $\begin{array}{l}268 \\
298\end{array}$ & $\begin{array}{l}212 \\
707\end{array}$ & $\begin{array}{r}467 \\
1868\end{array}$ & $\begin{array}{l}165 \\
550\end{array}$ \\
\hline
\end{tabular}

- Prepared model for estate investment, based on estate records.

- Project plan.

c All data refer to mature stands only.

ancluding factory labcur.

- Including factory for processing.

- Estimate of investment requircments.

- Book value, below market value.

h At estate, not tirluding transport to harbour, net of export tax.

1 Net of interests.

1 Including fertilizers and pesticides.

* Running costs only.

Surces: Cocoa, Wood (1963); rubber, Westgarth and Narayana (1964); oil-palm, E.W.G.S.O.D.E.P.A.L.M. (private communication) (1968); coconut-palm, Ceylon Department of Census and Statistics (1965, pp. 67-70). 
for decades. Mechanization is still in the experimental stage, and tapping will always remain nanual work. There is no pronuunced peak in labour demand. Tapping, the mest important cost item, is carried out regularly all through the year, with fixed assignments for each wr rker. This makes it possible to work with an all-the-year-round division of labour, one group being engaged in tapping, another in wceding, and so on.

TABLE 8.14

Costr of tea and rubber production in Ceylon, 1963.

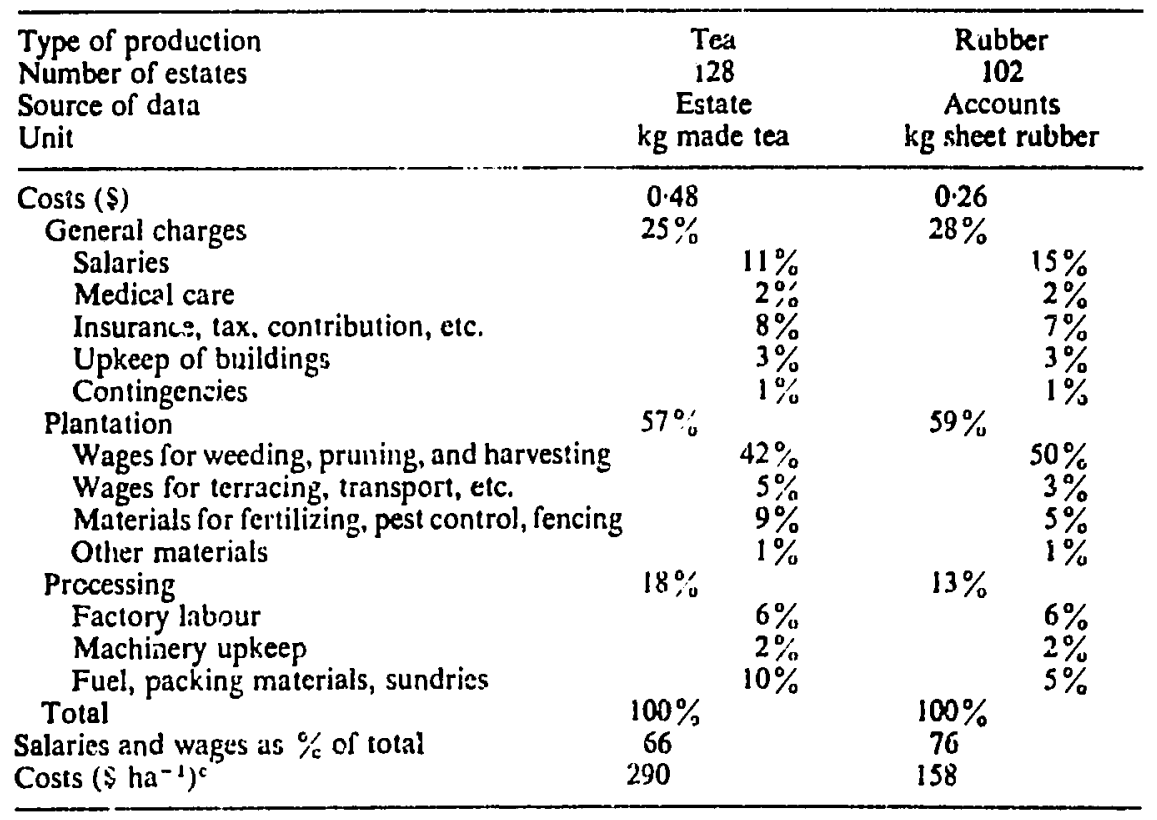

- Estate accourits in Ceylon do not include depreciation of rature stands, buildings, and the factory. Replacement costs are used instead. Replacements in the year 1963 were probably below an appropriate depreciation charge. Costs depicted above are therefore likely to underestimate capital costs.

- I Ceylon rupia $=\$ 0 . \$ 565$.

c Yield level: tea 600 kilograms per hectarc; rubber 600 kilograms per hectare.

Source: Ceylon Department of Census and Siatistics (1965. pp. 67-70).

(4) High costs in plantation establishineist in relation to the returns per hectare make depreciation one of the most important cost items. Thus rubber production sequires a lot of capital per unit of output compared with other perenuial crops.

(5) One of the important advantazes of estate rubber is the ease of introduction of innovations. New' tapping techniques and new clones radically chansed the economic prosperts of rubber production, which had looked 
rather bleak due to falling prices. New clones yield-under the conditions of estate production--1200-1600 kilograms of latex per hectare per year. Economies of scale are very pronounced with increased rubber production per hectare (see Fig. 8.6). With tea the increased yields mean higher

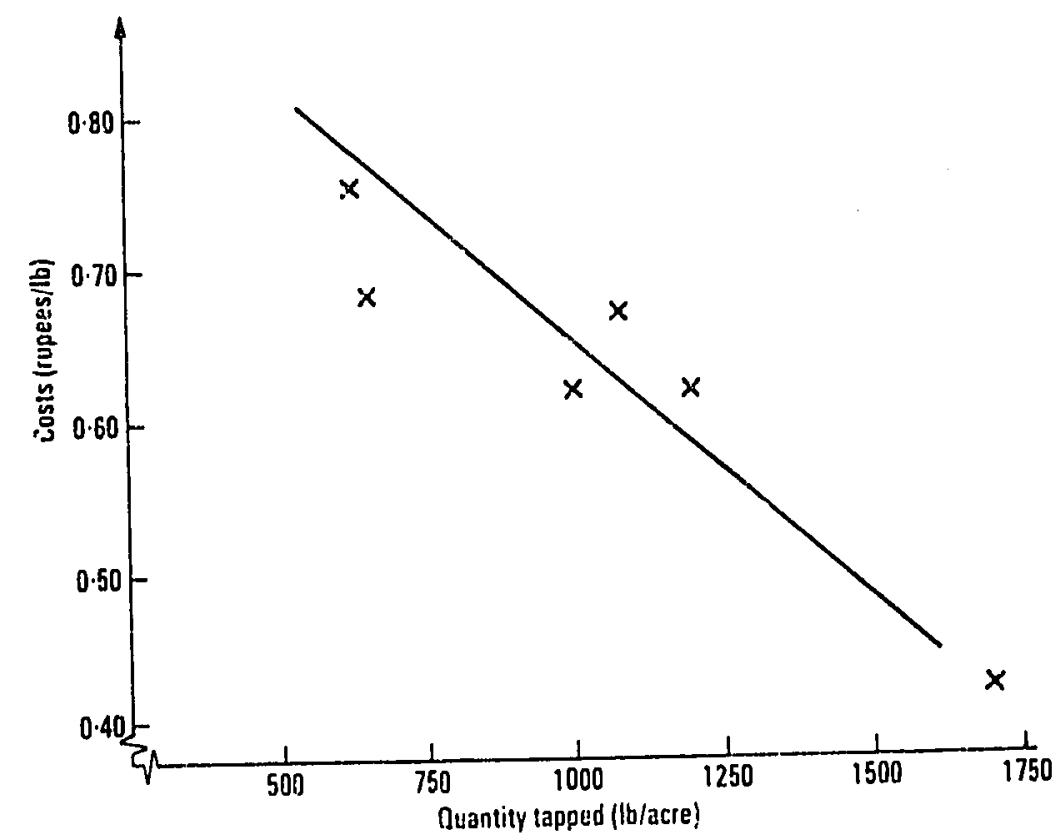

Fio. 8.6. Relation between yield per acre and costs per pound in scven rubber estates in Ceylon (from Hansen 1969).

plucking costs. With rubber, however, costs of tapping remain almost constant irrespective of the yield. Moreover, planting can take place earlier. Plantations traditionally required seven years before tapping co ald begin, but with the new planting material tapping may start after $5 \frac{1}{2}$ years.

(b) Rubber smallholdings. Compared with the tea or coffee bush, which has to be manured, weeded, pruned, and plucked regularly in order to keep it in proper productive condition, the rubber tree is remarkably undemanding. Processing is not tied to the producing farm. Rolling and smoking can be assigned to neighbours or larger processing units. Rubber therefore attracted smallholders in Ceylon, Sumatra, Malaysia, and Nigeria to enter into commercial tree-crop production.

Rubber estates generaily present a picture of orderliness, with trees grown in neat rows and the undergrowth kept down by constant cutting. Traditional 
smallholdings usually have a different appearance. The situation in Malaysia is depicted by Courtenay (1965, p. 124) as follows:

... the vailey floors are orcupied by rice fieids, irrigated by channels led along the hill foot from the central stream. Abuve ... these canais run the main footpaths, just beyond which are located the Maiay houses under the shade of coconut-palms and fruit trees. Behind and above the houses, the hillsides are planted with rubber, which may ofien be tapped by the rice farmer's wife or children.

Smallholder rubber is often interplanted with fruit, coconuts and arable crops. The trees do not always form continuous stands but may' be in clumps separated by other vegetation. Beyond the environs of the smallholder's house, the mixed stand of rubber and other crops usually gives way to a pure siand of rubber in the midst of tall undergrowth.

Smallholder rubber pluts in Malaysia average between 1 and 3 hectares. In contrast with estate planting ( 300 trees per hectare), final-stand planting on smallholdings is usually very dense, with $500-900$ trecs per hectare, the reason being that smallholders aim at high yields per hectare, disregarding higher labour input, while estates try to economize on labour by aiming at high yields per tree. Rubber tapping is not necessarily a regular task, and this makes rubber such an attractive crop for smallholders, since during the peak rice-planting and rice-harvesting seasons little labour need be devoted to rubber. Smallholders prefer to tap when time permits or when cash is needed, although irregular tapping may lower average returns. In some cases, smallholders tap only during periods when schools are closed-weekends and vacations. Another advantage of rubber for smallholders lies in the possible employment of female and child labour at low costs.

Smallholders use unselected seedlings usually. They do not receive maximum yields because of poor cleaning, lack of manuring, irregular tapping, overtapping where cash is needed, and often wasteful tapping techniques. They are, however, low-cost producers, and as such competitive with estates. Whereas estates are severely hit by slumping prices, smallholders may cultivate other crops nore intensively, and in the meantime the rubber trees may rest for 'rejuvenation', to produce larger yields when rubber prices rise again.

- The family labour is mainly employed in off-farm work.

- 159 coconut-palms, 70 various fruit trees, 100 pepper vines, 200 plantains.

c Vegetable gaiden.

- Intercropped under coconut-palms.

- The price per kilogram of rubber is lower than in estates, because rolling and smoking fees have to be deducted.

1 Modern plantations established with government subsidies.

- Including return from various fruit trees, pepper, plantains, etc.

"Including minor cíarges for tax.

I Including bullock labour.

Sources: Dahomey, S.E.R.E.S.A. (1959-60); Ceylon, personal enquiries. 
TABLE 8.15

Farm-management data of oil-palm, rubber-coconut, and coconut smallholdings

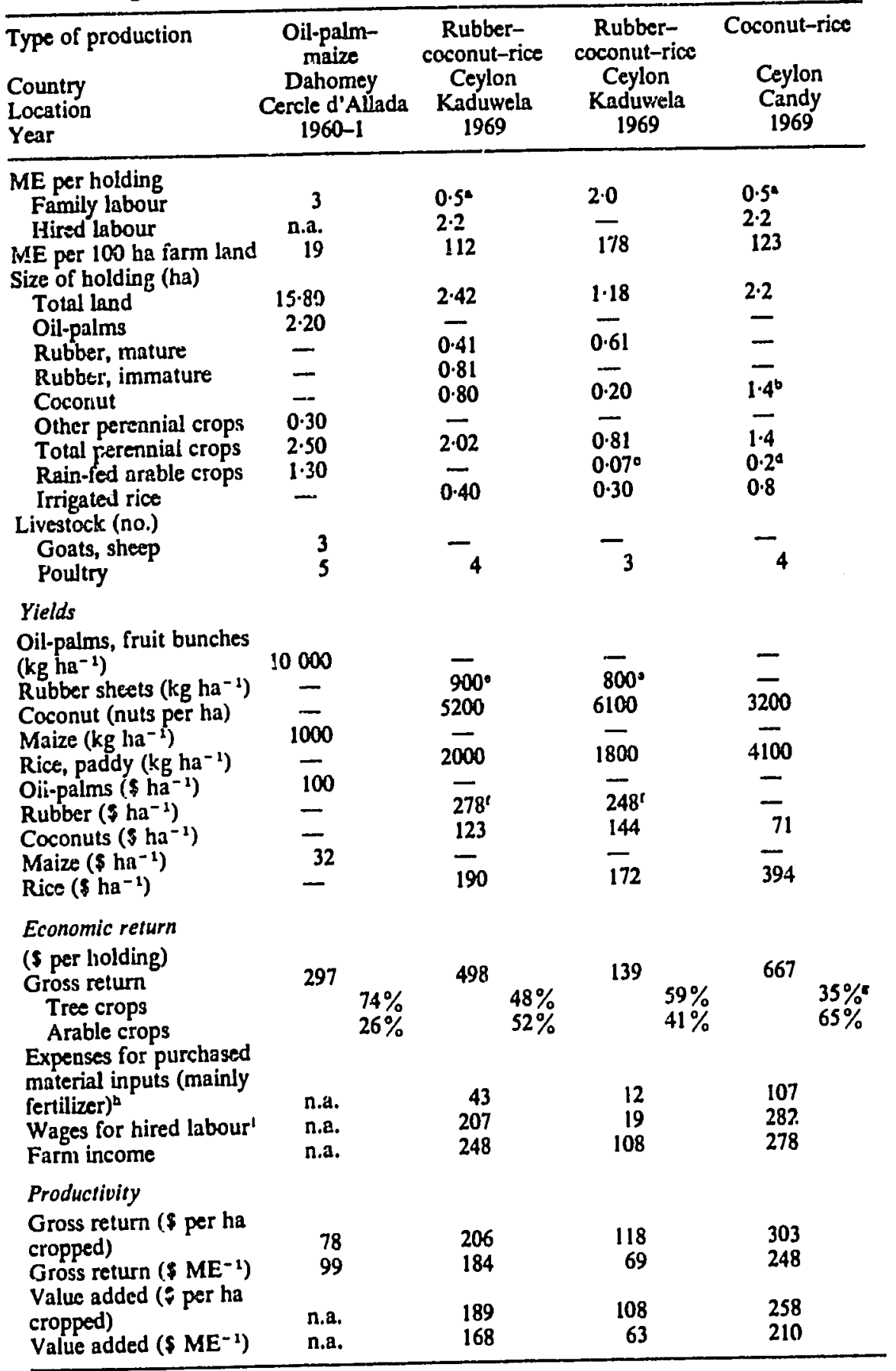


Table 8.15 illustrates the farm-cconomic situation of two rubber-growing smallholdings near Colombo, Ceylon. Rubber is the majcr cash crop and the plantations are considered as a capital asset. In both cases, new plantings with improved plants have replaced the traditional mixed stands. Coconuts are primarily consumed in the household or sold locally. Rice provides the food for the household.

\subsubsection{Oil-palm holdings}

Until recently, most of the oil-palm growing tcok place in West African smallholdings anc was part of subsistence-food production. However, a genetic breakthrough has made oil-palms an economically worthwhile estate crop. With oil-palms, the economic return per hectare during the vegetation cycle depends on several variables, almost all of which have been influenced by technical innovations.

(1) New improved varieties are available that mature after three to four years, instead of ten years as with old varieties. New varieties are easier to harvest, because the height of the stem is only a quarter of that of unimproved palms.

(2) New varieties yield heavier bunches, wit' heavier fruits. Two types of oil are produced from the fruit: palm oil from the pericarp and palmkernel oil from the kernel. New varieties have much more fatty pericarp. Traditional production yields about 1 ton of oil per hectare of mature palms. New varieties yield 3-5 tons and more.

(3) Oil milling and the transport of fruit bunches to the mill have benefited from innovations.

We consequently still find extensive areas where traditional oil-palm production takes place, but increasingly both estates and smallholdings are planting new varieties.

(a) Oil-palm estates in West Africa. Oil-palm estates have mainly been established in Malaysia and the Congo (Kinshasa). More recently Ivory Coast, Dahomey, and Cameroon have entered large-scale production through para-state bodies. Modern oil-palm cultivation lends itself to estate production. New varieties, and the corresponding husbandry techniques, can be applied $a d$ hoc on large areas. The perennial nature of the oil-palm, its significant response to weed and bush control, its constant employment of the labour force on continuous harvesting, and the need to move the fruit to the mill as quickly as possible after harvesting in order to avoid loss in quality are factors that favour large-scale p:oduction. The estates are generally very large, varying between 500 and 2000 hectares in Malaysia and 1000 and 4000 hectares in West Africa.

The farm-management characteristics of oil-palm estates may be summarized as follows (see Table 8.13):

(1) The initial capital investment is higher than with most other tree crops and is at about the same level as for tea and coffee. Establishment 


\section{SYSTEMS WITH PERENNIAL CROPS}

of the vil mill is the most important capital item; amortization charges are correspondingly high.

(2) Gross returns are higher than with most other tree crops, but are lower than with shrub crops like coffee or tea. However, the natural risks of production (disease or other natural calamities) are low.

(3) Oil-palm plantations offer an almost complete cover for the soil. They may well be rega cded as a soil-conserving type of land use.

(4) The labour input in running an estate is perhaps cven smaller than with other tree crops. Harvesting is a regular affair that is helped by truck transport.

(5) Large estates organized by state firms, as is the case with oil-palm estates in West Africa, are usually burdened by high overheads and management costs.

(b) Oil-palm smallholdings in Dahomey. Most West African oil-palm production is still based on unimproved, 'wild palm groves'. According to the analysis by Zeven (1967), there are three main types of oil-palm groves: secondary rainforest containing oil-palms, open palm bush with plant densities from a few palms per hectare to more than a hundred, and dense groves of palms. In addition there are here and there small and medium-sized plantations established by small entrepreneurs.

Smallholdings in the Cercle d'Allada, on the coast of Dahomey, where the rainfall is marginal for oil-palms, cover rather large areas, averaging 15.8 hectares covered more or less irregularly by oil-palms with plant densities varying from 20 to 200 palms per hectare (see Table 8.15). Harvesting, and transport of the bunches to the collecting points is the only work necessary with oil-palms. Labour-demanding processing by small hand-presses has already been replaced by proper oil milling. The return per work-day is about $\$ 0.50$, five times higher than with maize, and this in spite of low-yielding varieties. In addition to oil-palms, small neglected patches with robusta coffie are to be found close to the villages. Most of the working time is absorbed by growing maize and manioc for household needs. Two to five years of cropping are followed by five to seven years of fallow. The smaller the area in relation to the number of household members, the higher the food demand, and so the fallows are shorter and more manioc is grown instead of maize. In 1959-60, the average gross return of these holdings was estimated at \$297, most of which came from oil-palms. The labour input of 945 lours of field work per man-equivalent yielded a return of $\$ 99$ per man-uquivalent.

The problem of smallholder production is one of reorganization of farming, to take advantage of the genetic breakthrough, which is already exploited by the estates. An important effort to solve the problem has been made in Ivory Coast. Nucleus estates are increasingly surrounded by sniallholders, up to 20 kilometres away, who practise modern techniques of oil-palm production with the help of credit schemes and close technical supervision. The fruits are collected and processed by the mill of the estate. Initial experience shows 
that plantation establishment in smallholdings is mucl cheaper than in the estates, but tustandry is not usually as good.

\subsubsection{Coconut-palm holdings}

Most commercial coconut production takes place in the numerous smallholdings of the Philippines, Malaysia, Indonesia, Ceylon, and the East African coast. Intarmingled with the smallholdings, there are coconut estates.

(a) Coconut estates in Ceylon. Coconut estates in Ceylon vary in size from a few hectares to several hundred hectares. The characteristics of production are largely the same irrespective of size. Plant density is about 160 palms per hectare. Intercropping is rare. Some plantations are grazed by local cattle, but most managers prefer to farm without cattle. In the case study depicted in Table 8.14, each palm yields an average of forty-six nuts a year, which makes 7300 nuts per hectare. About 5900 nuts are required to produce one ton of copra. The nuts are picked five or six times a year, and the husk is separated from the nut in the field. The husks are used as mulching material. The kernel and the nutshell are separated at the farm. The fiesh is dried in a copra kiln, the shells beirg used as fuel, after which the ash is scattered on the plantation. Besides wages, the fertilizer input is the main item of expenditure, amounting to 28 per cent of the total cost. Palrns with a low yield, of less than thirty nuts a year, are interplanted with new palms, and chopped down as soon as the new palms begin to produce. There is a high degree of specialization. Permanent labourers are employed for weeding, transporting, and processing. Harvesting is done by ouiside task workers.

We may summarize the essential characteristics of coconut-palm estates as follows:

(1) The intensity of land use in coconut-palm estates is lower than with other tree crops. In the case study in Table 8.13, gross returns amount to $\$ 165$ per hectare.

(2) In addition, we have to take into account that the lapse of time between planting and the first and the full crop is particularly long. Traditional varieties take eight to ten years before the first crop is picked. The full yield can only be expected after fifteen years. The economic sropping time then may well extend to over fifty years.

(3) Cultivation requires comparatively few workers. The average figure for Ceylon is 20 man-equivalents per 100 hectares of coconut-palms, which is lower than is noted in the case study ( $\operatorname{Lim} 1965$, p. 121). Labour costs are nevertheless the most important item of cost, because few other inputs are required to run a coconut-palm estate. There are no peaks in labour demand. The main work, harvesting and preparing the nuts, occupies about 60 per cent of the total labour and is spread over the whole year. 
When estates establish plantations, they have to reckon with high costs, amounting, according to Piggot (1964), to $\$ 750-2000$ per hectare, largely because of the long lapse of time between p'.ntii , and the first harvest when the plantation has to be maintained without yield. The capital input is consequently high in relation to output and errployment in mature plantations, but the day-to-day running of the estate requires little cupital. The replacement of old palms is, compared with the costs of new plantitions, relatively inexpensive, because young palms can be interplanted in old stands to replace them gradually and without a break in production. Even the processing facilities, copra kilns, do not require a high financial input. The size of kiln may vary according to estate production, so that estate size does not depend on the capacity of the processing facilities.

(4) Estates usually carry pure stands, the soil being kept free from bush by slashing or cultivation. Coconut plantations in high-rainfall areas, however, lend themselves to mixed cropping or intergrazing, and this need not reduce nut yields provided the interplanted crops do not compete for water and nutrients. Thus interculture has to be restricted to seasons with high rainfall, and the crops have to be fertilized. Cashew, mangoes, bananas, pineapples, and various arable crops, like manioc or rice, may be found intermingled with coconut-palnis. Grazing under coconut-palms is extensively practised in Ceylon and in the south Pacific. Fox and Cumberland (1962) report from an estate in Samoa that Mimosa pudica as a fod ter crop under paims may carry $2 \frac{1}{2}$ livestock units per hectare.

(5) Considerable technical advances have been achieved in growing coconut-palms, as in the case of most other tree crops. New varieties, which yield after as little as six years, and which produce 2000-3000 kilograms of copra per hectare of mature palms, are now available. Fremond wrote in 1968 about Ivory Coast: 'We know that yields of definitely even more than 3000 kilograms of copra per hectare, with nut-producing after 4 years, perhaps even less, are henceforth possible.'

(b) Coconut-palm smallholdings. Coconut-palms lend themselves to snallscale production and are mainly grown in smallholdings. They are suited to interculture, almost all the operations in coconut growing are performed by manual labour, and there is no problem of overcropping as with rubber. The uses of the coconut are many and diverse, including copra, fresh nuts, fibre, fuel, leaves for roofing, and sap for beer. The dependence on large-scale processing facilities is not very pronounced. The main advantage of smallholder production arises from interculture in the early stages of plant development, which makes it much cheaper to establish stands of coconut-palms than in estates, where the young stand must be weeded for eight to ten years before larvesting begins.

Table 8.15 shows the farm-management data of three smallholdings with 
coconut production. In all three cases, coconuts are not a major cash crop, but are primarily grown for househcld consumption, while rubber and rice are mainly grown for cash. Another striking feature is the preference for nonfarm work. In two cases, family members are employed outside the farm, and hired labour is employed for the farm work. All three major crops grown in the holding-coconut-palms, rubber, and rice-lend themselves to task work, which can be carried out without much supervision by the farmer.

\subsection{Wealnessee of farming systems with perennial crops}

The natural production conditions of the hunid tropics are particularly good for the cultivation of perennial crops. Consequently, problems in production are not primarily due to the natural conditions and the inherent characteristics or the various crops, as is the case with rain-fed arable farming, but to the socio-economic organization of the production process. Both major types of exploitation, smallholdings as well as estates, show certain weaknesses, which may be summarized as follows:

\subsubsection{Weaknesses of smallholder farming with perennial crops}

Perennial crops require a high input of labour and relaitvely few material inputs, which would indicate that they couid be grown more economically in smallholdings than in estates, where labour is more expensive. Experience shows further that tropical sniallholders are usually very skilful in choosing optimum crops, crop sites, and crop mixtures. They are, however, inherently weak in husbandry in comparison with the performance of estates. Land, labour, and capital would frequently bring much higher returns if perennial crops were properly taken care of. Lack of proper husbandry is often accompanied by mixed cropping and interculture, although it is certainly not a necessary feature of these practices. Farmers on Taiwan show convincingly that very high levels of husbandry can be attained with interculture. However, few smallholders in the tropics cultivate their perennial crops at similar high standards. As a rule they can hardly be induced to cut down old fruit trees. Weeding, bush clearing, and mulching are neglected in many cases. Pruning, which is not heavy work and offers much latitude in timing, is carried out negligently if at all, and this in spite of the fact that seasonal underemployment prevails. The list of short-comings in husbandry could easily be expanded, but it is much more difficult to explain why most of the smallholders are poor in husbandry. There is certainly no single reason, but rather a host of possible explanations. Those most frequently put forward by the farmers themselves include the following:

(1) The production of seedlings is usually a specialized task that can hardly be carried out efficiently in smallholdin ${ }_{b}$ s. Optimum sriallholder 
development consequently depends on specialized nursery producers supplying the seedlings and the necessary loans.

(2) Smallholders almost invariably say that husbandry falis short, even of their own standards, because of peak demands in labour and lack of the necessary cash for equipment.

(3) Some difîculties are due to the length of the vegetation cycle of perennial crops. A smallholder wisually inherits or acquires a mixed stand of trees and shrubs of varying age and not planted in rows. Rcplanting in rows in one part of the plot after the other is difficult to organize. Infilling is a much more convenient way, but perpetuates a shrub and tree garden where yield-increasing innovations are difficult to apply.

(4) Other losses in yield are due to the relatively short time-horizon of smallholders. Practices that reduce the total yield of the perennial crops but bring about early returns, like heavy interculture in young plantations and early tapping of rubber, are often preferred, because smaliholders more or less corsciously reckon with higher discount rates than do estate owners.

(5) In many cases, husbandiry is poor hecause the returns from an additional hour of work are not considered worth the additional effort. Most smallholder's are still inhibited by the idea that their soil is not good, that the climate is adverse, that improved practices would not work, and that, consequently, increased efforts are not worth while. Because of this attitude, husbandry is generaily poor, and poor husbandry results in low returns per hour of work, which again leads to even poorer husbandry.

Although these and many other arguments are valid, it is nevertheless clear that they do rict afford a complete explanation of the lack of proper husbandry. If labour were indeed the main limiting factor, it should express itself in high marginal returns and the existence of a significant relationship between the labour available and the gross returns. This is not usually the case, however. The shortage-oi-labour argument often ofiers no rational explanation, because a small but properly cultivated area probably yields higher returns per hour of work than larger, neglected fields. The small but significant number of better farmers who work more intelligently shows that with less effort per unit of output, but with greater care. more money can be earned. Moreover, those smaltholders who are not willing to take on additional work can usually employ seasonal labour for fairly low wages.

It would seem that the main reason for poor husbandry is not any objective factor, but primarily a lag in cultural adaptation. Smallholders in many parts of the tropics, in particular in Africa, experienced within a few decades the change from shifting $\cdot$ sltivation with temporary homes to sedentary farming with perennial crops. Shifting cultivators know how to adjust to changing 
natural conditions, and so in this respect smallholders are very knowledgeable. But they are less well prepared for the tasks of transforming natural conditions by conscious human effort and of improving yields by the proper maintenance of the plants--something that farmers with centuries of land shortage or decades of cash cropping behind them have learned how to handle. The quality of the husbandry found in especially worthwhile cash activities, and in areas that have had a land shortage for a very long time, indicates the starting points for better husbandry:

(1) there must be a very strong incentive in the form of a high cash return per hour of work; or

(2) there must be a serious, long-term land shortage, which leaves no choice but to take care of plants, soils, and animals; or

(3) there must be production under close supervision.

The fact that most plantations are poorly husbanded may be considered an indication that, as a rule, neither the pressure nor the incentive has passed a certain threshold value required to get the smallholders on the way to proper husbandry.

The fact that peasant production can still compete with estates, despite obviously poor cultivation and husbandry techniques, is explained by the cheapness of production and the lower susceptibility to risks. Investment in an estate consists of the cost of:

(1) the factory;

(2) the establishment of the plantations;

(3) workers' houses, a hospital, roads, etc.; and

(4) bridging the initial period when there is no yield.

The advantage of peasant production is that the financial outlay is low apart from building the factory, or can be raised by the farmers themselves. Smallholdings have no production overheads. The recurrent cost schedule is different, since up to a certain level most of the labour that is employed is either unpaid fan." $y$ labour or receives far less than the rates laid down by unions that apply tc estates. Instead of having to pay back interest, a family is prepared to forg s the full income from the land until permanent crops produce yields. But it is not just a question of different demands on cash, or of the availability of labour that can scarcely be employed anywhere else; the whole situation is different as far as costs are concerned. $A$ large-scale estate must bear the costs of clearance work, whilst in the family holding the land is in any case cleared to grow subsistence crops. It costs little extra to plant seeds or to set plants of a future perennial crop in the cleared land. The mixture of perennial crops with arable crops in the early years bridges the period when there is no harvest. A plantation that competes with arable crops grown on the same land certainly does not produce the same yield as 
a pure crop, but it is comparatively cheap and simple to set up. ${ }^{1}$ These combined benefits give the smallholder a distinct cost advantage.

\subsubsection{Weaknesses of the estate economy}

The farm-management advantages of growing perennial crops on a large scale do not lie chiefly in the labour economy. The use of labour-saving equipment and transport is important only with perennial field crops like sisal or sugar-cane. The competitiveness of estates growing shrub or tree crops with the farmer's cheap production methods is based mainly on:

(1) the rapid and consistent use of technical advances in plant production;

(2) the more efficient organization of delivery of the crop to the processing factory;

(3) the more efficient processing of the product; and

(4) the better access to markets and capital.

Most managers of large-scale holdings, particularly the employees of large plantation companies, take advantage of modern technology. They harvest larger quantities per hectare and the yield is of considerably better quality. The processing of the crop is better, and results in a quality product that can be sold at higher prices. Moreover, by-products and residues are used more efficiently. All told, a return or income per hectare and per worker is obtained that is often higher than that of a smallholder. Estates, therefore, produce a high, taxable income. In addition, the proportion of the income charged as tax is much higher than in the case of snallholders.

On the other hand, there are a number of disadvantages:

(1) The estate economy is exposed to high risks and uncertainties. Estates have to meet high interest charges on borrowed capital. The production is usually devoted to only one crop, and a shift in emphasis froni one crop to another is a long-term business. The return from estates fluctuates widely because of natural hazards, for example wind damage with bananas, and because of changing prices on the world market. In the developing countries, the private-estate economy is threatened by nationalization, which acts as a barrier to investment. Semi-commercialized smallholdings are much better protected from risk: subsistence is guaranteed by cropping plants for immediate consumption, the proportion of the overall costs paid in wages is low, and there is normally no political danger.

(2) Estates with perennial crops depend on an ample supply of cheap labour. The fact that the tropical countries can supply plenty of cheap labour is one of the reasons why large-scale estates with perennial crops

1 Thus in Kenya the cost of establishing a large-scale coffee estate before the first yield is $\$ 750$ per hectare, whereas the research of MacArthur (1966) in neighbouring smallholdings shows a cost of $\$ 437$ per hectare (including the wages for workers belonging to the family). 
were established there, and explains their power to compete with products from temperate climates or products from the chemical industries. Rising wages, which are spreading with the organization of unions, hit large-scale estates with perennial crops very hard, because operations can be mechanized only with great difficulty or at unfavourable rates of substitution. Smallholdings operate with family labour and local seasonal workers, who are prepared to accept wages disproportionately lower than those of estate workers.

As risks in the marketing and political sectors increase, and as wages rise, smallholdings are becoming more competitive than large-scale producers, particularly with perennial crops rather than arajle crops, which are more amenable to motorization and mechanization. Naturally this general statement needs to be qualified in individual cases. The various perennial crops and advances in agricultural technology differ in their suitability for largescale or small-scale production.

As a rule of thumb, estate production is more competitive than smallholder production:

(1) When the production process is technically demanding. Where this is the case, the difference in yield between estates and smaliholdings is likely to be particularly great: and this is especially the case where cultural change among the smallholders is slow.

(2) If the produce of the land is bulky, requiring high transport r'sts. Here, the processing factory should preferably be located on the hoiding, with the fields as close as possible.

(3) Where the produce is perishable and has to be delivered for processing or sale in large quantities of even quality at defirite times.

\subsection{Development paths of farming systems with perennial crops}

There is a great deal of scope almost everywhere in the tropics for increase in the plantation area, in particular to replace shifting and semi-permanent cultivation. Increases in area depend only partly on capital, labour, and technical inforination. Plantation establishment-both in smallholdings and in estates-is largely a function of prices and price expectations. However, perhaps even more important than the scope for extension in area are the numerous possibilities of increasing output per hectare. The following considerations are among the most important.

\subsubsection{Increased application of technical innovations}

Organized agricultural research in the tropics began with perennial field crops like sugar-cane, progressed to arable crops and shrub crops, and was 
concerned only at a relatively late stage with tree crops. Growers are now in a position to reap the benefits of a great number of breakthroughs, particularly with tree crops. With traditional varieties, 30 per cent or less of the shrubs or trees produce 70 per cent and more of the crop. The development of high-yielding varieiics and clones has significantly changed the picture. With various tree crops a doubling of yieids is within reach. In addition, numerous other agronomic innovations are in the process of being introduced. They are summarized by Webster and Wilson (1967, p. 217) as follows:

(a) the use of improved planting material, sclected to give high yields of good quality produce, but possessing good secondary characteristics;

(b) cheap and practicable methods of propagating the improved planting material on a large scale;

(c) efficient transplanting and early care of the young trees, in order to obtain a full stand of plants that grow vigorously and reach the productive stage as quickly as possible;

(d) good horlicultural practice in respect of such matters, as spacing, shade management, windbreaks, pruning, etc.;

(e) methods of soil managemens, including soil conservation, cover crops, weed control, nulching and manuring, which will maintain soil fertility and sustain high yields;

(f) control of pests and diseases; and

(g) improved methods for the exploitation of the crop, such as modern techr:ques of tapping and yield-stimulation in rubber, or the use of synthetic growth substances to induce early and uniform fruiting in pineapples.

The relevant economic aspect of these innovations is that rising wages can be absorbed oy higher yields per hectare. In many cases the quantity of product required for the processing unit may in future be produced more economically on a fraction of the original land. The remaining land then becomes available for other uses.

\subsubsection{From mixed cropping to pure stands and interculture}

Yield-increasing innovations are best applied in pure stands, where they may be adapted to the special requirements of the crop. Mixed cropping is a handicap to mechanization alsn. We may assume, therefore, that mixed cropping is likely to decline. However, where land is scarce but where labour, capital, and technical knowledge are relatively plentiful, we can assume that various forms of interculture vill be extended and intensified. This trend is seen clearly in Taiwan for example.

\subsubsection{From holdings with one cash crop towards diversified commercial produc- tion}

The tendency towards pure stands in order to apply efiectively innovations specifically suited to one plant need not necessarily result in monoculture. This may be true of some perennial crops, but it is certainly not true of all. 
In high-potential areas with high population densities, it is much more likely that production development will lead to even more diversified huldings. The introduction of intensive aninal husbandry is of particular importance in this connection.

The development of Kikuyu agriculture, as depicted in Table ${ }^{\circ} .16$, are a case in point. Originally, stiifting cultivation with millet, maize. and oeans prevailad. Increasing population pressure led to semi-permanent and perruanent farming, reduced available grazing, and resulted in a process of involution. The efforts of the Swynnerton Plan brought a sweeping change in the farming systemts. Coffer and other casin crops were introduced. Commercial milk production with grade cattle began, and some leys were established. Tea production, hybrid maize, potatocs, and the application of mineral fertilizer were already spreading in the mid-sixties. It might well be expected that the impetus in smallholder development, which bega with coffee, would facilitate the introciuction of further innovations such as fodder growing and zero-grazing.

TARLE 8.16

Evolution the farming system in the Kikuyu districts of Kenta

\begin{tabular}{|c|c|c|c|c|}
\hline Year & $\begin{array}{l}\text { Type of } \\
\text { farming }\end{array}$ & $\begin{array}{l}\text { Cropping } \\
\text { pattern }\end{array}$ & $\begin{array}{l}\text { Livestock } \\
\text { econony }\end{array}$ & Land rights \\
\hline About 1860 & $\begin{array}{l}\text { Shifting } \\
\text { cultivation }\end{array}$ & $\begin{array}{l}\text { Maize, beans, } \\
\text { mixed cropping }\end{array}$ & $\begin{array}{l}\text { Ample grazing, } \\
\text { Zebu cattle, } \\
\text { goats }\end{array}$ & $\begin{array}{l}\text { Ample land, } \\
\text { rights of land sse }\end{array}$ \\
\hline About 1920 & $\begin{array}{l}\text { Semi-permanent } \\
\text { sultivation }\end{array}$ & $\begin{array}{l}\text { Maize, beens, } \\
\text { sweet potatoes, } \\
\text { mixed cropping }\end{array}$ & $\begin{array}{l}\text { Limitcd grazing, } \\
\text { Zebu cattle, } \\
\text { goats }\end{array}$ & $\begin{array}{l}\text { Linited land, } \\
\text { rights of land use, } \\
\text { cornmuual } \\
\text { grazing }\end{array}$ \\
\hline About 1950 & $\begin{array}{l}\text { Permanent } \\
\text { cultivation }\end{array}$ & $\begin{array}{l}\text { Maize, beans, } \\
\text { sweet pctatoes, } \\
\text { banana, wattle }\end{array}$ & $\begin{array}{l}\text { Roadside } \\
\text { grazing, mainly } \\
\text { goats, sorne } \\
\text { Zebu cattle }\end{array}$ & $\begin{array}{l}\text { Rights of land use, } \\
\text { most communal } \\
\text { grazing iurned } \\
\text { into individually } \\
\text { cropped plots }\end{array}$ \\
\hline About 1960 & $\begin{array}{l}\text { Permanent crops } \\
+ \text { permanent } \\
\text { cultivation + } \\
\text { some ley } \\
\text { farming }\end{array}$ & $\begin{array}{l}\text { Coffee, maize, } \\
\text { beians. sweet } \\
\text { potatoes, } \\
\text { banana, potatoes } \\
\text { vegetables, } \\
\text { pincapple, lays }\end{array}$ & $\begin{array}{l}\text { Roadside } \\
\text { grazing + some } \\
\text { grade cattle }\end{array}$ & $\begin{array}{l}\text { Private property } \\
\text { rights; land can be } \\
\text { leased and } \\
\text { mortgnged }\end{array}$ \\
\hline $\begin{array}{l}\text { Estimated } \\
\text { expansion path } \\
\text { for } 1980\end{array}$ & $\begin{array}{l}\text { Permanent crops } \\
+ \text { pernanent } \\
\text { cultivation }+ \\
\text { some sprinkler } \\
\text { irrigation }\end{array}$ & $\begin{array}{l}\text { Coffee, tea, } \\
\text { bearis, hybrid } \\
\text { maize, sweet } \\
\text { potatoes, } \\
\text { potatoes, fodder } \\
\text { grass, application } \\
\text { of mineral } \\
\text { fertilizer and } \\
\text { stable manure }\end{array}$ & $\begin{array}{l}\text { Gradc cattle, } \\
\text { mostly zero- } \\
\text { grazing, foultry } \\
\text { pigs }\end{array}$ & $\begin{array}{l}\text { Private property } \\
\text { rights; land can } \\
\text { be leased and } \\
\text { mortgaged; an } \\
\text { active land } \\
\text { market }\end{array}$ \\
\hline
\end{tabular}

This table is nothing more than a rough guide to the deveiopments which took place and which are expecled in the Kikuyu aress. See Kuthenberg (1966, p. 21'7). 


\subsubsection{Increasing importance of perennial food and fruit crops}

Bananas are one of the staple foods of tropical cultivators. With increasing population densities and with increaser croppirg on sloping, easily eroded land, it might well be expecied that bananas, in particular cooking bananas, will gain in area and economic importance. Industrialization and urbanization might also specifically favour fruit trees. Firstly, there is the influence of the market, demanding citrus, mangoes, papayas, bananas, etc. Secondly, there is the tendency for people living in mixed rural-suburban communities to plant fruit trees, coconut-palms, and bananas in their extended gardens. Tree plantations are particularly favoured by part-time farmers.

\subsubsection{Integration of estate and smallholder production}

Of particular interest are the tendencies to combine in 'nucleus-estate' projerts the advantages of estate production - the rapid application of innovations in production and processing-with the advantages of smallholder production--the low labour costs in plantation development and the smallholder's yrcference for investment in tree or shrub crops. Schemes of this nature show a promising start with oil-palnis (Malaysia and Ivory Coast) and tea (Kenya). The idea is that commercial estates are surrounded by a ring of smallholders, who obtain credit, advice, material inputs. machinery, and markets through the scheme management and who are subject to close supervision in their husbandry practices. Nucleus estates, combined with supervized smallholder production, seem to be a major alternative to the dualistic plantation-sinallholder econony that still prevails in extensive parts of the tropics. It is likely to be more popular because:

(1) capital costs are lower than with state-financed estate development;

(2) production is less sensitive to rising wages and labour unrest; and

(3) projects of this nature are in line with the political philosophy of numerous countries. 


\section{Grazing systems}

\subsection{Definition and geographical distribus:on of grazing systems}

STOCK-KEEPING in the tropics as the main activity of any enterprise or household is more or less confined to various types of nomadism and to ranching.

(1) In total nomadism, the animal owners do not have a permanent place of residence. They do not practise regular cultivation, and their farnilies move with their herds.

(2) In semi-nomadism, the stock owners have a permanent place of residence, which is kept for several years. In the vicinity of the residence, supplementary cultivation is carried out. Semi-nomads usually travel for long periods of time with their herds to distant grazing arnas. The husbandry practices of partial nomads, i.e. of farmers in permarient settlements, who live mainly by arable farming but who own cattle grazing on the communal land, are similar (see \$4.3.4).

(3) In ranshing, stationary animal husbandry organized according to commercic: principles is practised on large stretches of land.

In all these types of land use, the stock-keeper has to adapt his stock to the fodder produced by the natural vegetation. Climate, soil, vegetation, and animals form an integrated system, which the stockman, if he wishes to operate profitably, can influence only indirectly through such matters as the way he keeps his animals, the composition of the herds, animal density, times of grazing, and other considerations. Such considerations are especially important in dry regions, where the rainfall is not sufficient for arable cropping or tree crops, for example in the marginal zones of the Sahara and the semi-arid regions of Australia and East or southern Africa. Nomadism and ranching in the humid savannas, on land that is also suitable for arable farming, are practised principally in areas with low population densities, as in Madagascar, for example, or in various parts of Latin America.

Commercial ranches are almost always very large. The establishment of extensive holdings with permanent stock-keeping was considerably helped by technical advances in fencing, water supply, and vehicle transport, and holdings of this kind are found principally in America, Australia, and various parts of Africa. The common aim of ranchers is the conversion of naturally 
grown herbage into marketable produce, and this objective is achieved by employing small numbers of people for large herds of livestock. In subsistence herding, on the other hand, large numbers of livestock are kepi by numerous households, and the aim is above all to transform the energy stored in grasses, herbs, and shrubs in the tribal area into a regular supply of food.

Rainfall is the primary factor determining indigenous ways of using grassland (see Table 9.1). Where there is less than 50 millimetres average rainfall

TABLE 9.1

Types of indigenous stock-keeping in the tropics

\begin{tabular}{|c|c|c|}
\hline Rainfall (mm per year) & Pridominant type of farming & Animal mainly kept \\
\hline $\begin{array}{l}\text { Under } 50 \\
50-20 \\
200-400\end{array}$ & $\begin{array}{l}\text { Only occasional nomadic stock-keeping } \\
\text { Nomadism with long migrations } \\
\text { All types of nowadism, transhumance, and } \\
\text { supplementary arable farming }\end{array}$ & $\begin{array}{c}\text { Camels } \\
\text { Camels } \\
\text { Cattle, goats, } \\
\text { sheep }\end{array}$ \\
\hline $400-600$ & $\begin{array}{l}\text { Sem:-nomadism, transhumance, and par- } \\
\text { tial nomadism, with stronger emphasis on } \\
\text { arable farming }\end{array}$ & $\begin{array}{l}\text { Cattle, goats, } \\
\text { sheep }\end{array}$ \\
\hline $600-1000$ & $\begin{array}{l}\text { Transhumance and partial nomadism- } \\
\text { any semi-riomadism is mostly the result of } \\
\text { ethnic tradition }\end{array}$ & Cattle \\
\hline More than 1000 & $\begin{array}{l}\text { Partial nomadism and permanent stock- } \\
\text { keeping-any semi-nomadism is mostly the } \\
\text { result of ethnic tradition }\end{array}$ & Cattle \\
\hline
\end{tabular}

per year, which means in effect no rain at all in many years, we find only occasional visits by nomadic herds, but in the semi-desert and the dry steppes, with between 50 and 200 millimetres of rain, there is usually systematic nomadic grazing with camels, such as is found, for example, in the Sahara and northern Kenya. Where there is a rainfall of 200-1000 millimetres, semi-nomadism and partial nomadism are of much greater economic importance, and we find this kind of economy chiefly in the African savannas. Where there is a higher rainfall, permanent stock-keeping is a better economic proposition, and semi-nomadism where the rainfall is more than 1000 millimetres is a matter of tribal tradition rather than the only practical form of land utilization that conditions will allow.

Animal densities in grazing economies fluctuate greatly according to place and type of farming. In areas with a rainfall of 50-100 millimetres, 50 hectares and more are needed for one livestock unit (the equivalent of one cow or seven sheep). In regions with $200-400$ millimetres, the requirement is often 10-15 hectares, and where there are 400-600 millimetres 6-12 hectares are necessary. As the rainfall increases and is more evenly distributed, and farming becomes more intensive, the animal densities increase. Grass grows very extensively in tropical grazing areas where there is a high rainfall of 1000-2000 millimetres a year. Where high rainfall coincides with an even 
distribution of rain, such as occurs in some areas of Central and South America, animal densities of up to one livestock unit per hectare are possible.

\subsection{Total nomadism}

\subsubsection{General characteristics of total nomadism}

Total nomadism is usually carried on under decidedly marginal production conditions, or where it is not worth trying to overcome natural difficulties by applying cultivation techniques. The basic principle lies in as much adaptation as possible to natural conditions. From the point of view of agricultural evolution, nomadic stock-keeping belongs to the same primitive category as shifting cultivation, but this $r y$ no means prevents the type of adaptation being an extremely complex and carefully calculated system.

The nomad's animals have to keep moving because water and fodder are not sufficient for them to be kept permanently in one place. A consequence of the animals' movement is the movement of the household, since the psople live directly off animal products, particularly milk, and they are thus obliged to stay near the herd. This permanent migration precludes regular arable farming. The nomads' production is not tied to one particular place, since it comprises only animals and the implements necessary for animal-keeping. The pastures grazed by the animals are either freely available to all the members of the tribe or the group, or the nomads have to rent them.

The nomads who practise horizontal migration, as in the Saluara or Arabia, chiefly keep large animals (camels) and trek with their animals to where rain falls and fodder grows. On the other hand, there are noinads who practise vertical migration. They are rare in the tropics, although typical of nomadism in the subtropics of the northern hemisphere, where people who possess principally sheep and goats migrate to the various altitudes that temporarily carry fodder. Their routes are mostly shorter than those of the nomads of the plains, since the seasonal growth of fodder at various altitudes helps to ensure an even supply.

Nomadic groups operate chiefly in areas with little access to a market, and aim at diversified production in order to cover personal consumption as fully as possible. They have only one line of production, namely stock-keeping, vith the result that this activity has to perform a disproportionate number of roles compared with that of any single activity in arable holdings or commercial stock-keeping. It has to provide:

(1) milk and meat for the household;

(2) wool and skins for the houschold;

(3) dung for fuel;

(4) mounts and pack-animals; and

(5) cash products to pay for the purchase of crop foods, other plant products, and non-agricultural consumer goods. 


\section{GRAZING SYSTEMS}

These aims of stock-keeping must be fulfilled as regularly as possible, because storage presents much greater problems to a nomadic than to a stationary household. The natural conditions in a dry climate favour specialization in animals such as camels and slieep, which are capable of tolerating heat and trekking long distances. But the various needs of the houschold mean that the dominant type of animal is often supplemented by horses, mules, and wrikeys for transport, and by goats, hens, and sometimes cattle ior a more diversified food supply. Cattle require a good deal of water and fodder and are not so mobile as camels or sheep, and for these reasons they are not characteristic of total nomads but of semi-nomads and the stationary population. The nomadic household depends especially on a regular supply of milk, which is the staple food. The importance of the continuity of food supplies in nomadic systems is so emphasized that live-animal products (milk and blood tapped from live animals) are the ones most utilized, with terminal products (meat and the blood of slaughtered animals) being mainly consumed only on special occasions (Dyson and Hudson 1969, p. 76). Thus animals like the camel, with a long lactation period, are preferred, for the female camel supplies about $2-4$ kilograms of milk daily more than is needed by a calf during a 12-18 month lactation period (Capot-Rey 1962, p. 303; L. H. Brown 1963, p. 9; Schickele 1931, pp. 35 ff.).

To ensure that animals, and particularly lactating animals, have a fairly regular supply of fodder, the nomadic household treks after the available vegetation, the camp being shifted as soon as the fodder in its vicinity is used up or becnmes too dry. The nomad is by no means always on the move, but his mode of living and farming is characterized by a frequent change of camp, which in turn makes it practically impossible to crop fodder. There is in any case no permanent base at which to store fodder reserves, so that when and where fodder is scarce the shcrtage is overcome only because the nomad selects and breeds animals with greater ahility to store fat, as portable reserves in the animal's body, and to travel long distances, so that areas with little fodder can be crossed.

The aim in breeding is not so much a high yield of meat, wool, or milk per animal as a high level of resistance to trekking, drought, heat, cold, disease, and periodic shorlages of food. Advances in breeding geared towards increased output per animal and requiring improved animal feeding can scarcely be applied by nomads, who have to be prepared for a high production risk, particularly because migration leads frequently to the spread of animal diseases whose control is made more difficult by the need to travel. There are no stables or shelters to protect animals from extreme weather conditions, theft, or predators, and stock losses during droughts with extreme shortage of fodder and water are particularly serious. Experience shows that most nomads can expect that at irregular intervals a iarge proportion of their animals will die. 


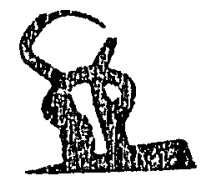

Because of the high production risks, the nomads try to accumulate herds that are as large as possible. The production aim is not financial gain, hut rather the supply of houseliold needs, provision against possible emergencies, and increase in social status, which rises in proportion to the number of animals owned. Nomads frequently have, in their livestock, assets of considerable value, but these cannot be regarded as economic capital, only as hoarded wealth. Livestock do not represent or indicate wealth: they are wealth. Moreover they are a means of social fulfilment and personal satisfaction, whereas comparable satisfaction cannot be obtained through money (Dyson and Hudson 1969). The society of the nomads is not organized on egalitarian principles, such as we often find among arable farmers, but is structured according to the number of animals owned. The possession of animals is by no means evenly uistributed among the families of a tribe. Normally 10-30 per cent of the families own 60-9C per cent of the animals. On the other hand, the natural conditions of production make it posisible for the poor to acquirc animals and rise in the social scale. For the wealthy nomad there is little sense in migrating with very large herds. A frequent change of camp would be necessary, and to avoid this it is usual for the owner of a large number of livestock to copy the practice of arable farmers in adjoining areas and have his animals tended in groups of limited size by herdsmenl, who are paid with a proportion of the young animals.

The investigations of ethnologists and geographers give us an idea of how nomadic stock-keeping is organized, and the following example is an interesting case. For an informative study of nomadism, see Schinkel (1970).

\subsubsection{A case study: camel nomads in the Sahara}

The nomads of the Sahara, of whom Chapelle (1957) gives a vivid picture, live mainly by grazing camels on pastures that receive less than 150 millimetres of rain a year. The families each own four to fifteen camels, and in some cases even more than thirty, according to thei level of prosperity. In addition they keep a few liens, sheep, goats, donkeys, and, in the marginal areas with more rain, cattle. In summer they migrate soutinwards, following the rainfall, and in autumn they go northwards. camping at wa!ering places. Journeys of 150-220 kilometres are common, an's are carried out at night, but when there is little fodder available they iravol thice as far. In southern Algeria and in the Fezzan, the camel nomads normaily trek 500 kilometres a year, and in extremely bad years even 700-800 kilometres.

How the pasture is grazed in the catchment area of - watering place depends on the distance the variolis types of animal call travel, so that grazing zones are formed. In the hot season, camels need to be watered only every two or three days, and in the cool season only every two to three weeks. ${ }^{1}$ They are remarkably tolerant of 1 Webster and Wilson (1967, p. 337) write in this coluncction: 'During the northern
winter, or rainy season, the moisture content of the trees and bushes browsed by the 
water with a high sodium and magnesium content. They rarely stray, and can defend themselves against small predators like jackals, and, therefore, when they are not needed near the camp for milk or as pack-animals, they graze in herds of thirty to forty at distances up to 80 kilometres from the camp. Where there is no danger of theft, camels are left to themselves, and they are therefore able, without any use of labour, to eat fodder that cannot be reachid by other types of domestic animal because of the long distance from water. Table 9.2 illustrates the input and return of camel-keeping in Egypt, where, on account of the proximity of markets, favourable prices are obtained. According to the estimates of Alwan (1968), a family with ten camels would have a gross income of \$327. Shepherds' fess are a cost item only for those who own large herds.

TABLE 9.2

Gross and net annual cash income from 100 head of camels in Egypt

\begin{tabular}{lr}
\hline Gross return (\$) & \\
Sale of young camels (20 at \$103) & 2058 \\
Culling sale (12 aged camels at \$91) & 1097 \\
Hair, hides, etc. & 114 \\
Total gross return & 3269 \\
Expenditure (\$) & \\
Shepherds' fees & 823 \\
Watering costs & 91 \\
Miscellaneous & 69 \\
Total expenditure & 983 \\
Net Cash Income (\$) & 2286 \\
\hline
\end{tabular}

Note: $\mathrm{E} \mathrm{t}=\$ 2.29$.

Source: Alwan (1968, p. 33).

Where cattle are kept, they too may graze in complete freedom, but only up to 4-8 kilometres fiom the watering place. In the hot season, rattle must be ivatered twice a day, and in the wet season every two to three days. Pastures that are a long way from the watering place cannot therefore be used by cattle. Goats and sheep graze close to the camp, but, since they terd to stray, and since they cannot defend themselves against jackals, they are guarded by day and put in kraals at night. Goat-keeping in this system involves an incipient form of feeding, since it is normal practice for the herdsman to lop branches off certain trees and to throw them onto the ground for the goats to eat.

The nomads of the Sahara who keep large animals supplement their income from stock-keeping by collecting ed 'hle fruits and by hunting. Some species of gazelle can live without access to water, since they extract the moisture they need from fodder, so that by hunting the gazelles the nomads are able to make use of pastures beyond the range of their own camels.

Nomads in general are reluctant to become settled, which is the prerequisite of arabin farming, but on the other hand they do need crop food. A household of five peof"s requires about 300 kilograms of gra:n and 500 kilograms of dates annually.

dromedary is quite sufficient to supply the total water raquirement of the animal, and water may not be drunk at all during this period. In the dry season the vegetation is desiccated and extra water, over and above winter requirements, is required for hest regulation.' 
The nced to obtain grain without spending cash leads to various combinations of arable farming and nomadic stock-keeping:

(i) Millet is sown here and there in damp hollows, without soil preparation. After sowing, the nomads move on and return at harvest time, which means that they practise a form of shifting cultivation without implements.

(2) Nomads eniploy settled workers whose ancestors were subjugated dependants and who cultivate arable crops for them.

(3) In the marginal areas of their territory, the nomads frequently own land that can support arable crops, and they hire it out in return for payment in kind.

Trade and transport between arable-farming areas and oases are a further source of income. The oasis dwellers produce dates but have to buy grain, meat, and skins, whereas the arable farmers need dates and can supply grain. Finally, the nomad exchanges his animal products for the oasis dwellers' dates and the arable farmers' grain. At the same time he provides them with transport, and thus he is engaged in transport and trade as well as in stock-keeping.

\subsubsection{Weaknesses of total nomadism}

Nomadism allows the use of areas of land that could not be used by a perman $-\cdots$ population without motor transport and a system of ranching. Compared with the rancher, who must invest large sums in tracks, vehicles, fencing, and watering places, the nomad operates at a low level of expenditure and produces cheap animal products. Total nomadism represents thereforc an agricultural system that is adapted to a pre-technical situation, and that might still be considered the best economic choice where price conditions and natural conditiors do not justify investment in ranching. Total nomadism, however, is not open to the opportunities of technical progress that are available to ranchers. It is technically difficult and expensive to keep a check on the health of wandering herds, and cross-breeding with more productive types causes more harm than good if the fodder basis is not modified. Because of the marginal nature of the nomads' territories, it is scarcely worth their while to try to improve the feed situation by cropping fodder, sowing more productive grasses, and rotating the pasture.

Static production techniques in total nomadism contrast, however, with economic and social changes in and around the area where they live. This presents the nomads with a number of problems, which include:

(1) Diminishing grazing areas, because arable farming is spreading into the peripheral zones.

(2) Loss of pasture in arable-farming areas, because a rapidly expanding arable-farming population is practising stock-keeping on an increasing scale.

(3) Loss of income because the motor vehicle is competing with traditional animal transport-the use of draught cattle and tractors reduces the sale of draught camels, and in many places prices for draught camels have dropped to a fraction of their former level. 
(4) Loss of income because urban traders are competing with the nomads in their traditional trading function.

(5) Loss of the political control that they were traditionally able to exert over entire regions.

(6) The fact that farmers 'who used to supply the nomads' need of plant products are gaining their independence.

(7) The attempts that development administrators are increasingly making to control the incidence and limic the degree of movements of the human population, which is one major element of present policy towards nomads. Movernents of herds and herdsmen are, however, almost unavoidable in a typical nomadic setting.

The nomads have had to accept a considerable reduction in status, employment, and income at a time when new requirements have established themselves, and the consumption of tea, sugar, and alcohol has become common. Moreover, the population of nomadic tribes has increased rapidly in recent times. Measured in terms of traditional methods of land use, their territories are proving to be more and more 'relatively overpopulater'.

\subsubsection{Development paths of total nomadism}

Since nomadism is found mainly in areas where ranching is not a paying proposition, and since these particular people have little desire for change, it is usually advisable to leave them undisturbed, that is to say in the anteroom of economic development. It is particularly difficult and expensive to make nomadic tribes stationary and to integrate them into a modern economy. The natural habitat does not favour the transfer from nomadism to semi-nomadism or partial nomadism, where herds are concentrated near the camp, the surrounding pastures are overgrazed, and parasites and deficiency diseases increase. It costs $\$ 6000-15000$ per family to make them stationary within the framework of irrigation projects. The nomads' attainments in arable farming are mostly poor, unless every operation can be closely supervised, as in the Gezira scheme in the Sudan, but as a rule there is insufficient state control and state authority. Nomads are particularly reluctant to farm small areas intensively, and tampering with water is a thing that they very much dislike. Experience has shown that nomads can be induced to become tationary much more easily through mechanized grain cropping than through irrigation farming. Where this is not possible, tcwns and industry offer more incentives to become stationary than does crop production. Where employment in non-agricultural pursuits and in arable farming is insufficient to absorb the nomad population, it is probably economically and socially wise to let them continue their traditional way of life instead of wasting funds trying to improve a land-use system that will anyway gradually disappear in the course of economic development. 


\subsection{Somi-nomadism}

\subsubsection{General characteristics of semi-nomadism}

Total nomadism, as depicted in the last section, is restricted to decidedly marginal climatic zones. Its economic importance, measured in terms of both subsistence and marketed production, is very slight, whereas semi-nomadism and partial nomadism, which are practised particularly in the $\Lambda$ frican savannas, are of greater significance. We find stock-keeping, with little -or no supplementary arable farming, among the semi-nomads of West Africa (Fulbe), Madagascar (Sakkalaven), or East Africa (Masai, Turkana, Pakot, etc.). The principal animal kept is the cow, but there are often quite large herds of goats and sheep. Partial nomadism is even more important and characterizes stock-keeping among those African tribes that practise a considerable amount of arable farming. ${ }^{1}$

The organization of stock-keeping in the savannas is fairly uniform. The fodder basis consists of open bush, untended pastures, fallow, and harvest residues. The herdsmen usually have expert knowledge of their pastureland. As Allan (1967, p. 4) writes:

They know the feed value of the different grazing-and-browse species, which they usually distinguish by specific names; and they recognize ecological associations, or pasture types, and can assess their value and stock-carrying capacity at different times of year. Masai herdsmen in Kenya and Tanganyika pointed out to me various species and associations that they regarded as good for supplying mineral deficiencies, for conditioning animals, for improving the potency of buils, and for making milk and beef.

They often show great skill in adapting to the growth patterns of different fodder plants in the rainy and dry seasons and to the difierent feed values of shrubs, trees, and grasses. They have exact knowledge of the position, quality, and capacity of watering places, but they traditionally operate under technical conditions and with economic aims that result in low output and make the introduction of technical advances difficult or even impossible.

The livestock have to go long distances to watering places and to pastures, for at night only a kraal can protect them from wild animals and thieves. This prevents them from taking advantage of valuable night-grazing time. During the day, the herds often graze close together, since this provides better protection against wild animals, but they are consequently almost continuously on the move. During the rainy season there is plenty of fodder, but in the dry season there is little. Annual grass and bush fires reduce the reserves of fodder for the dry season and help to impoverish plant growth and the soil. On the other hand, burning helps to control growing bush, to remove old grasses, to stimulate grass growth in the dry season, and to eradicate parasites, particularly ticks. Firing is therefore a part of the system

1 Partial nomadism is further considered in $\$ 4.3 .4$. 
that can scarcely be dispensed with. Most of the extensive tropical grasslands of the present day are man-made, vy the joint action of fire and rrazing.

Animals grow up alternatcly gaining weight in the rainy season and losing weight in the dry season. There is neither the technical nor the economic basis for conserving fodder (straw, hay, and silage), nor is there any such tradition. Consequently, rearing takes a long time. Fodder and mineral deficiencies cause long intercalving periods, and only about a half of the cows calve in any one year. Moreover, of the calves that are born only about 50 per cent survive, and in many places even fewer.

A basic feature of semi-nomadism is the tendency to hoard animalsmore possible than in total nomadism because of the better fodder basiscombined with the communal use of grassland, which allows everyone to send any number of animals to the tribal or communal pastures. Thus a tendency to overgrazing, i.e. the maintenance of animals on a piece of land to the detriment of its carrying capacity, is inherent and particularly obvious in the system, for the more animals an individual possesses the greater is his share in the communal pasture. Onc factor inducing the hoarding of cattle is the high risk of production. In this connection, French $(1967$, p. 153) writes:

The retention of aged beasts in the herd is deliberately based on the knowledge that such older animals have usually recovered from and developed some immunity to several diseases. Such older cows may reproduce less frequently than younger animals but they do provide an insurance against recurrent disasters. This retention of older animals and of mature males in excess of those required for breeding or work purposes, together with relatively high mortality rates of young stock, result in herd compositions which are very different from those in developed areas. Any attempt to improve pastures, feeding or management conditions must be associated with a change in herd compositions if their maximum productivity is to be realized.

Even more important are the social factors. Cattle are property, and accordingly they represent variable degrees of wealth, of social status, and of community influence. They are a man's legacy to his son. They can be exchanged to symbolize formal contracts of friendship and assistance. The transfer of cattle from the groom's family to the bride's is needed to validate a marriage (Dyson and Hudson 1969, p. 78). Herdsmen usually tend to hoard cattle in order to build a system of human bonds aimed at increasirty individual security. This may be done in the following ways:

(1) Some of the animals of relatives and acquaintances are kept in a family's own kraal and they give some of their animals to other people, so that in case of disease the losses for any one family are not total.

(2) Herdsmen lend animals to a neighbour or relative who has lost his animais through disease or theft, and thus ensure his help in their own times of need. The tendency to dispose of animals by lending is encouraged by the fact that large herds entail a rapid consumption of grass and necessitate long treks. 
(3) The owners of large herds, who in any case do not want to keep them! in one place, lend some animals to poorer members of the tribe, and in this way guarantee their allegiance.

(4) If a man wants to marry, he has to give cattle to the bride's father. In poor families this amounts to one or two, and in rich families to ten cows and more. If the woman is treated badly by her husband, she can return to her father without his being obliged to return the cattle. Conversely, the husband can send his wife back to her father and demand back his cattle if she behaves badly or if she is infertile. Consequently, both parties have a material interest in the success of the marriage, but equally both are obliged to hoard animals for some part of their lives in order to meet their obligations if the case arises.

Thus when an assessment is madr of animal populations, it is crucial to remember the social role of animals as well as the motive to maximize productivity. Rotenhan (1968), for example, established in Sukumaland that 40 per cent of the Wasukuma's partially noinadic animals were tied as brideprices of 10-20 head of cattle per marriage. Similar conditions prevail among semi-nomads.

The tendency to overgrazing is further encouraged by the fact that all members of the tribe have access to the communal pasture. People who acquire household surpluses from arable farming, or who work as seasonal labourers in the mining industry or on the plantations, are therefore inclined to hoard cattle in order to gain security as well as prestige. Permanent arable farmers tend to lend cut iheir animals to semi-nomads like the Fulbe in West Africa. Thus animal-keeping and animal-owning are by no means identical, and in animal ownership we find particularly sharply inflected Lorenz curves, which indicates that stock is concentrated in a few families (see Fig. 4.4).

\subsubsection{A case study: semi-nomadism of the Bahima, Uganda}

The Bahima have long-horned Ankolc cattle, which graze grasslands in northeast Uganda, 1000-1300 metres above sea level and with a rainfall of 700-900 millimetres. Their economic position is better than that of many other pastoral tribes, because they have at their disposal land which receives plenty of rain and for the present is not overgrazed, largely due to the lack of watering places and a bimodal pattern of rainfall, which prevents arable farming. In the tribal area only 11 livestock units occupy 100 hectares. In other pastoral regions of East Africa, where less fodder grows, the animal density is sometimes two to three tines as high. resulting in overgrazing, but the Bahima have as yet been spared the devastating damage that overgrazing causes.

The animals are the private property of the families. The head of the family bequeaths the animals to his sons at his cwn discretion, but the pastureland is the communal property of the tribe, and every member of the tribe can graze as many animals as he likes. Watering places belong to whoever has dug them for as long as 
they are occupied; or a a watering place is abandoned, anyone can use it. The herds of the Bahima are comparatively large, and on average a typical family of ten people owns fifty-three animals, which are practically all cattle.

In general, several families live and migrate together. Temporary kraals and huts are built at seasonal watering places. Where plenty of water is permanently available, larger and more permanent kraals and huts are built, and are shifted about every two years. The Bahima have plenty of grass, so they de not move the kraals or construct temporary secondary kraals because they are in search of fodder but because they are:

(1) searching for water;

(2) trying to escape disease through movement; or

(3) complying witl the custom of abandoning a place where an adult has died and is buried.

Calving takes place in the rainy season, and normally one hundrid cows produce seventy calves. Most bull calves are slaughtered immediately after birth, so that there is as much mill as possible for human consumption. Of the calves that the Bahima try to raise, about 20 per cent die in the first year, so thei from one hundred cows twenty-eight calves are brought up cach year. A fanily owning fifty-three cattle of which twenty are cows, as shown in Table 9.3, could have five to six new animals entering the herd cach year. However, account must be taken of high

TABLE 9.3

Returns in cattle-keeping of the Balima, Uganda, 1964

\begin{tabular}{lc} 
Persons per household & 10 \\
Stock numbers (LU) & 41 \\
Head of cattle & 53 \\
Number of cows included & 20 \\
Area available per head of cattle (ha) & $7 \cdot 2$ \\
Area available for the total stock (ha) & 383 \\
Economic refurn per household & \\
Cattle (kg live-weight) & 1700 \\
Milk (kg) & 6000 \\
Blood (kg) & 400 \\
Gross return of cattle and milk (\$) & 419 \\
Proceeds from selling & 41 \\
Proceeds from selling as \% of economic return & 10 \\
Productivity & \\
Cattle (LU per l00 ha) & 11 \\
Cattle (kg live-weight per ha) & 4.5 \\
Milk (kg ha & \\
Gross return ( $\$$ ha. & \\
\hline
\end{tabular}

The tribe's area of land divided by the nimber of cattle.

Including animals which died and which were eaten.

- In addition to the milk co isumed by the calves.

$\$ \$ 0.07$ per $\mathbf{k g}$ live-weight of cattle; $\$ 0.03$ per $\mathrm{kg}$ milk. There is a market for cattle but not for milk. Thus the calculation of the return on milk is hypothetical. The holding return is supplemented by collecting honey and by other minor activities.

- Officially registered sales. As well as thesc, the herdsmen exchange animal products for the plant products of neighbouring arable farmers.

Sources: Pursons (1960), Brown (1963). 
losses (5-10 per cent) through disease and accident, which reduce the number entering the herd to three to five animals a ycar.

The Bahima live chiefly on inilk and meat, and animals that die through accident or diseast: are for the most part eaten. Blood is consumed chiefly when there is little milk available. For some years the Bahima have been exchanging animal products for sorghum, legumes, and sweet potatoes from neighbouring arable farmers. A growing number of men marry women from neighbouring arable-farming tribes, who are then allowed to lay out gardens and plant crops.

The return of cattle and milk in terms of local prices amounts to $\$ 419$, but only 10 per cent is actually sold. This is therefore most decidedly subsistence farming. ${ }^{1}$

\subsubsection{Weaknesses of semi-nomadism}

Most types of semi-nomadism may he termed economically wasteful. In comparison with large-scale production on ranches, the productivity per hectare, per man-equivalent, and per animal is usually low. Where plant grow'th has not yet suffered severely from overgrazing, animal densities are often high, since the stock-keepers know how to maximize the number of animals on a given area. But where long-term overgrazing has been practised, the animal numbers per 100 hectares are already smaller than on ranches. In south-west Africa, for example, the animal densities in reservations are on average only 75 per cent of those on ranches operating under the same soil and climate conditions. However, lower productivity per animal is much more serious economically than the low animal densities. Whereas on ranches 20 per cent of the animals are normally sold every year, and these are highquality animals, the semi-nomads and partial nomads of Africa slaughter ard sell only 6-10 per cent of their stock, and these are poor-quality animals. L. Brown (1963) goes so far as to suggest that the efficiency in meat and milk production among the semi-nomads and partial nomads of Kenya is only one-third of what ranches acliteve in the same conditions.

The low productivity of semi-nomadic stock-keeping cannot be attributed to unfavourable natural conditions, which is the case among the total nomads, but is caused primarily by the combination of individual animal ownership with communal grazing and pre-technical veterinary methods. The tendency to overgrazing and to neglect of those measures that could help to increase the efficiency of grazing is rooted in traditional institutions. Everyone tries his best to maximize his number of animals, and no one feels it incumbent upon himself to improve the land, since he has to share it with others. Communal bodies that undertake to organize the use of pastureland

\footnotetext{
1 The situation of the Bahima, as described by Parsons in the mid-fifties, has changed drastically in recent times. I observed in 1971 that more and more Bahima are turning to settled housing and plantain cropping. $A$ tsetse eradication scheme has extended the grazing area and, together with the introduction of dipping, has led to high rates of increase in cattle numbers without overgrazing. Many herdsmen are no longer at subsistence level, but raise cattle for sale. Here semi-nomads have been changed to commercial producers by a sudden drastic improvemicnt in their situation.
} 
have not been able to survive, or even to establish themselves. Persistent vegetation harbours ticks, flies, and worms, while overstocking favours aridity and reduces the incidence of parasitic diseases. Consequently the pastoralists, who are not familiar with modern veterinary practices, consider overgrazing an unavoidable evil.

The combination of these factors leads to the permanent overgrazing of a large part of the grassland, and a decline in the quality of the pasture sets in. Perennial grasses with high returns per unit area are displaced by annual grasses and bush. Areas prone to crosion are grazed without any consideration until the grass and the cover are totally removed. L. H. Brown (1963, p. 16) describes a district in Kenya as follows:

Baringo District has reached an 'overgrazing end point' where most of the grass and the topsoil has already gone over largs stretches of country and the ground is blarketed with thornbush, largely useless to man and beast alike, which cannot be eradicated without the expenditure of large sums of money... Land in a 35-40 inch rainfall area, once capable perhaps of supporting a stock-unit to 4-5 acres, is now scarcely capable of carrying a stock-unit to 20 acres ... In the drier part of the district with a 20-25 inch rainfall, land once capable of supporting a stock-unit to 10 acres is now scarcely capable of supporting one to $30-40$ ... Baringo is a case where the human population, in an attempt to maintain enough stock for their needs, have already to a large extent destroyed their own habitat.

A consequence of communal grazing and private cattle ownership is the so-called cattle cycle. The first stage is a relatively small number of animals, plenty of fodder, sufficient grazing in the dry season, and a high rate of reproduction. With increasing numbers of animals, the fodder supply becomes less adequate, and there is a particular shortage in the dry season. There is still sufficient grazing to cover the animals' needs in the dry season, and the stock can reproduce, but at more or less regular intervals there is an extremely dry year, when fodder growth and water are insufficient, causing some of the animals to die. In the following year the cycle begins again, with fewer animals, plenty of fodder, and a high rate of reproduction. In some parts of Tanzania, for example in the Masai area, this cycle seems to take about ten to fifteen years to complete.

In partial nomadism the damage caused by the inefficient control of cattlekeeping goes beyond the loss of animals during the dry seasons. In arable farming with cash crops, a relatively large amount of money is earned, and it can be, assumed that the more successful third of the farmers save considerable sums. Some part of these savings are invested in stock and thus are lost to the nation's economic capital. In addition there are such developments as, for example, the 'cotton cycle'. Cotton cropping brings in considerable amounts of cash, a part of which is saved and invested in stock. This results in a concentration of stock in cotton-growing regions, with the simultaneous 


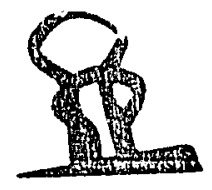

extension of arable farming. The area of pasture per livestock unit decreases and erosion damage increases. The animal-feed situation becomes worse than usual. In extremely bad years the result is a loss of animals, which again stimulates the desire tci buy more. Cotton cropping, the way to earn cash, is extended even further and the process begins all over again.

In particular, semi-nomadic stock-keeping is characterized by the following malpractices, which also apply to partial nomadism:

(1) Uncontrolled animal densities, overgrazing, and erosion damage in healthy habitats near settlements and at watering places.

(2) Insufficient fodder reserves, and thus an inadequate fodder distribution over the year.

(3) Hoarding of fully grown or infertile animals.

(4) A lack of information on the means of checking animal diseases.

(5) Long daily treks between the kraal, the pasture, and the watering place.

(6) Low levels of calving and a high mortality rate among calves-the calves compete with people for the milk from the cow and they are not fed adequately in the first months.

(7) Daytime grazing, often in the midday heat, instead of grazing at night or in the evening or morning.

(8) Theft of stock is regarded by several pastoral tribes as an honourable activity, so that animals have to be driven into a kraal for the night.

(9) Lack of systematic breeding-the camel nomads do carry out planned breeding, but the semi-nomads and partial nomads allow their cows to mate with unselected bulls.

New areas for cattle-keeping can be opened up by constructing watering places, since cattle should be watered twice daily if possible. Grass can be

F1G. 9.1. The size of the grazing area, showing its dependence on the distance from the watering place to the kraal.

(1) Watering place at the boma: large pasture area. (2) Watering place removed: smaller pasture area. (3) Watering place far removed: small pasturearea. From Groeneveld (1968, p. 228).

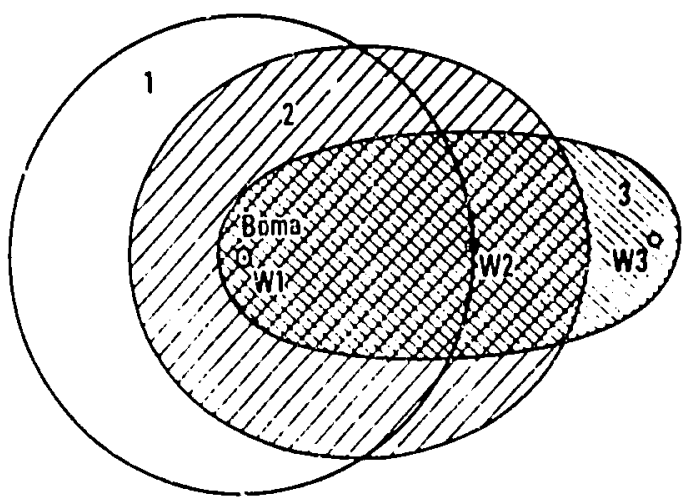

grazed for 4-6 kilometres round the watering place, so the available pasture is a function of the distance between the kraal and the watering place (see Fig. 9.1). Since there are few watering places, overgrazing is the result in the 
catchment area. Digging new watering places alleviates these conditions only temporarily. With little control or inanagement of grazing, the range deteriorates around the new watering points. Thus there is the danger that the range depletion is being spread by the measures intended to remedy it. Meanwhile, demands for additional water development continue to increase with the steady build-up of livestock numbers and the continuing decline in carrying capacity and range productivity. To stop this vicious cycle, and avoid its predictable consequences, water development obviously must be accompanied by appropriate management to maintain range productivity. The health of cattle must also be maintained, by veterinary means or measures to eradicate the tsetse fly.

\subsubsection{Development paths of semi-nomadism}

In the economic development of regions with semi-nomadism that are not suited to arable farming, the steps promising to be successful involve:

(1) A change to a different way of earning a living-there are far more workers than can be sensibly employeri in stock-keeping in dry regions, and the relative degree of overpopulation in the thinly settled dry regions is mostly greater than in the densely settled, high-rainfall arable regions.

(2) Establishment of organized management of grassland, supported by veterinary practices.

Whereas the total nomads usually use areas that are not amenable to commercial methods of farming, the methods of the semi-nomads dissipate the very resources that would make technically modern management worth while. But before grassland can be managed in an organized fashion, institutional controls have to be established that provide incentives to introduce technical advances. In this respect, there are a number of possibilities.

(a) Individual ranches. On the subject of individual ranches, Webster and Wilson write $(1967$, p. 280$)$ :

In view of the great disadvantages of communal grazing, it is often suggested that a change to individually owned and operated holdings is desirable, in order to obtain good pasture management. However, over a great deal of the pastoral country individual holdings are impracticable for several reasons. First, seasonal migration of stock is often essential because large areas of pasture can only be used for part of the year. Secondly, provision of water to individual holdings is often impracticable or uneconomic in areas where water is scarce. Thirdly, individual holdings would cften be unacceptable because few pastoral regions are uniform. Under individual tenure some prople would get only poor grazing, whereas under the communal system all have equal access to good and poor areas. Fourthly, the fericing of pastures and water supplies on individual holdings would be expensive, and in many places the absence of fencing materials would make it impracticable.

Individual ranches are therefore only sensible where the rainfall and drinking 


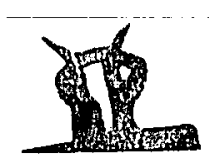

water are sufficient for an intensive pasture economy, or where there is an abundance of grassland. The Bahima in Uganda, for example, have plenty of grassland with a relatively high rainfall, and smaller ranches of 1300 hectares carrying 530 livestock units are being set up within the Ankole ranching scheme. But normally division of semi-nomadic and partially nomadic stock-keeping land into individual ranches is not an economically sound solution.

(b) Grazing schemes. Grazing schemes of a type that has been tried in various parts of Africa are a furcher step towards rationalization of the pasture economy in dry regions. The herdsmen are offered a number of investments and services, on condition that they submit their use of the grassland to controls checked by a grazing guard. Projects like this usually involve a number of measures:

(1) a regulation for animal density, which stipulates in most cases culling programmes;

(2) veterinary supervision and the payment of veterinary services;

(3) digging watering places so that the grassland can be grazed more evenly;

(4) the introduction of a grazing rotation;

(5) the control of grass-burning in the dry season, clearing the bush, and occasionally sowing more productive grasses;

(6) prohibition of grazing on badly eroded stretches; and

(7) the organization of marketing.

In their early stages, grazing schemes are under the wing of the agricultural administration, but the gradual transfer of management to grazing committees is usually planned. Experience shows that projects of this kind succeed in a few years in promoting animal health, regenerating fodder growth, consioerably increasing the grazing capacity, and consequentiy raising the income of the stock-keepers. But the grassland projects cannot be reconciled with the social function that tradition gives to stock-kecping. In most cases they fail after a few years because of the herdismen's opposition, and the following are the main reasons for their collapse:

(1) Many of the pastoral tribes are already living on a sub-marginal level. The reduction in stock numbers at first reduces the supply of milk and meat for the household. The herdsmen and their families apparently do rot have the means to bridge the time between the reduction ir: stocis and the higher return in milk and meat as a result of it.

(2) Culling programmes simply do not fit into the integrated sysiem of human bonds established by the lending, renting, exchanging, and presenting of cattle for different reasons in different situations.

(3) The limiting of stock numbers under the rules means that each family herd has to be split up into two-some animals are in the quota on the 
scheme and the remainder have to find their grazing elsewhere. As a result, herdsmen are separated from their families, and naturally the idea is unpopular.

(4) The reduction in stock numbers puts the greatest relative strain on the man with a lot of cattle, who is frequently an open or covert leader of the clan or tribe. Therefore grazing schemes are often opposed by those who have influence in their communities.

(c) Group ranches. In the majority of the range areas, economical and ecological considerations may make it acceptable for the pastoralists to come together on the basis of clans, families, or other groupings and establish ranching units, which might comprise two to twenty families and a stretch of land of between 600 and 12000 hectares. So far, the individual generally exercises grazing rights over the entire area recognized as the grazing ground of his clan. He thus has, along with other members of the clan or tribe, freedom to move with his herds over a considerable area, but has no specific individual rights to a particular portion of it. The new move would mean the division of the area into self-contained units as far as water is concerned. Only people belonging to a certain group of families would then have the right to graze there. The ownership of the land could go to the group or clan, provided that this could be legalized. Another perhaps more realistic approach would be the establishment of group ranches on the land of several individuals. However, in each case the individuals would retain the ownership of their cattle. Some of the Masai, for instance, are reported to have decided to divide their land into units of over 8000 hectares, to be owned by family groups whose interests are homogeneous and who have traditional respect for the elders in the group. It is intended that the land of each ranch shall be registered in the participants' names and that a management committee shall be formed whose function will be to run and develop the ranch, taking up ioans when necessary.

(d) Cooperctive or company ranches. Another possibility is the establishment of cooperative or company ranches. These should be run by a manager and raise their own funds. The individuals concerned might receive shares according to their contributions. They miglit be employed by the ranch management where this is convenient. Actually, the name 'cooperative' can be misleading. The institutional set-up is often much closer to that of a company than of a cooperative.

(e) Government ranches. Wherever grassland areas are available that are not claimed by pastoralists and cannot be handed over to private enterprise, the establishment of government ranches is advisable. In order to guarantee efficient management, they should be established and run by autonomous bodies as profit-making enterprises.

(f) Nucleus ranches. Another possibility to solve the problems of seminomadism is the combination of private or state nucleus ranches with the 
supervision of shifting herding in surrounding schemes. Such an arrangement has the following characteristics:

(1) An area newly opened up by watering places is declared a scheme area.

(2) Herdsmen are allowed to become scheme participants on condition that they submit their animal-husbandry practices to a clearly defined set of rules, the execution of which is closely supervised.

(3) The herdsmen are allowed to join the scheme with a limited number of cattle, the health of which is checked. No other cattle are allowed to graze in the scheme area, ald no scheme cattle are allowed to graze elsewhere.

(4) The herdsmen remain the owners of their cattle, but grazing, dipping. and castration are organized by the scheme management. All selling and buying of cattle has to be channelled through the scheme management.

(5) The scheme management is backed by a neighbouring nucleus ranch, which provides the services, the veterinary supervision, and the marketing facilities for the scheme cattle.

In group, cooperative, government, and company ranches, individual subsistence farming may well be incorporated into the enterprise. The allotment of land for cropping to members and workers within a system of shifting cultivation provides cleared land that can be planted with better grasses at low costs. Arable farming within a ranch may thus contribute to the reduction and control of bush and to the establishment of better grasses. However, two basic requirements must be fulfilled if money is to be invested in pastoral areas, nameiy:

(1) Limitation of the number of stock that attempt to graze any area to the number that area can carry without deterioration over a long period of time.

(2) Control of the movement of stock within any given area through rotational grazing systems or other such measures designed to maintain or improve the quality of the pastureland.

Without these two basic practices, no other range-improvement measure-whether additional water supplies, tsetse eradication, reseeding, or bush control-is likely to be of any lasting value. This is also true of veterinary services, which-except with devastating diseases like rinderpest-can be of economic value only within the framework of a rational system of land use.

Finally, it must be pointed out that the agricultural problems of most semiarid areas can be solved only by the removal of a great number of people from the pastoral way of life. There are often too many herdsmen who try to live on their stock and who therefore attempt tu retain, against advice, as many stock as they can for their own survival, thus continuing the destruction 
of their habitat. The relative degree of overpopulation is usually higher than in densely populated, high-potential areas.

\subsection{Ranching}

\subsubsection{General choracteristics of ranching}

Ranching, which is the commercial alternative to the various types of nomadism, is carried out on large stretches of land. Most ranches cover several thousand hectares, sometimes more than 100000 , and carry large, permanent herds of some 1000 or 10000 animals. The term ranch is generally used to refer to properties with well-defined boundaries (fenced or unfenced), legally owned, or having a long-term lease, and with certain developments present that were effected by the owner or lessee.

In ranching, the number of animals and workers, the capital investment, and the return per hectare are very low. However, ranches have large stock numbers and a large fixed capital per man-equivalent invested in, for example, fences and pumps, and there is usually a high income per man-equivalent. Production is limited to stock-keeping, and cropping of arable fodder is worth while only under iavourable price conditions, which are rare in the tropics. In most cases, only one type of animal is kept in any considerable numbers, and the airn is a single product, like wool or animals for slaughter, and other products, like the sheep's meai or the cattle's milk, are neglected. These are mostly marginal zones where diversification is not commercially worth while.

In particularly dry, stony areas far from markets, sheep-keeping predominates (south-west Africa, Australia, southern Argentina). Cattle do not have the same mobility, and are more demanding with regard to the frequency of watering and the amount of fodder. Whereas sheep are kept in some cases where only 150 millimetres of rain fall annually, cattle-keeping usually requires more than 400 millimetres. We find large-scale cattle ranches chiefly in the tsetse-free savannas of East and southern Africa, in Australia, and in Latin America.

The main objectives of ranch managenent are summarized by Webster and Wilson (1967, p. 256) as follows:

(1) To provide, as far as possible, a uniform and year-round supply of herbage for the maximum number of stock.

(2) To utilize the herbage at a stage that combines good nutrient quality with high yicld.

(3) To maintain the pasture in its most productive condition, by encouraging its best grass types and by promoting as full a ground cover as possible. This will protect the soil from direct solar radiation and the beating action of rainfall, thus preventing run-off and erosion. 
In evolving methods of management that will attempt to achieve these aims, ranch owners must give consideration to the following factors:

(1) the influence of seasonal growth and of grazing on the maintenance of the sward;

(2) the variation in the composition and feeding value of the herbage with stages in growth;

(3) the value of certain trees and shrubs as browse plants; and

(4) the need for bush control.

There are considerable difierences in the measures used by the ranchers to achieve these objectives. Ranches can be classified according to the following indicators of land-use intensity:

(1) Whether pastures are fenced, or to what extent the fencing divides the area.

(2) How far the watering points are from one another, or how much capital is invested in pumps, pipes, and troughs.

(3) Whether and how the pastures are managed (control of bush, planned burning, weed control, sowing of more productive grasses, rotational grazing, etc.).

(4) Whether and to what extent the supply and demand of fodder are balanced 'passively' by:

(i) calving or lambing at a time when there is plenty of fodder;

(ii) which type of production is chosen-on extensively managed ranches production is preferred that is less dependent on an even fodder supply than prcduction on intensively managed ranches, so that rearing animals is preferred to fattening them or dairying, and wool is preferred to mutton;

(iii) fodder reserves 'on the stalk';' and

(iv) balancing of fodder growth and animal numbers by selling when fodder becomes scarce, and buying when it is particularly abundant,

or balanced 'actively' by:

(i) the establishment of improved pastures;

(ii) cropping of arable fodder on irrigated plots; and

(iii) purchase of fodder.

1 Haymaking is rare in ranching systems for the following reasons (Webster and Wilson 1967, p. 269):

(1) Much of the land is unsuitable for mowing owing to its topography, uneven surface, or the presence of rocks, ant-hills, trees, and bushes.

(2) The low yields per hectare make haymaking uneconomic.

(3) The grass reaches an appropriate stage for hay at the height of the rains. At this time the weather makes haymaking either impossible, or at least difficult and liable to heavy losses. 
From the point of view of intensity, we distinguish chiefly between the open-grazing system, the field or paddock system, and paddock systems with an actively balanced system of fodder supply. In the open-grazing system, the herds must be continually watched by herdsmen. The productivity per animal and per hectare is relatively low, because rotational grazing and separation of age groups, etc., are difficult to achieve without fencing. In the field or paddock system, the work of guarding the animals is replaced by investment in fencing and watering places. Market productivity is higher, chiefly owing to the better organization of the fodder economy. The third stage in ranch
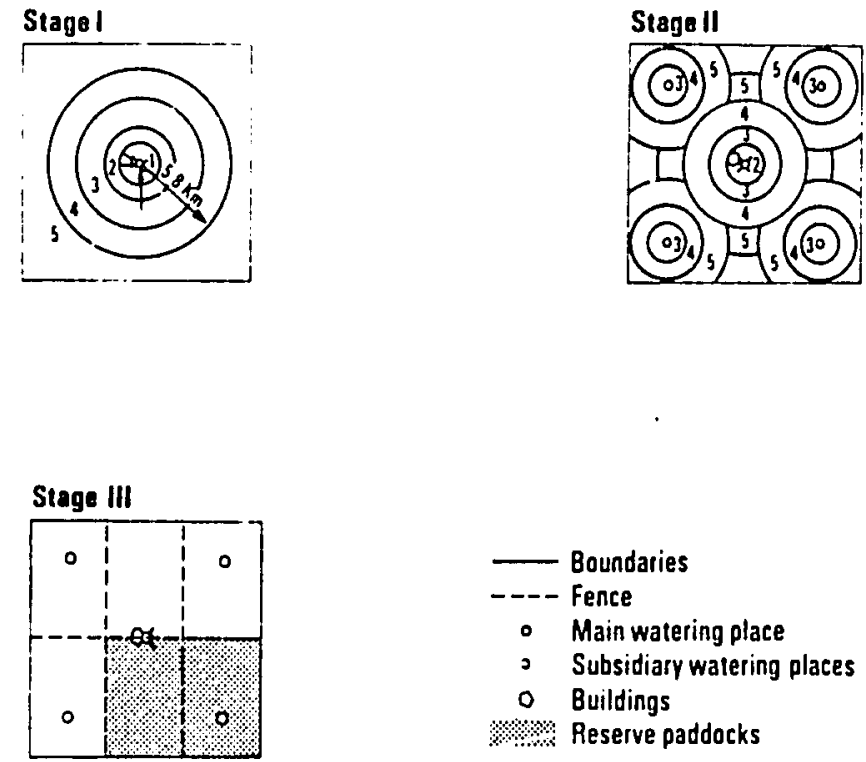

FIG. 9.2. Stages in ranch development. Stage I: no fencing, one water point, long daily migrations. (1) Bare soil, some weeds: (2) overgrazed area, vegetation mainly weeds: (3) overgrazed, some grass, much weed vegetation: (4) good pasture: (5) natural vegetation, scarcely grazed. Stage II: no fencing, severai water points. (2)-(5) as in Stage I. Stage III: paddock technique. In the dry season the reserve paddocks are grazed. From Andreae (1966, p. 23).

development, which is usually limited to ranches with irrigation facilities or in high-rainfall areas. is characterized by substantial investments in an actively balanced fodder supply and a correspondingly higher productivity per hectare.

Fig. 9.2 shows the principal stages in the development from open-grazing systems to paddock systems:

(1) Stage I: Where a ranch has only one watering place, concentric grazing rings are formed. Zone (1) is bare ground and secondary bush 19 
round the water, with scarcely any fodder in the dry season. Zone (2) is an overgrazed area with predominantly weed growth and little fodder in the dry season. Zone (3) is overgrazed area with weeds and annual grasses. Zone (4) is a reasonably used area with good pasture and fodder reserves available according to the grazing technique. Znne (5) is scarcely used natural vegetation, since it is a long way from the water ( $4-8$ kilometres), and provides fodder reserves in the dry season.

(2) Stage II. During the season when fodder is scarce, the fifth zone is a reserve. In so far as the dry season coincides with the cool part of the year, the animals can travel further and make use of the fodder growing in the outer zone. As several watering places are dug, the marginal zones of the ranch can be more easily developed. The distances covered by the animals become shorter. The result is the formation of vegetation zones round each watering place, with a better distribution of grazing and less overgrazing. (3) Stage III. Dividing the pasture into paddocks combined with fencing reduces the damage from overgrazing, facilitates separation of the animals into age groups, and allows reserve paddocks to be formed with hay on the stalk. The reserve paddocks are grazed in the dry season. Webster and Wilson (1967, p. 266) write:

A very simple system is that known as the 'three herd-four paddock' system. Each paddock is grazed continuously for three years and in the fourth year grazing is stopped just after the beginning of the rains, the accumulated grass is burnt off at the end of the dry season, and the paddock is then rested for a further one or two months at the beginning of the next rainy season.

The capital invested in progressing from Stage I to Stages II and III means that more cattle can be kept at a lower risk and will cause less damage to the pasture. It reduces the input of labour and shortens the time it takes to rear animals for slaughter from four to five years to three to four years.

The intensity of grassland use is reflected in the animal densities, which fluctuate between 2 and 50 livestock units per 100 hectares, according to local conditions. The lower limit is where fodder and water are so scarce that permanent stock-keeping becomes impossible, and nomadism or hunting is the most economic activity. Ranches supporting enough fodder to keep $30-40$ livestock units per 100 hectares are mostly found in zones where the rainfall is sufficient for arable farming and where, if there were no lack of labour and markets, arable farming would be more competitive than ranching.

\subsubsection{Two case studies}

(a) A Karakul ranch in south-west Africa. Sheep ranches differ as to whether they aim to produce wool (as in Australia, Argentina), or skins (as in southwest Africa). Mutton is a by-product, if it is valued at all, on the large sheep 
ranches. The production of Karakul skins is suited to particularly dry areas. The majority of Karakul lambs are slaughtered immediately after birth, with the consequence that the ewe is less burdened and in a better state to survive the dry season.

Schäfer (1963) provides an example of how a Karakul sheep ranch in south-west Africa is organized (see also Gundert 1962). The farm 'Haribes', whose data are contained in Table 9.4, comprises 77500 hectares of partly stony and partly sandy bush savanna, whose average rainfall over many years is 200 millimetres, although there are fluctuations from 90 to 340 millimetres. This area supports $10000 \mathrm{Karakul}$ sheep, 800 goats belonging to the workers, and a number of cows to provide milk for human consumption. When the grazing is ample, about 100 head of cattle are bought for fattening, but when fodder is scarce this does not occur. The main production aim is the skin of the Karakul lamb and the sale oi 'jreeding animals.

The total area is divided up by fences enclosing between 5000 and 19000 hectares, and is then subdivided into twenty-four sections according to the position of the watering places. Eighteen sictions are grazed in turn for two weeks at a time. Six sections, a quarter of the toial area, are not grazed at all, but constitute a fodder reserve in case there is insufficient rainfall. Shepherding has been replaced by jackal-proof fences.

We can distinguish a long and a short lambing season. Two-thirds of the births occur between May and August, and one-third in January and February, and at both these times of year fodder is relatively plentiful. The sheep are shorn after lambing. The lambs are taken immediately after birth to the main yard and sorted to see whether they are suitable for breeding or whether they have good skins. Slaughtering takes place in the yard.

Karakul skins contribute up to 50 per cent of the return from the ranch, which amounts to $\$ 72500$, and of which 29 per cent is obtained from selling breeding animals. The income from cattle-keeping varies according to the amount of fodder. Wool and mutton make no contribution. The local farm price of a sheep is $\$ 2.80$, which is lower than for a good lamb's skin. The traditional practice is to keep ewes as long as they bear lambs, which in effect means until they die of old age. In recent years it has been usual to slaughter and sell the ewes at the age of about seven years.

The salaries of the ranch managers are the main expense. They are higher than elsewhere on sheep ranches, because of the high skills required in breeding and producing Karakul. Wages are the next major item of expenditure. Material costs consist mainly of vehicles, maintenance, and the depreciation of fixed assets, particularly watering places. The productivity per hectare, at $\$ 0.93$ per hectare, of which $\$ 0.13$ is profit, is less than in all other forms of comnercial land use, but the gross return per man-equivalent amounts to $\$ 942$.

(b) A cattle ranch in Kenya. Cattle ranches, which are economically much more important than sheep ranches, may aim at different products. They can be differentiated as:

(1) ranches whose production aim is to raise and sell cattle for fattening;

(2) Ranches for raising and fattening, whose end product is animals fattened for slaughter; 
TABle 9.4

Farm-management data of a cattle ranch in Kenya and a Karakul sheep ranch in south-west Africa

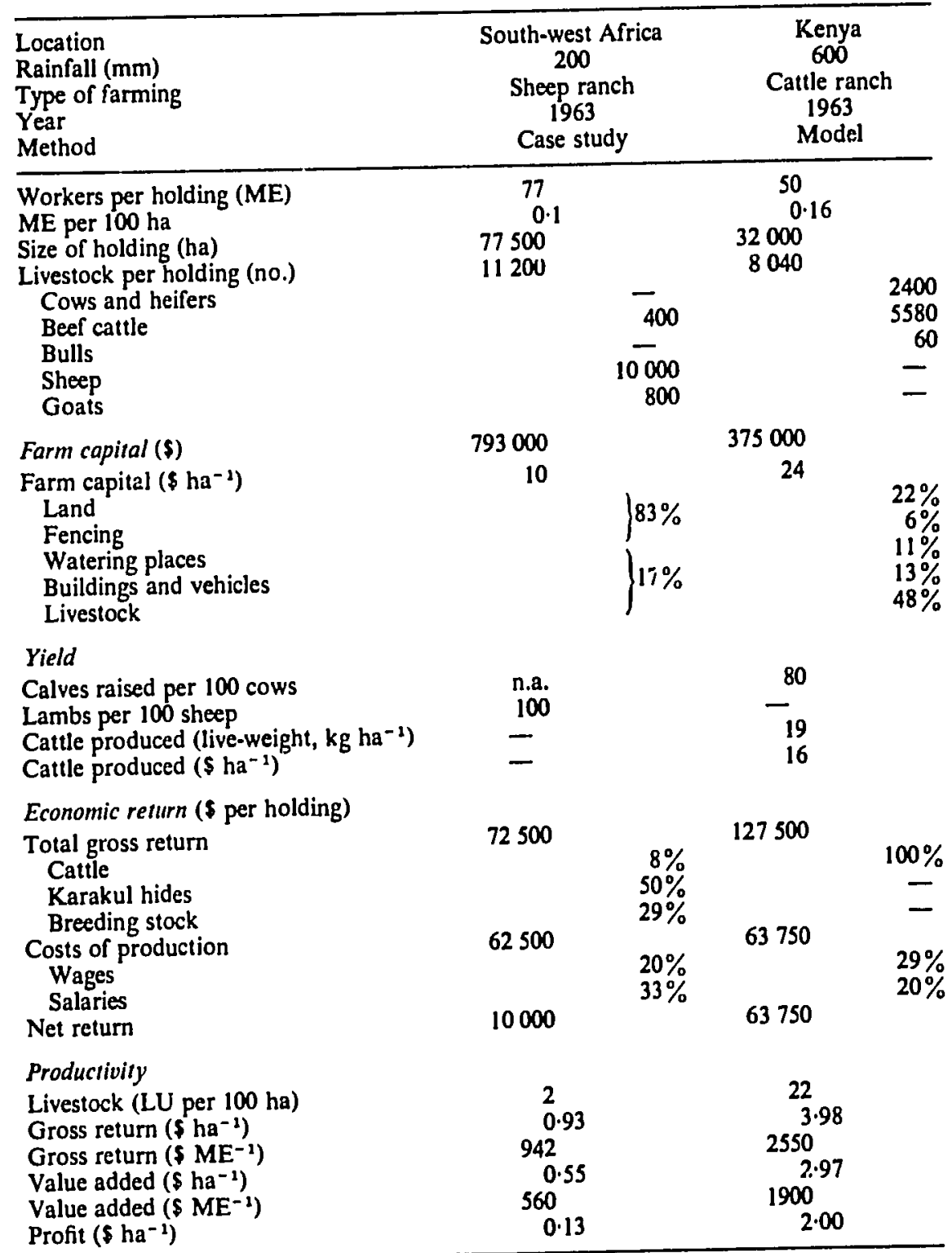

Sources: White (1963); Schäfer (1963). 
(3) fattening ranches, where the animals from native or commercial ranches are fattened; or

(4) dairy ranches.

This division of labour bei:ween ranches for breeding and ranches for fattening is characteristic of countries witt. advanced economies bised on labour division, like the United States of America or Argentina. It is rare in the tropics. Fattening ranches are only occasionally found, where nomads, seminomads, or arable farmers sell their unfattened animals, as for example in East Africa or Madagascar. They are of some importance in those areas of Latin America (northern Colombia, Sac Paulo, Brazil) wisere markets with substantial purchasing power are close to foddir-producing areas, where fodder growth at the various altitudes is conducive to the division of labour, and where immatures can be obtained in sufficient numbers at a relatively low price. Dairy ranching is also tied to the proximity of urban consumption centres. It is of increasing importance in, for example, Latin America, South Africa, and Kenya.

The data iu Table 9.4 apply to a cattle ranch in Kenya, in an area with 600 millimetres of rain and enough fodder to support 22 livestock units per 100 hectares. The production aim is animals for slaughter, for the urban market, and for export. The greater part of the ranch, which consists of 32000 hectares, is divided by fences into paddocks of 2000-3000 hectares, and in each there is watering place. The animals, grouped according to age, occupy the paddocks in a four-year rotation: year 1, breeding herd; year 2, heifers; year 3, oxen; and year 4, no grazing, regulated burn. In the dry season the grazing rotation is interrupted, and all three paddocks are open to all the animals. The normal animal density is 80 per cent of the fodder capacity, so that even in dry years there is sufficient grass. The chief maintenance expense is control of bush regeneration; as well as burning at fouryearly intervals, heavy equipment has to be used on some sections.

The calves are born in the rainy season, and eighty calves are reared per one hundred cows. The animals grow up alternately increasing in weight at times of abundant fodder and maintaining their weight in the two to three driest months, when they are not given any additional fodder. The increase in live-weight amounts to 19 kilograms per hectare per year. The cattle are an imfroved Zebu variety: the Boran. They are sold for slaughter when they are $31-4$ years old and at a weight of 350 kilograms.

With the price of cattle at $\$ 15.50$ per quintal, the return from the ranch comes to $\$ 127500$, which is $\$ 3.98$ per hectare. The major expenditure consists of wages and the salaries of ranch managers. Next in importance comes the depreciation of fences, pumps, and other fixed capital.

(c) Ranches in higher-rainfall areas of South America. Table 9.5 gives the farm-management data of ranching in various South American countries. Although operating on land with much higher potential for plant pro luction than that in the Kenya case study, they show the general characteristics of extensive stock-keeping: large size of holdings, low labour input per hectare, 
TABLE

Return on capital and factors contributing to it

\begin{tabular}{|c|c|c|c|c|c|c|}
\hline \multirow{2}{*}{$\begin{array}{l}\text { Country } \\
\text { L.ocation } \\
\text { Rainfall (mm) } \\
\text { Methou } \\
\text { Management }\end{array}$} & \multicolumn{2}{|c|}{$\begin{array}{c}\text { Paraguay } \\
\text { Eastem Chaco }\end{array}$} & \multirow{2}{*}{$\begin{array}{l}\text { Brazil } \\
\text { Pantanal } \\
1300 \\
\text { Case sludy } \\
\text { Average }\end{array}$} & \multirow{2}{*}{$\begin{array}{l}\text { Brazl! } \\
\text { Northern } \\
\text { Kio Grande } \\
\text { do Sul } \\
\text { isoo } \\
\text { Cage study } \\
\text { Good }\end{array}$} & \multicolumn{2}{|c|}{$\begin{array}{c}\text { Bolivia } \\
\text { Beni }\end{array}$} \\
\hline & $\begin{array}{c}1150 \\
\text { Model } \\
\text { Average }\end{array}$ & $\begin{array}{l}1150 \\
\text { Case study } \\
\text { Good }\end{array}$ & & & $\begin{array}{c}1650 \\
\text { Model } \\
\text { Average }\end{array}$ & $\begin{array}{c}1630 \\
\text { Case study } \\
\text { Good }\end{array}$ \\
\hline $\begin{array}{l}\text { Size (ha grazed) } \\
\text { Workers per ranch } \\
\text { Workers (ME per } 100 \mathrm{hs} \text { ) } \\
\text { Livestock (LU per ranch)" } \\
\text { Ronch carital (\$) } \\
\text { Lond } \\
\text { Cattie } \\
\text { Others }\end{array}$ & $\begin{array}{r}20000 \\
14 \\
0.07 \\
4500 \\
459000 \\
43 \% \\
46 \% \\
11 \%\end{array}$ & $\begin{array}{r}20000 \\
14 \\
0.07 \\
6700 \\
592000 \\
34 \% \\
34 \% \\
32 \%\end{array}$ & $\begin{array}{r}10000 \\
10 \\
1 \\
2300 \\
249000 \\
52 \% \\
37 \% \\
11 \%\end{array}$ & $\begin{array}{r}1000 \\
3 \\
0.3 \\
375 \\
110000 \\
68 \% \\
21 \% \\
11 \%\end{array}$ & $\begin{array}{r}4000 \\
0.1 \\
450 \\
43000 \\
26 \% \\
53 \% \\
21 \%\end{array}$ & $\begin{array}{r}7500 \\
8 \\
0.11 \\
1600 \\
128000 \\
16 \% \\
64: \\
20 \%\end{array}$ \\
\hline $\begin{array}{l}\text { On-farm prices } \\
\text { Cattle ( } \$ \text { per kg live-weight) } \\
\text { Labour ( } \$ \text { per ME and year) } \\
\text { Lond }\left(\$ \mathrm{ha}^{-1}\right)\end{array}$ & \multicolumn{2}{|c|}{$\begin{array}{r}0.14 \\
460 \\
10\end{array}$} & $\begin{array}{r}0.13 \\
390 \\
13\end{array}$ & $\begin{array}{r}0.17 \\
480 \\
75\end{array}$ & \multicolumn{2}{|c|}{$\begin{array}{r}0.19 \\
484 \\
2.80\end{array}$} \\
\hline $\begin{array}{l}\text { Yleld } \\
\text { Take-on \% } \\
\text { Production (kg live-weight per ha) } \\
\text { Production (kg live-weight per LU) } \\
\text { Gross return ( } \$ \text { per ranch) } \\
\text { Costs of production } \\
\text { Net retum }\end{array}$ & $\begin{array}{r}17 \\
18 \\
80 \\
30400 \\
18900 \\
31500\end{array}$ & $\begin{array}{r}20 \\
30 \\
90 \\
83800 \\
26800 \\
57000\end{array}$ & $\begin{array}{r}13 \\
11 \\
48 \\
14250 \\
10800 \\
3450\end{array}$ & $\begin{array}{r}22 \\
36 \\
96 \\
6100 \\
4280 \\
1820\end{array}$ & $\begin{array}{r}15 \\
7 \\
62 \\
5000 \\
4050 \\
950\end{array}$ & $\begin{array}{r}18 \\
19 \\
89 \\
26600 \\
14200 \\
12400\end{array}$ \\
\hline 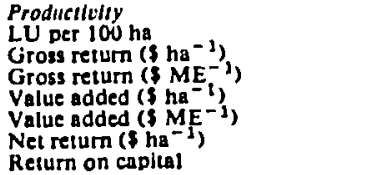 & $\begin{array}{l}22 \\
2.32 \\
3600 \\
1.89 \\
2720 \\
1.57 \\
6.8 \%\end{array}$ & $\begin{array}{r}33 \\
4 \cdot 18 \\
9980 \\
3 \cdot 17 \\
4530 \\
2.85 \\
9 \cdot 7 \%\end{array}$ & $\begin{array}{r}23 \\
1.42 \\
1.450 \\
0.73 \\
735 \\
0.34 \\
1.4 \%\end{array}$ & $\begin{array}{r}37 \\
6.10 \\
2030 \\
3.26 \\
1086 \\
1.82 \\
1.7 \%\end{array}$ & $\begin{array}{r}11 \\
1.25 \\
1250 \\
0.72 \\
722 \\
0.24 \\
2.2 \%\end{array}$ & $\begin{array}{r}21 \\
3.54 \\
3220 \\
2.17 \\
2035 \\
1.65 \\
9.7 \%\end{array}$ \\
\hline
\end{tabular}

- I LU $=1$ adult cow held for one year. Other atock is computed proportionally to its live-weight and :Ime beld. Since the average weight of adult cows generally differs between areas and levels of manageraent, the figures are not neceasarily average weight of adult cows generally differs between areas and
proportional to live-weight carried. - Average for all animals sold. Thus.

as well.

e Comployer.

\section{Best Arailable Document}


9.5

in South America's beef catle industry 1968

\begin{tabular}{|c|c|c|c|c|c|c|c|}
\hline \multicolumn{2}{|c|}{$\begin{array}{c}\text { Colombie } \\
\text { Cosis. } \\
\text { breeding zone }\end{array}$} & \multicolumn{2}{|c|}{$\underset{\text { Llanos }}{\text { Colombia }}$} & \multicolumn{2}{|c|}{$\begin{array}{c}\text { Venczuele } \\
\text { Apure } \\
\text { (western Linnos) }\end{array}$} & \multicolumn{2}{|c|}{$\begin{array}{l}\text { Venezucle } \\
\text { Easiern Llanos? }\end{array}$} \\
\hline $\begin{array}{l}1600 \\
\text { Case study } \\
\text { Average }\end{array}$ & $\begin{array}{l}1600 \\
\text { Model } \\
\text { Good }\end{array}$ & $\begin{array}{c}1500 \\
\text { Case sludy } \\
\text { Average }\end{array}$ & $\begin{array}{c}1500 \\
\text { Model } \\
\text { ToD }\end{array}$ & $\begin{array}{c}1700 \\
\text { Model } \\
\text { Average }\end{array}$ & $\begin{array}{l}1700 \\
\text { Case study } \\
\text { Good }\end{array}$ & $\begin{array}{c}1300 \\
\text { Case study } \\
\text { Average }\end{array}$ & $\begin{array}{c}1300 \\
\text { Case study } \\
\text { Good }\end{array}$ \\
\hline $\begin{array}{r}400 \\
9 \\
2.25 \\
300 \\
70000 \\
41.5 \% \\
40.5 \% \\
18 \%\end{array}$ & $\begin{array}{r}400 \\
11 \\
2.73 \\
600 \\
109000 \\
27 \% \\
33 \% \\
20 \%\end{array}$ & $\begin{array}{r}3000 \\
3.4 \\
0.11 \\
820 \\
96,000 \\
49.5 \% \\
44.5 \% \\
6 \%\end{array}$ & $\begin{array}{r}3000 \\
4.8 \\
0.16 \\
1000 \\
134000 \\
36^{\circ} \\
47 \% \\
170^{\circ}\end{array}$ & $\begin{array}{r}20000 \\
21 \\
0.11 \\
5330 \\
520000 \\
260^{\circ} \\
68 \% \\
6 \%\end{array}$ & $\begin{array}{r}20000 \\
25 \\
0 \cdot 13 \\
5330 \\
573000 \\
24^{\circ} \\
62 . \\
140^{\circ}\end{array}$ & $\begin{array}{r}7000 \\
7 \\
0.1 \\
860 \\
297000 \\
51 \% \\
38 \% \\
11:\end{array}$ & $\begin{array}{r}7000 \\
17 \\
0.24 \\
1450 \\
396000 \\
39 \div \\
48 \% \\
13 \%\end{array}$ \\
\hline \multicolumn{2}{|c|}{$\begin{array}{r}0.30 \\
470 \\
75\end{array}$} & \multicolumn{2}{|c|}{$\begin{array}{r}0.17 \\
350 \\
16\end{array}$} & \multicolumn{2}{|c|}{$\begin{array}{l}0.30 \\
740 \\
6 \% 10\end{array}$} & \multicolumn{2}{|c|}{$\begin{array}{r}0.35 \\
890 \\
22\end{array}$} \\
\hline $\begin{array}{r}21 \\
61 \\
83 \\
9350 \\
5760 \\
3390\end{array}$ & $\begin{array}{r}23 \\
147 \\
98 \\
17500 \\
8400 \\
9100\end{array}$ & $\begin{array}{r}11 \\
11 \\
40 \\
5430 \\
2590 \\
2840\end{array}$ & $\begin{array}{r}23 \\
35 \\
105 \\
18500 \\
8510 \\
9990\end{array}$ & $\begin{array}{r}8 \\
8 \\
29 \\
47800 \\
19150 \\
28650\end{array}$ & $\begin{array}{r}14 \\
13 \\
48 \\
70500 \\
32500 \\
38000\end{array}$ & $\begin{array}{r}21 \\
10 \\
78 \\
29200 \\
10300 \\
18900\end{array}$ & $\begin{array}{r}19 \\
22 \\
106 \\
62800 \\
28400 \\
34400\end{array}$ \\
\hline $\begin{array}{r}73 \\
23.40 \\
1040 \\
19.80 \\
884 \\
8.98 \\
3.8 \%\end{array}$ & $\begin{array}{r}150 \\
43 \cdot R 0 \\
1590 \\
36 \cdot 00 \\
1308 \\
22 \cdot 75 \\
8 \cdot 4 \%\end{array}$ & $\begin{array}{r}27 \\
1.81 \\
1610 \\
1.21 \\
1187 \\
0.95 \\
3.0 \%\end{array}$ & $\begin{array}{r}33 \\
6 \cdot 16 \\
3860 \\
3 \cdot 84 \\
2430 \\
3.33 \\
7.54\end{array}$ & $\begin{array}{r}27 \\
2.39 \\
2.280 \\
2.18 \\
2080 \\
1.43 \\
5.34\end{array}$ & $\begin{array}{r}27 \\
3.52 \\
2820 \\
2.82 \\
2280 \\
1.90 \\
6.6 \%\end{array}$ & $\begin{array}{r}12 \\
4 \cdot 17 \\
4170 \\
3.59 \\
3585 \\
2.70 \\
6.3 \%\end{array}$ & $\begin{array}{r}21 \\
8.98 \\
3690 \\
7.07 \\
2920 \\
4.91 \\
9.1 \%\end{array}$ \\
\hline
\end{tabular}

- Includes wages for family labour and depreciation: excludes interests paid. In the case of family-sized units (4 or fewer

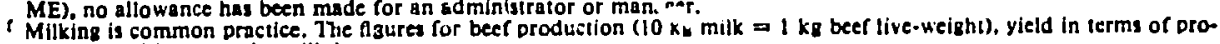
duction, and income take millk into account.

Source: Owen (1969).

\section{Best Available Documatat}


high investments in relation to labour costs and to output, a low productivity per hectare, but high returns per man-equivalent.

\subsubsection{Weaknesses of ranching}

Ranching is far from being a system that can te run particularly easily or lucratively, since it is characterized by:

(1) high fixed costs and very high initial investments;

(2) a long-term commitment to a particular type of production;

(3) high-risk production because of the constant threat of drought; and

(4) high costs for personnel in relation to the return from the ranch.

The high fixed costs stem less from the value of the land than from the investments necessary to develop and utilize ratural fodder. The costs of animals are the primary outlay. To build up a ranch requires either a high level of buying, or slow stocking with animals born on the ranch, and at least ten years of low return have to be bridged. Another costly item is the procuring of water. Grassland is of scarcely any value for cattle-keeping unless there are watering places within 4-5 kilometres; rotational grazing depends on watering places in every paddock. The watering places should have a reseive capacity of 50 per cent, so that sufficient water is left even in dry years to maintain the rotation. There is also the investment in fences and the cost of their maintenance, for ranching without fencing is normally not a viable activity. Fences reduce labour, facilitate the control of animal densities, permit the separation of sexes and age groups, simplify veterinary care and breeding, and make it possible for cattle to graze at night. On the other hand, they are expensive in relation to the return from the fenced-off areas, especially as wide use is normally made of long-lasting iron or wooden posts, which have to be transported from far away and impregnated against termites.

The result of investment is a long-term commitment to a particular type of production. The selected area is usually suitable only for either sheep or cattle, and it is virtually impossible to adapt production if economic conditions change.

The three related factors of high initial investment, specialization in a single type of production, and operation in marginal areas inevitably entail a high level of market risk. Ranches must also consider the unreliability of the rainfall. There is a danger in planning the animal density on the fodder capacity of average years, when a few consecutive dry years can result in loss of animals or hurried sales. Furthermore, ranches with a single product are at the mercy of price fluctuations.

The high expenditure on personnel is a further feature of large ranches. Admittedly these costs are extremely low per hectare, but they are high in relation to the return of the ranch. A large part of the expenditure pays for 
the services of the ranch manager, especially where diseases are particularly hazardous, as in sheep-keeping in the tropics generally, or in cattle-keeping in East Africa, where east. coast fever, the tsetse fly, and other dangers are present. Ranch managers with some veterinary knowledge are needed, and they can demand a correspondingly high salary, which can be covered only by a large herd. Since the foddei capacity of pastures is small, it is necessary to set up ranches on a very large scale.

The management problems of large-scale stock-keeping in the tropics and subtropics are therefore not dissimilar to those of plantations. High initial costs and the long-term commitment to one type of production make the early stages particularly difficult, and only if there are stable economic and social conditions is there any incentive to invest in undertakings that will show a market profit only after one or two decades.

\subsubsection{Development paths of ranching}

In few areas of agriculture is large-scale production so superior to smallscale production as in the case of stock-keeping in dry tropical regions. Not only the net return on labour and land, but also the gross return is far above what can be obtained in traditional semi-nomadic stock-keeping. The economies of scale are not mainly due to mechanization. Much more important are benefits arising from access to agricultural and veterinary progress, from proper stocking policies, which justify the high fixed costs of investment in improvements like watering places, and from high levels of management. Large-scale ranching is thus in a far better position to reap the benefits of technical progress that become available in grazing and animal husbandry. The general tendencies that technical progress in ranching seems to favour may be summarized as follows:

(1) The main prospect for increasing the output of livestock products lies in improved management of existing breeds, in particular in better grassland managemeni, rotational grazing, improved disease control, etc. Innovations are much more easily applied in large ranches than in partially or semi-nomadic herdings.

(2) The improvement of the basic genetic types of local cattle is bound to be a lnng and complex process. However, upgrading is of increasing importance. Breeding of other types that mature earlier is the usual objective.

Measured in ternı of the quantity and quality of the production per hectare, per animal, and per worker, and of the degree of competitiveness on the market, the large ranch proves to be more advantageous in every respect. However, large-scale ranching is not apprcpriate in all conditions, being unsuitable in those most marginal that are occupied by the total nomads. 


\title{
10. General tendencies in the development of farm systems
}

\author{
by J. D. MacArthur
}

Chapters 3 to 9 have been concerned with the main types of farming that occur in the tropics. The salient features and characteristics of each have been outlined and exemplified so as to allow attention to be drawn to the problems and development paths of each pattern of farm organization. For this purpose, sevan distinct farming systems were identified, each being significantly different from the others.

This method of treatment should not be taken to imply that very clear differences are to be found between farms that are classified under the various types. There are often no clear-cut divisions that can be drawn between holdings classed as one type and those coming in the next class. In some cascs, as for example for shifting, semi-permanent, and permanent arable systems, the cut-off point is taken at given values of the parameter $R$. Niajor differences exist between farming systems witt: low, middle, and high $R$ values, but there are wide areas of transition between these basically different types. The treatment used here has allowed the principal differences between types of farming to be highlighted. It is not, however, suggested that all types of tropical farming can be clessified precisely into one or other of these seven types.

Despite the frequent absence of clear distinctions letween particular systems of farm operation that arise from the combination of parts that have different operational features, some fairly comprehensive generalizations about the development paths of different types of farming can be made.

The range and balance of enterprise combinations that are reflected in any actual farming system is limited by a number of constraining factors. In a recent work, Duckham and Masefield (1970) have suggested that five main types of factor limit the possibie occurrence and importance of different types of crop and livestock found in any actual farm system.

(1) Ecological faciors determine what different types of production are possible and which species can thrive in the light of existing climatic, soil, and biological conditions, including the way in which different species interact within a single system. 
(2) Infra-structural features, concerning such things as land tenure and the supply of various off-farm inputs like water, power, expertise and advice, material inputs, and things of this kind, further restrict the choice of possible combinations that can arise from ecologically suitable enterprises. (3) External economic constraints will also profoundly influence the choice of attractive possibilities, through such features as location, the quality of of communications for the movement of produce, the organization and structure of marketing systems, the existence of alternative sources of food supply that can remove the need for subsistence production, the availability of credit, produce subsidies, and a whole host of other features, that effect the attractiveness of different systems of farming.

(4) Internal operational factors like farm size, the available labour force, owned resources that can be invested, and fixed improvements are also obvious important determinants.

(5) Finally personal acceptance of the adopted system can have some influence in those types of farming where a range of possibilities permits personal choices to be made.

Within the framework of successive limitations of this kind, development paths can be observed for different major types of tropical ecological situation. These indicate the directions along which farmers may adapt their systems of operations as circumstances change to alter one or other of the constraining factors. Fig. 10.1 shows in diagrammatic form the evolutionary paths that may be followed in the four major climate zones of the tropics. Starting from the basic, undifferentiated system for a particular situation, each line in the diagram shows a possible evolutionary path, its relative importance and feasibility being indicated by the thickness of the arrow.

In humid areas we find above all the change from shifting systems to irrigation farming, mainly with rice, and to the growing of perennial crops. These changes occur either directly from shifting systems or via the stage of semi-permanent cultivation. The pre-conditions for the spread of permanent rain-fed farming are usuall;" not yet present, while ley systems for these areas are still in the experimental stage. In the humid savannas the change is mainly from shifting systems to scmi-permanent systems and-with increasing population densities-to irrigation farming. Unregulated ley systems are found in areas that are free from the tsetse fy. Regulated ley farming, which is videly practised in the subtropics, has been introduced into the humid savannas of the tropics only in exceptional cases. In the dry savanna climate the tendency is to change from shifting cultivation to unregulated ley farming and fullly to permanent dry farming, with irrigation spreading wherever water is available. In grazing areas, the pattern of change is from open grazing to paddock sysiems. In high-altitude areas the evolutionary pattern is for the intensification of arable farming, developing rapidly from shifting cultivation 


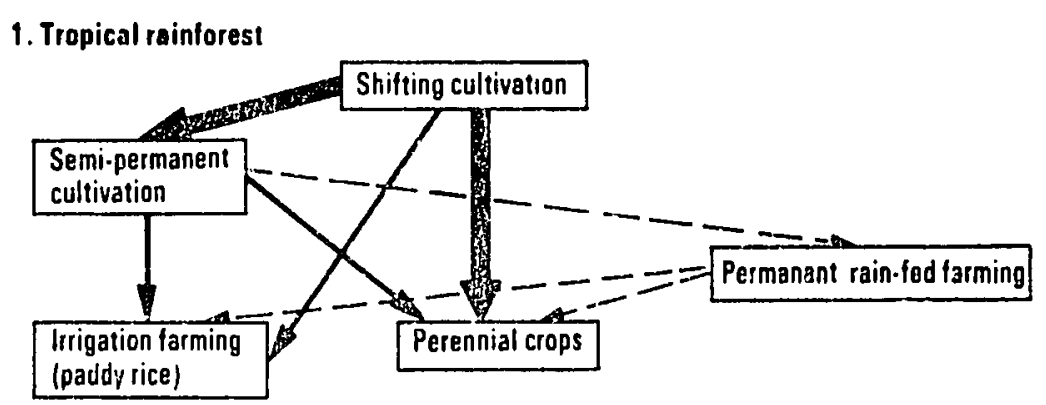

2. Humid Savannas

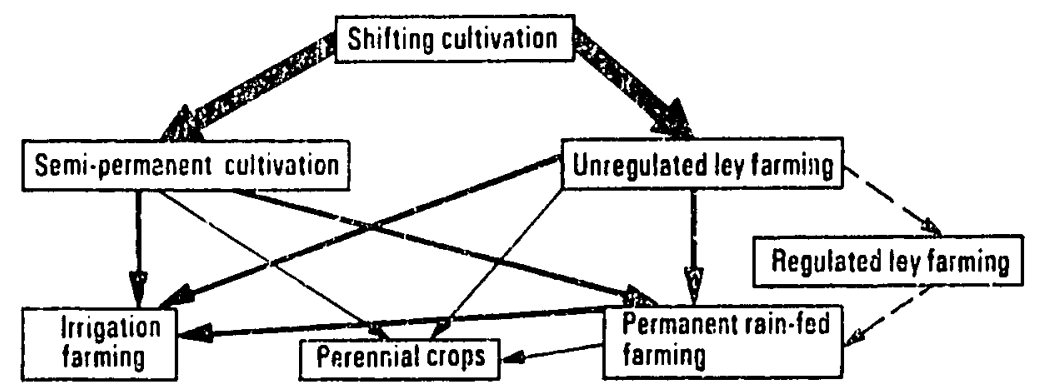

3. Dry sayannas

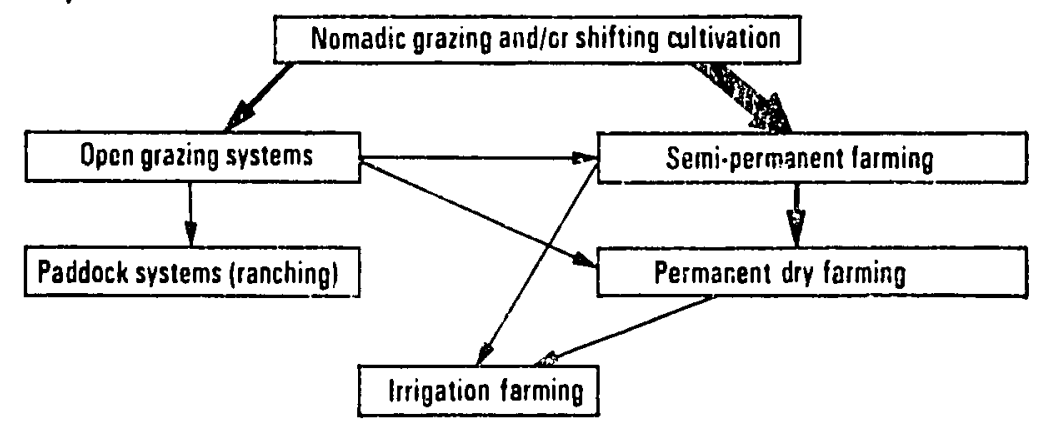

\section{High altitude}

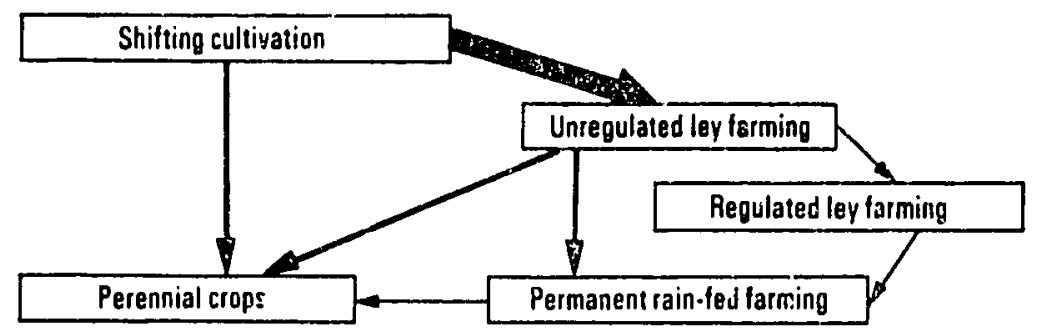

Fio. 10.1. General tendencies in the development of tropical farmilıg systems. These tendencies are valid for indigenous smallholders only. The establishment of large farms and estates is usually connected with the ad hoc adoption of an advanced system of farming. 

via unregulated ley farming to permantent farming, with the planting of
perennial crops wherever feasible.

These tendencies art accompanied by a number of major changes:

(1) from long-fallow to short-fallow systems;

(2) from short-fallow systems to permanent land use;

(3) from low-intensity crops to high-intensity crops;

(4) from natural grazing to cultivated fodder;

(5) from rain-fed farming to irrigation farming;

(6) from arable farming to the planting of perennial crops;

(7) from single cropping to multiple cropping; (8) foom the natural regeneration of soil fertility to intensive systems of
manuring and fertilizing;

(9) from hoe cultivation to animal traction or tractors.

Changes in adopted systems of farming, whether in the form of improvement, or intensification, or changes to another type of agricultural production, occur as the result of chariges in some or all of the constraining features considered above. These change: may arise either within the farm or outside it, and may be caused by new techniciai possibilities (new seed, pest control, irrigation, etc.) or te the resuit of a wide and complex range of social and economic factors. The foilowing are amongst the most important operating
in tropical arcas :oday.

(l) Population density, and the correlated subsistence-food demand, is a vitally important variable causing changes in farm organization. While there are certainly instances where population growth is mainly dependent on agricultural output, output is more often a function of population growth. ${ }^{1}$ It should not be overlooked, however, that this increased production, with pre-machine techniques, usually requires increasing labour inputs
per unit of output.

(2) Technical progress has already drastically changed farming patterns in most tropical countries. Farming systems are likely to be increasingly influenced by innovations and there seems to be no end to them. In contrast with the situation in pre-technical systems, changes of this kind may allow increases in output to arise with decreasing units of input.

(3) Tiie development of urban purchasing power and export markets has proved to be a decisive variable in many places, because changes in price
relations are very important to tropical far Iners.

(4) An important role is also played by changes in human aspirations. There are many firm indications that tropical smallholders change rapidly from target workers to modified target workers and finally to commercial

Boserup (1965). 
farmers who try to maximize income, albeit within the limitation of other objectives, security in particular.

To promote economic development and to mect other objectives, governments in most tropical countries adopt a variety of policy measures designed to modify agricultural production. These changes will be reflected at the farm level in the systems of farming that are followed. Generally these measures are designed to assist or accelerate evolutionary developments of the kind outlined in Fig. 10.1. In some instances, official intervention, through the government policy, is mercly incidental in nature, as in the establishment of proper conditions for orderly marketing. which can lead to difierent levels of adjustment in production on individual farms. However, at the other extreme, government action can take the form of creation and control of all aspects of complete farming situations, as in settlement schemes of different kinds, especialiy irrigation settlements. To consider such policy measures is beyond the scope of this book. Nevertheless, it is important to stress that changes in government policy are very important factors influencing the development and evaluation of farming systems. Every policy measure directed towards agriculture will be reflected in changes in farm production systems. It is hoped that this book, by its analysis of the characteristics, weaknesses, and possibilities of each of the major types of farming in tropical areas, will help to provide a better background to the appreciation of different farming situations and their adjustment through policy actions of different kinds. 


\section{Bibliography}

Adamantids, D. (1956). Monographie pastorale du Ruanda Urundi. Bull. agric. Corgo belge 47, 3585ff.

Aereboe, F. (1919). Allgemeine landwirtschaftliche Betriebslehre. Parey, Berlin.

AGmon, R. (1966). Agricultural training and demonstration project of BoboDioulasso, Upper Volfa, in relation to savanna development, pp. 100-8. Khartoum (Rome, 1967).

AGRAwaL, G. D. (1957). Studies in the economics of farm management in Uttar Pradesh. Government of India Press, New Delhi.

ALKALI, M. M. (1967). Mixed farming in northern Nigeria. Ministry of Agriculture Kaduna.

ALLAN, W., GLUCKMAN, M., et al. (1948). Land holding and land usage among the plateau Tonga of Mzabulke District. Rhodes-Livingstone Papers, no. 14, Cape Town.

- (1949). Studies in African land usage in northern Rhodesia. Rhodes-Livingstone Papers, no. 15, Cape Town.

- (1967). The African husbandman. Oliver and Boyd, London.

ALWAN, A. S. (1968). Socio-economic issues of nomads' settlement in the Western Desert of the U.A.R. Land Reform 1, 28-35.

ANDreaE, B. (1963). Die extensive Weidewirtschaft in den Tropengebieten der Kontinente. Ber. Landw. 41, 11 ff.

- (1964). Betriebsformen in der Landwirtschafi. Ulmer, Stuttgart.

- (1966). Weidewirtschaft im südlichen Afrika. Geogr. Z. 15 (special issue).

ANGLAdetTE, A. (1966). Le riz. Maisonneuve and Larosse, Paris.

ATтEMs, M. (1967). Bauernbetriebe in tropischen Höhenlagen Ostafrikas. (AfrikaStudien, no. 25). IFO Institut, München.

hustralia, Bureau of Agricultural Economics (1961). The coffee industry in PapuaNew Guinea (mimeo). Canberra.

BARKER, R. and JoOTHIPAN, A. (1968). Economic efficiency and profitability of rice farming in the Philippines and Thailand. Fm. Mgmt. Notes Asia Far East 4, no. 1. BARraU, J. (1961). Subsistence agriculture in Polynesia and Micronesia. Honolulu.

BartLET, H. H. (1962). Fire, primitive agriculture and grazing in the tropics. In Man's role in clianging the face of earth, Chicago. pp. 692-720.

Barton, R. F. (1922). Ifugao economy. Am. Archeol. Ethnol. 15, no. 5.

BASAK, K. C. and CHANDA, R. C. (1964). Studies in the economics of farm management in Sambalpur District, Orissa. Government of India Press, New Delhi. 
BAUER, P. T. (1948). The rubber industry. Longmans, Green, London.

BAum, E. (1968). '-and use in the Kilombero Valley. In Smallholder farming and smallholder development in Tanzania (ed. H. Ruthenberg), pp. 23-50. (AfrikaStudien, no. 24). IFO Institut, München.

BECK, R. S. (1963). An economic study of coffee-banana farms in the central Machame area, 1961 (mimeo). Ministry of Agriculture, Dar-es-Salaam.

BECKETT, W. H. (1944). Akokasa-A survey of a Gold Coast village. Monograph on Social Anthropology, no. 10, London School of Economics and Political Science, London. BeINAERT, A. (1941). La technique culturelle sous l'équateur. Bull. Inf. I.N.E.A.C. 4,
I2ff.

Beukering, J. A. van (1952). Types of farming. Carrib. econ. Rev. 4, 140-63.

BinNs, B. O. (1955). Plantations and other centrally operated estates (Food and Agriculture Organization Studies no. 28) Rome.

BLANCKENBURG, P. VON (1963). Rubber farming in Benin area, preliminary report (mimeo). Nigerian Institute of Social and Economic Research, Ibadan.

wirt (1964). Afrikanische Bauernwirtschaft auf dem Wege in eine moderne Landwirtschaft. Z. ausl. Landw., Sonderl. (special issue).

BOSERUP, E. (1965). The conditions of agricultural growth. Aldine, London. BouCHER, L. J. (1967). Surface irrigation (mimeo). Food and Agriculture Organ-
ization, Rome.

BOUCHET, P. (1955). Le secteur expérimental de modernisation agricole des terres neuves (Sénégal). Agron. trop. 10, no. 2, 174-216.

Boutillier, J. L. (1960). Bongouanou, Côte d'luoire. Paris.

vallée Cantuéle, P., Causse, J., Laurent, C., and Doye, H. (1962). La moyenne vallée du Sénégal. Presse Universitaire de France. Paris.

BoYE, P. (1968). Animal husbandry in palm plantations (mimeo). In: Conference on Agricultural Research Priorities for Economic Development in Africa, Abidjan

BRADFIELD, R. (1960). Opportunities for soil scientists in freeing the world from hunger. Proc. 7th Int. Congr. Soil Sci., Madison.

(1968). Farming systems in Africa. Conference on Agricultural Research Priorities for Economic Development in Africa, Abidjan 1968 (mimeo).

Bratton, C. A. and Robertson, L. S. (1954). Farming methods and returns on 126 rice farms in Roxa Isabela, in 1952. Philipp. Agric. 37.

BrémAud, O. and PAGOT, J. (1962). Grazing lands, nomadism and transhumance in the Sahel. Problems of the arid zones. UNESCO, Paris.

Brinkmann, TH. (1922). Die Ökonomik des landwirtschaftlichen Betriebes. In Grundriss der Sozialökonomik, chap. 7, Mohr, pp. 27-124. Tübingen. (1924). Bodennutzungssysteme. In Handwörterbuch der Staatswissenschafien,
vol. 1, Fischer, pp. 959-73. Jena.

BrouWERs, M. (1965). Report to the government of Cameroon on land use and agricultural development of Cameroon. Food and Agriculture Organization, Rome. Brown, D. W. (1960). A reconnaissance study of farming organization in the Kamia Keng food production area (nimeo). University of Malaya, 1960. 
Brown, L. H. (1963). The development of the semi-arid areas of Kenya (mimeo). Ministry of Agriculture, Nairobi.

Buchanan, K. M. and Pugh, J. C. (1958). Land and Feople in Nigeria. University of London Press, London.

Buck, J. L. (1930). Chinese farm economy. Chicago University Press, Cinicago.

Bureau pour le développement de la production agricole (B.D.P.A.) (1967). Techniques rurales en Afrique. Ministère de la Coopération, Paris.

Burle, L. (1961-2). Le Cacaoyer. Maisonneuve, Paris.

BURNETT, J. R. (1954). Crop production. In Agriculture in the Sudan (ed. J. D. Tothill). Oxford University Press, London.

BUTtERWORTH, K. (1964). Profit from beef (mimeo). Rhodesia National Farmers' Union, Salisbury and Lusaka.

BUYs, C. J. and MöLLER, C. A. (1961). Economic surcey of tobacco farming in certain irrigation regions in Transvaal (Department of Agriculture, Bull. 373). Pretoria.

CANTOR, L. M. (1967). A world geography of irrigation. Oliver and Boyd, Edinburgh. CAPOT-ReY, R. (1962). The present state of nomadism in the Sahara. In Problems of the arid zones. UNESCO, Paris.

CARRUTHERS, I. D. (1968). Irrigation development planning; aspects of Pakistan experience. Agricultural Development Studies, Wye College Report 2, chap. 6, London.

Ceylon Department of Census and Statistics (1965). Statistical abstracts. Colombo. Champion, J. (1963). Le bananier. Maisonneuve and Larosse, Chang, Сh. Сн. (1963). Analysis of rice farming methods in Taiwan. Taipei.

Chang, S. K. and LiN, P. C. (1967). Rice cultural practice in Taiwan (mimeo) Taichung District Agricultural Improvement Station, Taiwan.

ChapelLe, J. (1957). Nomades noires du Sahara. Librairie Plon, Paris.

CHEN, СH. S. (1963). Taiwan, an economic and social geography. Taipei.

CHEVALIER, A. (1926). Les principaux systèmes des cultures du globe. Rev. Bot. appl. Agric. Colon. 55, no. 55.

Chia-nan Irrigation Association (h.d.). Standard diagram of rotation irrigation.

ClARK, C. and HASWELL, M. (1964). The economics of subsistence agriculture. McMillan, London.

CLAYTON, E. (1963). Economic planning in peasant agriculture (Kenya). Wye College, Kent.

Clemm, M. von (1964). Agricultural productivity in Mt. Kilimanjaro. Econ. Bot. 18, no. 2, 99-121.

Collinson, M. P. (1962-5). Reports on survey at Bukumbi, Usmao and other locations of Sukumaland, Tanzania (mimeo). Ukiriguru.

ConkLIN, H. C. (1957). Hanunó agriculture. A report on an integral system of shifting cultivation on the Philippines. Food and Agriculture Organization, Rome.

Cook, O. F. (1921). Milpa agriculture, a primitive tropical system. In Smithsonian Report for 1919. Washington.

20-(22 pp.) 
Coster, R. N. (1958). Peasant farming in the Petauke and Katete area of the Eastern Province of northern Rhodesia. Department of Agriculture, Bull. no. 15, Lusaka. Coulibaly, S. (1961). Les paysans Senoufo de Korhogo. Cah. d'outre-mer 14, 27-59. Courtenay, P. P. (1965). Plantation agriculture. Bell and Sons, London.

Cunnison, 1. G. (1954). The Humr and their lard. Sudan Notes Rec. 35, part 2, $50-68$.

Daniel. E. F. (1960). Farm planning and management. Government of India Press, New Delhi.

Davies, W. and Skidmore, C. L. (1966). Tropical pastures. Faber and Faber, London.

Delvert, J. (1962). Le paysan Cambodgien. Joint Publication Research Service, Washington.

Dequin. H. (1964). Die Landwirtschaft Saudisch-Arabiens und ihre Entwicklungsmöglichkeiten. DLG, Frankfurt.

Dion, H. G. (1950). Agriculture in the Altiplano of Bolivia. Food and Agriculture Organization, Rome.

Dittmar, K. (1954). Allgemeine Völkerkunde. Viehweg, Braunschweig.

DRIVER, P. N. and DEASI, D. K. (1957). Stıdies in the economics of farm management in Bombay State. Government of India Press, New Delhi.

DuCkhaM, A. N. and MASEFIELD, G. B. (1970). Farming systems of the world. Chatto and Windus, Londen.

DUFOURNET, R. (1961). Riziculture de la région Tananarive. Bull. Madagascar 11, no. $180,378-86$.

Dumont, R. (1951). Etude de quelques économies agraires au Sénégal et au Casamance. Agron. trop. 6, 229ff.

(1959). Evolution des champagnes Malgaches. Tananarive.

(1966). Types of rural economy. Methuen, London.

Dyson, R. and Hudson, N. (1969). Subsistence herding in Uganda. Scient. Am. 220, no. 2, 76-89.

EDWARDS, D. (1961). An economic study of small-scale farming in Jamaica. University Press, Glasgow.

ENGelbrecht, H. (1930). Die Landbacizonen der $\Sigma_{1}$ de. In $H$. Wagner Gedächtnisschrift. Justus Perthes, Gotha.

Enjalbert, H. (1956). Paysans noirs: les Kabrćs du Nord-Togo. Cah. d'outre-mer 9, no. 34, 137-80.

Evans, L. J. C., Phillips, T. A. and Wadney, A. D. (1961). Cocoa plantations in new areas-cost of establishment and profitability. In Cocoa growing. Cadbury Ltd., Bournville.

Fals-Borda, O. (1955). Peasant society in the Colombian Andes. University of Florida Press, Gainsville.

FARMER, B. H. (1957). Pioneer peasant colonisation in Ceylon. Oxford University Press, London, Toronto, and New York. 
FAUCHER, D. (1949). Géographie agraire. Génin, Paris.

FinNEGAN, R. H. (1965). Survey of the Limba people of northern Sierra Leone. London.

Floyd, B. N. (1960). Changing pattern of Ajrican land use in southern Rhodesia. Dissertation, Syracuse.

Food and Agriculture Organization (1958, 1960). Coffee in Latin America. United Nations, New York.

- (1961). Ministry of Agriculture and Natural Resources, Western Secretariat, Ibadan (mimeo).

- (1963). The farm settlement scheme in the Western Region, Nigeria, appendix 1, 2, no. 1720. Rome.

- (1965). Progress in land reform, fourth report. Rome.

- (1966). Coconut as part of a mixed farming system. Rome.

Forde, D. C. and Scotr, R. (1966). The native economies of Nigeria (ed. M. F. Perham). Faber and Faber, London.

Foreman, W. J. (1959). Farm resource productivity in west Uttar Pradesh. Indian J. Agric. Econ. 14, no. 4, 115-28.

Fox, J. W. and Cumberland, K. B. (1962). Western Samoa. Whitcombe and Tombs, Christchurch, New Zealand.

Frank, CH. S. (1967). The sugar industry in East Africa. East African Publishing House, Nairobi.

FrÉCHOU, H. (1966). L'élevage et le commerce du bétail dans le nord du Cameroun. Cah. O.R.S.T.O.M. 3, no. 2 .

Freeman, J. D. (1955). Iban agriculture. Stationary Office, London.

Fremond, Y. (1968). Coconut-palms selection. Conference on Agricultural Research Priorities for Economic Development in Africa, Abidjan (mimeo), report 8/10.

FRENCH, M. H. (1967). Animal production and savanna areas. Report on Meeting on Savanna Development, Khartoum 25.10-6.11.1966, pp. 153-6. Food and Agriculture Organization, Rome.

FRIEDRICH, K. H. (1968). Coffee-banana holdings at Bukoba. Smallholder farming and smallholder development in Tanzania (ed. H. Ruthenberg), pp. 175-212. (AfrikaStudien, no. 24). IFO Institut, München.

Froelich, J. C., Alexandre, P. and Cornevin, R. (1963). Les populations du Nord-Togo. Presse Universitaire de France, Paris.

Gaidf, M. (1956). Au Tchad les transformations subies par l'agriculture traditionnelle sous l'influence de la culture cotonnières. Agron. Trop. 12, no. 5-6, 597-645.

Galett, R., Baldwin, K. D. and Dina, J. O. (1956). Nigerian cocoa-farmers. Oxford University Press, London.

GeERTz, C. (1963). Agricultural involution. The process of ecological change in Indonesia. University of Califrrnia Press, Los Angeles.

Geortay, G. (1956). Données de çase pour la gestion de paysannats de cultures vivrières en région équatoriale forestière. Bull. Inf. I.N.E.A.C. 5 , no. 4. 
GeRLINGs, J. H. J. (1967). Problems of nomadism. I.T.C.-UNESCO, Centre ior Integrated Survey, Delft.

Giolioli, E. G. (1965). Staff organization and tenant discipline on an irrigated land settlement. E. Afr. agric. For. J. 30, no. 3, 202-5.

Gill, CH. M. Sh. and NAQvi, A. A. (1966). Cost of production of major crops 1961-2 to 1963-4. The Board of Economic Inquiry, West Pakistan, Lahore.

Gill, N. (1963). Report to the government of Nigeria on the farm settlement scheme in the Western Region (mimeo). Food and Agricultural Organization, Rome.

GluCKMAN, M. (1941). Economy of the Central Barotse Plain. Rhodes (Livingstone papers no. 7). Livingstone.

Gourou, P. (1936). Les paysans du delta Tonkinois. Editions d'art et d'histoire, Paris.

(1940). La terre et l'homme on Extrême-Orient. Hartmann, Paris.

(1951a). Indochine, part II: Development of upland areas in the Far East, vol. 1. Instit'ite of Pacific Relations, New York.

$(1951 b)$. The quality of land use of tropical cultivators. Man's role in changing the face of the earth, pp. 336-49. Chicago.

- (1956). Milieu local et colonisation réunionaise. Cah. d'outre-mer 9, 36-57.

(1964). Changes in civilization and their influence on landscape. Impact Sci.

Soc. 14, no. 1 .

- (1966). The trupical world. Longmans, London.

Greenwood, M. (1949). Mixed farming and fertilizers in northern Nigeria. In Proceedings of the First Commonwealth Conference on Tropical and Subtropical Soils.

Harpenden.

GRIST, D. H. (1959). Rlie. Longnans, Lunuon.

Groeneveld, S. (1968). Traditional farming and coconut-cattle schemes in the Tanga region. Ii S:,:allholder jarming and smallholder development in Tanzania (ed. H. Ruthenberg). (Afrika-Studien, no. 24) IFO Irstitut, München.

GUILlARD, J. (1965). Golonpoui, analyse des conditions de inodernisation d'un village du Nord-Cameroun. Mouton, Paris.

Guillebaut, C. W. (1958). An economic survey' of the sisal industry of Tanganyika. Nisbet, London.

Guillemin, R. (1956). Evolution de l'agriculture autochthone dans les savannes de l'Oubangui. Agron. trop. 12, nos. 1, 2, 3.

Guinard, A. (1961). Le système cultural de la région de Man, Côte d'Ivoire. Agron. trop. 16, no. 2, 148-78.

- (1967). Conservation and improvement of soil fertility in Africa, part 2. Wld. Crops 19, no. 6, 29-31.

GUNDERT, H. (1962). Die betriebswirtschaftlichen Verhältnisse in dell südlichen Distrikten von Sildwestafrika. Dissertation, Holenheim.

HaAN, J. H. (1964). Het economisch aspect der erosic. In Stroomgebiedsontwikkeling Tropische Landinrichting (mimeo). Wageningen. 
HADField, J. (1962). Report on the peasant farming survey, 1960-1 (mimeo). Northern Rhodesia.

HAHN, E. (1892). Die Wirtschaftsformen der Erde. Petermanns geogr. Mit!. 38, 8ff. - (1910). Die Brandwirtschaft in der Bodenkultur. Berlin.

HANSEN, S. (1969). An uutline of a rubber programme in Ceylon (nimeo). Rubber Research Institute of Ceylon, Dartonfield.

HARLER, C. R. (1966). Fight thousand pounds of tea from one acre. Investors' Guardian 208, no. 6450.784ff.

Fiarruson, J. E. (n.d.). Dairy management survey (mimeo). Rhodesia National Fármers' Union, Salistury and Lusaka.

HASWELL, M. R. (1953). Economics of agriculture in a savanna village (Garnbia). Colon. Res. Stud. no. 8.

- (1963). The changing pattern of economic activity in a Gambian village (mimeo). London.

HAVILAND, W. E. (1952). Tohacco farm organisation, costs and land use in Southern Rhodesia. Rhodesia agric. J. 49.

- (1954). The economic development of the tobacco industry of Northern Rhodesia. S. Afr. J. Econ. 2z, 130. 4.

HEADY, E. O. and Dillon, J. L. (1961). Agricultural production functions. Iowa State University Press, Ames.

Henskovits, M. J. (1964). The economic life of primitive people. Routledge, New York.

- (1965). The human factor in changing Africa. Alfred A. Knopf, New York.

HEYER, J. U. (1965). An investigation of the limits of peasant agricultural production (mimeo). University College of Nairobi.

(1966). Agricultural development and peasant farming in Kenya. Dissertation University of London.

HICKLING, C. F. (1961). Tropical inland fisheries. Longmans, London.

HuLL, P. (1963). The migrant cocoa farmer of Southern Ghana. University Press, Cambridge.

Ho, R. (1964). Mixed farming and multiple cropr.ing in Malaya. In Land use and mineral deposits in Hong Kong (ed. S. G. Davis). Hong Kong.

- (1967). Farmers of Central Malaya. Australian National University, Canberra. Ho, Tong Peng (1964). I.a plantation d'état Preah Sihanouk à Ratanakiri (Cambodge). Revue gén. Caoutch. 41, no. 9.

Hoy, D. R. (1961). Agricultural land use of Guadaioupe. Natural Resource Council, Washington.

HsieH, S. C. (1966). The effect of improved cropping systems on farm earning capacity in Taiwan. Philipp. Agric. 49, no. 9, 787-98.

HUPPERTz, J. (1951). Viehhaltung und Stallwirtschaft bei den einheimischen Ackerkulturen in Afrika und Asien. Erdkunde 5, no. 1, 36-51.

I.N.E.A.C. (Institut National pour l'Étude Agronomique du Congo Belge) (1958). Normes de main-d'oeuvre pour les travaux agricoles au Congo Belge. 
Iso, E. (1964). Rice and crops in its rotation in subtropical zones. Japan Food and Agriculture Organization Association, Tokyo.

IzIKowItz, K. G. (1951). Hill peasant in Indochina. Göteborgs etnografiska mus., Goteburg.

JAMLEKHA, K. O. (1957). A study of the economics of a rice growing village in Central Thailand. Dissertation, Ann Arbor, Michigan.

Japan Ministry of Agriculture (1960). The economics of farm management survey, 1960. (Japanese.)

J̈̈TzoLD, R. and BaUM, E. (1968). The Kilombero Valley (Afrika-Studien no. 28). IFO Institut, München.

Johnston, B. E. (1963). The staple food economics of western tropical Africa. Stanford University Press, Stanford.

Jones, W. O. (1959). Manioc in Africa. Stanford Unjversity Press, Stanford.

- (1968). Plantation. Int. Encycl. soc. Sci. 2, 154-9.

Joosten, J. H. L. (1962). Wirtschaftliche und agrarpolitische Aspekte tropischer Landbausysteme (mimeo). Institut fuer landwirtschaftliche Betriebslehre, Göttingen.

JoRdan, H. D. (1967). Rice production. In Conference on Agriculture Research Priorities for Economic Development in Africa, Abidjan 1967 (inimco).

JURION, F. and HENRY, J. (1967). De l'agriculture itinérante à l'agriculture intensifiée. I.N.E.A.C. hors sírie. Bruxelles.

KAYSER, B. (1960). Economies et sociétés rurales dons les régions tropicales, books 1 and 2. Centre de documentation universitaire, Paris.

Kenya Coffee Growers Association (1968). Coffee estate expenses (mimeo). Nairobi. KNAPP, R. (1956). Weide-Wirtschaft in Trockengebieten. In Giessener Beiträge zur Entwicklungsforschung, vol. 1. Fischer, Stuttgart.

KROON. A. H. J. DE (1967). Characteristics and development tendencies of permanent arable farming on unirrigated land in the humid tropics with particular emphasis on the uplands in South-east Asia (conference paper). Institut für ausländische Landwirtschaft. Stuttgart-Hohenhein.

KuLs, W. (1963). Bevölkerung, Siedlung und Landwirtschaft im Hochland von Godjam, Nordäthiopien. Frankfurt.

Kulthongkham, S. and ONG, ShaO-ER (1964). Rice economy of Thailand. Bangkok. KUNG, P. (1962). Irrigation farming and multiple cropping in the Ganges-Kobadak project area (Food and Agriculture Organization. report 1456). Rome. 1962.

LACOMBE-OrLAC, M. (1967). Contribution à l'étude de l'emploi du temps du paysan dans la zone arachidière. Hanene-Sénégal (mimeo). Institut de Science Economique Appliquée, Dakar.

LAWSON, R. M. (1966). Change and growth in traditional agriculture in the Lower Volta. In: Studies in rural economic growth (mimeo). University of Ghana.

LEE, S. C. (1967). An economic study of land use in Taoyuan and Shimen reservoir area, 1964. Chung Hsing University, Taichung. 
(1967b). An economic study of land use, Tainan Haien and City, 1966. Chung Hsing University, Taichung.

Lembezat, H. (1961). Les populations du Nord-Cameroun et de l'Adamolia. Presse Universitaire de France, Paris.

LEsHNIK, L. L. (1967). The system of dry-farming in the West Nimar District of Central India. In Jahrbuch des Südasien-Instituts der Universität, Heidelberg 1966. Harrassowitz, Wiesbaden.

LIEBIG, J. voN (1878). Chemische Briefe. 6th edn., Winter'sche Verlagshandlung, Leipzig and Heidelberg.

LIM, Y. (1965). Export industries and pattern of economic growth in Ceylon (microfilm). Dissertation, Michigan.

- (1968). Impact of the tea industry on the growth of the Ceylonese economy (mimeo). University of Hawaii.

LitTle, K. L. (1951). Mende rice farm and its costs (Sierra Leone). Routledge, Bruxelles.

Lock, G. W. (1962). Sisal. Longmans, London.

LORD, R. F. (1963). Economic aspects of mechanized farming at Nachingwea in the Southern Province of Tanganyika. London.

lowndes, A. G. (1956). The sugar industry of Fiji. Angus and Robertson, Sidney. LuCas, P. (1965). Premiers résultats d'enquête obtenus dans le village pilote de Laptinkaha, Côte d'Ivoire. Agron. trop. 20, no. 2, 147-219.

LUDWIG, D. H. (1967). Ukara-Ein Sonderfall tropischer Bodenumtzung im Raum des Victoria-Sees (Afrika-Studien, no. 22). IFO Institut, München.

LUning, H. A. (1961). An agro-economic surtey in Katsina Province (Nigeria). Government Printer, Kaduna.

- (1969). The economic transformation of family rice-farming in Surinum (Agricultural Research Reports no. 718). Wageningen.

MacArthur, J. D. (1964). Some economic studies of African farms in Rift Valley Province, Nandi District, Elgeyo, and West Pakot District (mimeo). Nakuru, Kenya.

- (1966). Some economic aspects of agricultural development in Nyeri District, 1963 (mimeo). Nakutu.

(1969). The economics of perennial crops (mimeo). Institut fuer auslaendische Landwirtschaft, Berlin.

- and ENGLAND, W. T. (1963). A report on alt economic survey of farming in the Molo-Mait-Narok area, 1962/63 (mimeo). Nakuru, Kenya.

McWilliam, M. D. (1957). The African tea industry (mimeo). Nuffield College, Oxford.

- (1959). The Kenya tea industry. E. Afr. Econ. Rev. no. 6.

MaLCoLm, D. W. (1953). Sukumaland, an African people and their country. Oxford University Press, London, New York, and Toronto.

MANSHARD, W. (1961). Die geographische Grundlage der Wirtschaft Ghanas. Steiner, Wiesbaden.

- (1968). Einführung in die Agrargeographie der Tropen. Bibliographisches Institut, Mannheim. 

Martin, A. (1956). The oil-palm economy of the Ibilio farmer. Ibadan University
Press, Ibadan.

MASSFL, B. F. and Johnson, R. W. M. (1968). Economics of smallholder farming in Rhodesiz. Studies in agricultural developinent, vol. 8, suppl. Food, 1968. Research
Institute, Stanford University.

Mathur, P. N. (1963). Studies in the economics of farm management in Madhya Pradesh. Government of India Press, New' Delhi.

Mauritius commission of enquiry (1962). The sugar industry (mimeo). London.

MaY, ST. and PlazA, G. (1958). The United Fruit Company of Latin America. National Planning Association, Washington.

MeLlassoux, C. (1964). Anthropologie économique des Gouro de Côte d'Ivoire. Mouton, Paris. MIIJIR, J. and MAKINNEN, T. (1965). Organisation and operation of three Ethiopian
case farms. Imperial Ethiopian College, Dire Dawa. MLLIKEN, M. (1968). Dairying in Mauritius. Revue agric. sucr. fle Mourice, supple.
47, no. 2.

MIRACLE, M. P. (1964). Traditional agricultural methods in the Congo Basin (mimeo). Ford Pesearch Institute, Stanford University.

Miluat). Agriculture in the Congo Basin. University of Wisconsin Press, Madison, Milwaukee, and London.

Mobeig, P. (1952). Pioniers et planteurs de Sao Paulo. Paris.

MoERMAN, M. (1969). Agricultural change and peasant choice in a Thai village. University of California Press, Berkeley and Los Angeles. Mohr, B. (1969). Reiskultur in Westafrika (Afrika-Studien, no. 44). IFO Institut,
München.

Morel, R. and QuANTiN, P. (1954). Les jachères et la régénération du sol en climat Soudano-Guinéen d'Afrique Central. Agron. trop. no. 2, 105-36.

MoRgan-ReEs, A. M. and Howard, R. H. (1955). An economic survey of African farming among the Sala of the Mumbwa District of Northern Rhodesia. Lusaka.

Mulluss, L. (1960). Production practices, costs and returns for major enterprises on rice fanns in the delta of Mississipi. Bull. Miss. St. Univ. no. 595 .

MurukU, I. K. (1966). The economics of coffee production on smallholdings. Kenya Coff. Lecture at Coffee Extension Seminar, Sept. 1966, Coffee Research
Station, Ruiru.

National Council of Applied Economic Research (1961). Economically weak tea gardens in north-east India. Government of India Press, New Delhi.

Nerting, R. MCC. (1968). Hill farmers of Nigeria. Seattle and London.

Newton, K. (1960). Shifting cultivation and crop rotations in the tropics. Papua New Guin. agric. J. 13, no. 3, 81-118.

NG Kay Fong, Tan Chee Lian, and Wikkramatuleke, R. (1966). Three farmers of Singapore. F'acif. Viewpoint 7, no. 2, 169ff.

Nicolaisen, J. (1963). Ecology and culture of the pastoral Tuareg. National Museum of Copenhagen. 
Nigeria, Northern Region Department of Agriculture (1955). Farming systems in Kano Province. Sols af: . 3, no. 4, 519-23.

NIXDORF, O. (1968). Arbeitsaufwand der Bewirtschaftung einer Kaffeepflanzung in Nord-Paraná, Brasilien. Unpublished.

NoWAK, E. (1954). Land und Volk der Konso. Geogr. Abh. no. 14.

NYE, P. H. and GreENLAND, D. J. (1961). The soil under shiffing cultivation. Commonwealth Agricultural Bureau, Reading.

OLSEN, K. H. (1963). Die geographische Bedingtheit agrarischer Wirtschaftsformen. In: $Z$. ausl. Landw., 2, no. 1, 1-17.

Otremba, E. (1953). Allgemeine Agrar- und Industriegeographie. Frankh, Stuttgart. OWEN, R. voN (1969). Produktionsstruktur und Entwicklungsmöglichkeiten der Rindfleischerzeugung in Südamerika. Dissertation, Göttingen University.

OzAKI, C. (1960). Farm household economic survey in Japan (Agricultural Development Series 13). Tokyc.

Ozbrien, R. (1962-3). An agricultural survey of Phase I of Kushtia Unit, GangesKobadak Project (mimeo). Food and Agriculture Organization, Rome.

PaAuw, D. S. (ed.) (1962). Prospects for East Sumatran plantation industries: a symposium. Yale University.

Pariss, A. van (1957). Rotations de plantes vivrières dans la région de Nioka (Haute-Ituri). Landbouwtijdschr. Belg- Kongo 48, no. 6, 1515-44.

Parsons, D. J. (1960). The system of agriculture practised in Uganda (mimeo). Kawanda Research Station, Kampala.

Pauwels, M. F. (1960). Landhuishoudkundig onde onder?oek bij de Jupaliri. Rijksuniversiteit, Gent.

Pelissier, P. (1966). Les paysans du Sénézal. Imprimerie Fabregue, Saint-Yrieux.

Pelzer, K. J. (1948). Pioneer settlement in the Asiatic tropics. American Geographic Society, New York.

(1957). Agriculture in the hunid tropics. History and outlook of plantation agriculturc in south-east Asia and its ourlook. Pacific Science Conference, Bangkok.

Perham, M. F. (ed.) (1966). The native economies of Nigeria. University of London Press, London.

Petu, D. A. and Upton, M. (1964). An economic study of farming in two villages in Ilorin Emirate, Nigeria (mimeo).

PhiLLIPS, J. (1959). Agriculture and ecology in Africa. Faber and Faber, London.

- (1961). The development of agriculture and forestry in the tropics. Faber and Faber, London.

- (1964). Shifting cultivation. In The ecology of man in the tropical environment (I.U.C.N. no. 4). Morges.

PrgGor, C. J. (1964). Coconut growing. Oxford University Press, London.

PinXten, K. (1954). De Inlands Landbouwbedrijuen in Belgisch-Kongo en RuandaUrundi, vols. 1 and 2. Ministerie van Kolonien, Bruxelles. 
Planning Commission (1962). Study of the problems of minor irrigation. Government of India Press, New Delhi.

Portères, R. (1952). Aménagement de l'économie agricole el rurale au Sénégal. Bambey.

Pössinger. H. (1967). Plantagenbetriebe oder Bauernbetriebe am Beispicl des Sisals in Ostafrika (Afrika-Studien no. 13). IFO Institut, München.

- (1968). Landwirtschaftliche Entwicklung in Angola and Mozambique (AfrikaStudien, no. 31). IFO Institut, München.

Presidents Science Advisory Committce Report (1967). World food problems. The White House, Washington.

Purseglove, J. W. (1946). Land use in the overpopulated areas of Kabale, Kigezi District. Uganda. E. Afr. agric. J. 12, no. 1, 3-10.

ReEs, A. M. (1958). An economic survey of Plateau Tonga improved farmers. Agric. Bull Dep. Agric. North. Rhod. no. 14.

and Howard, R.H. (1955). An economic survey of commercial farming among the Sala of the Mumbwa district of Northern Rhodesia. Agric. Bull. Dep. Agric. North. Rliod. no. 10.

Rhodesia Ministry of Agriculture (1963). Cost of production of flue-cured tirginia tobacco. Salisbury.

- (1964). Beef cattle production costs. Salisbury.

Richards, A. I. (1961). Land, labour and diet in Northern Rhodesia. Oxford University Press, London.

Robertson, L. S. and TABlante, N. B. (1954). Investment and income on 132 coconut farms in Indary, Cavite, in 1952. Philipp. Agric. $3 B$.

ROTENHAN, D. vON (1966). Bodenriutzung und Viehhaltung in Sukumaland, Tansania (Afrika-Studien, no. 11). IFO Institut, München.

_ (1968). Cotton farming in Sukumalard. In Smallholder farming and smallholder development in Tanzania (ed. H. Ruthenberg', pp. 51-86. (Afrika-Studien no. 24). IFO Institut, Müichen.

ROUNCE. N. V. (1949). The agriculture of the cultitation steppe of the Lake, Western and Central Provinces of Tanganyika. Dept. of Agric. Tanganyika, Longmans, Salisbury, 1946.

RUTHENBERG, H. (1963) Ansätze und Hindernisse der weiteren landwirtschaftlichen Entwicklung Madagaskars. Z. ausl. Landu'., Sonderh. 4, no. 1, 18-59.

(1964). Agricultural development in Tanganyika (Afrika-Studien no. 2). (FO Institut, Berlin.

(1965). Probleme des Uberganges vom Wanderfeldbau und semipermanenten Feldbau zum permanenten Regenfeldbau in Afrika südlich der Sahara. Agrarwirtschaft 14, no. 1, 25-32.

(1966). Agricultural production deselopment policy in Kenya (Afrika-Studien, no. 10). IFO Institut, Berlin.

(1967). Organisationsformen der Bodennutzung und Viehhaltung in den Tropen und Subtropen, dargesiellt an ausgewählten Beispielen. In Handbuch der Landwirtschuft und Ernährung in den Entwicklungsländern (ed. P. von Blanckenburg and H.-D. Cremer). Ulmer, Stuttgart. 
(ed.) (1968). Smallholder farming and smallholder development in Tanzania (Afrika-Studien, no. 24). ÏFO Institut, Münchcn.

RUTTAN, V. W. (1965). The economic demand for irrigation acreage, new methodology and snme preliminary projections 1954-1980. John Hopkins Press, Baltimore.

SOOTHIPAN, A., and Venegas, E. C. (1966). Changes in rice growing in the Philippines and Thailand. W/d. Crops 18, no. 1, 18-33.

Samuel, P. (1950). Agriculture équatoriale Bantou et agricuiture Européenne. Bull. agric. Congo Belge 41, no. 3, 579-662.

SATEC: Une opération de développement rural en pays Mossi (Haute-Volta). Agron. trop. 19, no. 7, 579-97.

SAUTTER, C. (1968). Les structures agruires en Afrique tropicale. Centre de Documentation Universitaire, Sorbonne.

SavonNet, C. (1961). Un système de culture perfectionée pratiqué par les BwabaBobo-Oulé de la région de Houndé (Haute-Volta) Etud voltaiq. no. 1, 19-52. SCHÄFER, H. (1963). Tierzucht und Tierhaltung in Steppengebieten. DLG, Frankfurt. Schickele, R. (1931). Die Weidewirtschaft in den Trockengebieten der Erde. Probleme Weltwirt. 53.

Schinkel, H. G. (1970). Haltung, Zucht, und Pflege des Viehs bei den Nomaden Ost- und Nordostafrikas. Akademie Verlag, Beriin.

SCHLIPPE, P. DE (1956). Shiffing cultivation ir Africa. Routledge and Kegan, London. - (1957). Enquête préliminaire du système agricole des Barundi de la région Bututsi. Bull. agric. Congo Belge 48, no. 4, 827-82.

S.E.D.E.S. (Société d'Etudes pour le Développement Economique et Social) République de Côte d'Ivoire (1965). Région de Korhogo, Paris.

S.E.R.E.S.A., République du Dahomey (1959-60): Étude régionale du cercle d'Allada. Cotonou (mimeo).

ShaO-ER ONG (n.d.) Farming systems and suggested changes in the Kushita Unit, Pakistan (mirneo). Food and Agriculture Organization, report no. 55/12/8827.

SHAw, D. J. (1965). Managil--eine Erweiterung des Gezira-Projektes-Beispiel eines Bewässerungsprojektes im Sudan. $Z$. ausl. Landw. Materialsamml. 4, no. 2, 88-128

SHEPHERd, W. O. and BA'Asher, M. M. (1967). Forage resources of the Sudan savanna. Food and Agriculture Organization Meeting on Savanna Detelopment, Khartoum 1966.

Sick, W. D. (1969). Wirtschafısgeographie von Ecuador. Geographisches Institut, Stuttgart.

Simpson, I. G., Yassin, M. M., and Dishoni, S. (1966). Development of agriculture and organisational planning in the main Gezira area. Department of Agriculture, Khartoum.

Sing, A., Singli, G., Athwal, S. S. and Randhawa, N. S. (1957). Studies in the economics of farm management in Punjab, 1954-55. Government of India Press, New Delhi.

SmrTh, R. (1957). A report on Kusasi agriculture. Department of Agriculture, Accra. S.O.D.E.P.A.L.M. (Société pour le Développement et l'Exploitation du Palmier à l'Huilc) (1965). Étude de base, 60000 ha de palmier (manuscript). Abidjan. 
SORDOILLET, R. (1968). Rational water utilization. In: Conference on Agricultural Research Priorities for Economic Development in Africa, Abidjan 1968 (mimeo).

SPENCER, J. E. (1966). Shiffing cultivation in soush-eastern Asia. University of California Press, Berkeley and Los Angeles.

Staner, P. (1955), Les paysannats indigènes du Congo Belge et du Ruanda-Urundi. Bull. agr. Congo Belge 46, no. 3, 468-558.

Sroffils, E. H. J. (1949). Les systèmes de cultures et la fertilité uvi • Bull. agr.
Congo Eelge 40 , no. 2, 1564f. STRENGF, H. voN (1961). Wild coffee in Kaffa province of Ethiopia. Trop. ugric. 38, no. 4, 297--301.

Sultan, M. (1954). Survey of milk production in the Jamaica development circle in 1952-53. Delite Press, New Delhi.

Taiwan Department of Agriculture (1966). Record of farm record-keeping families in Taiwan, 1985. Taipei.

TAKE, CH. A. P. (1963). Socio-cconomic factors affecting the pioductivity of agriculture in Okigwi Division, Eastern Region (minieo). Nigerian Institute of Social and Economic Research, Ibadan.

Tanzania Sisal (1969). Mon. Bull. agric. Econ. Statis. 18, no. 5, pp. 1-8.

TAYLOR, W. CH (1956). The Firestone operations in Liberia. National Planning Association, Washington.

TAX, S. (1963). Pemy capitalism. A Guatemalan Indian economy. University of Chicago Press, Chicago.

TEMPANY, H. and GRIST, H. D. (1958). Tropical agriculture. Longmans, London.

Terra, G. J. A. (1957). Landbouwstelsels en bedrijsstelsels in de tropen. Landbouwk. Tijdschr., 's-Grat. 6, 430-8.

- (1958). Farm systems in south-cast Asia. Neth. J. agric. Sci. 6, no. 3, 157-82. Thailand Ministry of Agriculture (1959). Report on economic survey of rice farmers in Nakom Phatom Province, 1955/56. Bangkok.

THORNTON, D. and ROUNCE, N. V. (1963). Ukara island and the agricultural practices of the Wakara. Tanganyika Notes Rec. no. 1, 25f.

'ThuRnwald, R. (1965). Economics in primitive communiries. Oxford University Press.

Timoshenko, V. P. and Swerling, B. C. (i957). The world's sugar. Stanford University Press.

Tondeur, M. G. (1956). L'agriculture nomade au Congo Belge. Food and Agriculture Organization. Agric. Nomade 1, 15-108.

Tosi, J. A. (1966). Economics and the natural environment (mimeo). Tropical Science Centre, San Josć.

Toukre, K., Gaudefroy-Demombynes, P. and Fauche, J. (1954). Perfectionnement des techniques culturales au Sénégal. Anns Centre Réch. agron. Bambey Sènégal.

TRAPNELl, C. G. and COETHER, J. N. (1957). The soils, vegetations and agriculturul systems of north-western Rhodesia. Government Printer, Lusaka.

TrIPPNer, J. (1955). Ackerdüngung in der Provinz Ching-hai, China. Anthropos, 50. 
TULIPPE, O. and WILmET, J. (1964). Géographie de l'agriculture en Afrique Centrale. Essai de synthese. Bull. Soc. belge Étud. géogr. 33, no. 1.

UPToN, M. (1966). Tree crops: a long-term investment. J. agric. Econ. 17, no. 1, 82-90.

(1967). Agriculture in south western Nigeria. Univ. Reading Dev. Stud. no. 3. URQuardT, D. H. (1961). Cocoa. Longmans, London.

Versluys, J. D. N. (1953-4). The Gezira scheme in the Sudan and the Russian Kolkhoz: a comparison of two experiments. Econ. Dev. cult. Change, 2, no. 1, 32-59, no. $2,120-35$, no. 3, 216-35.

VINK, G. J. (1951). De grondslagen van het indonesische Landbouwbedrijf. Venmann and Zonen, Wageningen.

Wagner, G (1956). The Bantu of North Kavirondo. Vol. 2. Oxford University Press, London.

WAIBF, L. (1933), Probleme der Iandwirtschaftsgeographie. Hirth, Breslau.

VIEBSTER, C. C. and WiLson, P. N. (1967). Agriculture in the tropics. Longmans, London.

West Bengal Government (1968). Study in farm management and costs of production of crops, vol. 5. Calcutta.

WestGaRth, D. R. and NARAYANA, R. (1964). The effect of rubber price and yield per acre on estate production costs. J. Rubb. Re's. Inst. Malaya 18.

WHITE, C. M. N. (1959). A preliminary survey of Luvale rural economy. Manchester. WHITE, H. D. (1963). Economics of beef ranching in Kenya (mimeo). Department of Agriculture. Nakuru.

Whrte, St. (1941). Agricultural economy of the hill pagans of Dikwa Emirate, Camerouns. Emp. J. exp. agric. 9, no. 3.

Whyte, R. O. (1967). Milk production in developing countries. Faber and Faber, London.

Wickizer, V. D. (1951). Coffee, tea and cocoa. Stanford University Press.

WILDE, J. C. DE (1967). Experiences with agricultural development in tropical Africa, vols. 1 and 2. Johns Hopkins Press, Baltimore.

WILDe, L. DE (1963). Uber die Ackerkultur der Tutshokwe. Z. ausl. Landw., 2, no. 3, 112-16.

WILLS, J. B. (1962). The general pattern of land use. In Agriculture and land use in Ghana, pp. 201-25. Oxford University Press, London, Accra, New York.

WILMET, J. (1963). Systèmes agraires et techniques agricoles au Katanga. Mem. Acad. $R$. Sci. d'outre-mer 14, no. 5.

WILson, T. B. (1958). The West Johore coconut production survey (Department of Agriculture, Bull. no. 104). Kuala Lumpur.

WINTER, E. H. (1955). Bwamba economy. East African Institute of Social Research, Kampala.

WrtTfOGeL, K. (1931). Wirtschaft und Gesellschaft Chinas. Hirschfeld, Leipzig.

WoermanN, E. (1959). Landwirtschaftliche Betriebssysteme. Handw. Sozialwiss. 6, 477ff. 
Wohltmann, F. (1892). Die natïrlichen Faktoren der tropischen Agrikultur. Dunker and Humblot, Leipzig.

WonG, C. T. (1968). Enlarging the size of farm business through intensive land use in Hong Kong. Fm. Mgmt. Notes Asia Far East 4, no. 2.

Wood, G. A. R. (1963). Costs of cacao production. Cocoa growing Cadbury Lid. pp. 36-50.

Wörz J. G. G. (1966). Genossenschaftliche und parmerschaftliche Produktionsförderung in der sudanischen Landwirtschaft. DLG, Frankfurt.

WRIGHT, S. J. (1953). Report on the possibility of mechanising tea cultivation in Ceylon. Tea. 24, 59f.

Young, J. E. DE (1958). Village life in modern Thailand. University of California Press, Berkeley and Los Angeles.

Yu-CHu Hsu (1962). A case study of a farm at Ching-Shui, Taichung, Taiwan. The Republic of China, 1960. The Council on Economic and Cultural Affairs, Inc., New York.

Yudelman, M. (1964). Africans on the land. Economic problems of African agricultural development in Southern, Central and East Africa, with special reference to Southern Rhodesia. Harvard University Press, Cambridge, Massachusetts.

ZaChaRIAS, C. W. B. (1957). Studies in the economics of farm management in Madras (1954-55). Government of India Press, New Delhi.

ZEVEN, A. C. (1967). The semi-wild oil-palm and its industry in Africa. (Agricultural Research Report 689). Wageningen. 


\title{
Index
}

\author{
Adamawa, 103 \\ Aereboe, F., 2 \\ Africa, 109, 115, 166, 167, 177, 181, 182 , \\ 220,268 \\ Central, 19, 25 \\ East, 48, 60, 62, 85, 100, 127, 130, 137, \\ $194,212,220,222,230,242,252,260$. \\ $262,271,277,281$ \\ South, 207, 209, 252, 271 \\ South-west, 264, 271, 274, 276 \\ south of the Sahara, $60,82,142$ \\ West, $2,18,36,48,59,60,85,128,137,190$. \\ $193,195,215,222,232,240,260,262$ \\ Agrawal, G. D., 158,160 \\ Alade, 233 \\ Algeria, 256 \\ Alkali, M. M., 96, 127 \\ Allada, Cercle d', 239, 241 \\ Allan, W., 19, 25, 35, 66, 260 \\ alpacas, 59 \\ Alwan, A. S., 257 \\ Amazon Basin, 137 \\ America, \\ Central, 22, 85, 195, 206, 214 \\ Latin, 3, 36, 47, 54, 59, $113,130,131,138$. \\ 193, 205, 214, 215, 220, 222, 225.226. \\ $252,271,277$ \\ South, $85,195,254$ \\ Andes, 86, 100 \\ Andreae, B., 171, 273 \\ Andrha Pradesh, 157, 158 \\ Angladette, A., 152 \\ Angola, 55, 56, 66, 85, 193 \\ animal, \\ density, 253, 262, 264, 274 \\ draught, $66,70,97,110,113,122,123$. \\ $157,162,163,188$ \\ economy, 88, 262 \\ husbandry, 36, 67, 85, 88, 96, 97, 110, 127, \\ 154. 164, 188, 224 \\ mount, 254 \\ pack, 254 \\ power, 133, 155 \\ traction, 111, 113,114 \\ Ankole, \\ cattle, 262 \\ ranching sclieme, 268 \\ Apure, 279 \\ Arabia, 133, 254 \\ Arabs, 44 \\ Arcot District, South, 152 \\ Argentina, 271, 274, 277 \\ Asia, 101, 167, 195 \\ South, 101 \\ South-east, 130, 13!, 136, 138, 142, 163. \\ 166,182 \\ Assam, 17, 228, 230 \\ Australia, 86, 88, 207, 210, 252, 271 \\ 274 \\ Northern, 166 \\ avocado, 228 \\ Bahima, 262, 263 \\ Bahaya, 215, 218 \\ Baku, 84 \\ Bailundu, 55, 56 \\ Baldwin, K. D., 233, 234 \\ bamboo, 46 \\ Bamum, 103 \\ Bana, 103 \\ banana, 42, 43, 61, 105, 131, 161, 163, 189, \\ $192,197,198,208,214,215,217,223$, \\ $227,233,243,247$ \\ dwarf, 213 \\ ensete, 213 \\ groves, 117, 131, 206 \\ Barbados, 207 \\ Bari, 103 \\ Baringo District, 265 \\ Barker, R., IS8 \\ barley, $(7,93,138$ \\ Barrau, J., 202 \\ Batta, 103 \\ Bauchi, 102 \\ Baule, 102 \\ Baum, E., 20, 24, 39, 40, 57, 58, 74 \\ beans, 100, 105, 107, 117, 121, 143, 190, 191, \\ $192,195,215,224,225,234$ \\ soya, 146 \\ spring, 165 \\ Beck, R. S., 223, 224 \\ beef production, 194, 271, 276, 278 \\ Beinaert. A., 33 \\ Belgian Colonial Government, 49, 53 \\ Bemba, 32, 35, 43
}


304

Bengal, 169

East, $169,172,173$

West, 169, 171, 173

Bengawan, 187

Berron, 102

berseem, 162, 163

bilharzia, 14

Binafo, 187

Blanckenburg, P.v., 196, 205

Bobo, 102

Bolivia, 59

Bombay, 116, 160, 16!, 162 .

Deccan, 117, 121, 123

Boran cattle, 277

Borneo, 37, 40

Boserup, E., 115, 285

Boucher, L. J., 137

Bradfield, R., 9, 147, 187

Brazil, 36, 54, 86, 193, 194, 195, 198, 207, $210,212,221,223,225,226,227,228$, 232,278

southern, 189, 196, 198, 205, 220, 224, 225

bride-price, 262

Brinkmann, Th., 2, 55

Brouwers, M., 35, 52

Brown, L. H., 255, 264, 265

Buck, J. L., 153, 154, 155

Budde, L., 160

buffalo, 154, 161, 175

Bukoba, 198, 215, 216, 217, 219

Bureau pour le Développement de la Production agricole (B.D.P.A.), 71, 156

Burma, 48, 173

burning, 22, 47, 260, 277

Burundi, 59, 103

bush control, 270

bush fire, 260

regeneration, 67

cabbage, 107, 138, 165, 175

cacao, 190, 192, 197, 198, 200, 203, 204, 206, $214,232,235$

calabashes, 234

Calcutta, 173

Calopogonium, 53

calving interval, 68, 97, 217, 261

camel, 253, 254, 256, 257

Cameroon, 103, $111,112,114,115,116,235$, 240

Candy, 239

Cantor, L. M., 134

Capot-Rey, R., 255

Carruthers, I. D., 141, 176, 185

carts, 110,113

cashew, 243

\section{NDEX}

catena; $60,62,105,106,144$

cattle, 59, 67, 80, 85, 91, 95, 112, 118, 212 . $221,224,225,231, .260,271,275$, 277

dairy, 85,129

economy, 67, 68, 94, 218

grade, $88,95,250$

grazing, 55, 91, 260, 271

hoarding, 110, 261

keeping, 263, 265

N'dama, 80

Zebu, 117, 128, 250, 277

Centrosema pubescens, 203

Ceylon, 4, 54, 101, 136, 137, 166, 193, 194, $198,206,228,229,230,232,234,235$, $236,237,238,239,240,242,243$

Rubber Research Institute, 200

Chamba, 102

Champion, J., 208

Chang, Ch. Ch., 156

Chapelle, J., 256

Chen, Ch. S., 148

Chia-Nan Irrigation Association, 146

Chigara, 106

China, 104, 119, 135, 154, 155, 163

chitcmene system, 23, 35

clearing

land, 22, 37, 41, 89, 119

mechanical, 200

techniques, 22

cloves, 197

clover

grass mixtures, 87, 88, 162

coconut, 197, 232, 238, 239, 240, 242, 243 groves, 75

palms, 142, 143, 190, 191, 192, 194, 203 243

coffee, 131, 135, 189, 190, 191, 192, 196, 197 , $198,203,204,205,215,217,221,222$, $224,226,227,228,231,234,237,240$, 250,251

arabica, 219

estate, $221,222,229$

grower, 85

growing techniques, 228

production, 219, 225

robuste, 215, 222, 241

sitios, 225

cola tree, 233

collecting, 2

Colombia, 59, 195, 226, 227, 279

Colombo, 240

Colonial Belgian Administration, 49

Colonial Governments, 44

commercialization, 5,34

communal work, 81, 181

compost, 34, 109, 122, 164, 228 


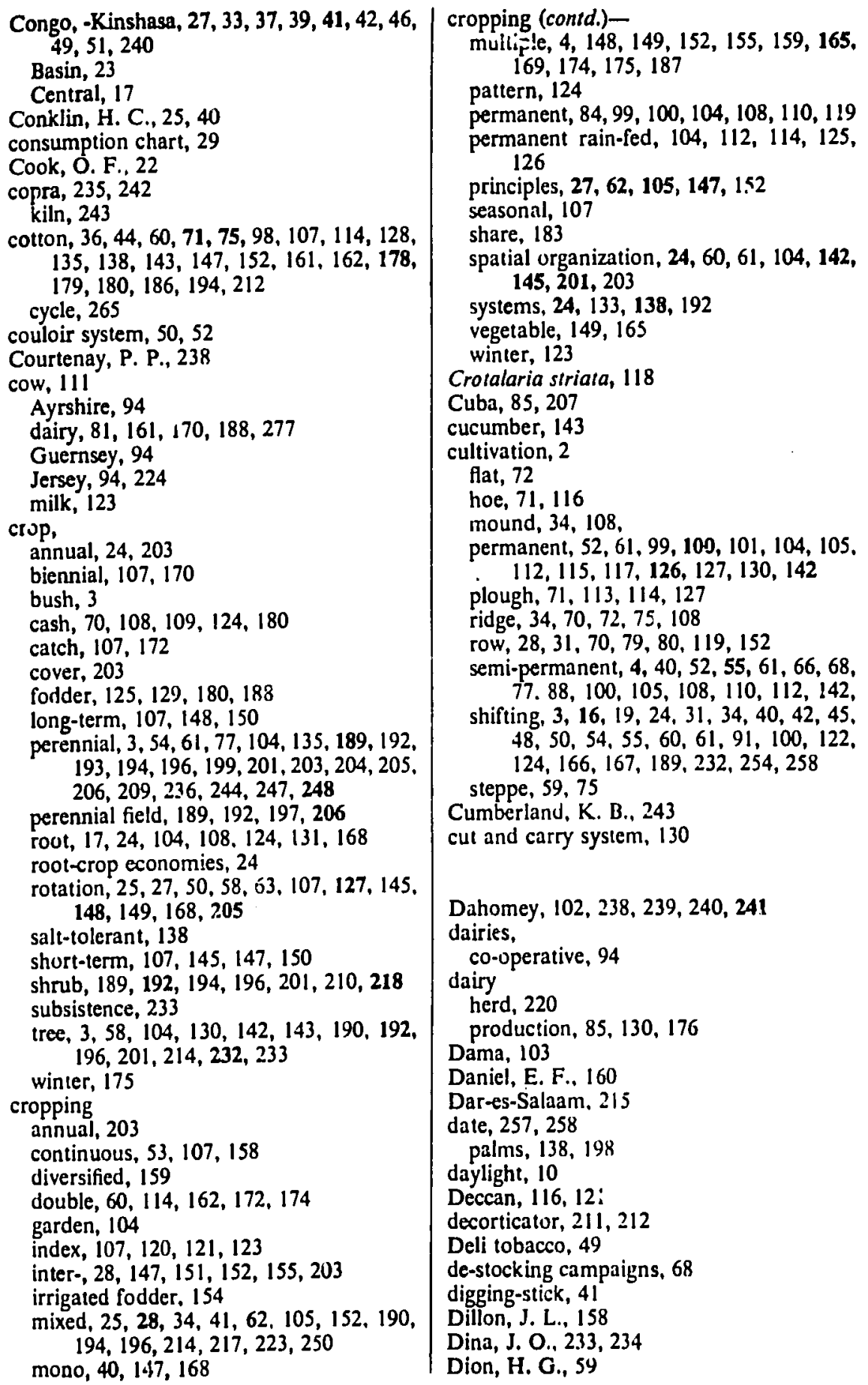


306

Dipping, 68, 94, 270

Dittmar, K., 5

Dogon, 102

drainage, 138, 181, 182

Driver, P. N., 123

dromedary, 257

Duckham, A. N., 282

ducks, 154

Dumont, R., 27, 50, 53, 60, 66, 109, 121

dung-land, 61

dung for fuel, 254

Dyson, R., 255, 256, 261

Egypt, 257

Eleusine, 38

El Salyador, 193, 206, 226, 227, 228

England, W.T., 85, 93

Ensete edula Horan, 213

Equador, 59

erosion, 10, 65, 88, 182, 194, 213

control, 104, 108, 265

estate, 193, 208, 222, 226, 232, 235, 236, 237, 244,247

banana, 189, 193, 208, 214

cacao, 232, 235

coconut, 193, 206, 235, 242

coffee, 193, 194, 205, 220, 229, 240, 247

nucleus, 241, 251

oil-palm, 193, 235, 240

production, 210, 237, 248

rubber, 193, 234, 235, 236, 237

sisal, 189, 193, 194, 201, 208, 211

sugar-cane, 193, 201, 206, 207, 208

tea, 193, 229, 231, 236, 240

Ethiopia, 59, 66, 84, 87, 100, 103, 109, 190, 213,222

evolution, 48, 79, 124

expansion areas, 124

exploitation system, 138, 193

Faidherbia albida, 62, 111, 121, 128

fallow,

block, 65

bush, 206

grass, 20, 59

half-year's, 63

long rest, 65

period, $46,65,117,119,145$

seasonal, 111

systems, $2,16,20,25,31,34,55,56,59$, $63,65,83,108,115$

tumble-down, 27, 41

Fals-Borda, O., 59

\section{INDE Y}

farm, 6

Chinese, 117

large-farm areas, 84,85

management, 74, 116, 132

Taiwanese, 176

farming,

contract, 210

dry, 4,55

hoe, 4

irrigation, 4, 54, 59, 99, 131, 132, 133 , $136,139,142,150,152,160,172,177$, 178

large-scale, $85,88,178$

ley, $53,75,83,92,95,110$

permanent, 4, 58, 79, 89, 99, 101, 104, $105,107,110,118,122,124,130,131$, 139,250

semi-permanent, $4,16,22,51,55,57,58$, $61,67,73,74,99,105,119,124,250$

stationary, 3, 190

subsistence, $5,73,234$

system, $2,7,124,142,164,189,223,234$, 250,282

tobacce, 85,163

farmstead,

earth, 109

farmyard, 105

Faucher, D., 3, 4, 55

iencing, 89, 104, 273, 274, 280

fertilizer, 104, 105, 107, 108, 109, 118, 165 , 168

economy, 31, 34, 65, 87, 100, 108, 110 , 152,176

mineral, 36, 53, 67, 80, 81, 97, 98, 119 , $118,128,152,162,164,173,180,196$, 232,250

fertility,

soil, $31,33,45,81,100,110,234$

Fezzan, 256

tield,

system, 3, 99

Fiji, 207, 210

Fipa, 103

fish, 109,163

production, 154

flax, 149

Florida, 207

fodder, $154.170,178$

arable, 89,111

bushes, 199

economy, 111

grass, 118

production, 101

tree, 62

folding systems, $34,59,66,88,108,121$

food

subsistence 119,215 


\section{INDEX}

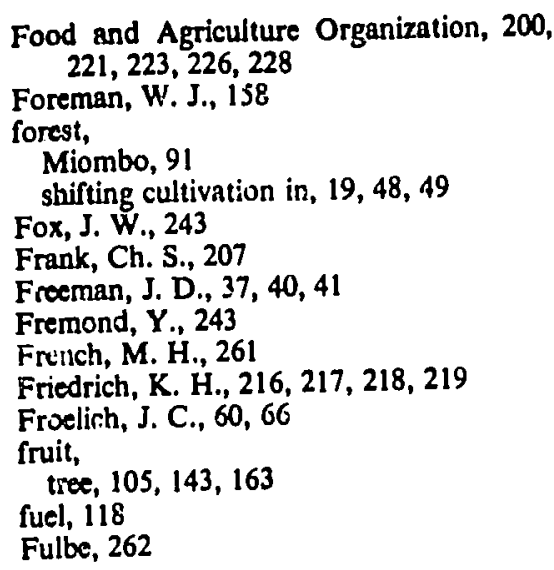

Galetti, R., 233, 234

Gambia, 70, 143

Ganges Delta, 169

garden,

kitchen, 117

permanent, 61, 77, 104, 112, 142

gazelle, 257

Geertz, C., 31, 46, 49, 101, 124, 157, 167

Gezira, 136, 154, 160, 180

Board, 178, 181

scheme, 178, 179, 183, 186, 259

Ghana, 17, 34, 102, 195, 234

Giglioli, E. G., 177

goat, $118,120,123,125,224,253,254,257$

Gogo, 103

Golonpoui, 111, 112, 115, 116

gourd, 165, 234

Gourou, P., 115

grass,

elephant, $18,58,75,87,94,188$

Guatemala, 188

Imperata, 17, 46, 206

Kikuyu, 87, 94

natural grass regeneration, 87

Rhodes, 94

tropical, 129, 130

grassland,

irrigated, 188

tumble-down, 97

utilization, 5, 97, 106, 267

grazing, $60,112,118,203,250$

bush, 112

committie, 268

communal, 67, 77, 83, 88, 267

fallow, 67, 169, 172

guards, 268

night, 86, 88, 260

permanent, 121 grazing, (contd.)-

rights, 81, 269

rotational, 78, 87, 89, 97, 270, 272, 277

schemes, 268

systems, 129, 130, 252, 273

zero, 127, 129, 130, 250

Greenland, D. I., 3, 4, 18, 23, 33

Grocneveld, S., 190, 191, 266

groundnut, $44,70,98,101,118,119,120$,

$121,123,138,143,152,160,161,191$, $192,194,232,234$

Guatemala, 17, 33, 37

Guernsey, 93, 94

Guillard, J., 111, 112, 115, 116

Guillebaud, C. W., 211

Guillemin, R., 47

Guinard, A., 127, 128

Guinea, 102

Gundert, H., 275

gum arabic, 2

Gurensi, 102

Guyana, 155, 207

Hanunóo, 25

hand drill machine, 122

Hiansen, S., 237

Haribes, 275

Haswell, M. R., 70

Haviland, W. E., 90

Hawaii, 207, 209

hay,

making, 87, 272, 274

Heady, E. O., 158

Henry, J., 43

herbicides, 97, 99, 175

herding,

subsistence, 253

berdsmen, 260,261

semi-nomadic, 62, 154

Herskovits, M. J., 7

Heyer, J. U., 78

Hickling, C. F., 154

high-altitude areas,

tropical, 88, 89, 95

Himachal Pradesh, 60

Ho, R., 144

Hodeida, 139

hoe system, 24, 56, 71, 72, 89

holding,

banana, 195, 213

banana-coffec, 215, 216, 219, 223

Burmese rice, 136

cacao, 195, 232

cashew, 195

Chinese type of, 154, 157

coconut-palm, 195, 239, 242 
holding, (contd.)-

coffee, 194, 195, 219

colton, 59, 72, 74, 78, 136,

groundnut, 70

groundnut-millet, 59, 72, 119, 120, 160, 161,165

irrigation, 157, 188

large, large-scale, 91,196

inaize-millet, 117, 120

milk-maize, 92

millet, 118

millet-wheat, 121, 123

nil-palm, 195, 239, 240, 241

rice, $73,142,147,159,168,169,170,173$, 174

rice-jute, $169,172,173$

rubber, 195, 234, 239, 240

semi-commercialized, 196

sisal, 195, 210

small, 6, 78, 84, 91, 92, 94, 96, 179, 196, 227

sugar-cane, 162, 206

tea, 228

tobacco, 90

vanilla, 195

wheat-cotton, 162

Honduras, 214

British, 33

Hong Kong, 164, 165

Hopeh Province, 155

housing,

stationary, 57, 77, 99, 105, 108, 110

Hudson, N., 255, 256, 261

hunting, 257, 274

Jbadan, 234

Itban, 40, 41

implements, 4

India, 9, 48, 59, 101, 113, 114. 116, 122, 123 , $128,135,138,142,152,154,157,160$, $161,162,165,166,173,193,195,207$, 213, 230

Indian Constitution, 122

Indonesia, 54, 59, 193, 207, 242

I.N.E.A.C. (Institut National pour l'Étude Aggronomique du Congo Belge), 37

infillings, 190, 206

Inselberg, 05,106

intercropping, 25, 28, 152. 242, 243, 245

interculture, 28, 191, 205, 249

interplanting, 28, 107, 231

involution, 48,79

Iraq, 133

Iraque, 103

Irrigation, 82, 100, 101, 103, 105, 122, 132, $136,137,141,159,160,161,173,184,188$ irrigation $_{8}$ (contd.) -

administration, 139

artificial, 132

basin, 133, 135, 186

controlled, 181

furrow, 133, 135, 179, 186

intermittent, 185

large-scale, 135, 176, 182

large-scheme, 177

method, 133, 138

minor, 138, 142, 176, 182, 184

practices, 182

rotational, 138, 145, 146, 148, 162

schemes, 176, 177

seasonal, 130, 136

shifting system of, 145

sprinkler, 133, 135, 138, 209, 214

summer, 149

supplementary, 136

surface, 134

system, 132, 137, 155, 188

Iso, E., 151

Israel, 154

Ivory Coast, 18, 102, 128, 191, 192, 195, 200, $208,215,240,241,243,251$

\section{Jamaica, 207}

Japan, 154, 155, 156, 169, 170, 171, 174, 175, $181,184,187,229,230$

Java, 101, 104, !33, 136, 154, 167, 173, 210 , 229

Joosten, J. H. L., 3

Jordan, H. D., 168

Jumeisha farm, 139

Jurion, F., 43

jute, 149, 170, 172

Kaduwela, 239

Kakamega District, 117, 118, 120

Kamuku, 102

Kano Plains, 84, 102

Kanuri, 102

Kaolack, 71

Karakul ranch, 274

h.avirondo, 206

Kenya, 3, 59, 78, 84, 85, 87, 88, 89, 92, 94 , $95,103,105,113,117,120,131,177$, $193,195,206,213,220,222,225,226$, $228,229,247,250,251,253,260,264$, $265,275,276,277$

Kenya Coffee Growers Association, 229

Keyu, 103

kharif, 113, 161, 162,

season, 114, 122

Kiberege Strip, 39, 75 
Kiga, 103

Kinga, 103

Kikuyu, 103, 105, 112, 131, 250

Kilimanjaro, Mt., 223, 225

Kilombero Valley, 20, 21, 39, 40, 57, 58, 73, 74

Kipsigi, 103

Kisii District, 112

Kita, 102

Konso, 103

Kroon, A. H. J., de, 48

Kulthongkham, S., 159

Kung, P., 171

Kuru, 103

Kwimba, 68, 72, 125, 126

labour,

capacity, 78, 125

division of, 39,70

economy, 36, 69, 78, 89, 112, 155, 154

efficiency of, 78, 244

input, 39, 40,71, 109, 119, 156, 159, 200, 226,231

marginal returns of, $125,157,158$

productivity of, 13, 126

requirements, 107, 108

seasonality of, 72, 115

Lacombe-Orlhac, M., 72

lactation period, 255

Lahore, 161

Lake Victoria, 75, 101, 105, 118, 120, 125, 198

land,

consolidation, 81,127

development, 124

ownership, 84

preparation, 114, 116, 141

reform, 141, 184

rights, 110,127

tenure, 96,141

latex, 237

leaching, 185

legumes, 108, 169, 172

fodder, 178,180

grain, 123

pasture, 96

Leguminosae, 105, 106, 170

Leshnik, L. L., 113

lettuce, 35

lcy.

establishment, 87

imp . . . ment, 97

intensity of, 87

management, 86, 87

short-term, 81

ley, (contd.)-

system, 2, 59, 60, 67, 79, 80, 81, 83, 84, 85 $86,87,88,89,91,92,95,97,98,99$

Liberia, 193 $100,108,125$

Liebig, Justus v., 153

Lim, Y., 230, 242

livestock, 165, 175, 221, 256, 260, 271

eronomy, 77, 125

density, 112, 125, 264, 265

property, 69, 262

rearing, 62

llamas, 59

Llanos, Eastern, Western, 279

Lock, G. W., 211, 212

Lorenz curve, 262

Losso, 102

Louisiana, 207

Luanda, 66

lubia, 180,186

lucerne, 83, 138, 162

Ludwig, D. H., 76, 103, 106, 121

MacArthur, J. D., 8, 85, 93, 197, 201, 204 247

Machakos District, 78

Machame, 223

Madagascar, 4, 54, 59, 66, 116, 130, 136, $142,147,154,155,156,166,190,193$, $195,252,260,277$

Madras, 9, 152, 155, 156, 161, 163, 172

Maghreb, 154

Maize, $17,24,43,60,62,71,75,94,98,100$. $105,107,108,117,118,121,124,143$, $149,161,162,190,191,192,194,196$, $212,215,224,233,234,250$

malaria, 141

Malaysia, 33, 193, 195, 234, 235, 237. 238, $240,242,251$

Mali, 102, 109

Malinke, 102

Makonde, 103

Malthusian process, 100, 117

Mamprusi, 102

Managil Extension, 179,

Mandara, 102

Mandji, 103

mango, $62,75,243$

Manhaua, 29

manioc, $17,24,43,44,60,103,104,105$, $107,108,116,118,120,124,150,190$ 191, 192, 196, 23? 7.34

Manshard, W., 1, 34

manure, 110, 122, 152, 224

animal, 67, 103, 109, 128, 153, 175, 218 
manure, (contd.) green, 34, 66, 91, 104, 118, 127, 128, 146, leaf, 118 $149,148,151,175$

pig, 164, 232

stable, 176

manuring

practices, 153

market gard sining,

Chinese sysiem of, 163

Masai, 260, 265, 269

Masefield, G. B., 282

Matengo, 103

matrimony vine, 165

Mauritius, 206, 207, 208, 210

May, St., 214

Mbuga, 76

Mbugu, 103

McWilliam, M. D., 228

meat, 110. 254

production, 154, 264

mechanization, 155, 186

Meillassoux, C., 191, 192

melon, 234

water, 149

or iental pickling, 151

Meru, 103

Mexico, 207

Mexican Highlands, 100

migration, horizontal, vertical, 254

Milfor, 187

milk, i 10, 122, 224, 254

production, $84,154,217,231$,

millet, 17, 24, 41, 62, 71, 100, 106, 108, 116, $119,122,123,124,143,160,161,172$. 196,258

bulrush, 118

finger, $35,43,117,152,161,163$

pearl, $160,161,163$

Milpa agriculture, 22, 37

Mimosa pudica, 243

Mindoro, 25

Miombn. 91

Miracle, M. P., 20, 22, 23, 26, 32, 35, 59

Mohr, B., 143

Molo-Mau-Narok, 92

monoculture, 194, 203, 209, 214, 222

Mozambique, 29, 85, 195

mulch, 215

Mullins, L., 1.56

Multar, 161

Mundang, 103

Musgu, 103

mustard,

leaf, 165

Mwea-Tebere, 177

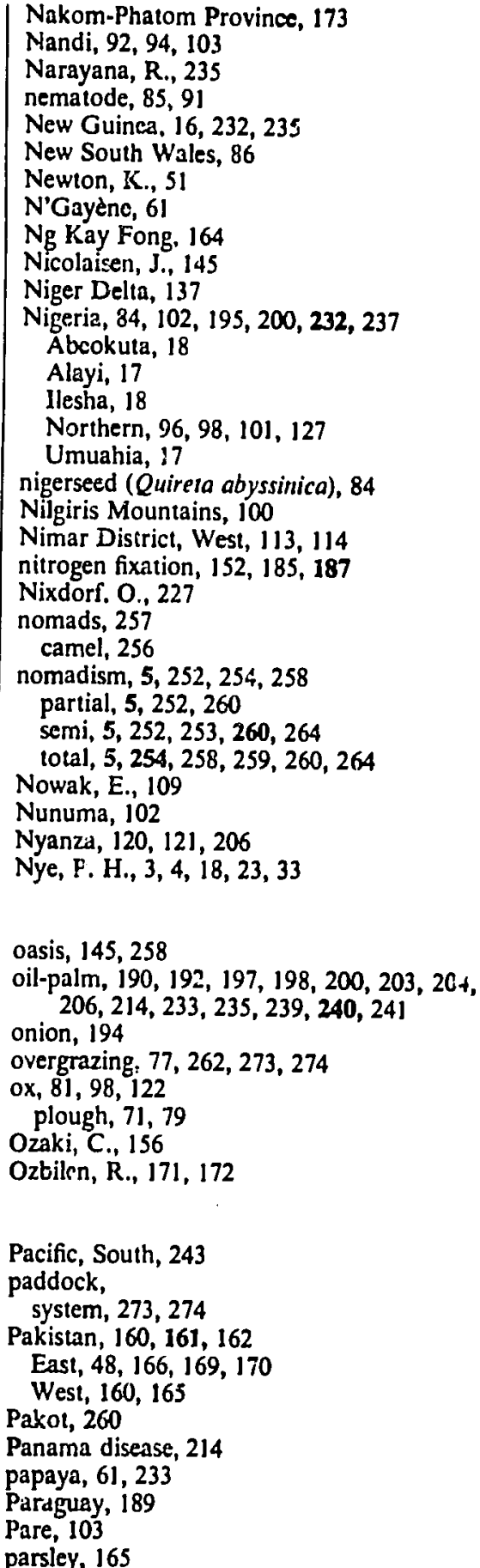




\section{INDEX}

ire, 106, 257, 274

mmunal, 62, 118, 261

igated, 184

srmanent, 98, 128, 130

iannat, 49,51

. 105, 117, 190, 191

hick, 123, 160, 161, 162

igeon, 105

inut, 146

issier, P., 60, 6I, 66

Izer, K. J., 130

ne Niolo, 27

pper, 234

:ru, 59, 207

:sticides, 175, 178

eta, 187 hilippines, 9, 17, 25, 40, 147, 157, 158, 167,
$193,195,242$

hysiognomy,

two-storey, 202

multi-storey, 202, 203

piètinage, 156

pig, 164, 165, 170

Piggot, C. J., 243

pineapple, 189, 192, 204, 243, 250

Pinxten, K., 42, 50

pit system, 34

plantain, 215, 224, 264

plantation, 49, 189, 196, 200, 214, 225, 228, 230

planting,

interplanting, 28, 150, 151, 202

phased, 25, 64

relay, $28,105,147,149,150,151,155,158$

row, 128

under, 206

Plaza, G., 214

plough,

horse-drawn, 84

ox-, 67, 70, 71, 76, 96, 109, 117

regions, 72

system, $5,24,128$

tractor-drawn, 76, 89, 109, 187

deep, 80

tractor, 94, 180

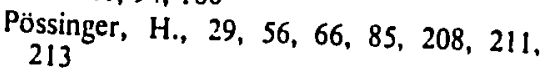

Polynesian Islands, 202

Porka System, 34

Portères, R., 65

Portuguese, 44

potato, 60, 100, 231, 250

Pueraria javanica, 53, 203

Pucrto Rico, 209

Punjab, 135, 161, 162

pyrethrum, 85, 92, 224
Queensland, 209, 210

Rabi, 113, 114, 122, 161, 162

radish, Chinese, 165

ranching, 54, 267, 271, 277

cattle, 275

company, 269, 270

development, 273

co-operative, 269,270

government, 269, 270

group, 269, 270

Karakul, 274, 275, 276

management, 269

nucleus, 269

system, 252, 258, 264, 271

rape seed, $149,152,162,175$

raspador, 212

ratoon, ratooning, 147, 161, 204, 208

reforestation, 205

Reunion, 207

Rhodesia, 32, 43, 85, 89, 90

rice,

deep-water, 166

hill, 17, 24, 39, 40, 53, 128

nurseries, 143, 149, 166, 185

ratoon, 118,147

spring, 149,175

summer, 149, 175

swamp, 133, 137

terraces, 152

varieties, 187

wet, $9,54,59,60,62,75,105,106,118$. $120,130,131,133,135,138,139,142$. $145,146,148,149,152,157,158,160$, $16 !, 166,167,170,172,175,187,194$, 238,243

Richards, A. I., 31, 32, 35, 43

ridging, mechanized, 109

rinderpest, 270

risk, 12

rotation, 3, 104, 105, 108, 154

annual, 107

biannual, 121

biennial, 107

irrigation, 146

pseudo, 27, 38, 107

system, 2, 20, 83, 84, 86

triennial, 107

Rotenhan, D. von, $60,63,64,68,69,71,72$, $74,76,82,115,126,262$

Rounce, N. V., 82

Ruanda, 103

rubber, 40, 142, 143, 192, 198, 206, 203, 204, $206,214,234,235,236,238,243,245$,

Rufiji Delta, 137 
Rundi, 103

Russia, 231

Ruthenberg, H., 182, 250

Ruttan, V.W., 181, 185

safflower, 123

Sahara, 4, 142, 145, 252, 253, 254, 256, 257

Sahiwal, 93

Sakkalaven, 260

salinity, 182

salt,

accumulation, 138

Samoa, 195, 243

Samuel, P., 42

Sand Veld, 89

Sao Paulo, 221, 223, 225, 277

Sarawak, 17, 40,41

savanna,

African, 67, 70, 85, 101, 127, 253, 260

dry, 108, 284

humid, 284

Schäfer, H., 275, 276

Schickele, R., 255

Schlippe, P. de, 27, 30, 39, 63, 107

seasonality, i4

Senegal, $60,61,62,65,66,70,71,72,84$. $101,102,116,119,120,121,122$

S.E.R.E.S.A.. Dahomey, 238

Serere, $84,117,121$

Setaria splendida, 188

settlement schemes, 82, 85, 88, 124

shade plants, ?03

Shambala, 103

Shao-er Ong, 159

sheep, $59,92,118,120,123,125,253,254$, 275,276

shifting systems, 16, 24, 44, 104, 105, 109, 124,284

Shinyanga, 68, 74, 126

Sick, W. D., 59, 205

siege methods, siege situation, 115, 117

Sierra Leone, 17

silage, $87,129,261$

simsim, 18

Singapore, 143, 144, 160, 163, 164

sisal, 192, 195, 197, 198, 203, 204, 208, 210, $212,219,231,247$

hedges, 62, 75, 198

hybrid, 212

slaughter of cows, 122

smallholder, 119, 131, 176, 193, 196, 214, $215,222,232,234,237,238,244,246$, 247

production, 248

smallholdings, 124, 130, 135, 195, 196, 206 ,

$207,210,212,222,226,232,244,250$

S.O.D.E.P.A.L.M. (Saciett Fur le Développement et l'Exploitation du soil, Palmier à l'Huile), 200, 235

conservation, $45,109,117,119,127$

fertility, ic, 11, 77, 101, 104, 117, 121, $122,145,230$

hardpan, 60

mining, 77, 80, 108, 117

night, 109, 110, 175

Sokoto, 102

Soothipan, A., 158

sorghum, 18, 43, 60,71, 98, 105, 106, 114, $116,117,118,120,122,123,138,147$, $162,178,179,180$

soya-bean, 146

spade systems, 155

Spencer, J. E., 16, 19, 23, 24, 36, 44, 46

stock-keeping, 253, 257, 258, 260

Stylosanthes, 128

Sudan, 2, 33, 103, 135, 136, 138, 154, 178, $179,180,183,259$

sugar-cane, $62,85,107,122,123,135,138$, $145,146,147,148,151,161,152,170$, $189,192,204,205,209,213,220$

Sukumaland, $60,63,64,68,69,71,72,74$, $75,76,78,79,81,126,262$

Sumatra. 17, 49, 234, 237

sunflower, 212

Surinam, 166

siveet potatoes, 9, 24, 60, 62, 104, 105, 106, $107,116,124,143,146,147,149,151$, 250

Swynnerton Plan, 250

Taichung District, 149, 174, 175, 187

Taiwan, 31, 104, 116, 131, 136, 145, 146, $147,148,149,151,156,157,159,160$, $166,169,170,174,276,181,184,207$, $209,210,229,231,232,244,249$

Tananarive, 116, 147

Tan Chec Lian, 164

Tanga, 191

Tanganyika, 260

Tanzania, $2,20,21,23,34,35,39,57,58,59$. $60,63,64,68,69,71,72,73,75,76,103$, $126,137,191,195,198,208,211,212$, $215,216,218,219,222,223,224$

taro, 24, 62, 102

Tax, S., 37

tea, 13i, 192, 198, 204, 228, 229, 231, 232. $236,23 \%$

teff (Eragrostis abyssinica), 84, 100

Teita, 103

Terra, G. J. A., 3, 4

terraces, 106, 131 
terracing, 103, 109

Teso system, 84

Thailand, $4,156,159,160,166,169,170$, 173, 174

ticks, 260

Tigre, 103

Tilapia, 155

Tjoremas, 187

tobacco, $44,49,89,90,143,148,149$, $151,161,209$

Togo, 102

tomatoes, 143

Tondeur, M. G., 41, 42, 50

tool systems, 24, 113

Tourte, R., 121

traction power, 104, 110

tractor, 5, 96, 97

transhumance, 5,253

Travancore, 154

tribes, pastoral, 262

Trinidad, 129, 195, 207

trypanosomiasis, 80

tsetse-fly, 55, 59, 67, 75, 80, 281

eradication, 270

Turkana; 260

Turu, 103

Uganda, 84, 103, 262, 263

Ukara Island, 101, 105, 106, 117, 118, 119, $120,121,125$

Ukerewe, 68, 72, 125, 126

Umlagewirtschaft, 55

United Arab Republic, 207

United Fruit Company, 214

Upper Volta, 71

Upton, M., 233, 234

U.S.A., 155, 156, 170, 176, 277

U.S.S.R., 8

Uttar Pradesh, 157, 158, 161, 162

vanilla, 195

vegetables, 104, 105, 106, 117, 122, 123,142, $143,165,170,217,250$

vegetation,

cycle, 107, 135

system, 19

Venezucla, 59, 195, 279

Versluys, J. D. N., 180

Wachagga, 224

Wagner, G., 206

Wahaya, 215,218
Waibel, L., 1

Wakara, 103, 115, 118, 119, 121

Wasukuma, 66, 78, 119, 262

water,

application, 133, 185

availability, 135, 160

charge, 183

distribution, 133, 142, 154, 182

hyacinth, 163

quality, 138

reliability, $132,135,137$

supply, 133, 181, 183

watering place, $256,258,260,262,266$, 273

wattle, 250

Webster, C. C., 30, 88, 95, 96, 127, 152, 153 $249,256,267,271,272,274$

weed, 118

control, 98

killer, 166

weeder,

mechanical, 98

ox-drawn, 70, 80, 119

weeding,

mechanical, 79

Westgarth, D. R., 235

West Indies, 104, 130

wheat, $60,92,94,100,114,122,123,138$, $146,148,151,155,160,161,162,169$. 170,175

White, H. D., 276

Whyte, R. O., 129

W:kkramatileke, R., 164

Wilson. T. B., 30, 88, 95, 96, 127, 152, 153 , $249,256,267,271,272,274$

Wissrnann, H.v., i

Wittfogel, K., 141, 177

work, off-farm, 244

Woermann, E., 2, 6

Wörz, J. G. G., 179

Wong, C. T., 165

Wood, G. A. R., 235

wool, 254, 274

Wright, S. J., 231

yam, 17, 24, 103, 191, 192, 234

Yangambi, 33, 50, 53, 54

Yemen, North, 135, 139

Yoruba country, 232, 233, 234

Zacharias, C. W. B., 156

Zambia, 18, 23, 35, 85

Zande, 39

Zebu cattle, 93, 117, 128

Zeven, A. C., 241 